\title{
RELAP5-3D \\ Developmental Assessment: Comparison of Versions 4.0.3is and 2.4.2is
}

\author{
Paul D. Bayless
}

September 2012

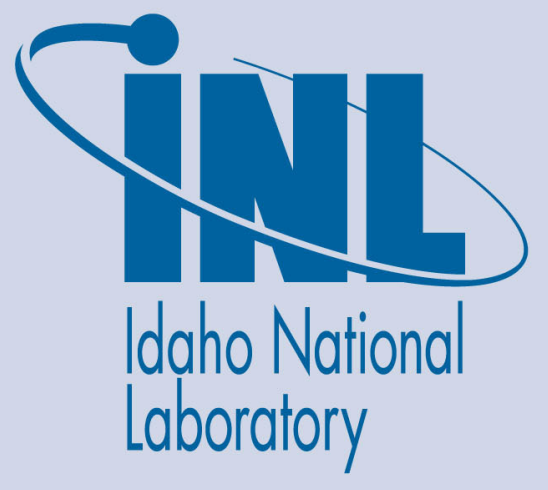

The INL is a U.S. Department of Energy National Laboratory operated by Battelle Energy Alliance 
INL/EXT-12-27156

\title{
RELAP5-3D Developmental Assessment: Comparison of Versions 4.0.3is and 2.4.2is
}

\author{
Paul D. Bayless
}

September 2012

\begin{abstract}
Idaho National Laboratory
Idaho Falls, Idaho 83415
\end{abstract}

http://www.inl.gov

Prepared for the

U.S. Department of Energy

Under DOE Idaho Operations Office

Contract DE-AC07-05ID14517 


\section{DISCLAIMER}

This information was prepared as an account of work sponsored by an agency of the U.S. Government. Neither the U.S. Government nor any agency thereof, nor any of their employees, makes any warranty, expressed or implied, or assumes any legal liability or responsibility for the accuracy, completeness, or usefulness, of any information, apparatus, product, or process disclosed, or represents that its use would not infringe privately owned rights. References herein to any specific commercial product, process, or service by trade name, trade mark, manufacturer, or otherwise, does not necessarily constitute or imply its endorsement, recommendation, or favoring by the U.S. Government or any agency thereof. The views and opinions of authors expressed herein do not necessarily state or reflect those of the U.S. Government or any agency thereof. 
RELAP5-3D/4.0.3 


\begin{abstract}
Figures have been generated comparing the parameters used in the developmental assessment of the RELAP5-3D code using versions 4.0.3is and 2.4.2is. The figures, which are the same as those used in Volume III of the RELAP5-3D code manual, compare calculations using the semi-implicit solution scheme with available experiment data. These figures provide a quick, visual indication of how the code predictions changed between these two code versions and can be used to identify cases in which the assessment judgment may need to be changed in Volume III of the code manual. Changes to the assessment judgments made after reviewing all of the assessment cases are also provided.
\end{abstract}


RELAP5-3D/4.0.3 


\section{CONTENTS}

ABSTRACT iii

CONTENTS ..V

FIGURES vii

TABLES XXV

1. INTRODUCTION ……………………………………………………………... 1-1

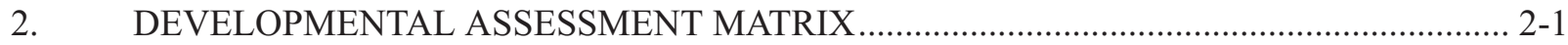

2.1 Methodology and Case Selection ............................................................................ 2-1

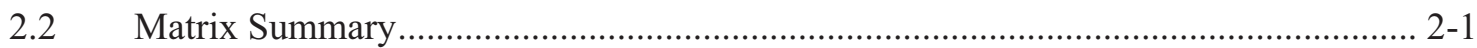

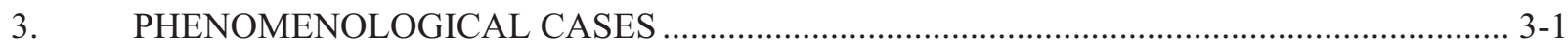

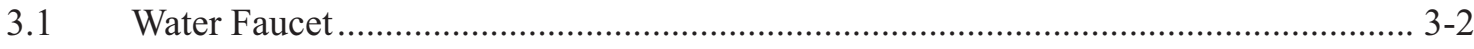

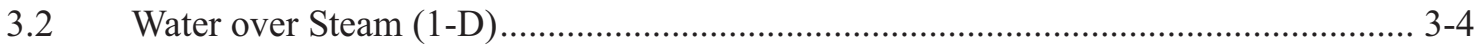

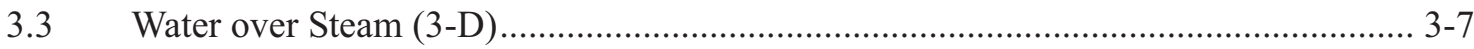

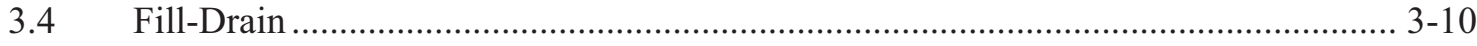

3.5 Bubbling Steam through Liquid ........................................................................ 3-15

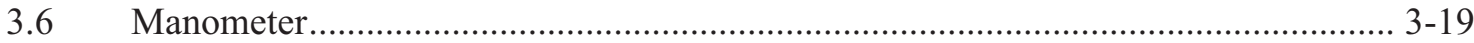

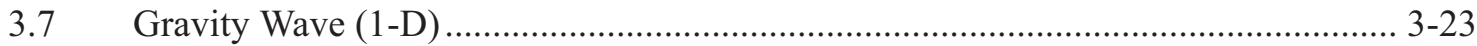

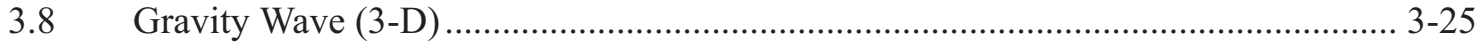

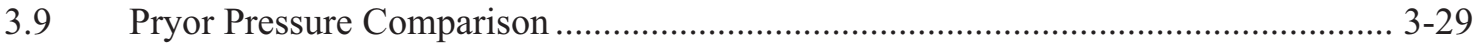

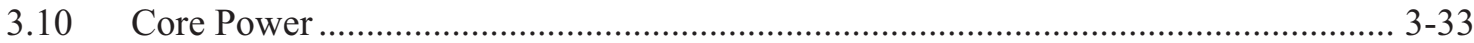

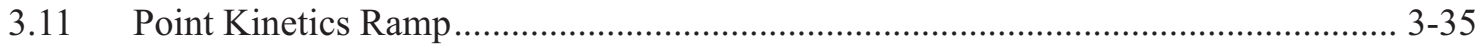

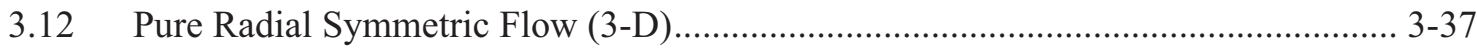

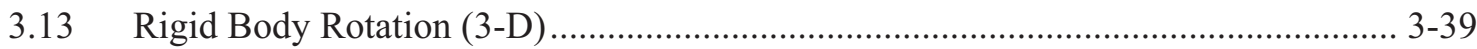

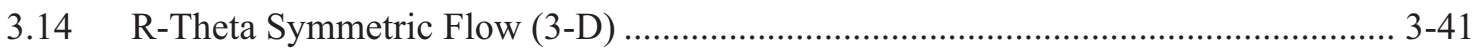

3.15 Conduction Enclosure ….................................................................................. 3-44

3.16 Conduction Enclosure: 1-D Transient Model............................................................... 3-48

3.17 Conduction Enclosure: 2-D Transient Model............................................................. 3-51

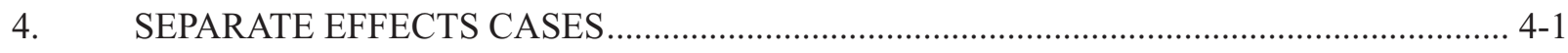

4.1 Edwards-O’Brien Blowdown Test …................................................................... 4-2

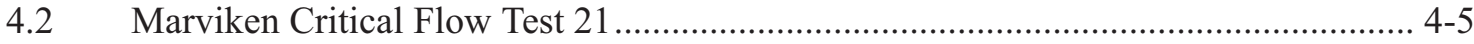

4.3 Marviken Critical Flow Test 22 …...................................................................... 4-10 
4.4 Marviken Critical Flow Test 24 ….............................................................................. 4-17

4.5 Marviken Jet Impingement Test 11 ...................................................................... 4-24

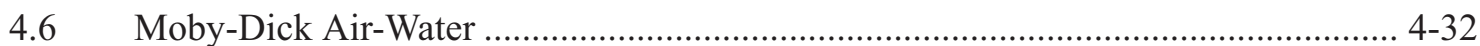

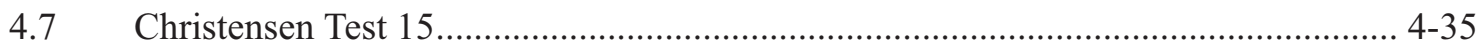

$4.8 \quad$ GE Level Swell - $1 \mathrm{ft}$ - Test 1004-3 .................................................................... 4-38

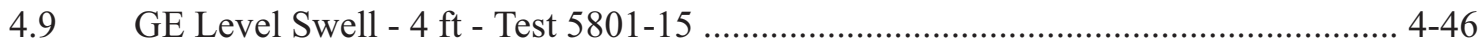

4.10 Bennett Heated Tube Tests 5358, 5294, and 5394 ................................................ 4-53

4.11 ORNL THTF Tests 3.07.9B, 3.07.9N, 3.07.9W and 3.09.10I................................ 4-56

4.12 Royal Institute of Technology Tube Test 261 .......................................................... 4-62

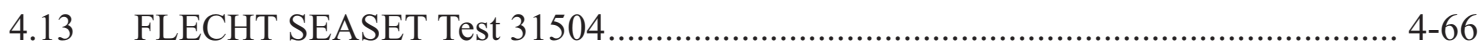

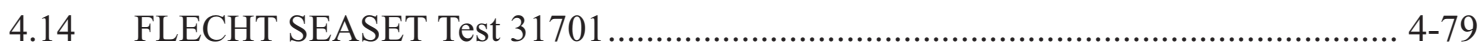

4.15 Dukler-Smith Air-Water Flooding ......................................................................... 4-89

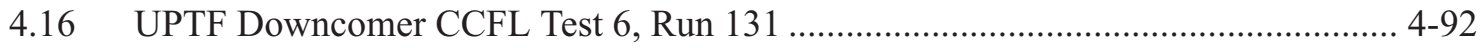

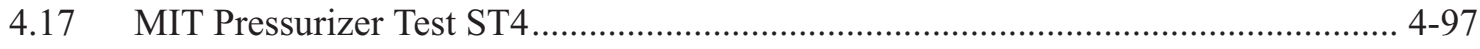

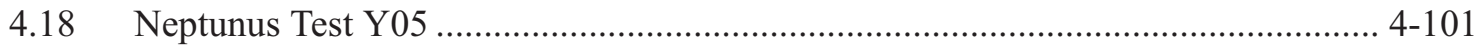

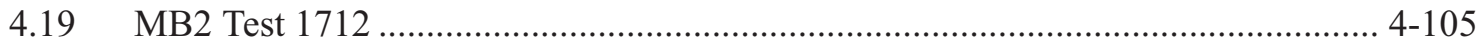

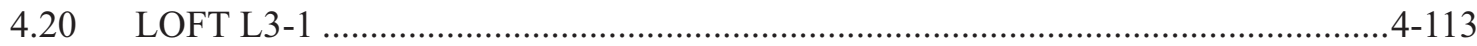

4.21 Full-Scale Reactor Coolant Pump .............................................................................4-116

4.22 GE 1/6-Scale Jet Pump ..................................................................................... 4-121

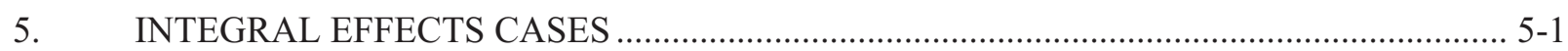

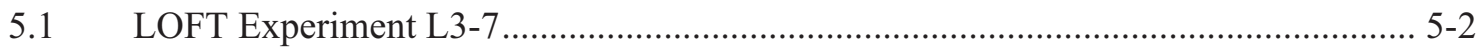

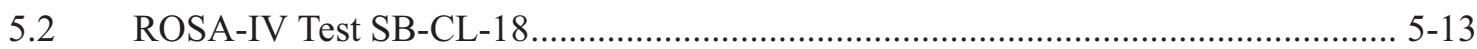

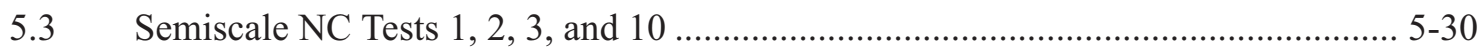

5.4 LOBI Test A1-04R (Large Break) ................................................................... 5-45

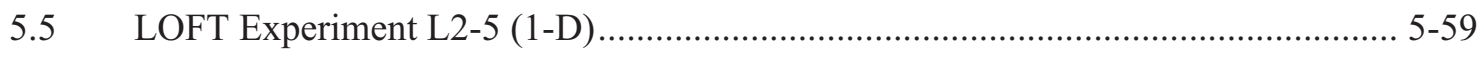

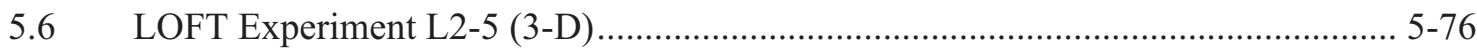

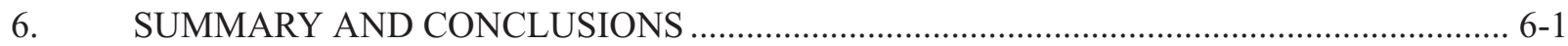




\section{FIGURES}

Figure 3.1-1. RELAP5-3D nodalization for the water faucet test case................................. 3-2

Figure 3.1-2. Comparison of RELAP5-3D calculated liquid velocity with the exact solution for the water faucet case. ............................................................... 3-3

Figure 3.1-3. Comparison of RELAP5-3D calculated liquid fraction with the exact solution for the water faucet case. ............................................................... 3-3

Figure 3.2-1. RELAP5-3D nodalization diagram for the 1-D water over steam problem. .... 3-4

Figure 3.2-2. Void fraction in the top three volumes (7-9) for the 1-D water over steam problem. ......................................................................................... 3-5

Figure 3.2-3. Void fraction in the middle three volumes (4-6) for the 1-D water over steam problem.

Figure 3.2-4. Void fraction in the bottom three volumes (1-3) for the 1-D water over steam problem.

Figure 3.3-1. RELAP5-3D nodalization diagram for the 3-D water over steam problem. .... 3-7

Figure 3.3-2. Void fraction in the top three axial levels (7-9) for the 3-D water over steam problem. ...................................................................................... 3-8

Figure 3.3-3. Void fraction in the middle three axial levels (4-6) for the 3-D water over steam problem..................................................................................... 3-8

Figure 3.3-4. Void fraction in the bottom three axial levels (1-3) for the 3-D water over steam problem.

Figure 3.3-5. Void fraction in each of the eight segments of axial level 5 for the 3-D water over steam problem.

Figure 3.4-1. Nodalization diagram for Fill-Drain test. .................................................. 3-10

Figure 3.4-2. Injection flow liquid velocity comparison for the Fill-Drain test................... 3-11

Figure 3.4-3. Bottom volume pressure comparison for the Fill-Drain test. ......................... 3-11

Figure 3.4-4. Mixture level comparison in volume 3-01 for the Fill-Drain test.................... 3-12

Figure 3.4-5. Mixture level comparison in volume 3-02 for the Fill-Drain test................... 3-12

Figure 3.4-6. Mixture level comparison in volume 3-03 for the Fill-Drain test................... 3-13

Figure 3.4-7. Mixture level comparison in volume 3-04 for the Fill-Drain test................... 3-13

Figure 3.4-8. Mixture level comparison in volume 3-05 for the Fill-Drain test................... 3-14

Figure 3.5-1. RELAP5-3D nodalization for the bubbling steam through liquid test case. .. 3-15

Figure 3.5-2. Mass flow rate of saturated steam at time-dependent junction 002 for the bubbling steam through liquid case. ...................................................... 3-16

Figure 3.5-3. Mixture level in pipe volume 2 for the bubbling steam through liquid case. . 3-16

Figure 3.5-4. Mixture level in pipe volume 3 for the bubbling steam through liquid case. . 3-17

Figure 3.5-5. Mixture level in pipe volume 4 for the bubbling steam through liquid case. . 3-17

Figure 3.5-6. Total system mass for the bubbling steam through liquid case. .................... 3-18

Figure 3.6-1. Schematic of oscillation manometer. ........................................................ 3-19

Figure 3.6-3. Comparison of water levels in the left leg for Manometer test. ..................... 3-20

Figure 3.6-2. Nodalization diagram of nitrogen-water Manometer test input model........... 3-20

Figure 3.6-4. Comparison of liquid velocities for Manometer test. .................................... 3-21 
Figure 3.6-5. Comparison of bottom pressure for Manometer test. 3-21

Figure 3.6-6. Comparison of water levels in the right leg for Manometer test.

Figure 3.6-7. Comparison of water levels in the left leg for Manometer test without mixture level tracking.

Figure 3.7-1. RELAP5-3D nodalization diagram for the 1-D gravity wave problem

Figure 3.7-2. Calculated liquid and vapor velocities at mid-pipe, gravity wave 1-D, Card 1 Option 7 on.

Figure 3.7-3. Calculated liquid and vapor velocities at mid-pipe, gravity wave 1-D, Card 1 Option 7 off.

Figure 3.8-1. RELAP5-3D nodalization diagram for the 3-D gravity wave problem.......... 3-25

Figure 3.8-2. Calculated liquid and vapor velocities mid-duct, $x$-interval 1, gravity wave 3-D, Card 1 Option 7 on.

Figure 3.8-3. Calculated liquid and vapor velocities mid-duct, $\mathrm{x}$-interval 2, gravity wave 3-D, Card 1 Option 7 on.

Figure 3.8-4. Calculated liquid and vapor velocities mid-duct, $x$-interval 3, gravity wave 3-D, Card 1 Option 7 on.

Figure 3.8-5. Calculated liquid and vapor velocities mid-duct, $\mathrm{x}$-interval 1, gravity wave 3-D, Card 1 Option 7 off.

Figure 3.8-6. Calculated liquid and vapor velocities mid-duct, $\mathrm{x}$-interval 2, gravity wave 3-D, Card 1 Option 7 off.

Figure 3.8-7. Calculated liquid and vapor velocities mid-duct, $\mathrm{x}$-interval 3 , gravity wave 3-D, Card 1 Option 7 off.

Figure 3.9-1. Nodalization diagram for the Pryor pressure test problem.

Figure 3.9-2. Void fraction for Pryor pressure test, semi-implicit case with maximum $\mathrm{dt}=0.02 \mathrm{~s}$

Figure 3.9-3. Void fraction for Pryor pressure test, semi-implicit case with maximum $\mathrm{dt}=0.02 \mathrm{~s}$

Figure 3.9-4. Volume 1 pressure for Pryor pressure test, semi-implicit case with maximum $\mathrm{dt}=0.02 \mathrm{~s}$. 3-30

Figure 3.9-5. Volume 1 pressure for Pryor pressure test, semi-implicit case with maximum $\mathrm{dt}=0.02 \mathrm{~s}$.

Figure 3.9-6. Time step size for Pryor pressure test, semi-implicit case with maximum $\mathrm{dt}=0.02 \mathrm{~s}$

Figure 3.9-7. Void fraction for Pryor pressure test, semi-implicit case with maximum $\mathrm{dt}=10-4 \mathrm{~s}$.

Figure 3.9-8. Volume 1 pressure for Pryor pressure test, semi-implicit case with maximum $\mathrm{dt}=10-4 \mathrm{~s}$. $3-32$

Figure 3.10-1. Decay heat comparison for the ans79.i test problem. 3-33

Figure 3.10-2. Decay heat comparison for the ans79ac.i test problem. 3-34

Figure 3.10-3. Decay heat comparison for the ans79G.i test problem. 3-34

Figure 3.11-1. Reactivity comparison for the point kinetics ramp problem 3-35 
Figure 3.11-2. Fission power comparison for the point kinetics ramp problem with $\mathrm{dt}=10-5 \mathrm{~s}$.

Figure 3.11-3. Fission power comparison for the point kinetics ramp problem with $\mathrm{dt}=0.01 \mathrm{~s}$. 3-36

Figure 3.12-1. RELAP5-3D nodalization for the pure radial symmetric flow problem. ....... 3-37

Figure 3.12-2. Radial velocity distribution for the pure radial symmetric flow problem. ..... 3-38

Figure 3.12-3. Radial pressure distribution for the pure radial symmetric flow problem..... 3-38

Figure 3.13-1. RELAP5-3D nodalization for the rigid body rotation problem.................. 3-39

Figure 3.13-2. Azimuthal velocity distribution for the rigid body rotation problem. ........... 3-40

Figure 3.13-3. Radial pressure distribution for the rigid body rotation problem. ................ 3-40

Figure 3.14-1. RELAP5-3D nodalization for the r-theta symmetric flow problem. ............. 3-41

Figure 3.14-2. Radial velocity distribution for the r-theta symmetric flow problem........... 3-42

Figure 3.14-3. Azimuthal velocity distribution for the r-theta symmetric flow problem...... 3-42

Figure 3.14-4. Radial pressure distribution for the r-theta symmetric flow problem............ 3-43

Figure 3.15-1. Heat structure layout with boundary conditions for the conduction enclosure problem................................................................................ 3-44

Figure 3.15-2. View of heat structure surfaces included in the conduction enclosures......... 3-45

Figure 3.15-3. Area factors used to define axial contact of heat structure cells as well as contact between separate heat structure geometries.

Figure 3.15-4. Steady state temperature for the heated plate problem defined in Equation (3.15-1) based on a 3800-term expansion of the series solution given in Equation (3.15-2).

Figure 3.15-5. Local steady state temperature error for the RELAP5-3D solution vs. series solution.

Figure 3.15-6. Heated plate steady state series solution and the RELAP5-3D solution along $\mathrm{x}$ equal to $0.04 \mathrm{~m}$.

Figure 3.15-7. Heated plate steady state series solution and the RELAP5-3D solution along $\mathrm{x}$ equal to $0.48 \mathrm{~m}$.

Figure 3.16-1. Rod area factors and end boundary conditions for 1-D conduction enclosure.3-48

Figure 3.16-2. 1-D conduction enclosure axial temperature vs. time (in hours) based on a 10,000-term expansion of the series solution given in Equation (3.16-4)..... 3-49

Figure 3.16-3. 1-D conduction enclosure temperature comparison with analytical solution at $10 \mathrm{~h}$

Figure 3.16-4. 1-D conduction enclosure local percent error for the rod with heated ends vs. position along the rod and time.

Figure 3.17-1. Boundary conditions for the transient heated plate model for 2-D conduction enclosure. $3-51$

Figure 3.17-2. Area factors for the 2-D plate transient heat conduction model. $3-51$

Figure 3.17-3. Plate temperature after one hour for 2-D conduction enclosure. $3-52$

Figure 3.17-4. Plate temperature after two hours for 2-D conduction enclosure. $3-52$

Figure 3.17-5. Plate temperature after three hours for 2-D conduction enclosure. 3-53 
Figure 3.17-6. 2-D conduction enclosure temperature comparison with analytical solution. Temperature is taken at point $\mathrm{x}=0.2 \mathrm{~m}, \mathrm{y}=0 \mathrm{~m}$.

Figure 3.17-7. Local percent error of the transient temperature response for 2-D conduction enclosure at a time of one hour. 3-54

Figure 3.17-8. Local percent error of the transient temperature response for 2-D conduction enclosure at a time of two hours

Figure 3.17-9. Local percent error of the transient temperature response for 2-D conduction enclosure at a time of three hours.

Figure 4.1-1. Edwards-O'Brien test facility.

Figure 4.1-2. Diagram of the RELAP5-3D Edwards-O'Brien model. 4-3

Figure 4.1-3. Non-uniform temperature distribution for Edwards-O'Brien model. 4-3

Figure 4.1-4. Measured and calculated pressures for the Edwards-O'Brien blowdown test. 4-4

Figure 4.1-5. Measured and calculated void fractions for the Edwards-O'Brien blowdown test. $4-4$

Figure 4.2-1. Marviken Critical Flow Test 21 discharge pipe. .............................................. 4-5

Figure 4.2-2. Marviken Critical Flow Test 21 test nozzle. ................................................... 4-6

Figure 4.2-3. Marviken Critical Flow Test 21 nodalization diagram. .................................... 4-7

Figure 4.2-4. Marviken CFT 21 pressure at vessel bottom (boundary condition). ................. 4-8

Figure 4.2-5. Marviken CFT 21 temperature at vessel bottom (boundary condition)............ 4-8

Figure 4.2-6. Measured and calculated mass flow rate for Marviken CFT 21...................... 4-9

Figure 4.2-7. Measured and calculated mixture density in the discharge pipe for Marviken CFT 21

Figure 4.3-1. Marviken Critical Flow Test 22 pressure vessel........................................... 4-10

Figure 4.3-2. Marviken Critical Flow Test 22 discharge pipe, test nozzle, and rupture

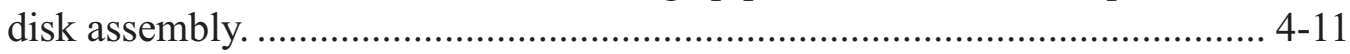

Figure 4.3-3. Marviken Critical Flow Test 22 test nozzle................................................. 4-12

Figure 4.3-4. Marviken Critical Flow Test 22 nodalization diagram.................................. 4-13

Figure 4.3-5. Measured and calculated vessel pressure for Marviken CFT 22................... 4-14

Figure 4.3-6. Measured and calculated mass flow rate for Marviken CFT 22.................... 4-15

Figure 4.3-7. Measured and calculated temperature profile at $0 \mathrm{~s}$ for Marviken CFT 22... 4-15

Figure 4.3-8. Measured and calculated temperature profile at $15 \mathrm{~s}$ for Marviken CFT 22. . 4-16

Figure 4.3-9. Measured and calculated mixture density in the discharge pipe for Marviken CFT 22............................................................................... 4-16

Figure 4.4-1. Marviken Critical Flow Test 24 pressure vessel........................................... 4-17

Figure 4.4-2. Marviken Critical Flow Test 24 discharge pipe, test nozzle, and rupture

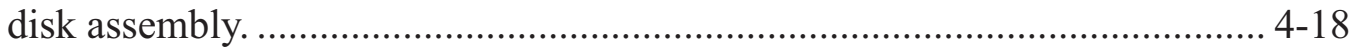

Figure 4.4-3. Marviken Critical Flow Test 24 test nozzle. .................................................. 4-19

Figure 4.4-4. Marviken Critical Flow Test 24 nodalization diagram.................................. 4-20

Figure 4.4-5. Measured and calculated vessel pressure for Marviken CFT 24................... 4-21

Figure 4.4-6. Measured and calculated mass flow rate for Marviken CFT 24.................... 4-21

Figure 4.4-7. Measured and calculated vessel temperature profile at $0 \mathrm{~s}$ for Marviken CFT 24. 
Figure 4.4-8. Measured and calculated vessel temperature profile at $15 \mathrm{~s}$ for Marviken CFT 24

Figure 4.4-9. Measured and calculated mixture density in the discharge pipe for Marviken CFT 24 4-23

Figure 4.5-1. Test facility for Marviken JIT-11...................................................... 4-25

Figure 4.5-2. Pressure vessel for Marviken JIT-11 ..................................................... 4-26

Figure 4.5-3. Discharge pipe for Marviken JIT-11 .................................................. 4-27

Figure 4.5-4. Nozzle for Marviken JIT-11 ......................................................... 4-28

Figure 4.5-5. RELAP5-3D nodalization for Marviken JIT-11. ...................................... 4-29

Figure 4.5-6. Vessel pressure boundary condition for Marviken JIT-11 . ......................... 4-30

Figure 4.5-7. Measured and calculated mass flow rate for Marviken JIT-11 .................... 4-30

Figure 4.5-8. Measured and calculated mixture density in the discharge pipe for Marviken JIT-11.................................................................................. 4-31

Figure 4.6-1. Moby-Dick test loop. ............................................................................ 4-32

Figure 4.6-2. Nodalization diagram of the RELAP5-3D Moby-Dick experiment model.... 4-33

Figure 4.6-3. Measured and calculated axial pressure distribution for Moby-Dick

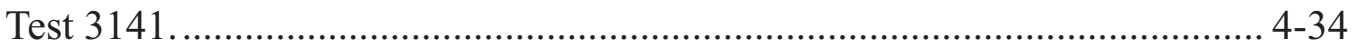

Figure 4.7-1. Test facility schematic for Christensen Test 15. ................................... 4-35

Figure 4.7-2. RELAP5-3D model nodalization for Christensen Test 15.......................... 4-36

Figure 4.7-3. Measured and calculated test section void profiles for Christensen Test 15. . 4-37

Figure 4.8-1. Test schematic for GE Small Blowdown Vessel test 1004-3....................... 4-38

Figure 4.8-2. Nodalization diagram for GE Small Blowdown Vessel test 1004-3............. 4-39

Figure 4.8-3. Comparison of experiment data with the pressure imposed by

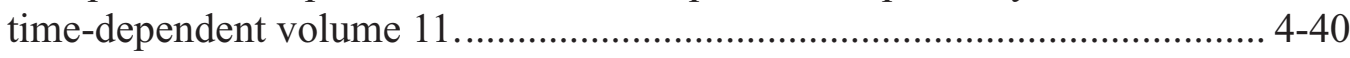

Figure 4.8-4. Measured and calculated void fraction at $2 \mathrm{ft}(0.6 \mathrm{~m})$ above the bottom of the vessel (level 1) for GE level swell Test 1004-3.

Figure 4.8-5. Measured and calculated void fraction at $4 \mathrm{ft}(1.2 \mathrm{~m})$ above the bottom of the vessel (level 2) for GE level swell Test 1004-3

Figure 4.8-6. Measured and calculated void fraction at $6 \mathrm{ft}(1.8 \mathrm{~m})$ above the bottom of the vessel (level 3) for GE level swell Test 1004-3....

Figure 4.8-7. Measured and calculated void fraction at $8 \mathrm{ft}(2.4 \mathrm{~m})$ above the bottom of the vessel (level 4) for GE level swell Test 1004-3.

Figure 4.8-8. Measured and calculated void fraction at $10 \mathrm{ft}(3.0 \mathrm{~m})$ above the bottom of the vessel (level 5) for GE level swell Test 1004-3.

Figure 4.8-9. Measured and calculated void fraction at $12 \mathrm{ft}(3.7 \mathrm{~m})$ above the bottom of the vessel (level 6) for GE level swell Test 1004-3.

Figure 4.8-10. Measured and calculated void fraction profile in the vessel at $10 \mathrm{~s}$ for GE level swell Test 1004-3.

Figure 4.8-11. Measured and calculated void fraction profile in the vessel at $40 \mathrm{~s}$ for GE level swell Test 1004-3.

Figure 4.8-12. Measured and calculated void fraction profile in the vessel at $100 \mathrm{~s}$ for GE level swell Test 1004-3. 
Figure 4.8-13. Measured and calculated void fraction profile in the vessel at $160 \mathrm{~s}$ for GE level swell Test 1004-3

Figure 4.8-14. Volume and volume-average void fractions at $160 \mathrm{~s}$ for GE level swell Test 1004-3 (semi-implicit calculations).

Figure 4.9-1. GE Large Blowdown Vessel schematic diagram............................................ 4-46

Figure 4.9-2. Nodalization diagram for GE Large Blowdown Vessel test 5801-15............. 4-47

Figure 4.9-3. Comparison of experiment data with the pressure imposed by time-dependent volume 106

Figure 4.9-4. Measured and calculated void fraction profile in the vessel at $2 \mathrm{~s}$ for GE level swell Test 5801-15.

Figure 4.9-5. Measured and calculated void fraction profile in the vessel at $5 \mathrm{~s}$ for GE level swell Test 5801-15.

Figure 4.9-6. Measured and calculated void fraction profile in the vessel at $10 \mathrm{~s}$ for GE level swell Test 5801-15.

Figure 4.9-7. Measured and calculated void fraction profile in the vessel at $20 \mathrm{~s}$ for GE level swell Test 5801-15.

Figure 4.9-8. Effect of level tracking model on calculated void fractions for levels 1-3 using the semi-implicit solution scheme

Figure 4.9-9. Effect of level tracking model on calculated void fractions for levels 4 and 5 using the semi-implicit solution scheme.

Figure 4.9-10. Effect of level tracking model on calculated void fractions for levels 1-3 using the nearly-implicit solution scheme.

Figure 4.9-11. Effect of level tracking model on calculated void fractions for levels 4 and 5 using the nearly-implicit solution scheme.

Figure 4.10-1. Nodalization diagram for the Bennett test facility. 4-53

Figure 4.10-2. Measured and calculated axial wall temperatures for Bennett heated tube low mass flux Test 5358.

Figure 4.10-3. Measured and calculated axial wall temperatures for Bennett heated tube intermediate mass flux Test 5294.

Figure 4.10-4. Measured and calculated axial wall temperatures for Bennett heated tube high mass flux Test 5394.

Figure 4.11-1. Experiment setup of the ORNL Thermal Hydraulic Test Facility (THTF) steady state film boiling tests.

Figure 4.11-2. Test section of the ORNL Thermal Hydraulic Test Facility. 4-57

Figure 4.11-3. Nodalization diagram for the ORNL THTF steady state experiments. 4-58

Figure 4.11-4. Measured and calculated steady state rod surface temperatures for ORNL THTF Test 3.07.9B.

Figure 4.11-5. Measured and calculated steady state rod surface temperatures for ORNL THTF Test 3.07.9N.

Figure 4.11-6. Measured and calculated steady state rod surface temperatures for ORNL THTF Test 3.07.9W....

Figure 4.11-7. Measured and calculated steady state axial rod surface temperatures for ORNL THTF Test 3.09.10I 
Figure 4.11-8. Measured and calculated steady state axial gas temperatures for ORNL THTF Test 3.09.10I.

Figure 4.11-9. Measured and calculated steady state axial void fractions for ORNL THTF Test 3.09.10I 4-61

Figure 4.12-1. RIT Tube Test facility diagram. 4-62

Figure 4.12-2. Locations of temperature measurements for RIT Tube Test 261. 4-63

Figure 4.12-4. Measured and calculated tube surface temperatures for RIT Tube Test 261 with the default CHF model. 4-64

Figure 4.12-3. Nodalization diagram for the RIT test facility. 4-64

Figure 4.12-5. Measured and calculated tube surface temperatures for RIT Tube Test 261 with the PG-CHF model. ........................................................................ 4-65

Figure 4.13-2. FLECHT SEASET bundle cross section. ............................................... 4-66

Figure 4.13-1. FLECHT SEASET unblocked bundle flow diagram for forced reflood. ...... 4-67

Figure 4.13-3. RELAP5-3D nodalization for the FLECHT SEASET forced reflood experiments. 4-68

Figure 4.13-4. Measured and calculated rod surface temperatures for FLECHT SEASET forced reflood Test 31504 at the 0.62-m (24-in.) elevation. 4-68

Figure 4.13-5. Measured and calculated rod surface temperatures for FLECHT SEASET forced reflood Test 31504 at the 1.23-m (48-in.) elevation 4-69

Figure 4.13-6. Measured and calculated rod surface temperatures for FLECHT SEASET forced reflood Test 31504 at the 1.85-m (72-in.) elevation.

Figure 4.13-7. Measured and calculated rod surface temperatures for FLECHT SEASET forced reflood Test 31504 at the 2.46-m (96-in.) elevation. 4-70

Figure 4.13-8. Measured and calculated rod surface temperatures for FLECHT SEASET forced reflood Test 31504 at the 2.85-m (111-in.) elevation. 4-70

Figure 4.13-9. Measured and calculated rod surface temperatures for FLECHT SEASET forced reflood Test 31504 at the 3.08-m (120-in.) elevation. 4-71

Figure 4.13-10.Measured and calculated rod surface temperatures for FLECHT SEASET forced reflood Test 31504 at the 3.38-m (132-in.) elevation. 4-71

Figure 4.13-11.Measured and calculated steam temperatures for FLECHT SEASET forced reflood Test 31504 at the 1.23-m (4-ft) elevation. $4-72$

Figure 4.13-12.Measured and calculated steam temperatures for FLECHT SEASET forced reflood Test 31504 at the 1.85-m (6-ft) elevation. 4-72

Figure 4.13-13.Measured and calculated steam temperatures for FLECHT SEASET forced reflood Test 31504 at the $2.46-\mathrm{m}$ (8-ft) elevation.

Figure 4.13-14.Measured and calculated steam temperatures for FLECHT SEASET forced reflood Test 31504 at the $2.85-\mathrm{m}(9.25-\mathrm{ft})$ elevation. $4-73$

Figure 4.13-15.Measured and calculated steam temperatures for FLECHT SEASET forced reflood Test 31504 at the 3.08-m (10-ft) elevation. 4-74

Figure 4.13-16.Measured and calculated steam temperatures for FLECHT SEASET forced reflood Test 31504 at the 3.54-m (11.5-ft) elevation. 4-74

Figure 4.13-17.Measured and calculated total bundle mass inventory for FLECHT SEASET forced reflood Test 31504. 
Figure 4.13-18.Measured and calculated void fractions at 0.92 to $1.23-\mathrm{m} \mathrm{(3} \mathrm{to} 4-\mathrm{ft}$ ) elevations for FLECHT SEASET forced reflood Test 31504.

Figure 4.13-19.Measured and calculated void fractions at 1.23 to $1.54-\mathrm{m}$ (4 to $5-\mathrm{ft}$ ) elevations for FLECHT SEASET forced reflood Test 31504. 4-76

Figure 4.13-20.Measured and calculated void fractions at 1.54 to $1.85-\mathrm{m}$ ( 5 to $6-\mathrm{ft}$ ) elevations for FLECHT SEASET forced reflood Test 31504. 4-76

Figure 4.13-21.Measured and calculated void fractions at 1.85 to $2.15-\mathrm{m}$ (6 to $7-\mathrm{ft}$ ) elevations for FLECHT SEASET forced reflood Test 31504.

Figure 4.13-22. Measured and calculated void fractions at 2.15 to $2.46-\mathrm{m}$ ( 7 to 8 -ft) elevations for FLECHT SEASET forced reflood Test 31504.

Figure 4.13-23.Measured and calculated axial void profile at $300 \mathrm{~s}$ for FLECHT SEASET forced reflood Test 31504 .

Figure 4.14-2. FLECHT SEASET bundle cross section. 4-79

Figure 4.14-1. FLECHT SEASET unblocked bundle flow diagram for forced reflood. ...... 4-80

Figure 4.14-3. RELAP5-3D nodalization for the FLECHT SEASET forced reflood experiments. 4-81

Figure 4.14-4. Measured and calculated rod surface temperatures for FLECHT SEASET forced reflood Test 31701 at the $0.62-\mathrm{m}$ (24-in.) elevation. 4-81

Figure 4.14-5. Measured and calculated rod surface temperatures for FLECHT SEASET forced reflood Test 31701 at the 0.99-m (39-in.) elevation. 4-82

Figure 4.14-6. Measured and calculated rod surface temperatures for FLECHT SEASET forced reflood Test 31701 at the 1.22-m (48-in.) elevation. 4-82

Figure 4.14-7. Measured and calculated rod surface temperatures for FLECHT SEASET forced reflood Test 31701 at the 1.78-m (70-in.) elevation. 4-83

Figure 4.14-8. Measured and calculated rod surface temperatures for FLECHT SEASET forced reflood Test 31701 at the 2.46-m (96-in.) elevation. 4-83

Figure 4.14-9. Measured and calculated rod surface temperatures for FLECHT SEASET forced reflood Test 31701 at the 2.85-m (111-in.) elevation. 4-84

Figure 4.14-10.Measured and calculated rod surface temperatures for FLECHT SEASET forced reflood Test 31701 at the 3.08-m (120-in.) elevation. 4-84

Figure 4.14-11.RELAP5-3D calculated rod bundle bottom and top quench behavior for FLECHT SEASET forced reflood Test 31701.

Figure 4.14-12.Measured and calculated steam temperatures for FLECHT SEASET forced reflood Test 31701 at the $1.23-\mathrm{m}$ (4-ft) elevation.

Figure 4.14-13.Measured and calculated steam temperatures for FLECHT SEASET forced reflood Test 31701 at the 1.85-m (6-ft) elevation.

Figure 4.14-14.Measured and calculated steam temperatures for FLECHT SEASET forced reflood Test 31701 at the 2.46-m (8-ft) elevation. 4-86

Figure 4.14-15.Measured and calculated steam temperatures for FLECHT SEASET forced reflood Test 31701 at the $2.85-\mathrm{m}$ (9.25-ft) elevation.

Figure 4.14-16.Measured and calculated steam temperatures for FLECHT SEASET forced reflood Test 31701 at the 3.08-m (10-ft) elevation. 
Figure 4.14-17.Measured and calculated steam temperatures for FLECHT SEASET forced reflood Test 31701 at the 3.54-m (11.5-ft) elevation. $4-88$

Figure 4.14-18.Measured and calculated total bundle mass inventory for FLECHT SEASET forced reflood Test 31701. 4-88

Figure 4.15-1. Schematic of the Dukler-Smith Air-Water Test Facility (from Reference 4.15-3) 4-89

Figure 4.15-2. Nodalization diagram for the Dukler-Smith test facility. 4-90

Figure 4.15-3. Comparison of RELAP5-3D predictions to Dukler-Smith data. 4-91

Figure 4.15-4. RELAP5-3D calculated superficial liquid velocity versus superficial gas velocity for the Dukler-Smith test.

Figure 4.16-1. Schematic of the UPTF. 4-92

Figure 4.16-2. Key dimensions of the UPTF. 4-93

Figure 4.16-3. Cross-section of the UPTF reactor vessel.............................................. 4-93

Figure 4.16-4. RELAP5-3D nodalization for UPTF Test 6.......................................... 4-94

Figure 4.16-5. Downcomer pressure in UPTF Test 6, Run 131.................................... 4-94

Figure 4.16-6. Collapsed liquid level in the lower plenum in UPTF Test 6, Run 131......... 4-95

Figure 4.16-7. Break mass flow in UPTF Test 6, Run 131 ............................................ 4-95

Figure 4.16-8. Fluid density in the broken cold leg in UPTF Test 6, Run 131................. 4-96

Figure 4.16-9. The effect of nodalization on collapsed liquid level in UPTF Test 6, Run 131.

Figure 4.17-1. Schematic of MIT Pressurizer test facility. 4-97

Figure 4.17-3. Measured and calculated pressure at the top of the tank for MIT pressurizer Test ST4.

Figure 4.17-4. Measured and calculated wall temperature profile at $35 \mathrm{~s}$ for MIT pressurizer Test ST4. 4-98

Figure 4.17-5. Measured and calculated fluid temperature profile at $35 \mathrm{~s}$ for MIT pressurizer Test ST4.

Figure 4.17-2. RELAP5-3D nodalization of MIT pressurizer.

Figure 4.17-6. Measured and calculated pressure at the top of the tank for MIT pressurizer Test ST4 with the mixture level tracking turned off.................. 4-100

Figure 4.18-1. Neptunus test facility pressurizer. 4-101

Figure 4.18-2. Nodalization diagram for the Neptunus pressurizer model. 4-102

Figure 4.18-3. Transient boundary condition flow rates for Neptunus Test Y05. 4-102

Figure 4.18-4. RELAP5-3D model input boundary flows for Neptunus Test Y05. 4-103

Figure 4.18-5. Measured and calculated pressurizer dome pressure for Neptunus Test Y05. 4-104

Figure 4.18-6. Measured and calculated pressurizer steam temperature for Neptunus Test Y05. 4-104

Figure 4.19-1. MB-2 schematic diagram. 4-106

Figure 4.19-2. MB-2 tube bundle cross section. 4-107

Figure 4.19-3. Nodalization diagram for MB-2 LOF Test 1712. 4-108 
Figure 4.19-4. Measured and RELAP5-3D primary flow rate during MB-2 steady state Test 1712 .

Figure 4.19-5. Measured and RELAP5-3D main feed water temperature during MB-2 steady state Test 1712 .

Figure 4.19-6. Measured and calculated main feed water flow rate during MB-2 steady state Test 1712 ....

Figure 4.19-7. Measured and calculated steam flow rate during MB-2 steady state Test 1712 .

Figure 4.19-8. Measured and calculated steam line pressure during MB-2 steady state Test 1712 .

Figure 4.19-9. Measured and calculated narrow range water level during MB-2 steady state Test 1712

Figure 4.19-10.Measured and calculated primary side fluid temperatures during MB-2 steady state Test 1712 .

Figure 4.20-1. LOFT L3-1 Accumulator A and surgeline schematic.

Figure 4.20-2. RELAP5 LOFT L3-1 accumulator model nodalization.

Figure 4.20-3. Measured and calculated accumulator gas dome pressure versus volume for LOFT Test L3-1.

Figure 4.20-4. Measured and calculated accumulator gas dome pressure for LOFT Test L3-1.

Figure 4.20-5. Measured and calculated accumulator liquid level for LOFT Test L3-1..... 4-115

Figure 4.21-1. Full-size reactor coolant pump. .......................................................... 4-116

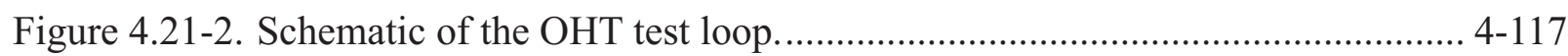

Figure 4.21-3. RELAP5-3D nodalization for the OHT pump tests.................................... 4-117

Figure 4.21-4. OHT pump head degradation multipliers. ................................................ 4-118

Figure 4.21-5. Pump differential pressures for a suction pressure of $2.80 \mathrm{MPa}$ for the reactor coolant pump case.

Figure 4.21-6. Pump differential pressures for a suction pressure of 4.69 MPa for the reactor coolant pump case

Figure 4.21-7. Pump differential pressures for a suction pressure of 6.42 MPa for the reactor coolant pump case

Figure 4.22-1. 1/6-scale model jet pump.

Figure 4.22-2. Schematic of the jet pump and vessel. 4-122

Figure 4.22-3. Jet pump test assembly and instrumentation. 4-123

Figure 4.22-4. Jet pump assembly and blowdown facility schematic. 4-124

Figure 4.22-5. RELAP5-3D nodalization for the 1/6-scale jet pump test. 4-125

Figure 4.22-6. Calculated flow parameters for forward drive flows at high and low pressure and temperature for the $1 / 6$-scale jet pump case. $4-126$

Figure 4.22-7. Measured and calculated flow parameters for forward drive flows for the $1 / 6$-scale jet pump case.

Figure 4.22-8. Measured and calculated flow parameters for reverse drive flows for the $1 / 6$-scale jet pump case. 
Figure 5.1-1. Schematic of the LOFT facility.................................................................. 5-2

Figure 5.1-2. RELAP5-3D nodalization for the LOFT facility Experiment L3-7. ............... 5-3

Figure 5.1-3. Measured and calculated reactor vessel upper plenum pressure for LOFT Experiment L3-7 ................................................................................. 5-4

Figure 5.1-4. Measured and calculated steam generator secondary pressure for LOFT Experiment L3-7.................................................................................. 5-4

Figure 5.1-5. Measured and calculated pressurizer liquid level for LOFT Experiment L3-7 ....................................................................................... 5-5

Figure 5.1-6. Measured and calculated break flow rate for LOFT Experiment L3-7. .......... 5-5

Figure 5.1-7. Measured and calculated broken loop cold leg fluid density for LOFT Experiment L3-7 ................................................................................... 5-6

Figure 5.1-8. Measured and calculated intact loop cold leg fluid density for LOFT Experiment L3-7 . .................................................................................... 5-6

Figure 5.1-9. Measured and calculated intact loop hot leg fluid density for LOFT Experiment L3-7.

Figure 5.1-10. Measured and calculated intact loop hot leg fluid temperature for LOFT Experiment L3-7 ................................................................................. 5-7

Figure 5.1-11. Measured and calculated intact loop cold leg fluid temperature for LOFT Experiment L3-7 . ................................................................................ 5-8

Figure 5.1-12. Measured and calculated broken loop cold leg fluid temperature for LOFT Experiment L3-7................................................................................... 5-8

Figure 5.1-13. Measured and calculated broken loop hot leg fluid temperature for LOFT Experiment L3-7

Figure 5.1-14. Measured and calculated core inlet fluid temperature for LOFT Experiment L3-7.

Figure 5.1-15. Measured and calculated reactor vessel upper plenum fluid temperature for LOFT Experiment L3-7.

Figure 5.1-16. Measured and calculated fuel cladding surface temperature $1.57 \mathrm{~m}$ above the bottom of the fuel for LOFT Experiment L3-7.

Figure 5.1-17. Measured and calculated fuel cladding surface temperature $0.28 \mathrm{~m}$ above the bottom of the fuel for LOFT Experiment L3-7.

Figure 5.1-18. Measured and calculated hot leg fluid velocity for LOFT Experiment L3-7. 5-11

Figure 5.1-19. Measured and calculated HPIS volumetric flow for LOFT Experiment L3-7. $5-12$

Figure 5.2-1. Schematic of the ROSA-IV large scale test facility (LSTF).......................... 5-13

Figure 5.2-2. RELAP5 input model reactor vessel nodalization for ROSA-IV SB-CL-18 test. $5-14$

Figure 5.2-3. RELAP5-3D input model loop nodalization for ROSA-IV SB-CL-18 test. .. 5-15

Figure 5.2-4. Measured and calculated pressurizer pressure, ROSA-IV Test SB-CL-18. ... 5-15

Figure 5.2-5. Measured and calculated pressure of steam generator A, ROSA-IV Test SB-CL-18. $5-16$

Figure 5.2-6. Measured and calculated pressure of steam generator B, ROSA-IV Test SB-CL-18. 
Figure 5.2-7. Measured and calculated pressurizer liquid level, ROSA-IV

Test SB-CL-18.

Figure 5.2-8. Measured and calculated break mass flow rate, ROSA-IV

Test SB-CL-18.

Figure 5.2-9. Measured and calculated vessel liquid level, ROSA-IV Test SB-CL-18. ..... 5-18

Figure 5.2-10. Measured and calculated differential pressures across loop seal A, ROSA-IV Test SB-CL-18.

Figure 5.2-11. Measured and calculated differential pressures across loop seal B, ROSA-IV Test SB-CL-18.

Figure 5.2-12. Measured and calculated mass flow rate in the broken loop cold leg, ROSA-IV Test SB-CL-18.

Figure 5.2-13. Measured and calculated mass flow rate in the broken loop hot leg, ROSA-IV Test SB-CL-18.

Figure 5.2-14. Measured and calculated mass flow rate in the intact loop cold leg, ROSA-IV Test SB-CL-18.

Figure 5.2-15. Measured and calculated mass flow rate in the intact loop hot leg, ROSA-IV Test SB-CL-18.

Figure 5.2-16. Measured and calculated density in the broken loop cold leg, ROSA-IV Test SB-CL-18.

Figure 5.2-17. Measured and calculated density in the broken loop hot leg, ROSA-IV Test SB-CL-18.

Figure 5.2-18. Measured and calculated density in the intact loop cold leg, ROSA-IV Test SB-CL-18.

Figure 5.2-19. Measured and calculated density in the intact loop hot leg, ROSA-IV Test SB-CL-18.

Figure 5.2-20. Measured and calculated mass flow rate accumulator-cold, ROSA-IV Test SB-CL-18.

Figure 5.2-21. Measured and calculated mass flow rate accumulator-hot, ROSA-IV Test SB-CL-18.

Figure 5.2-22. Measured and calculated heater rod surface temperature for axial levels $3(1.018 \mathrm{~m})$ and $5(1.830 \mathrm{~m})$, ROSA-IV Test SB-CL-18.

Figure 5.2-23. Measured and calculated heater rod surface temperature for axial levels $6(2.236 \mathrm{~m})$ and $8(3.048 \mathrm{~m})$, ROSA-IV Test SB-CL-18.

Figure 5.2-24. Measured and calculated heater rod surface temperature for axial level 9 (3.610 m), ROSA-IV Test SB-CL-18.

Figure 5.2-25. Measured and calculated pressurizer pressure for different water properties, ROSA-IV Test SB-CL-18.

Figure 5.2-26. Measured and calculated break mass flow rate for different water properties, ROSA-IV Test SB-CL-18.

Figure 5.2-27. Measured and calculated vessel liquid level for different water properties, ROSA-IV Test SB-CL-18.

Figure 5.2-28. Measured and calculated heater rod surface temperature for axial level $3(1.018 \mathrm{~m})$ and different water properties, ROSA-IV Test SB-CL-18. 5-27 
Figure 5.2-29. Measured and calculated heater rod surface temperature for axial level $5(1.830 \mathrm{~m})$ and different water properties, ROSA-IV Test SB-CL-18. 5-28

Figure 5.2-30. Measured and calculated heater rod surface temperature for axial level $6(2.236 \mathrm{~m})$ and different water properties, ROSA-IV Test SB-CL-18. 5-28

Figure 5.2-31. Measured and calculated heater rod surface temperature for axial level $8(3.048 \mathrm{~m})$ and different water properties, ROSA-IV Test SB-CL-18. 5-29

Figure 5.2-32. Measured and calculated heater rod surface temperature for axial level $9(3.610 \mathrm{~m})$ and different water properties, ROSA-IV Test SB-CL-18. 5-29

Figure 5.3-1. Semiscale Mod-2A single-loop configuration............................................ 5-30

Figure 5.3-2. Nodalization of RELAP5-3D Semiscale natural circulation test model......... 5-31

Figure 5.3-3. Calculated primary system mass flow rate at $60 \mathrm{~kW}$ core power for Semiscale Test S-NC-1.

Figure 5.3-4. Calculated hot leg liquid temperature at $60 \mathrm{~kW}$ core power for Semiscale Test S-NC-1. ................................................................................... 5-32

Figure 5.3-5. Calculated cold leg liquid temperature at $60 \mathrm{~kW}$ core power for Semiscale Test S-NC-1.

Figure 5.3-6. Calculated primary system pressure at $60 \mathrm{~kW}$ core power for Semiscale Test S-NC-1.

Figure 5.3-7. Measured and calculated primary system mass flow rate at $60 \mathrm{~kW}$ core power for Semiscale Test S-NC-2.....

Figure 5.3-8. Calculated primary system liquid and vapor mass flow rates at $60 \mathrm{~kW}$ core power for Semiscale Test S-NC-2.

Figure 5.3-9. Measured and calculated hot leg liquid temperature at $60 \mathrm{~kW}$ core power for Semiscale Test S-NC-2.

Figure 5.3-10. Measured and calculated cold leg liquid temperature at $60 \mathrm{~kW}$ core power for Semiscale Test S-NC-2

Figure 5.3-11. Measured and calculated reactor vessel upper plenum pressure at $60 \mathrm{~kW}$ core power for Semiscale Test S-NC-2.

Figure 5.3-12. Measured and calculated primary system mass flow rate for Semiscale Test S-NC-3.

Figure 5.3-13. Measured and calculated primary system pressure for Semiscale Test $\mathrm{S}=\mathrm{NC}-3$.

Figure 5.3-14. Measured and calculated hot leg liquid temperature for Semiscale Test $\mathrm{S}=\mathrm{NC}-3$.

Figure 5.3-15. Measured and calculated cold leg liquid temperarture for Semiscale Test S-NC-3.

Figure 5.3-16. Measured and calculated primary system mass flow rate for Seimscale Test S-NC-10 Part 2. 5-38

Figure 5.3-17. Measured and calculated primary system pressures for Semiscale Test S-NC-10 Part 2.

Figure 5.3-18. Measured and calculated hot leg liquid temperatures for Semiscale Test S-NC-10 Part 2. 
Figure 5.3-19. Measured and calculated cold leg liquid temperatures for Semiscale Test S-NC-10 Part 2.

Figure 5.3-20. Measured and calculated primary system pressure for Semiscale

Test S-NC-10 Part 3

Figure 5.3-21. Measured and calculated primary system mass flow rate for Semiscale Test S-NC-10 Part 3.

Figure 5.3-22. Measured and calculated hot leg liquid temperature for Semiscale Test S-NC-10 Part 3.

Figure 5.3-23. Measured and calculated cold leg liquid temperature for Semiscale Test S-NC-10 Part 3.

Figure 5.3-24. Measured and calculated primary system mass flow rate for Semiscale Test S-NC-10 Part 4 with core power of $100 \mathrm{~kW}$.

Figure 5.3-25. Measured and calculated primary system mass flow rate for Semiscale Test S-NC-10 Part 4 with core power of $60 \mathrm{~kW}$.

Figure 5.3-26. Measured and calculated primary system pressures for Semiscale Test S-NC-10 Part 4 with core power of $100 \mathrm{~kW}$.

Figure 5.3-27. Measured and calculated hot leg liquid temperatures for Semiscale Test S-NC-10 Part 4 with core power of $100 \mathrm{~kW}$.

Figure 5.3-28. Measured and calculated cold leg liquid temperatures for Semiscale Test S-NC-10 Part 4 with core power of $100 \mathrm{~kW}$......................................... 5-44

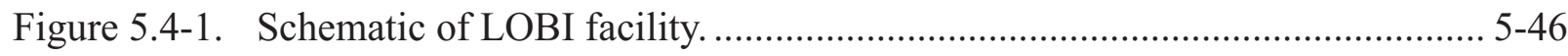

Figure 5.4-2. Noding diagram for the LOBI facility. ................................................ 5-47

Figure 5.4-3. LOBI reactor vessel nodalization. ......................................................... 5-48

Figure 5.4-4. LOBI steam generator nodalization. …….............................................. 5-49

Figure 5.4-5. Broken loop pressure behavior for LOBI Test A1-04R................................ 5-50

Figure 5.4-6. Intact loop pressure behavior for LOBI Test A1-04R. ................................ 5-51

Figure 5.4-7. Broken loop mass flow rate (pump side) for LOBI Test A1-04R................... 5-51

Figure 5.4-8. Broken loop mass flow rate (vessel side) for LOBI Test A1-04R................. 5-52

Figure 5.4-9. Accumulator discharge flow rate for LOBI Test A1-04R.............................. 5-52

Figure 5.4-10. Fluid density at the accumulator injection point for LOBI Test A1-04R. ..... 5-53

Figure 5.4-11. Measured and calculated fluid temperature at the accumulator injection point for LOBI Test A1-04R.................................................................. 5-53

Figure 5.4-12. Measured and calculated core differential pressure for LOBI Test A1-04R. . 5-54

Figure 5.4-13. Measured and calculated lower core heater rod temperature (Level 2) for LOBI Test A1-04R. ........................................................................... 5-54

Figure 5.4-14. Measured and calculated lower core heater rod temperature (Level 4) for LOBI Test A1-04R. $5-55$

Figure 5.4-15. Measured and calculated mid-core heater rod temperature (Level 5) for LOBI Test A1-04R.

Figure 5.4-16. Measured and calculated mid-core heater rod temperature (Level 6) for LOBI Test A1-04R. 
Figure 5.4-17. Measured and calculated mid-core heater rod temperature (Level 7) for LOBI Test A1-04R.

Figure 5.4-18. Measured and calculated mid-core heater temperature (Level 8) for LOBI Test A1-04R.

Figure 5.4-19. Measured and calculated upper core heater rod temperature (Level 9) for LOBI Test A1-04R.

Figure 5.4-20. Measured and calculated upper core heater rod temperature (Level 11) for LOBI Test A1-04R.

Figure 5.5-1. Schematic of the LOFT facility...

Figure 5.5-2. RELAP5-3D nodalization for the LOFT facility Experiment L2-5 (1-D vessel).

Figure 5.5-3. Measured and calculated reactor vessel upper plenum pressure for the LOFT L2-5 1-D case.

Figure 5.5-4. Measured and calculated steam generator pressure for the LOFT L2-5 1-D case.

Figure 5.5-5. Measured and calculated pressurizer liquid level for the LOFT L2-5 1-D case

Figure 5.5-6. Measured and calculated mass flow rate in the broken loop cold leg for the LOFT L2-5 1-D case.

Figure 5.5-7. Measured and calculated mass flow rate in the broken loop hot leg for the LOFT L2-5 1-D case. $5-63$

Figure 5.5-8. Measured and calculated mass flow rate in the intact loop hot leg for the LOFT L2-5 1-D case.

Figure 5.5-9. Measured and calculated mass flow rate in the intact loop cold leg for the LOFT L2-5 1-D case.

Figure 5.5-10. Measured and calculated speed for primary coolant pump 2 for the LOFT L2-5 1-D case.

Figure 5.5-11. Measured and calculated density in the broken loop cold leg for the LOFT L2-5 1-D case. $5-65$

Figure 5.5-12. Measured and calculated density in the broken loop hot leg for the LOFT L2-5 1-D case. 5-65

Figure 5.5-13. Measured and calculated density in the intact loop hot leg for the LOFT L2-5 1-D case. $5-66$

Figure 5.5-14. Measured and calculated density in the intact loop cold leg for the LOFT L2-5 1-D case.

Figure 5.5-15. Measured and calculated accumulator liquid level for the LOFT L2-5 1-D case. $5-67$

Figure 5.5-16. Measured and calculated HPIS flow for the LOFT L2-5 1-D case. $5-67$

Figure 5.5-17. Measured and calculated LPIS flow for the LOFT L2-5 1-D case. $5-68$

Figure 5.5-18. Measured and calculated reactor vessel upper plenum coolant temperature for the LOFT L2-5 1-D case.

Figure 5.5-19. Measured and calculated reactor vessel lower plenum coolant temperature for the LOFT L2-5 1-D case. 
Figure 5.5-20. Measured and calculated fuel centerline temperature $0.69 \mathrm{~m}$ above the bottom of the fuel rod for the LOFT L2-5 1-D case.

Figure 5.5-21. Measured and calculated fuel cladding surface temperature $0.05 \mathrm{~m}$ above the bottom of the fuel rod for the LOFT L2-5 1-D case.

Figure 5.5-22. Measured and calculated fuel cladding surface temperature $0.20 \mathrm{~m}$ above the bottom of the fuel rod for the LOFT L2-5 1-D case.

Figure 5.5-23. Measured and calculated fuel cladding surface temperature $0.38 \mathrm{~m}$ above the bottom of the fuel rod for the LOFT L2-5 1-D case.

Figure 5.5-24. Measured and calculated fuel cladding surface temperature $0.53 \mathrm{~m}$ above the bottom of the fuel rod for the LOFT L2-5 1-D case.

Figure 5.5-25. Measured and calculated fuel cladding surface temperature $0.64 \mathrm{~m}$ above the bottom of the fuel rod for the LOFT L2-5 1-D case.

Figure 5.5-26. Measured and calculated fuel cladding surface temperature $0.81 \mathrm{~m}$ above the bottom of the fuel rod for the LOFT L2-5 1-D case.

Figure 5.5-27. Measured and calculated fuel cladding surface temperature $0.94 \mathrm{~m}$ above the bottom of the fuel rod for the LOFT L2-5 1-D case.

Figure 5.5-28. Measured and calculated fuel cladding surface temperature $1.04 \mathrm{~m}$ above the bottom of the fuel rod for the LOFT L2-5 1-D case.

Figure 5.5-29. Measured and calculated fuel cladding surface temperature $1.25 \mathrm{~m}$ above the bottom of the fuel rod for the LOFT L2-5 1-D case.

Figure 5.5-30. Measured and calculated fuel cladding surface temperature $1.37 \mathrm{~m}$ above the bottom of the fuel rod for the LOFT L2-5 1-D case.

Figure 5.5-31. Measured and calculated fuel cladding surface temperature $1.47 \mathrm{~m}$ above the bottom of the fuel rod for the LOFT L2-5 1-D case.

Figure 5.5-32. Measured and calculated fuel cladding surface temperature $1.57 \mathrm{~m}$ above the bottom of the fuel rod for the LOFT L2-5 1-D case.............................. 5-75

Figure 5.6-1. Schematic of the LOFT facility................................................................ 5-76

Figure 5.6-2. RELAP5-3D nodalization for the LOFT facility Experiment L2-5 (1-D vessel)

Figure 5.6-3. RELAP-3D nodalization for the LOFT reactor vessel downcomer (3-D vessel). $5-78$

Figure 5.6-4. RELAP5-3D nodalization for the LOFT reactor vessel core region (3-D vessel).

Figure 5.6-5. Measured and calculated reactor vessel upper plenum pressure for the LOFT L2-5 3-D case.

Figure 5.6-6. Measured and calculated steam generator pressure for the LOFT L2-5 3-D case.

Figure 5.6-7. Measured and calculated pressurizer liquid level for the LOFT L2-5 3-D case. $5-81$

Figure 5.6-8. Measured and calculated mass flow rate in the broken loop cold leg for the LOFT L2-5 3-D case. $5-81$

Figure 5.6-9. Measured and calculated mass flow rate in the broken loop hot leg for the LOFT L2-5 3-D case. $5-82$ 
Figure 5.6-10. Measured and calculated mass flow rate in the intact loop hot leg for the LOFT L2-5 3-D case.

Figure 5.6-11. Measured and calculated mass flow rate in the intact loop cold leg for the LOFT L2-5 3-D case.

Figure 5.6-12. Measured and calculated speed for primary coolant pump 2 for the LOFT L2-5 3-D case.

Figure 5.6-13. Measured and calculated density in the broken loop cold leg for the LOFT L2-5 3-D case.

Figure 5.6-14. Measured and calculated density in the broken loop hot leg for the LOFT L2-5 3-D case.

Figure 5.6-15. Measured and calculated density in the intact loop hot leg for the LOFT L2-5 3-D case.

Figure 5.6-16. Measured and calculated density in the intact loop cold leg for the LOFT L2-5 3-D case. $5-85$

Figure 5.6-17. Measured and calculated accumulator liquid level for the LOFT L2-5 3-D case. $5-86$

Figure 5.6-18. Measured and calculated HPIS flow for the LOFT L2-5 3-D case. $5-86$

Figure 5.6-19. Measured and calculated LPIS flow for the LOFT L2-5 3-D case. 5-87

Figure 5.6-20. Measured and calculated reactor vessel upper plenum coolant temperature for the LOFT L2-5 3-D case.

Figure 5.6-21. Measured and calculated reactor vessel lower plenum coolant temperature for the LOFT L2-5 3-D case.

Figure 5.6-22. Measured and calculated fuel centerline temperature in Ring 1, Sector 3, $0.69 \mathrm{~m}$ above the bottom of the fuel rod for the LOFT L2-5 3-D case.

Figure 5.6-23. Measured and calculated fuel cladding surface temperature in Ring 1, Sector 2, $0.05 \mathrm{~m}$ above the bottom of the fuel rod for the LOFT L2-5 3-D case.

Figure 5.6-24. Measured and calculated fuel cladding surface temperature in Ring 1, Sector 2, $0.20 \mathrm{~m}$ above the bottom of the fuel rod for the LOFT L2-5 3-D case.

Figure 5.6-25. Measured and calculated fuel cladding surface temperature in Ring 1, Sector 2, $0.38 \mathrm{~m}$ above the bottom of the fuel rod for the LOFT L2-5 3-D case.

Figure 5.6-26. Measured and calculated fuel cladding surface temperature in Ring 1, Sector 2, $0.53 \mathrm{~m}$ above the bottom of the fuel rod for the LOFT L2-5 3-D case.

Figure 5.6-27. Measured and calculated fuel cladding surface temperature in Ring 1, Sector 2, $0.64 \mathrm{~m}$ above the bottom of the fuel rod for the LOFT L2-5 3-D case.

Figure 5.6-28. Measured and calculated fuel cladding surface temperature in Ring 1, Sector 2, $0.81 \mathrm{~m}$ above the bottom of the fuel rod for the LOFT L2-5 3-D case. 
Figure 5.6-29. Measured and calculated fuel cladding surface temperature in Ring 1, Sector 2, $0.94 \mathrm{~m}$ above the bottom of the fuel rod for the LOFT L2-5 3-D case.

Figure 5.6-30. Measured and calculated fuel cladding surface temperature in Ring 1, Sector 2, $1.04 \mathrm{~m}$ above the bottom of the fuel rod for the LOFT L2-5 3-D case.

Figure 5.6-31. Measured and calculated fuel cladding surface temperature in Ring 1, Sector 2, $1.25 \mathrm{~m}$ above the bottom of the fuel rod for the LOFT L2-5

3-D case.

Figure 5.6-32. Measured and calculated fuel cladding surface temperature in Ring 1, Sector 2, $1.37 \mathrm{~m}$ above the bottom of the fuel rod for the LOFT L2-5

3-D case.

Figure 5.6-33. Measured and calculated fuel cladding surface temperature in Ring 1, Sector 2, $1.47 \mathrm{~m}$ above the bottom of the fuel rod for the LOFT L2-5 3-D case.

Figure 5.6-34. Measured and calculated fuel cladding surface temperature in Ring 1, Sector 2, $1.57 \mathrm{~m}$ above the bottom of the fuel rod for the LOFT L2-5 3-D case.

Figure 5.6-35. Measured values showing radial variation in the fuel cladding surface temperature $0.53 \mathrm{~m}$ above the bottom of the fuel rod for the LOFT L2-5

3-D case.

Figure 5.6-36. Calculated values showing radial variation in the fuel cladding surface temperature $0.53 \mathrm{~m}$ above the bottom of the fuel rod for the LOFT L2-5 3-D case.

Figure 5.6-37. Measured values showing radial variation in the fuel cladding surface temperature $0.81 \mathrm{~m}$ above the bottom of the fuel rod for the LOFT L2-5 3-D case.

Figure 5.6-38. Calculated values showing radial variation in the fuel cladding surface temperature $0.81 \mathrm{~m}$ above the bottom of the fuel rod for the LOFT L2-5 3-D case.

Figure 5.6-39. Measured values showing azimuthal variation in fuel cladding surface temperatures $0.66 \mathrm{~m}$ above the bottom of the fuel rod for the LOFT L2-5 3-D case.

Figure 5.6-40. Calculated values showing azimuthal variation in fuel cladding surface temperatures $0.66 \mathrm{~m}$ above the bottom of the fuel rod for the LOFT L2-5 3-D case. 


\section{TABLES}

Table 2.2-1. Phenomenological assessment cases. ..................................................... 2-1

Table 2.2-2. Separate effects assessment cases........................................................ 2-2

Table 2.2-3. Integral effects assessment cases. ....................................................... 2-3

Table 6.0-1. Assessment changes from last code version. ............................................. 6-2 
RELAP5-3D/4.0.3 


\section{RELAP5-3D Developmental Assessment: Comparison of Versions 4.0.3is and 2.4.2is}

\section{INTRODUCTION}

This document contains plots comparing the semi-implicit simulation results for the developmental assessment cases using RELAP5-3D versions 4.0.3is and 2.4.2is. Its purpose is to provide a quick, visual comparison of results from the current and previous developmental assessment runs to identify any changes in results that may require changes to the Volume 3 text. These changes would be in addition to those associated with specific numerical values called out in the text and tables; i.e. have any of the assessment judgments changed?

Most of the text in the assessment report has been removed in the creation of this report. All of the diagrams and early report chapters have been retained so that the figure numbers in this report match those in the assessment report. In the figure legends, "new" refers to calculations using Version 4.0.3is, and "old" refers to calculations using Version 2.4.2is.

Differences observed in the comparison figures are divided into two categories. Significant differences signify that the assessment judgment may need to be changed. Noticeable differences signify that the two simulations are not identical, but a change in the assessment finding is unlikely. Significant differences were observed in the cases listed below:

- $\quad$ Point kinetics ramp

- $\quad$ Moby-Dick air-water

- $\quad$ FLECHT SEASET Test 31504

- $\quad$ FLECHT SEASET Test 31701

- $\quad$ MIT pressurizer Test ST4

- $\quad$ ROSA Test SB-CL-18

- $\quad$ LOBI Test A1-04R

- $\quad$ LOFT L2-5 (1-D)

- $\quad$ LOFT L2-5 (3-D).

Noticeable differences were observed in the cases listed below:

- Water over steam (1-D) 
RELAP5-3D/4.0.3

- Water over steam (3-D)

- $\quad$ Bubbling steam through liquid

- $\quad$ Pryor pressure

- $\quad$ Marviken CFT-21

- $\quad$ Marviken CFT-22

- $\quad$ Marviken CFT-24

- $\quad$ GE level swell Test 1004-3

- $\quad$ GE level swell Test 5801-15

- $\quad$ Bennett heated tube Test 5358

- $\quad$ ORNL THTF Tests 3.07.9B and 3.09.10I

- $\quad$ FLECHT Test 31504

- $\quad$ FLECHT Test 31701

- $\quad$ UPTF Test 6

- $\quad$ MIT pressurizer Test ST4

- $\quad$ Neptunus Test Y05

- $\quad$ MB2

- $\quad$ LOFT Experiment L3-7

- $\quad$ ROSA Test SB-CL-18

- $\quad$ Semiscale natural circulation Tests $1,2,3$, and 10

- $\quad$ LOBI Test A1-04R

- $\quad$ LOFT Experiment L2-5 (1-D)

- $\quad$ LOFT Experiment L2-5 (3-D). 
The large number of differences is likely unique to this comparison, as it has been about six years since the last code version was released, and there have been a number of error corrections in the interim. All of the differences were reviewed, as well as differences in the nearly-implicit calculations, to determine their effect on the assessment findings. Changes were made in the assessment judgments for these cases:

- $\quad$ Bubbling steam through water

- $\quad$ Fill-Drain

- $\quad$ Manometer

- $\quad$ Point kinetics ramp

- $\quad$ ORNL THTF Test 3.07.9N

- $\quad$ Neptunus Test Y05

- $\quad$ LOFT L3-7

- $\quad$ LOFT L2-5 (1-D)

- $\quad$ LOFT L2-5 (3-D).

Further details are provided in Chapter 6. 
RELAP5-3D/4.0.3 


\section{DEVELOPMENTAL ASSESSMENT MATRIX}

Most of the text has been removed, although the first two sections have been maintained to preserve table numbering consistent with Volume III.

\subsection{Methodology and Case Selection}

\subsection{Matrix Summary}

Table 2.2-1 lists the phenomenological assessment cases and the principal phenomena or code models that each addresses.

Table 2.2-1. Phenomenological assessment cases.

\begin{tabular}{|l|l|}
\hline \multicolumn{1}{|c|}{ Case Description } & \multicolumn{1}{c|}{ Models Validated } \\
\hline \hline Bubbling steam through liquid & Level tracking, entrainment \\
\hline Conduction enclosure & Conduction enclosure \\
\hline Conduction enclosure 1-D transient & Conduction enclosure \\
\hline Conduction enclosure 2-D transient & Conduction enclosure \\
\hline Core power & Point kinetics \\
\hline Fill/drain & Level tracking \\
\hline Gravity wave 1-D & Stratification, force term \\
\hline Gravity wave 3-D & Stratification, force term \\
\hline Manometer & $\begin{array}{l}\text { Noncondensables, wall friction, liquid level, } \\
\text { oscillations }\end{array}$ \\
\hline Point kinetics ramp & Point kinetics \\
\hline Pryor pressure comparison & Water packing \\
\hline Pure radial symmetric flow (3-D) & 3-D momentum equations \\
\hline Rigid body rotation (3-D) & 3-D momentum equations \\
\hline R-theta symmetric flow (3-D) & 3-D momentum equations \\
\hline Water faucet & Hydro numerics, gravity, momentum equation \\
\hline Water over steam (1-D) & Gravitational head, liquid level, gravity \\
\hline Water over steam (3-D) & Gravitational head, liquid level, gravity \\
\hline
\end{tabular}


The separate effects cases and the phenomena they address are provided in Table 2.2-2.The full-scale pump test calculation was not performed for Version 2.4.2, as this model was not available in that code version.

Table 2.2-2. Separate effects assessment cases.

\begin{tabular}{|c|c|}
\hline Case Description & Models Validated \\
\hline Bennett Heated Tube Tests 5358, 5294 and 5394 & $\begin{array}{l}\text { Non-equilibrium heat transfer, CHF, subcooled } \\
\text { boiling, steam cooling }\end{array}$ \\
\hline Christensen Test 15 & Subcooled boiling heat transfer, void profile \\
\hline Dukler air-water flooding & CCFL \\
\hline Edwards' Pipe & $\begin{array}{l}\text { Vapor generation, flashing, critical flow, pressure } \\
\text { wave propagation }\end{array}$ \\
\hline FLECHT-SEASET Test 31504 & $\begin{array}{l}\text { Reflood model (low reflood rate), two-phase level, } \\
\text { natural circulation, subcooled boiling, steam } \\
\text { cooling, quench front, interphase evaporation, } \\
\text { entrainment, CCFL, condensation heat transfer }\end{array}$ \\
\hline FLECHT-SEASET Test 31701 & $\begin{array}{l}\text { Reflood model (high reflood rate), two-phase } \\
\text { level, steam cooling, entrainment, CCFL, } \\
\text { condensation heat transfer, quench front }\end{array}$ \\
\hline Full-scale reactor coolant pump & Two-phase pump behavior \\
\hline GE 1/6-scale jet pump & Jet pump \\
\hline GE Level Swell, 1 ft. Test 1004-3 & Vapor generation, interphase drag, two-phase level \\
\hline GE Level Swell, 4 ft. Test 5801-15 & Vapor generation, interphase drag, two-phase level \\
\hline LOFT L3-1 & Accumulator model \\
\hline Marviken Test 22 & $\begin{array}{l}\text { Subcooled choking model, flashing, two-phase } \\
\text { level }\end{array}$ \\
\hline Marviken Test 24 & $\begin{array}{l}\text { Subcooled choking model, flashing, two-phase } \\
\text { level }\end{array}$ \\
\hline Marviken Test CFT 21 & $\begin{array}{l}\text { Subcooled critical flow, saturated liquid critical } \\
\text { flow }\end{array}$ \\
\hline Marviken Test JIT 11 & $\begin{array}{l}\text { Saturated vapor critical flow, interfacial drag in } \\
\text { bubbly/slug, pool boiling, void profile }\end{array}$ \\
\hline MB2 Test 1712 & Steam generator behavior \\
\hline MIT Pressurizer & $\begin{array}{l}\text { Wall condensation, interfacial heat transfer, } \\
\text { pressurizer level, thermal stratification }\end{array}$ \\
\hline Moby Dick air-water & Critical flow \\
\hline Neptunus & Pressurizer \\
\hline
\end{tabular}


Table 2.2-2. Separate effects assessment cases.

\begin{tabular}{|l|l|}
\hline \multicolumn{1}{|c|}{ Case Description } & \multicolumn{1}{c|}{ Models Validated } \\
\hline \hline ORNL THTF Tests 3.07.9B, 3.07.9N, 3.07.9W & CHF, film boiling, steam cooling \\
\hline ORNL THTF Test 3.09.10 & Void profile in rod bundles, radiation heat transfer \\
\hline Royal Institute of Technology Tube Test 261 & CHF \\
\hline $\begin{array}{l}\text { UPTF Downcomer Countercurrent Flow Test 6, } \\
\text { Run 131 }\end{array}$ & $\begin{array}{l}\text { Downcomer CCFL, lower plenum refill, } \\
\text { condensation, noncondensables, two-phase level, } \\
\text { thermal stratification, interphase drag, entrainment }\end{array}$ \\
\hline
\end{tabular}

Table 2.2-3 presents the integral effects cases.

Table 2.2-3. Integral effects assessment cases.

\begin{tabular}{|l|l|}
\hline \multicolumn{1}{|c|}{ Case Description } & \multicolumn{1}{c|}{ Experiment Type } \\
\hline \hline LOBI Test A1-04R & Large break LOCA \\
\hline LOFT L2-5 (1-D) & Large break LOCA \\
\hline LOFT L2-5 (3-D) & Large break LOCA \\
\hline LOFT L3-7 & 1-in. small break LOCA \\
\hline ROSA-IV Test SB-CL-18 & 6-in. small break LOCA \\
\hline Semiscale NC Tests 1,2,3,10 & Loop natural circulation \\
\hline
\end{tabular}


RELAP5-3D/4.0.3 


\section{PHENOMENOLOGICAL CASES}

This chapter presents the phenomenological assessment case results. 


\subsection{Water Faucet}

Figures comparing simulations using two code versions are presented. Diagrams are included so that the figure numbering is the same as that in Volume III of the RELAP5-3D code manual. No differences were observed in the figures.

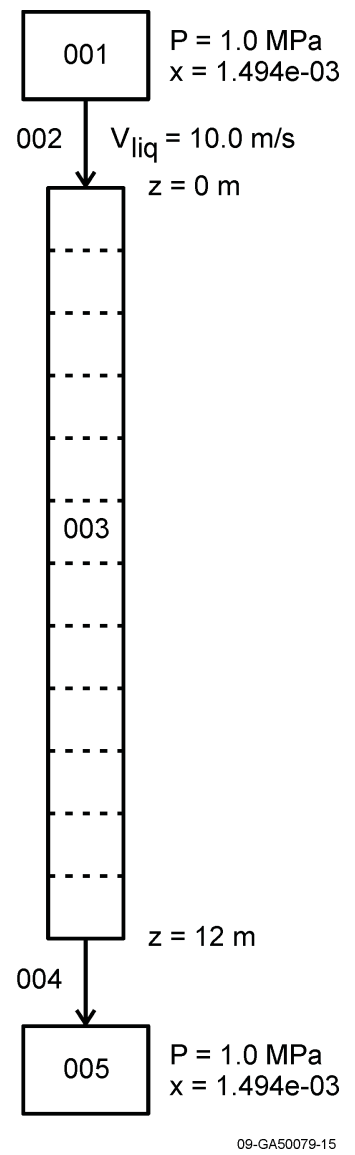

Figure 3.1-1. RELAP5-3D nodalization for the water faucet test case. 


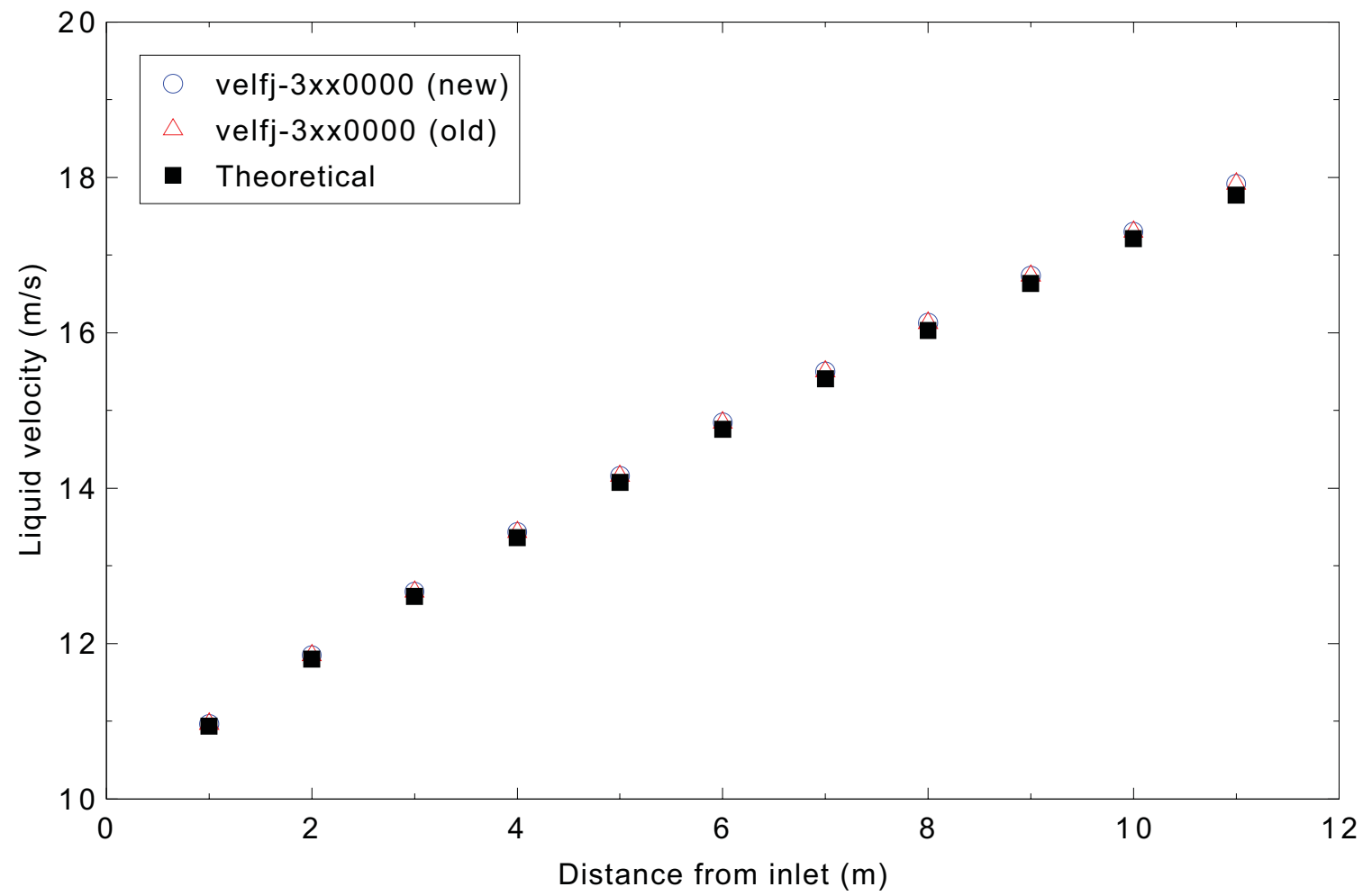

Figure 3.1-2. Comparison of RELAP5-3D calculated liquid velocity with the exact solution for the water faucet case.

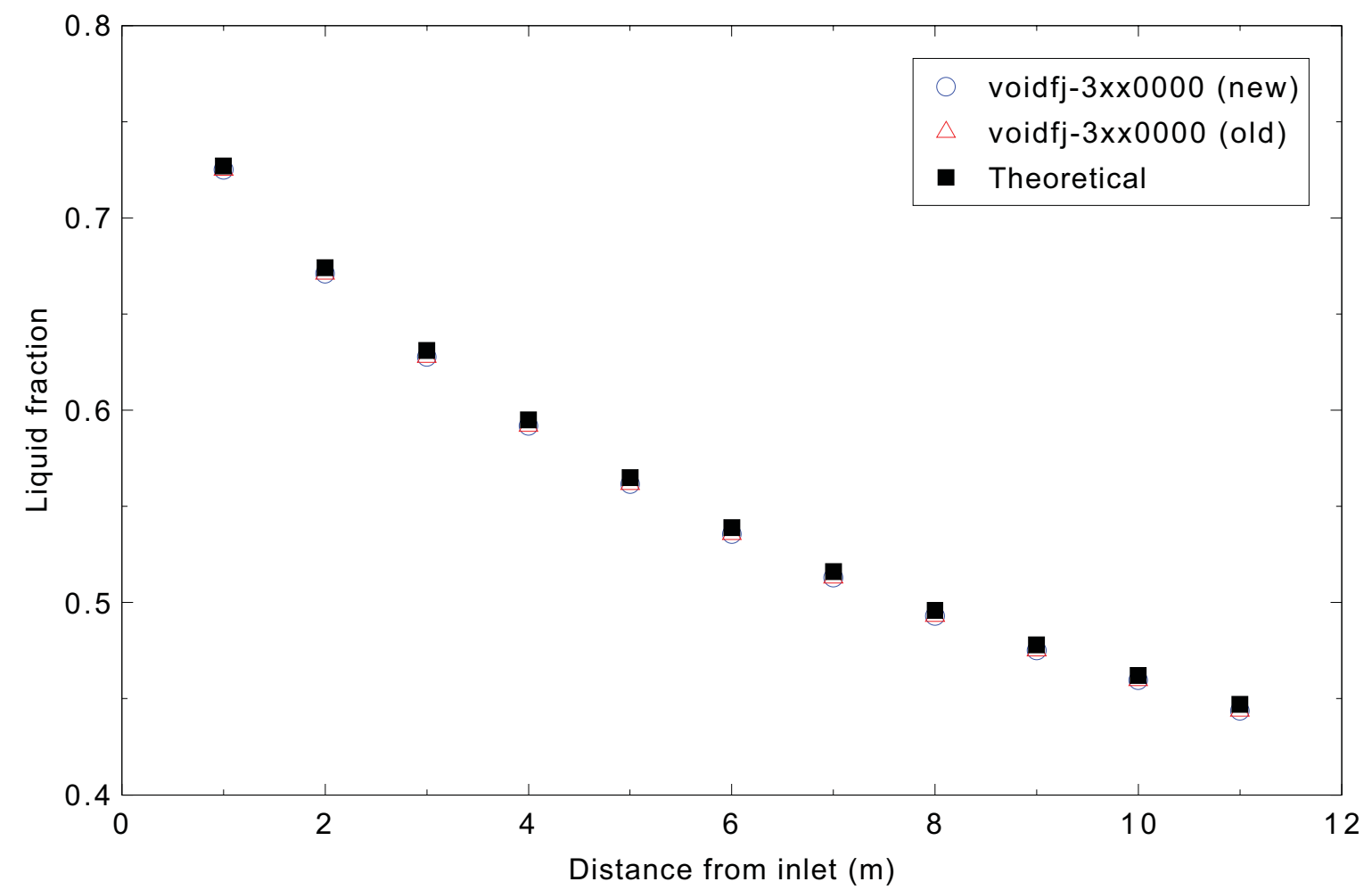

Figure 3.1-3. Comparison of RELAP5-3D calculated liquid fraction with the exact solution for the water faucet case. 


\subsection{Water over Steam (1-D)}

Figures comparing simulations using two code versions are presented. Diagrams are included so that the figure numbering is the same as that in Volume III of the RELAP5-3D code manual. Noticeable differences were observed in Figures 3.2-2, 3, and 4.

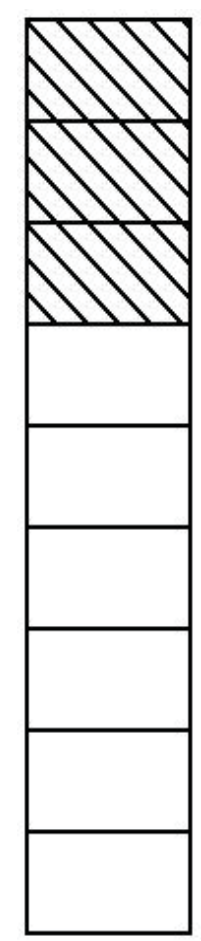

Figure 3.2-1. RELAP5-3D nodalization diagram for the 1-D water over steam problem. 


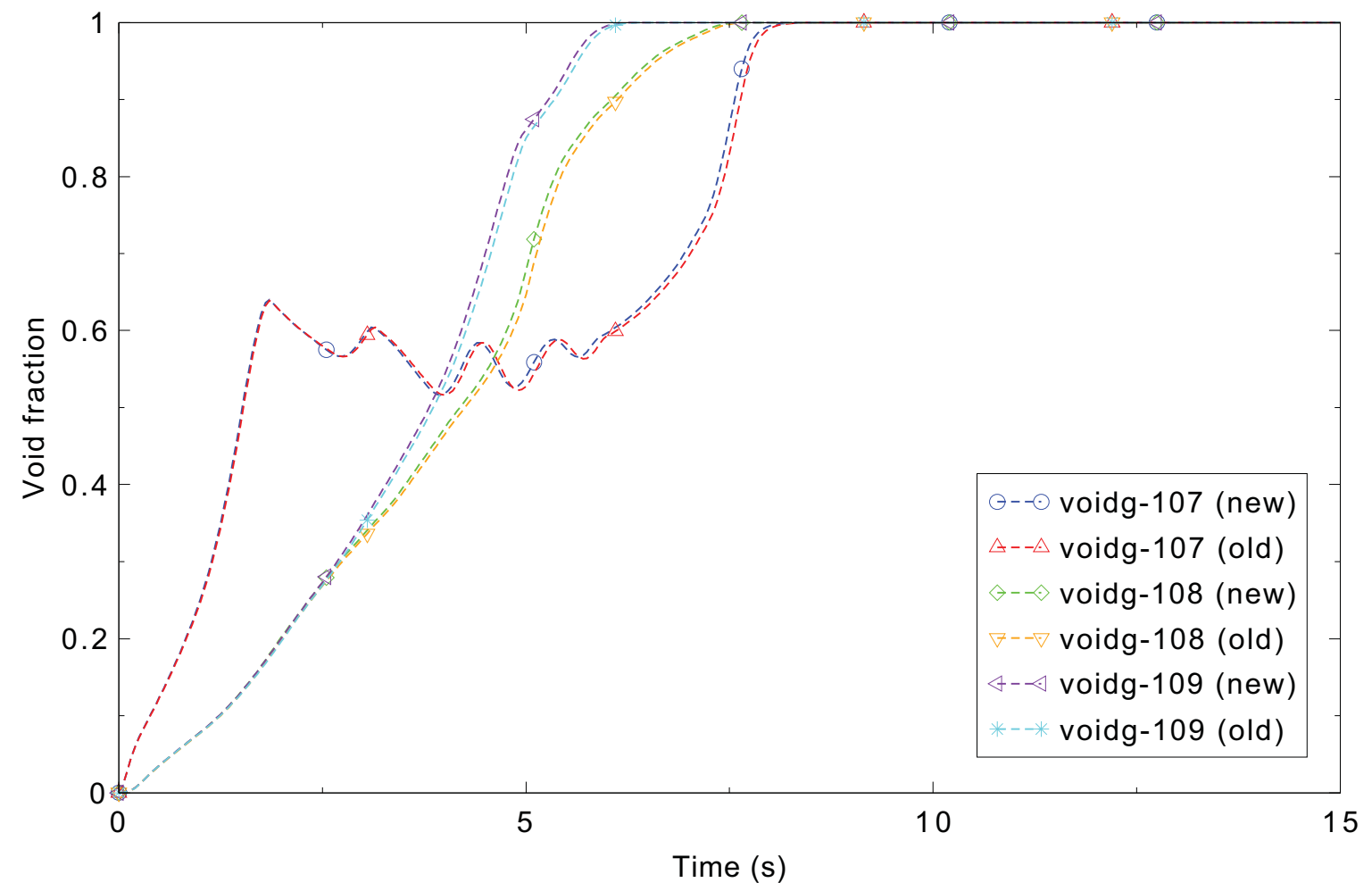

Figure 3.2-2. Void fraction in the top three volumes (7-9) for the 1-D water over steam problem.

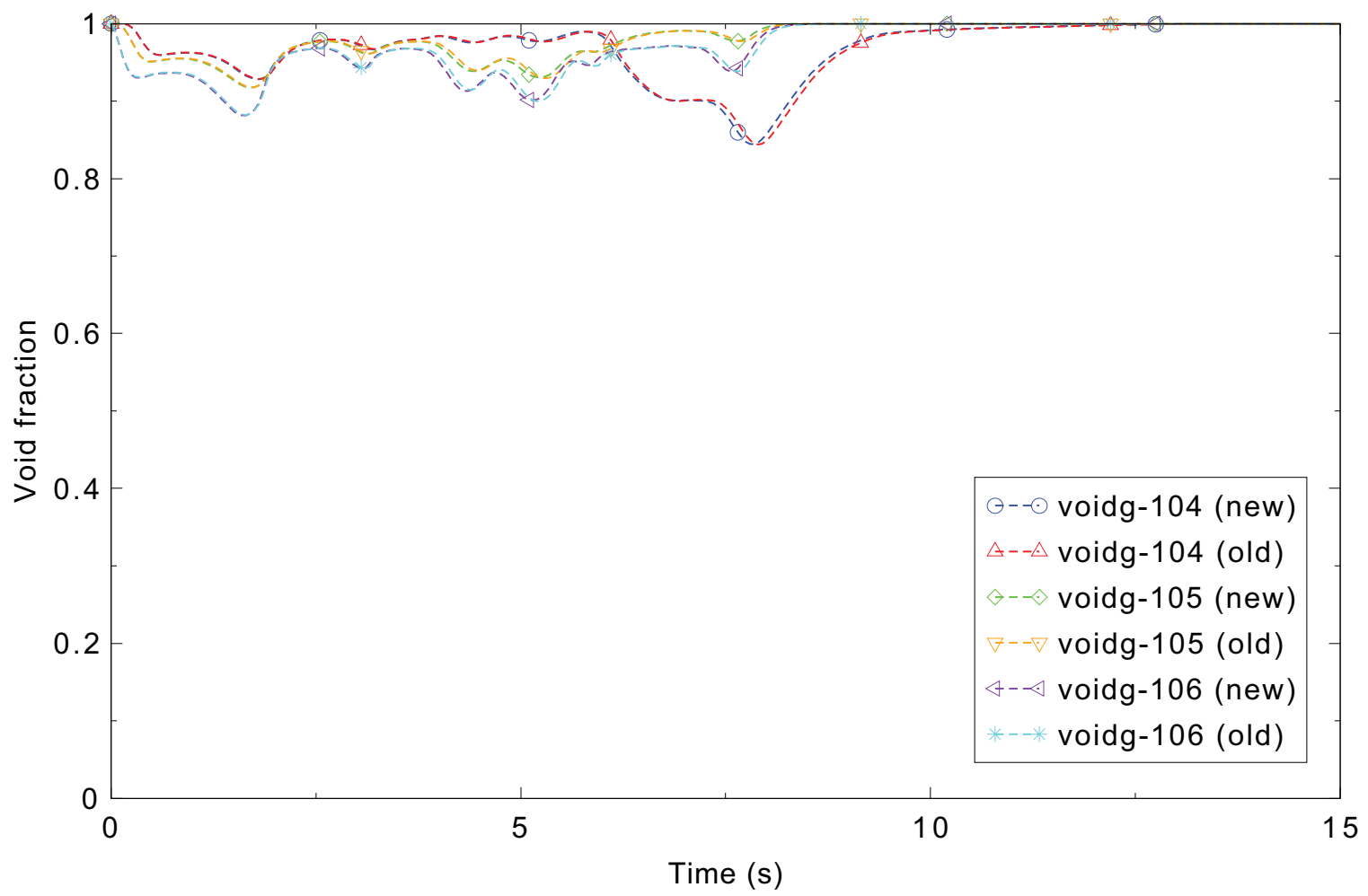

Figure 3.2-3. Void fraction in the middle three volumes (4-6) for the 1-D water over steam problem. 


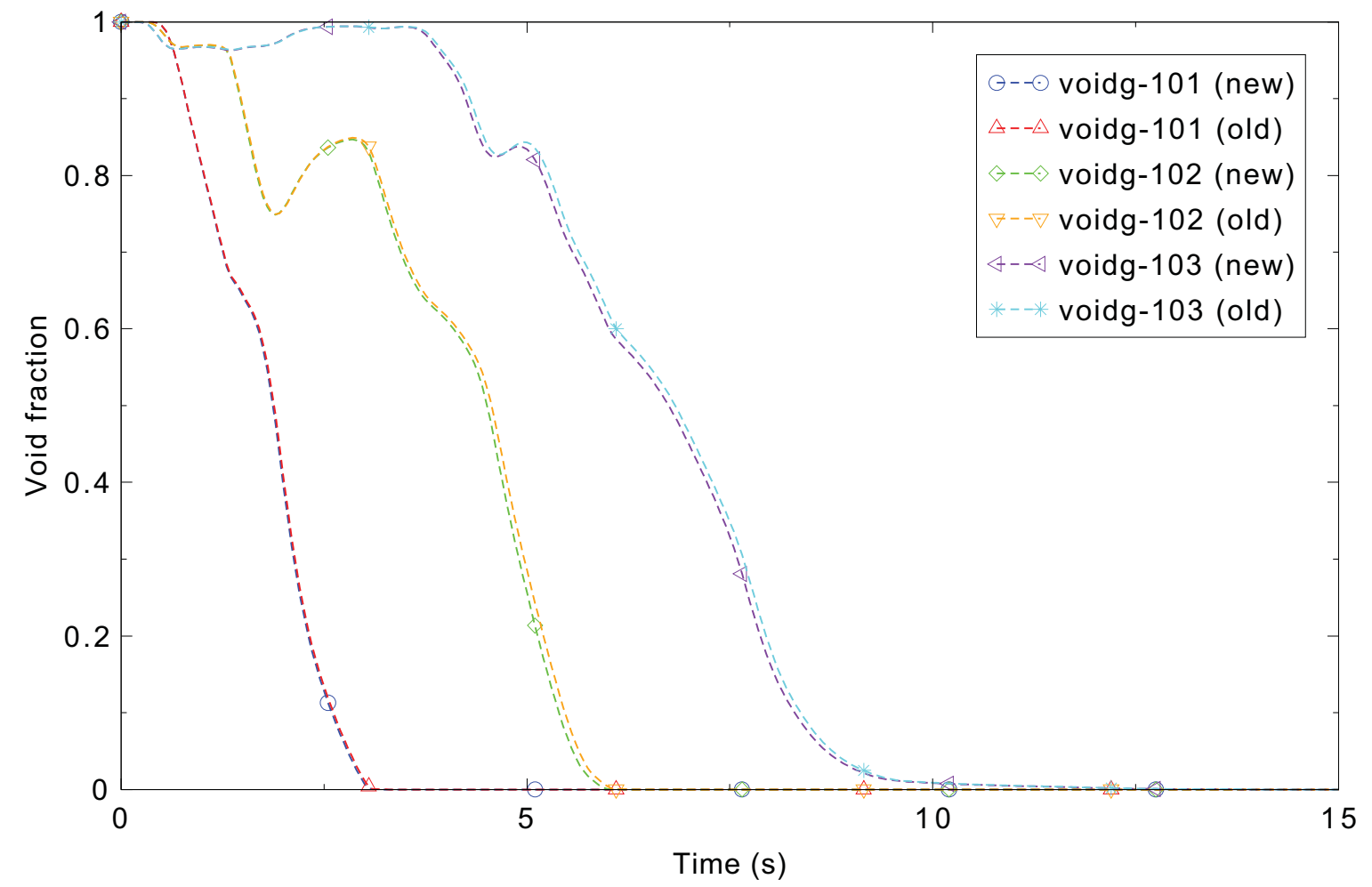

Figure 3.2-4. Void fraction in the bottom three volumes (1-3) for the 1-D water over steam problem. 


\subsection{Water over Steam (3-D)}

Figures comparing simulations using two code versions are presented. Diagrams are included so that the figure numbering is the same as that in Volume III of the RELAP5-3D code manual. Noticeable differences were observed in Figures 3.3-2, 3, 4, and 5.

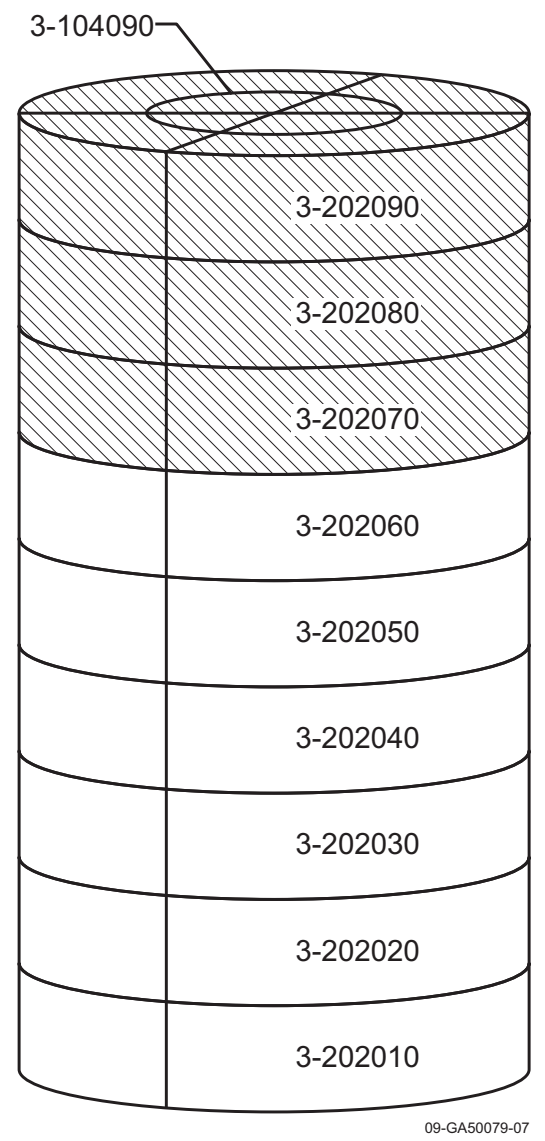

Figure 3.3-1. RELAP5-3D nodalization diagram for the 3-D water over steam problem. 


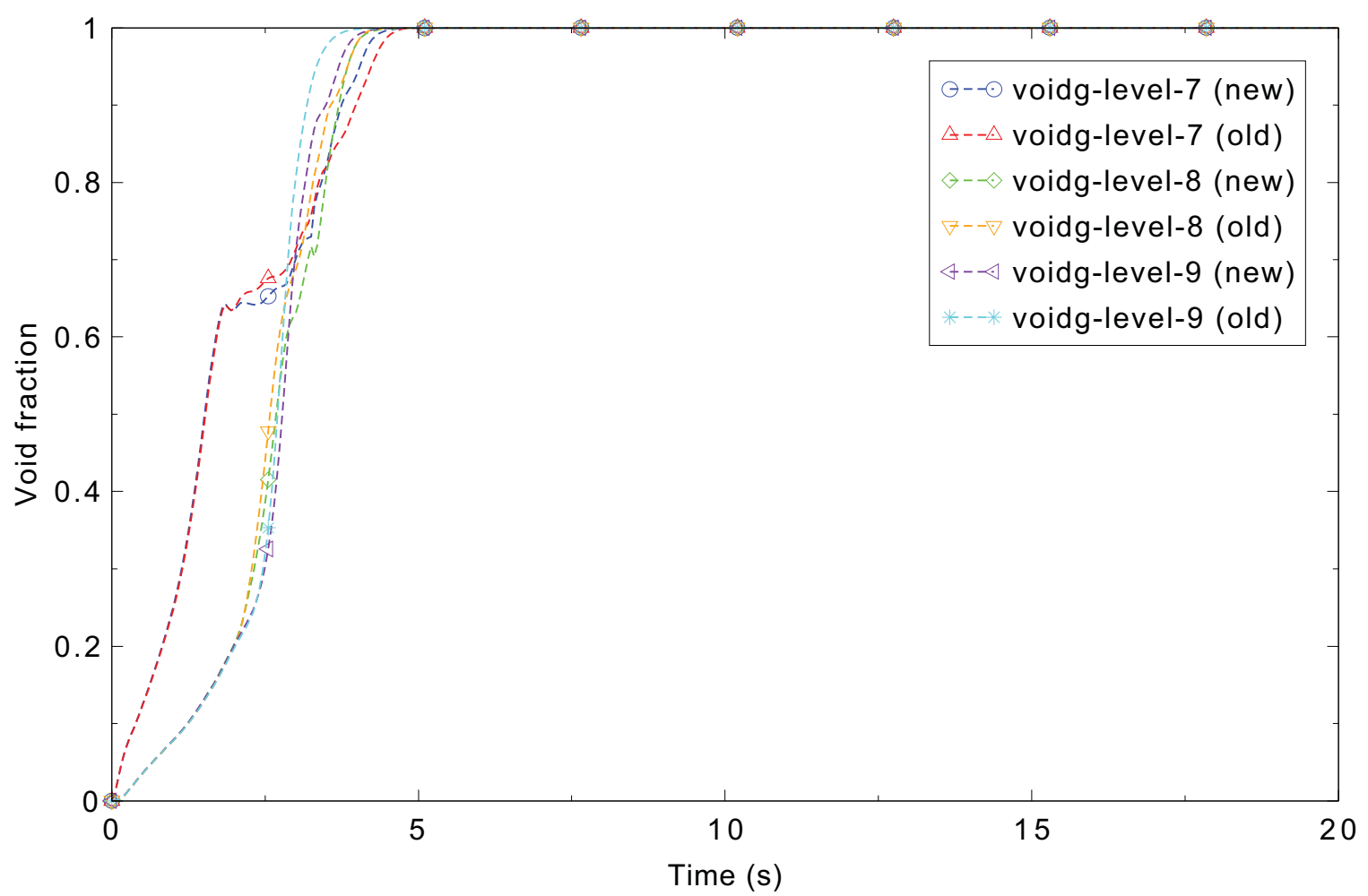

Figure 3.3-2. Void fraction in the top three axial levels (7-9) for the 3-D water over steam problem.

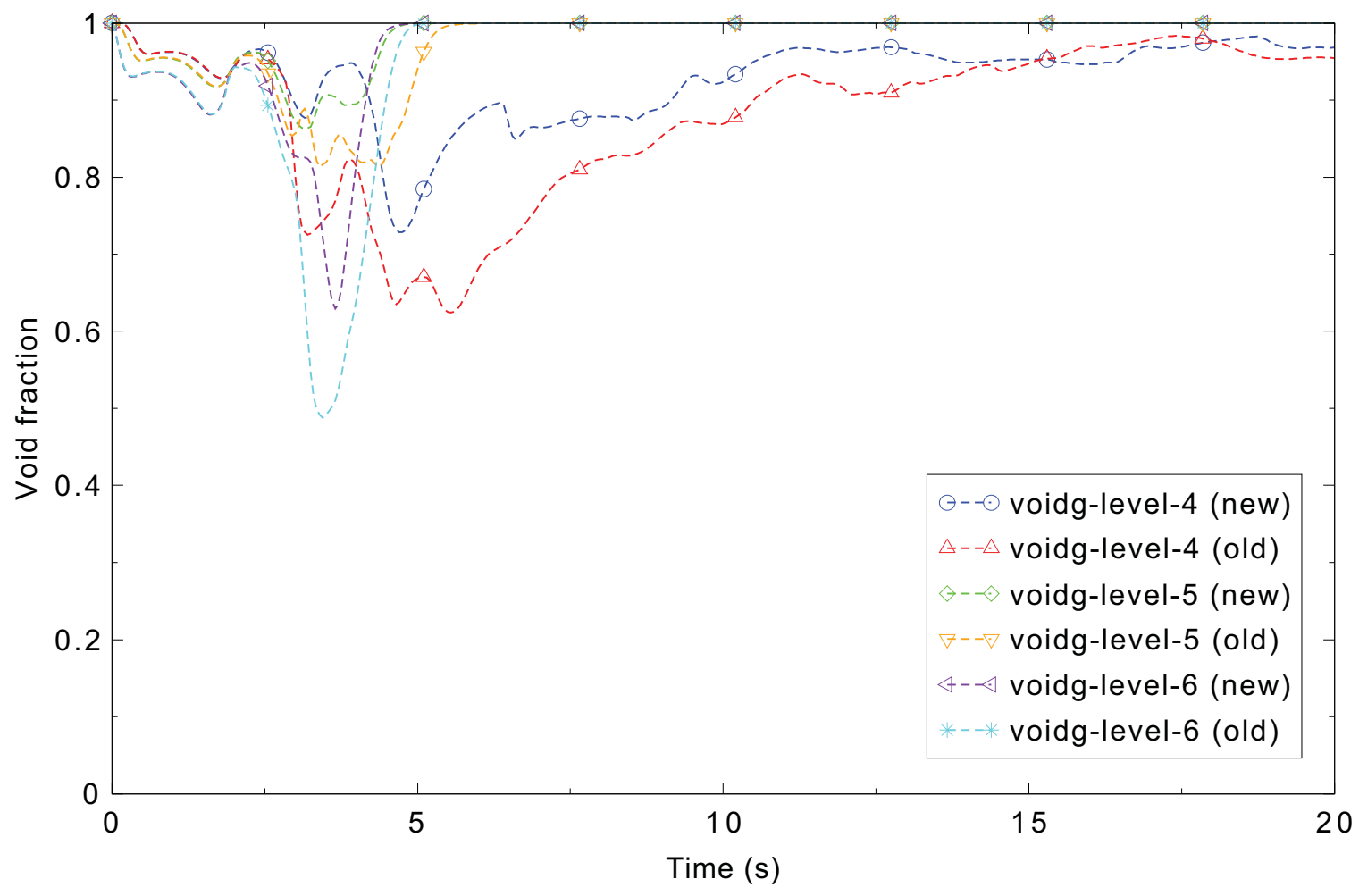

Figure 3.3-3. Void fraction in the middle three axial levels (4-6) for the 3-D water over steam problem. 


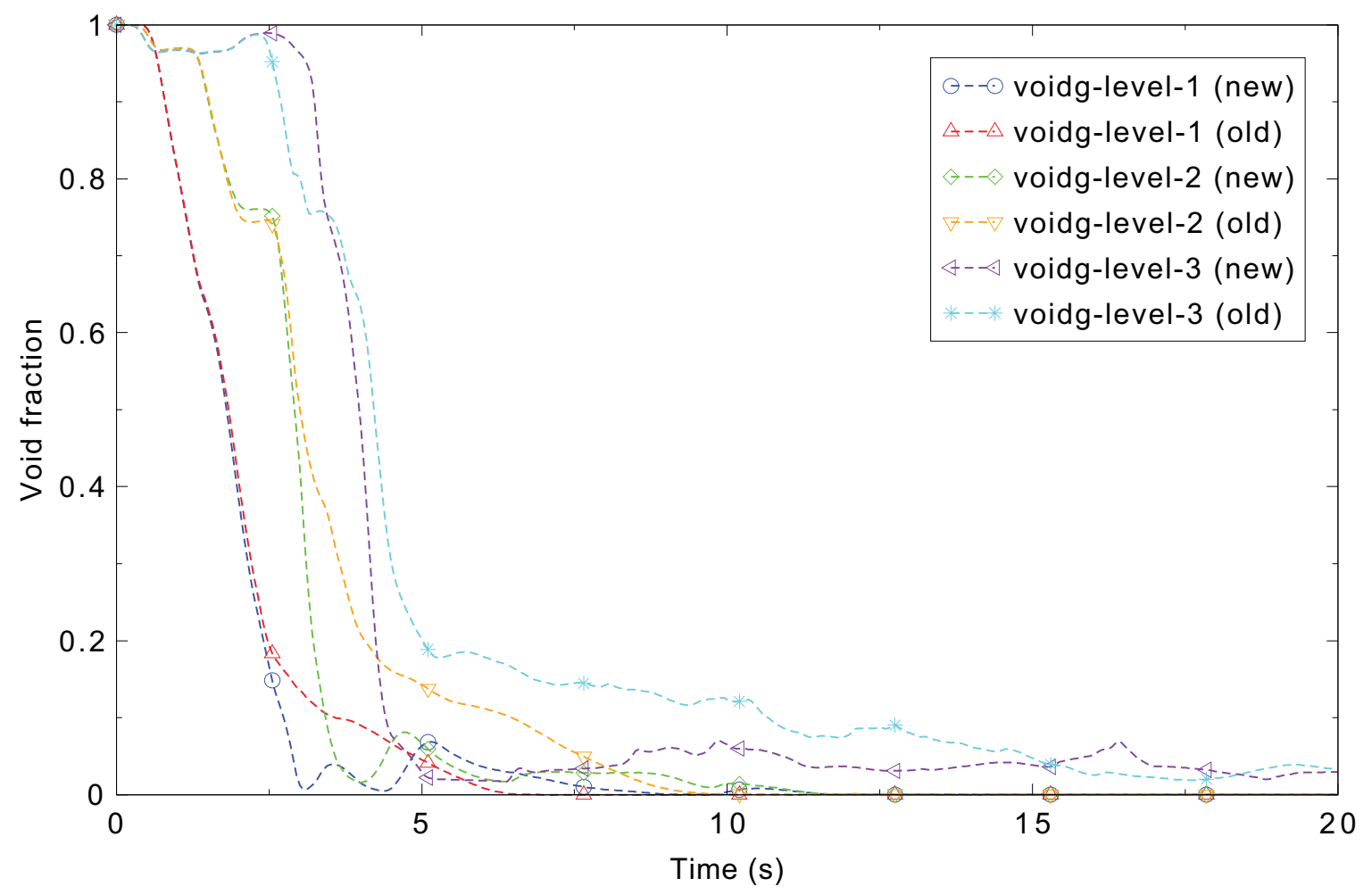

Figure 3.3-4. Void fraction in the bottom three axial levels (1-3) for the 3-D water over steam problem.

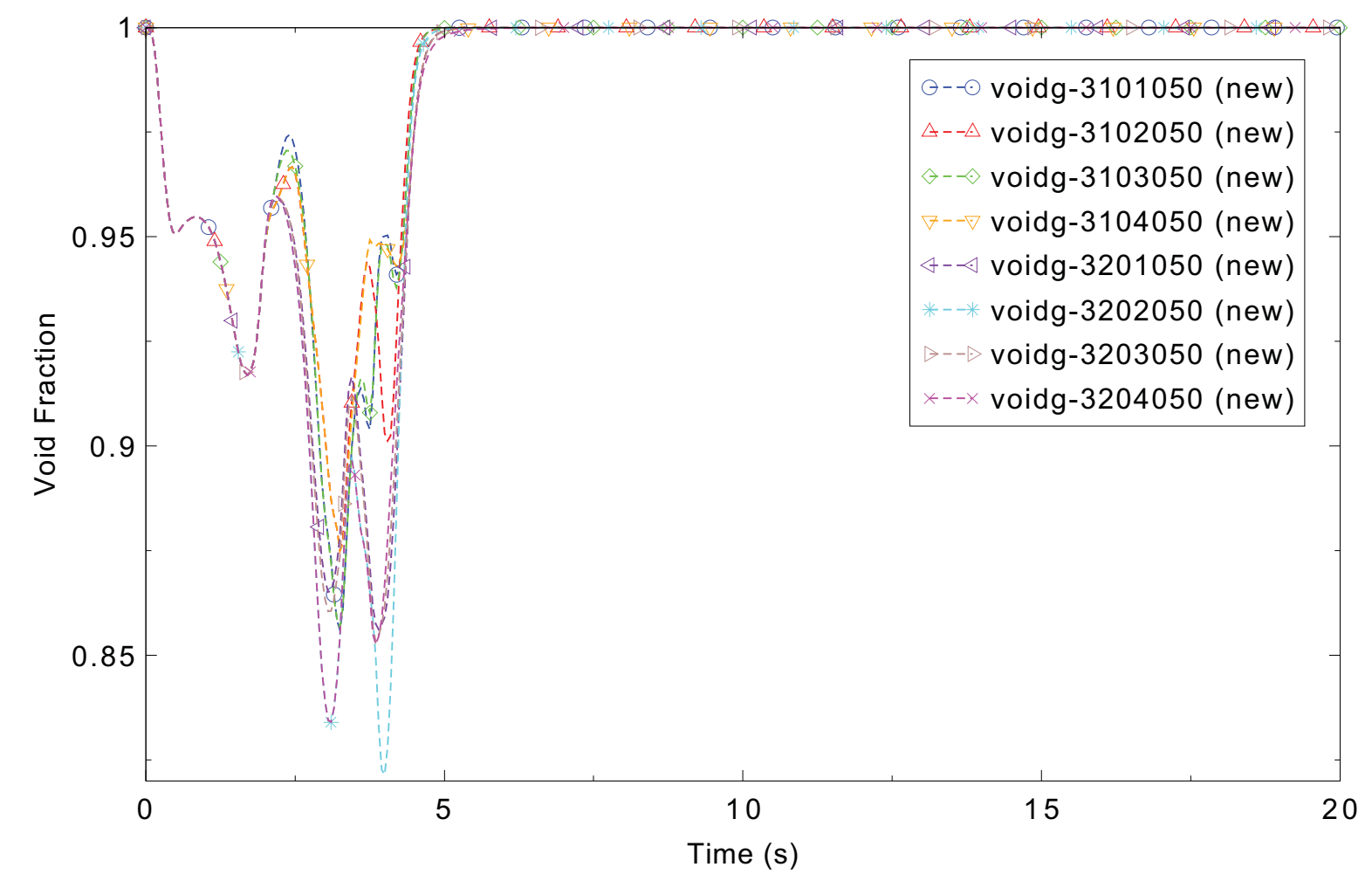

Figure 3.3-5. Void fraction in each of the eight segments of axial level 5 for the 3-D water over steam problem. 


\subsection{Fill-Drain}

Figures comparing simulations using two code versions are presented. Diagrams are included so that the figure numbering is the same as that in Volume III of the RELAP5-3D code manual. No differences were observed in the figures.

The test problem, shown at the right in Figure 3.4-1, uses a 10-volume vertical pipe (Component 3 ) with a time-dependent junction (Component 2) adding liquid to and then removing liquid from the bottom volume of the pipe. The top is connected to a time-dependent volume (Component 5) at atmospheric pressure. The pipe is oriented such that volume 1 is at the bottom and volume 10 is at the top. It is initially filled with vapor at atmospheric pressure. The time-dependent junction starts filling the pipe at time 0 and continues to $50 \mathrm{~s}$. Then it reverses direction and starts draining the liquid until $100 \mathrm{~s}$ when the problem ends. During the first $50 \mathrm{~s}$, the liquid fills each volume in turn and by $50 \mathrm{~s}$, when the fill reverses, volume 5 is filled to $46 \%$. A time step size of $0.05 \mathrm{~s}$ was used for both the semi-implicit and nearly-implicit advancement schemes.

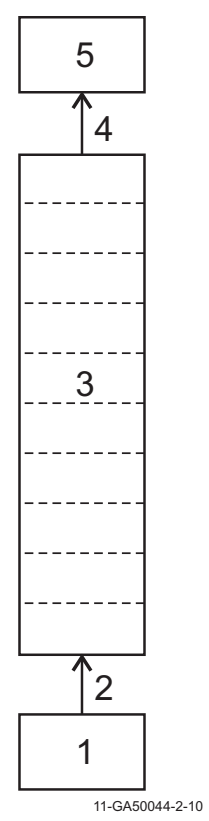

Figure 3.4-1. Nodalization diagram for Fill-Drain test. 


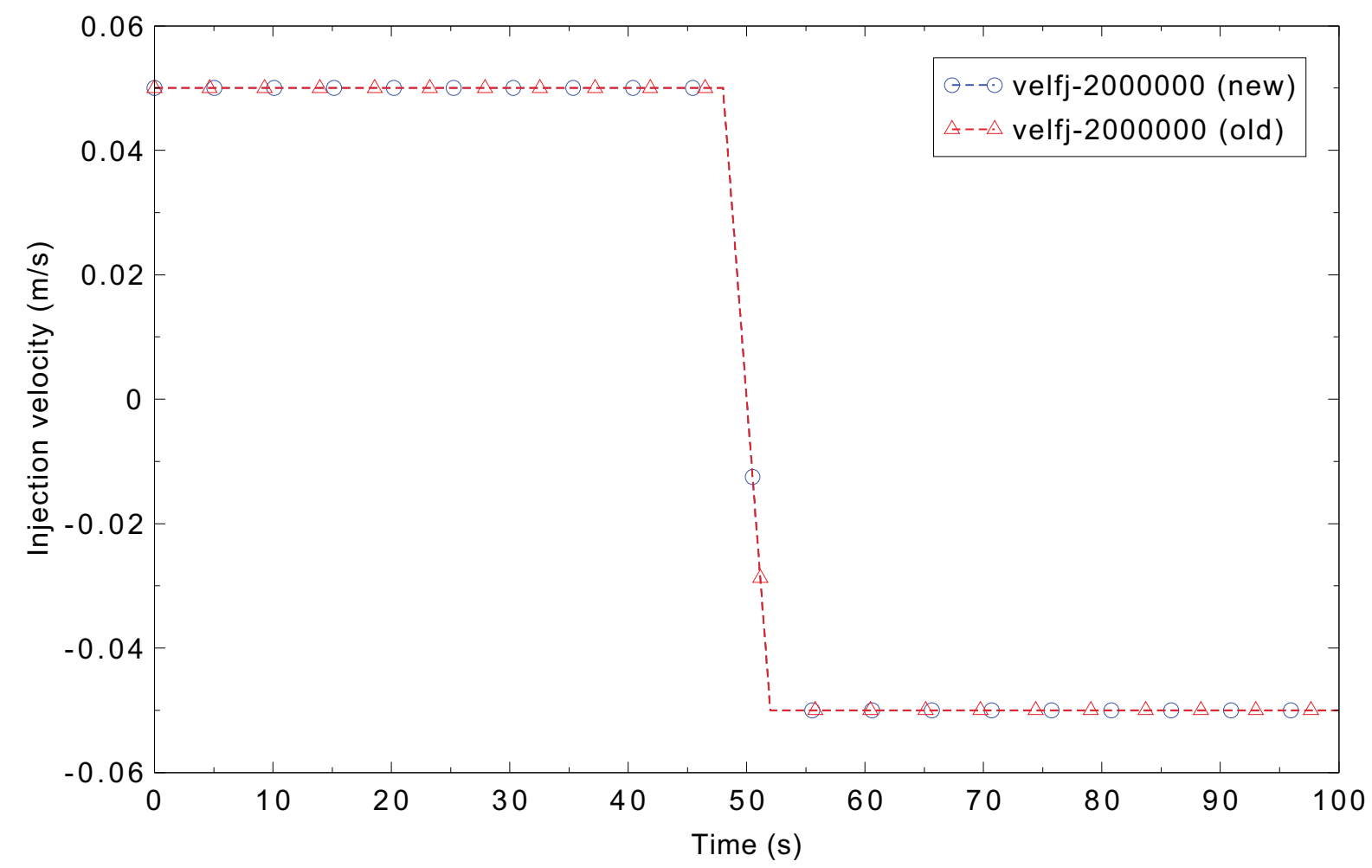

Figure 3.4-2. Injection flow liquid velocity comparison for the Fill-Drain test.

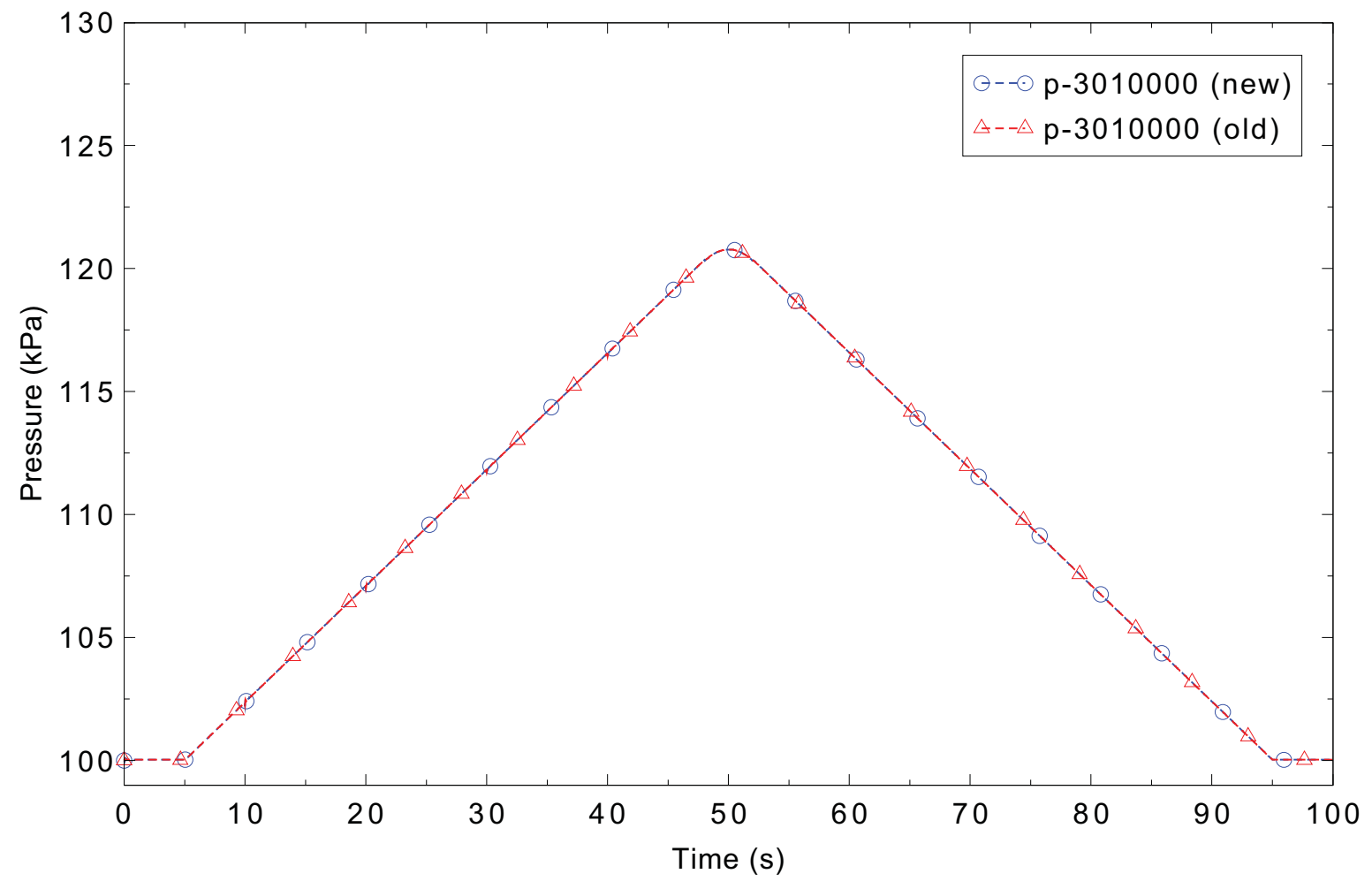

Figure 3.4-3. Bottom volume pressure comparison for the Fill-Drain test. 


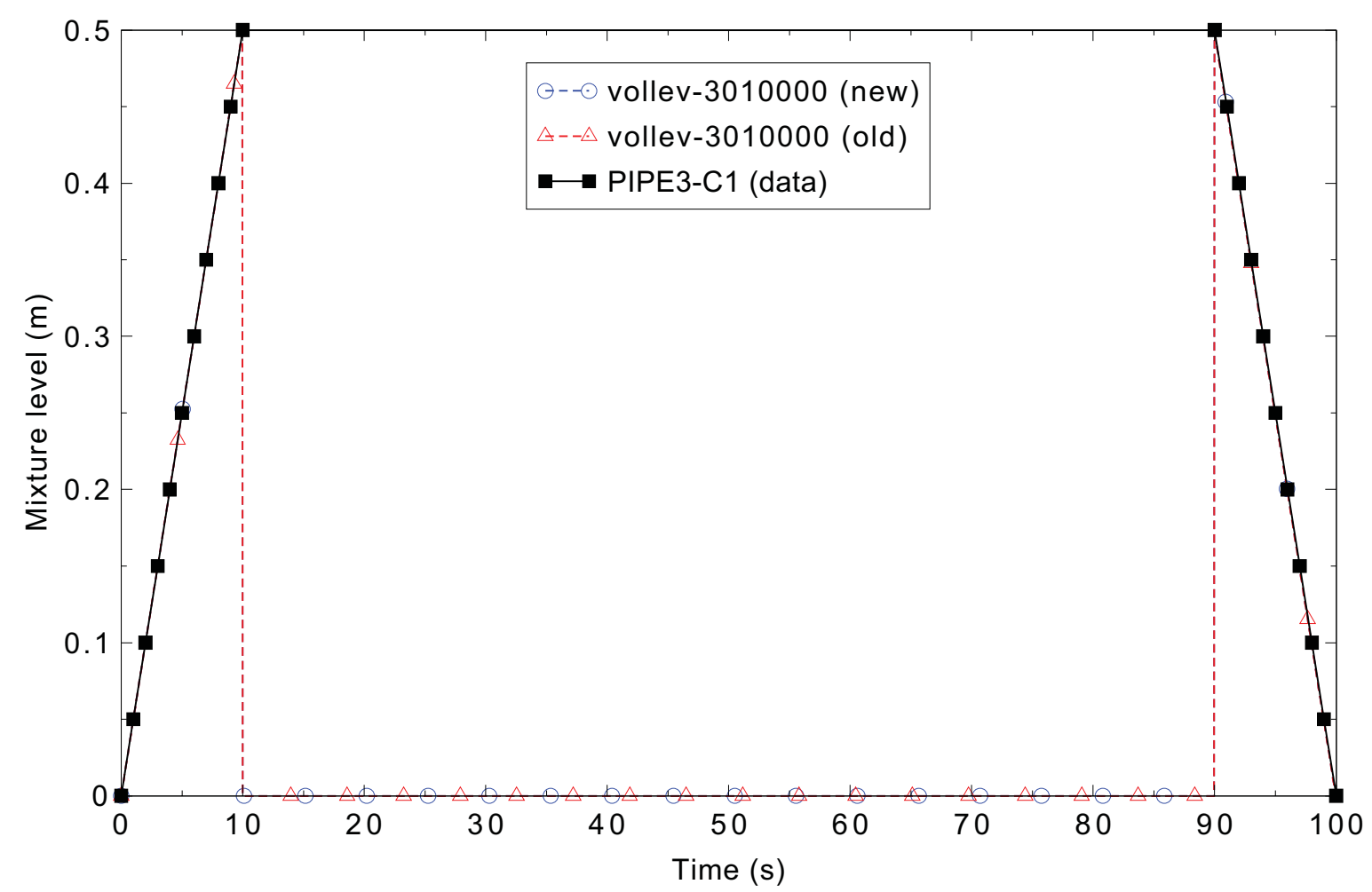

Figure 3.4-4. Mixture level comparison in volume 3-01 for the Fill-Drain test.

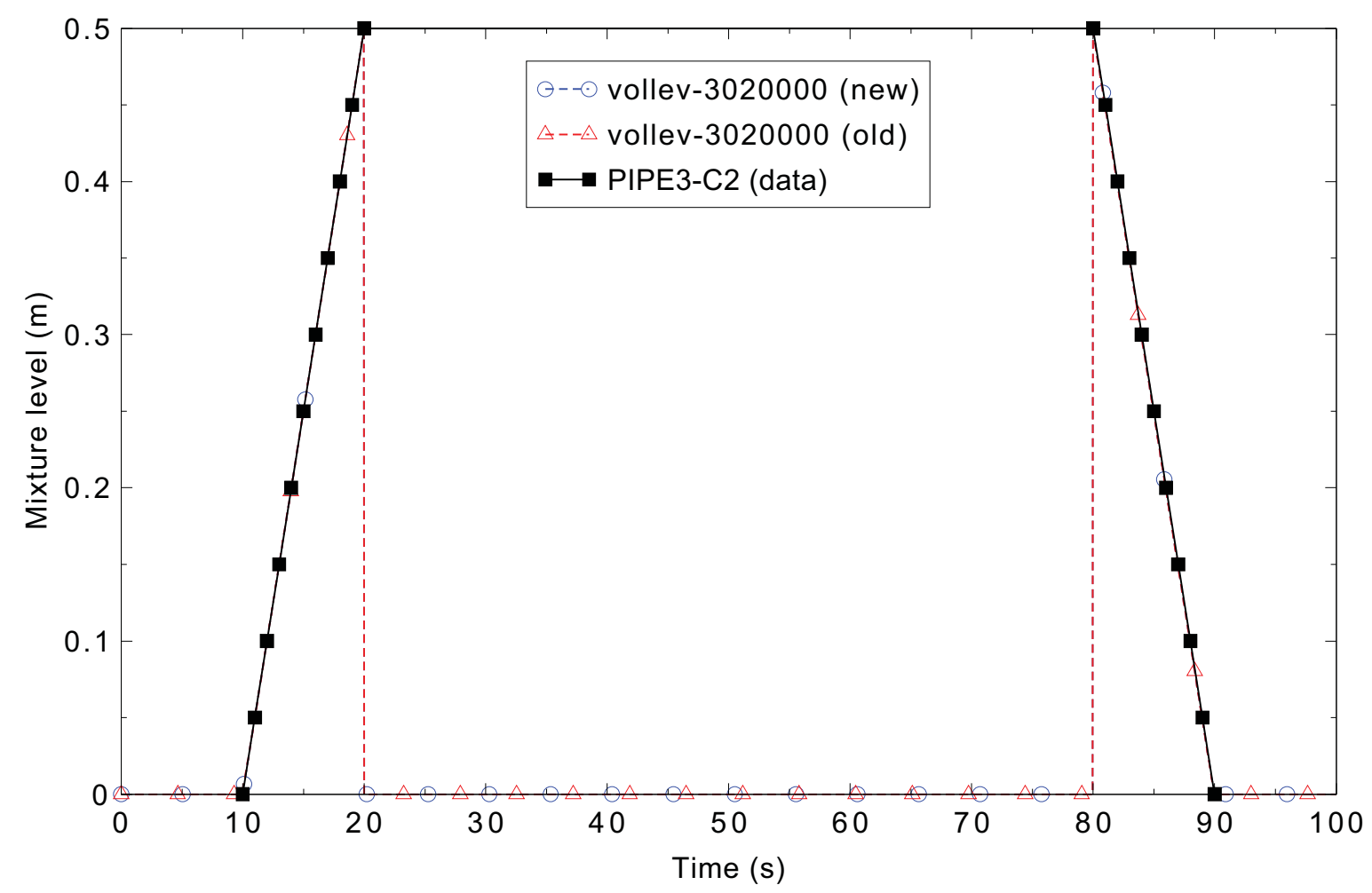

Figure 3.4-5. Mixture level comparison in volume 3-02 for the Fill-Drain test. 


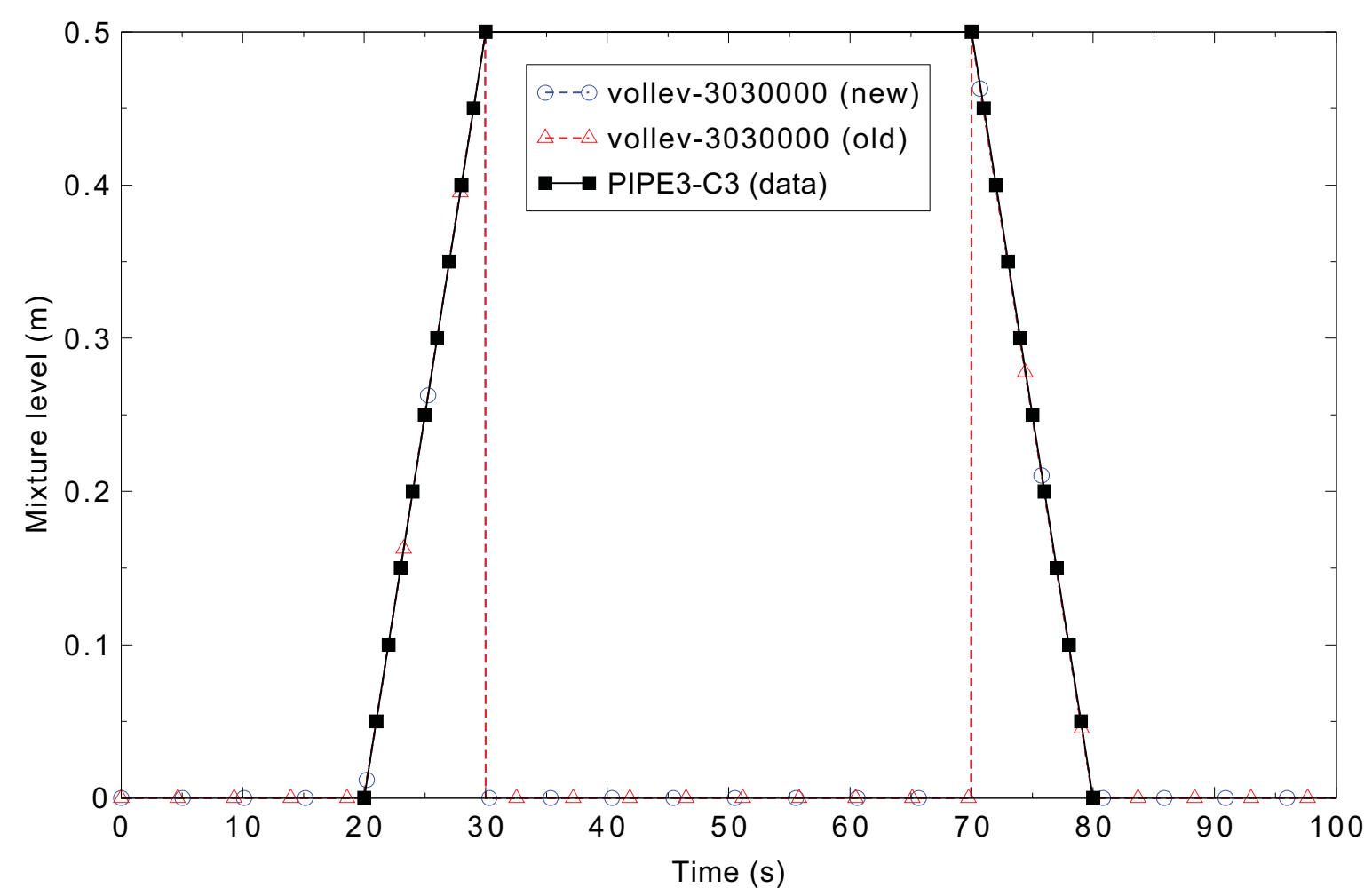

Figure 3.4-6. Mixture level comparison in volume 3-03 for the Fill-Drain test.

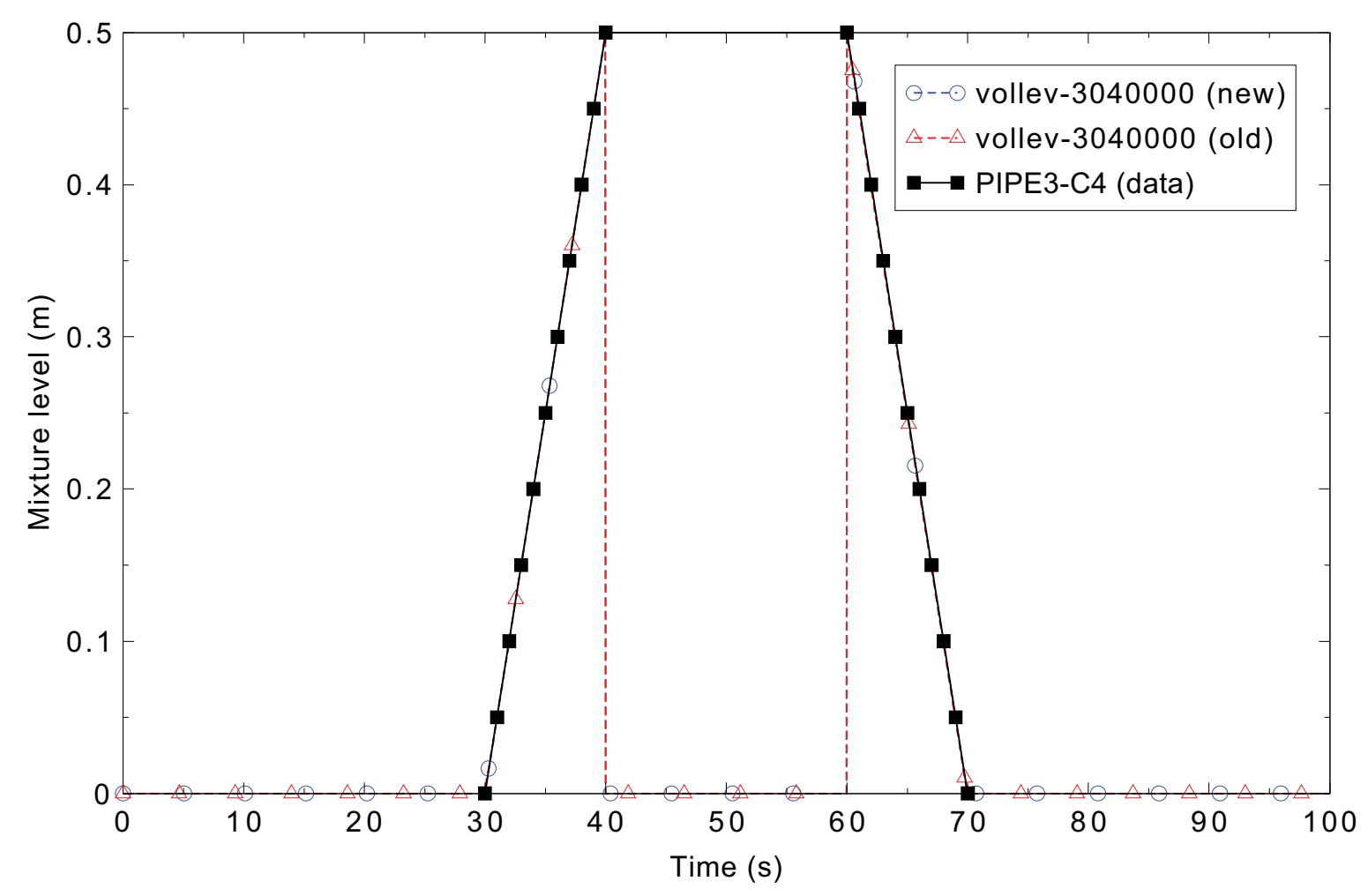

Figure 3.4-7. Mixture level comparison in volume 3-04 for the Fill-Drain test. 


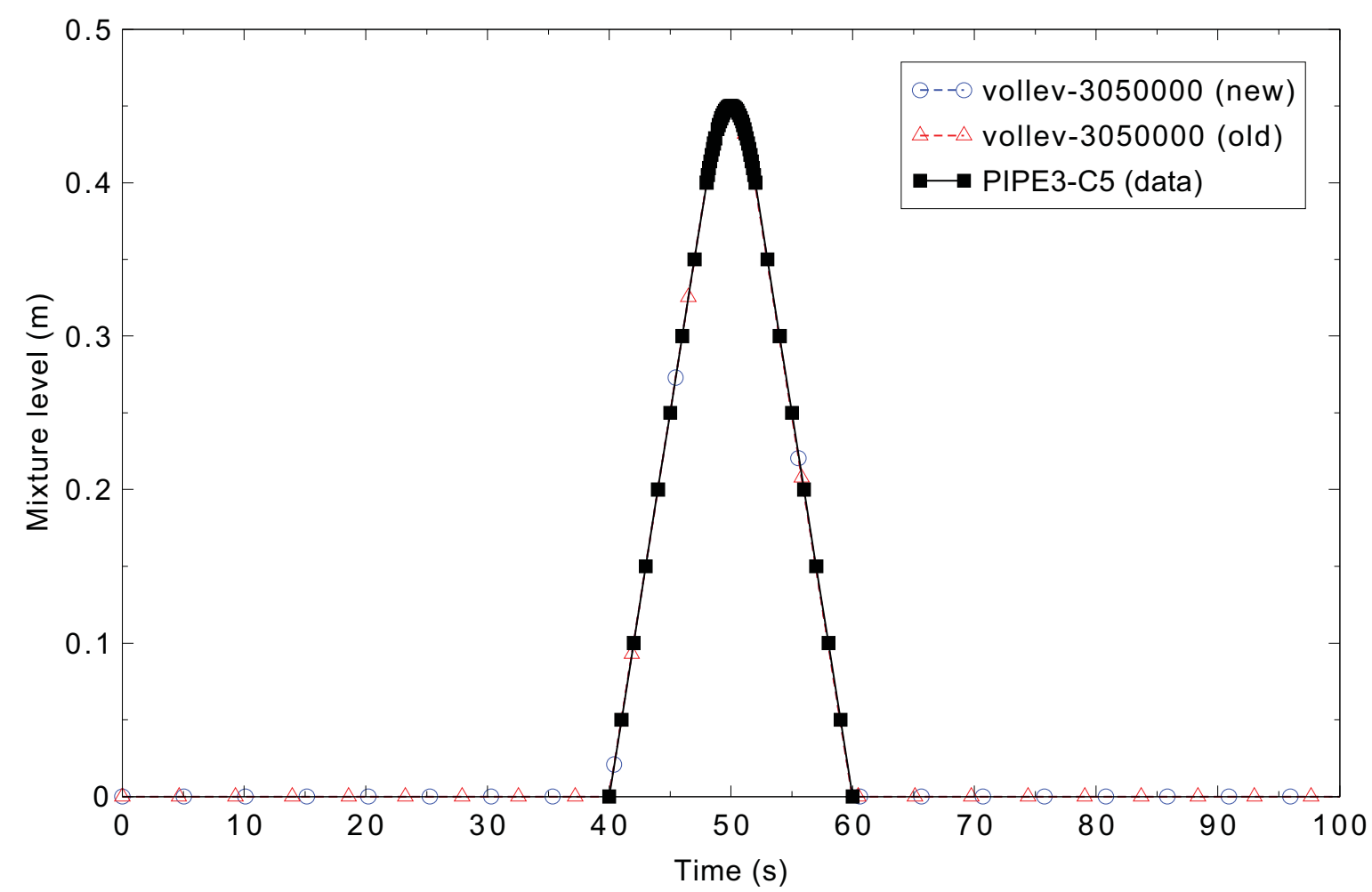

Figure 3.4-8. Mixture level comparison in volume 3-05 for the Fill-Drain test. 


\subsection{Bubbling Steam through Liquid}

Figures comparing simulations using two code versions are presented. Diagrams are included so that the figure numbering is the same as that in Volume III of the RELAP5-3D code manual. Noticeable differences were observed in Figures 3.5-3, 4, 5, and 6.

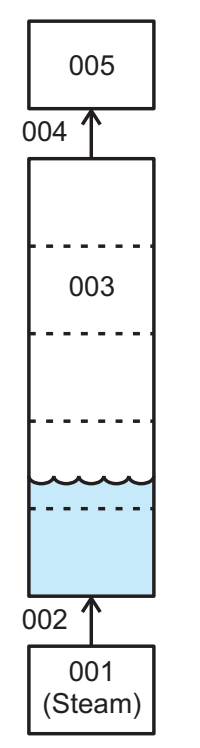

Figure 3.5-1. RELAP5-3D nodalization for the bubbling steam through liquid test case. 


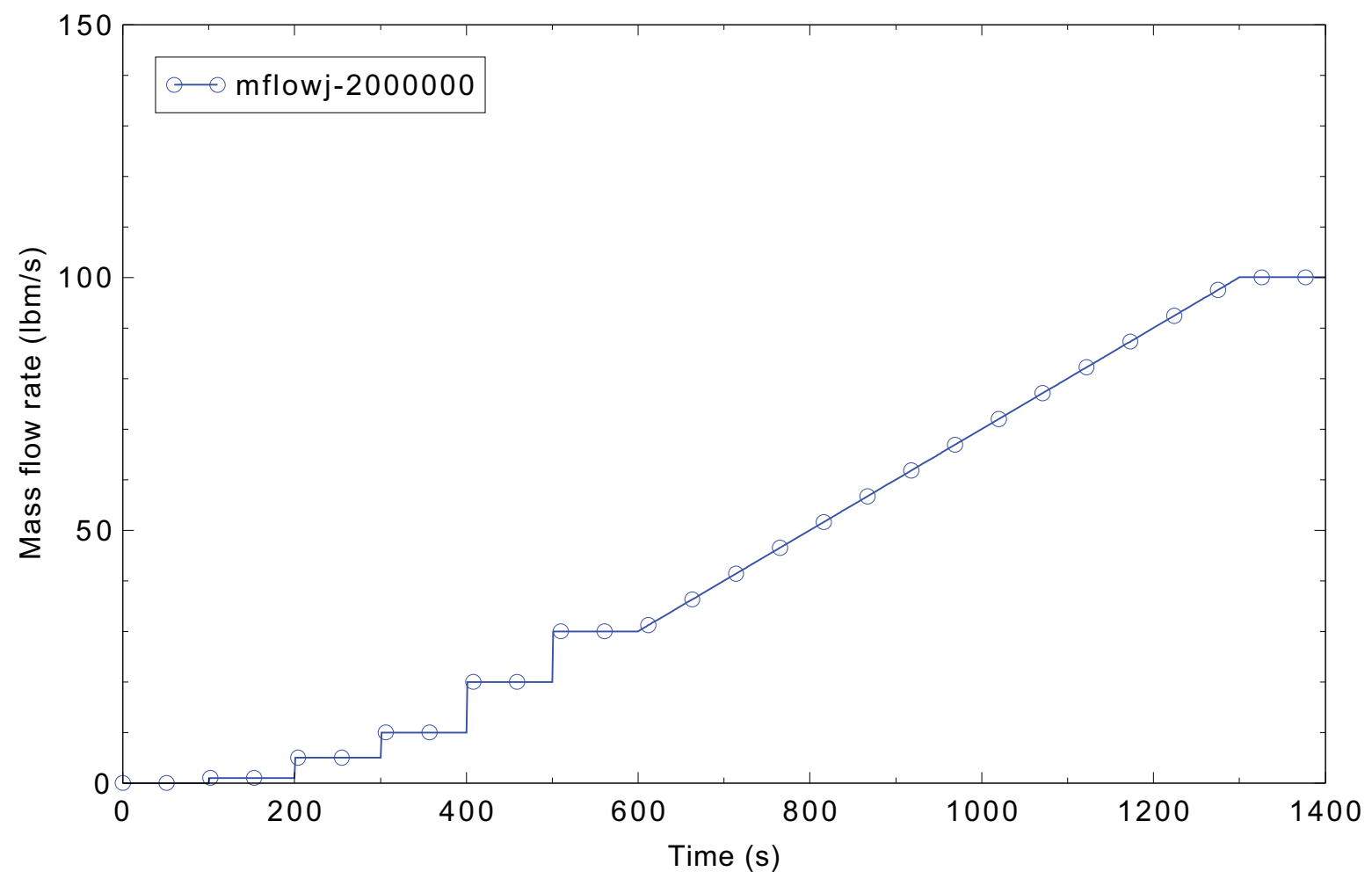

Figure 3.5-2. Mass flow rate of saturated steam at time-dependent junction 002 for the bubbling steam through liquid case.

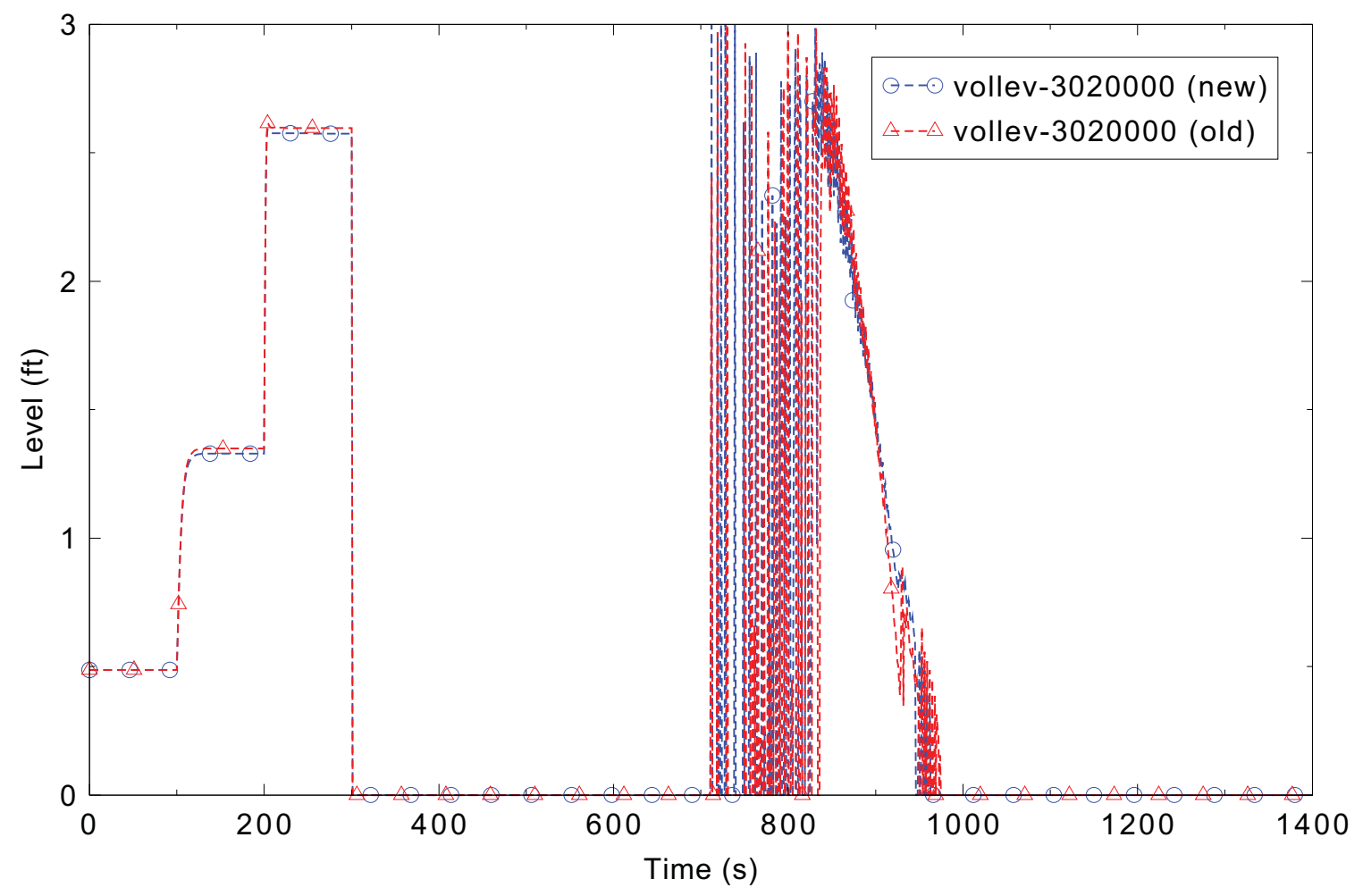

Figure 3.5-3. Mixture level in pipe volume 2 for the bubbling steam through liquid case. 


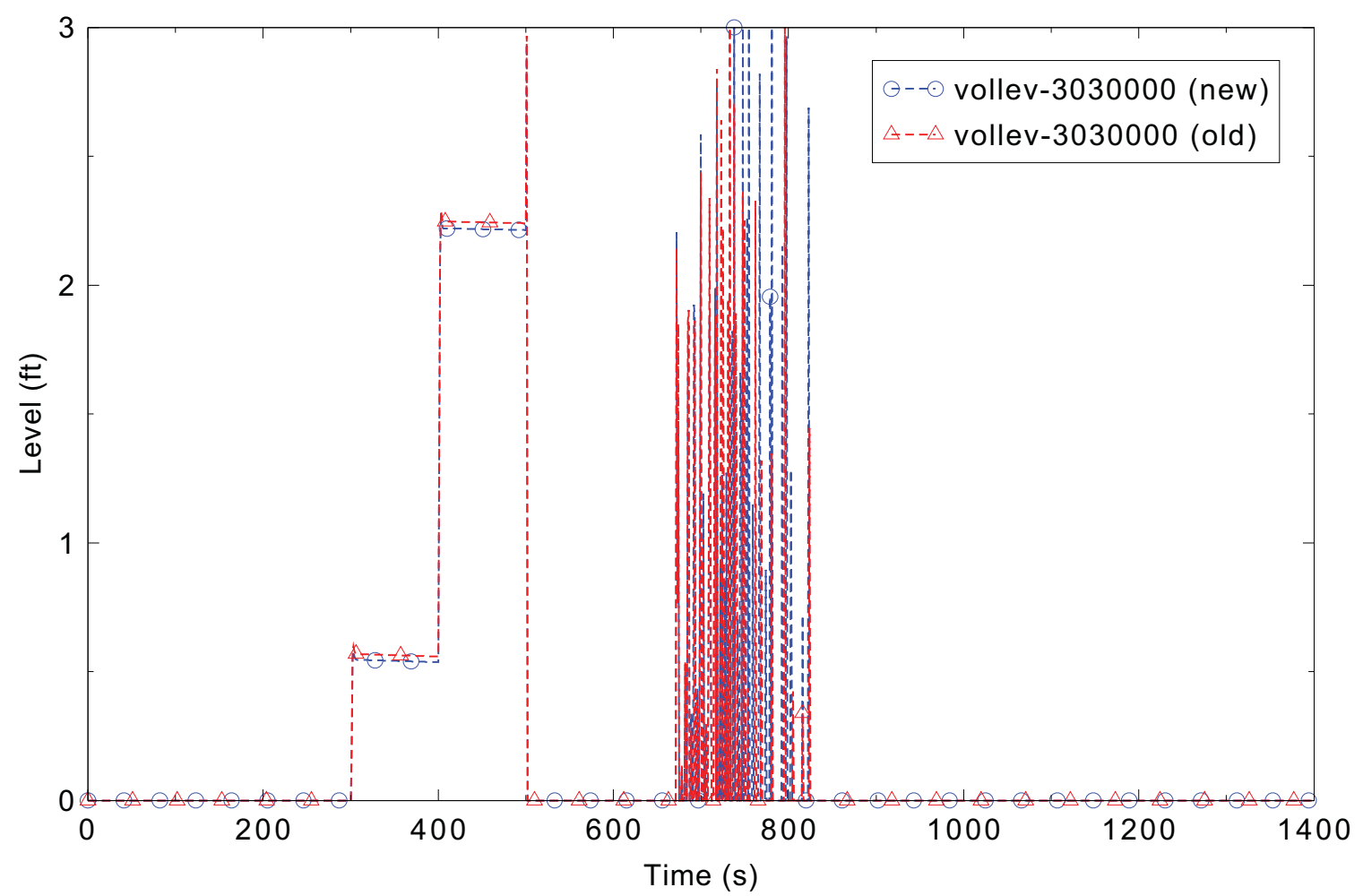

Figure 3.5-4. Mixture level in pipe volume 3 for the bubbling steam through liquid case.

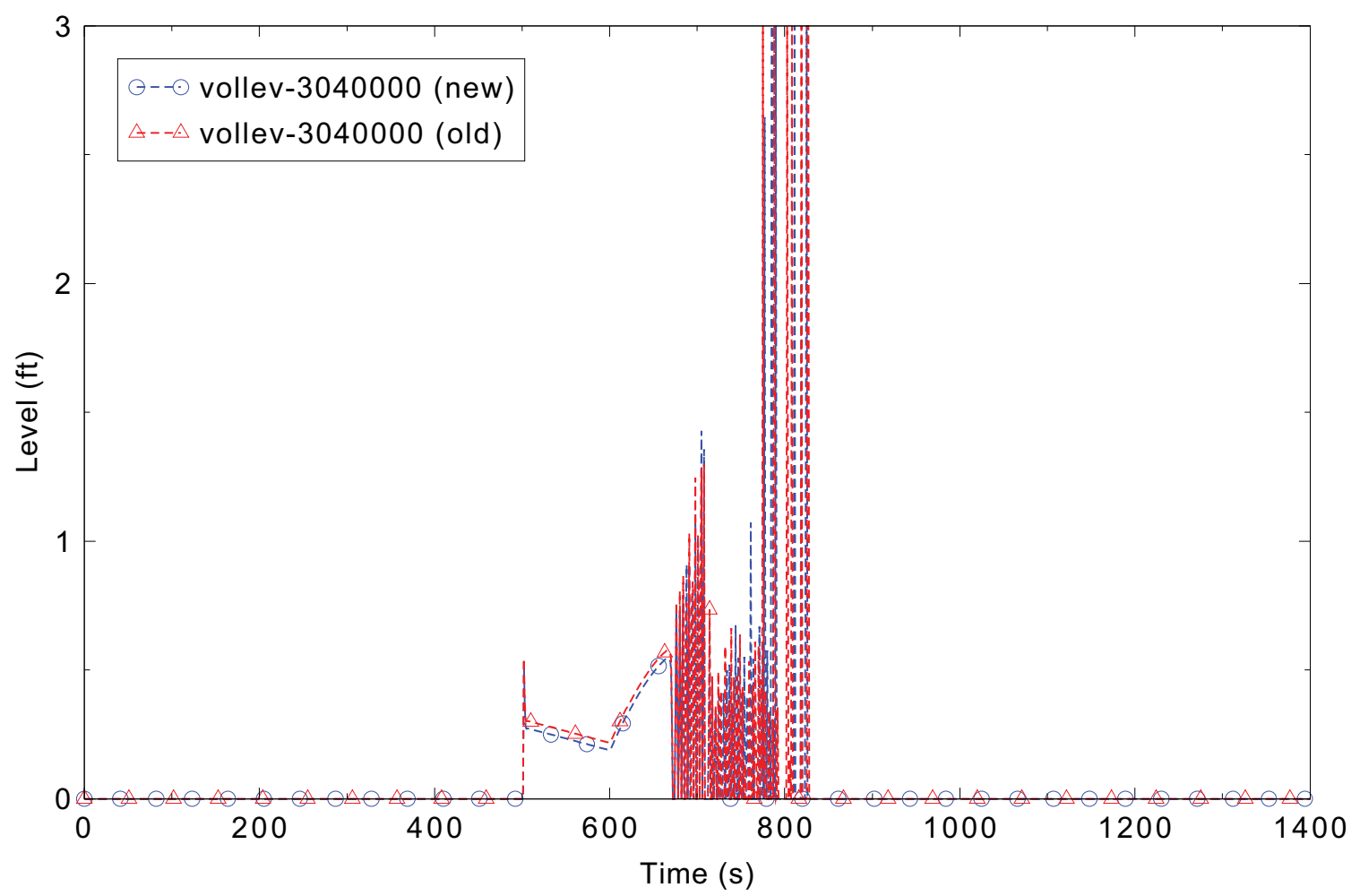

Figure 3.5-5. Mixture level in pipe volume 4 for the bubbling steam through liquid case. 
RELAP5-3D/4.0.3

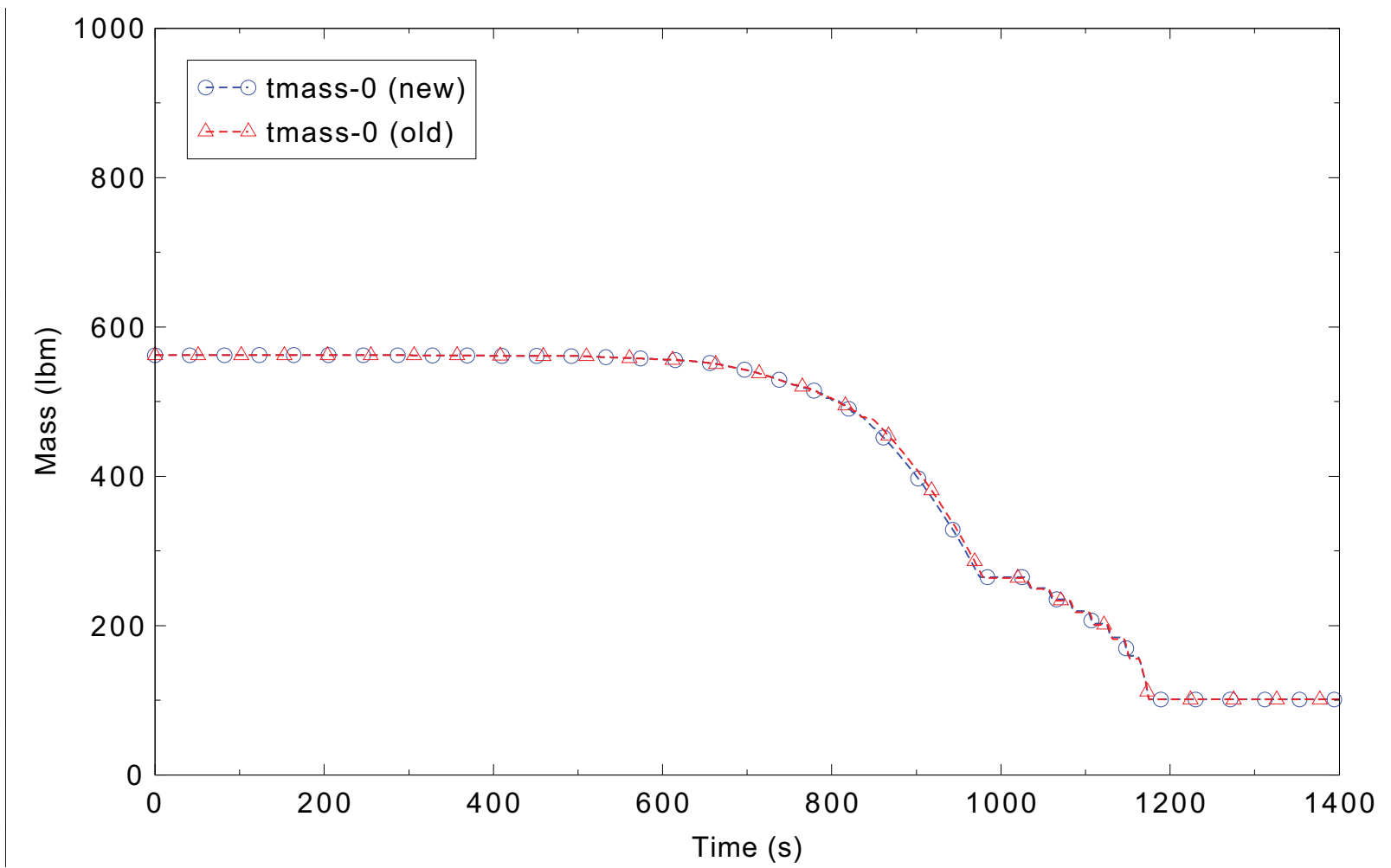

Figure 3.5-6. Total system mass for the bubbling steam through liquid case. 


\subsection{Manometer}

Figures comparing simulations using two code versions are presented. Diagrams are included so that the figure numbering is the same as that in Volume III of the RELAP5-3D code manual. No differences were observed in the figures.

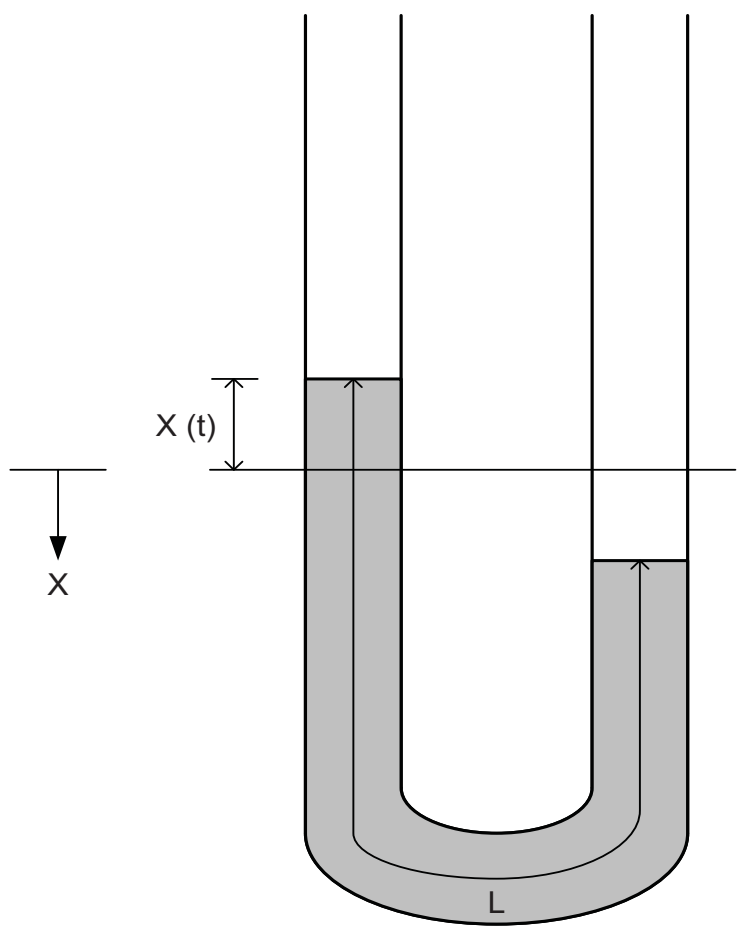

Figure 3.6-1. Schematic of oscillation manometer. 


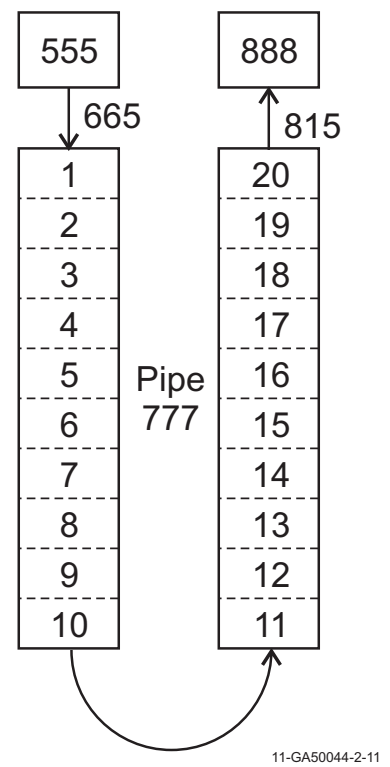

Figure 3.6-2. Nodalization diagram of nitrogen-water Manometer test input model.

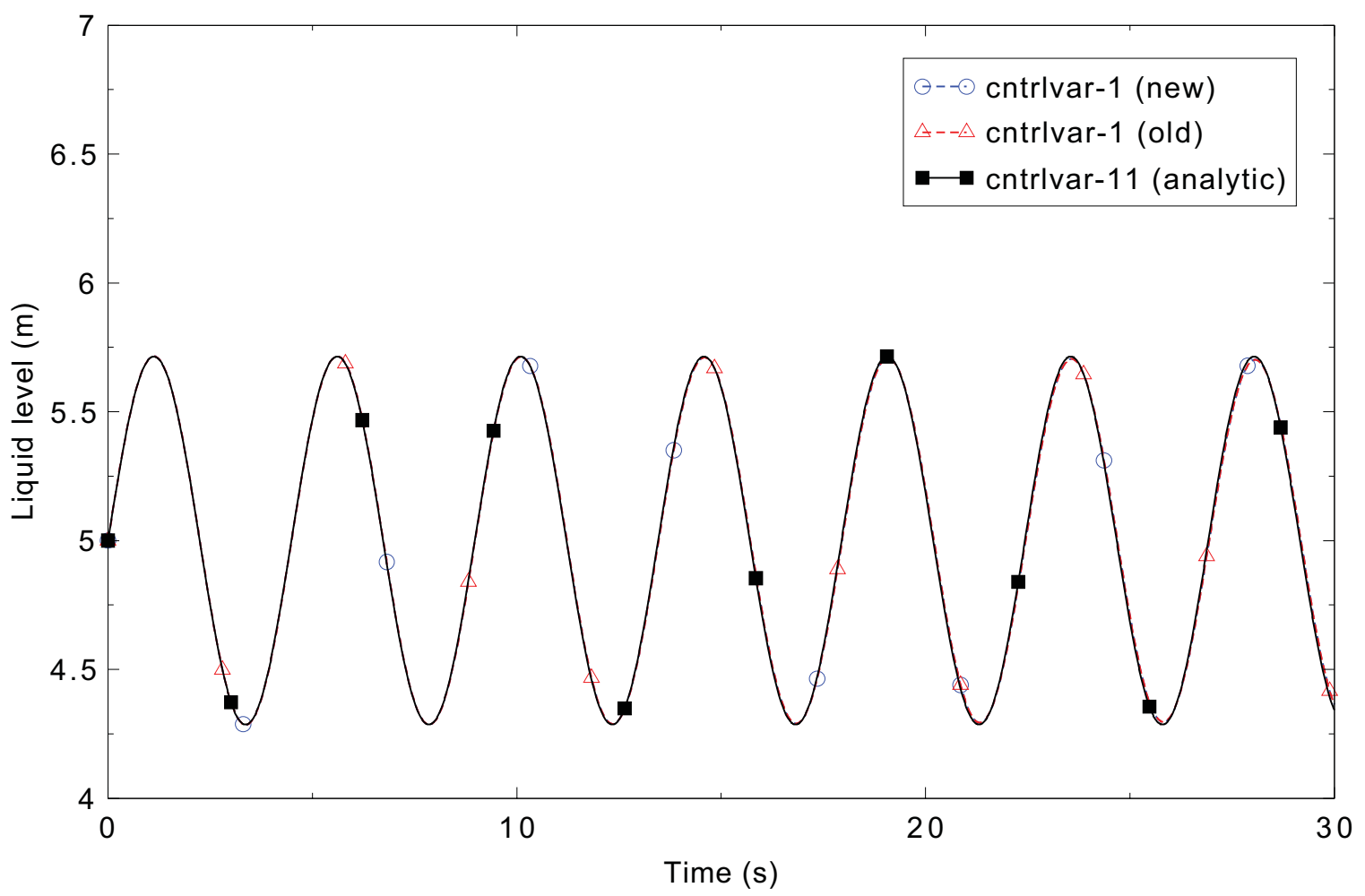

Figure 3.6-3. Comparison of water levels in the left leg for Manometer test. 


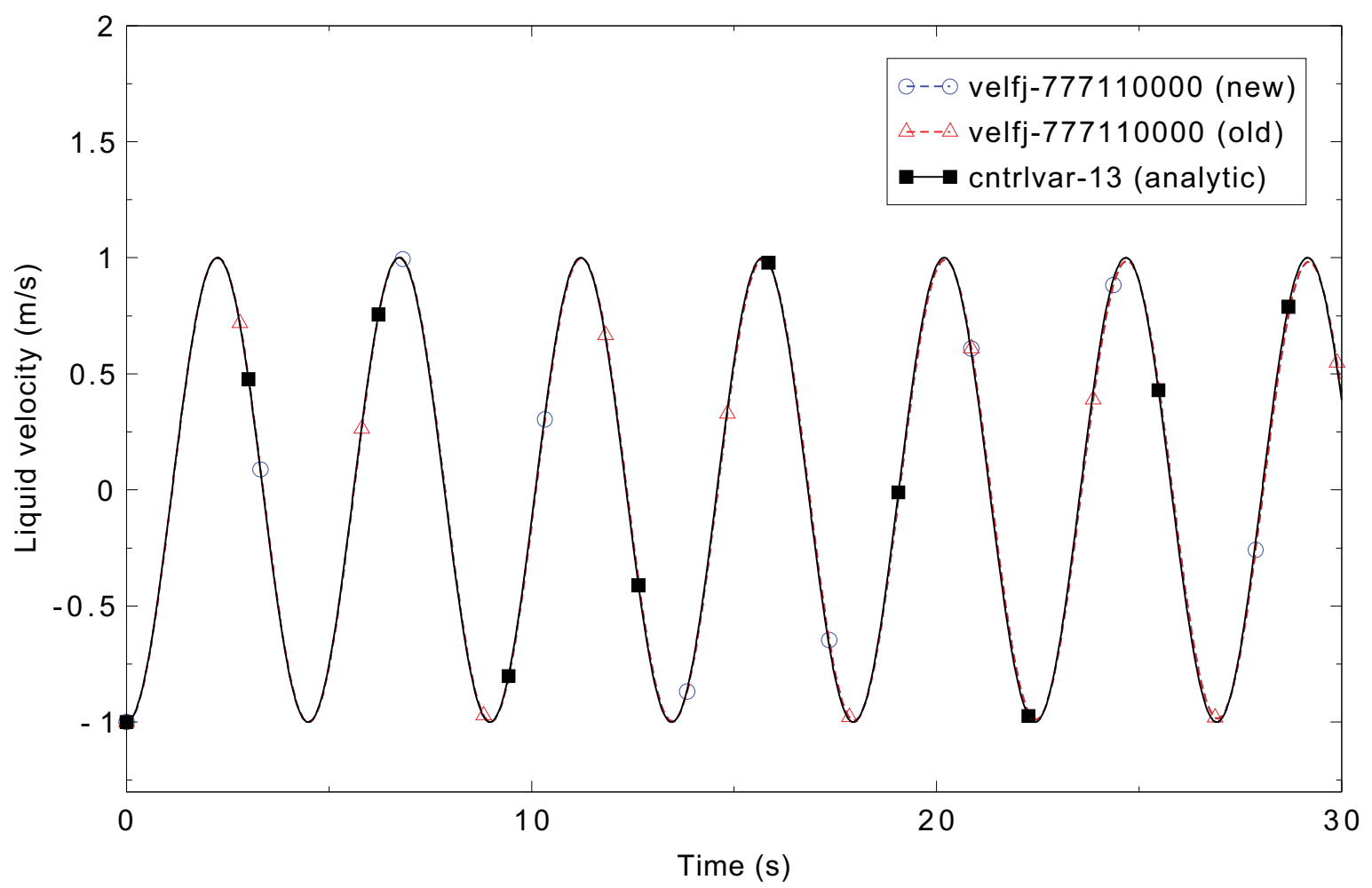

Figure 3.6-4. Comparison of liquid velocities for Manometer test.

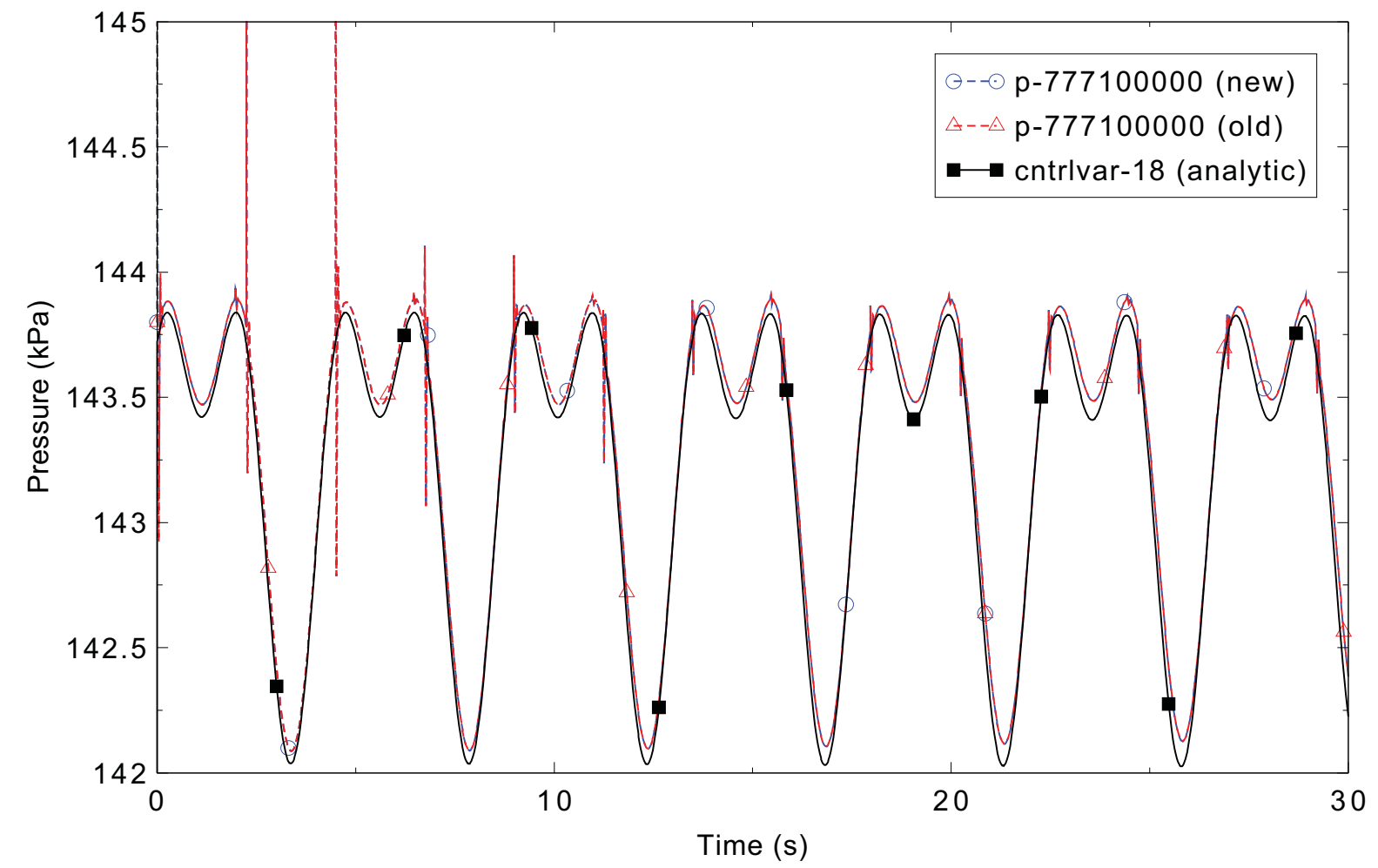

Figure 3.6-5. Comparison of bottom pressure for Manometer test. 


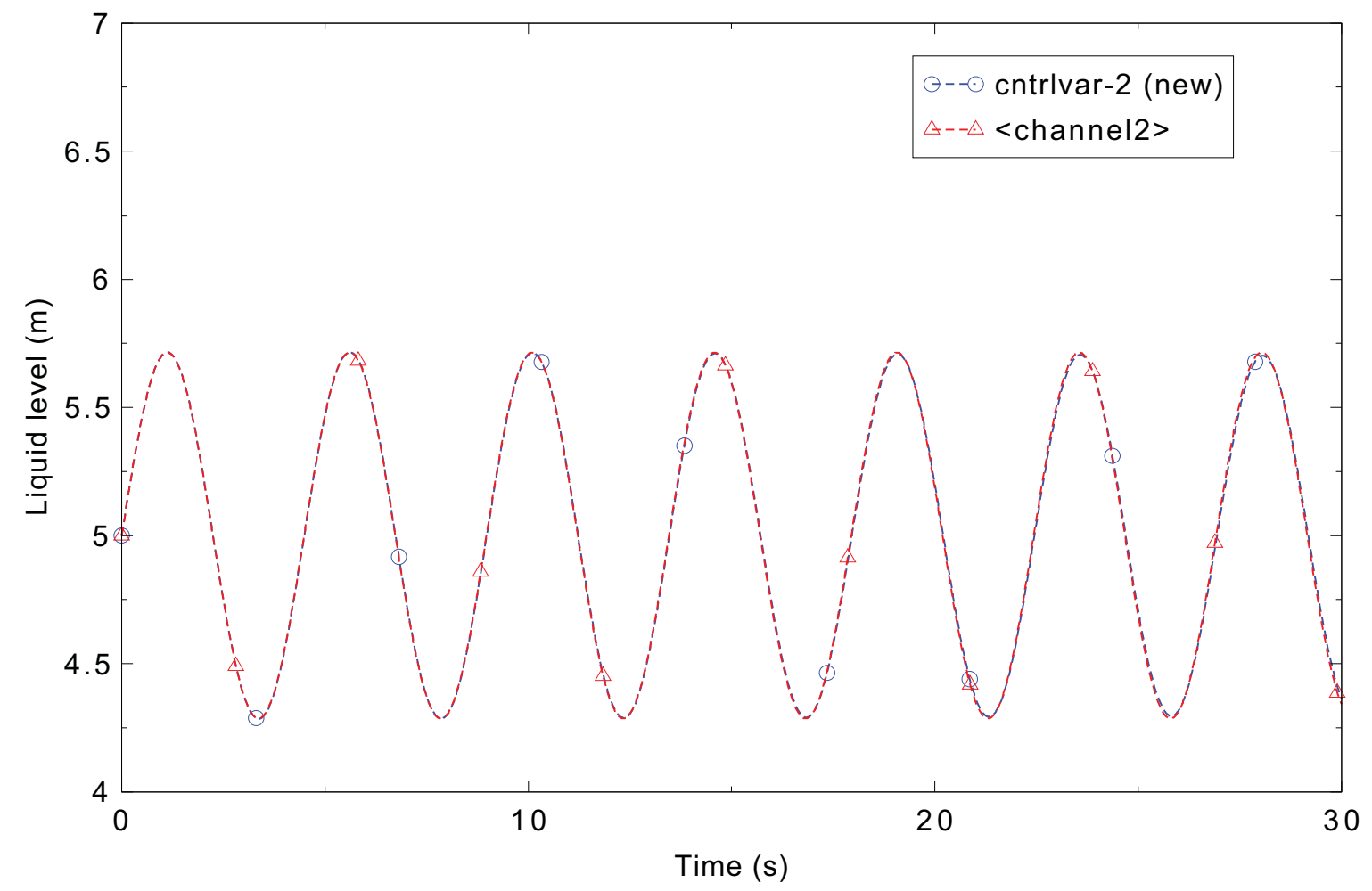

Figure 3.6-6. Comparison of water levels in the right leg for Manometer test.

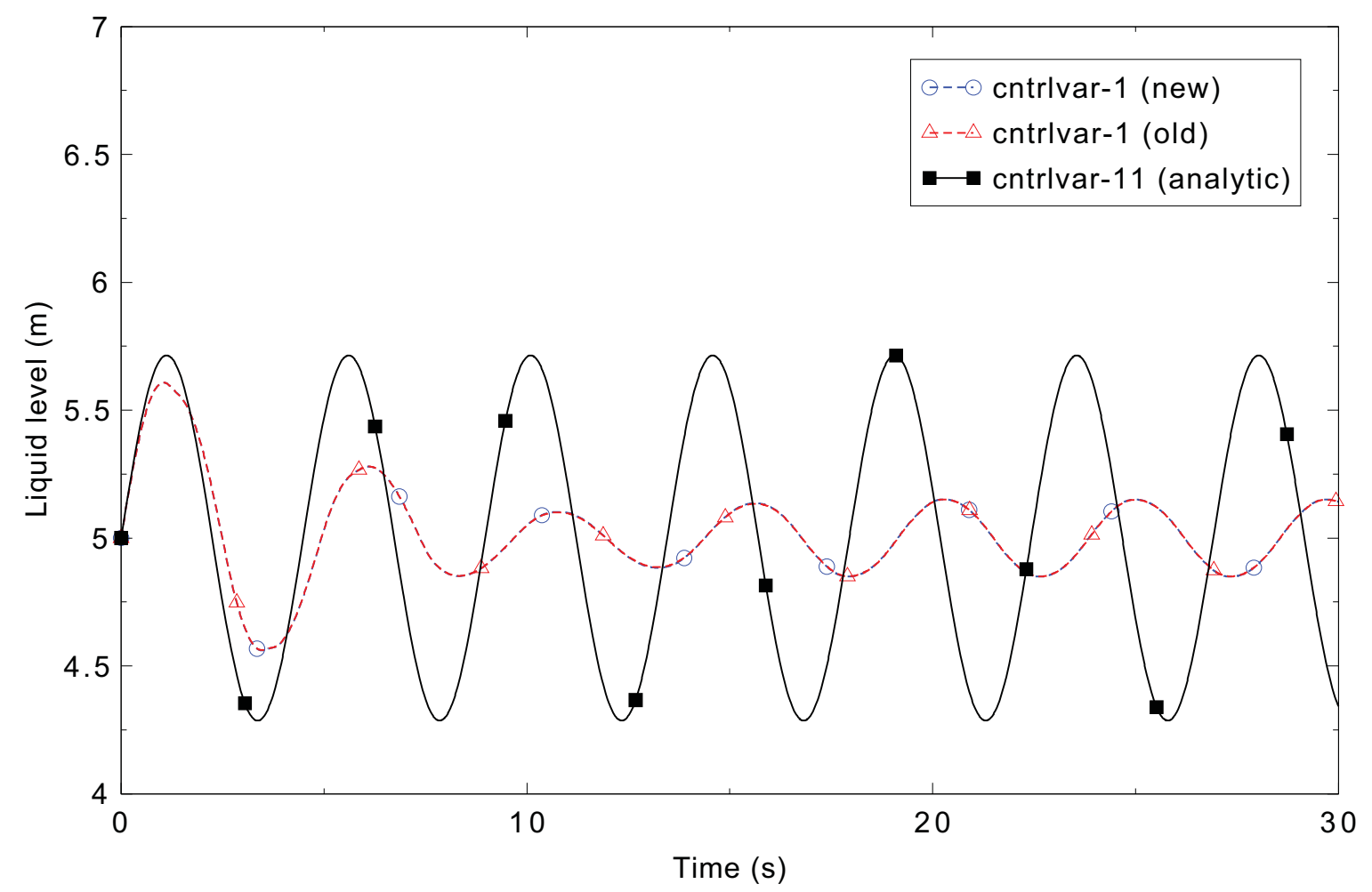

Figure 3.6-7. Comparison of water levels in the left leg for Manometer test without mixture level tracking. 


\subsection{Gravity Wave (1-D)}

Figures comparing simulations using two code versions are presented. Diagrams are included so that the figure numbering is the same as that in Volume III of the RELAP5-3D code manual. No differences were observed in the figures.

$\square$ Saturated Vapor

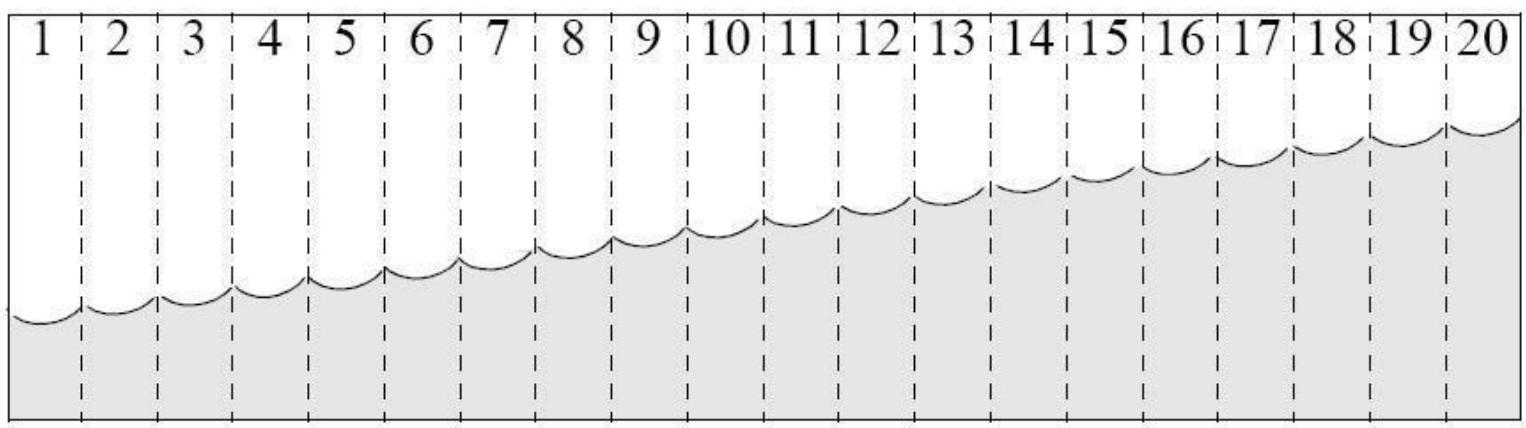

Figure 3.7-1. RELAP5-3D nodalization diagram for the 1-D gravity wave problem.

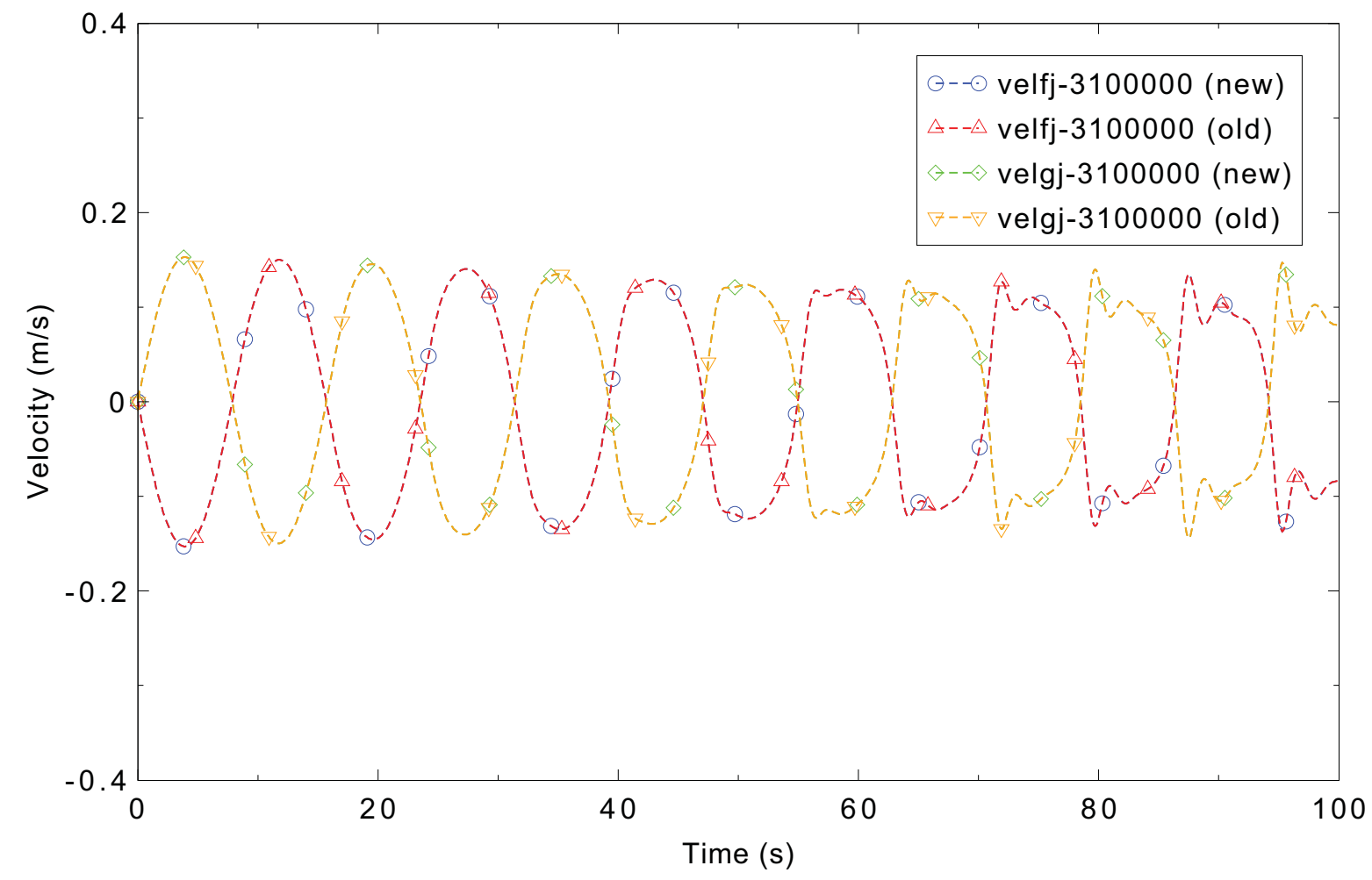

Figure 3.7-2. Calculated liquid and vapor velocities at mid-pipe, gravity wave 1-D, Card 1 Option 7 on. 
RELAP5-3D/4.0.3

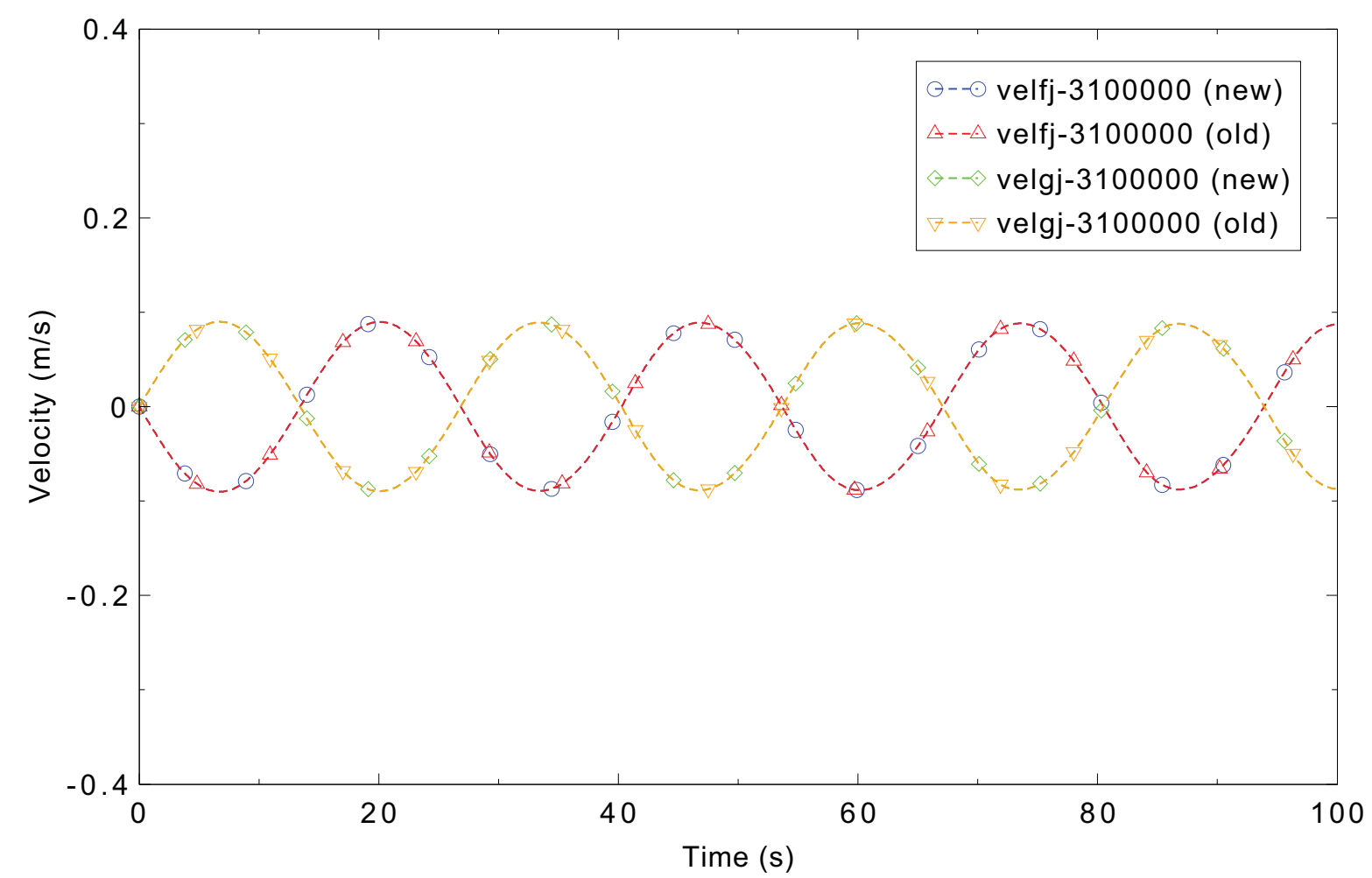

Figure 3.7-3. Calculated liquid and vapor velocities at mid-pipe, gravity wave 1-D, Card 1 Option 7 off. 


\subsection{Gravity Wave (3-D)}

Figures comparing simulations using two code versions are presented. Diagrams are included so that the figure numbering is the same as that in Volume III of the RELAP5-3D code manual. Noticeable differences were observed in Figures 3.8-5, 6, and 7.

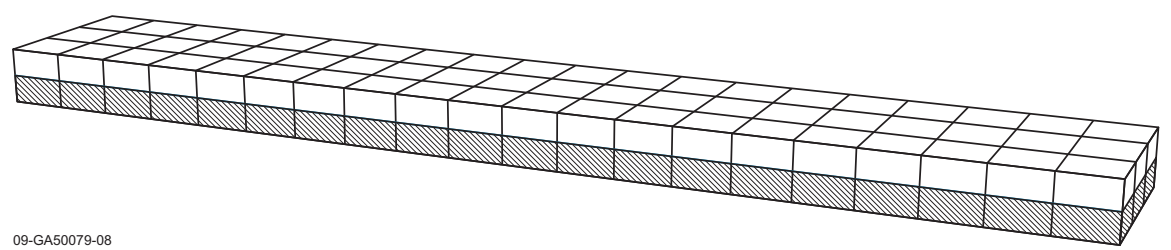

Figure 3.8-1. RELAP5-3D nodalization diagram for the 3-D gravity wave problem.

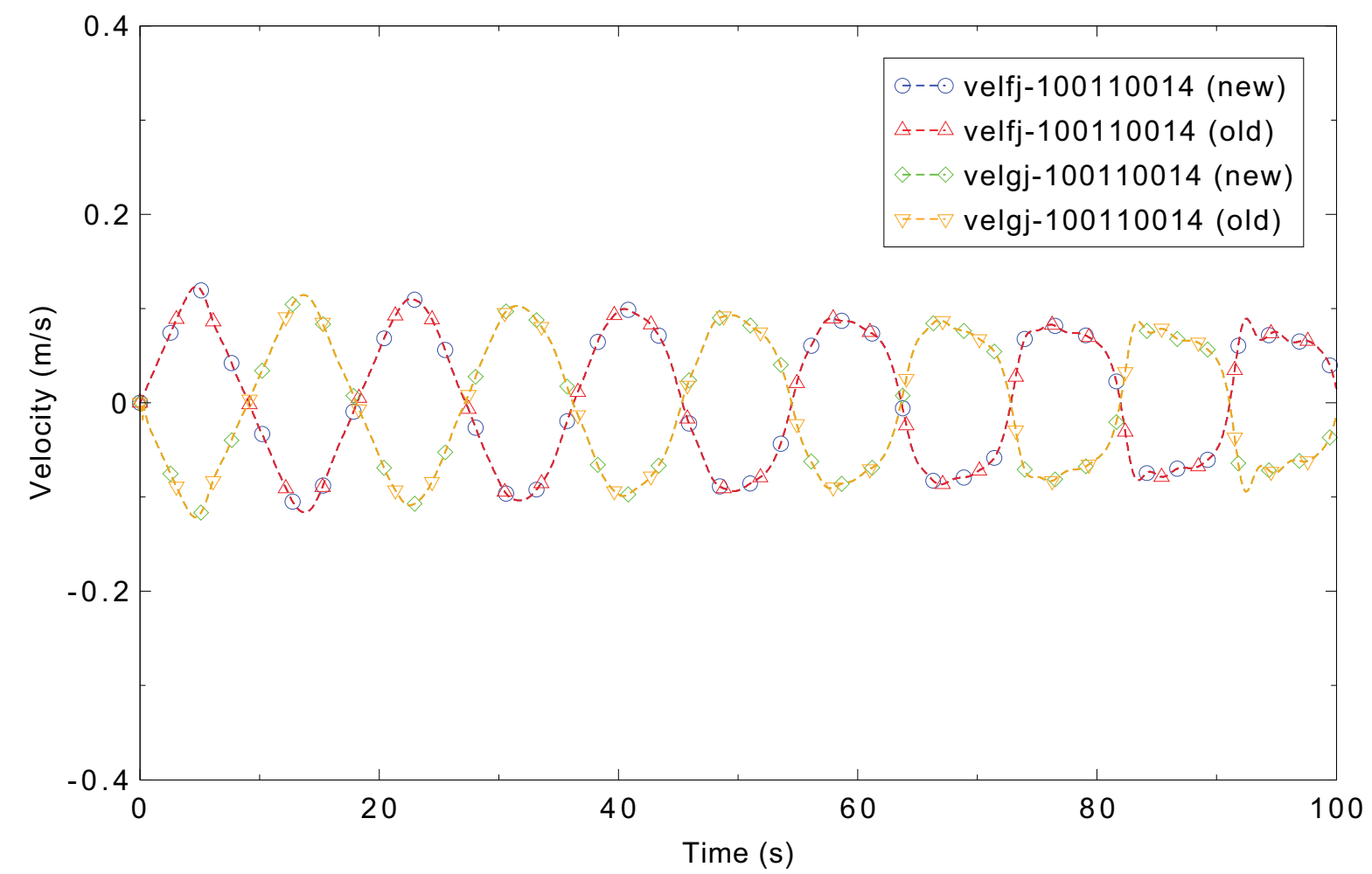

Figure 3.8-2. Calculated liquid and vapor velocities mid-duct, $\mathrm{x}$-interval 1, gravity wave 3-D, Card 1 Option 7 on. 


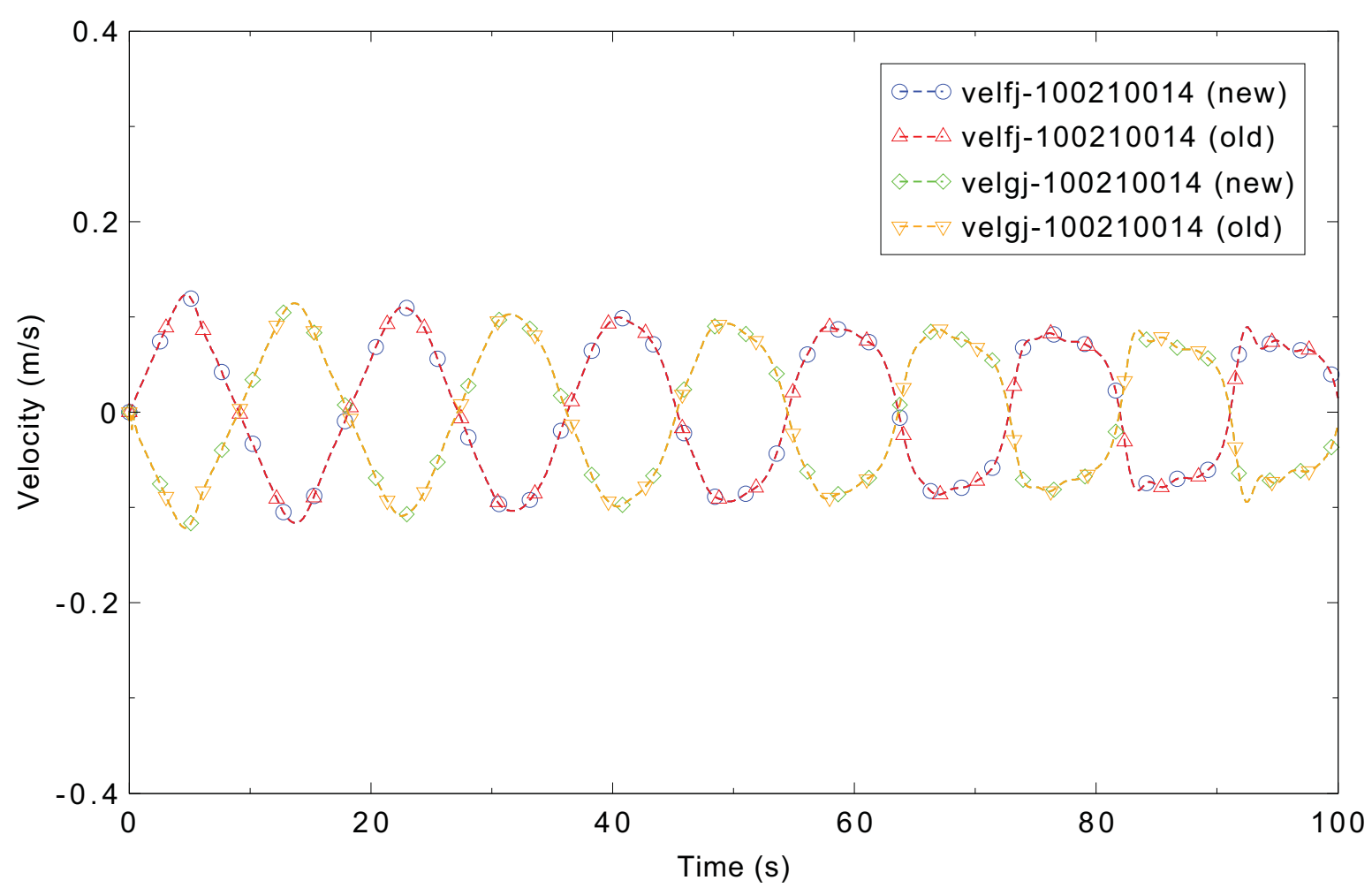

Figure 3.8-3. Calculated liquid and vapor velocities mid-duct, $x$-interval 2, gravity wave 3-D, Card 1 Option 7 on.

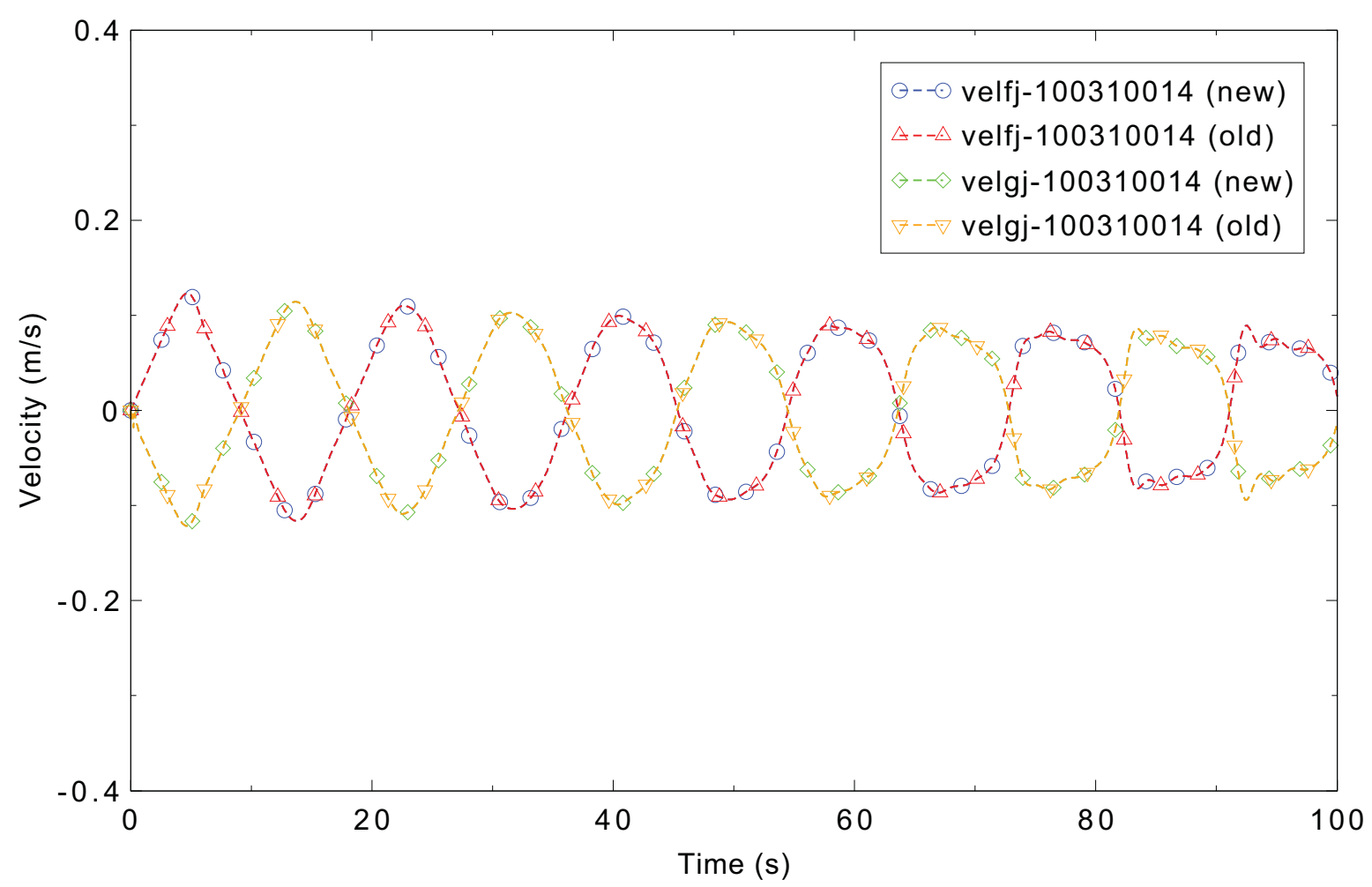

Figure 3.8-4. Calculated liquid and vapor velocities mid-duct, $x$-interval 3, gravity wave 3-D, Card 1 Option 7 on. 


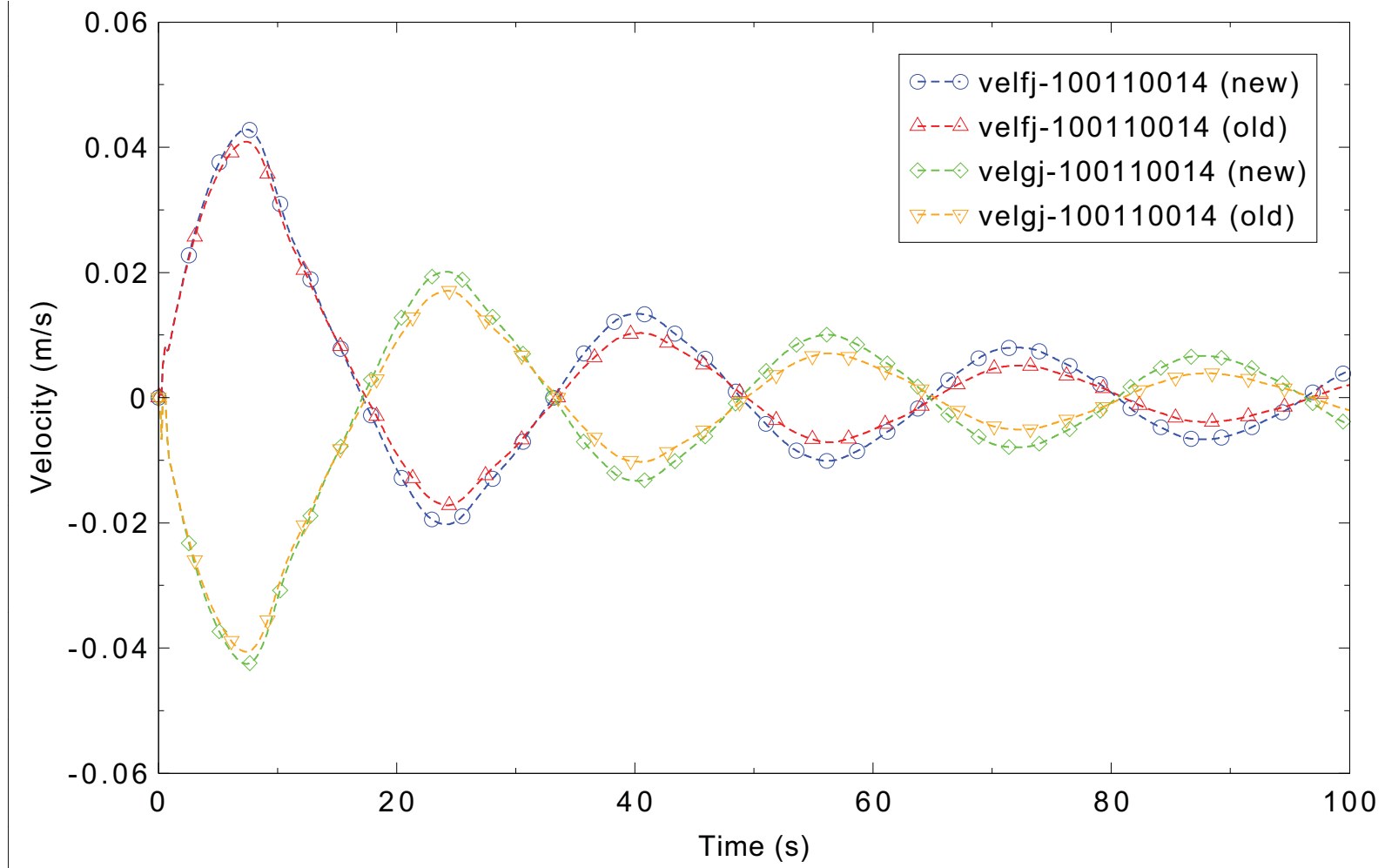

Figure 3.8-5. Calculated liquid and vapor velocities mid-duct, $\mathrm{x}$-interval 1, gravity wave 3-D, Card 1 Option 7 off.

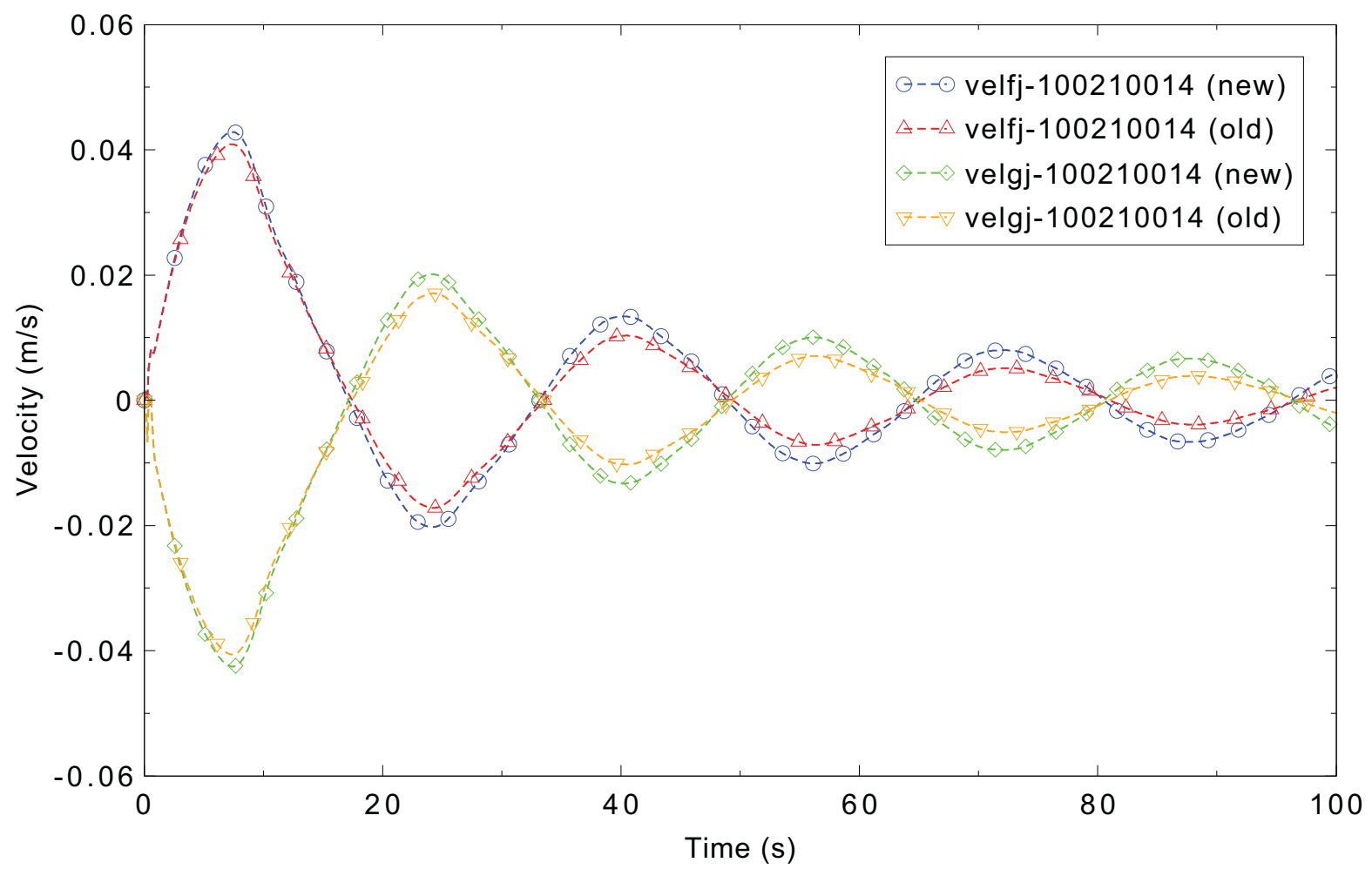

Figure 3.8-6. Calculated liquid and vapor velocities mid-duct, $x$-interval 2, gravity wave 3-D, Card 1 Option 7 off. 
RELAP5-3D/4.0.3

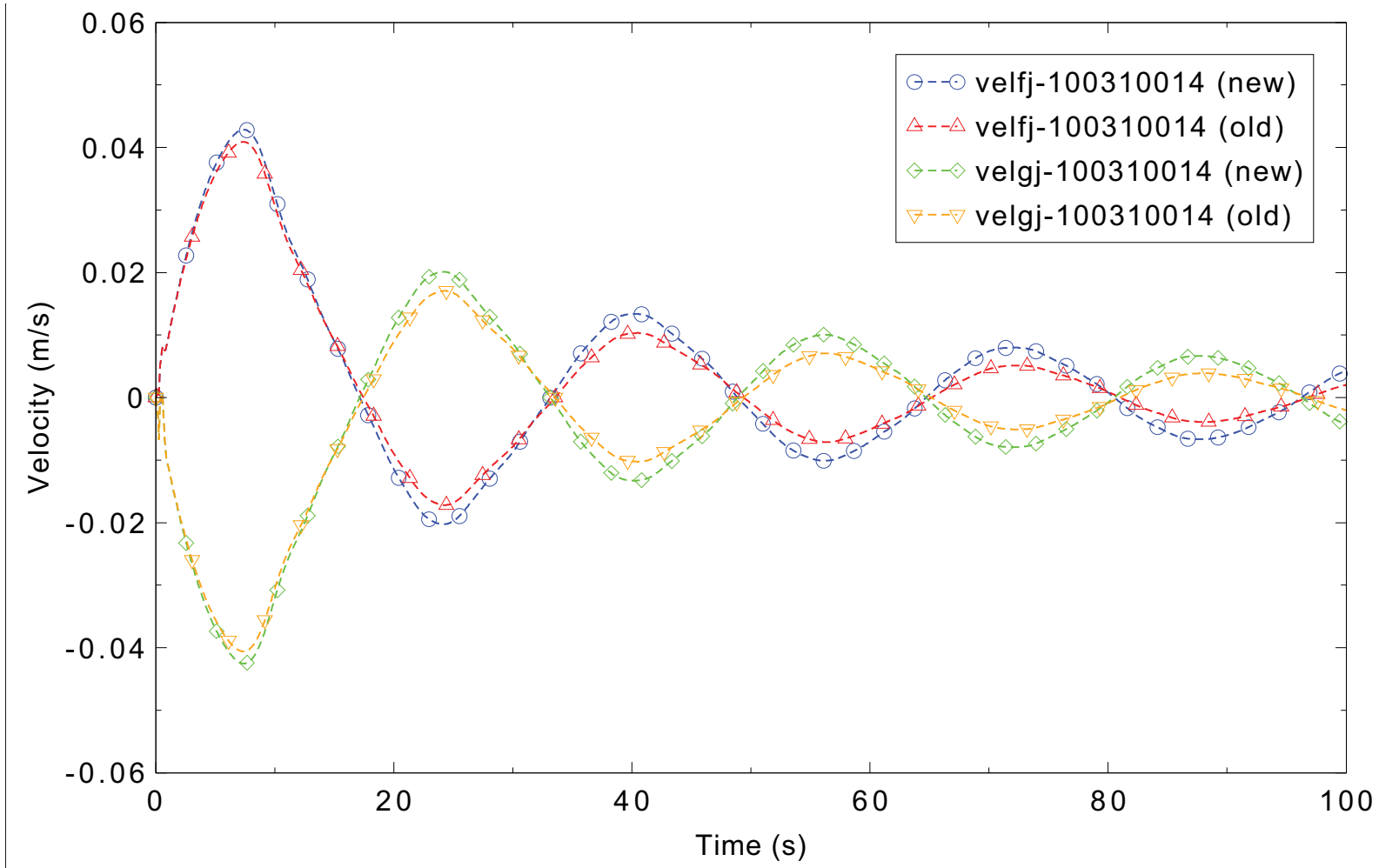

Figure 3.8-7. Calculated liquid and vapor velocities mid-duct, x-interval 3, gravity wave 3-D, Card 1 Option 7 off. 


\subsection{Pryor Pressure Comparison}

Figures comparing simulations using two code versions are presented. Diagrams are included so that the figure numbering is the same as that in Volume III of the RELAP5-3D code manual. Noticeable differences were observed in Figures 3.9-4, 5, 6, 7, and 8.

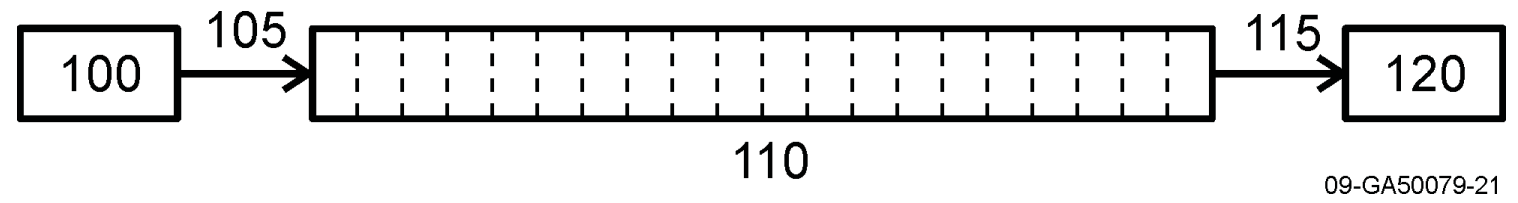

Figure 3.9-1. Nodalization diagram for the Pryor pressure test problem.

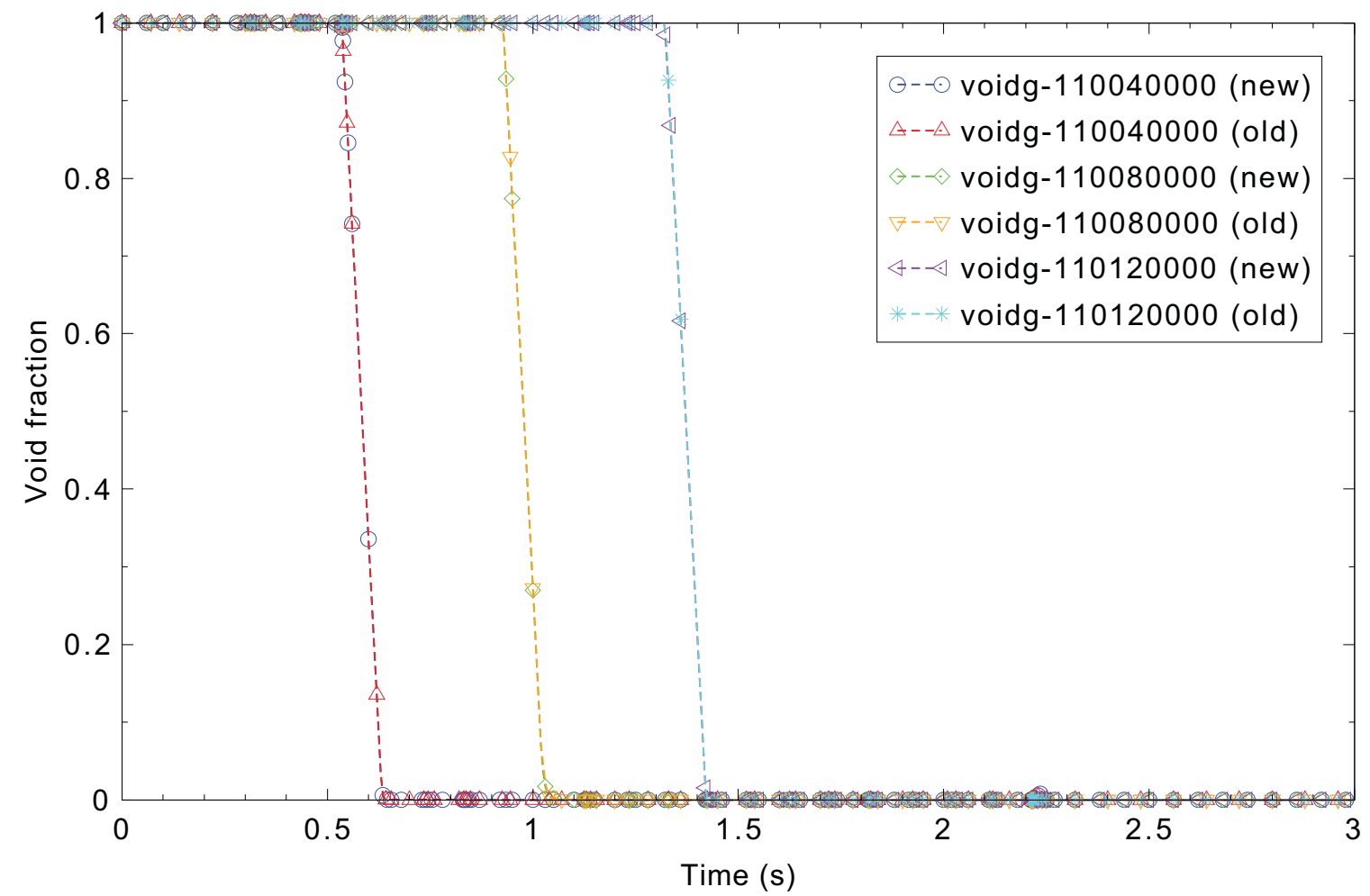

Figure 3.9-2. Void fraction for Pryor pressure test, semi-implicit case with maximum $\mathrm{dt}=0.02 \mathrm{~s}$. 


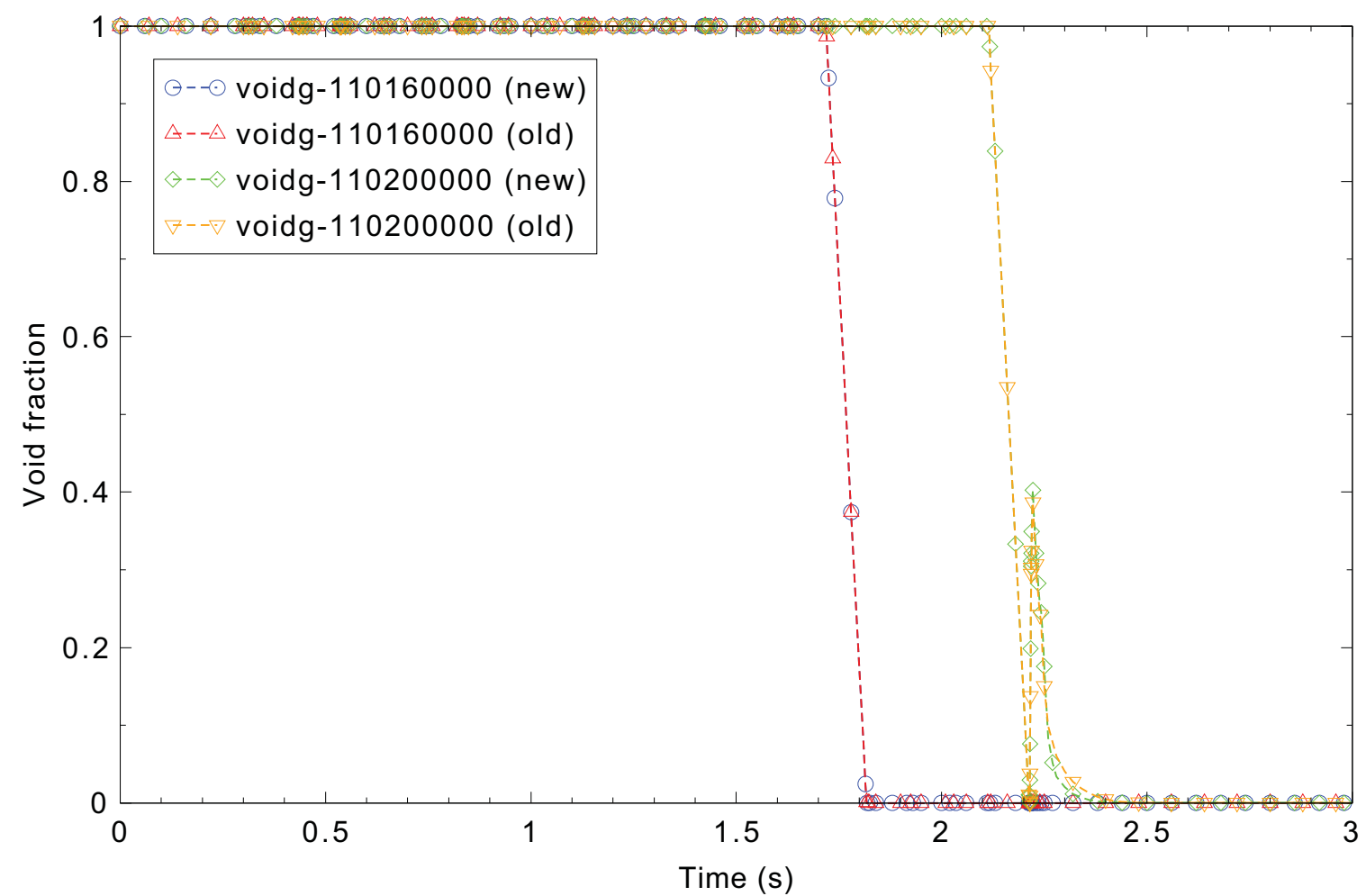

Figure 3.9-3. Void fraction for Pryor pressure test, semi-implicit case with maximum $\mathrm{dt}=0.02 \mathrm{~s}$.

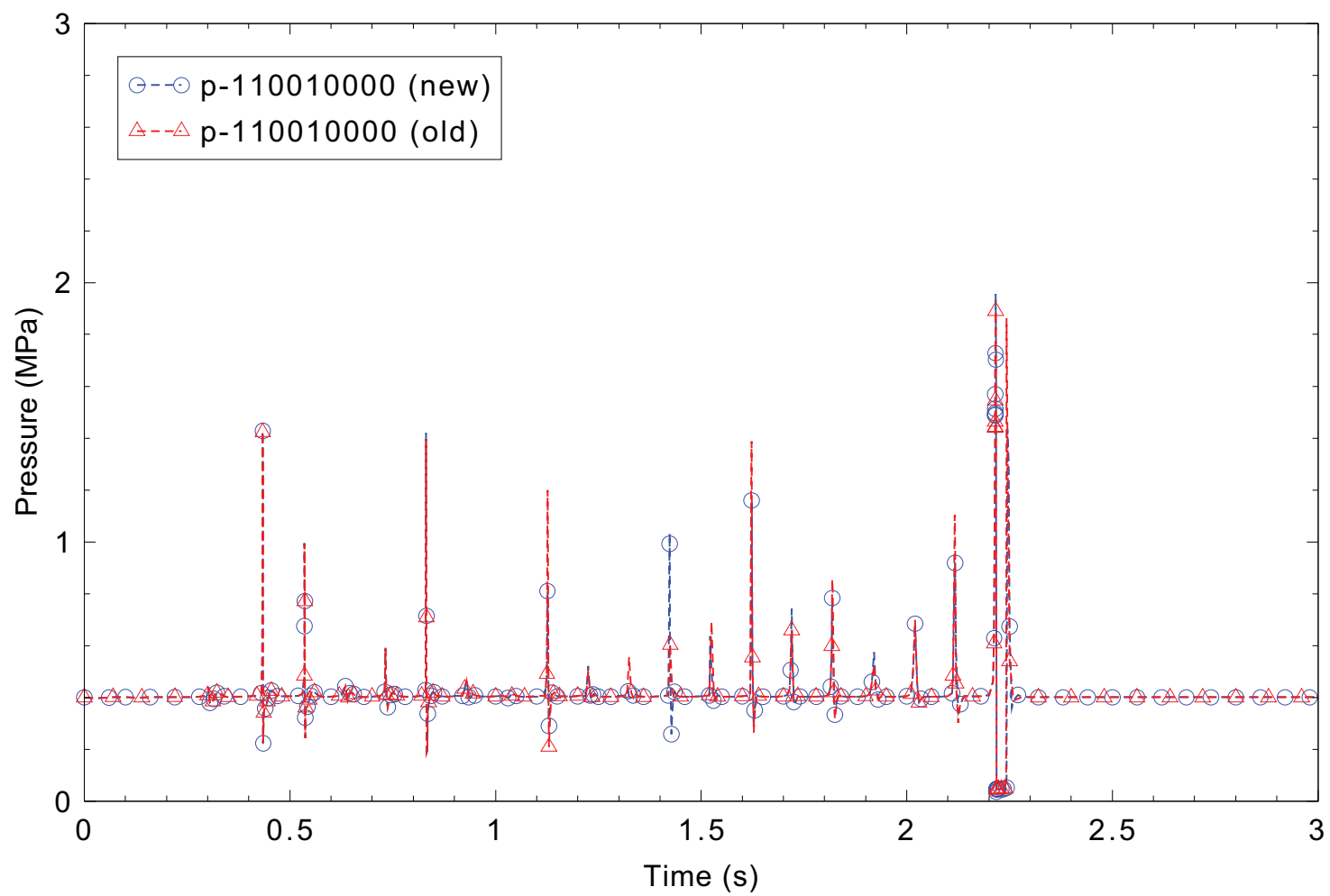

Figure 3.9-4. Volume 1 pressure for Pryor pressure test, semi-implicit case with maximum $\mathrm{dt}=0.02 \mathrm{~s}$. 


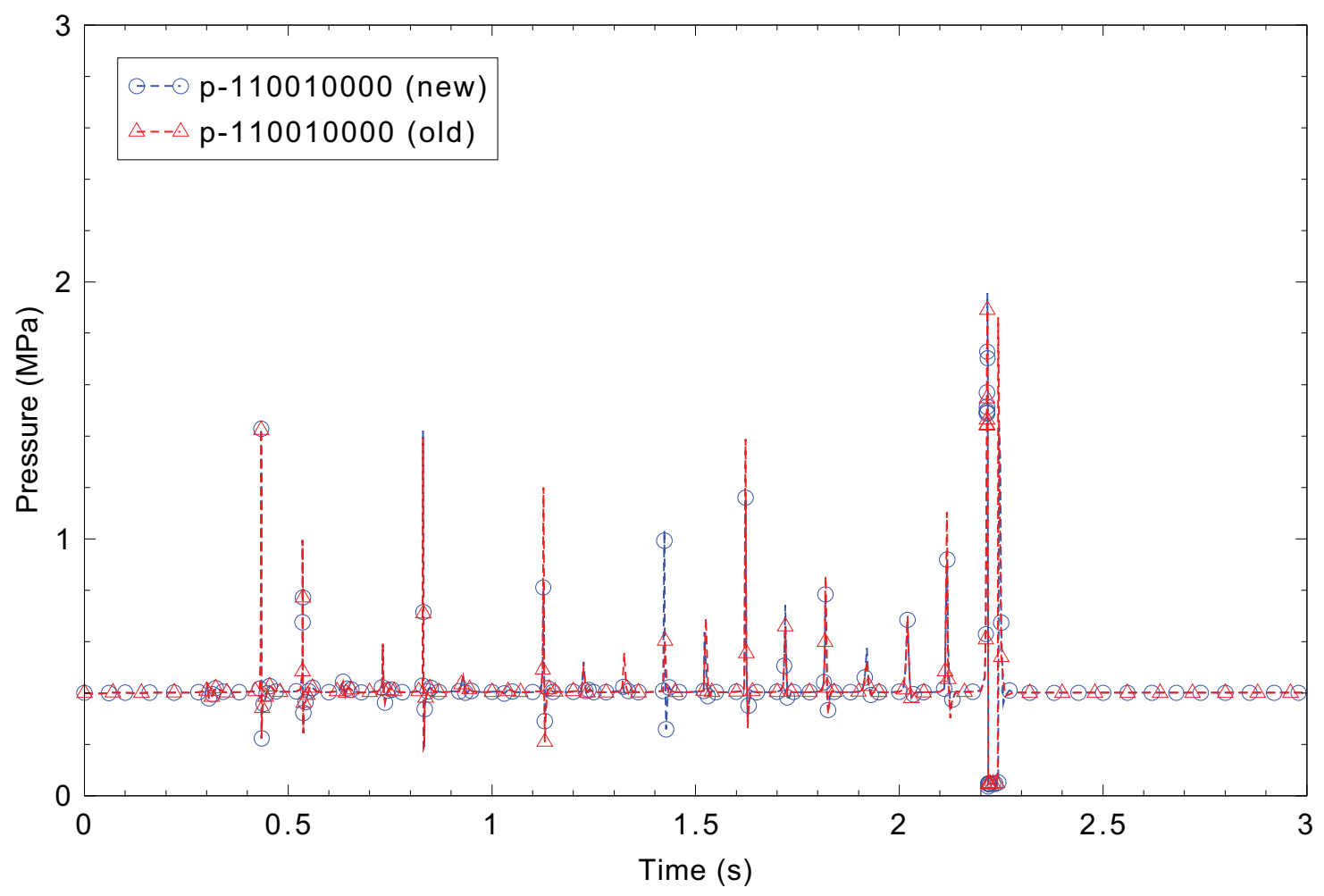

Figure 3.9-5. Volume 1 pressure for Pryor pressure test, semi-implicit case with maximum $\mathrm{dt}=0.02 \mathrm{~s}$.

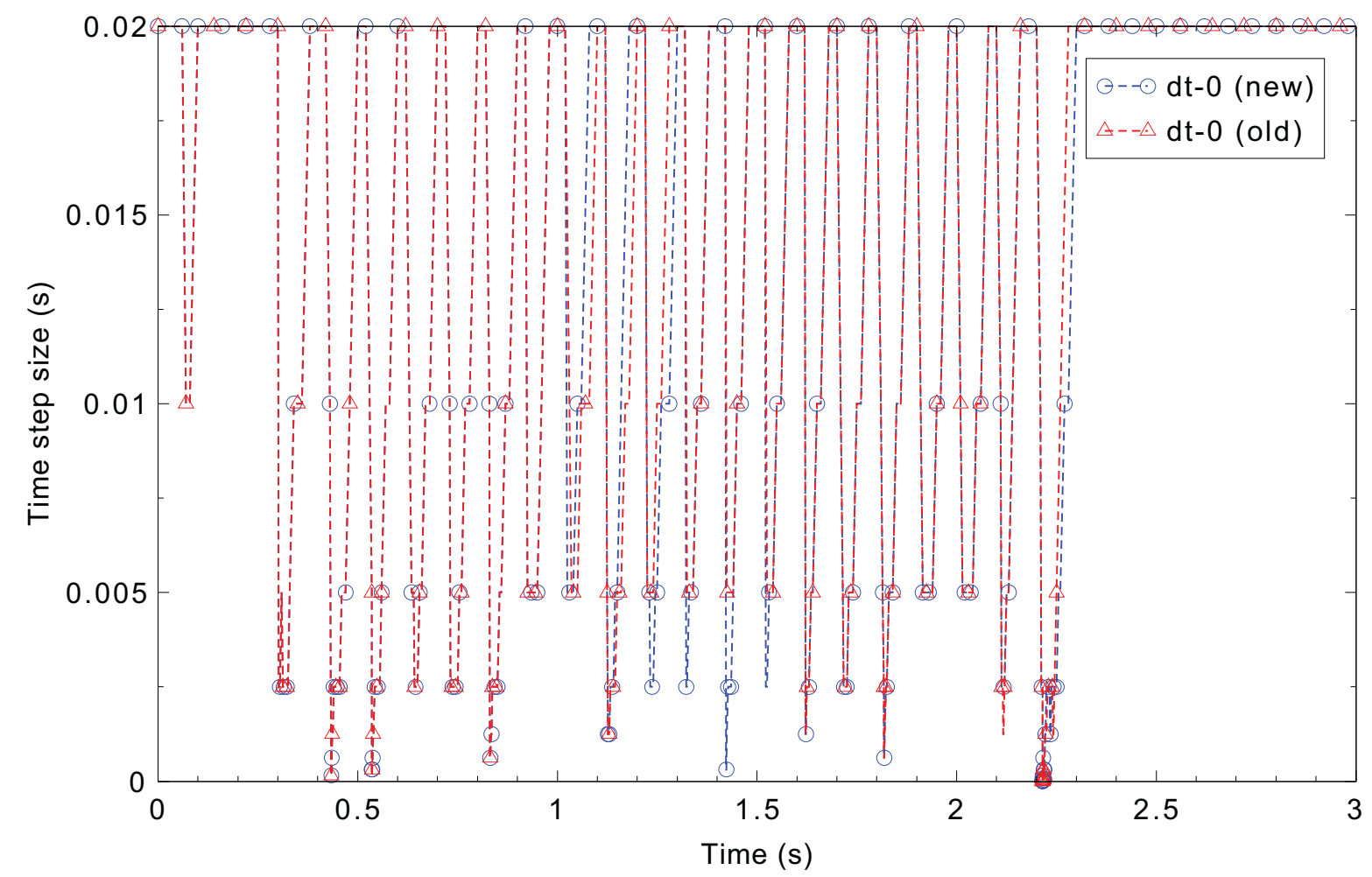

Figure 3.9-6. Time step size for Pryor pressure test, semi-implicit case with maximum $\mathrm{dt}=0.02 \mathrm{~s}$. 


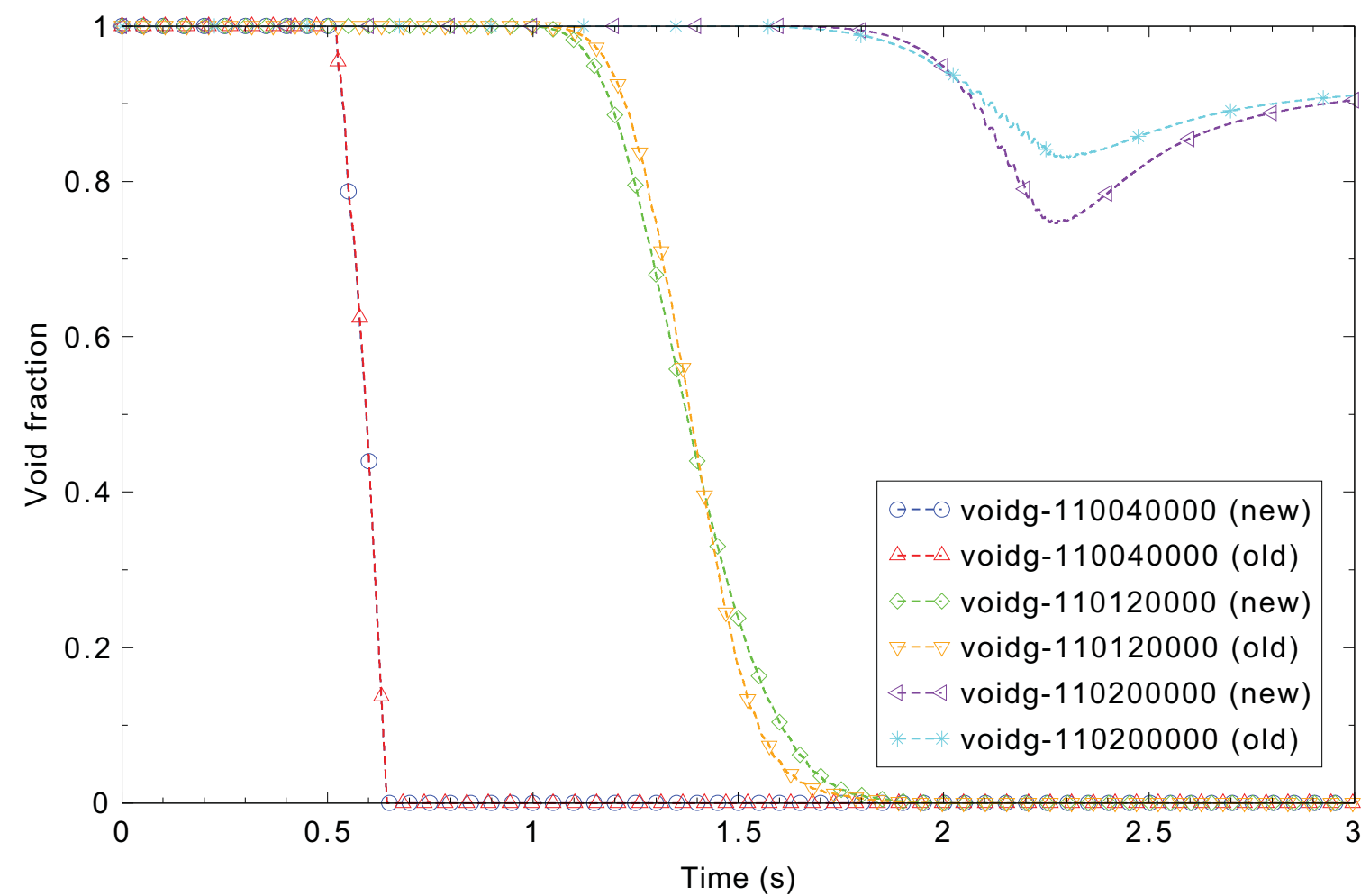

Figure 3.9-7. Void fraction for Pryor pressure test, semi-implicit case with maximum $\mathrm{dt}=10^{-4} \mathrm{~s}$.

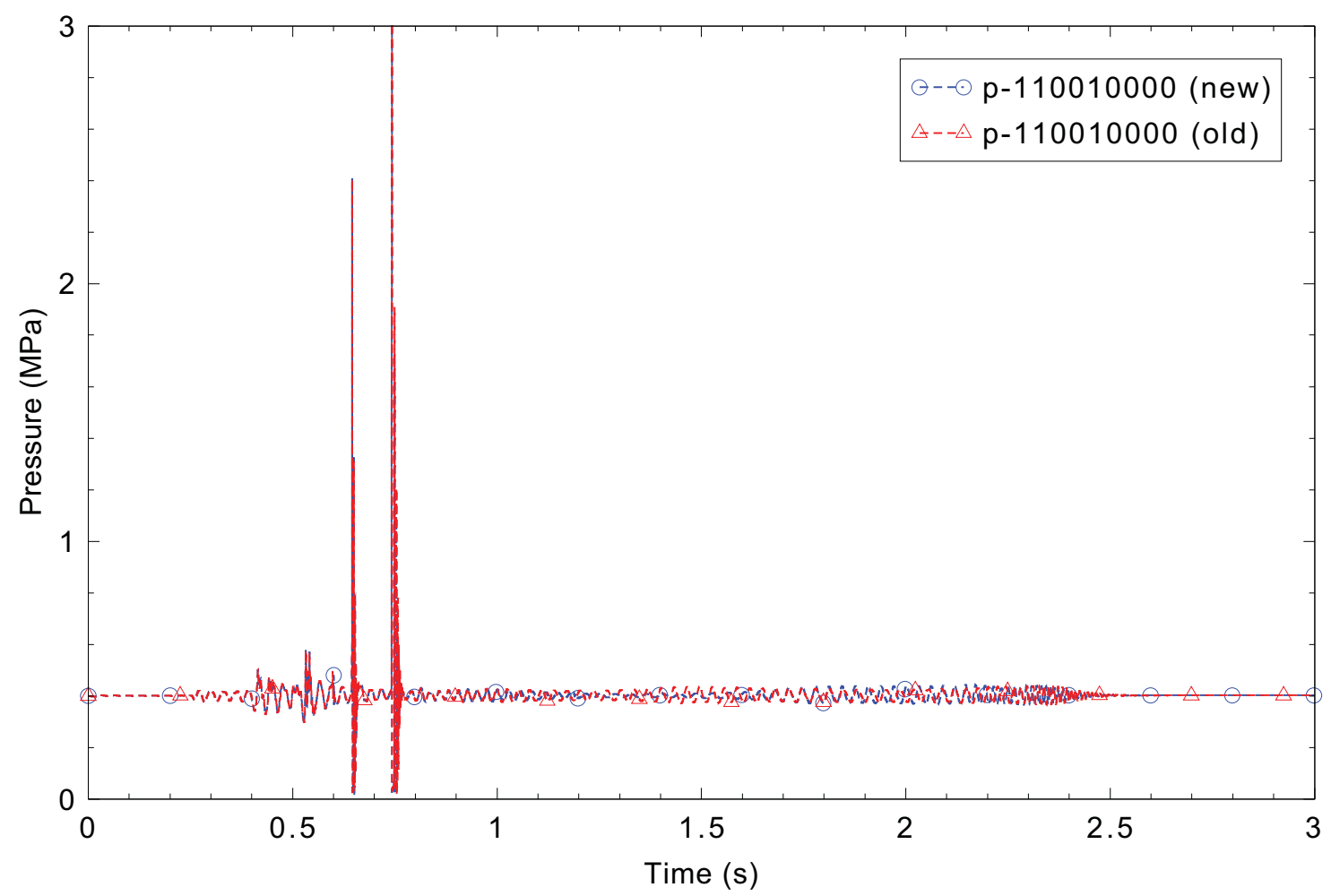

Figure 3.9-8. Volume 1 pressure for Pryor pressure test, semi-implicit case with maximum $\mathrm{dt}=10^{-4} \mathrm{~s}$. 


\subsection{Core Power}

Figures comparing simulations using two code versions are presented. No differences were observed in the figures.

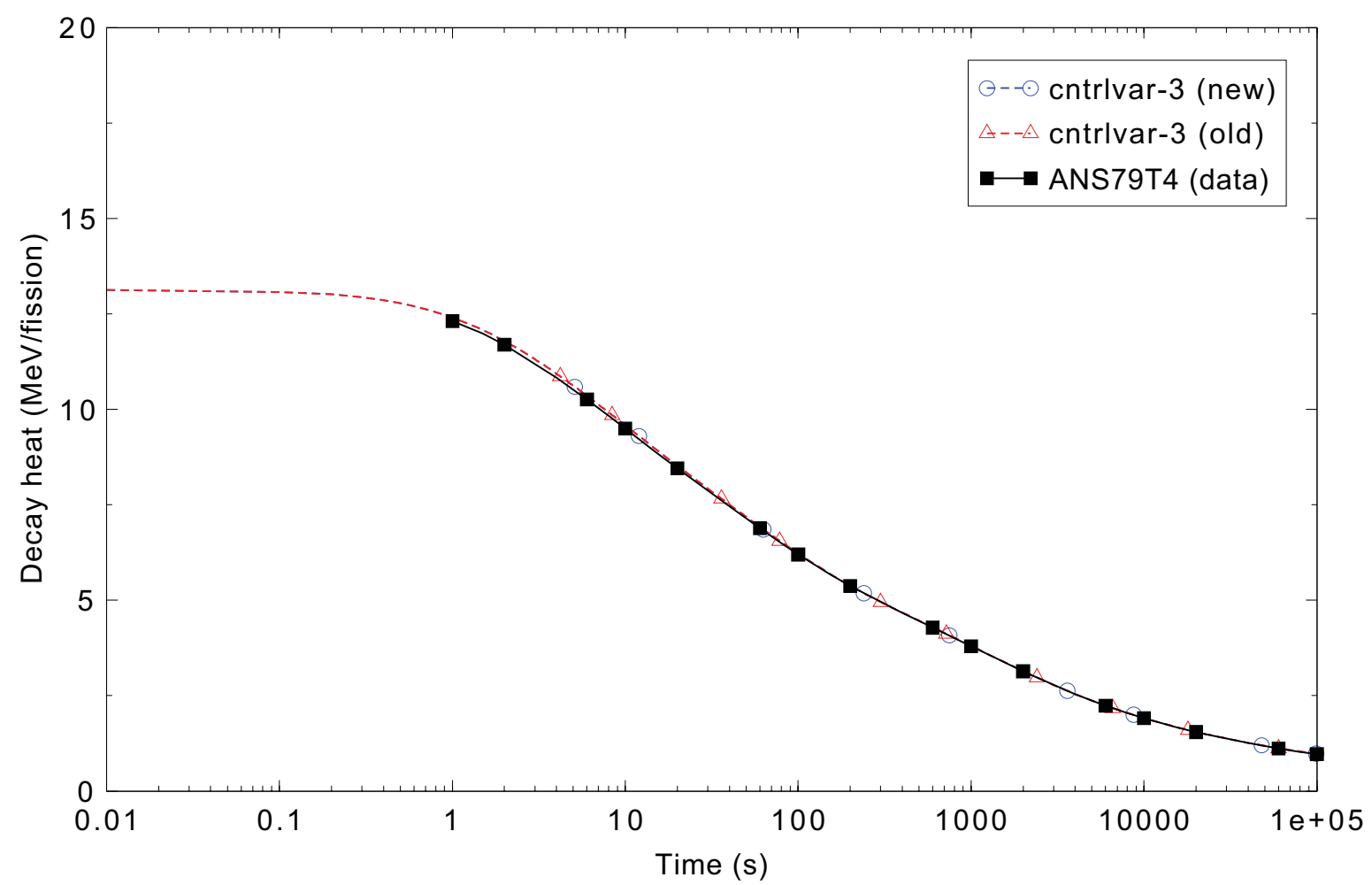

Figure 3.10-1. Decay heat comparison for the ans79.i test problem. 


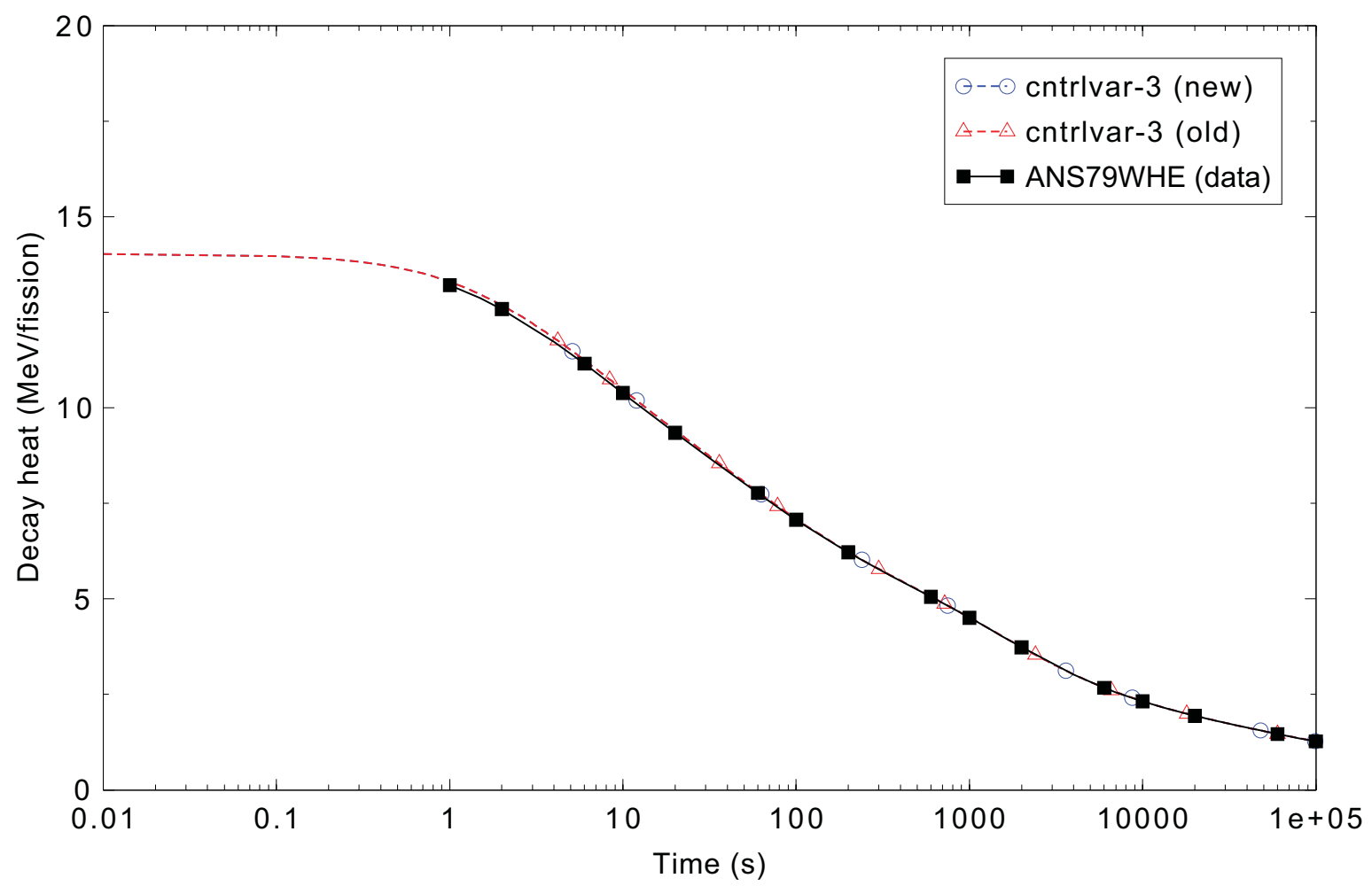

Figure 3.10-2. Decay heat comparison for the ans79ac.i test problem.

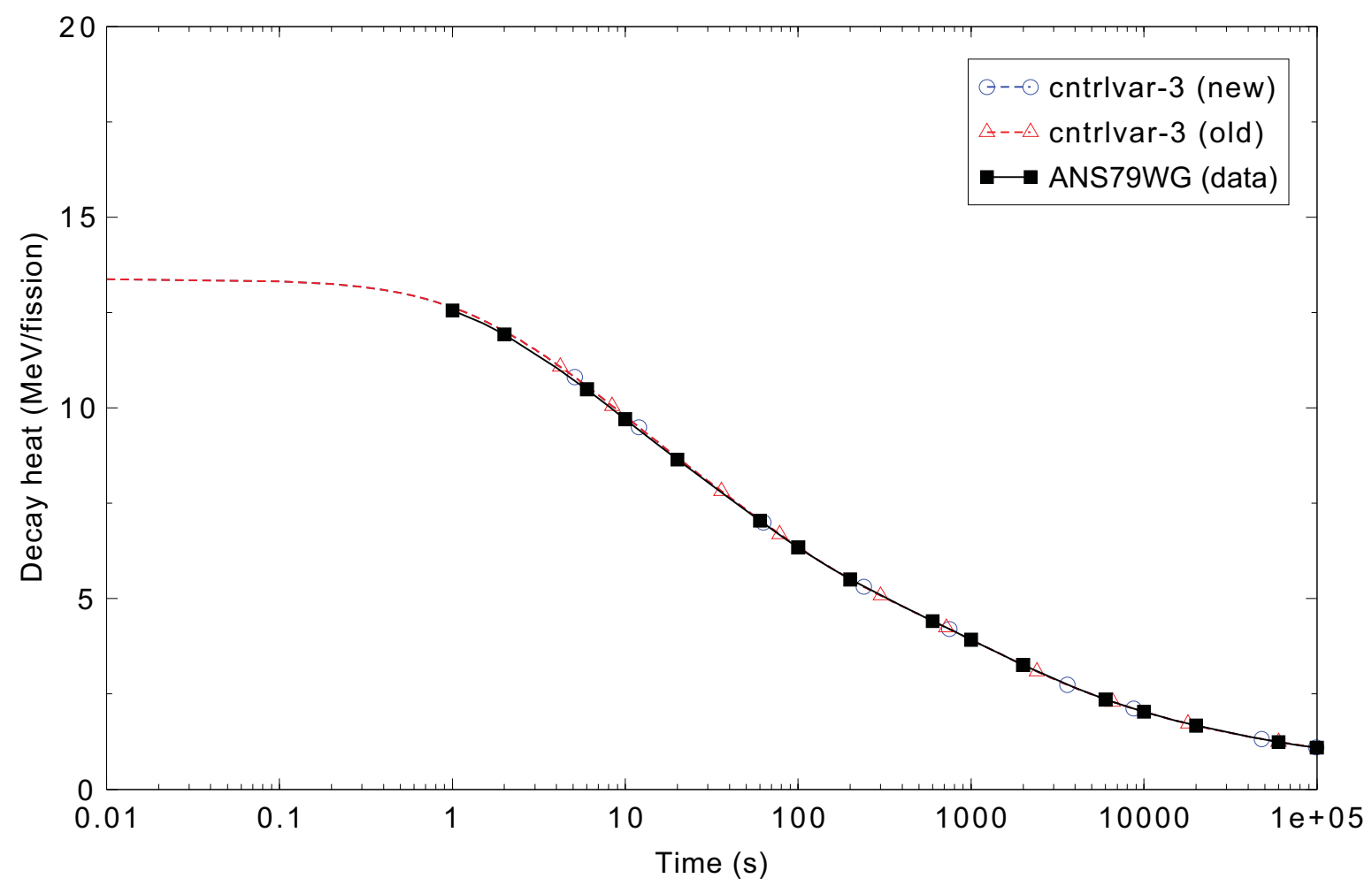

Figure 3.10-3. Decay heat comparison for the ans79G.i test problem. 


\subsection{Point Kinetics Ramp}

Figures comparing simulations using two code versions are presented. A significant difference was observed in Figure 3.11-2.

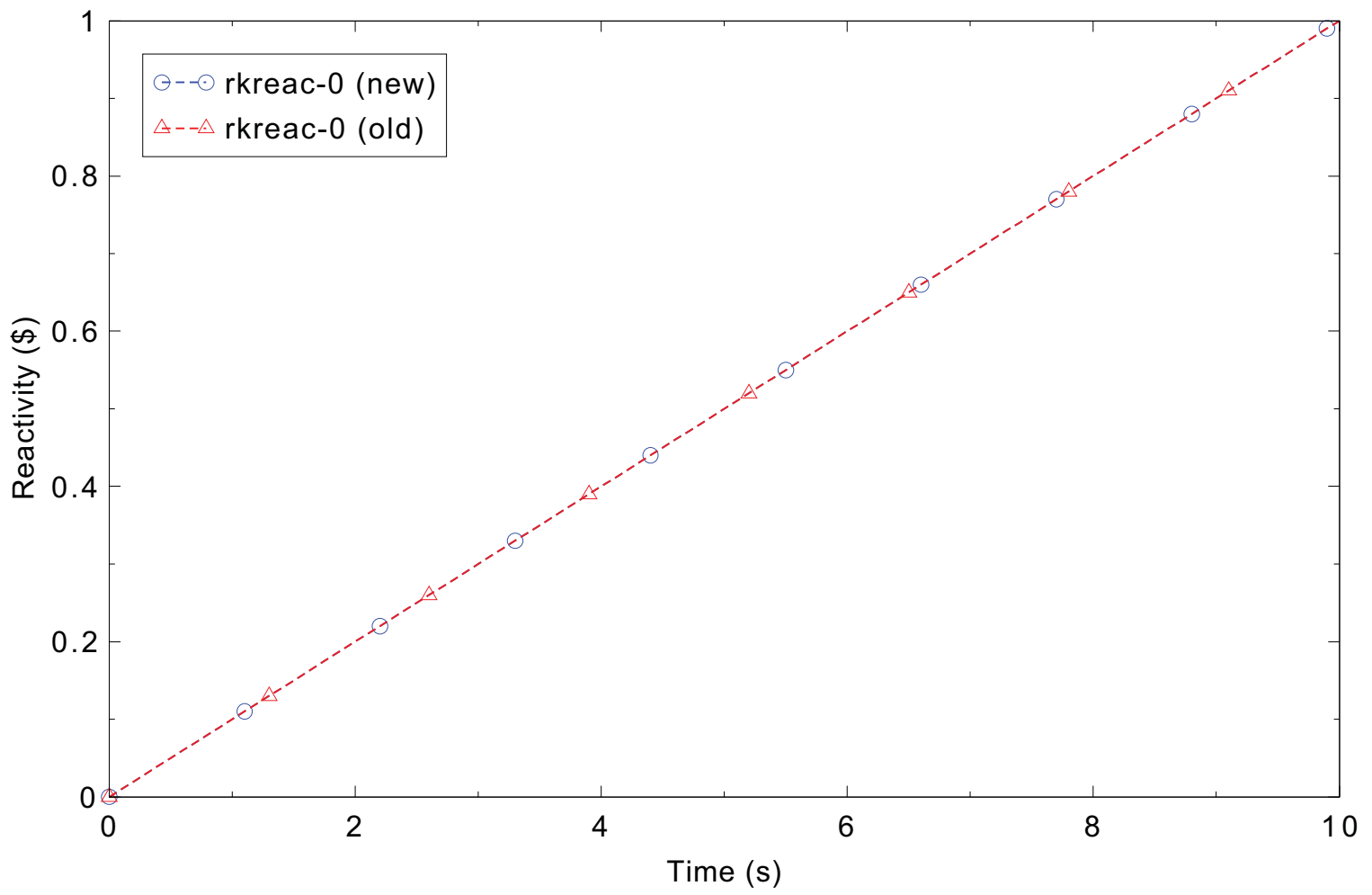

Figure 3.11-1. Reactivity comparison for the point kinetics ramp problem. 


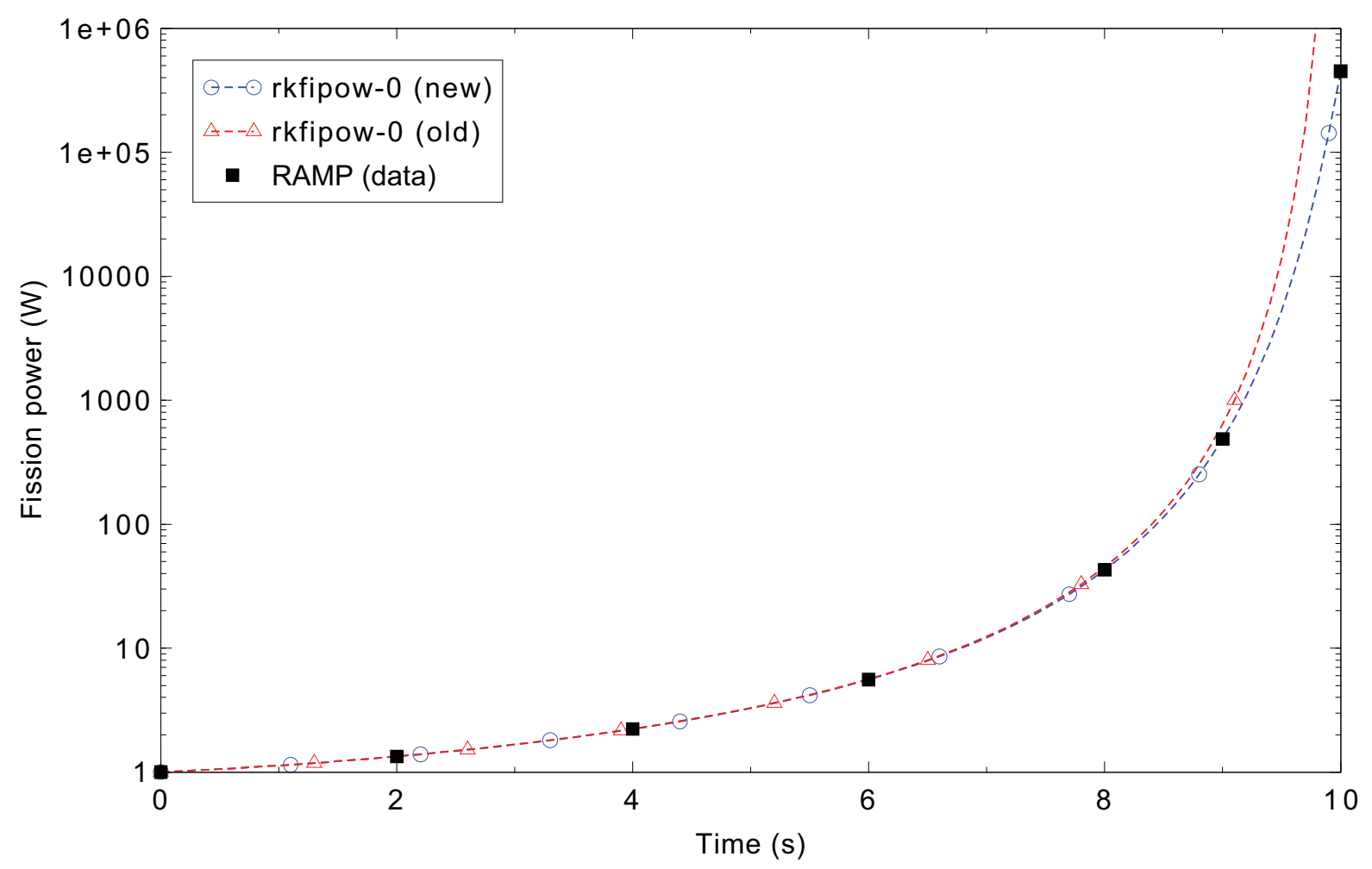

Figure 3.11-2. Fission power comparison for the point kinetics ramp problem with $\mathrm{dt}=10^{-5} \mathrm{~s}$.

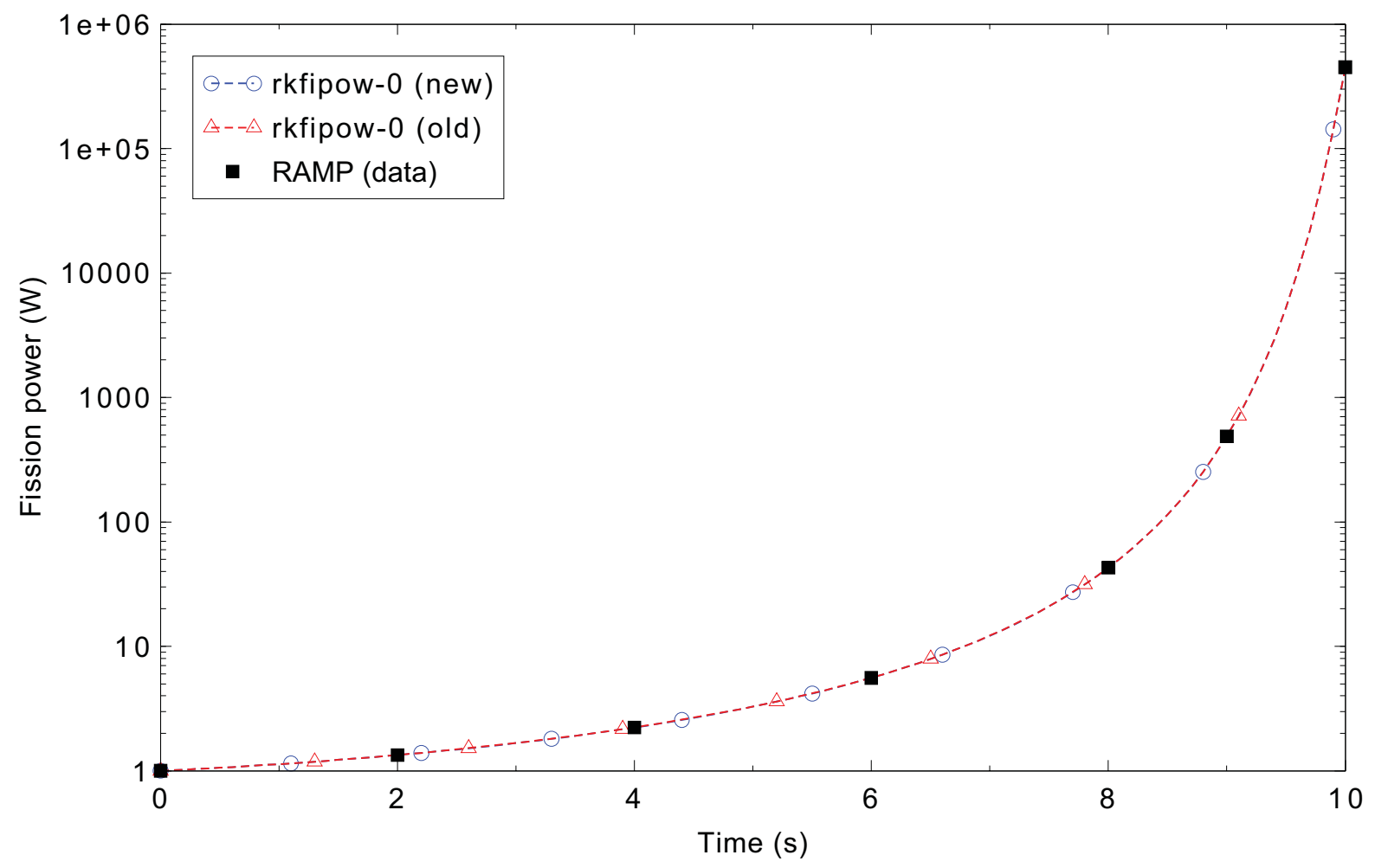

Figure 3.11-3. Fission power comparison for the point kinetics ramp problem with $\mathrm{dt}=0.01 \mathrm{~s}$. 


\subsection{Pure Radial Symmetric Flow (3-D)}

Figures comparing simulations using two code versions are presented. Diagrams are included so that the figure numbering is the same as that in Volume III of the RELAP5-3D code manual. No differences were observed in the figures.

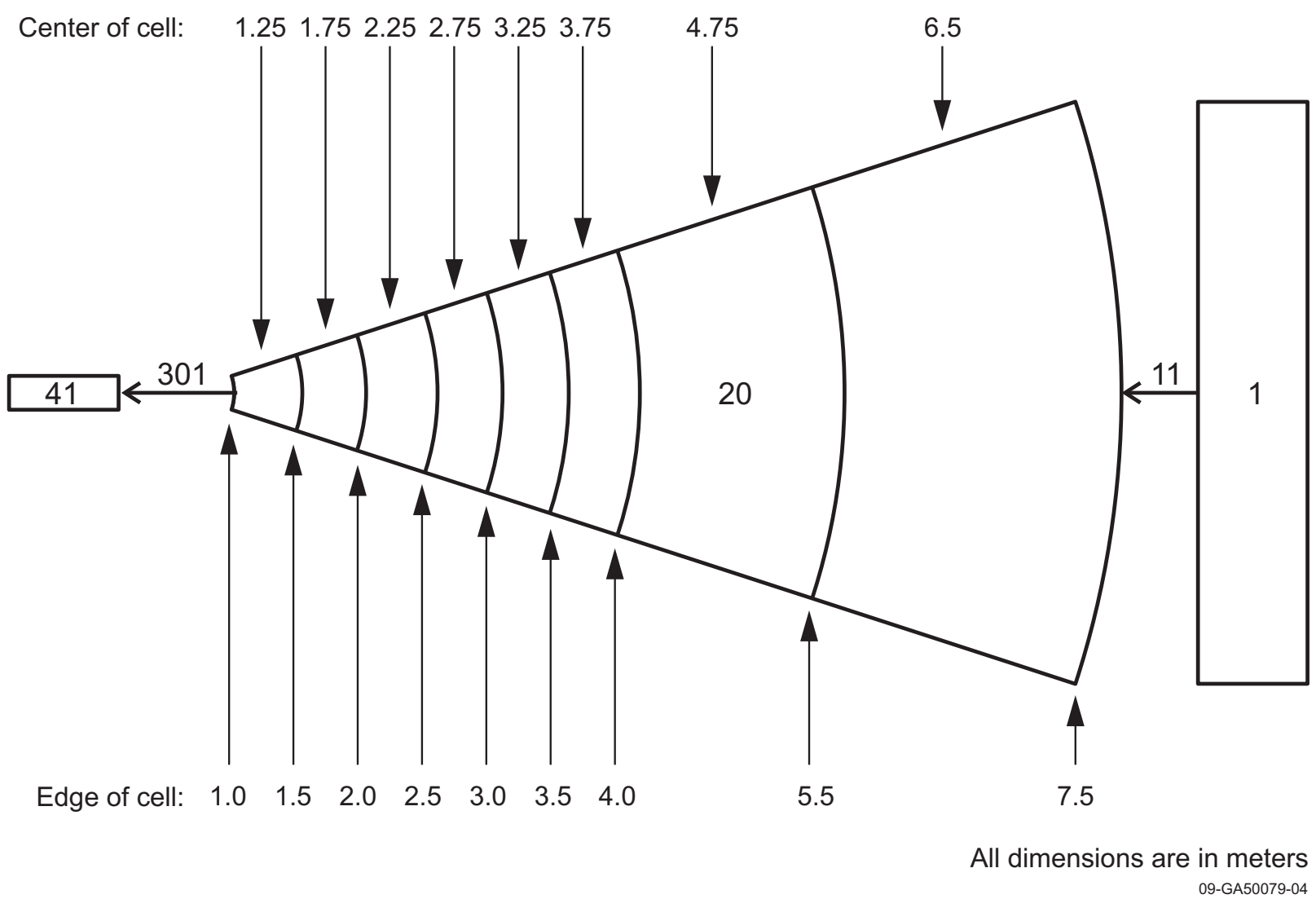

Figure 3.12-1. RELAP5-3D nodalization for the pure radial symmetric flow problem. 


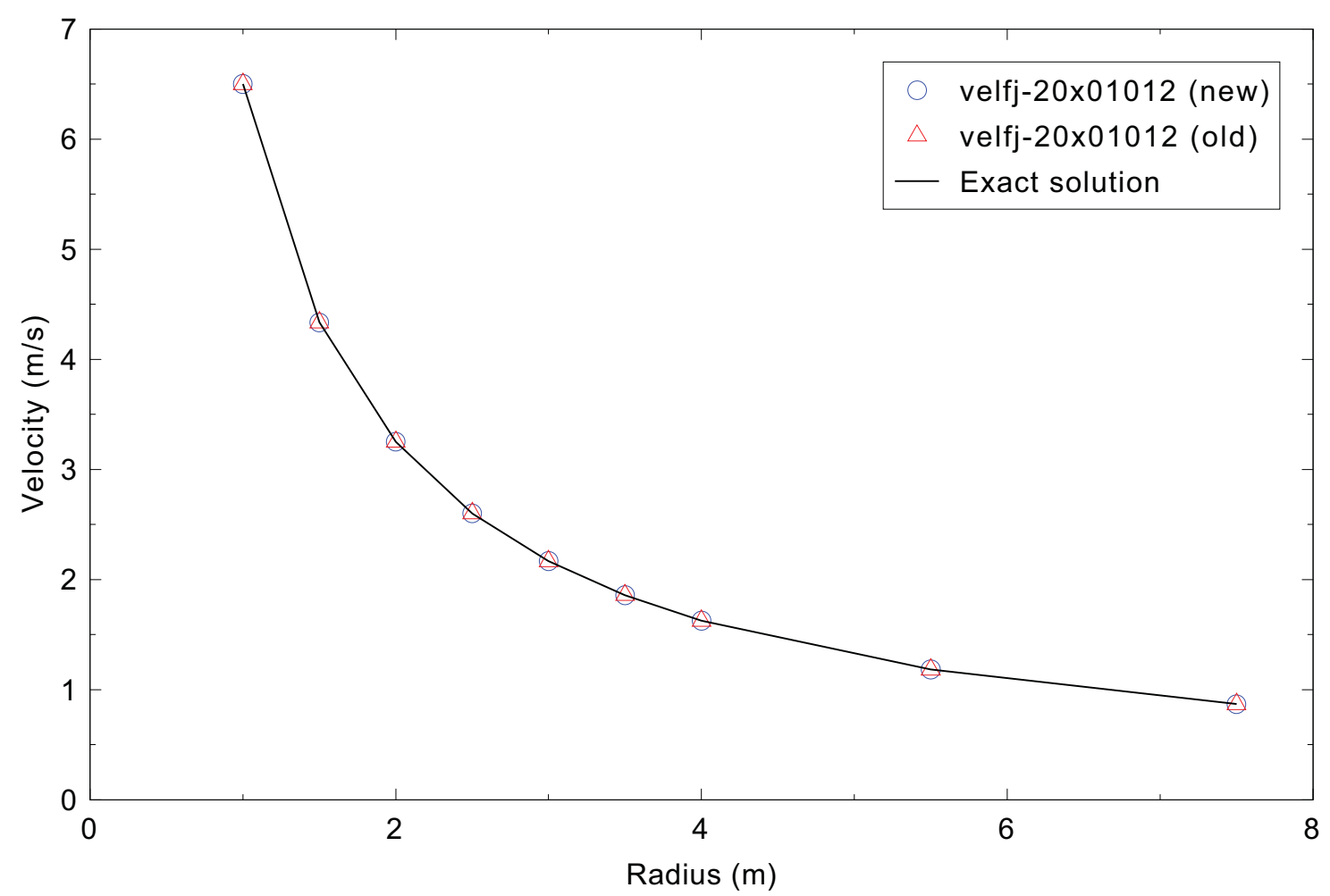

Figure 3.12-2. Radial velocity distribution for the pure radial symmetric flow problem.

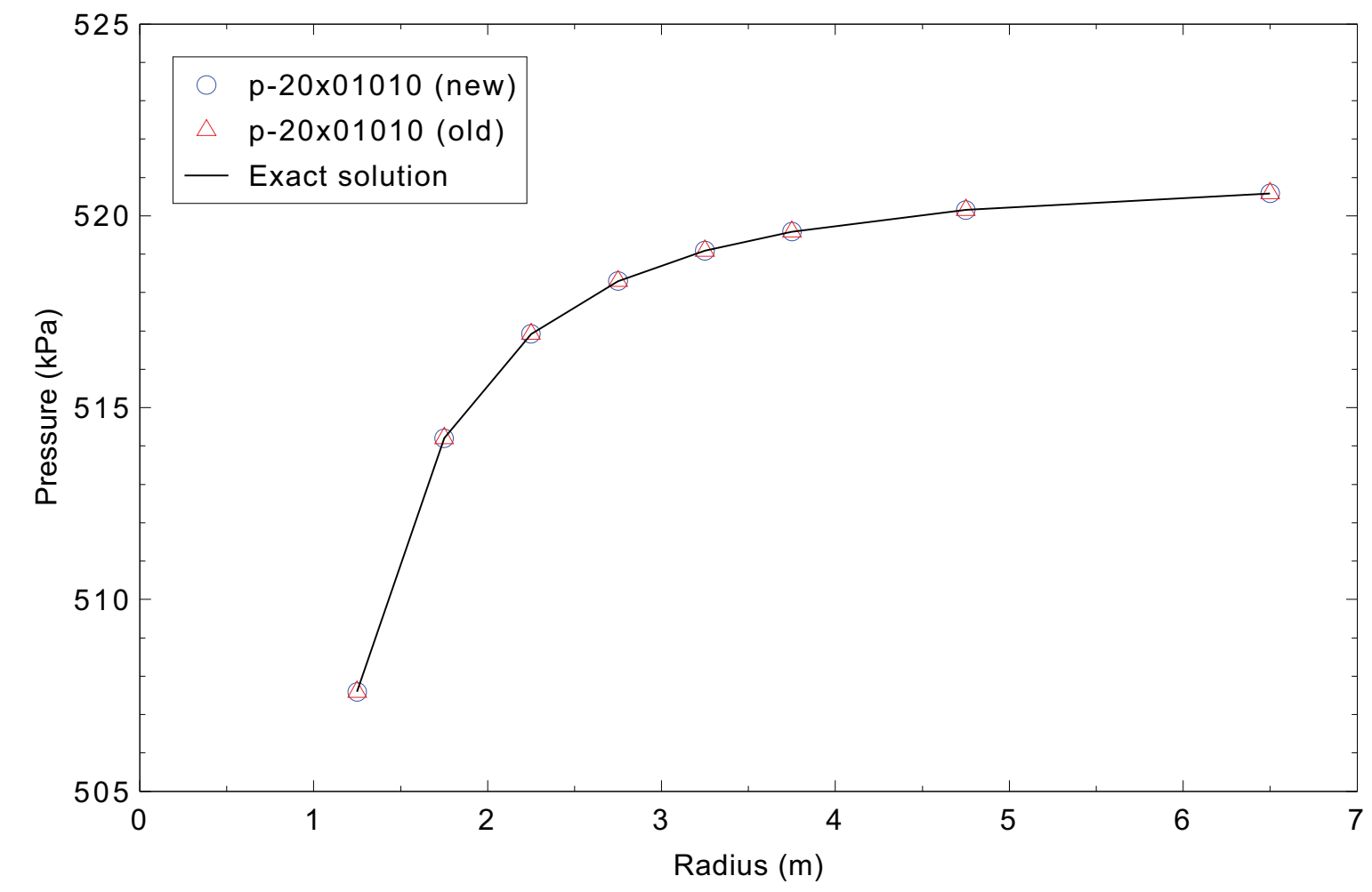

Figure 3.12-3. Radial pressure distribution for the pure radial symmetric flow problem. 


\subsection{Rigid Body Rotation (3-D)}

Figures comparing simulations using two code versions are presented. Diagrams are included so that the figure numbering is the same as that in Volume III of the RELAP5-3D code manual. No differences were observed in the figures.

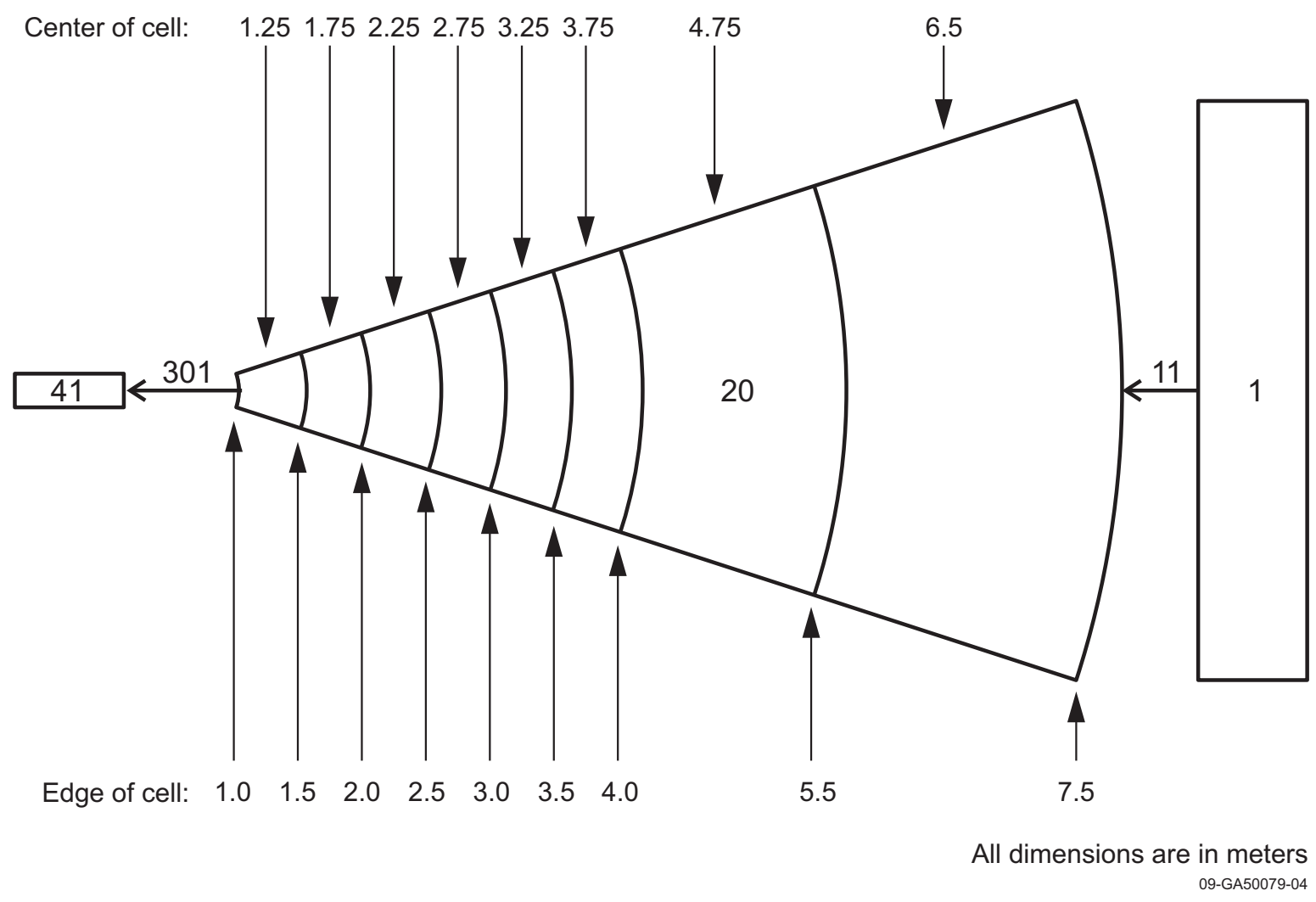

Figure 3.13-1. RELAP5-3D nodalization for the rigid body rotation problem. 


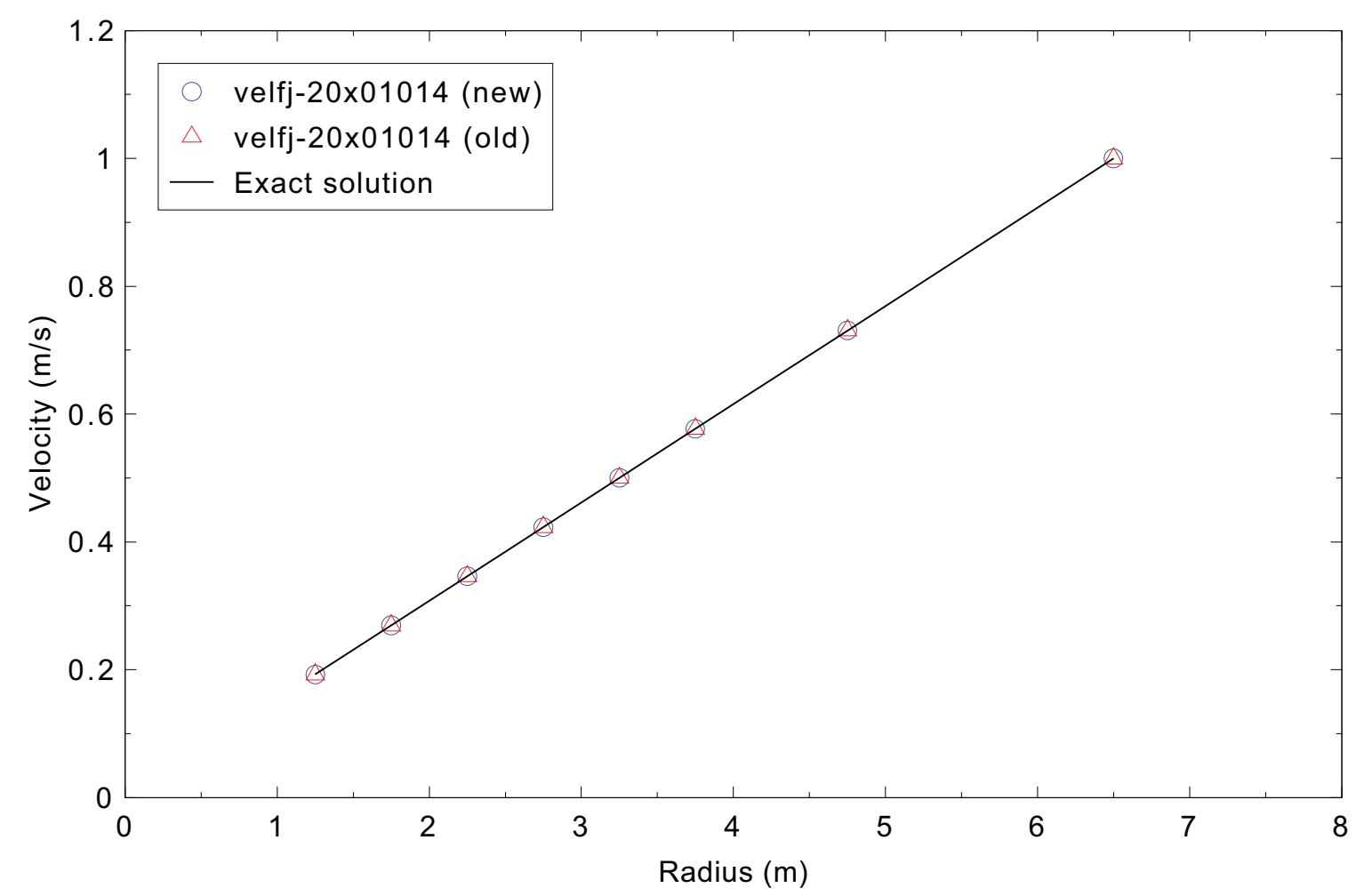

Figure 3.13-2. Azimuthal velocity distribution for the rigid body rotation problem.

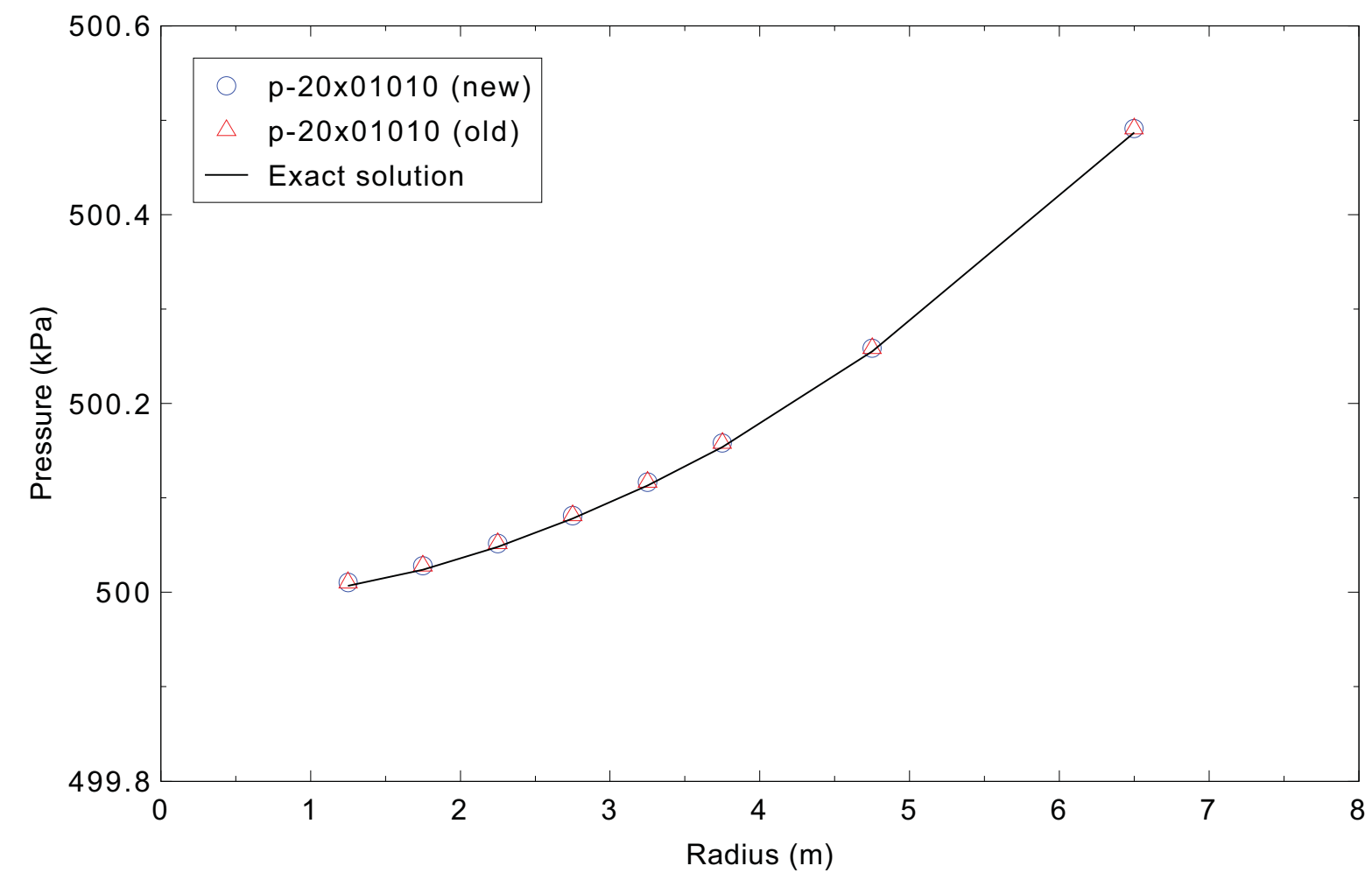

Figure 3.13-3. Radial pressure distribution for the rigid body rotation problem. 


\subsection{R-Theta Symmetric Flow (3-D)}

Figures comparing simulations using two code versions are presented. Diagrams are included so that the figure numbering is the same as that in Volume III of the RELAP5-3D code manual. No differences were observd in the figures.

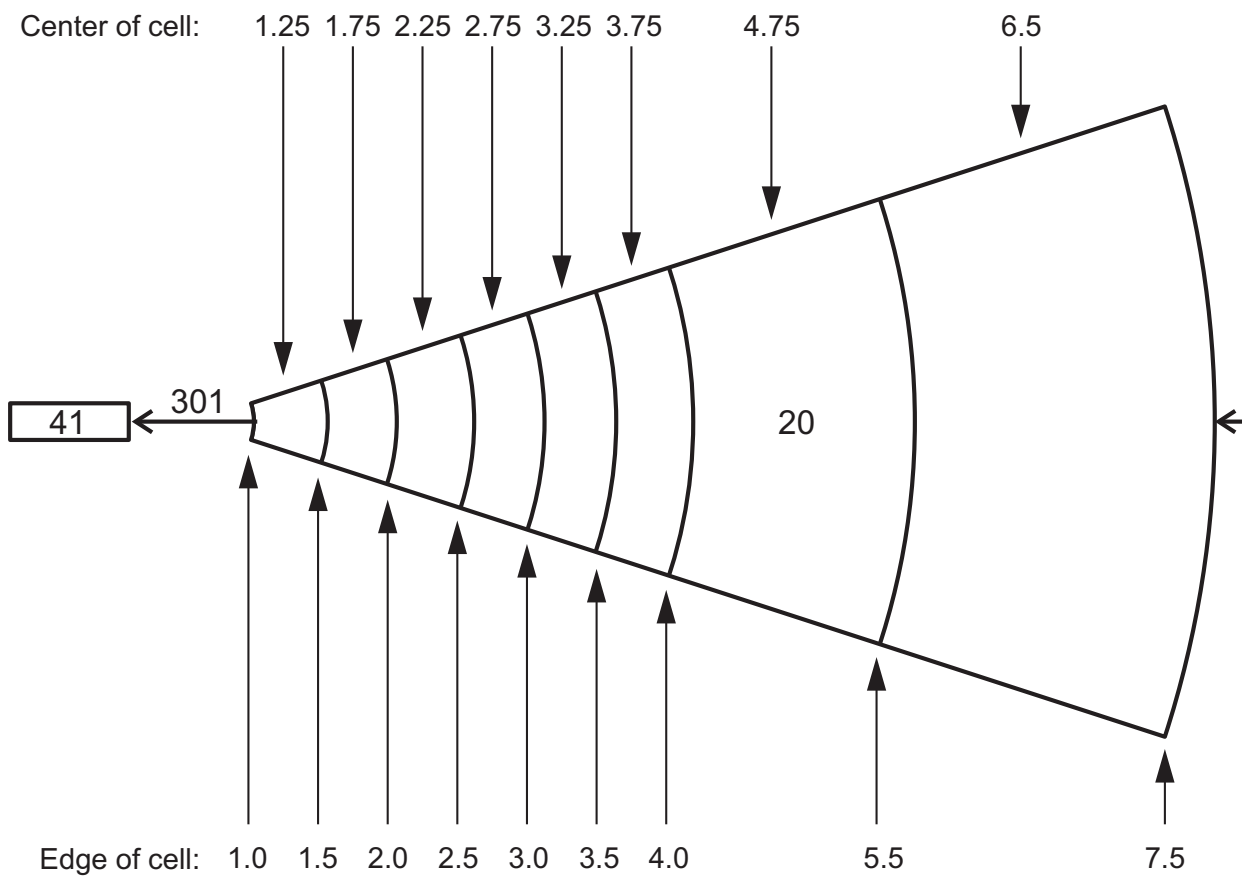

Figure 3.14-1. RELAP5-3D nodalization for the r-theta symmetric flow problem. 


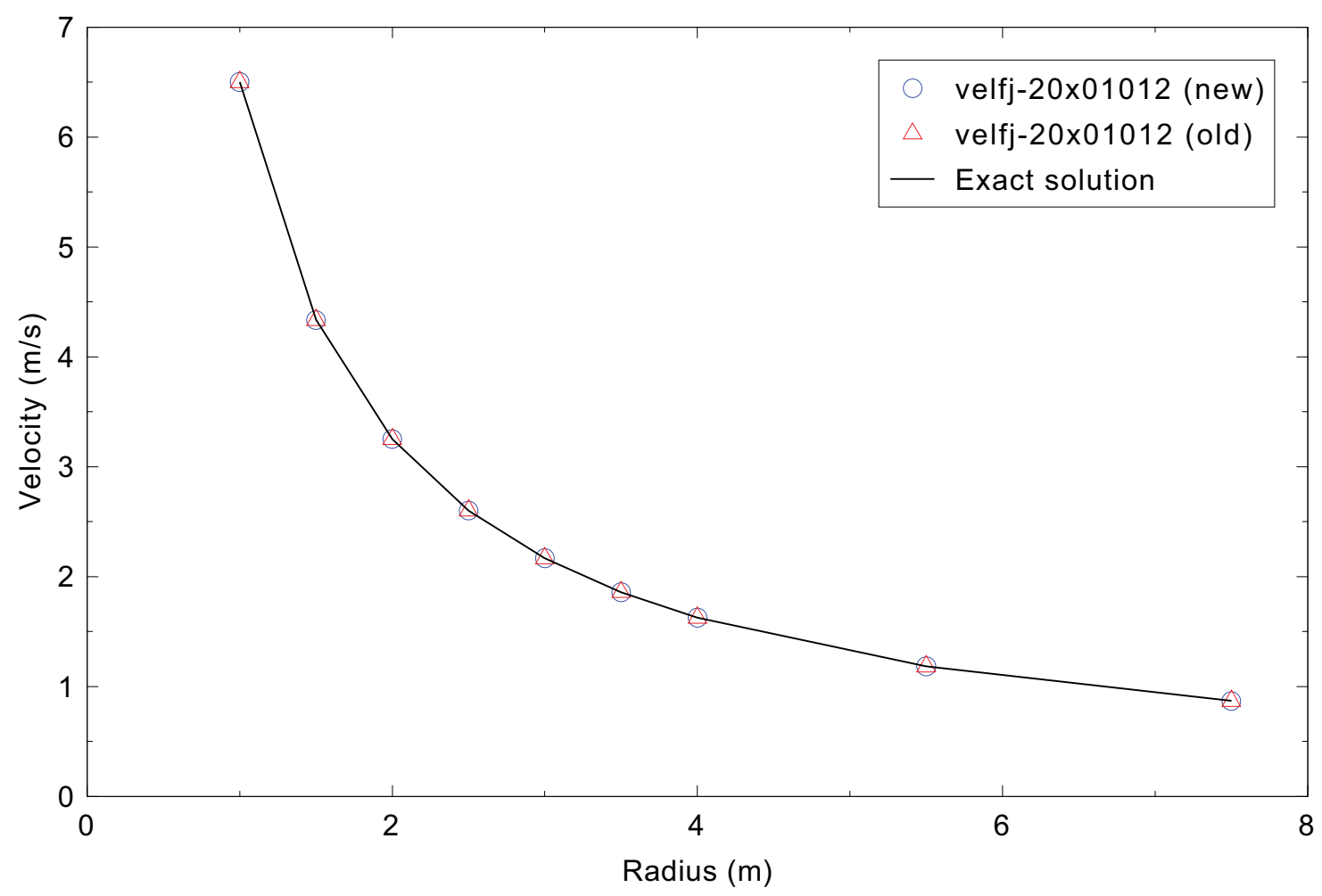

Figure 3.14-2. Radial velocity distribution for the r-theta symmetric flow problem.

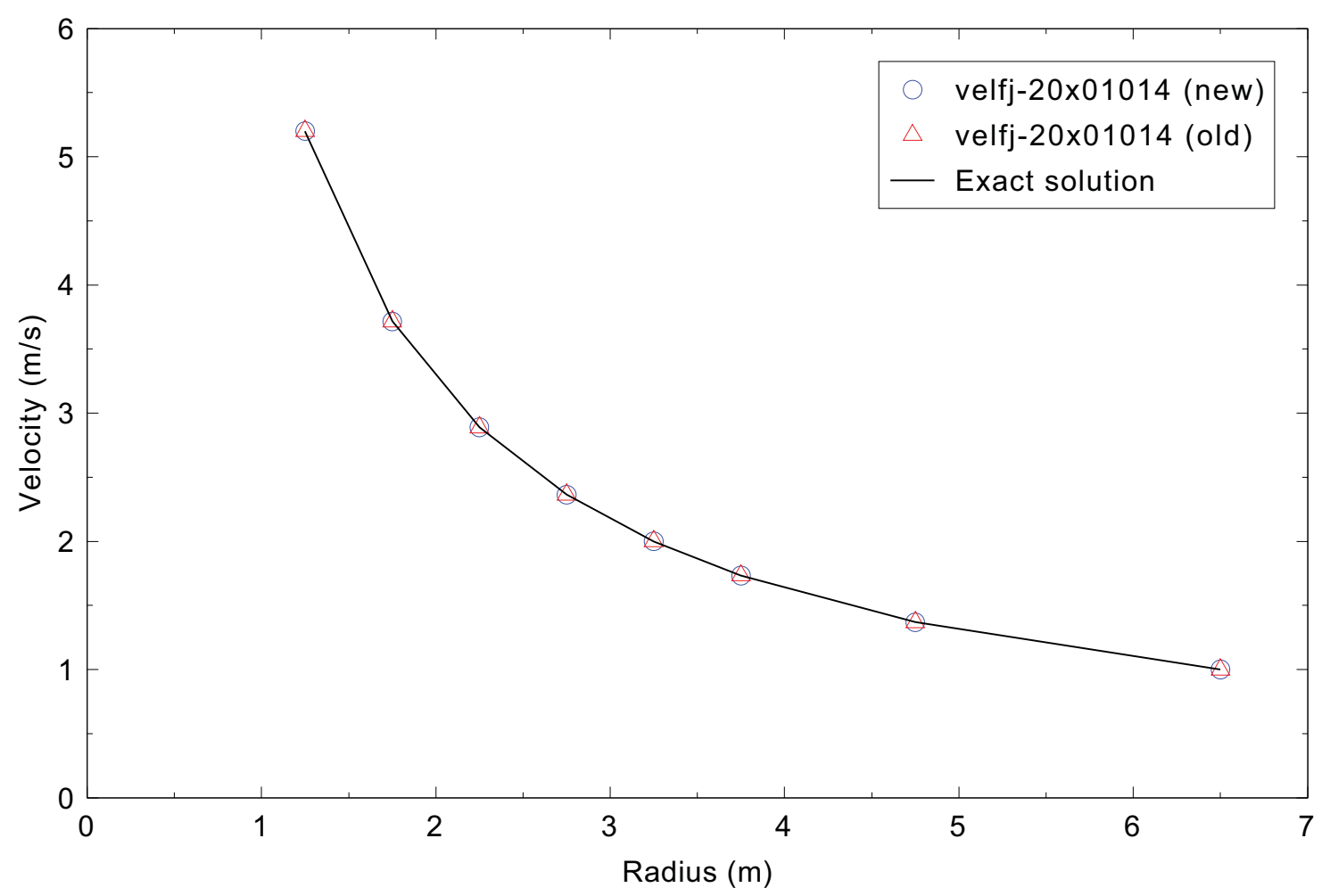

Figure 3.14-3. Azimuthal velocity distribution for the r-theta symmetric flow problem. 


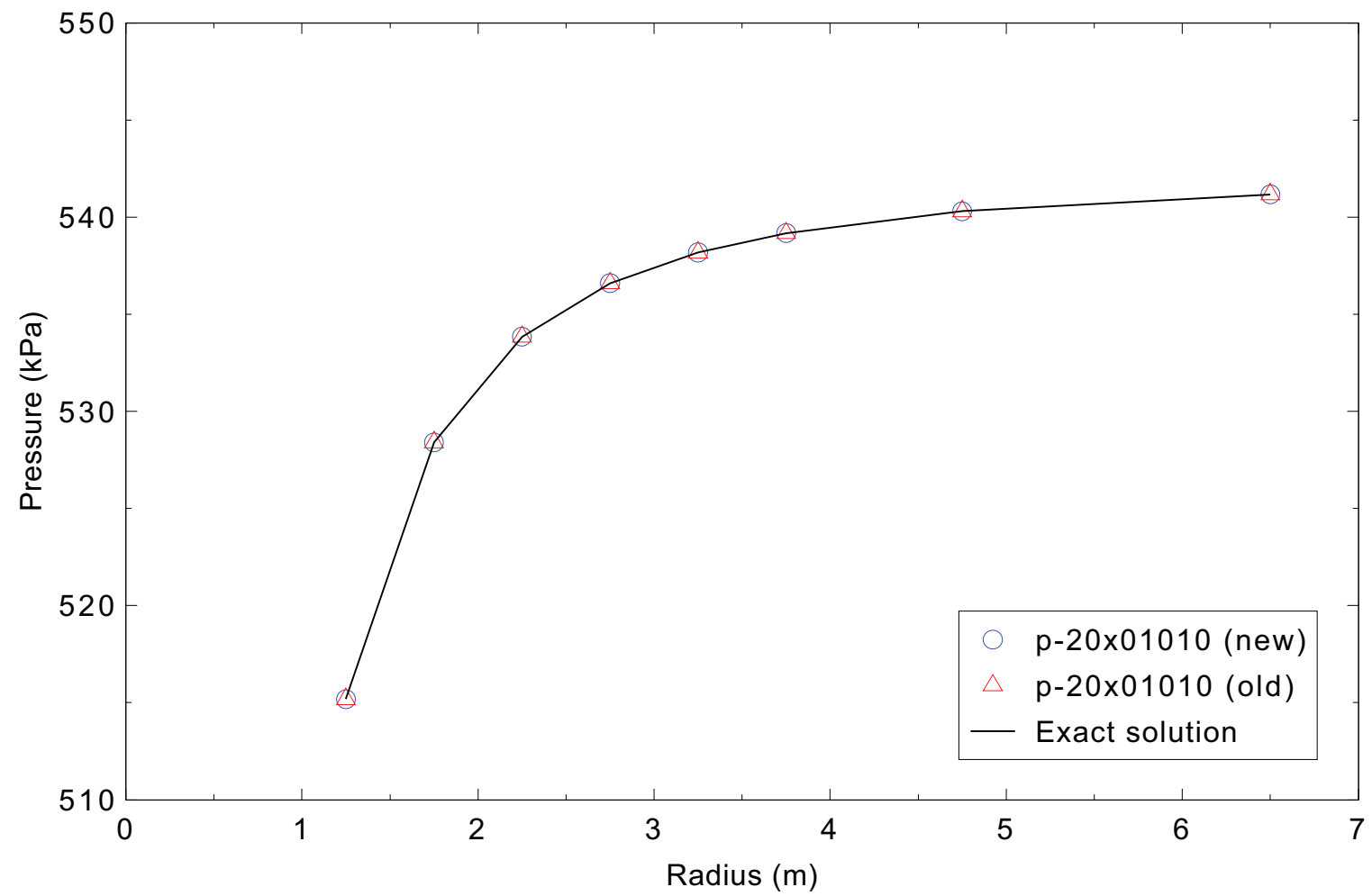

Figure 3.14-4. Radial pressure distribution for the r-theta symmetric flow problem. 


\subsection{Conduction Enclosure}

Figures comparing simulations using two code versions are presented. Diagrams are included so that the figure numbering is the same as that in Volume III of the RELAP5-3D code manual. The 3-D figures should be ignored, as they may not reflect the current code version. No differences were observed in the figures.

\section{Heat Structure-Boundary Conditions}

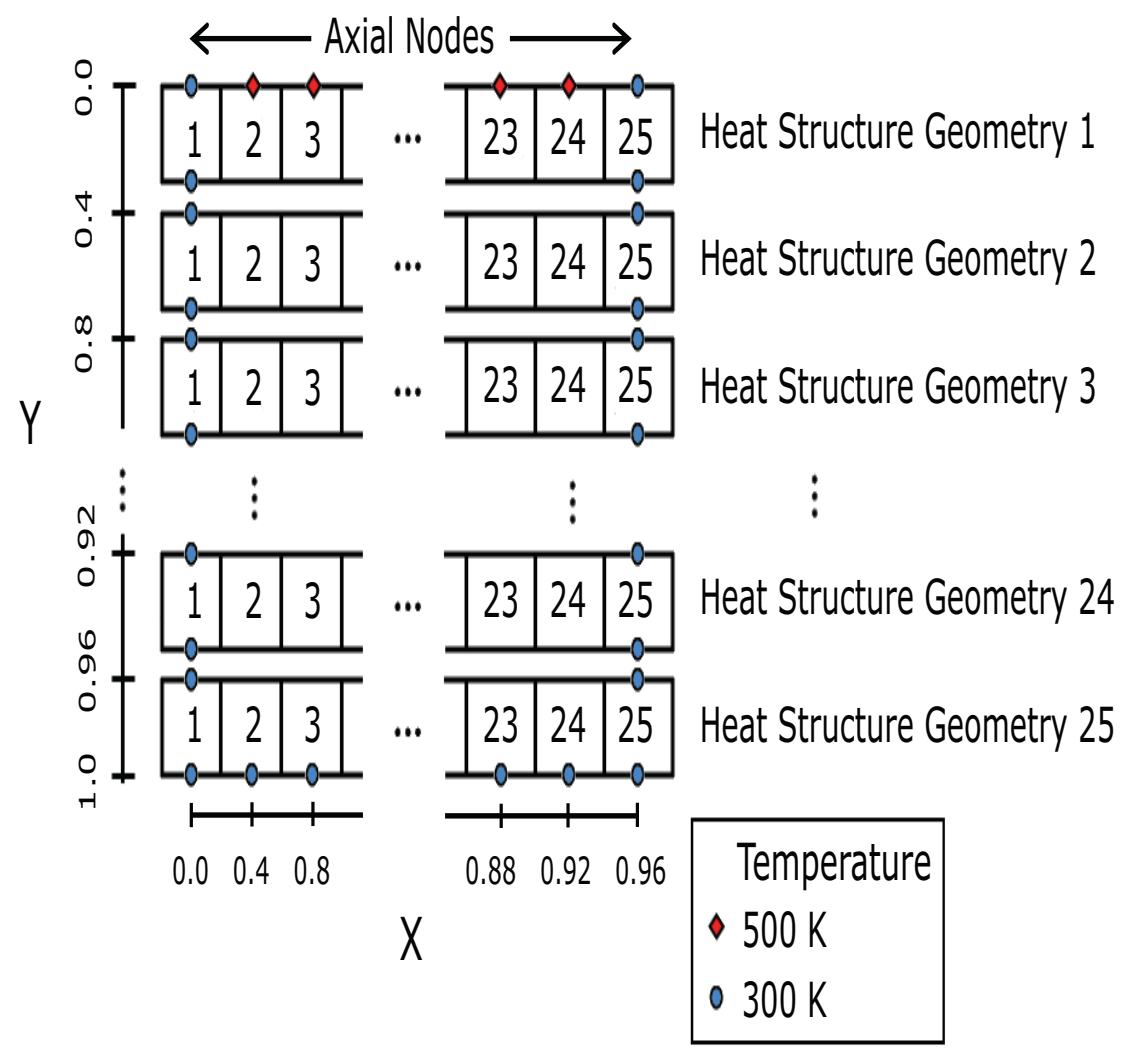

Figure 3.15-1. Heat structure layout with boundary conditions for the conduction enclosure problem. 


\section{Conduction Enclosure Configuration}

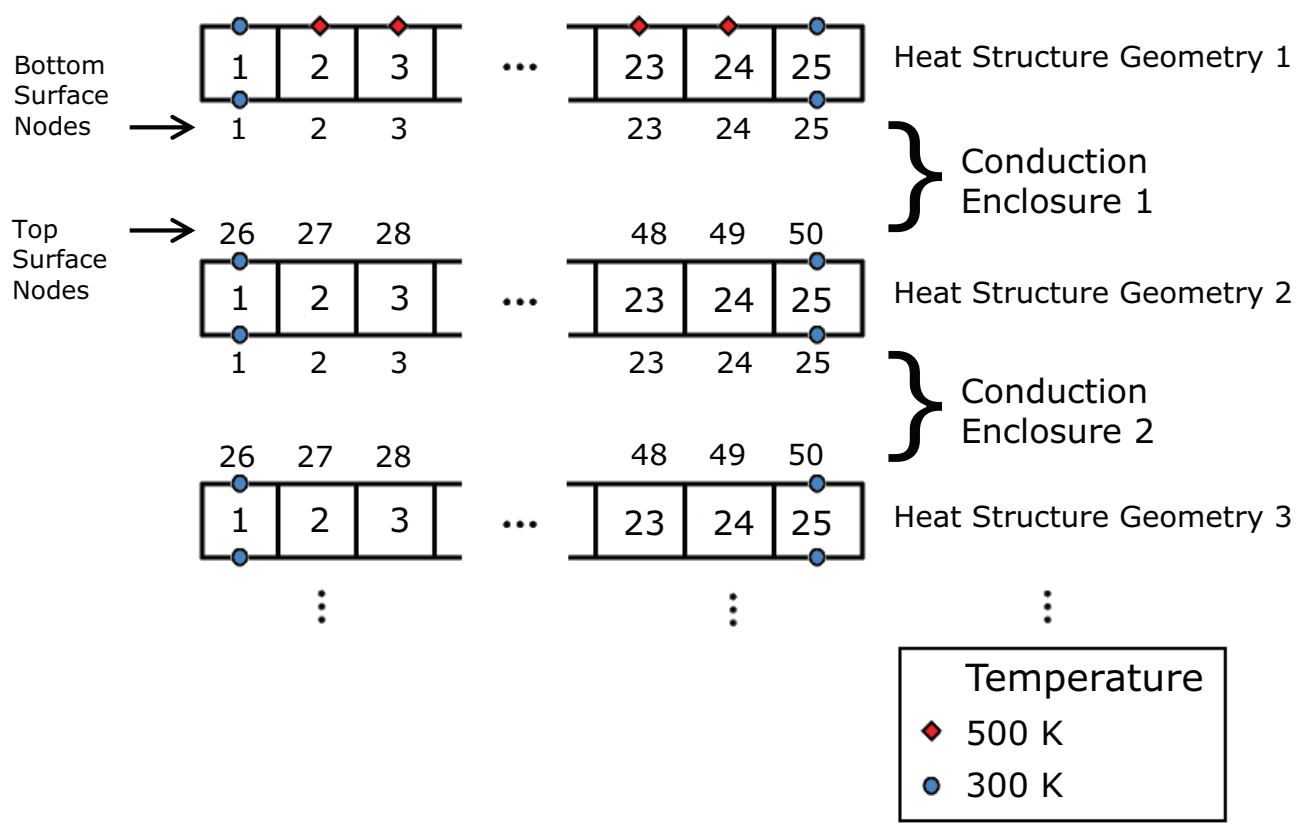

Figure 3.15-2. View of heat structure surfaces included in the conduction enclosures.

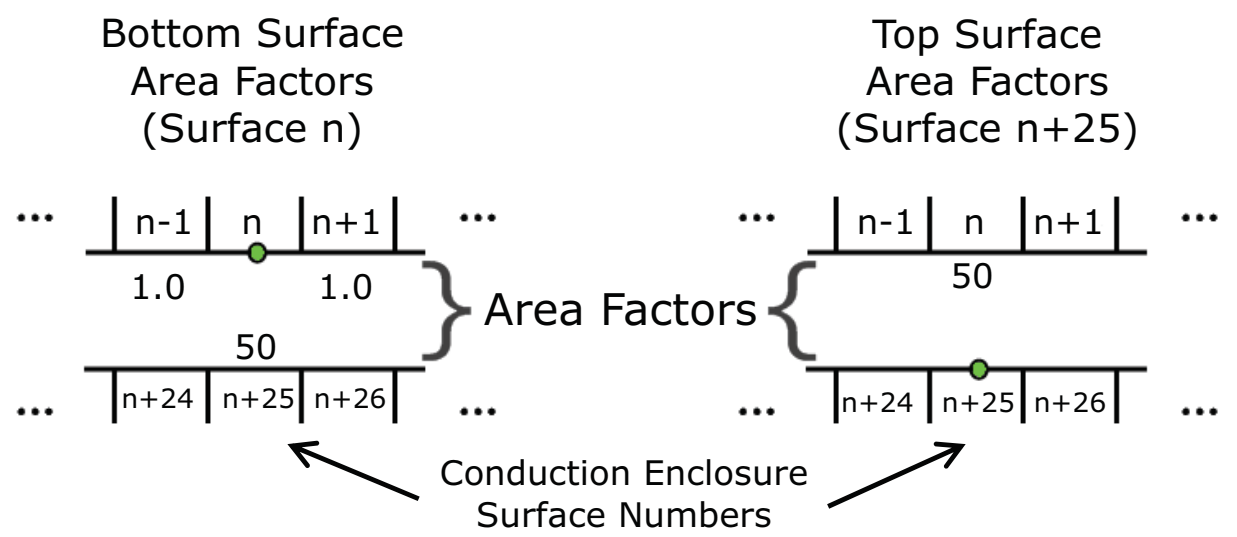

Figure 3.15-3. Area factors used to define axial contact of heat structure cells as well as contact between separate heat structure geometries. 


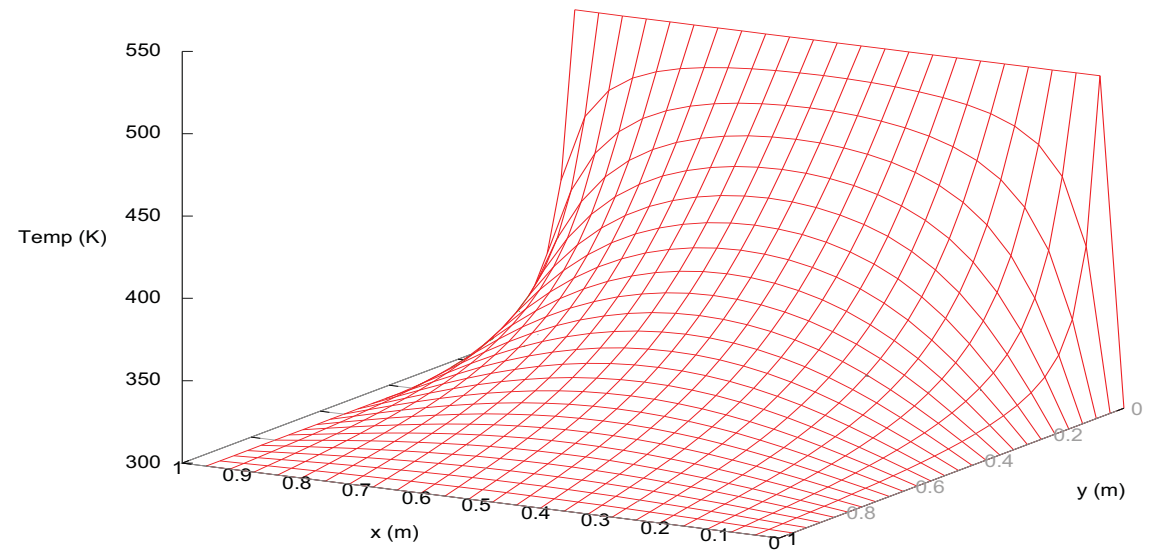

Figure 3.15-4. Steady state temperature for the heated plate problem defined in Equation (3.15-1) based on a 3800-term expansion of the series solution given in Equation (3.15-2).

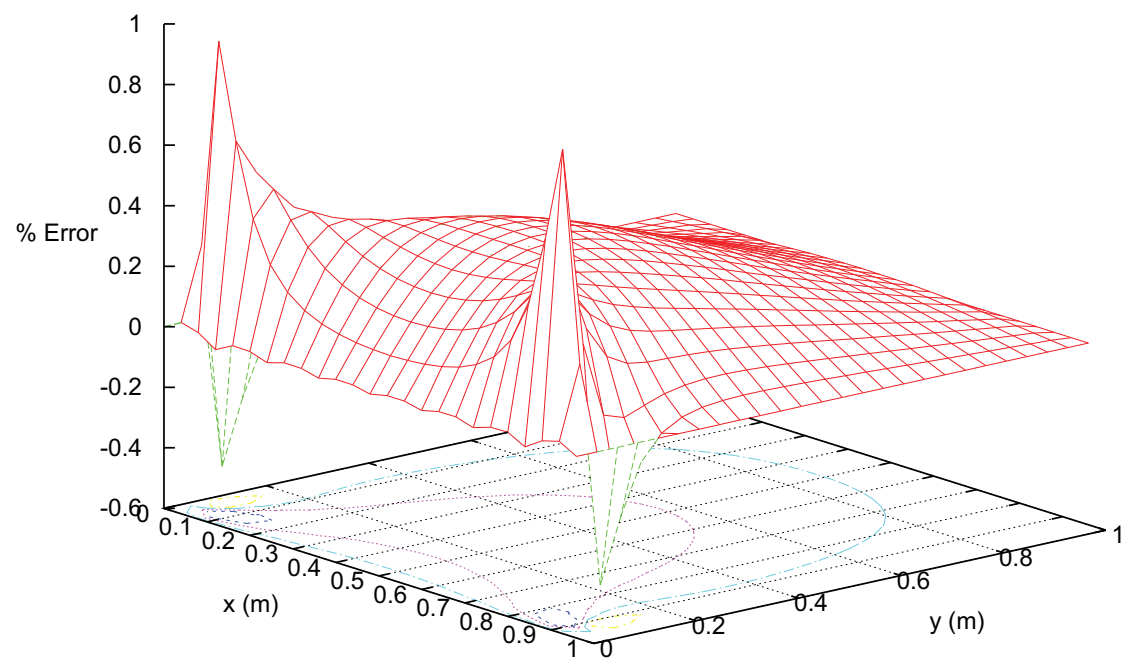

Figure 3.15-5. Local steady state temperature error for the RELAP5-3D solution vs. series solution. 


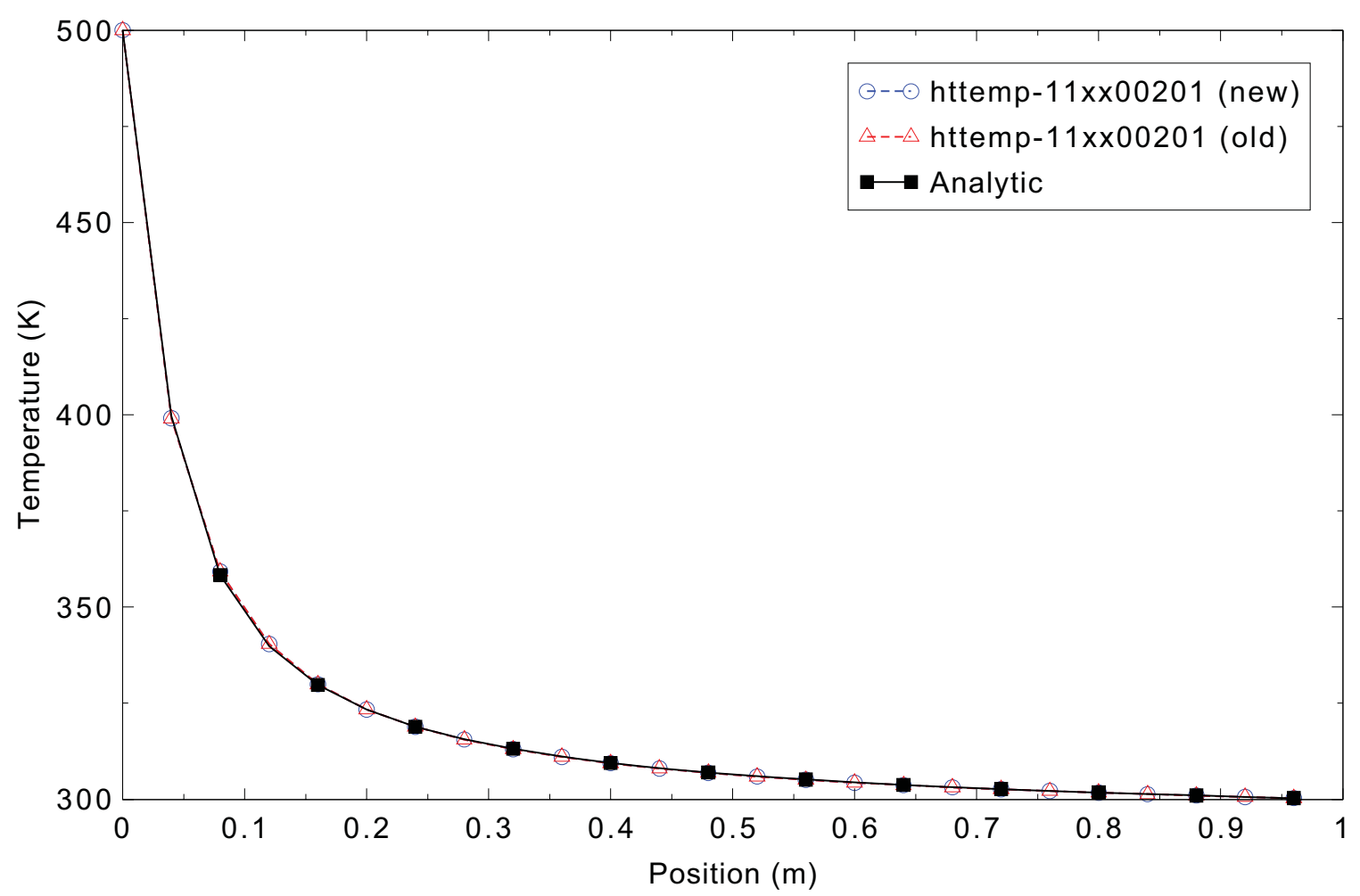

Figure 3.15-6. Heated plate steady state series solution and the RELAP5-3D solution along $\mathrm{x}$ equal to $0.04 \mathrm{~m}$.

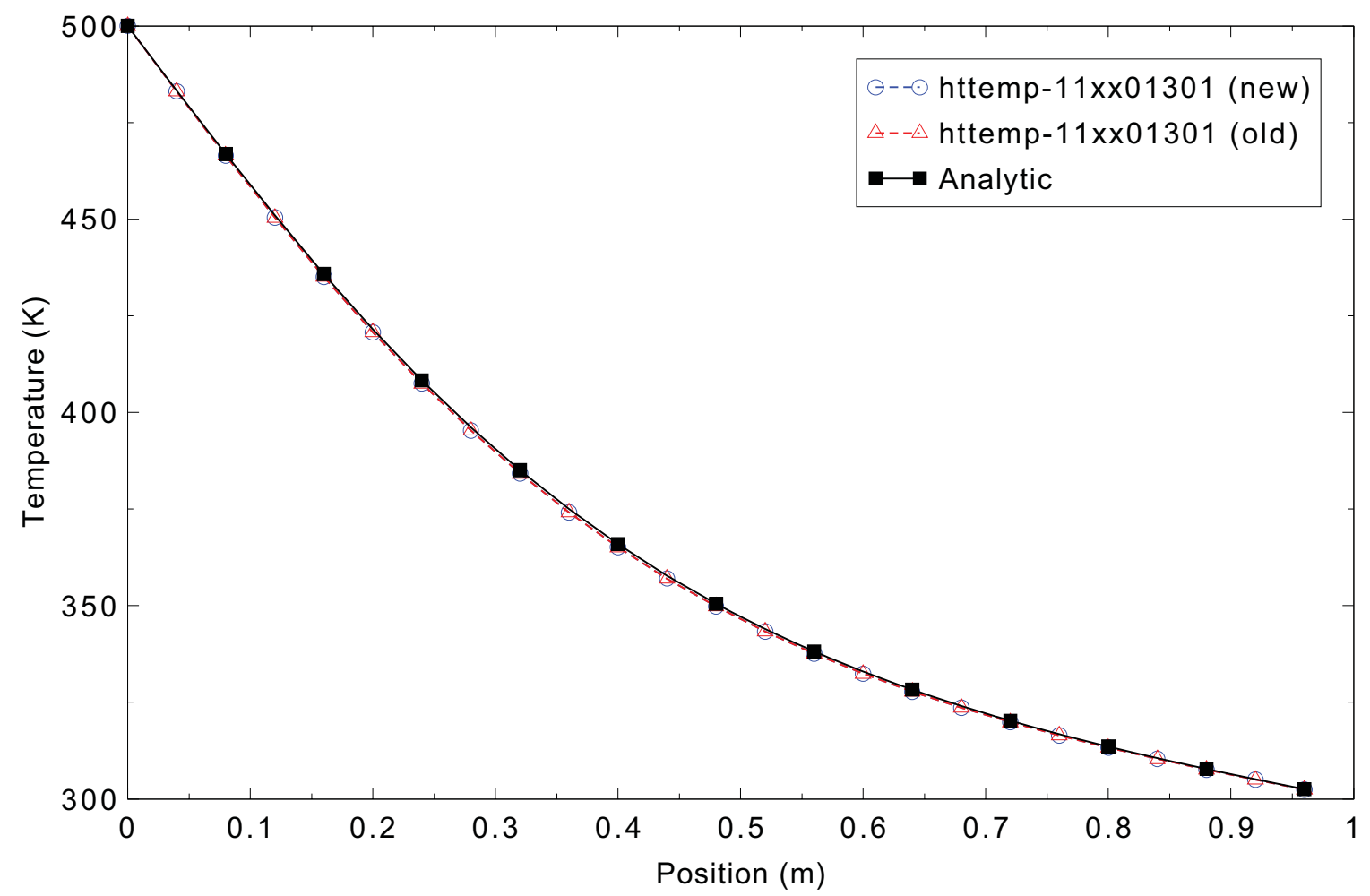

Figure 3.15-7. Heated plate steady state series solution and the RELAP5-3D solution along $\mathrm{x}$ equal to $0.48 \mathrm{~m}$. 


\subsection{Conduction Enclosure: 1-D Transient Model}

Figures comparing simulations using two code versions are presented. Diagrams are included so that the figure numbering is the same as that in Volume III of the RELAP5-3D code manual. The 3-D figures should be ignored, as they may not reflect the current code version. No differences were observed in the figure.

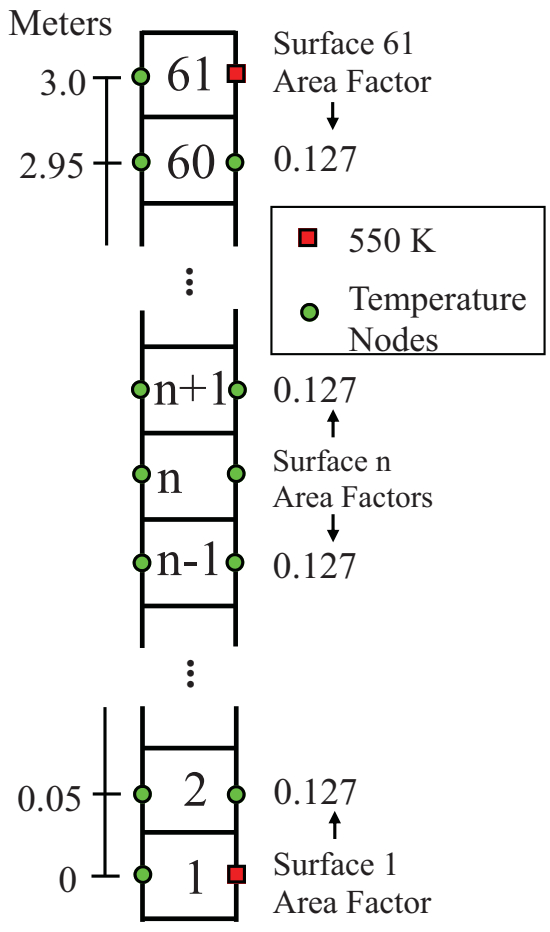

Figure 3.16-1. Rod area factors and end boundary conditions for 1-D conduction enclosure. 
RELAP5-3D/4.0.3

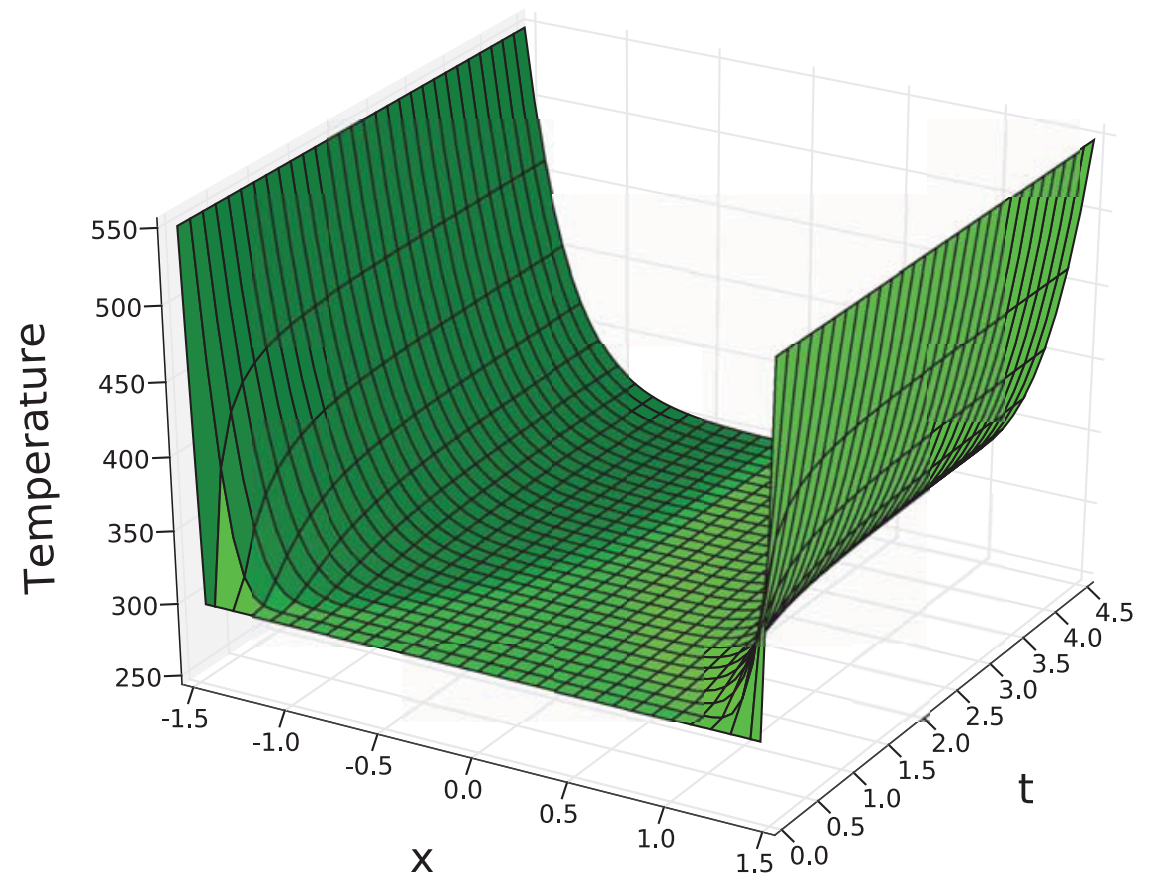

Figure 3.16-2. 1-D conduction enclosure axial temperature vs. time (in hours) based on a 10,000-term expansion of the series solution given in Equation (3.16-4).

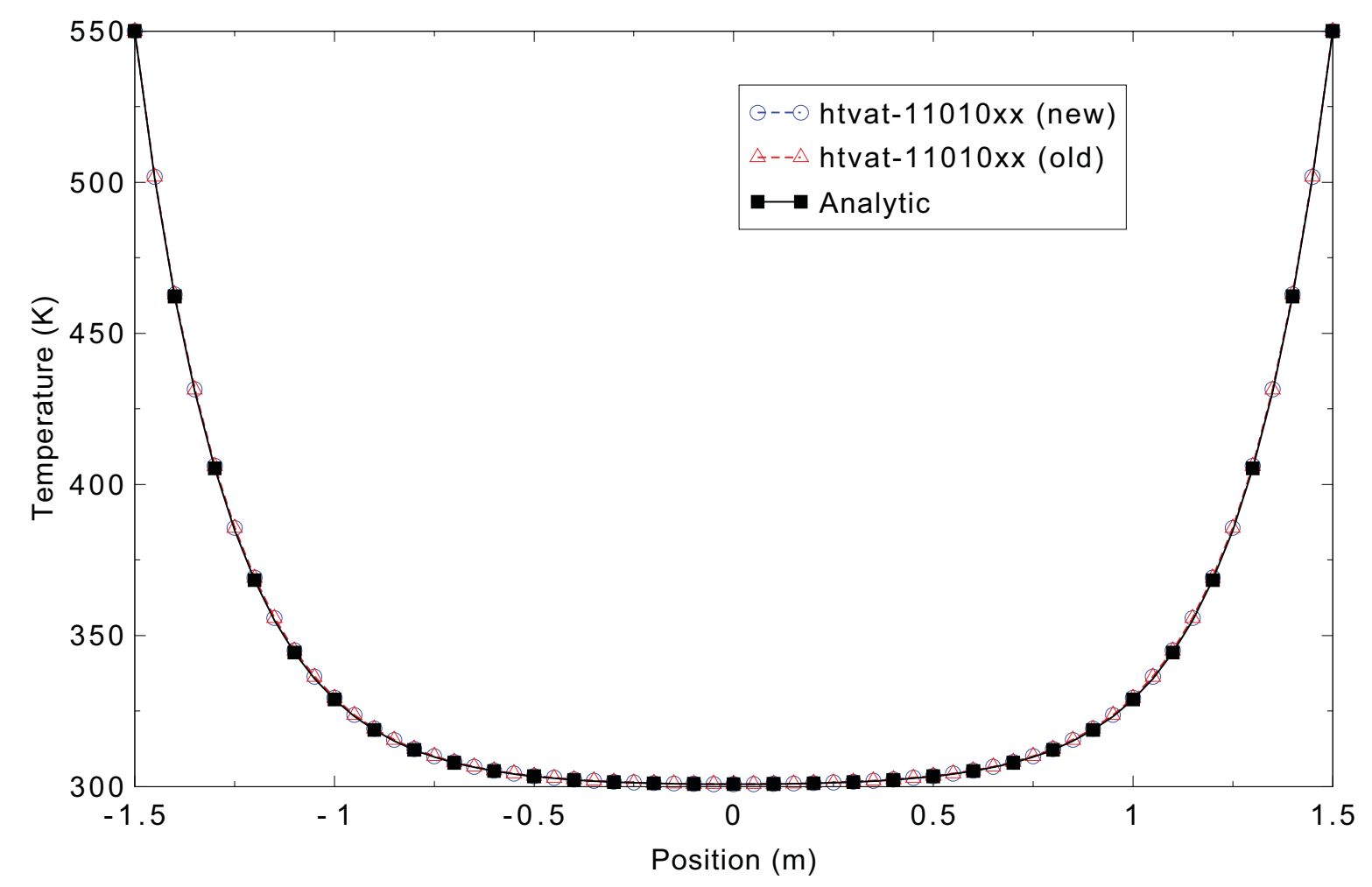

Figure 3.16-3. 1-D conduction enclosure temperature comparison with analytical solution at $10 \mathrm{~h}$. 


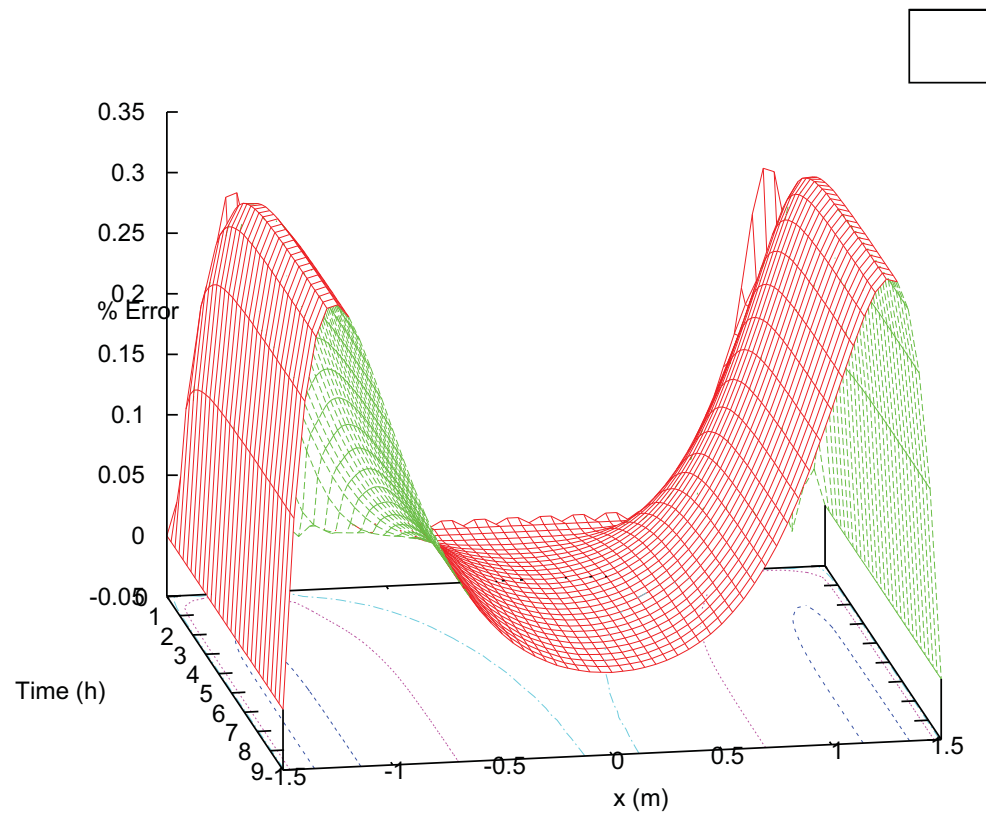

Figure 3.16-4. 1-D conduction enclosure local percent error for the rod with heated ends vs. position along the rod and time. 


\subsection{Conduction Enclosure: 2-D Transient Model}

Figures comparing simulations using two code versions are presented. Diagrams are included so that the figure numbering is the same as that in Volume III of the RELAP5-3D code manual. The 3-D figures should be ignored, as they may not reflect the current code version. No differences were observed in the figure..

\section{Heat Structure-Boundary Conditions}

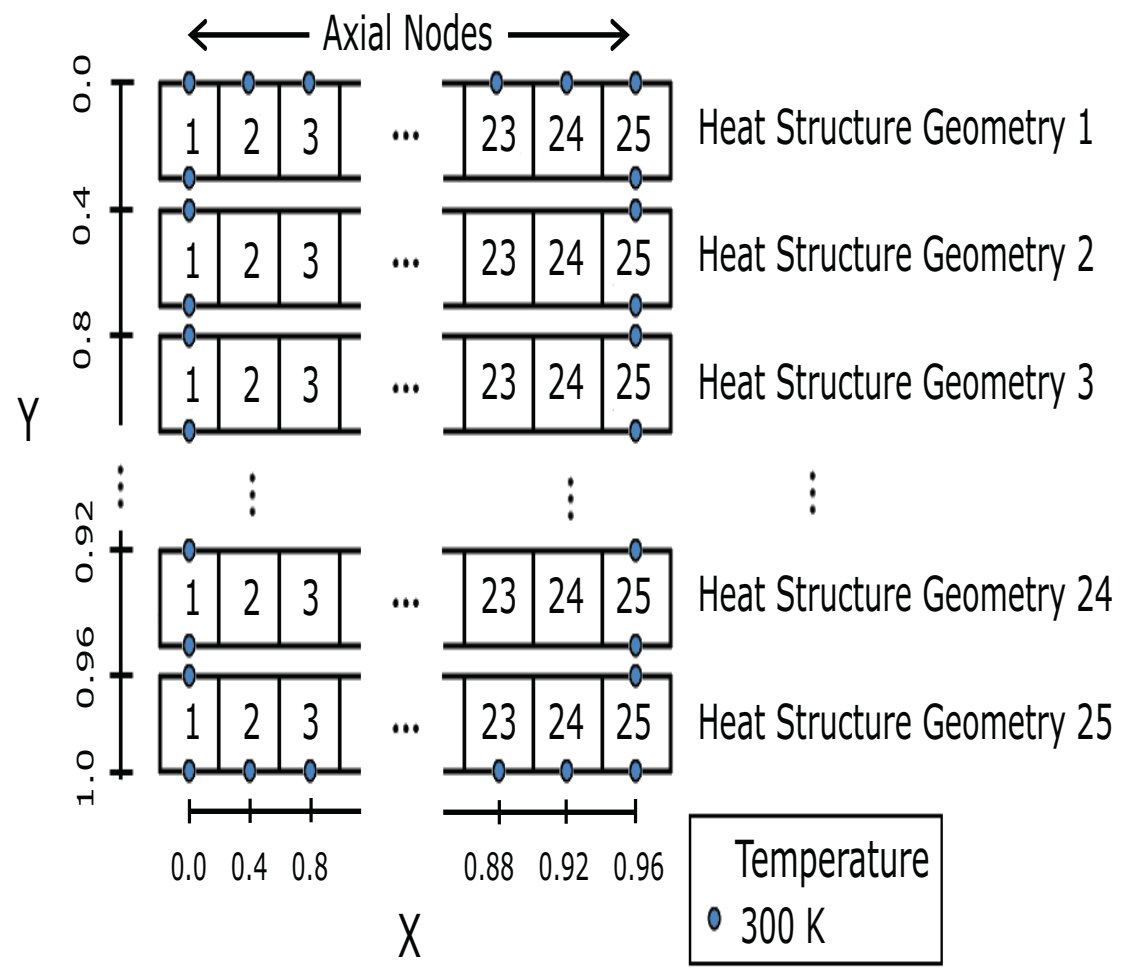

Figure 3.17-1. Boundary conditions for the transient heated plate model for 2-D conduction enclosure.

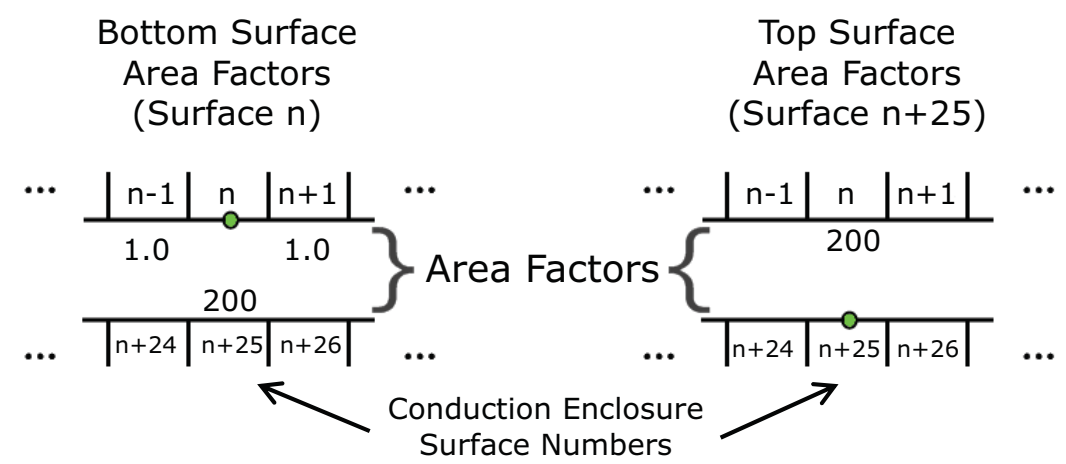

Figure 3.17-2. Area factors for the 2-D plate transient heat conduction model. 


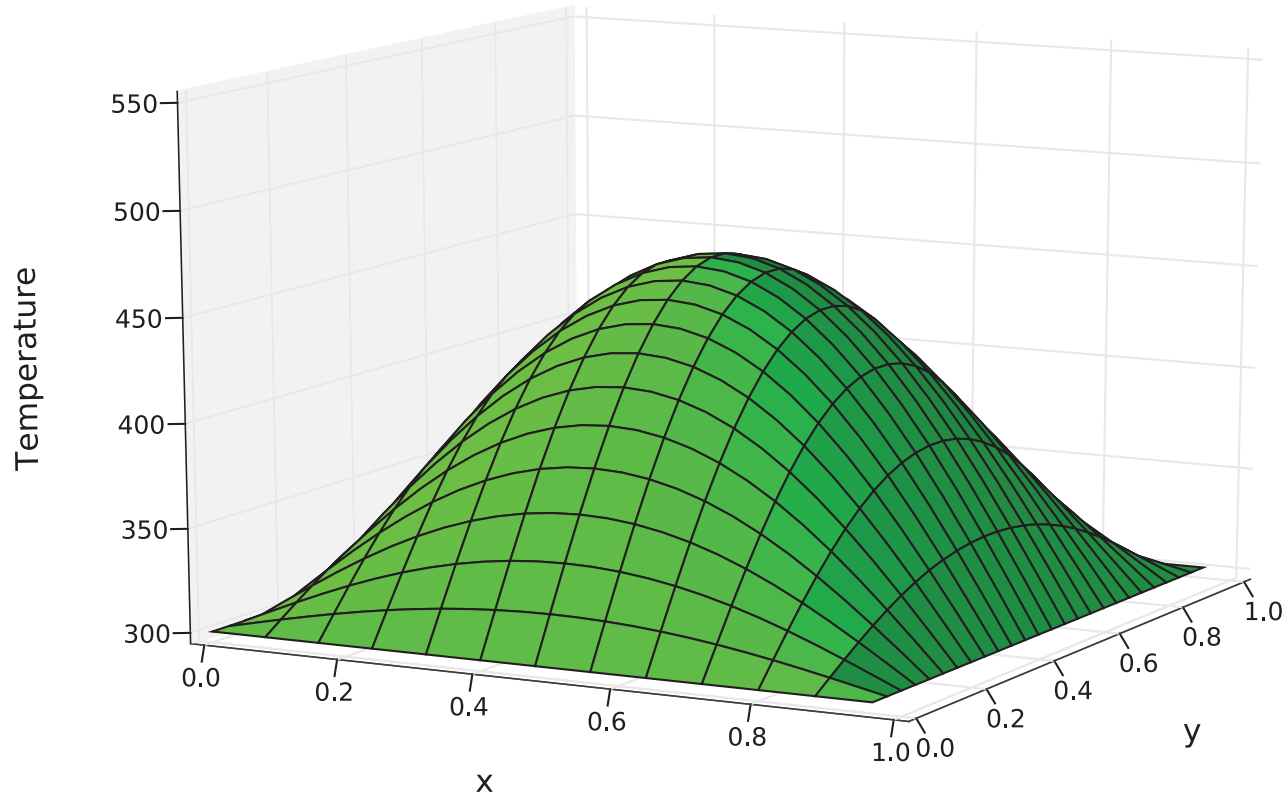

Figure 3.17-3. Plate temperature after one hour for 2-D conduction enclosure.

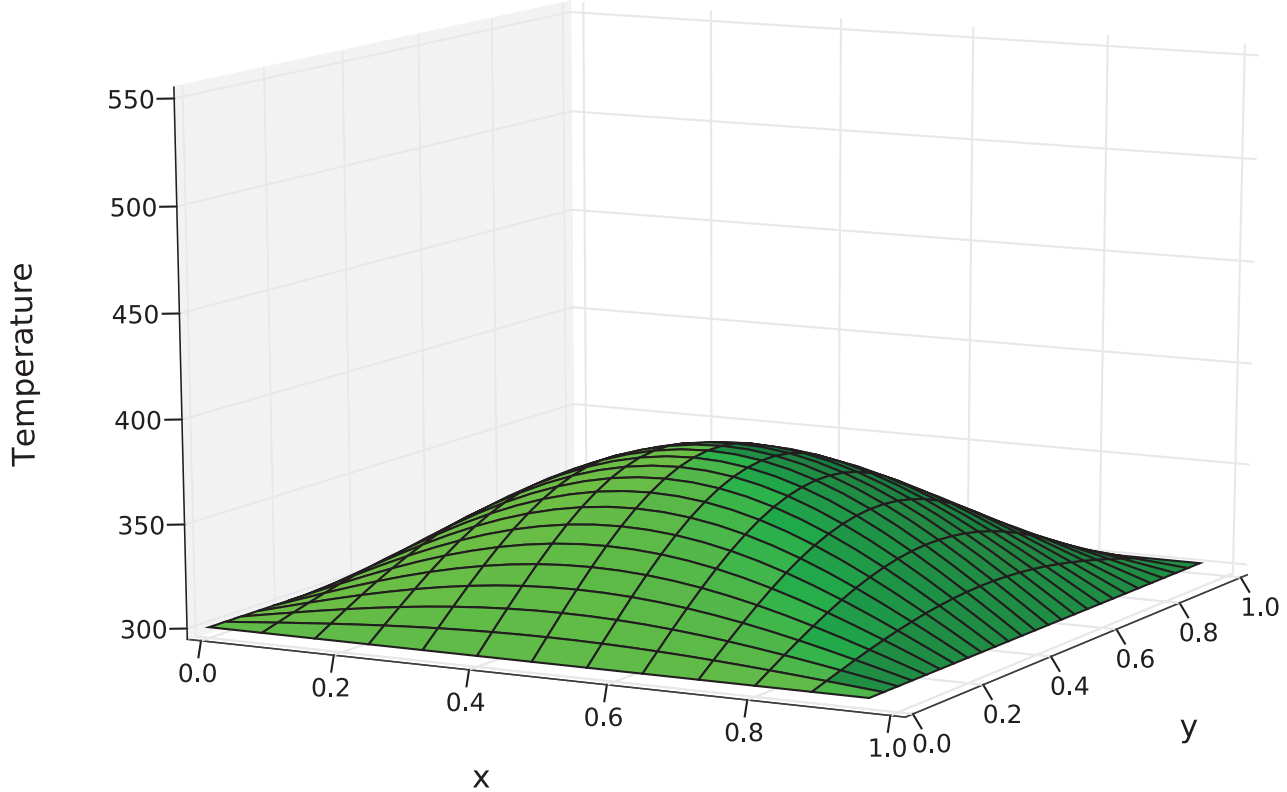

Figure 3.17-4. Plate temperature after two hours for 2-D conduction enclosure. 


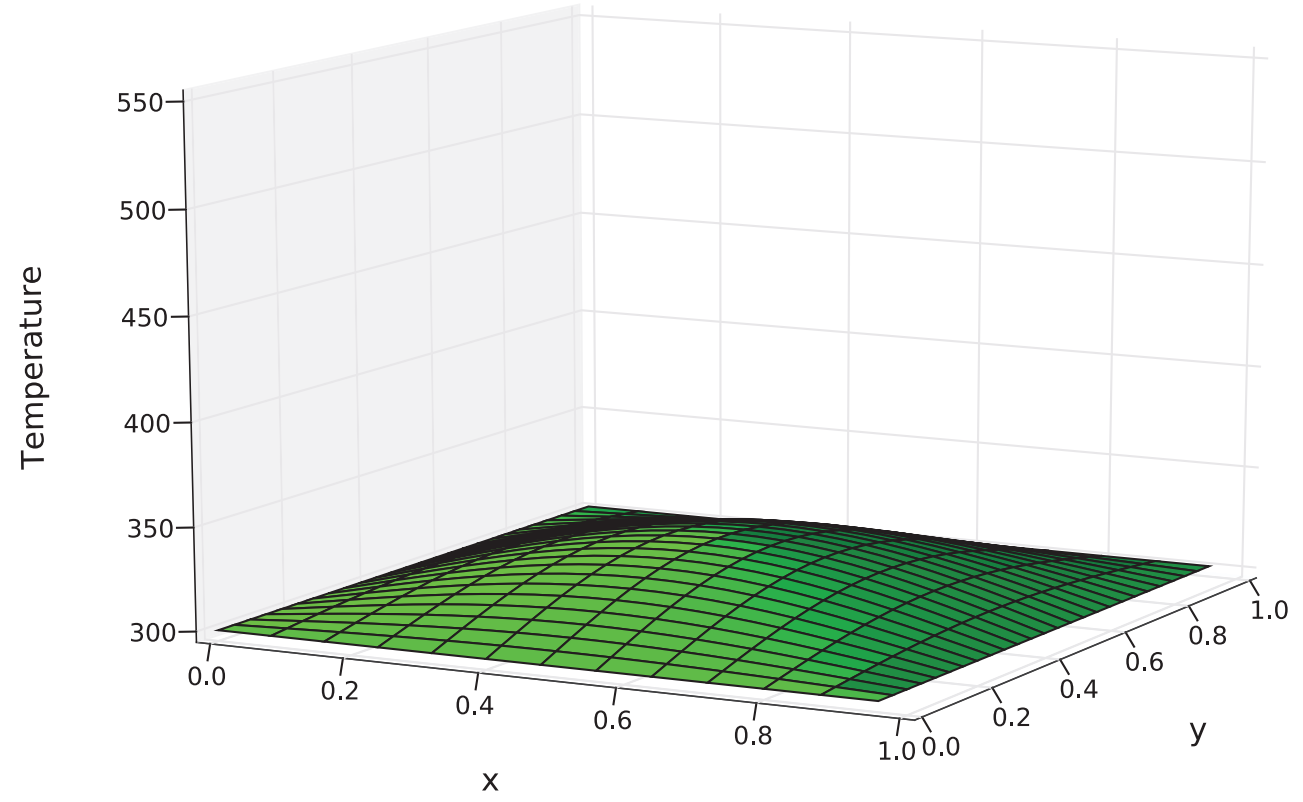

Figure 3.17-5. Plate temperature after three hours for 2-D conduction enclosure.

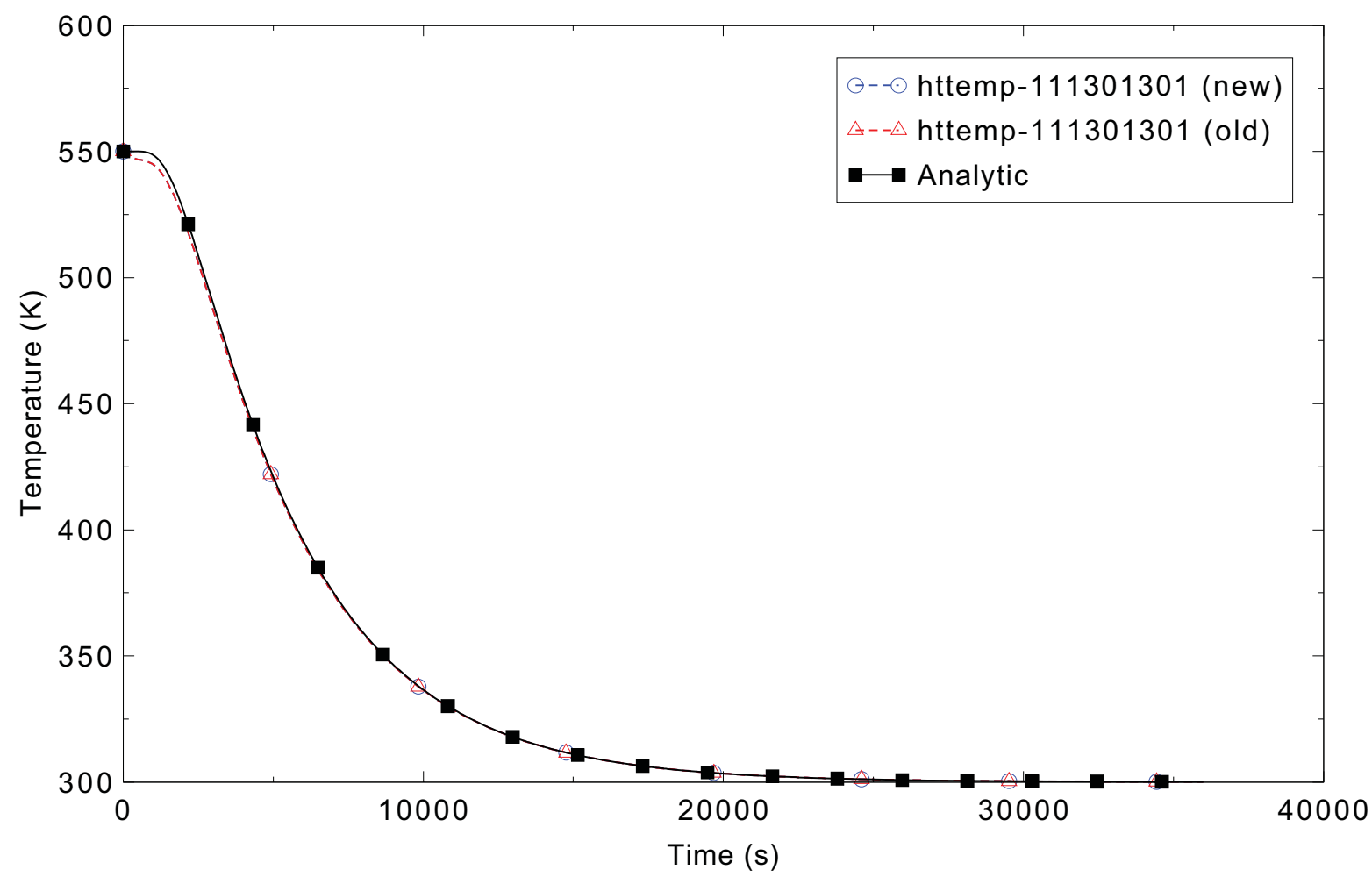

Figure 3.17-6. 2-D conduction enclosure temperature comparison with analytical solution. Temperature is taken at point $\mathrm{x}=0.2 \mathrm{~m}, \mathrm{y}=0 \mathrm{~m}$. 


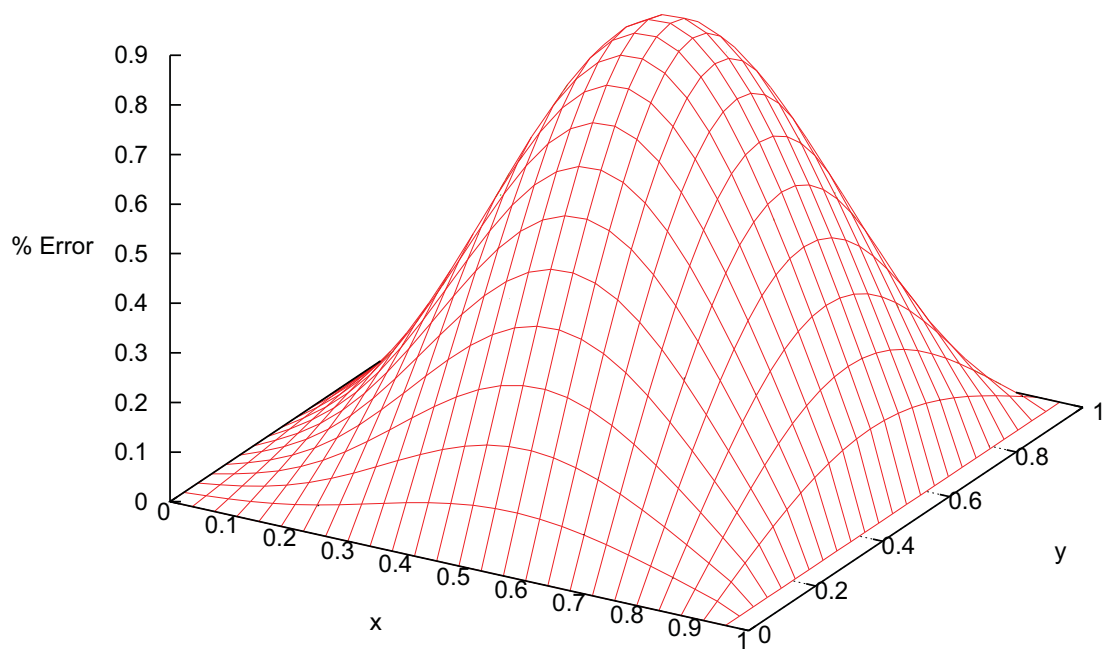

Figure 3.17-7. Local percent error of the transient temperature response for 2-D conduction enclosure at a time of one hour.

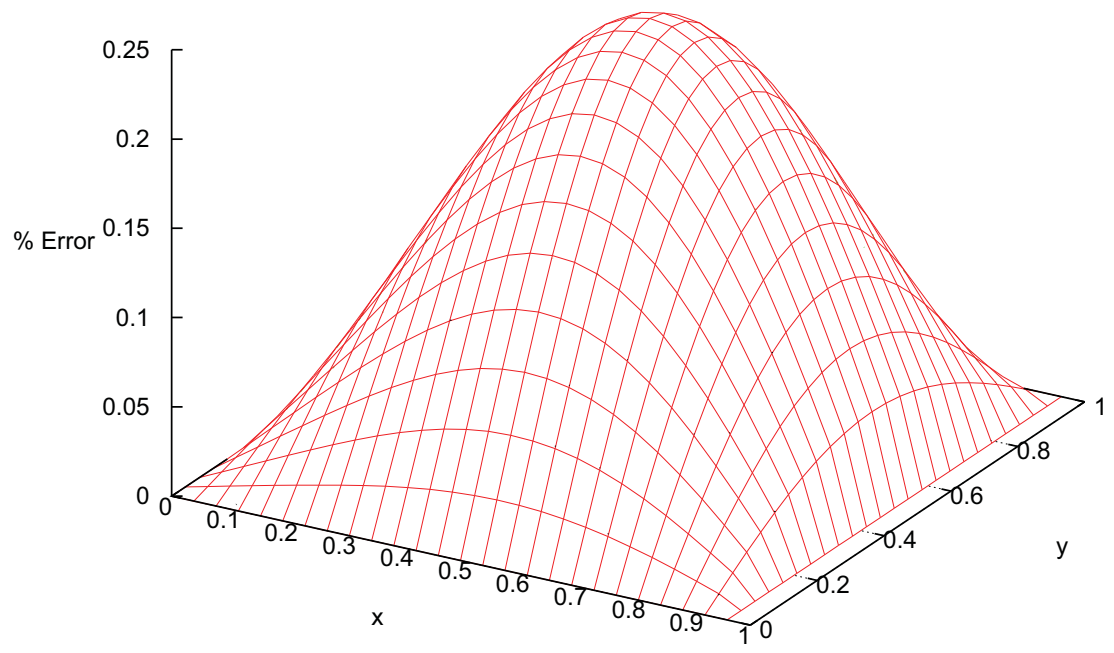

Figure 3.17-8. Local percent error of the transient temperature response for 2-D conduction enclosure at a time of two hours. 
RELAP5-3D/4.0.3

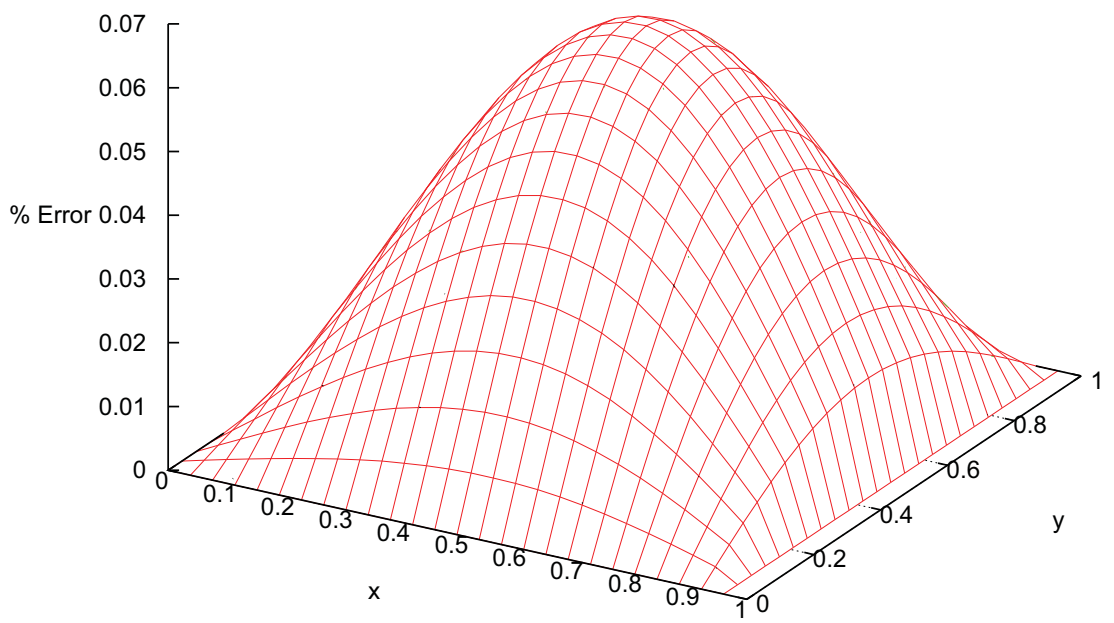

Figure 3.17-9. Local percent error of the transient temperature response for 2-D conduction enclosure at a time of three hours. 
RELAP5-3D/4.0.3 


\section{SEPARATE EFFECTS CASES}

The chapter presents the separate effects assessment case results. 


\subsection{Edwards-O’Brien Blowdown Test}

Figures comparing simulations using two code versions are presented. Diagrams are included so that the figure numbering is the same as that in Volume III of the RELAP5-3D code manual. No differences were observed in the figures.

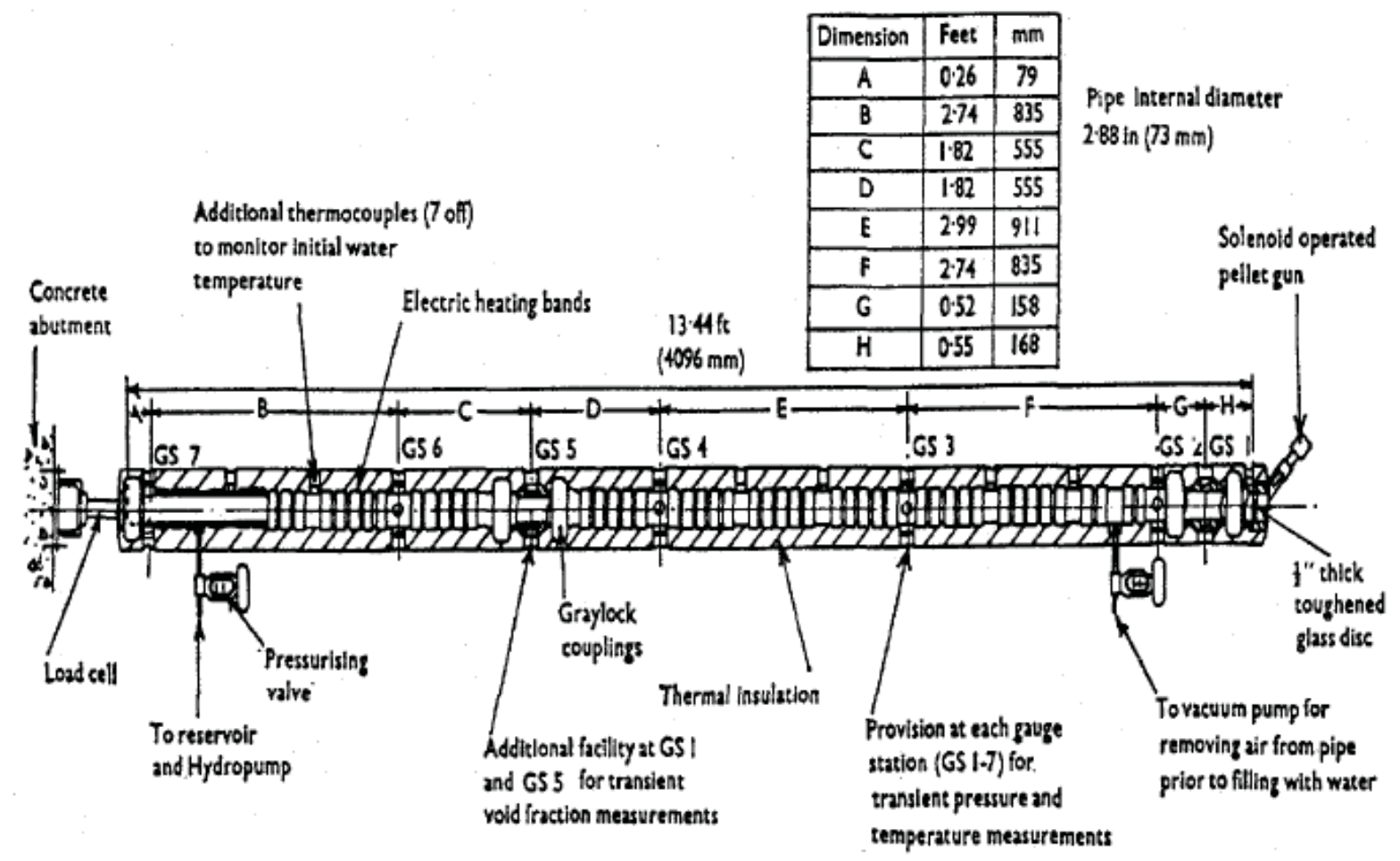

Figure 4.1-1. Edwards-O’Brien test facility. 


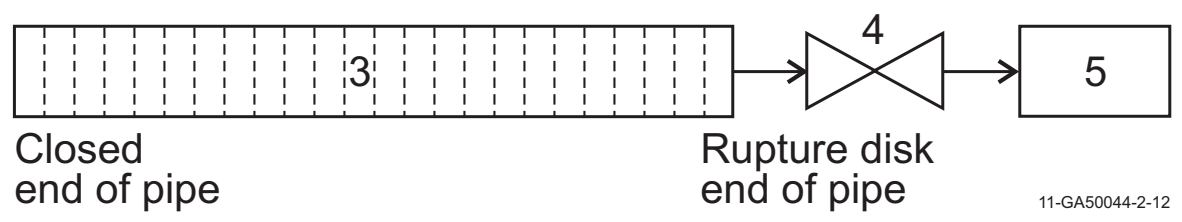

Figure 4.1-2. Diagram of the RELAP5-3D Edwards-O'Brien model.

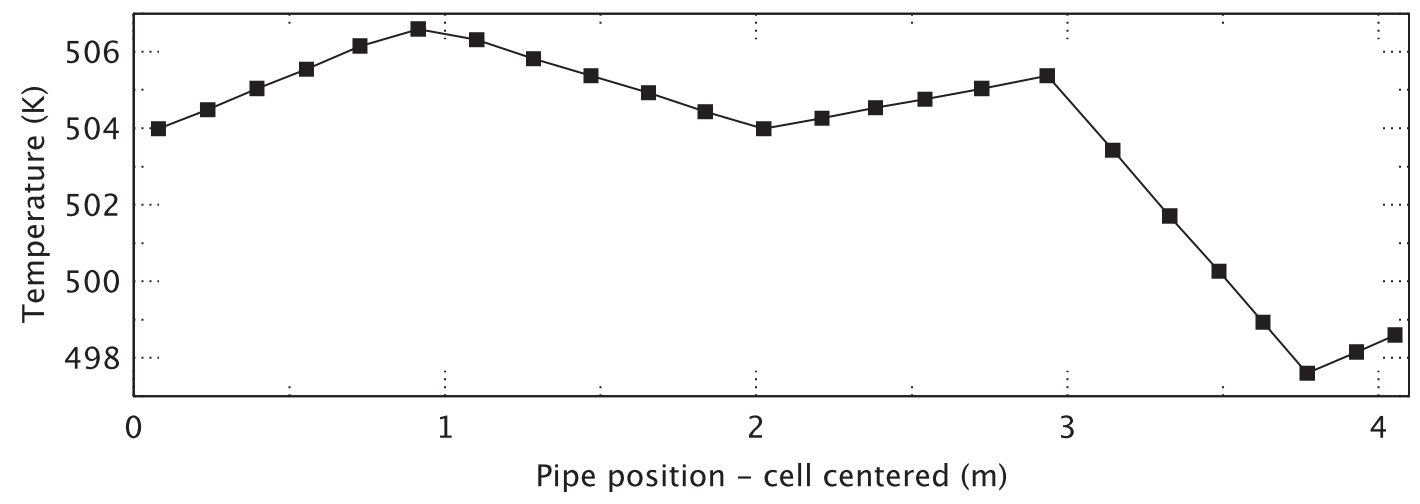

Figure 4.1-3. Non-uniform temperature distribution for Edwards-O'Brien model. 


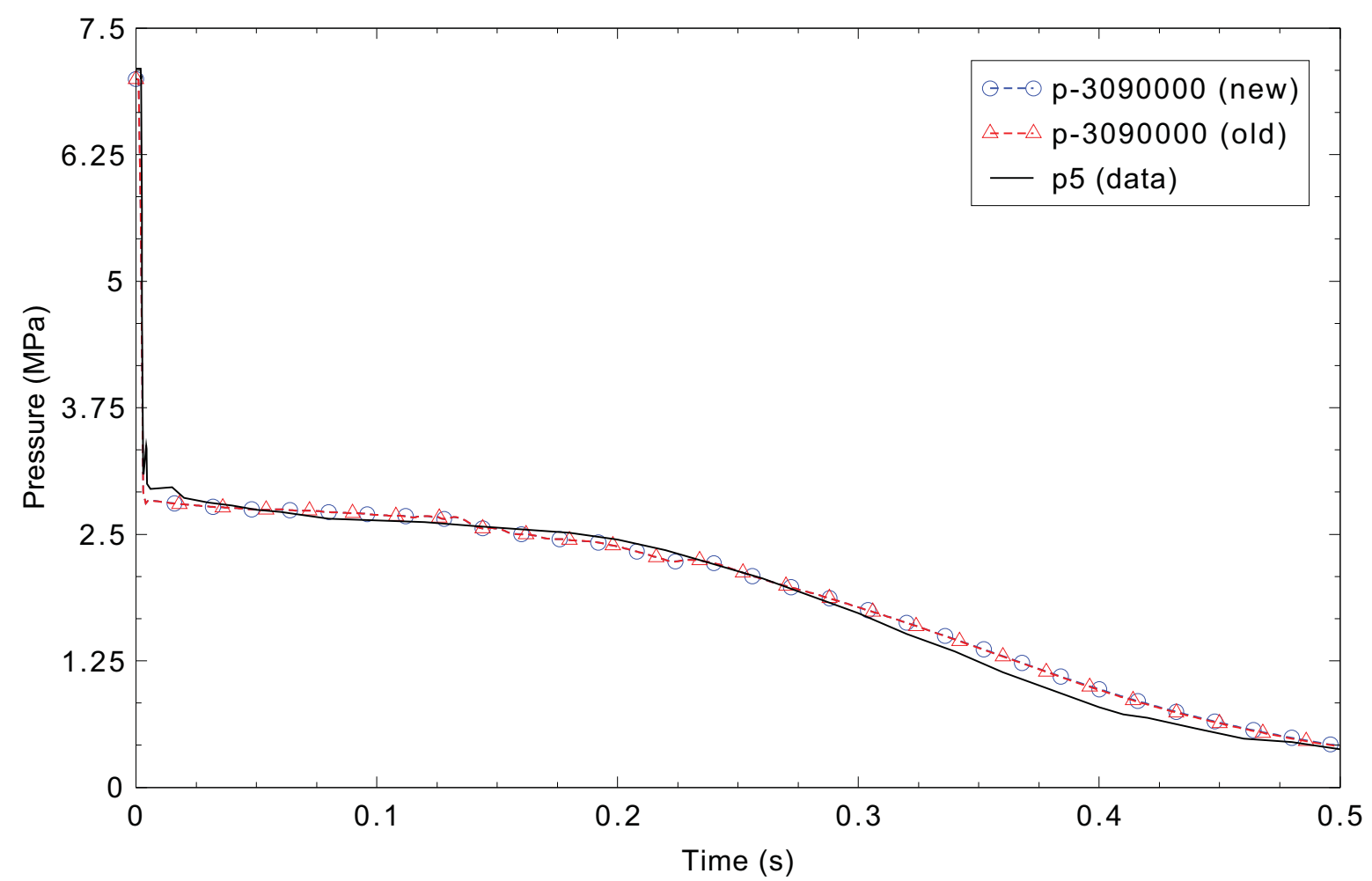

Figure 4.1-4. Measured and calculated pressures for the Edwards-O'Brien blowdown test.

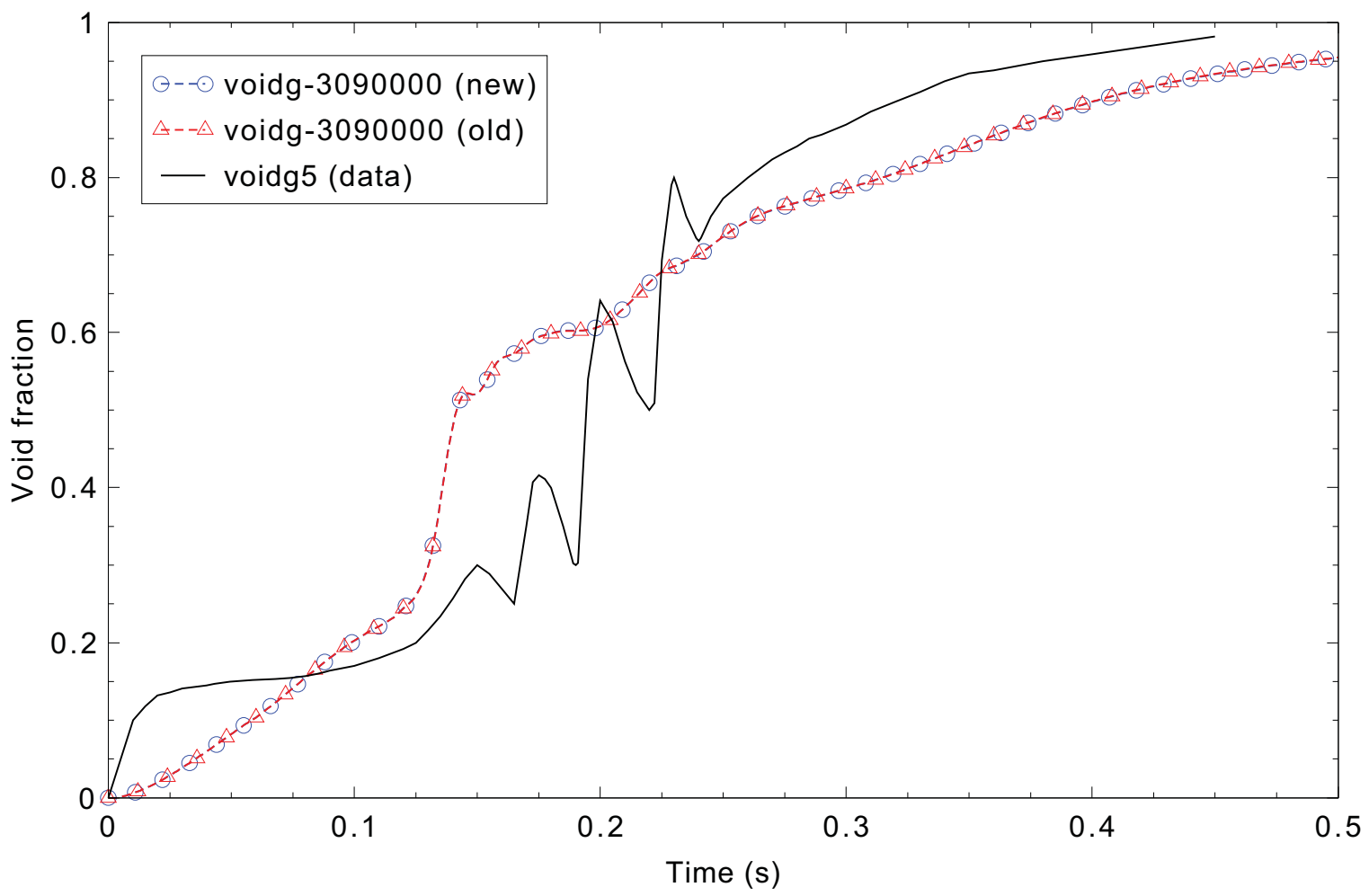

Figure 4.1-5. Measured and calculated void fractions for the Edwards-O'Brien blowdown test. 


\subsection{Marviken Critical Flow Test 21}

Figures comparing simulations using two code versions are presented. Diagrams are included so that the figure numbering is the same as that in Volume III of the RELAP5-3D code manual. Noticeable differences were observed in Figures 4.2-6 and 7.

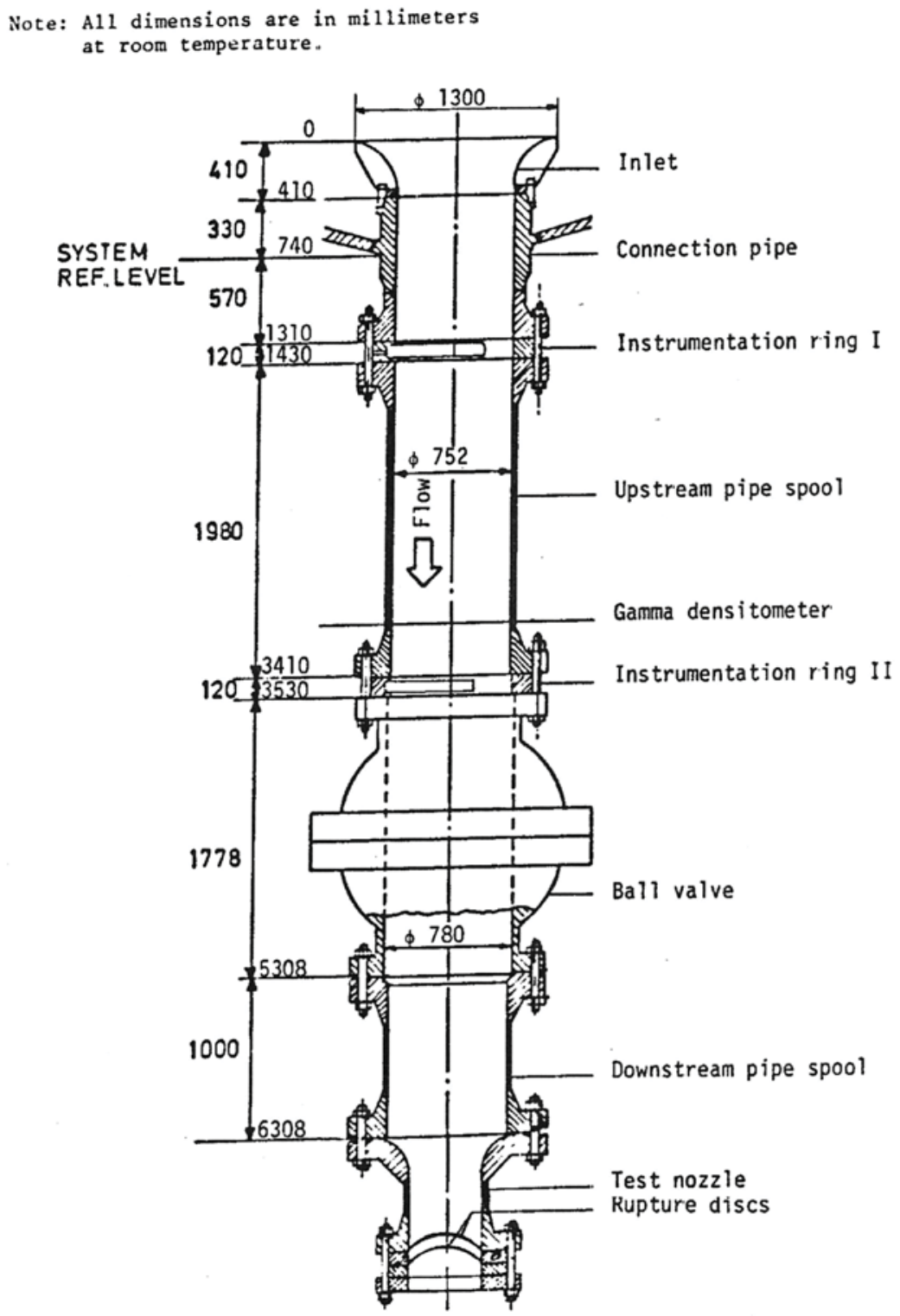

Figure 4.2-1. Marviken Critical Flow Test 21 discharge pipe. 


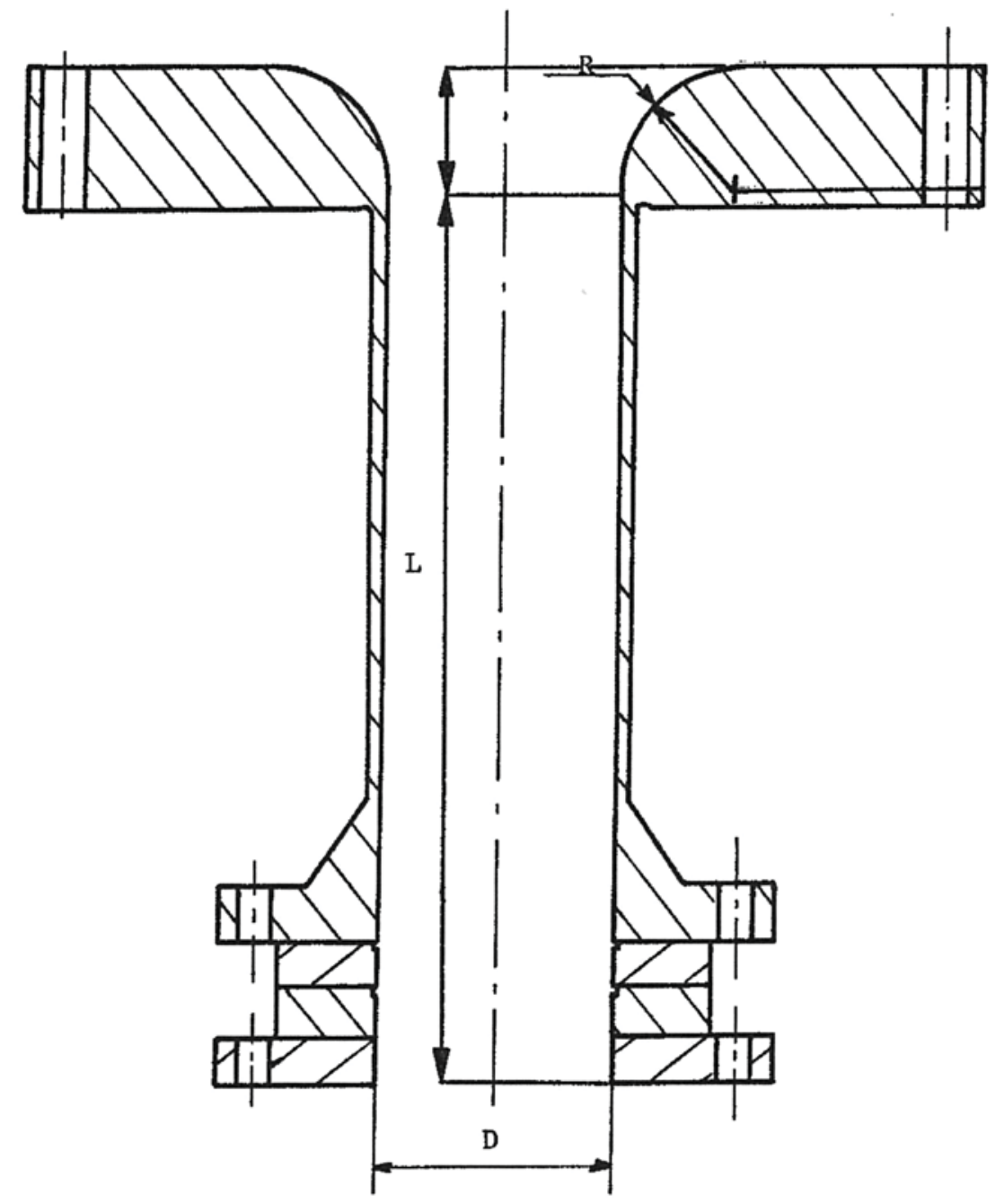

Figure 4.2-2. Marviken Critical Flow Test 21 test nozzle. 


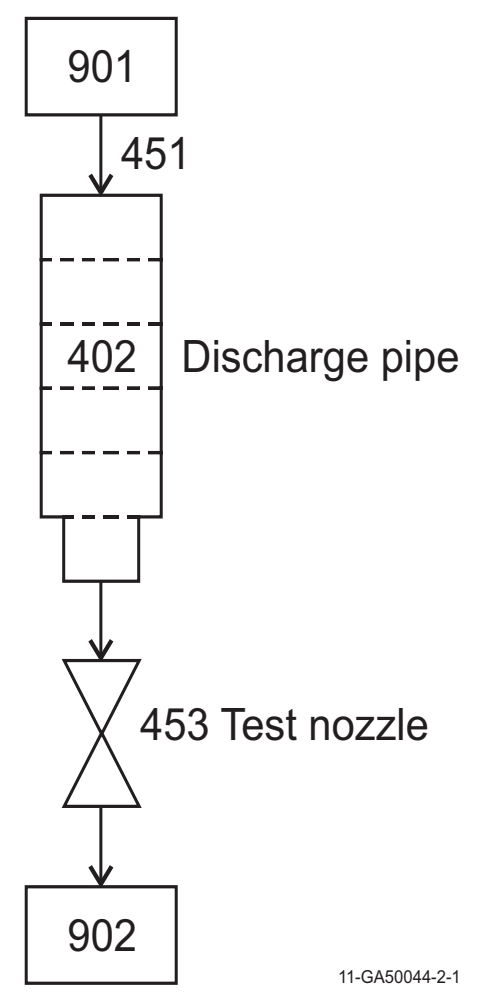

Figure 4.2-3. Marviken Critical Flow Test 21 nodalization diagram. 


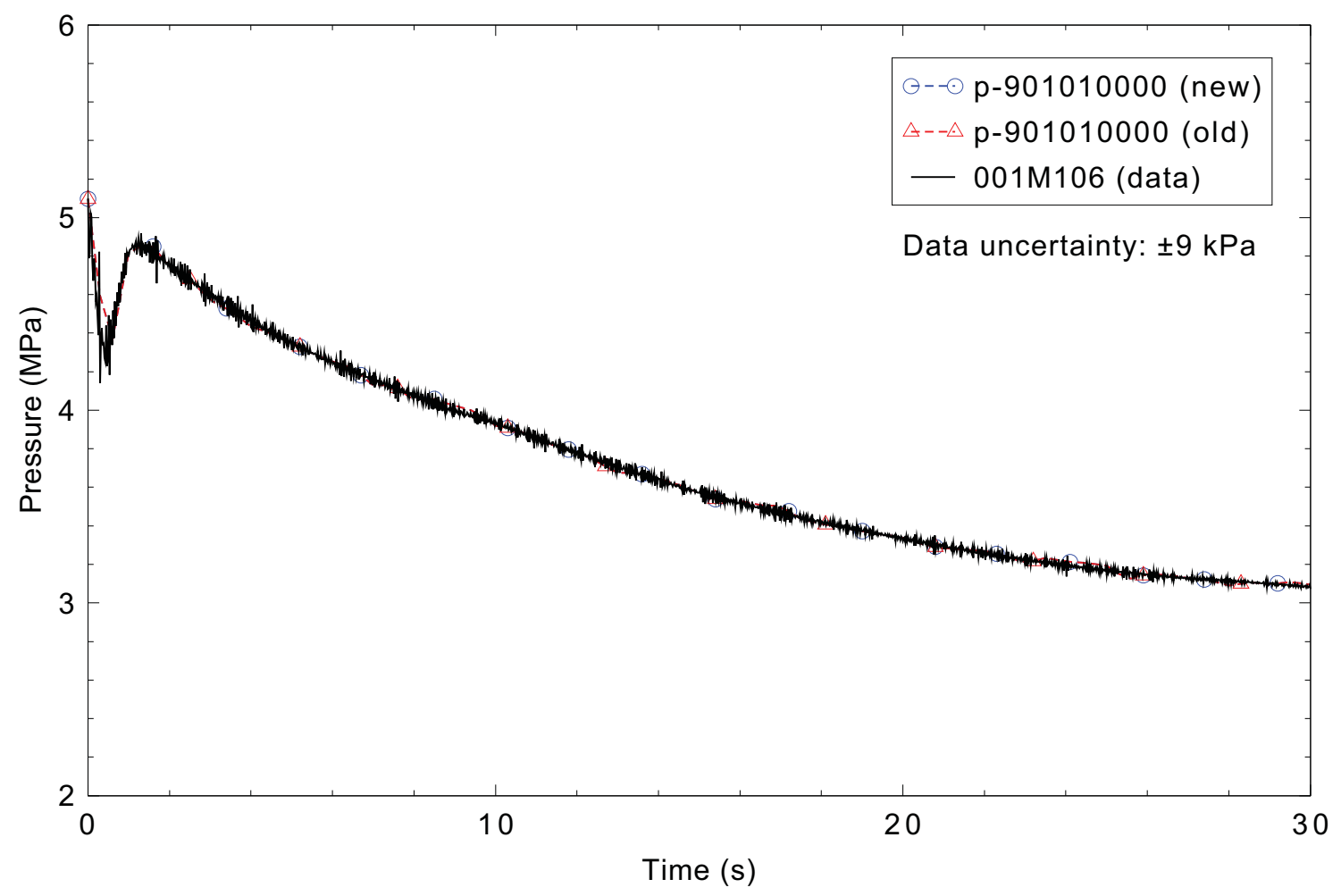

Figure 4.2-4. Marviken CFT 21 pressure at vessel bottom (boundary condition).

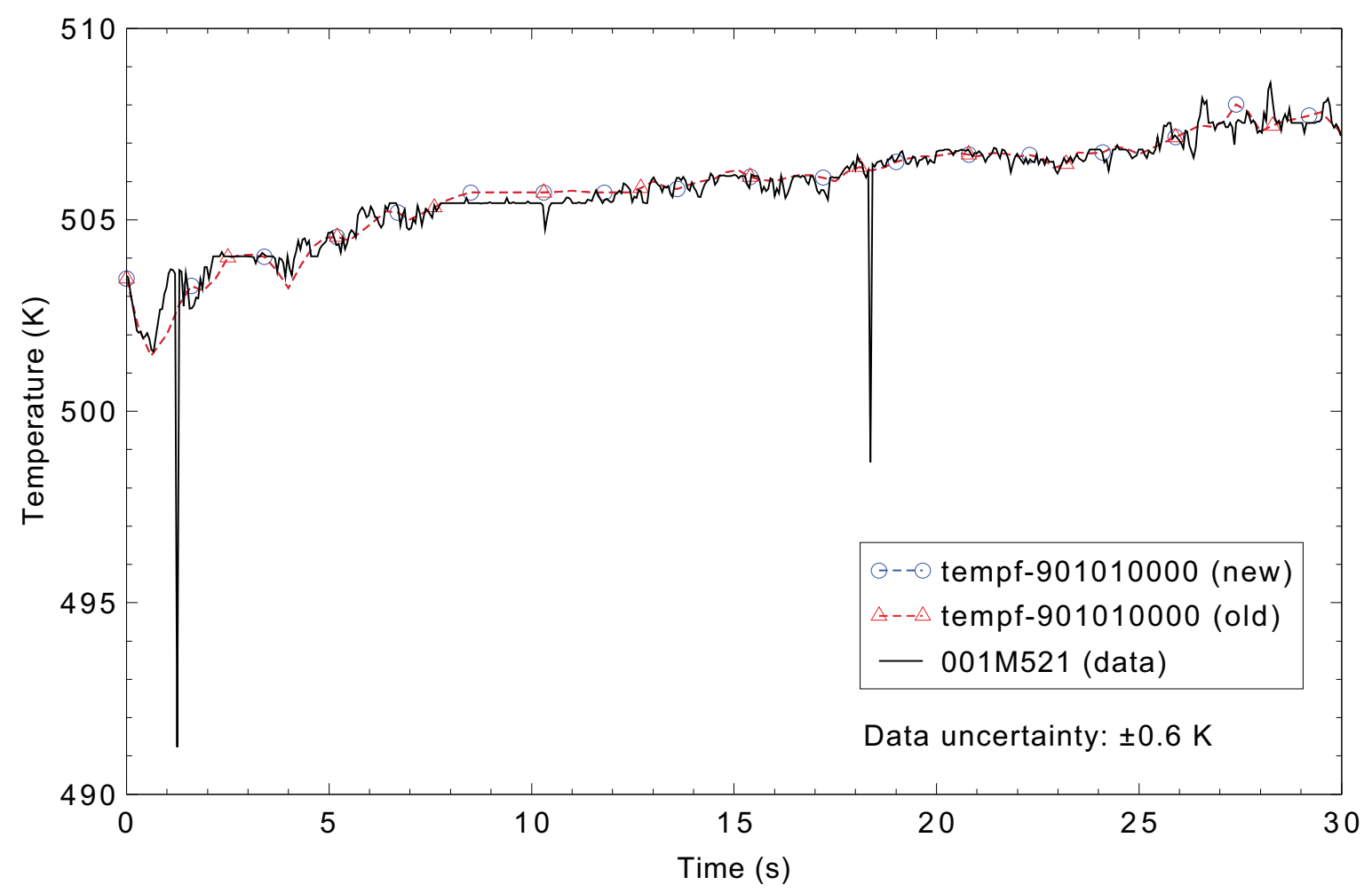

Figure 4.2-5. Marviken CFT 21 temperature at vessel bottom (boundary condition). 


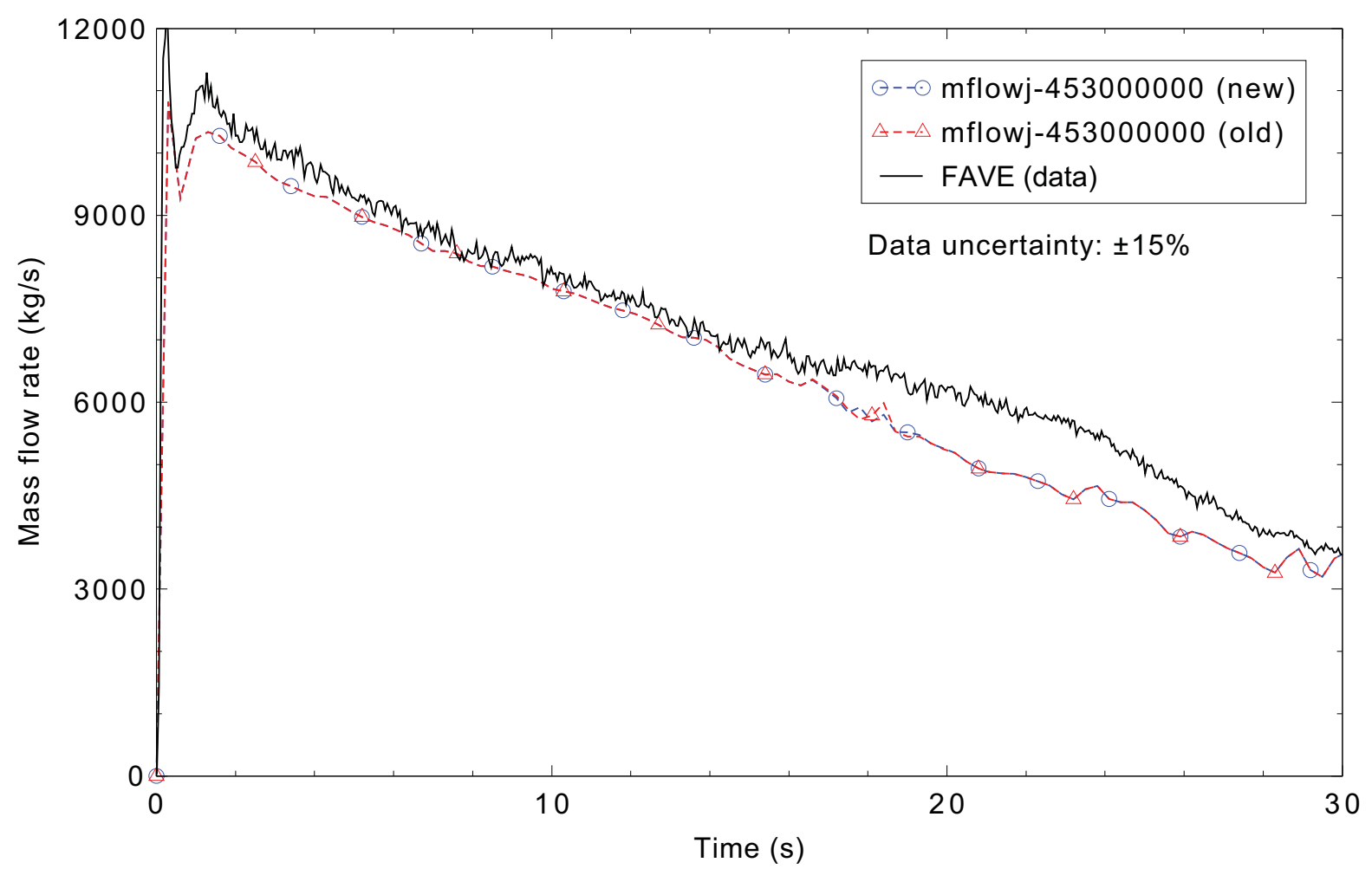

Figure 4.2-6. Measured and calculated mass flow rate for Marviken CFT 21.

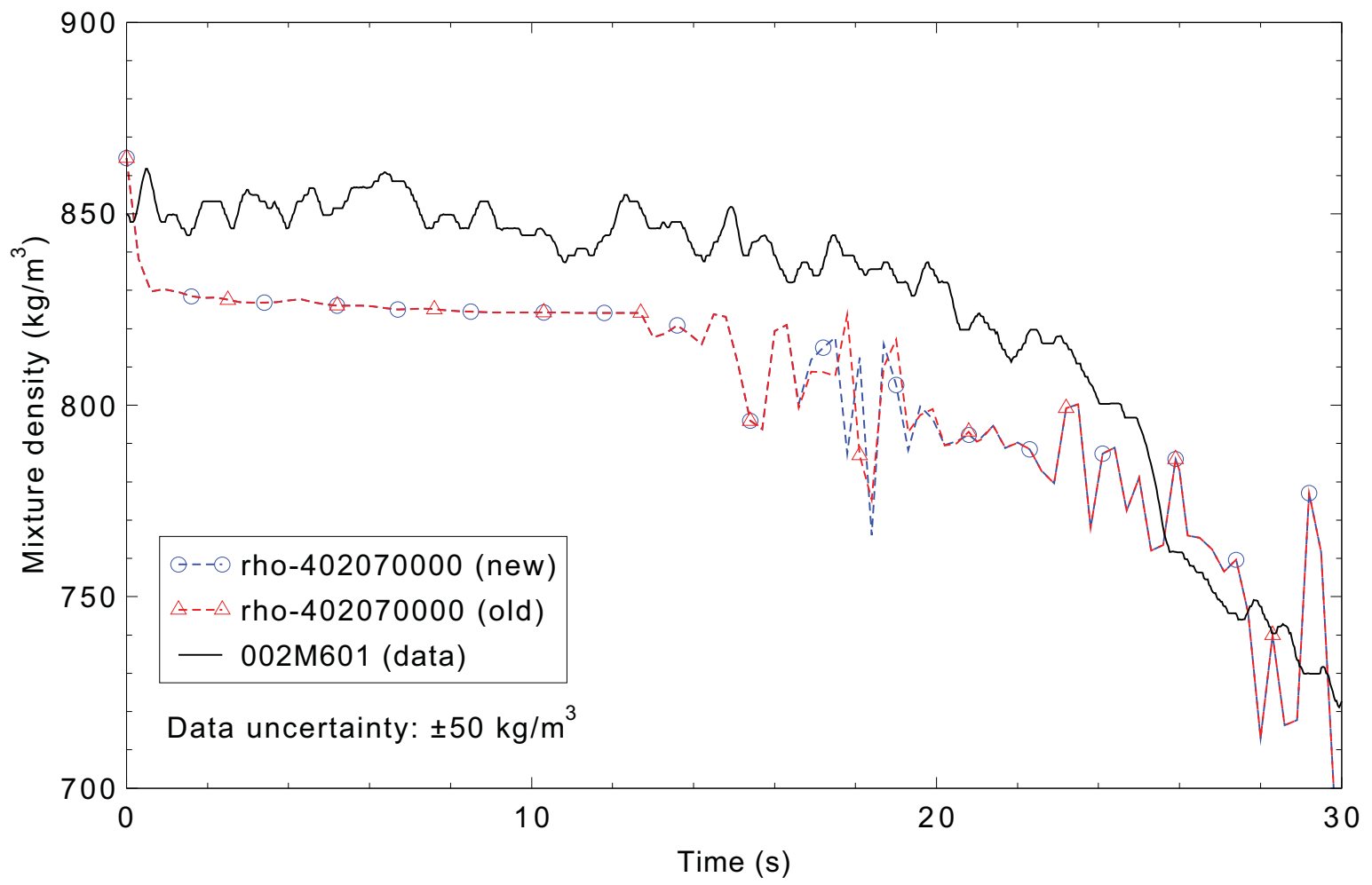

Figure 4.2-7. Measured and calculated mixture density in the discharge pipe for Marviken CFT 21. 


\subsection{Marviken Critical Flow Test 22}

Figures comparing simulations using two code versions are presented. Diagrams are included so that the figure numbering is the same as that in Volume III of the RELAP5-3D code manual. Noticeable differences were observed in Figure 4.3-6.

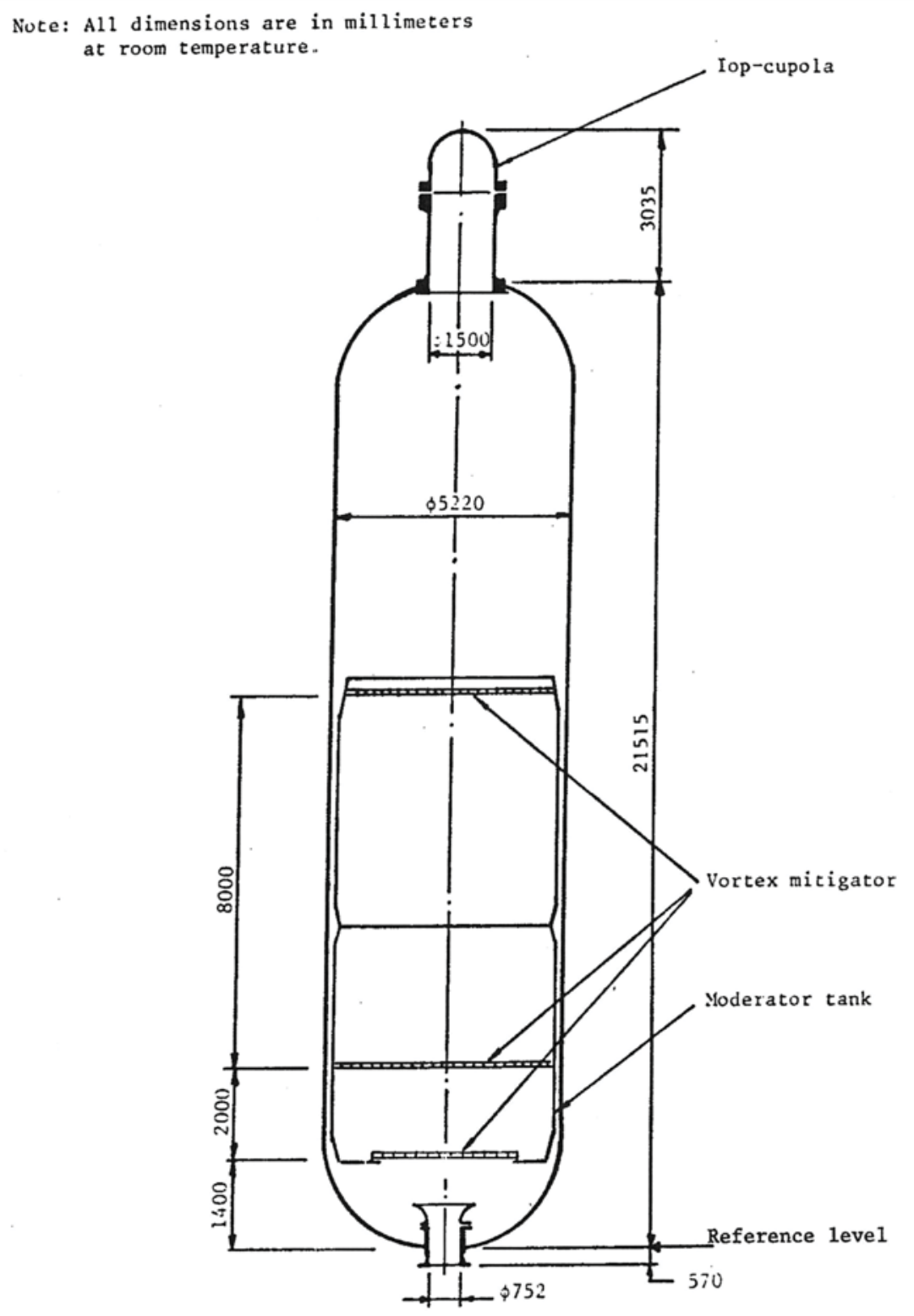

Figure 4.3-1. Marviken Critical Flow Test 22 pressure vessel. 
Note: All dimensions are in millimeters at room temperature.

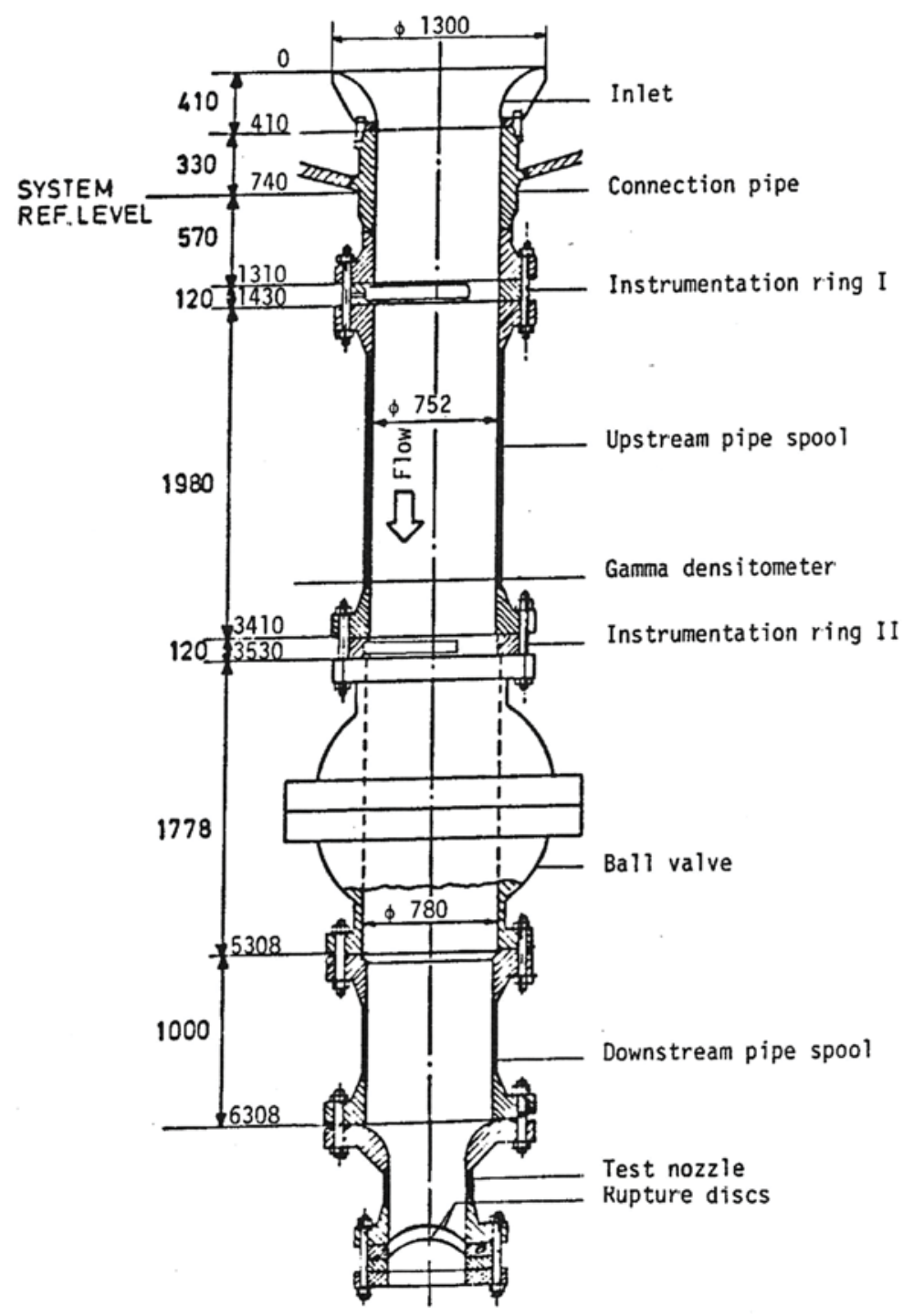

Figure 4.3-2. Marviken Critical Flow Test 22 discharge pipe, test nozzle, and rupture disk assembly. 


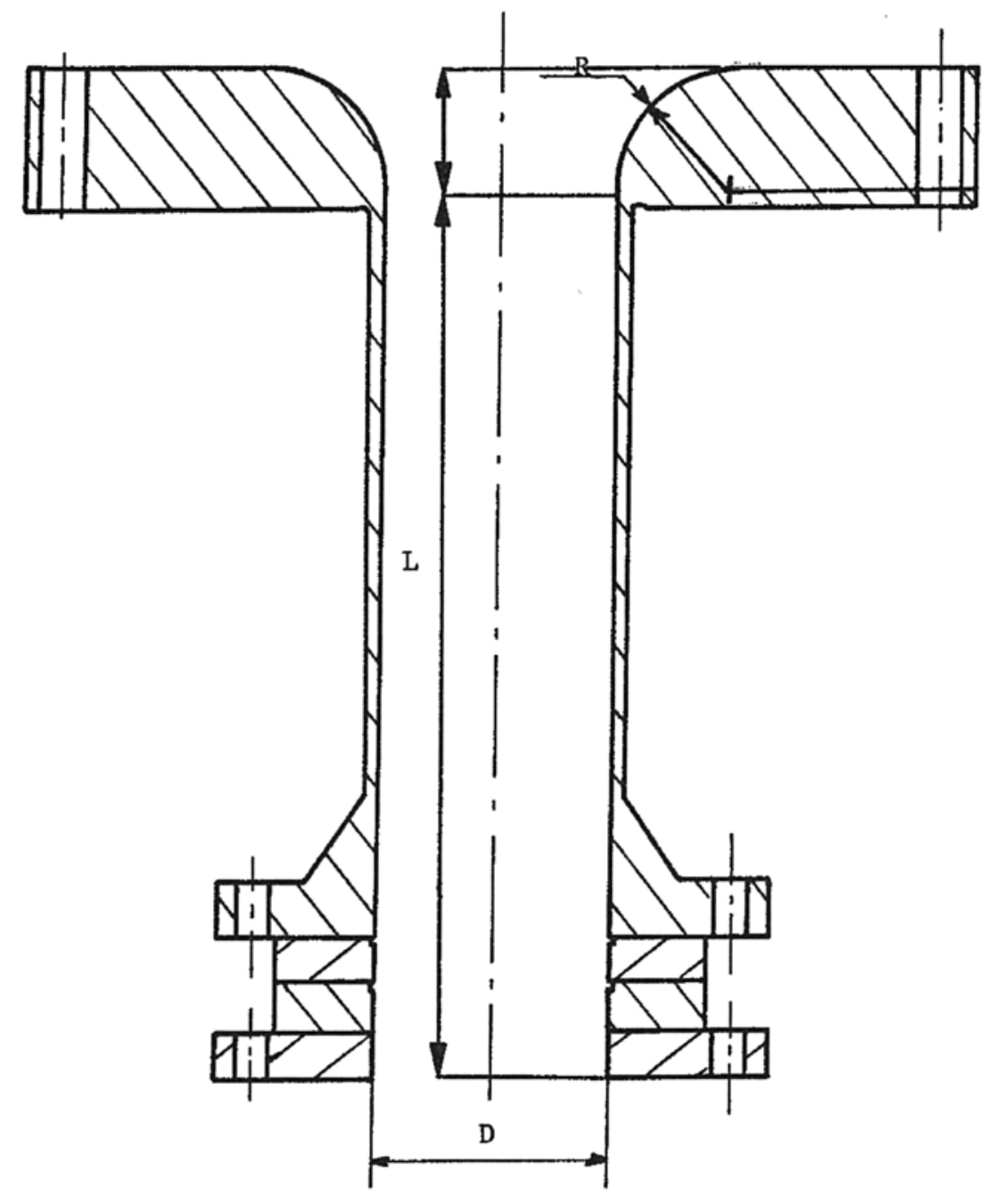

Figure 4.3-3. Marviken Critical Flow Test 22 test nozzle. 


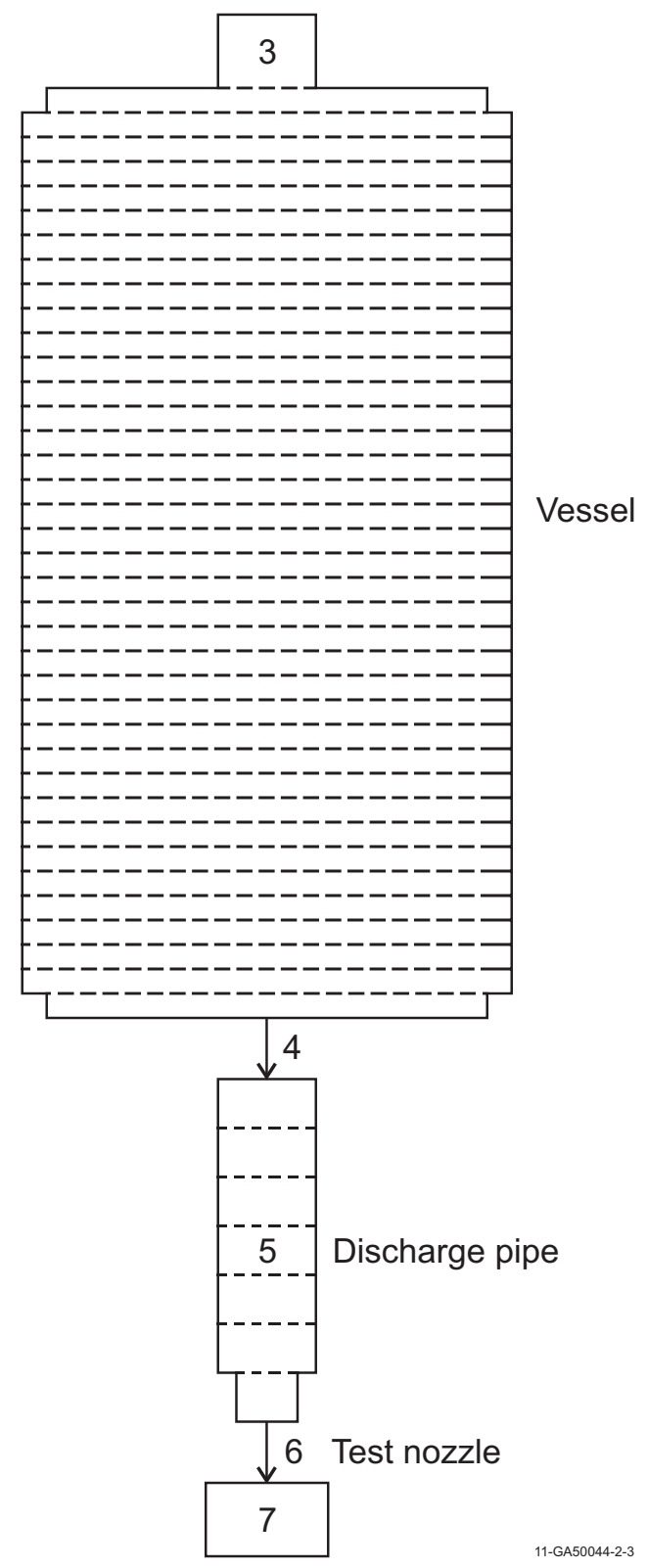

Figure 4.3-4. Marviken Critical Flow Test 22 nodalization diagram. 


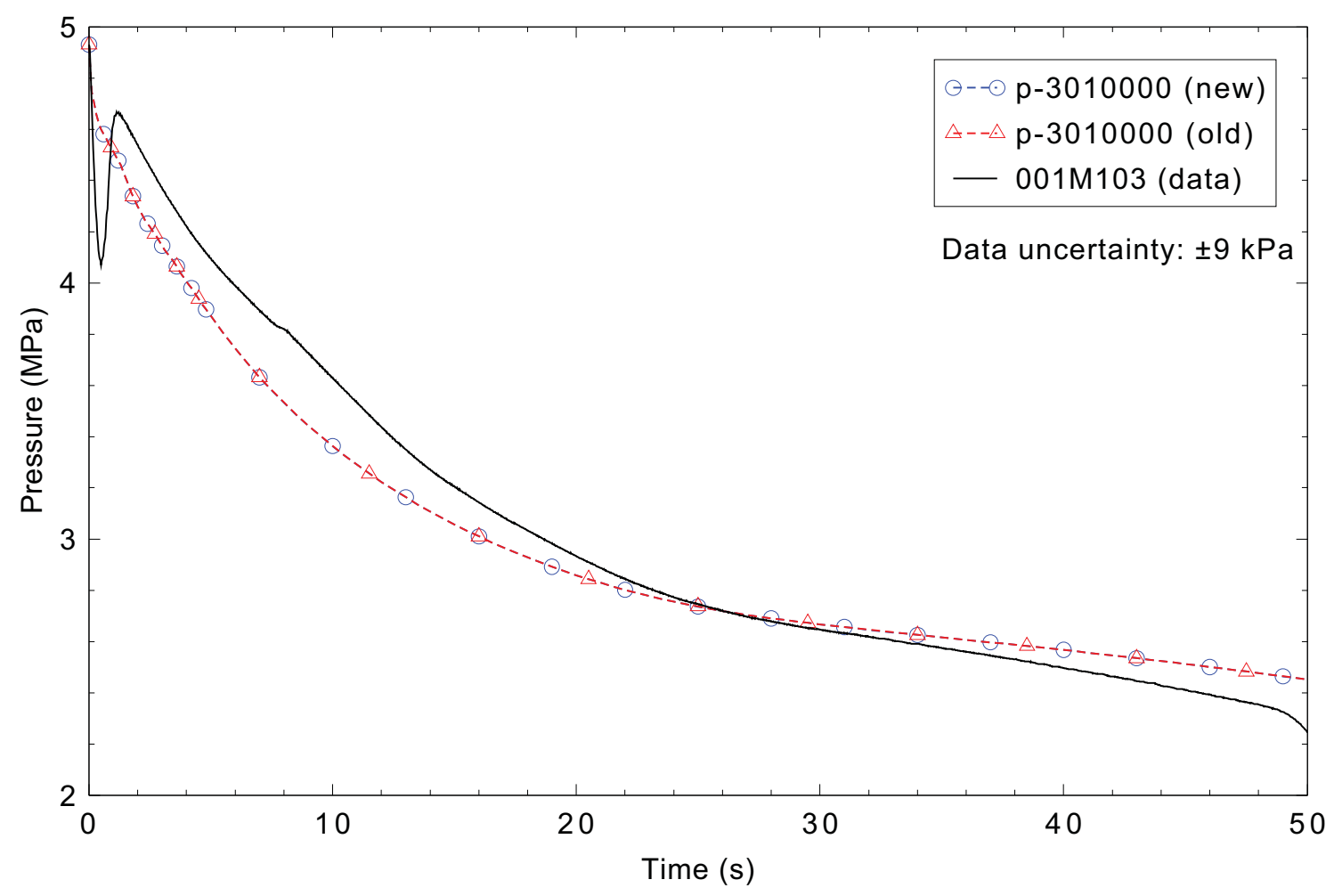

Figure 4.3-5. Measured and calculated vessel pressure for Marviken CFT 22. 


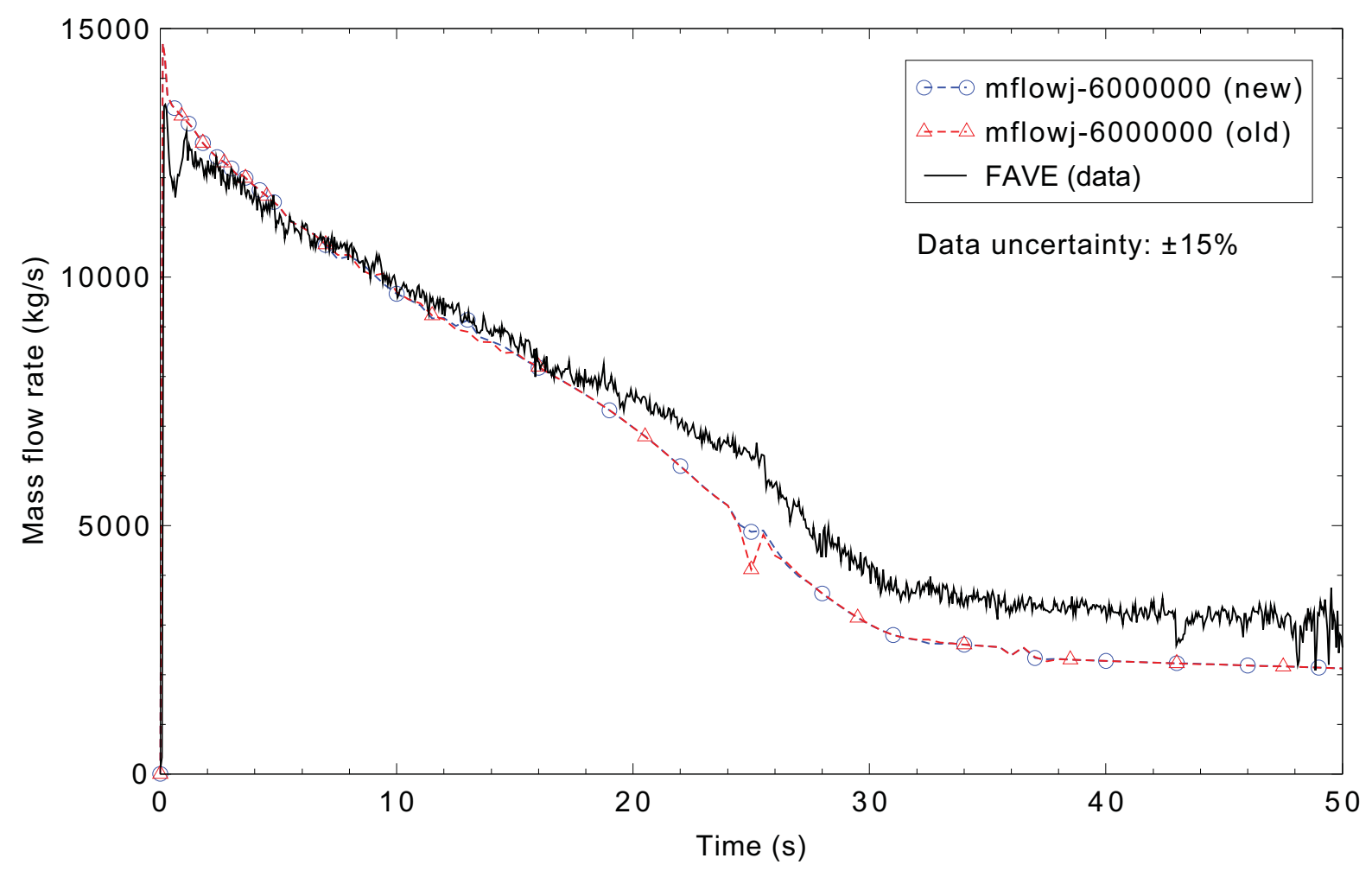

Figure 4.3-6. Measured and calculated mass flow rate for Marviken CFT 22.

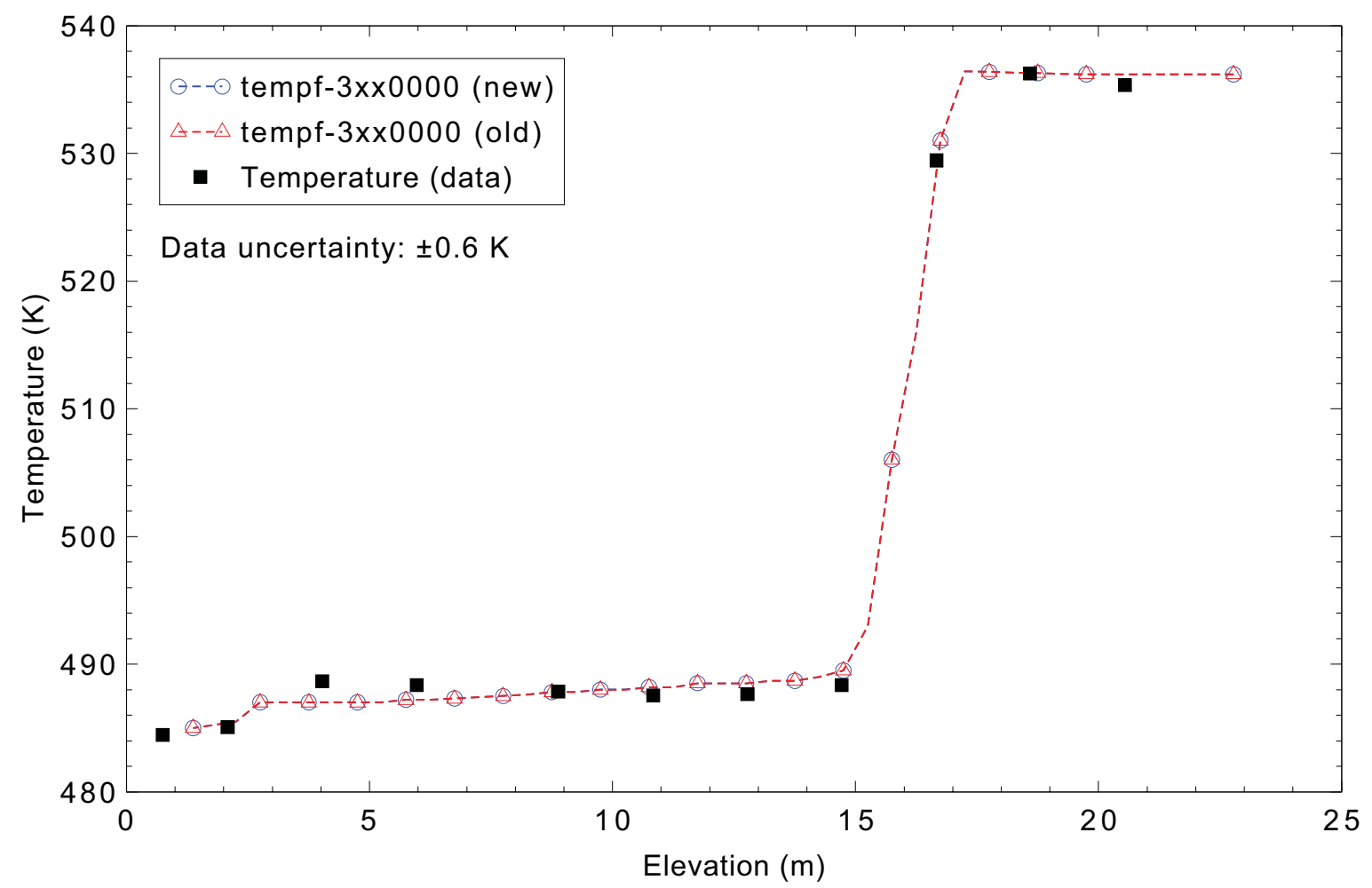

Figure 4.3-7. Measured and calculated temperature profile at $0 \mathrm{~s}$ for Marviken CFT 22. 


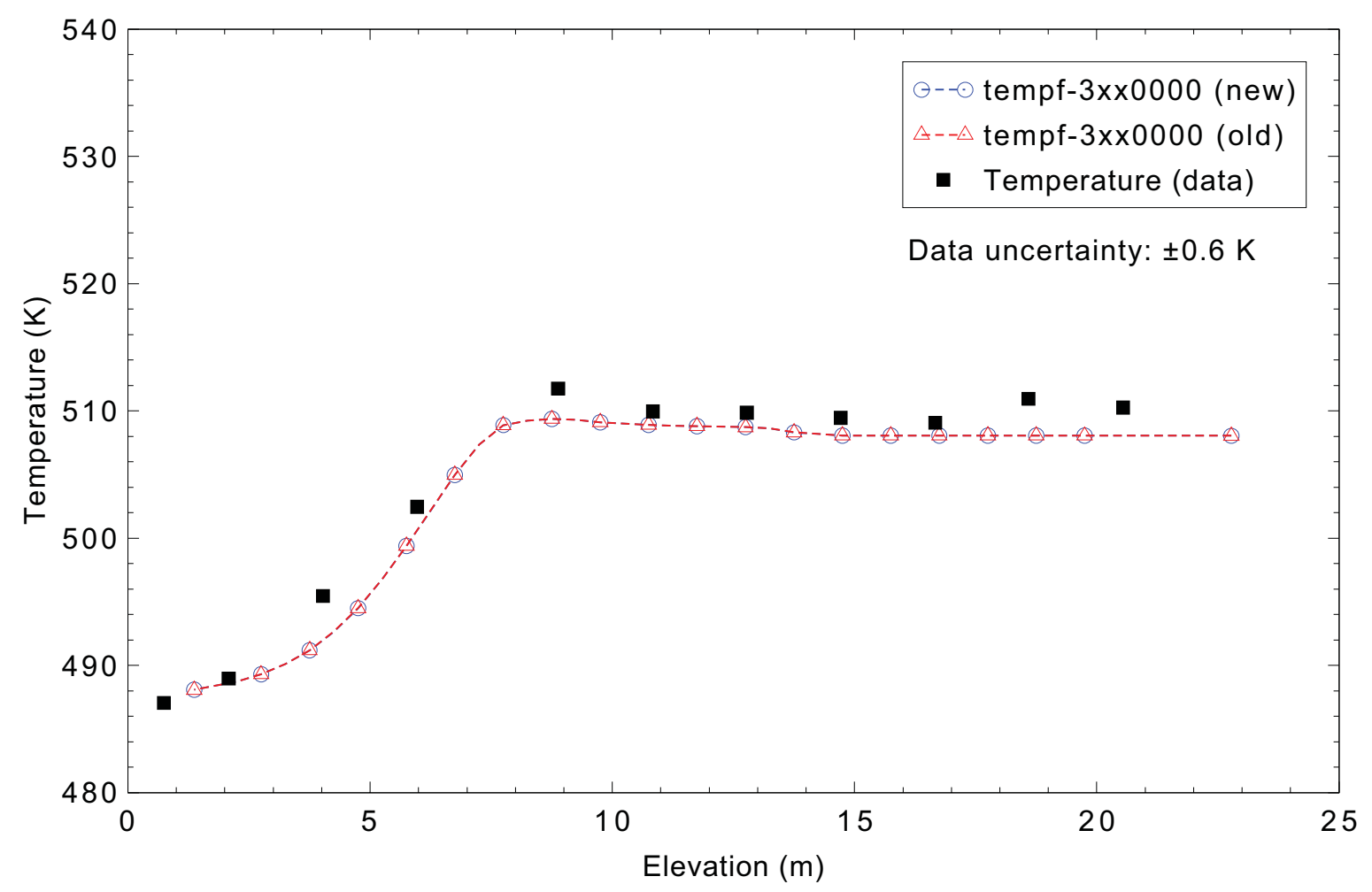

Figure 4.3-8. Measured and calculated temperature profile at $15 \mathrm{~s}$ for Marviken CFT 22.

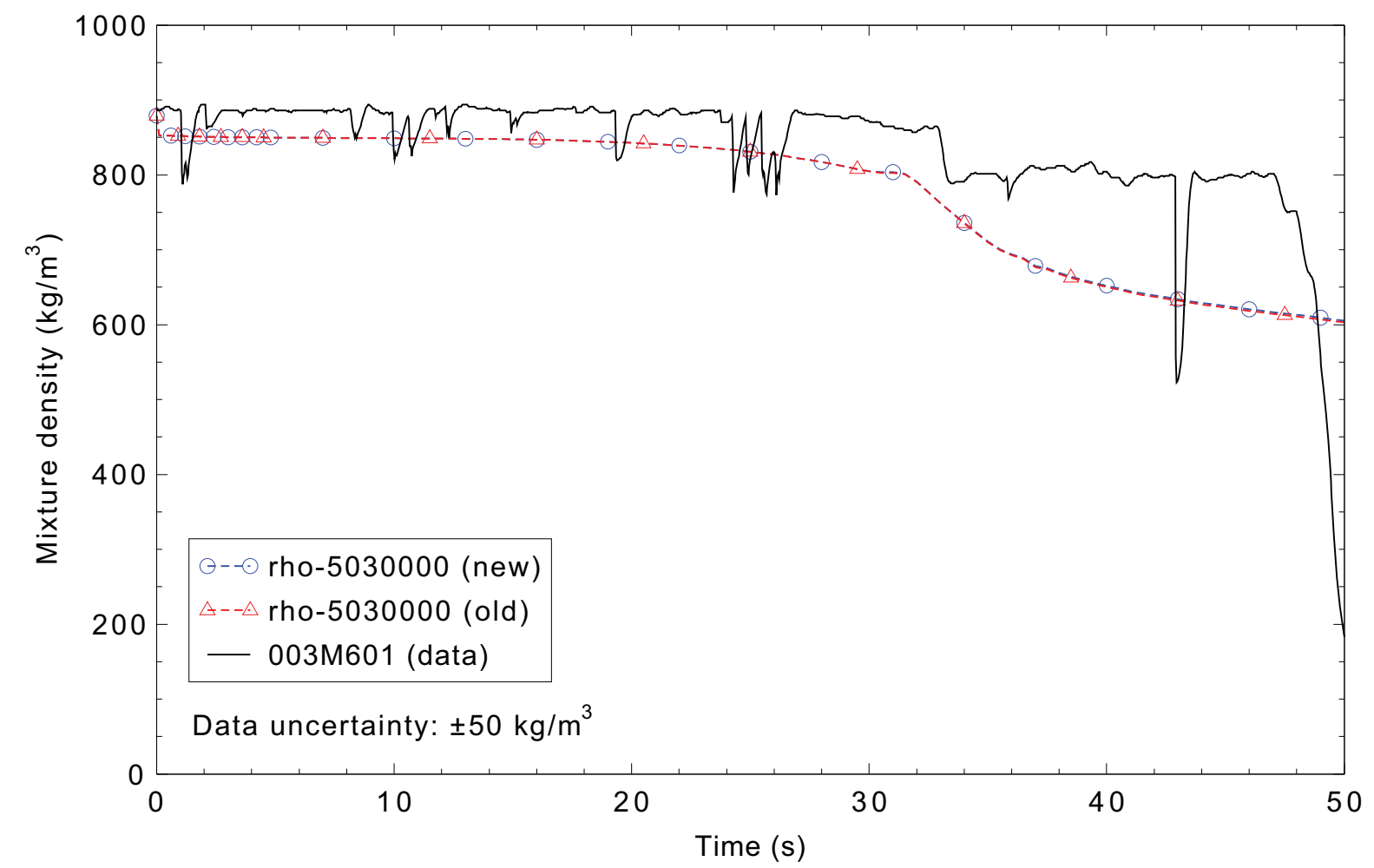

Figure 4.3-9. Measured and calculated mixture density in the discharge pipe for Marviken CFT 22. 


\subsection{Marviken Critical Flow Test 24}

Figures comparing simulations using two code versions are presented. Diagrams are included so that the figure numbering is the same as that in Volume III of the RELAP5-3D code manual. Noticeable differences were observed in Figure 4.4-9.

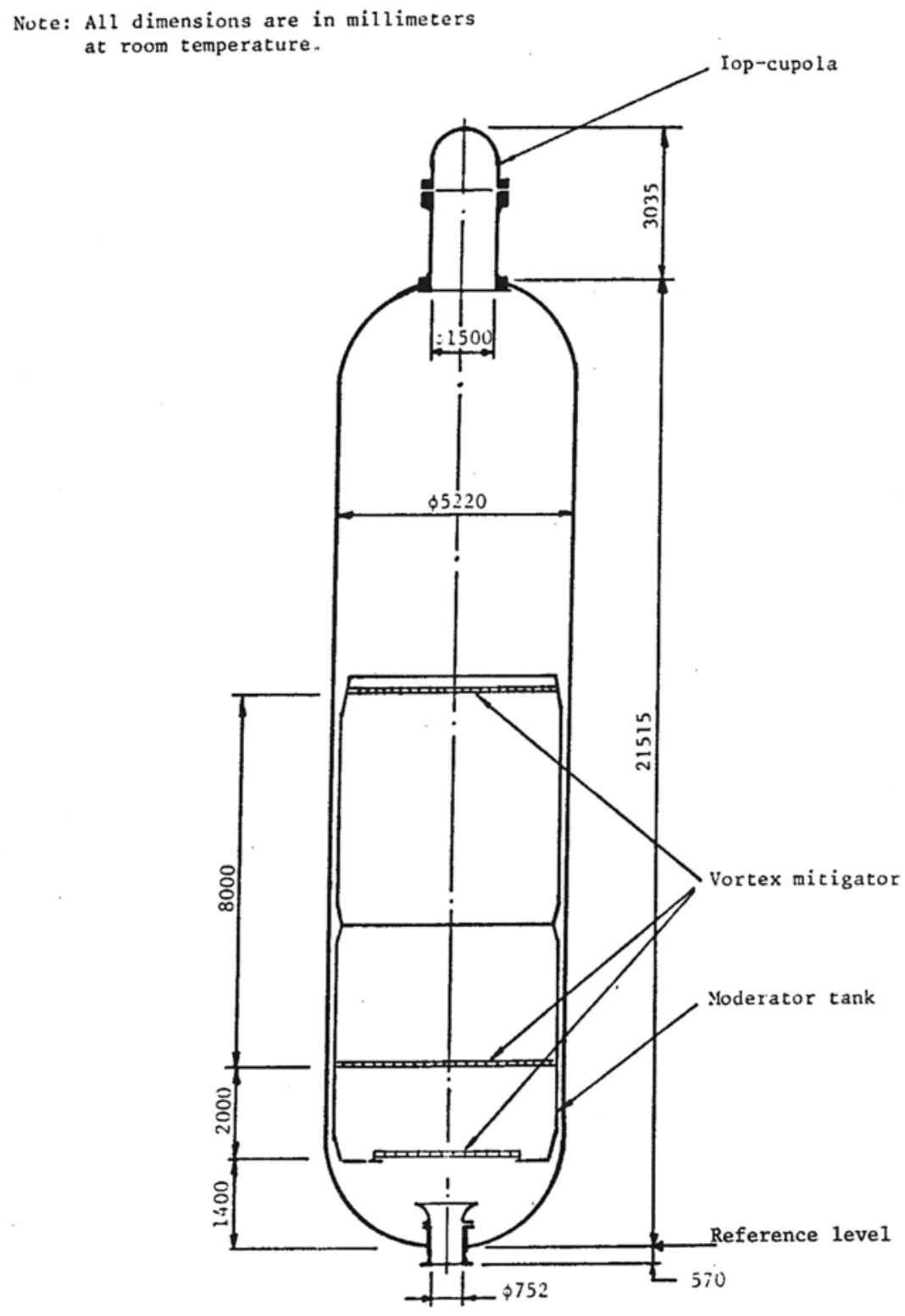

Figure 4.4-1. Marviken Critical Flow Test 24 pressure vessel. 
Note: All dimensions are in millimeters at room temperature.

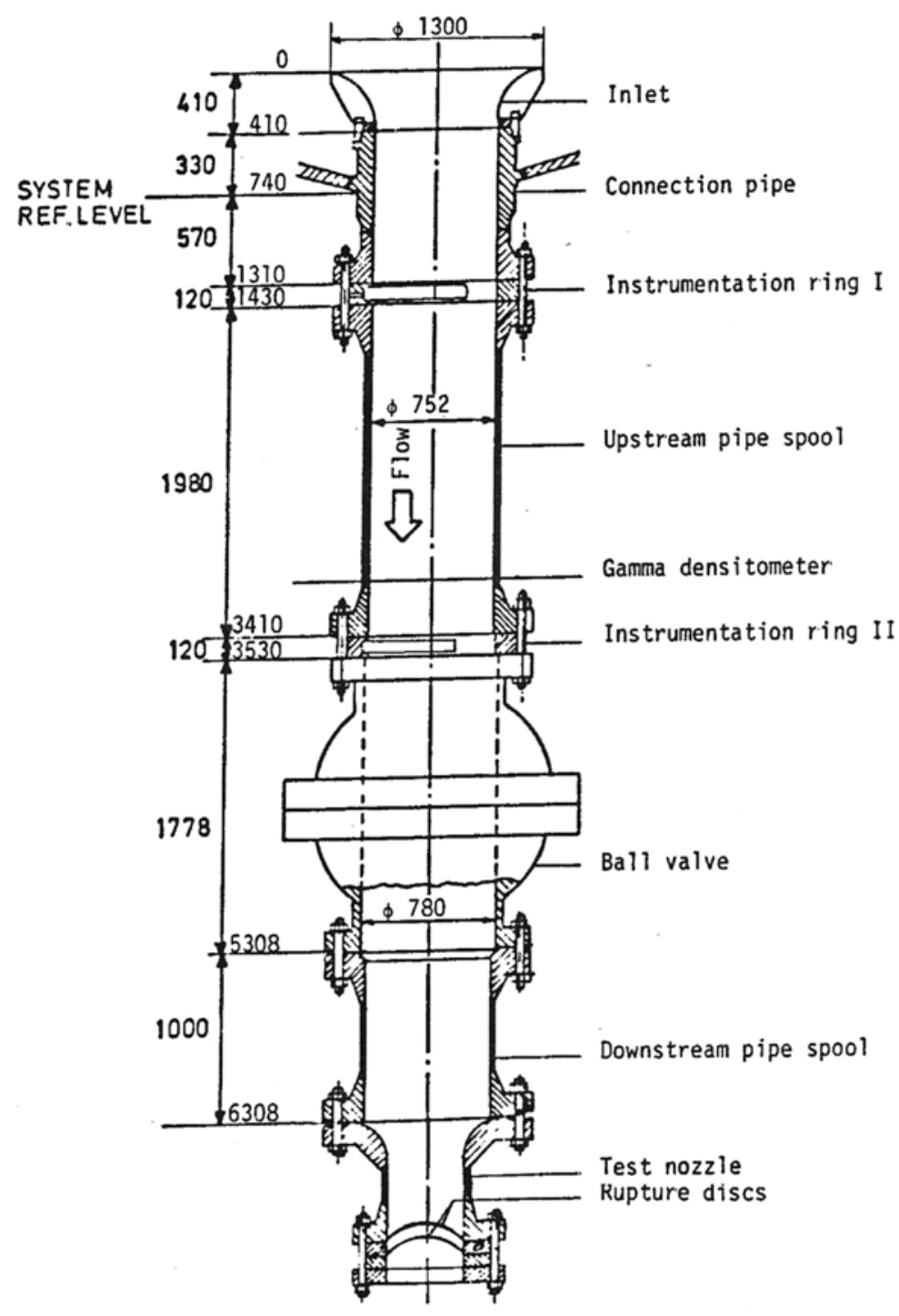

Figure 4.4-2. Marviken Critical Flow Test 24 discharge pipe, test nozzle, and rupture disk assembly. 


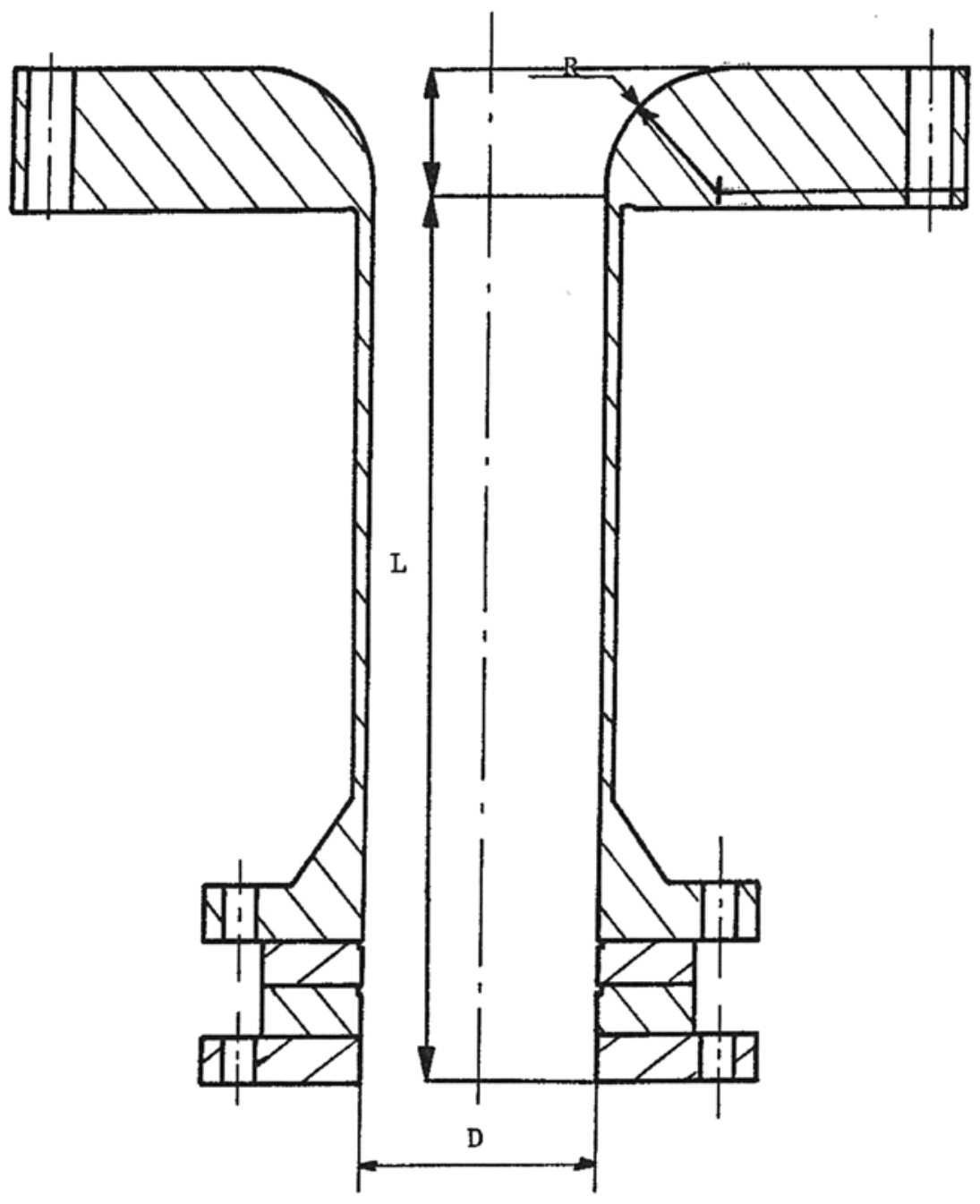

Figure 4.4-3. Marviken Critical Flow Test 24 test nozzle. 


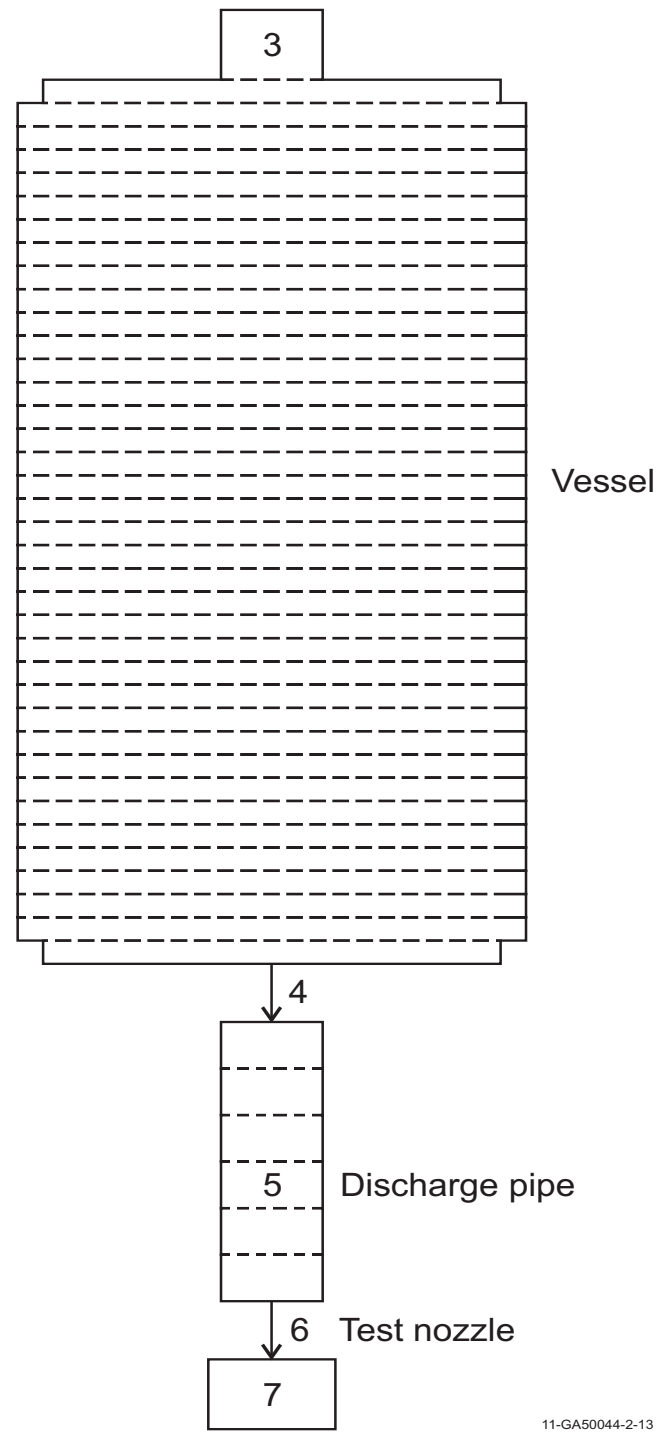

Figure 4.4-4. Marviken Critical Flow Test 24 nodalization diagram. 


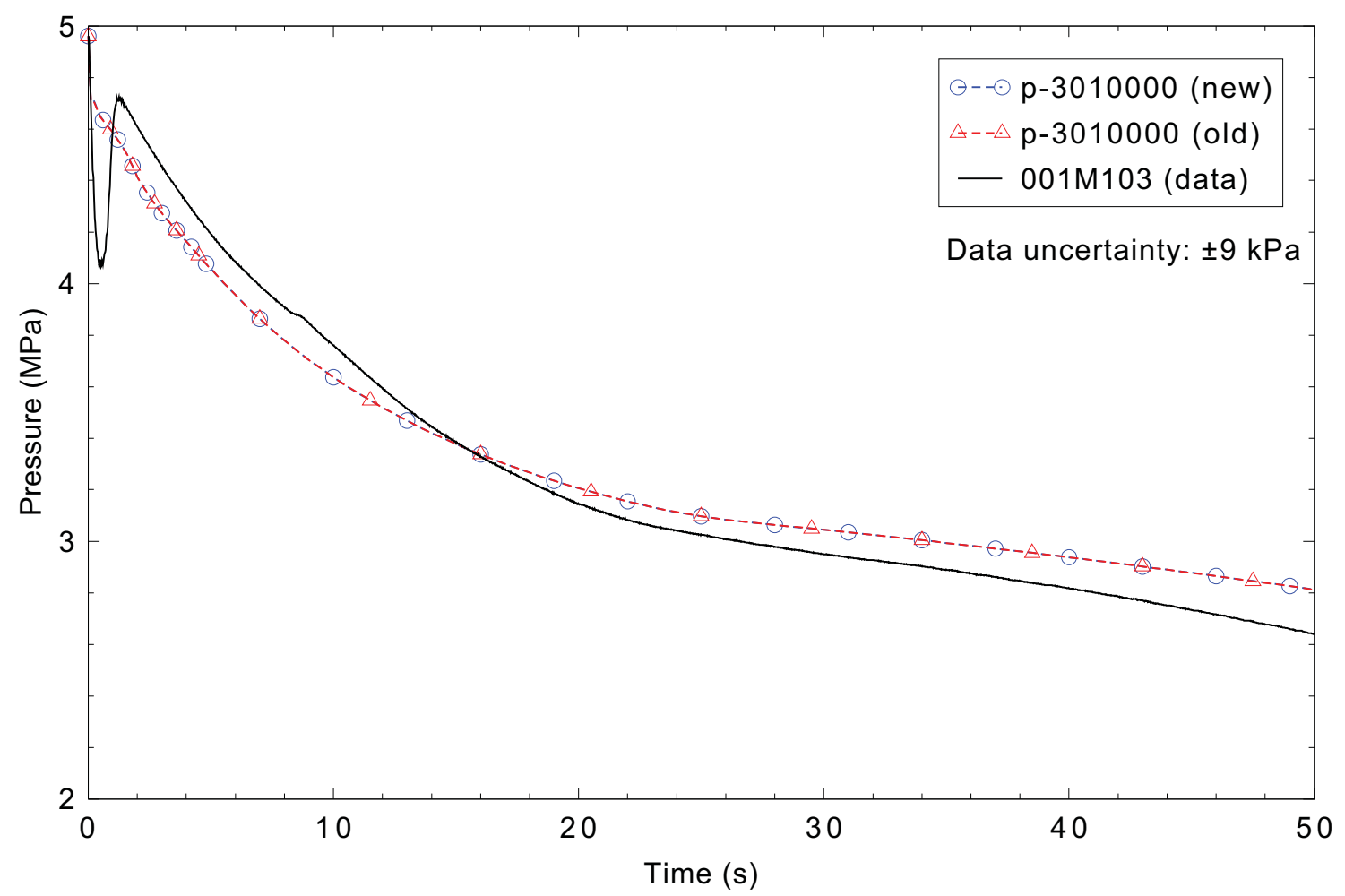

Figure 4.4-5. Measured and calculated vessel pressure for Marviken CFT 24.

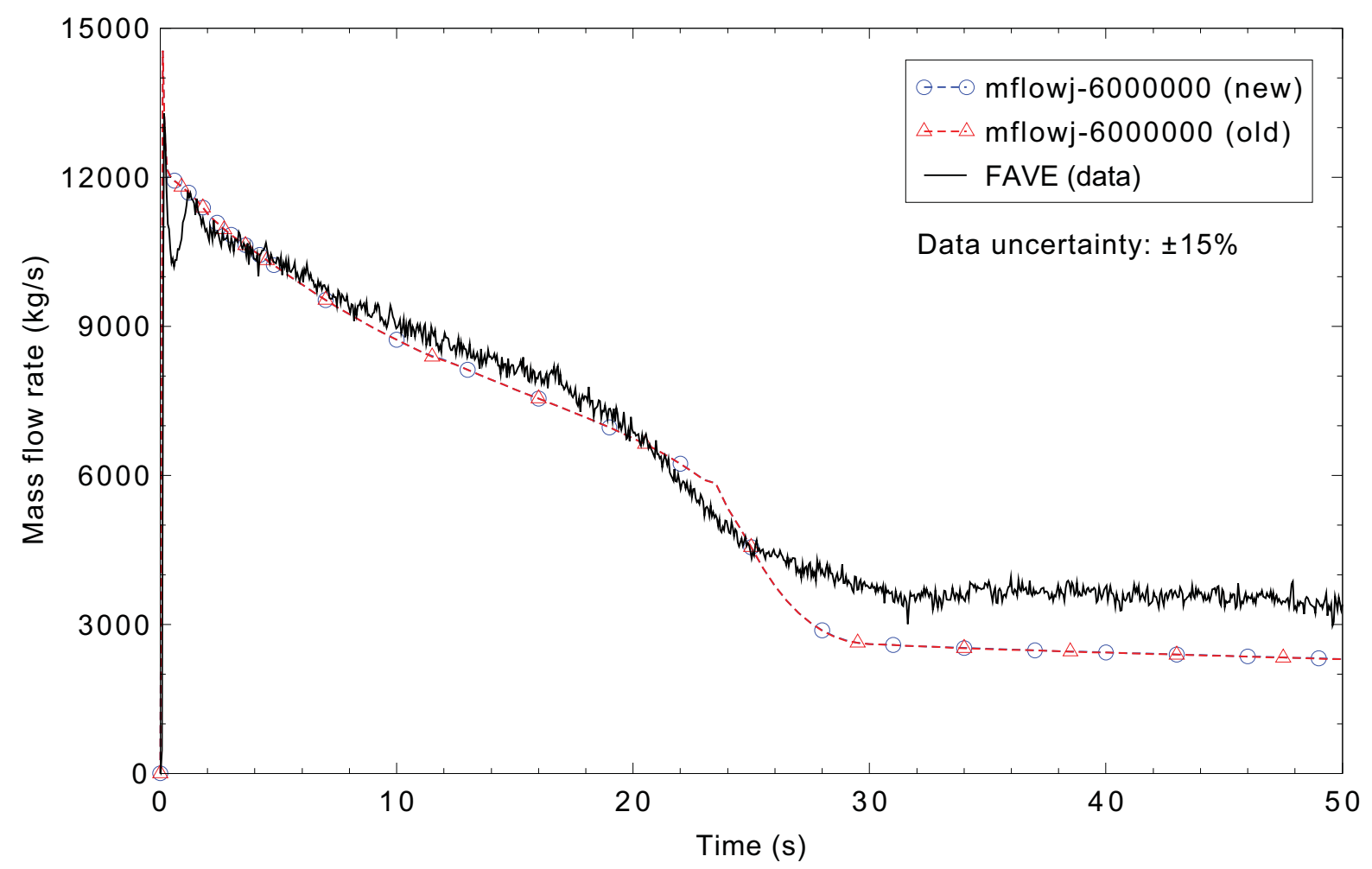

Figure 4.4-6. Measured and calculated mass flow rate for Marviken CFT 24. 


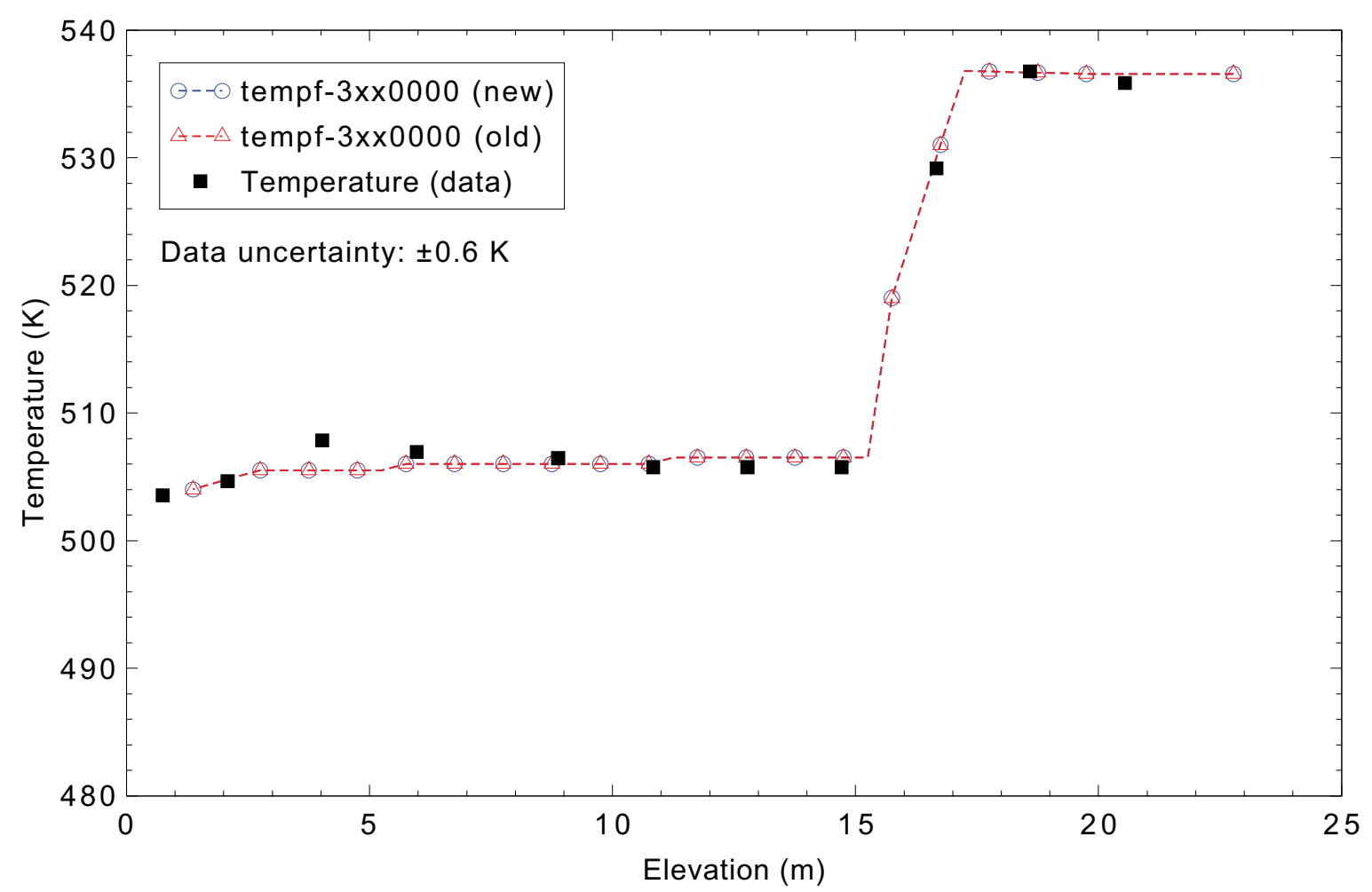

Figure 4.4-7. Measured and calculated vessel temperature profile at $0 \mathrm{~s}$ for Marviken CFT 24.

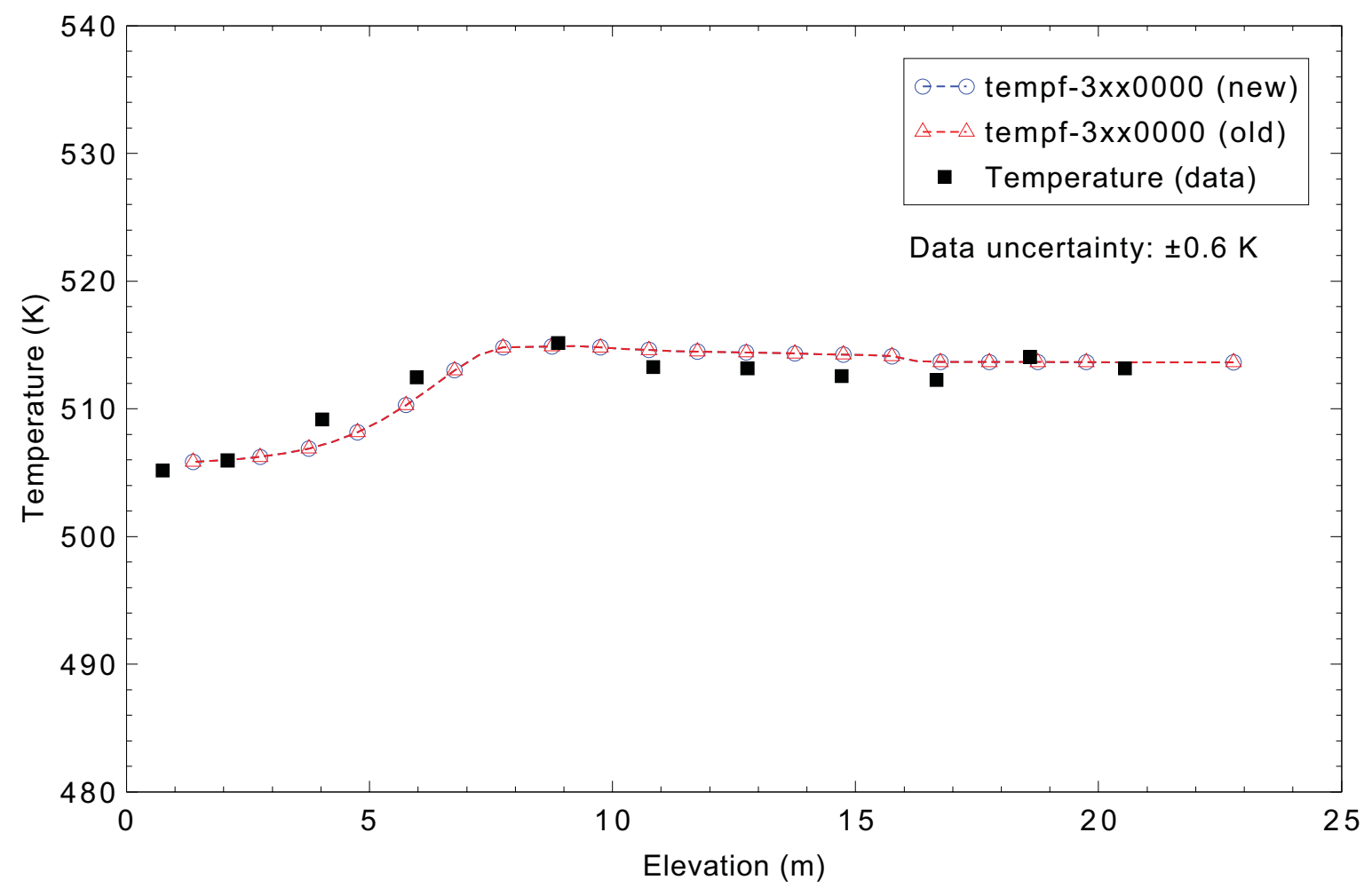

Figure 4.4-8. Measured and calculated vessel temperature profile at $15 \mathrm{~s}$ for Marviken CFT 24. 
RELAP5-3D/4.0.3

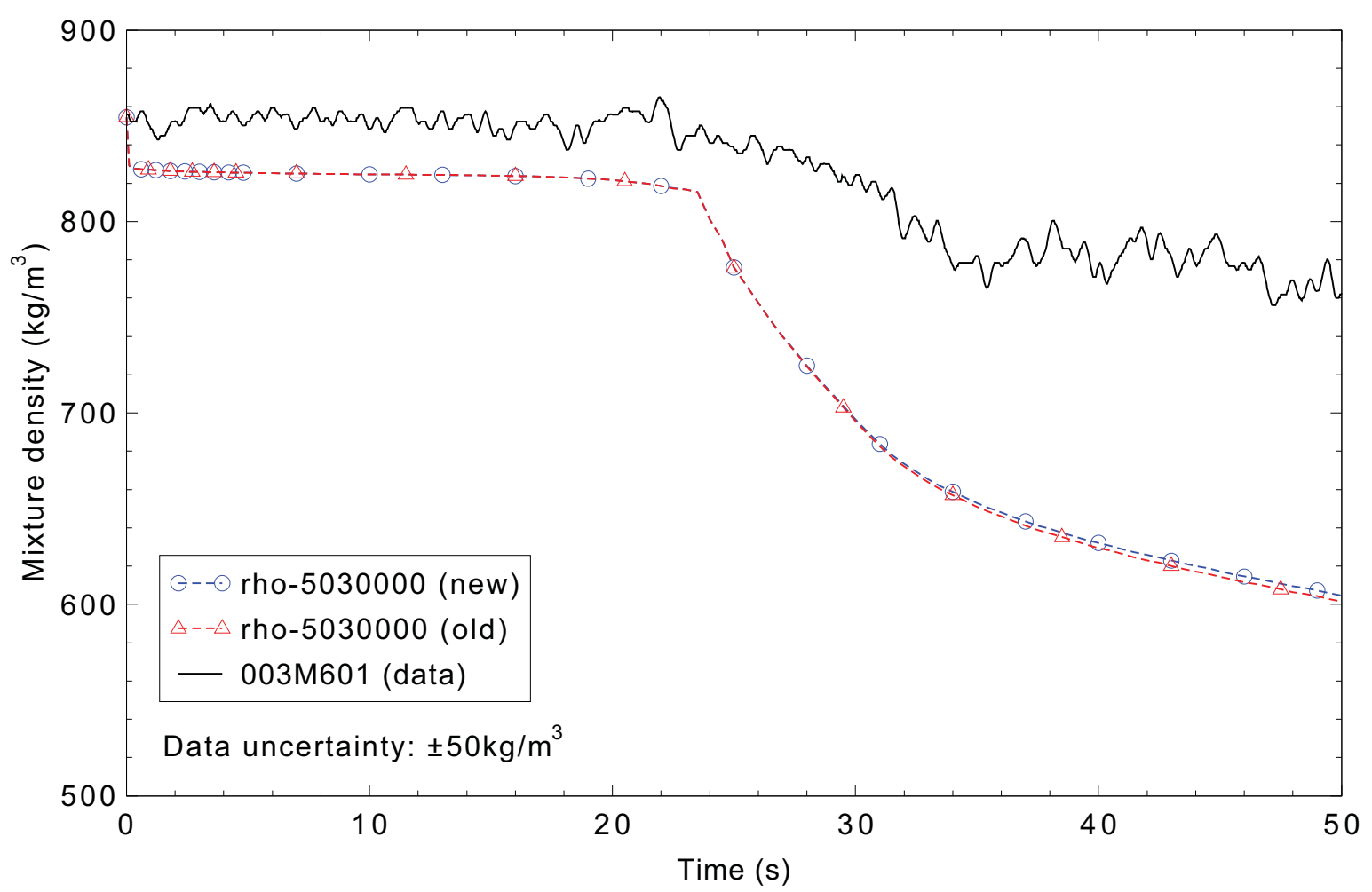

Figure 4.4-9. Measured and calculated mixture density in the discharge pipe for Marviken CFT 24. 
RELAP5-3D/4.0.3

\subsection{Marviken Jet Impingement Test 11}

Figures comparing simulations using two code versions are presented. Diagrams are included so that the figure numbering is the same as that in Volume III of the RELAP5-3D code manual. No differences were observed in the figures. 


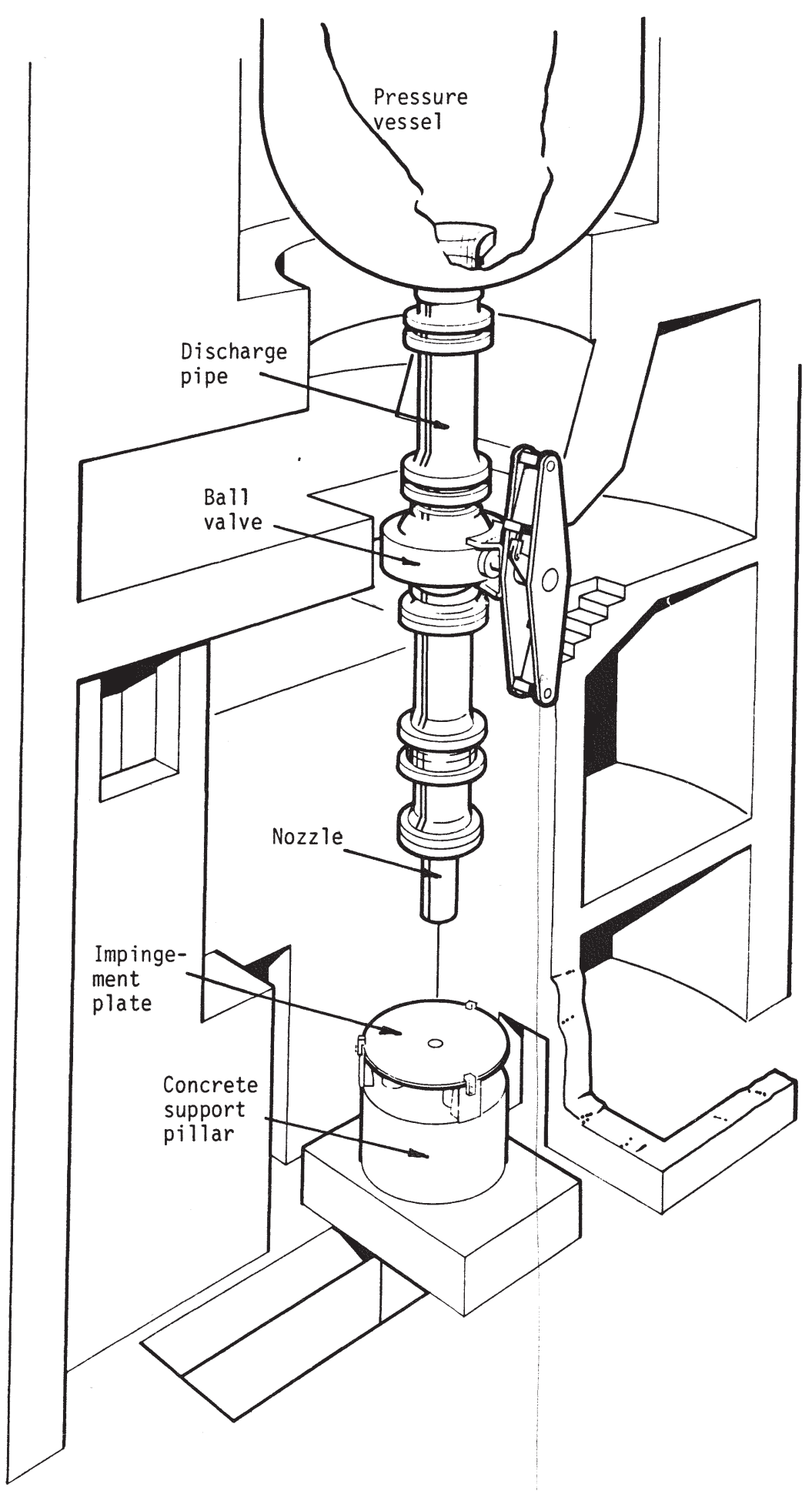

Figure 4.5-1. Test facility for Marviken JIT-11. 
Nute: All dimensions are in millimeters at room temperature.

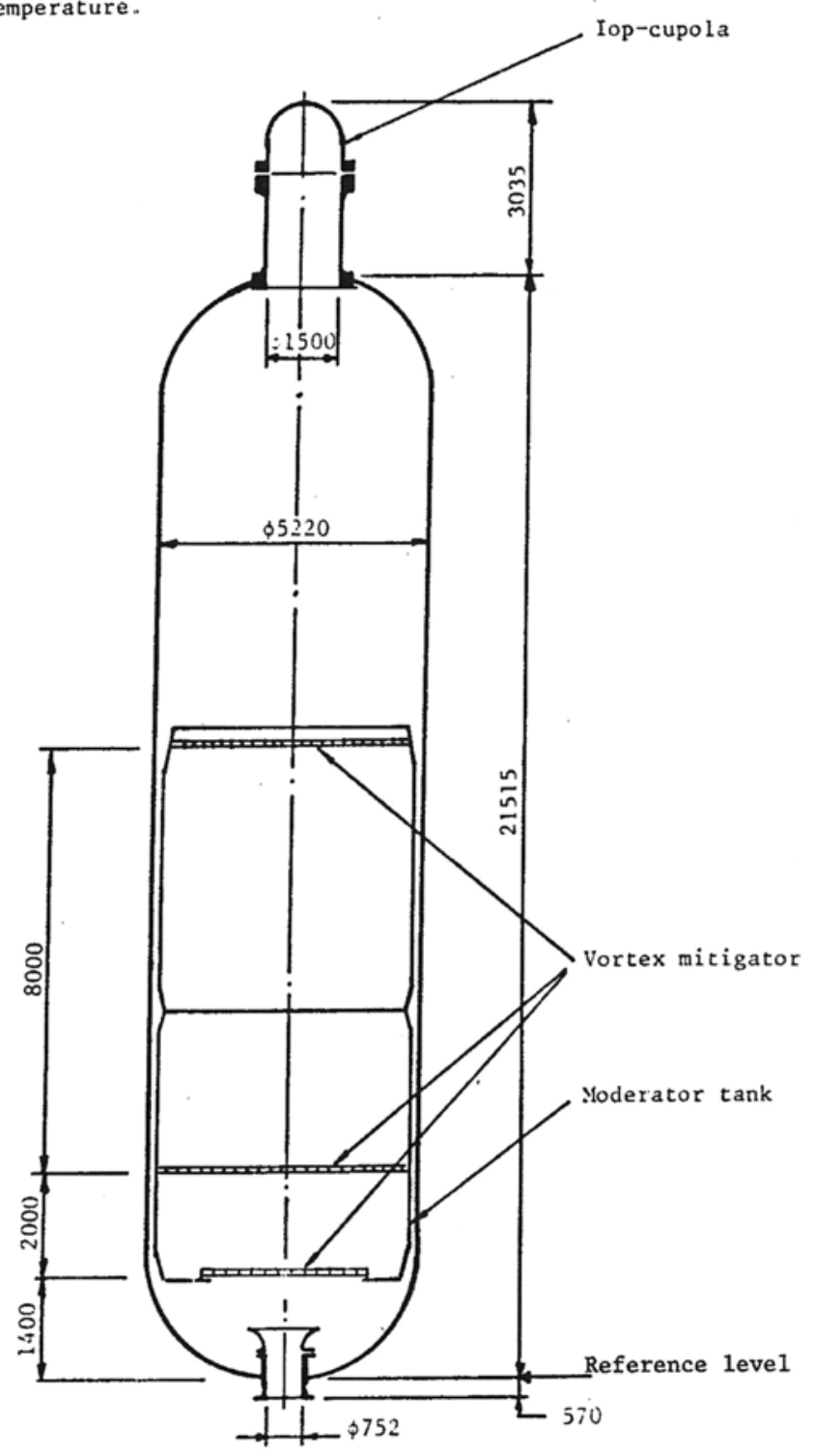

Figure 4.5-2. Pressure vessel for Marviken JIT-11. 


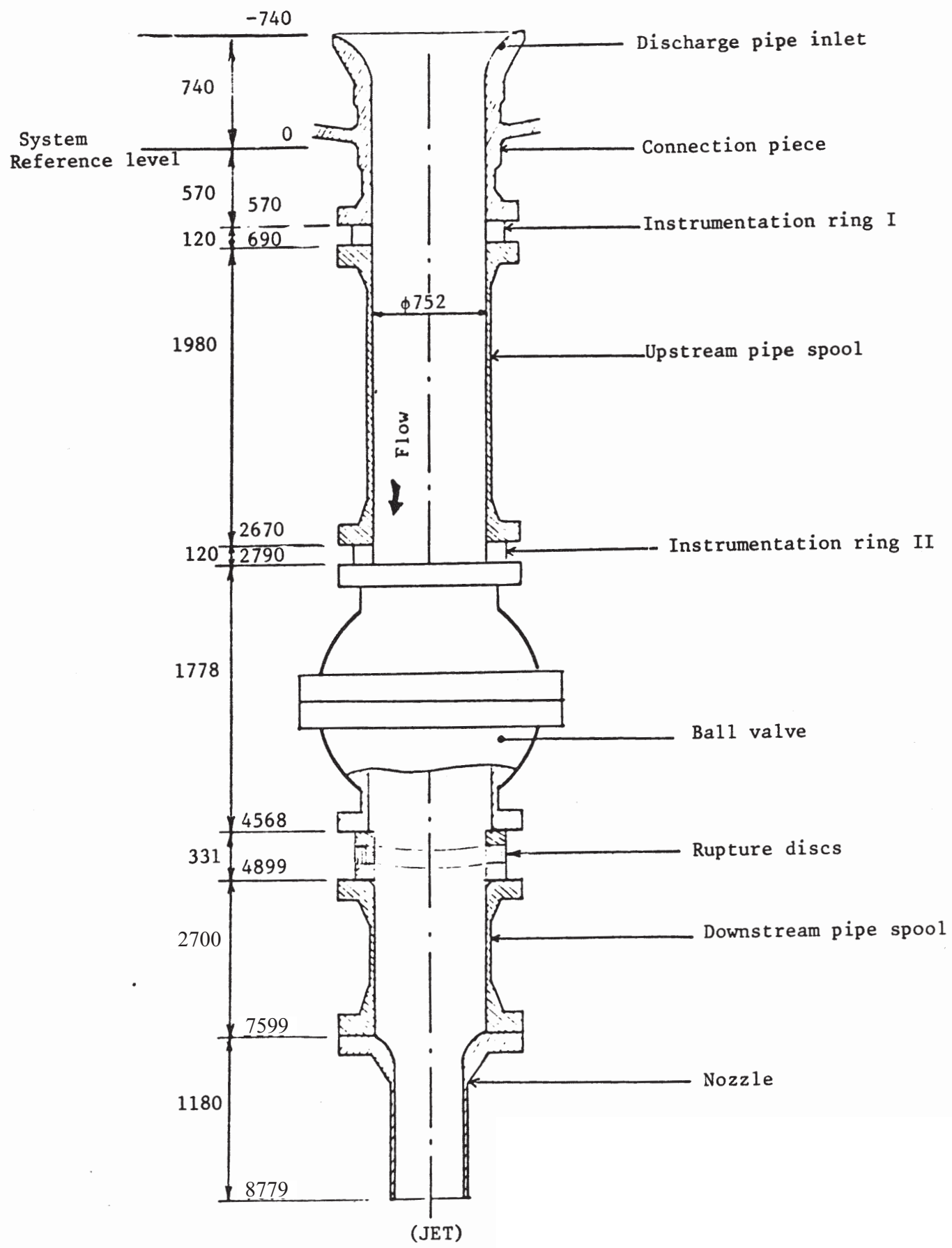

Figure 4.5-3. Discharge pipe for Marviken JIT-11. 


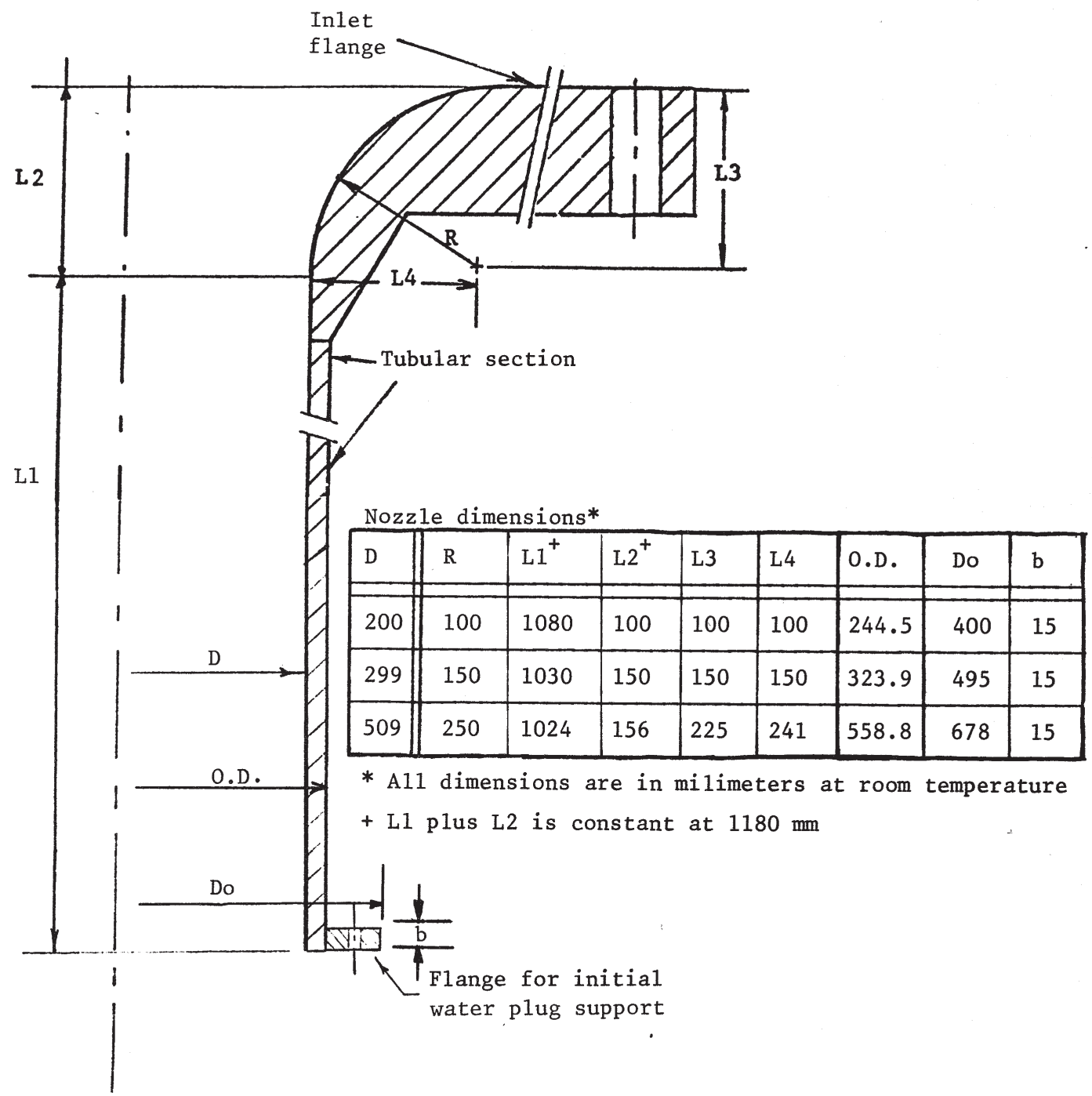

Figure 4.5-4. Nozzle for Marviken JIT-11. 


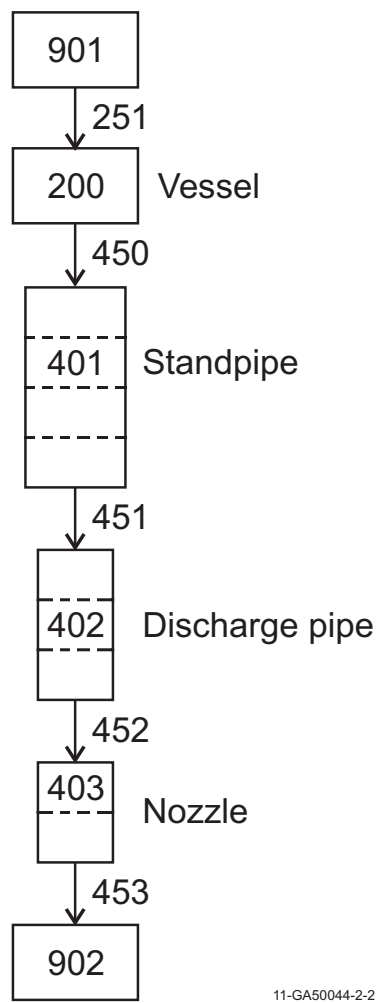

Figure 4.5-5. RELAP5-3D nodalization for Marviken JIT-11. 


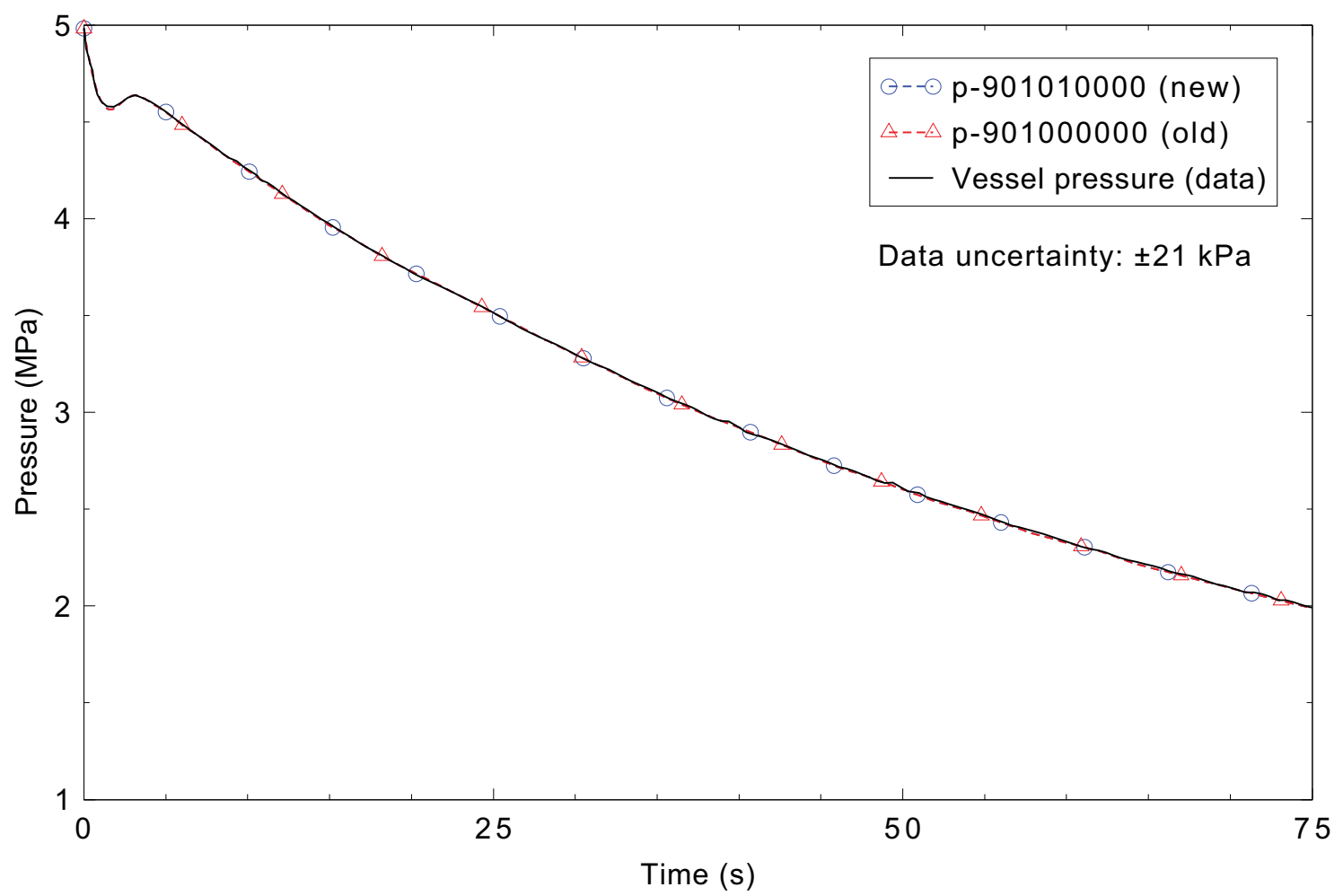

Figure 4.5-6. Vessel pressure boundary condition for Marviken JIT-11.

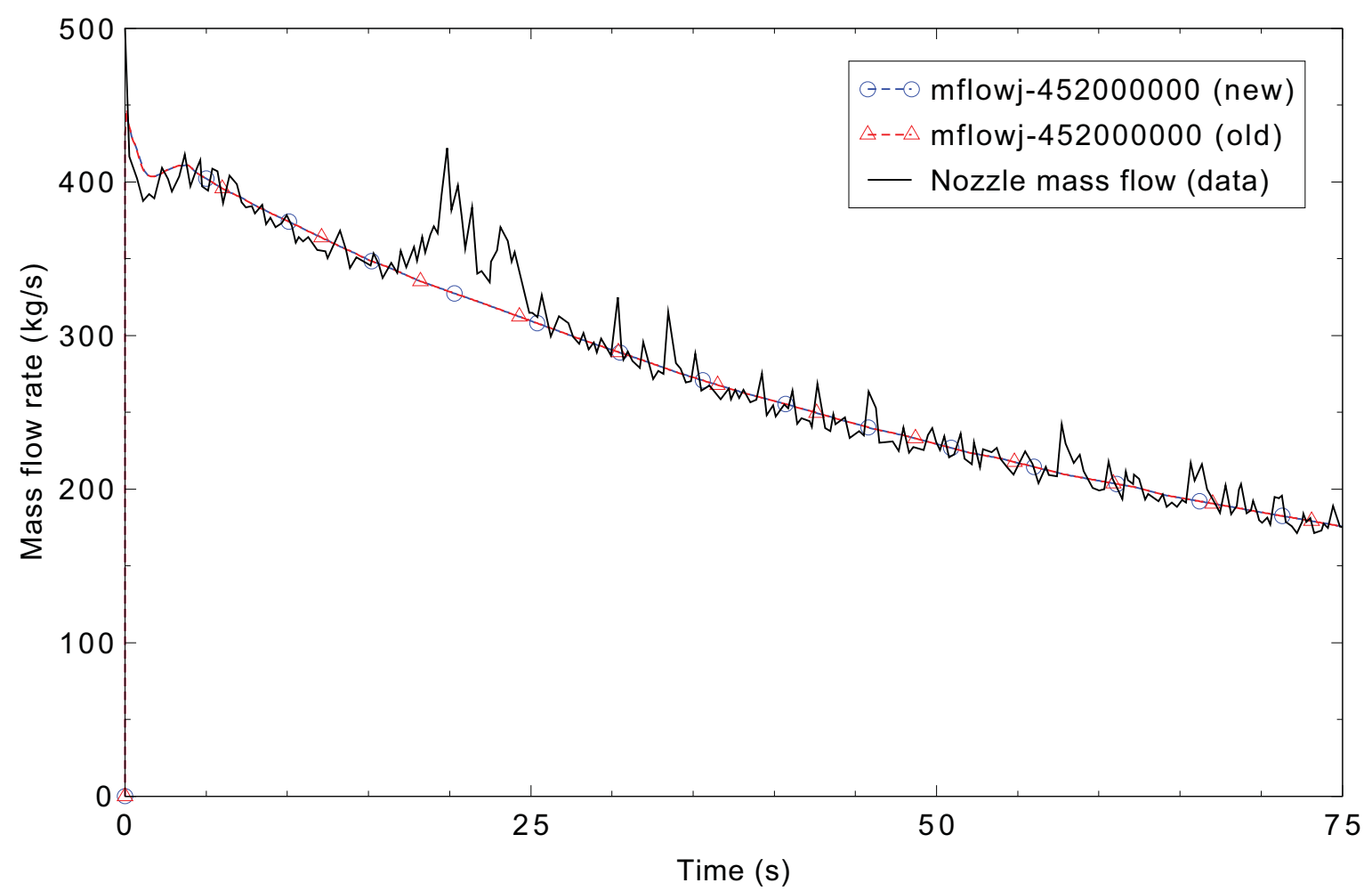

Figure 4.5-7. Measured and calculated mass flow rate for Marviken JIT-11. 


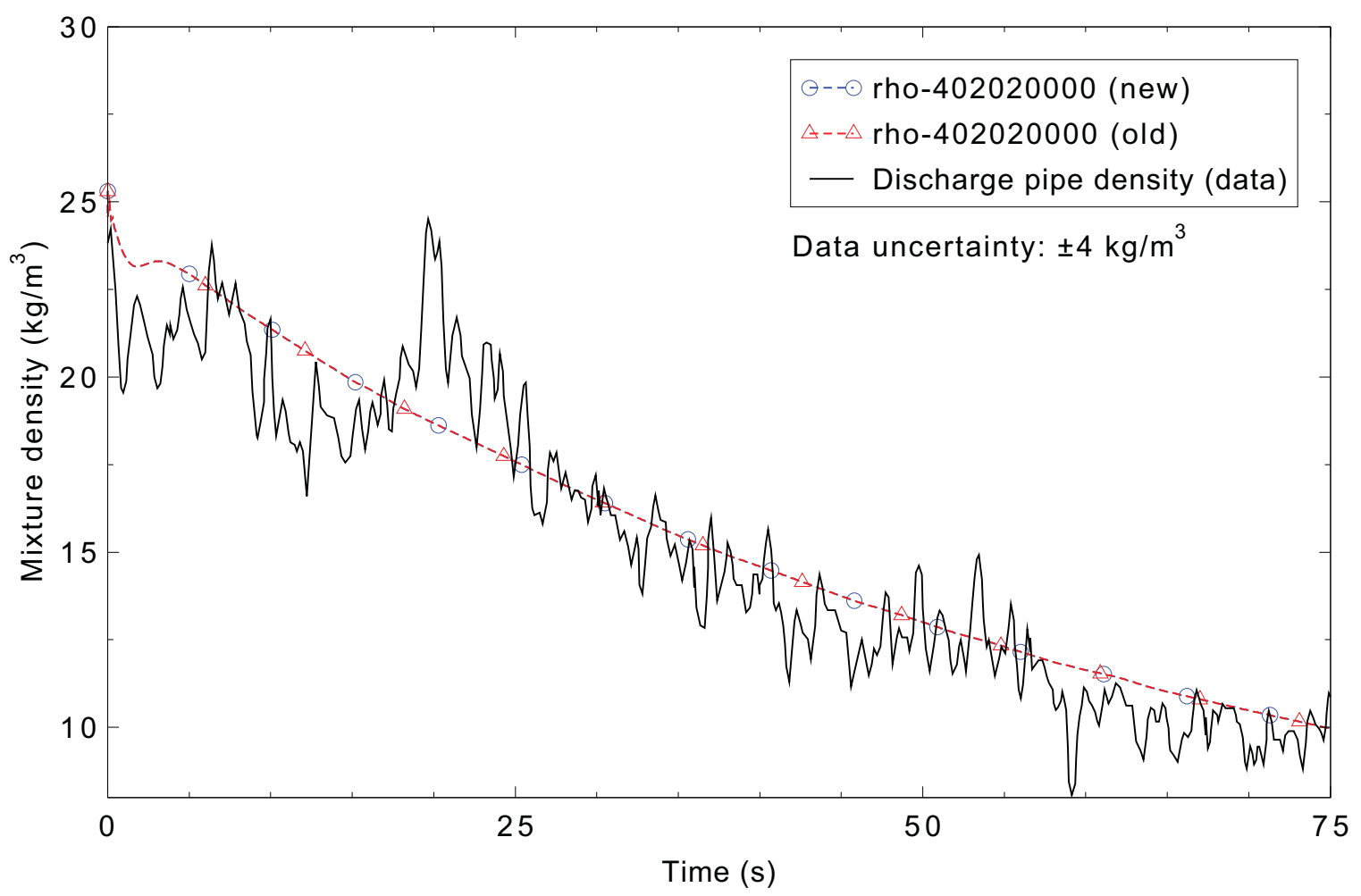

Figure 4.5-8. Measured and calculated mixture density in the discharge pipe for Marviken JIT-11. 


\subsection{Moby-Dick Air-Water}

Figures comparing simulations using two code versions are presented. Diagrams are included so that the figure numbering is the same as that in Volume III of the RELAP5-3D code manual. A significant difference was observed in Figure 4.6-3.

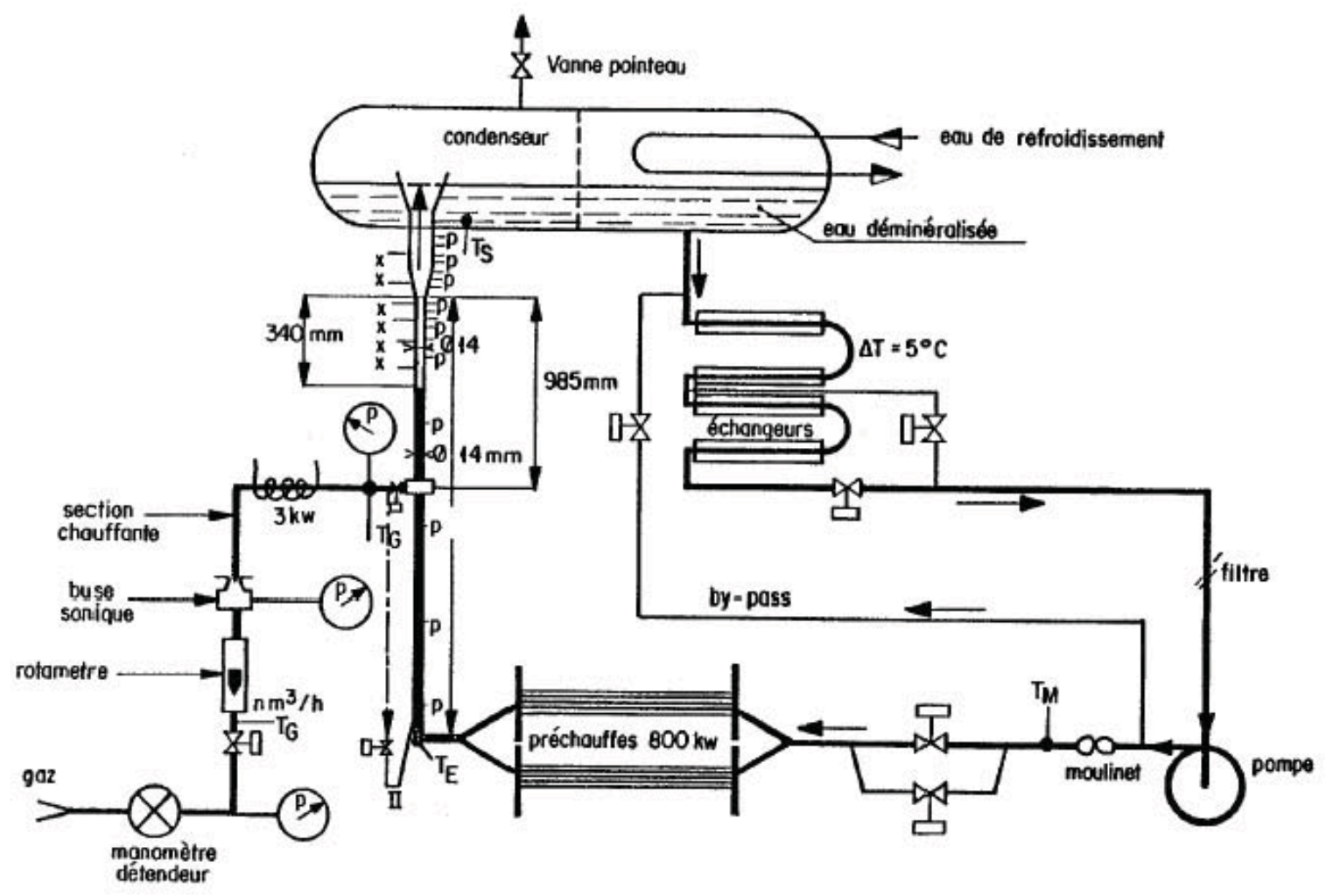

Figure 4.6-1. Moby-Dick test loop. 
Note: diagram is not to scale. The width of the test section is exaggerated versus the length.

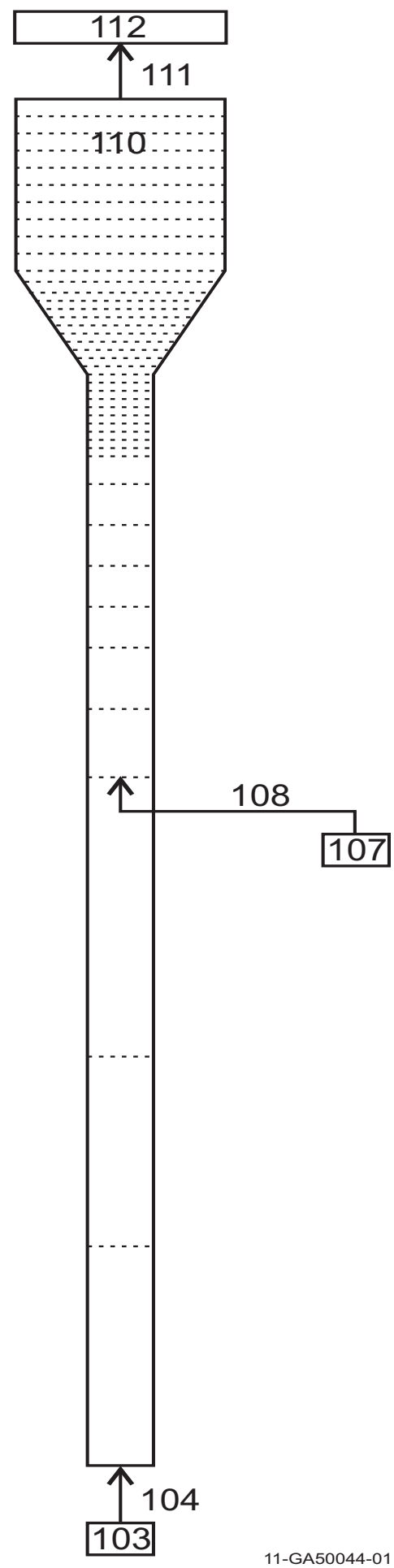

Figure 4.6-2. Nodalization diagram of the RELAP5-3D Moby-Dick experiment model. 


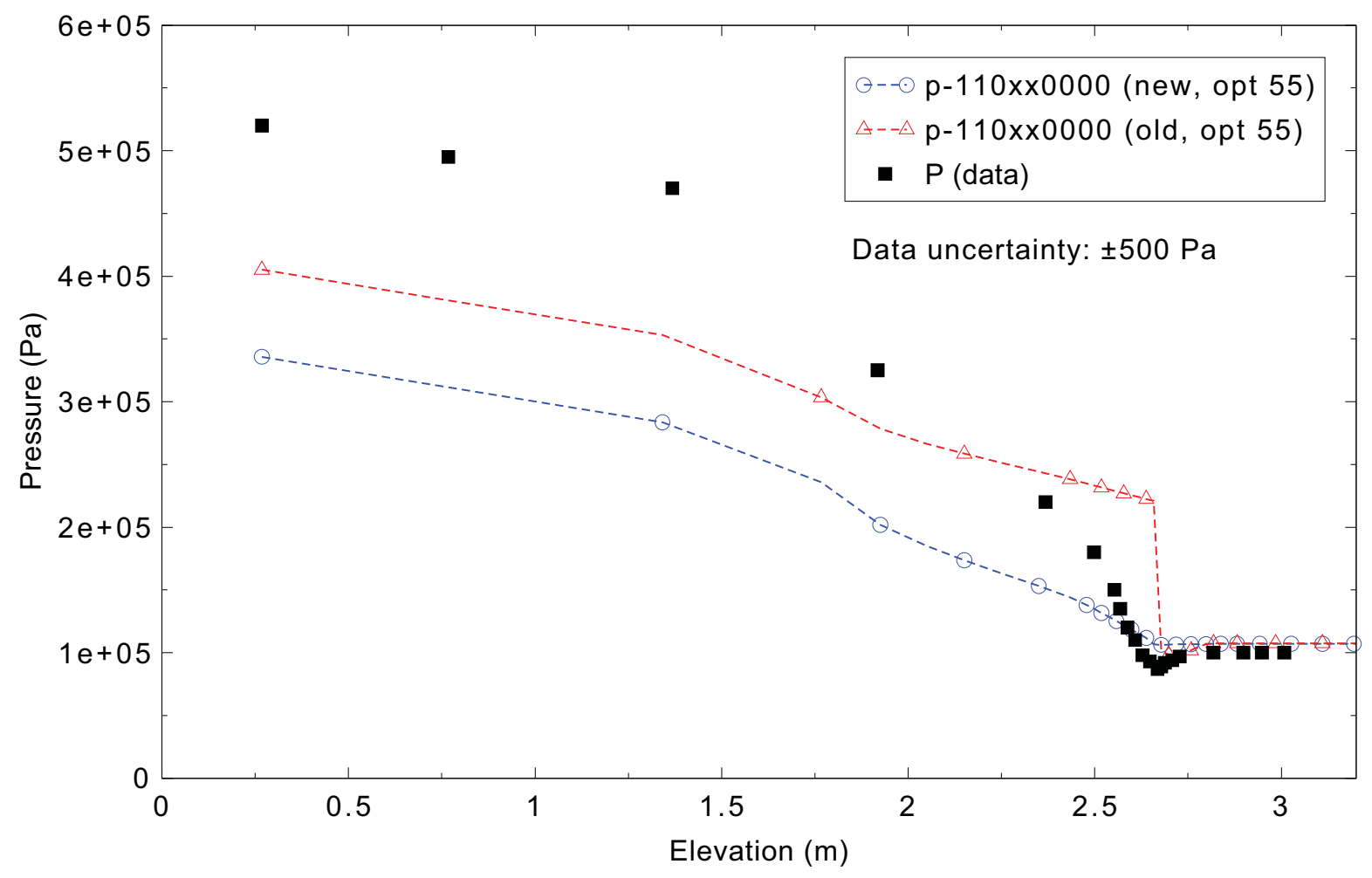

Figure 4.6-3. Measured and calculated axial pressure distribution for Moby-Dick Test 3141. 


\subsection{Christensen Test 15}

Figures comparing simulations using two code versions are presented. Diagrams are included so that the figure numbering is the same as that in Volume III of the RELAP5-3D code manual. No differences were observed in the figure.

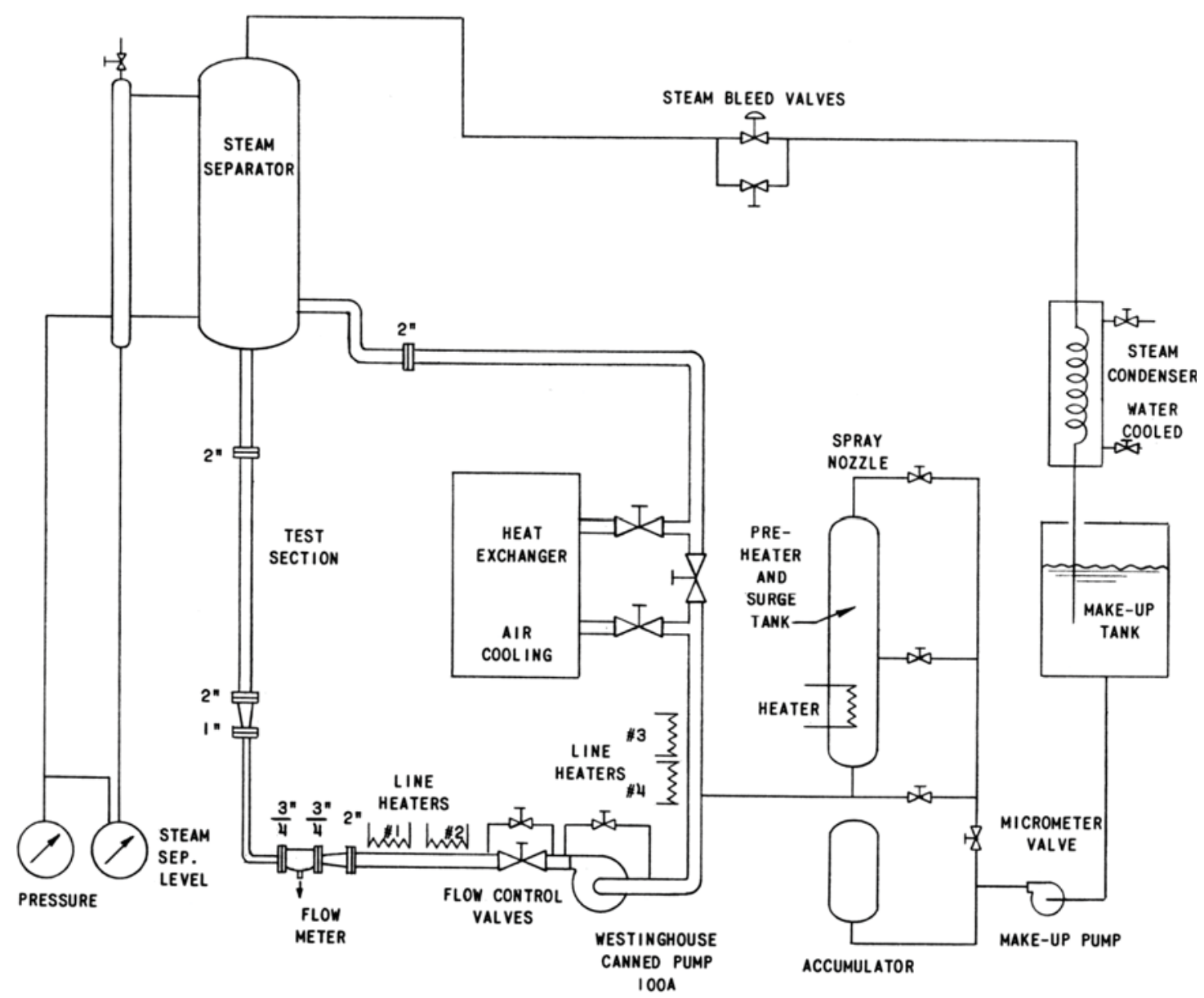

Figure 4.7-1. Test facility schematic for Christensen Test 15. 
RELAP5-3D/4.0.3

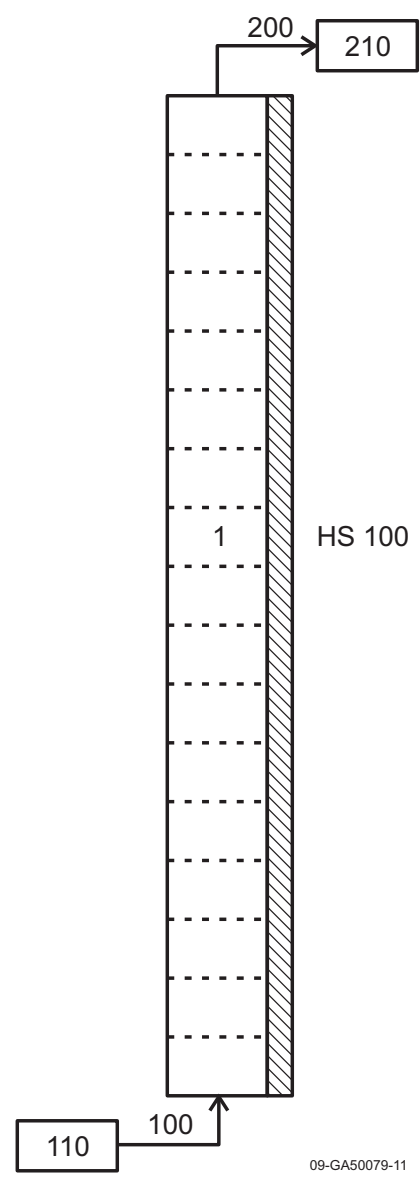

Figure 4.7-2. RELAP5-3D model nodalization for Christensen Test 15. 


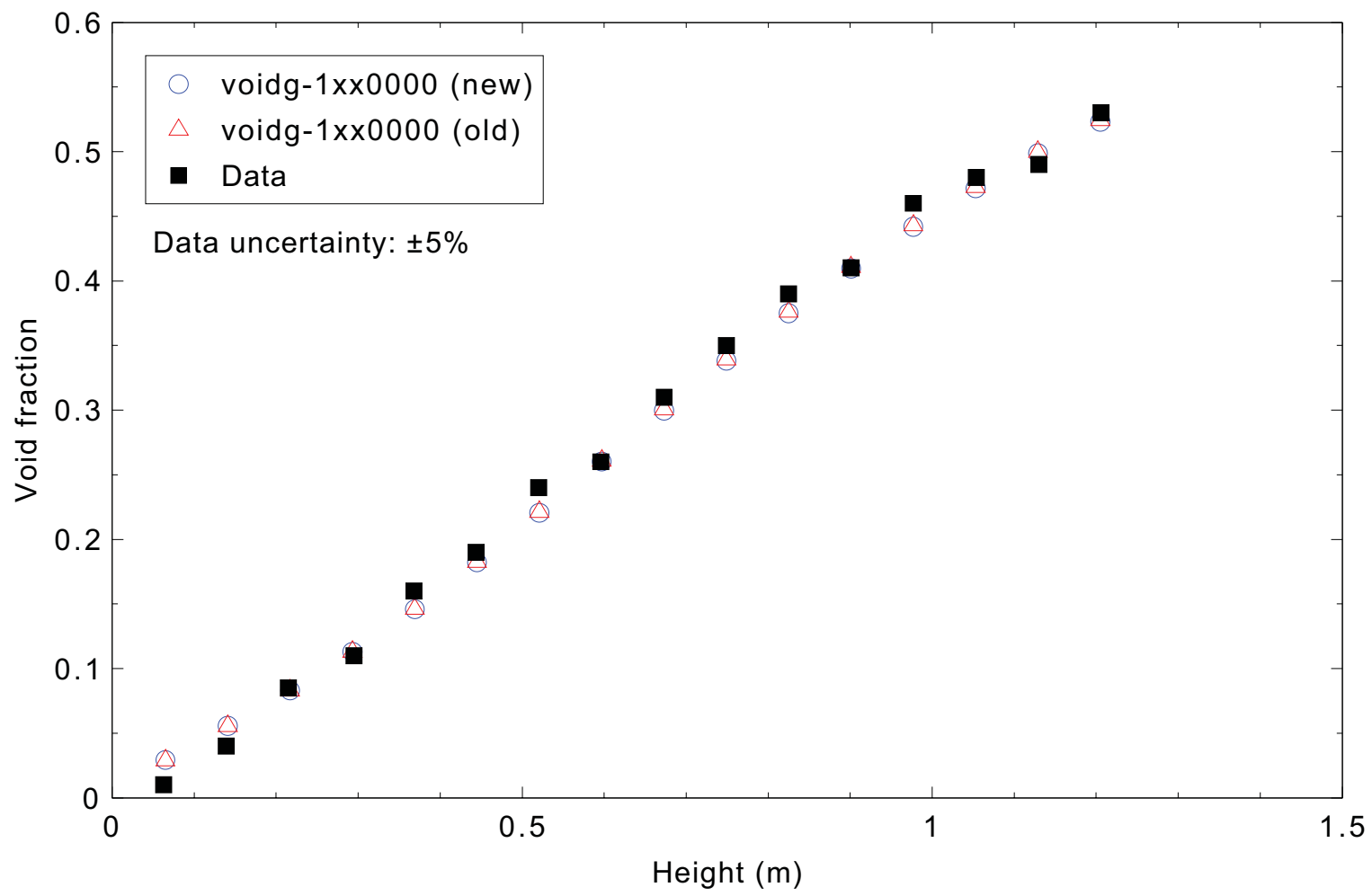

Figure 4.7-3. Measured and calculated test section void profiles for Christensen Test 15. 


\subsection{GE Level Swell - $1 \mathrm{ft} \mathrm{-} \mathrm{Test} \mathrm{1004-3}$}

Figures comparing simulations using two code versions are presented. Diagrams are included so that the figure numbering is the same as that in Volume III of the RELAP5-3D code manual. Noticeable differences were observed in Figures 4.8-9 and 14.

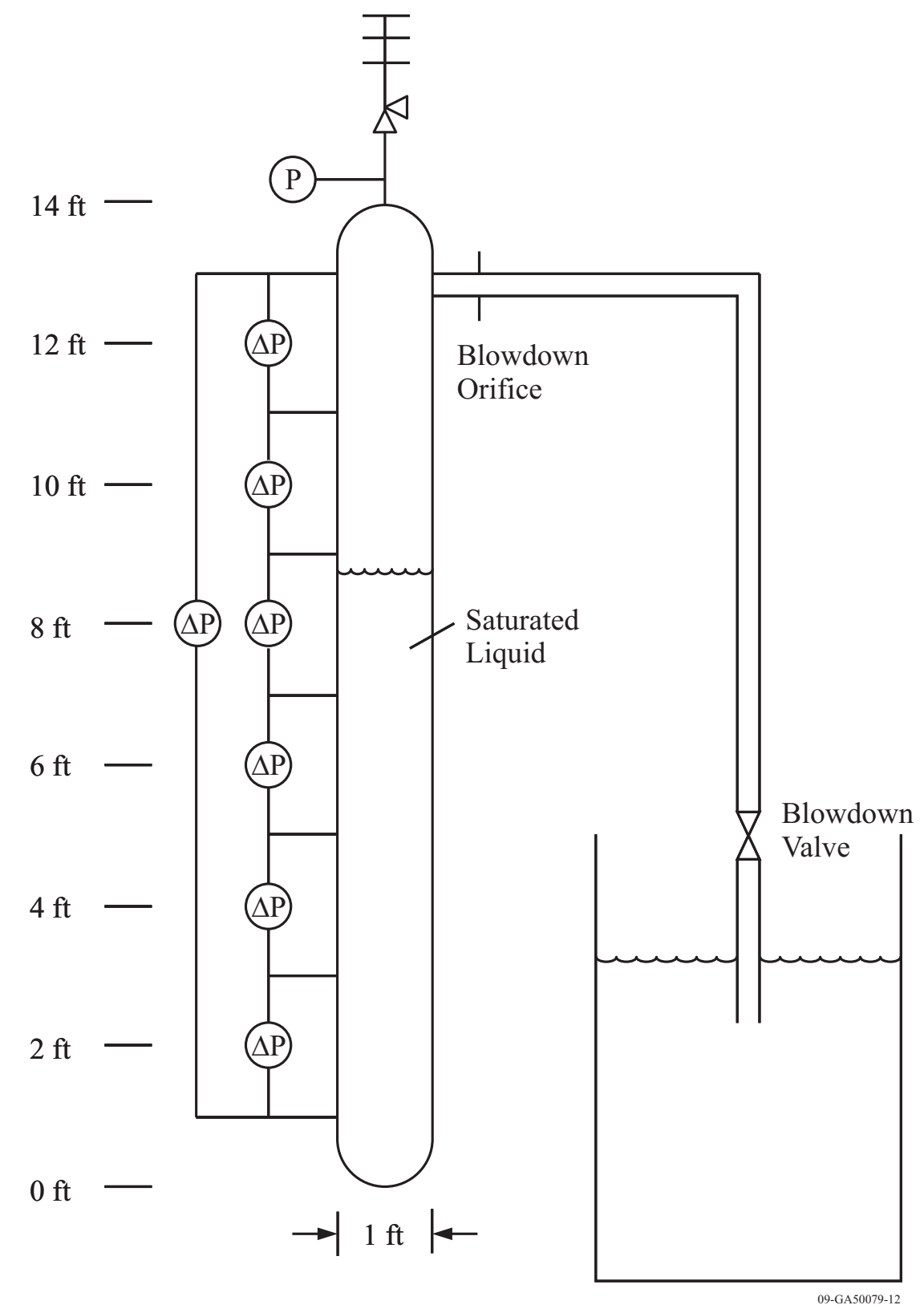

Figure 4.8-1. Test schematic for GE Small Blowdown Vessel test 1004-3. 


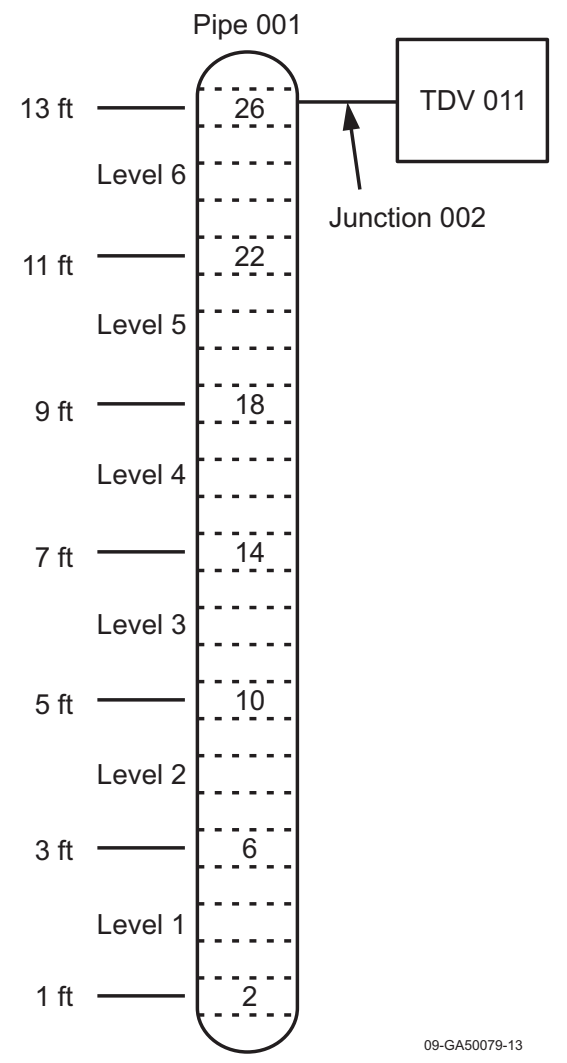

Figure 4.8-2. Nodalization diagram for GE Small Blowdown Vessel test 1004-3. 


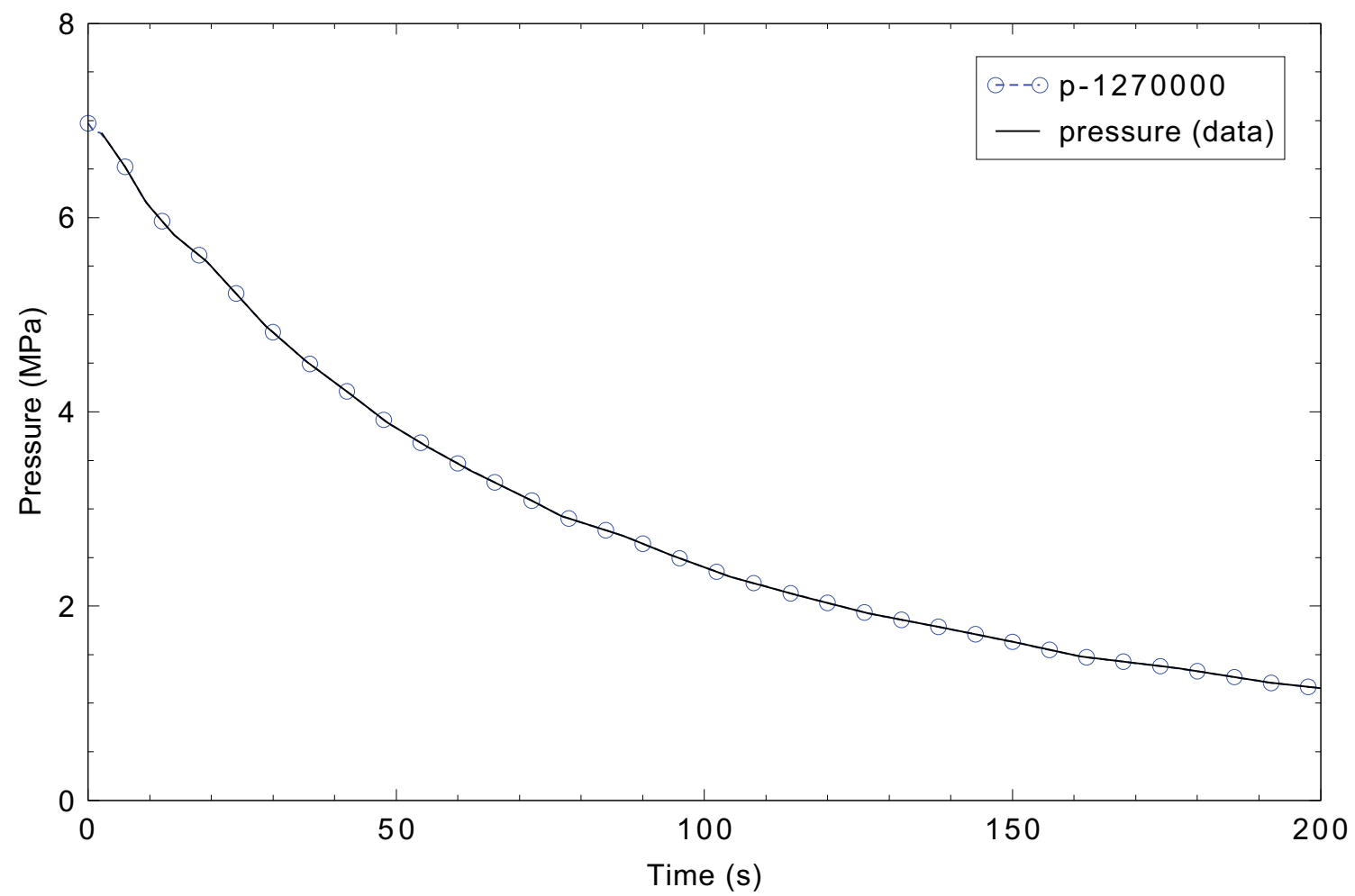

Figure 4.8-3. Comparison of experiment data with the pressure imposed by time-dependent volume 11 .

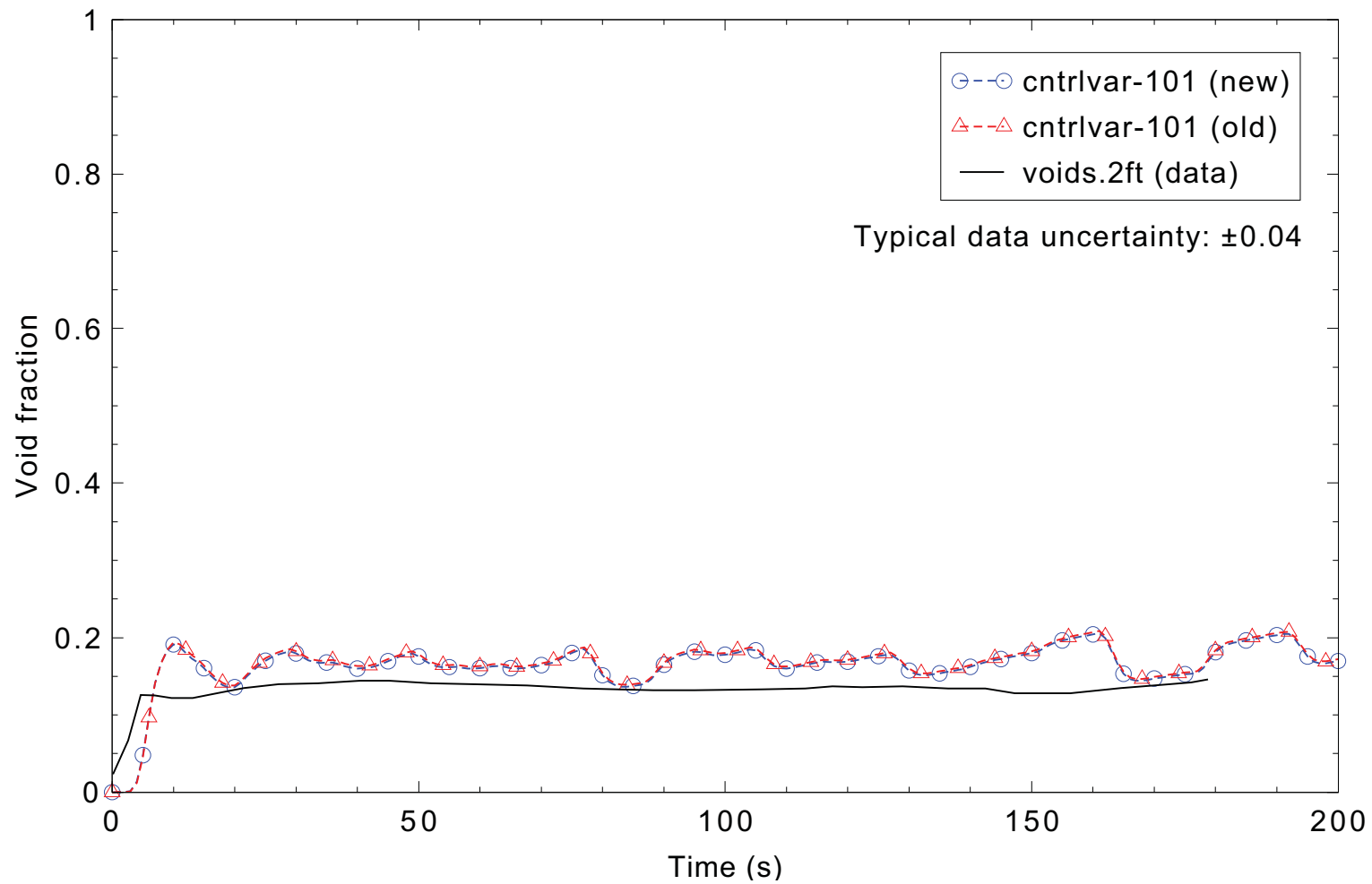

Figure 4.8-4. Measured and calculated void fraction at $2 \mathrm{ft}(0.6 \mathrm{~m})$ above the bottom of the vessel (level 1) for GE level swell Test 1004-3. 


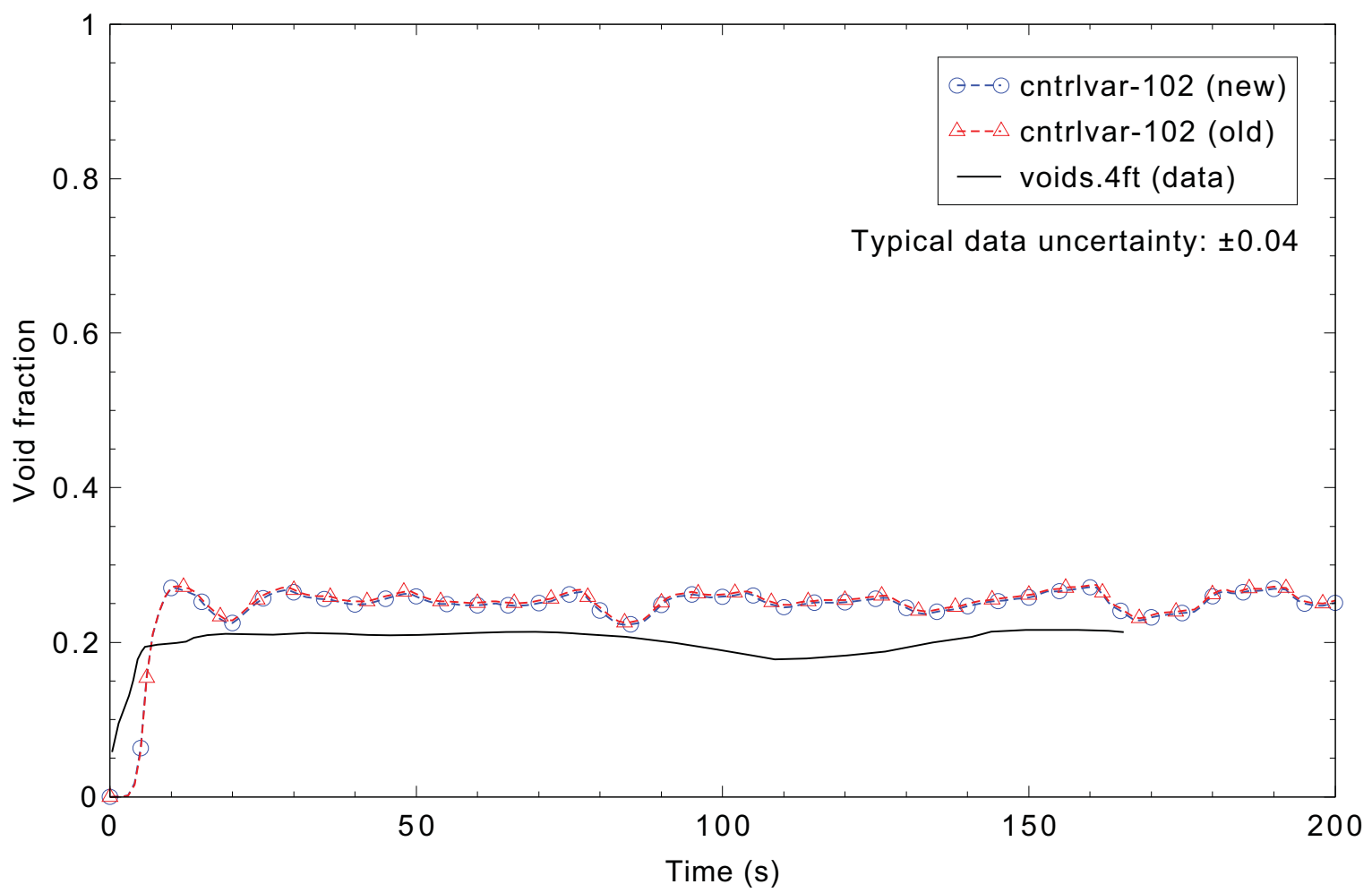

Figure 4.8-5. Measured and calculated void fraction at $4 \mathrm{ft}(1.2 \mathrm{~m})$ above the bottom of the vessel (level 2) for GE level swell Test 1004-3.

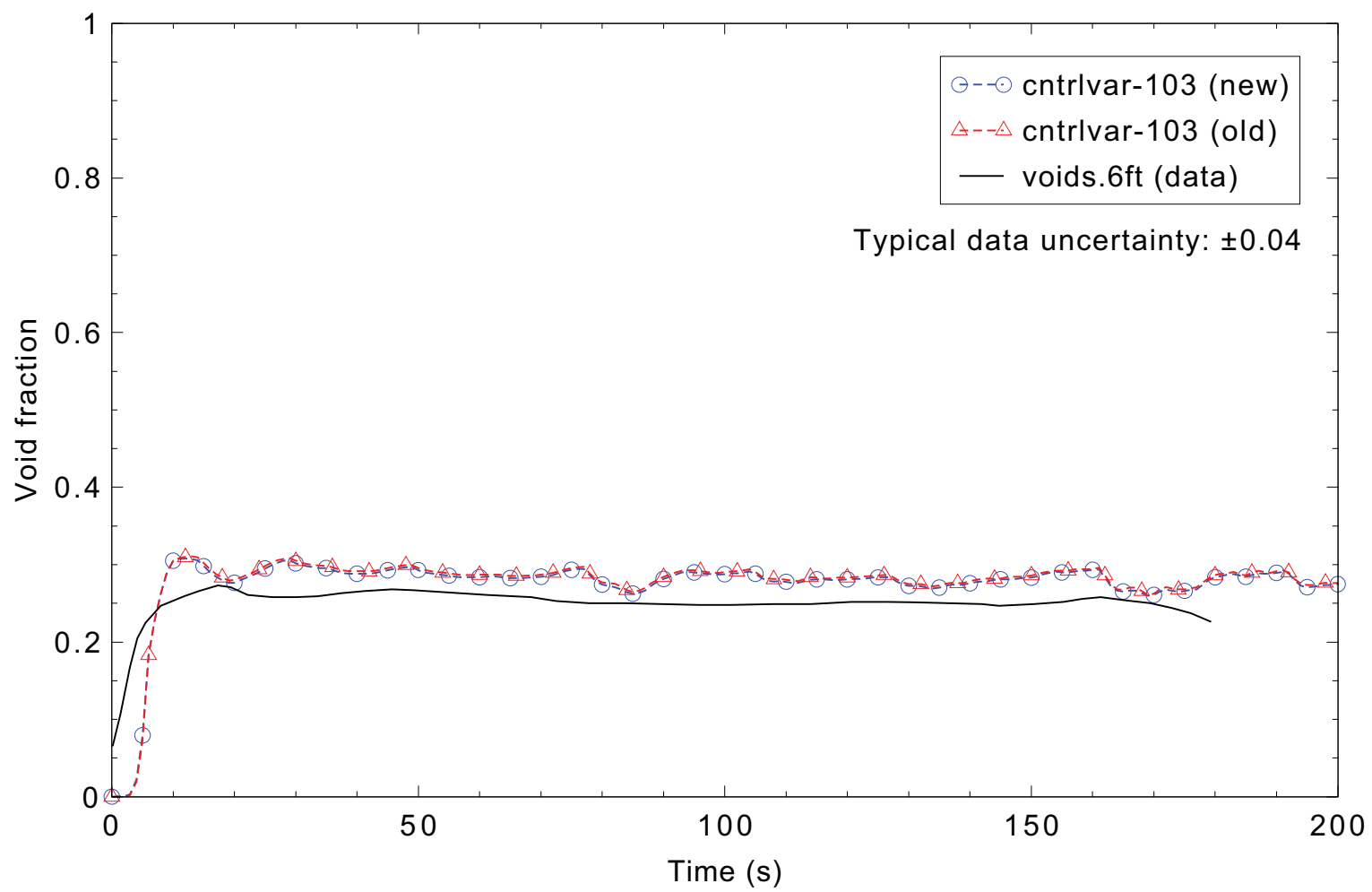

Figure 4.8-6. Measured and calculated void fraction at $6 \mathrm{ft}(1.8 \mathrm{~m})$ above the bottom of the vessel (level 3) for GE level swell Test 1004-3. 


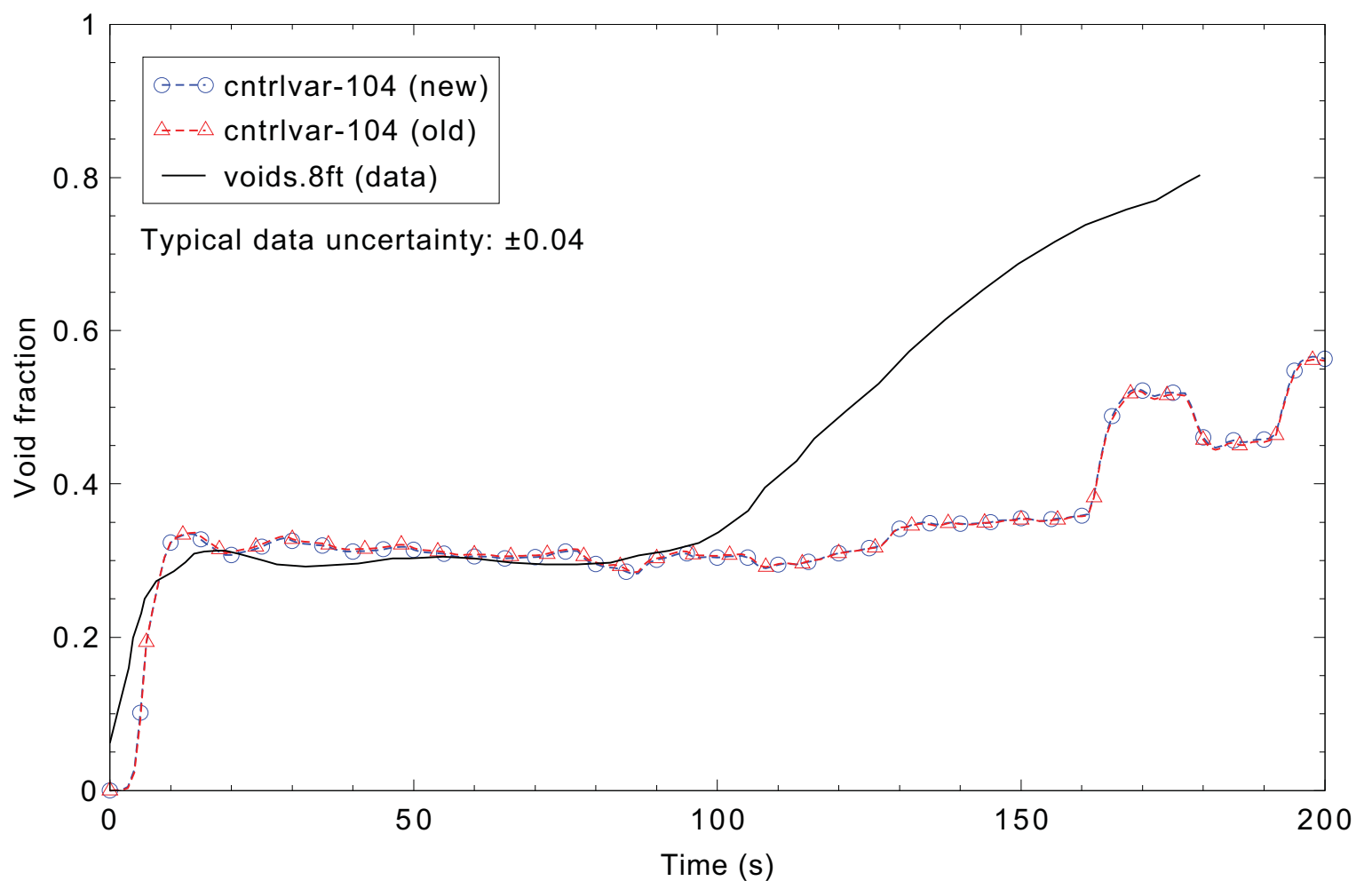

Figure 4.8-7. Measured and calculated void fraction at $8 \mathrm{ft}(2.4 \mathrm{~m})$ above the bottom of the vessel (level 4) for GE level swell Test 1004-3.

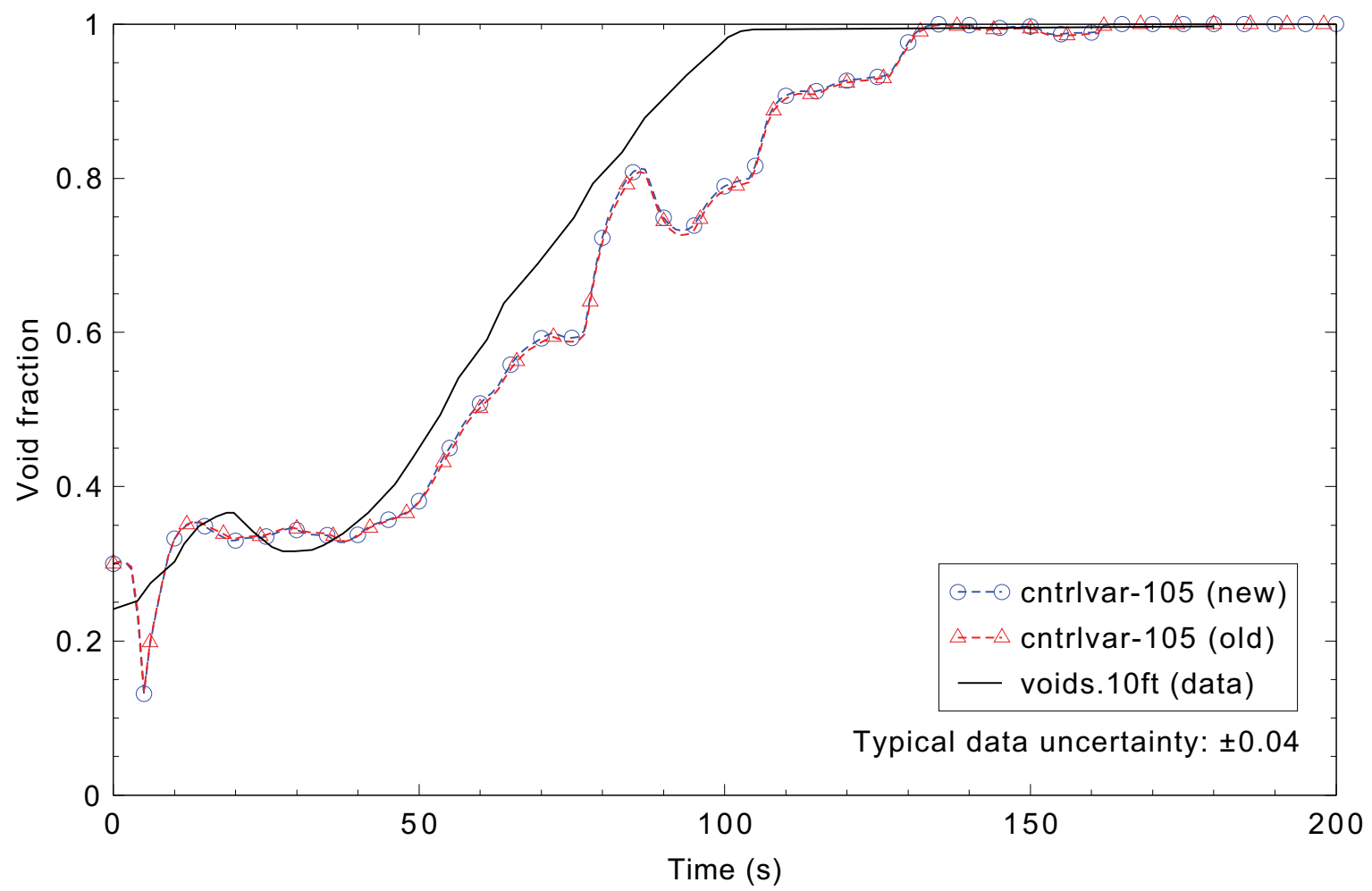

Figure 4.8-8. Measured and calculated void fraction at $10 \mathrm{ft}(3.0 \mathrm{~m})$ above the bottom of the vessel (level 5) for GE level swell Test 1004-3. 


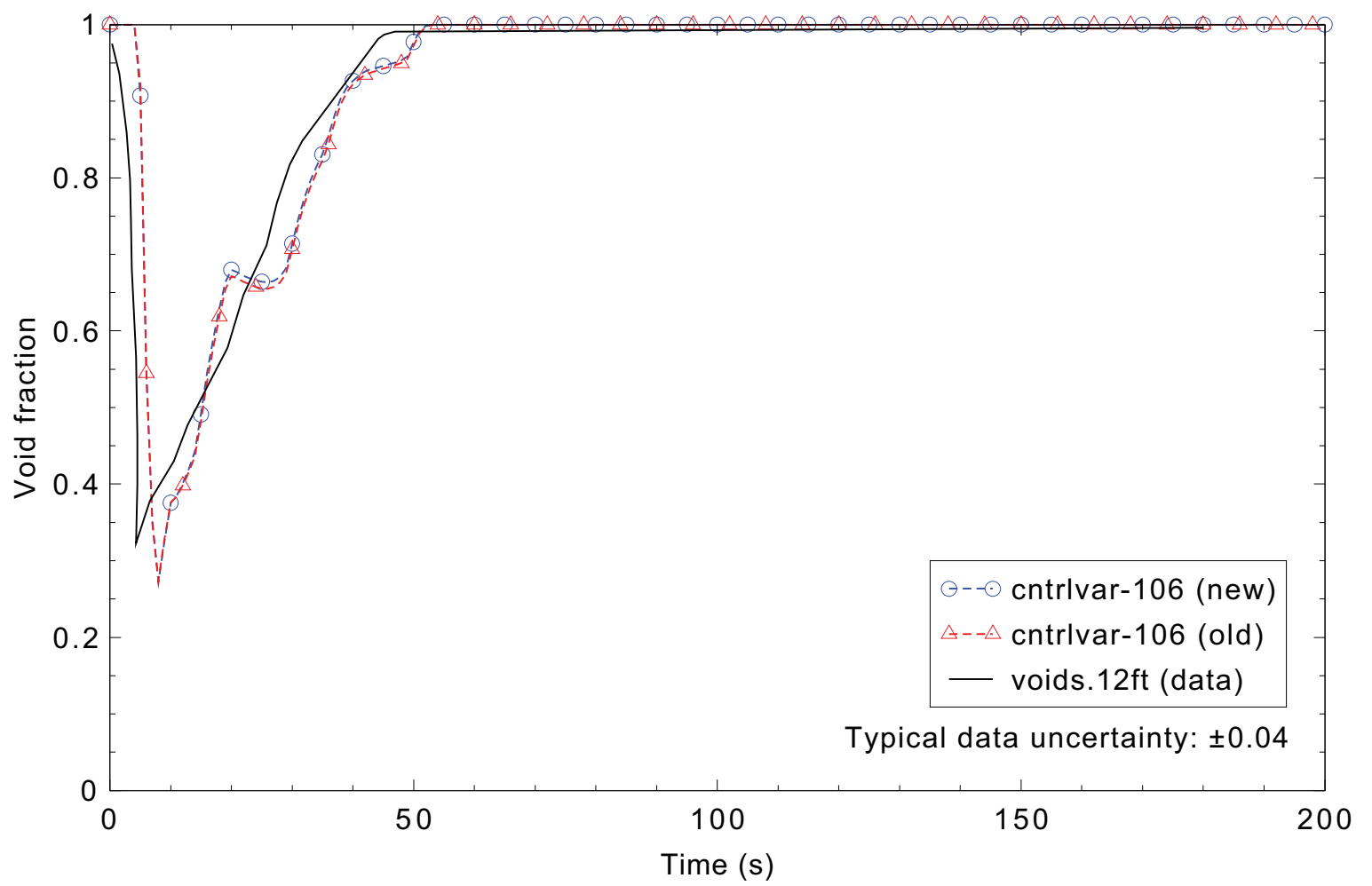

Figure 4.8-9. Measured and calculated void fraction at $12 \mathrm{ft}(3.7 \mathrm{~m})$ above the bottom of the vessel (level 6) for GE level swell Test 1004-3.

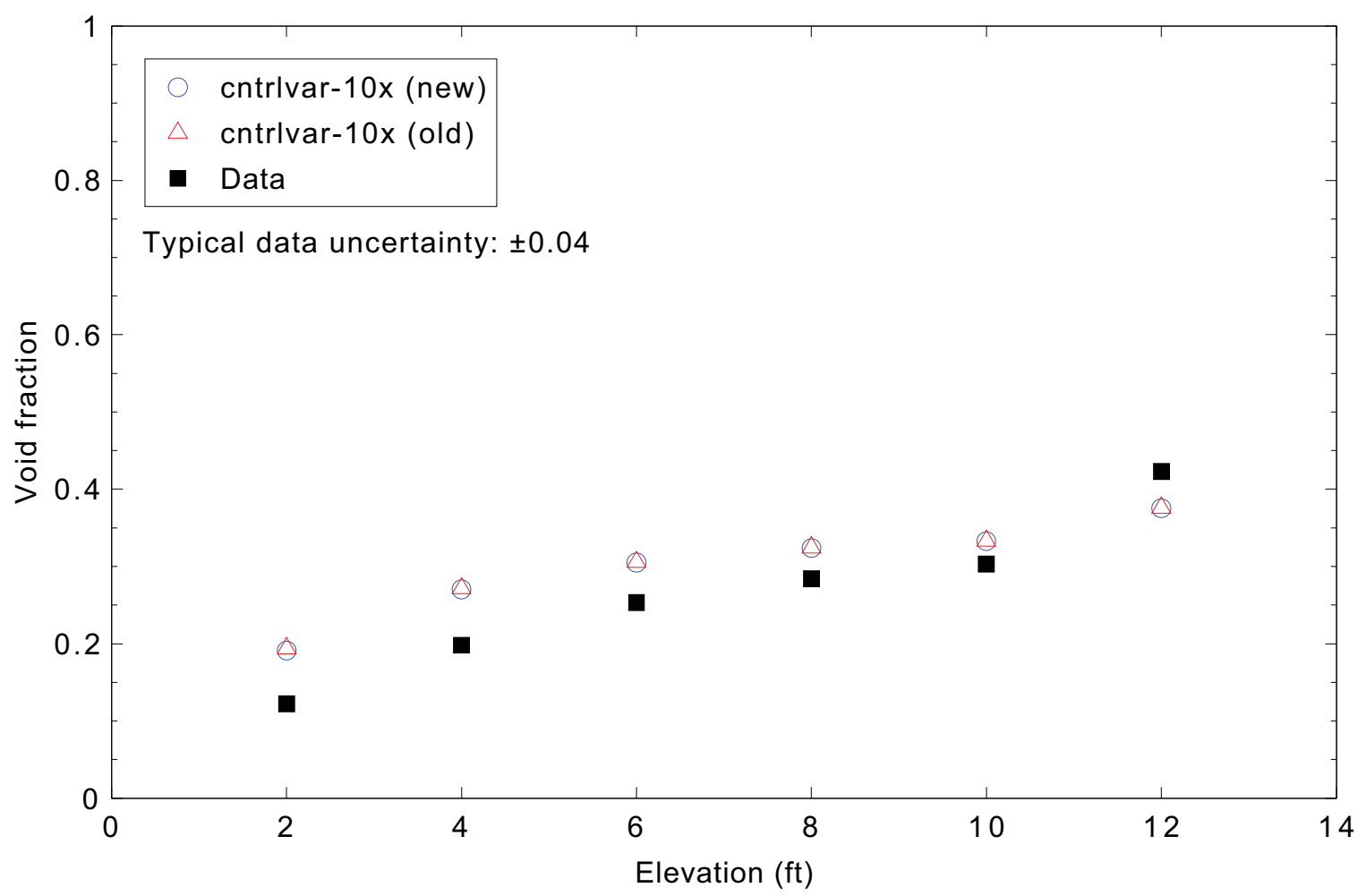

Figure 4.8-10. Measured and calculated void fraction profile in the vessel at $10 \mathrm{~s}$ for GE level swell Test 1004-3. 


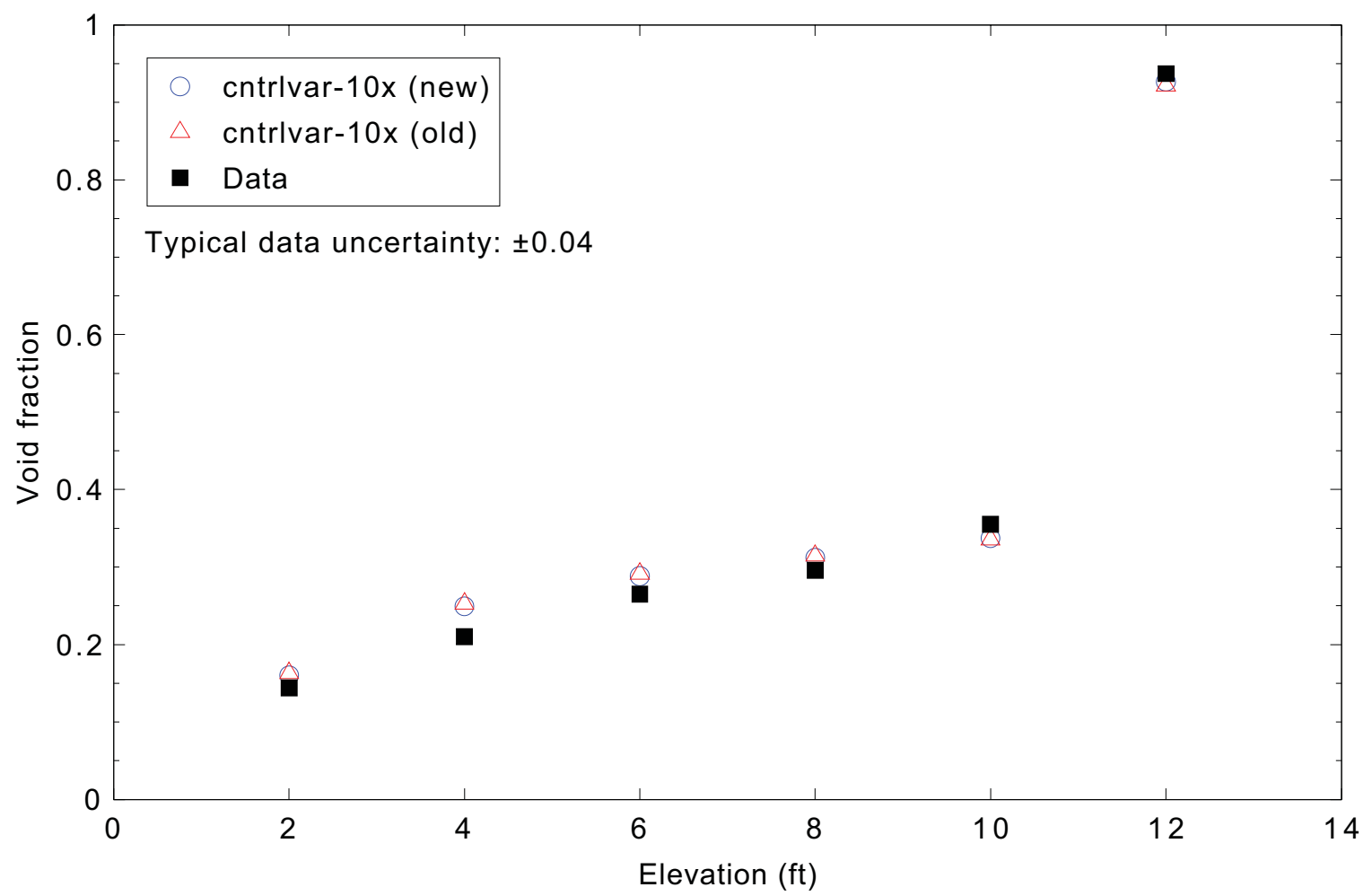

Figure 4.8-11. Measured and calculated void fraction profile in the vessel at $40 \mathrm{~s}$ for GE level swell Test 1004-3.

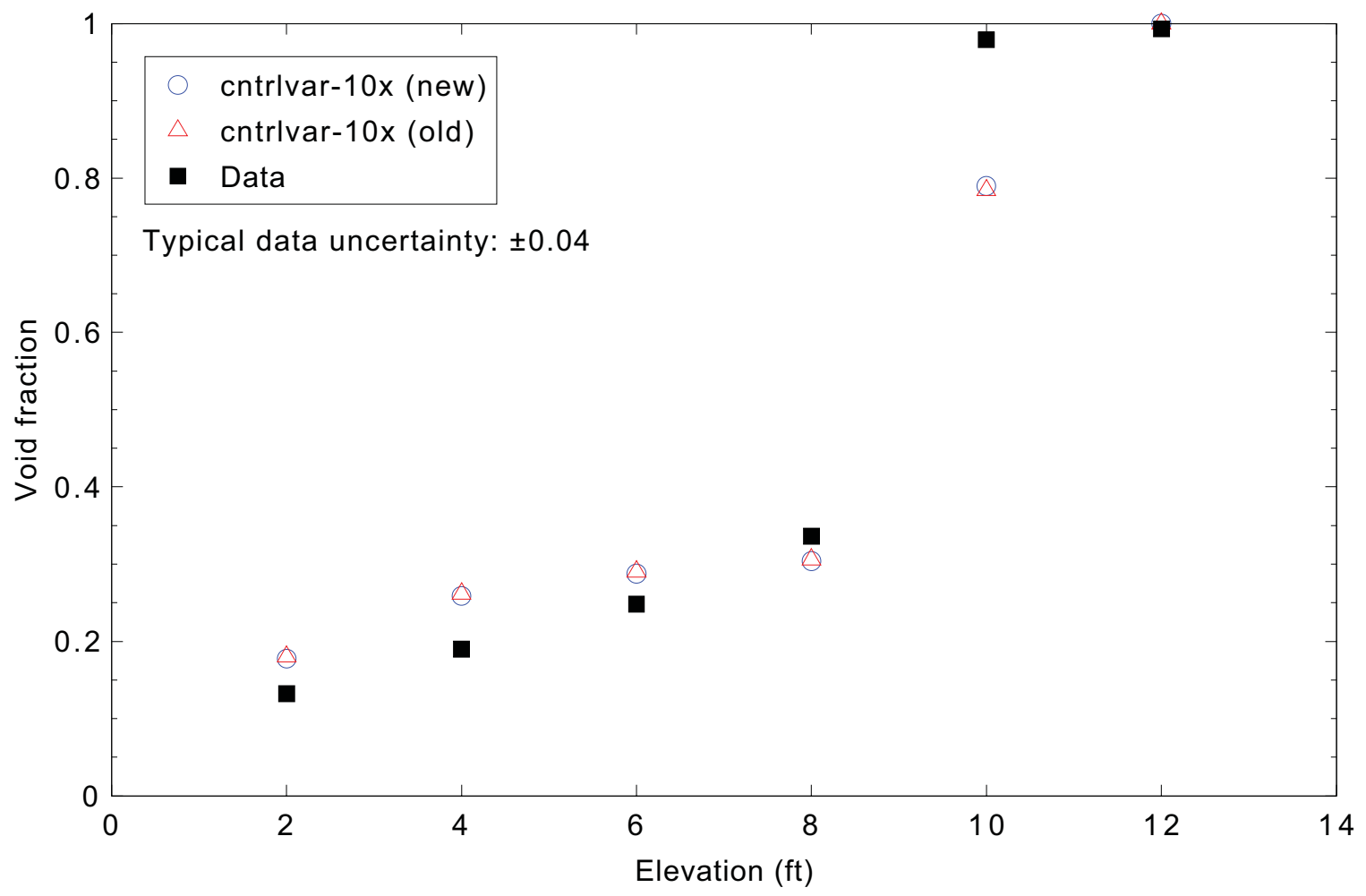

Figure 4.8-12. Measured and calculated void fraction profile in the vessel at $100 \mathrm{~s}$ for GE level swell Test 1004-3. 


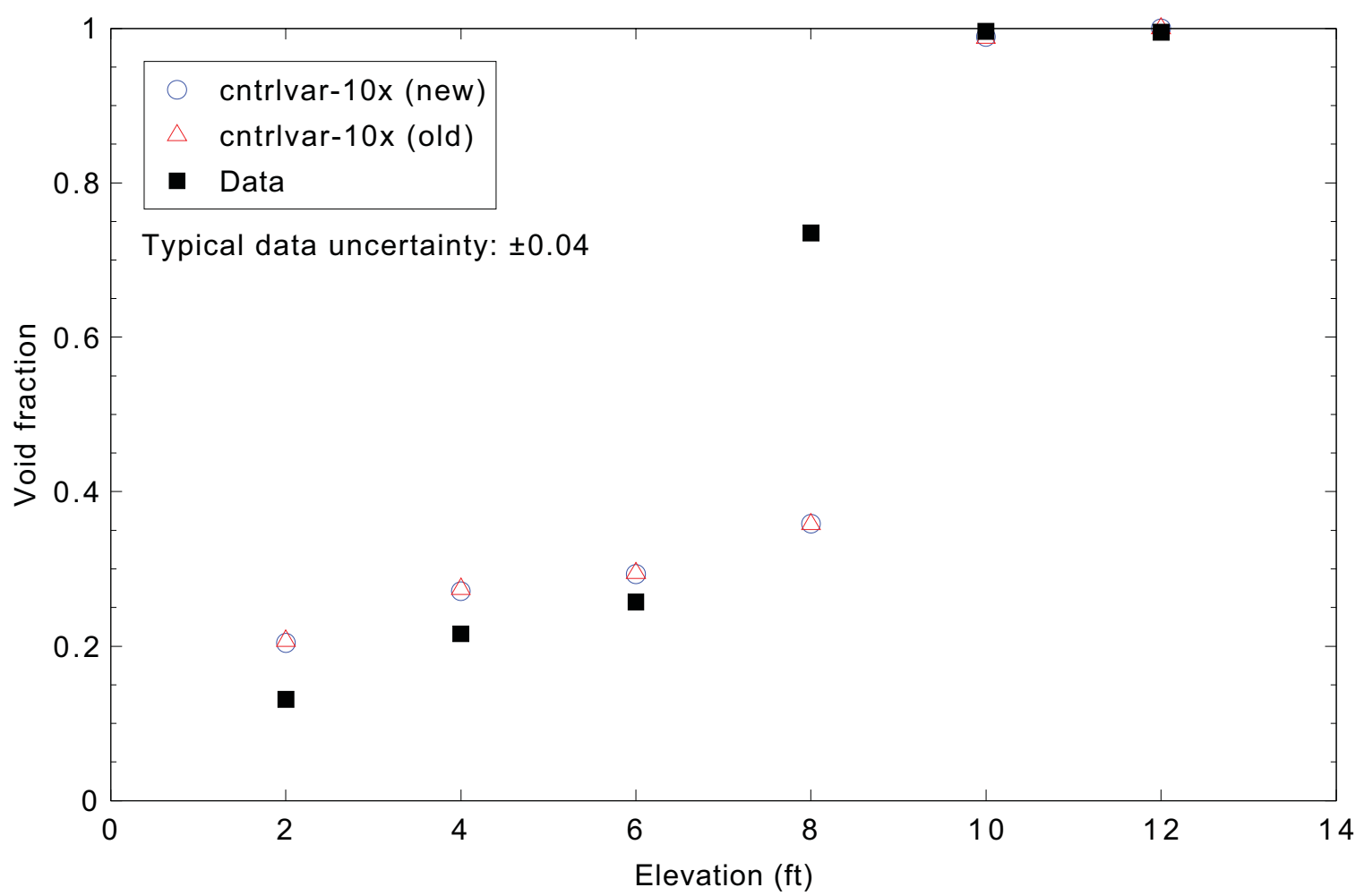

Figure 4.8-13. Measured and calculated void fraction profile in the vessel at $160 \mathrm{~s}$ for GE level swell Test 1004-3.

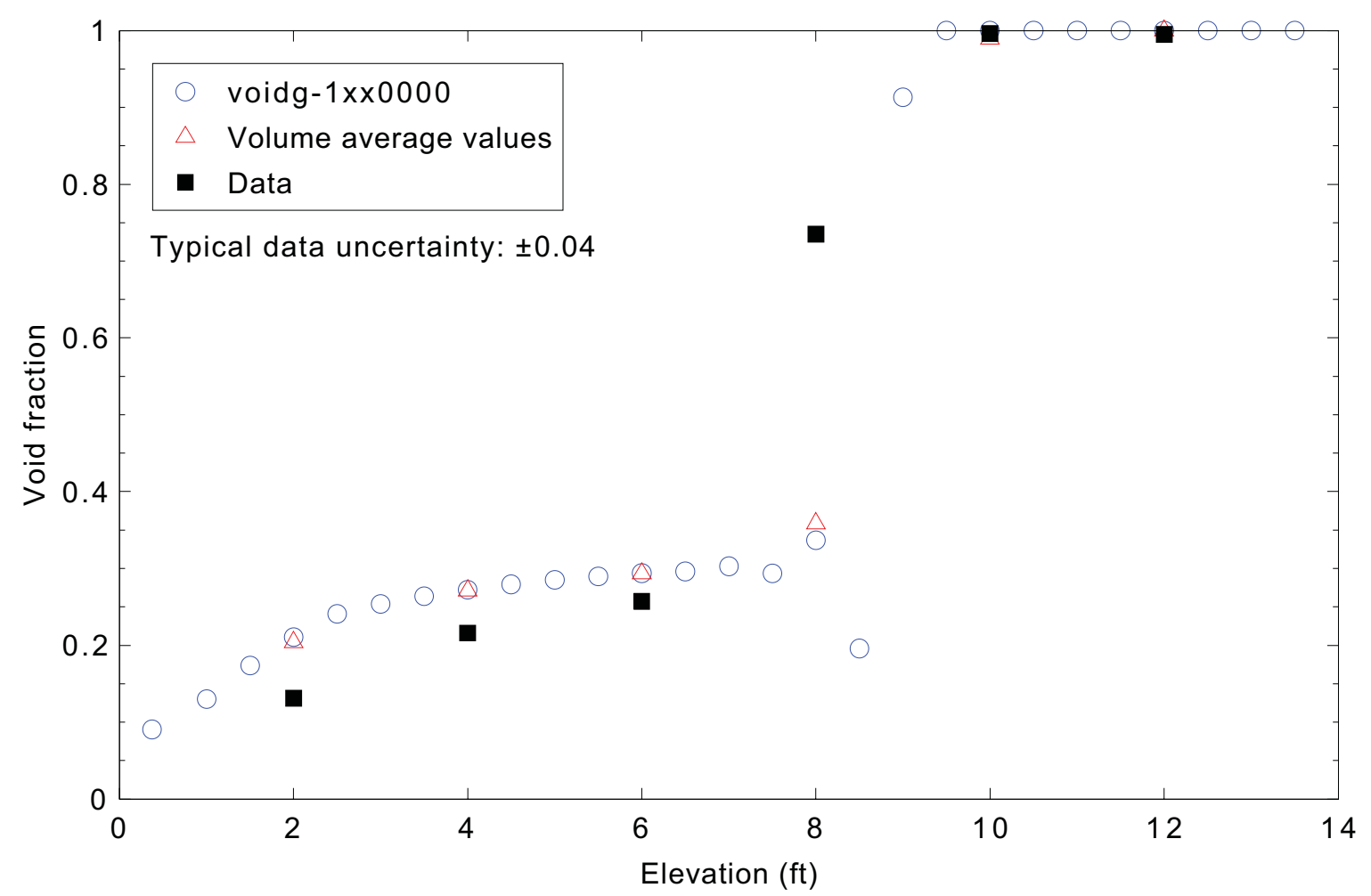

Figure 4.8-14. Volume and volume-average void fractions at $160 \mathrm{~s}$ for GE level swell Test 1004-3 (semi-implicit calculations). 


\subsection{GE Level Swell - $4 \mathrm{ft}$ - Test 5801-15}

Figures comparing simulations using two code versions are presented. Diagrams are included so that the figure numbering is the same as that in Volume III of the RELAP5-3D code manual. Noticeable differences were observed in Figures 4.9-4, 5, 6, and 7.

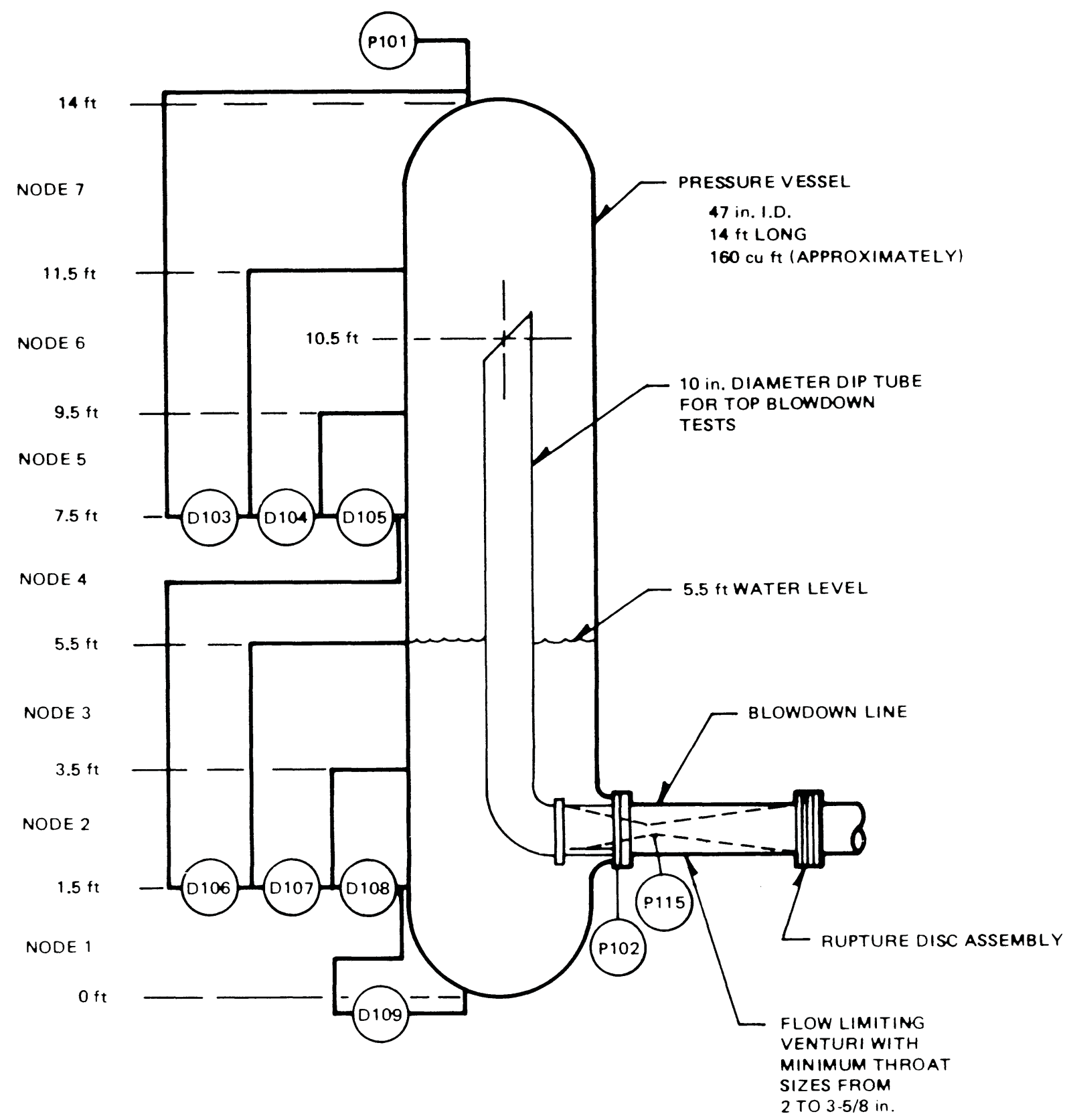

Figure 4.9-1. GE Large Blowdown Vessel schematic diagram. 


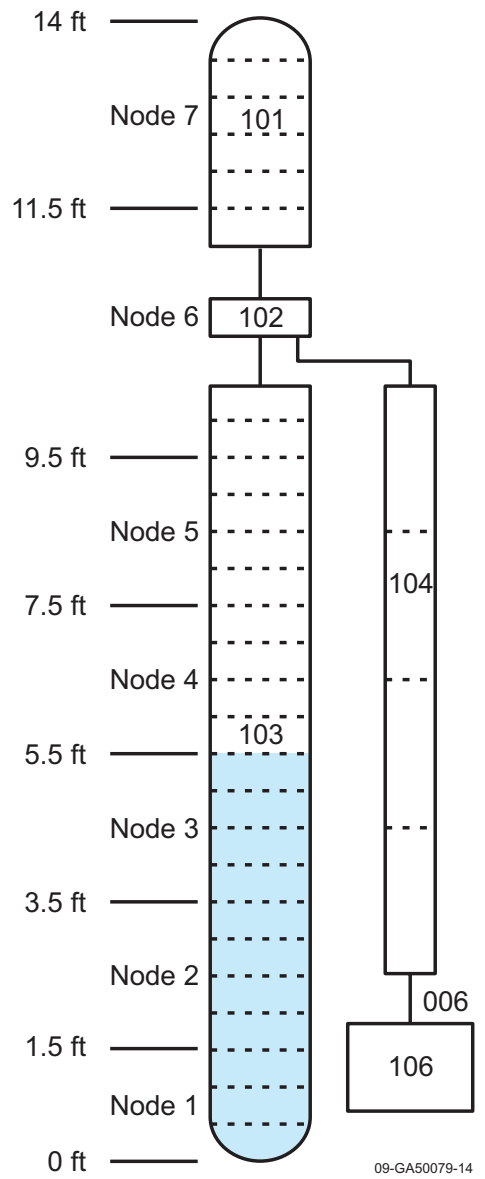

Figure 4.9-2. Nodalization diagram for GE Large Blowdown Vessel test 5801-15. 


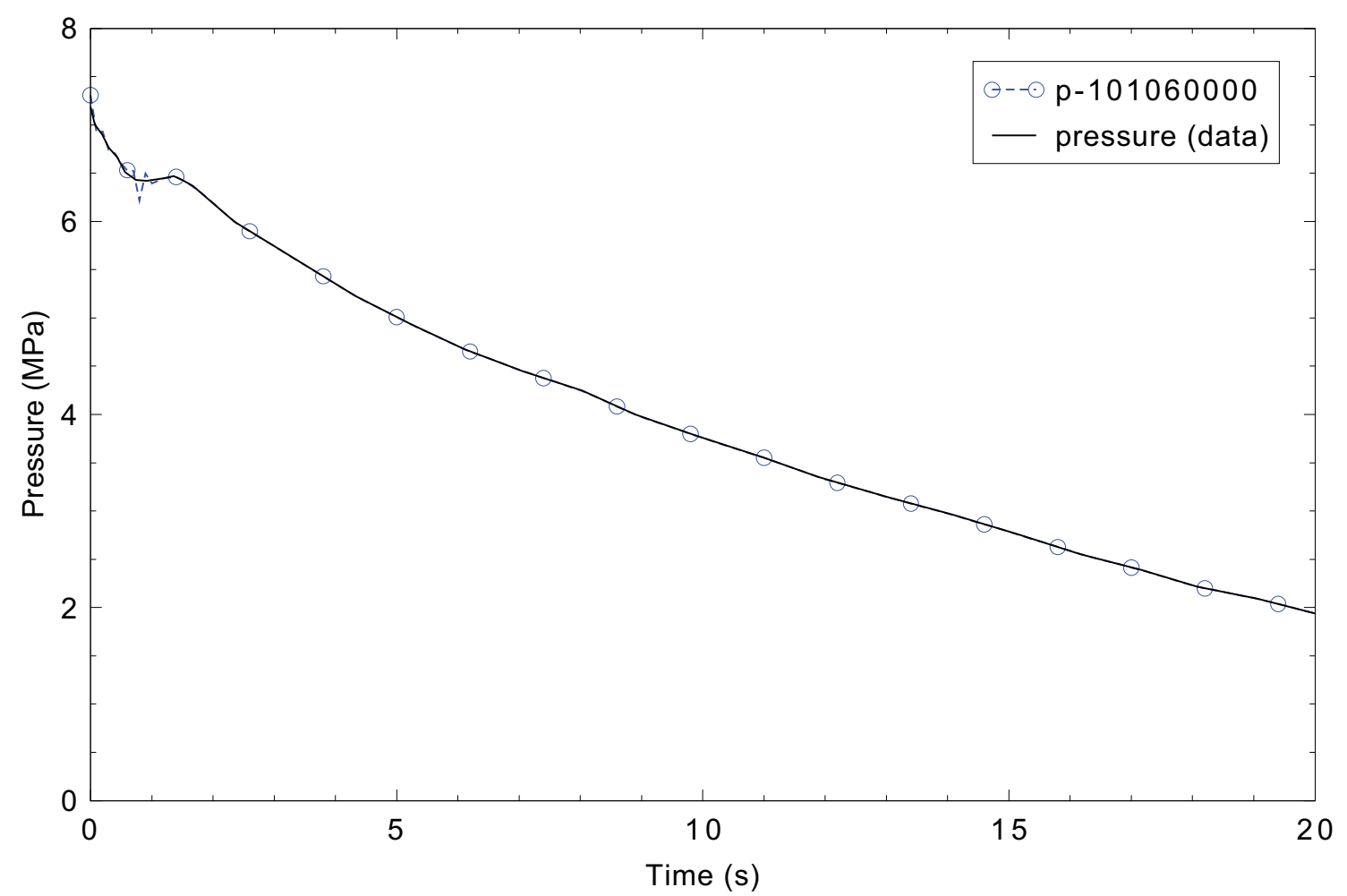

Figure 4.9-3. Comparison of experiment data with the pressure imposed by time-dependent volume 106.

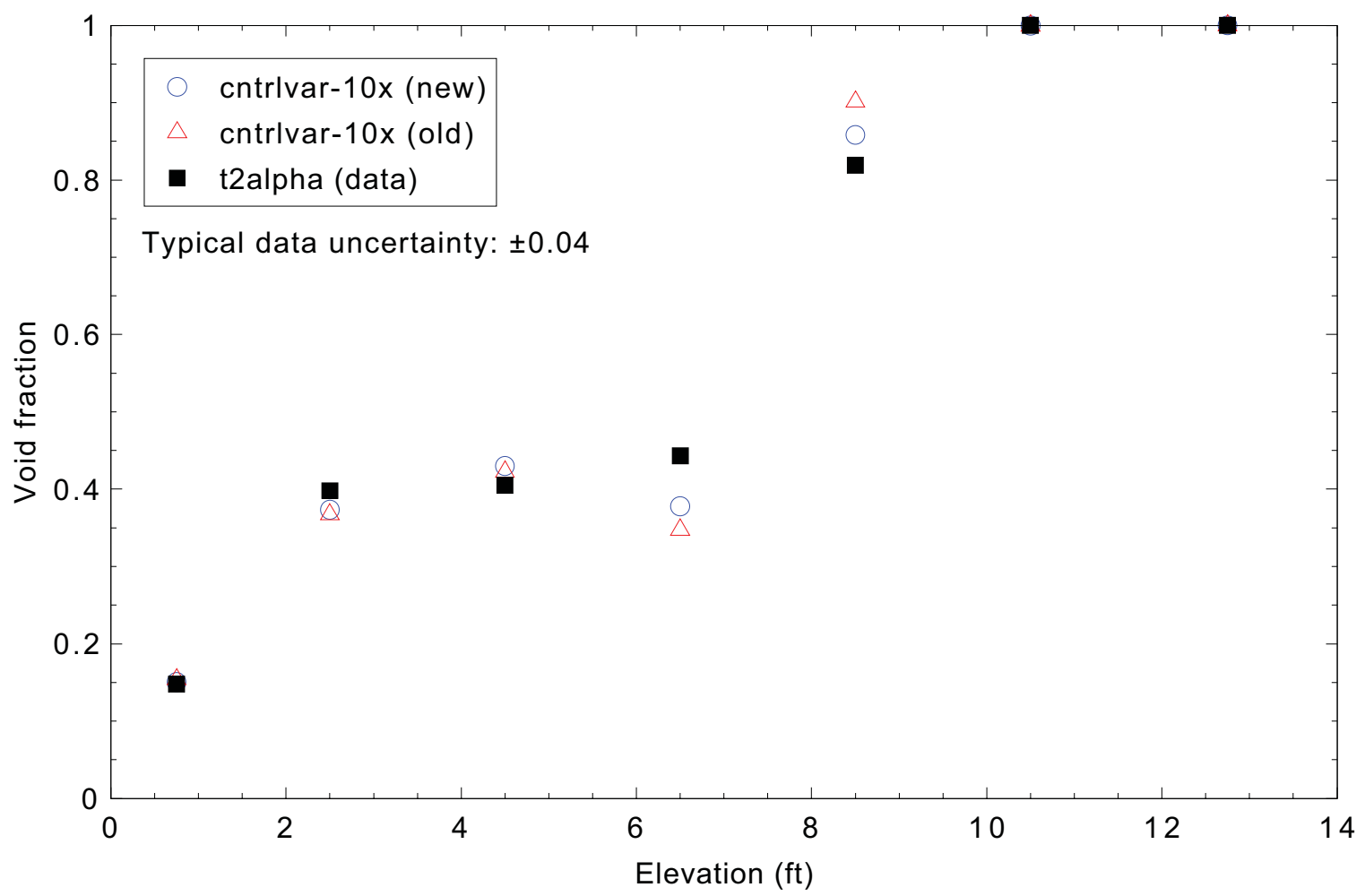

Figure 4.9-4. Measured and calculated void fraction profile in the vessel at $2 \mathrm{~s}$ for GE level swell Test 5801-15. 


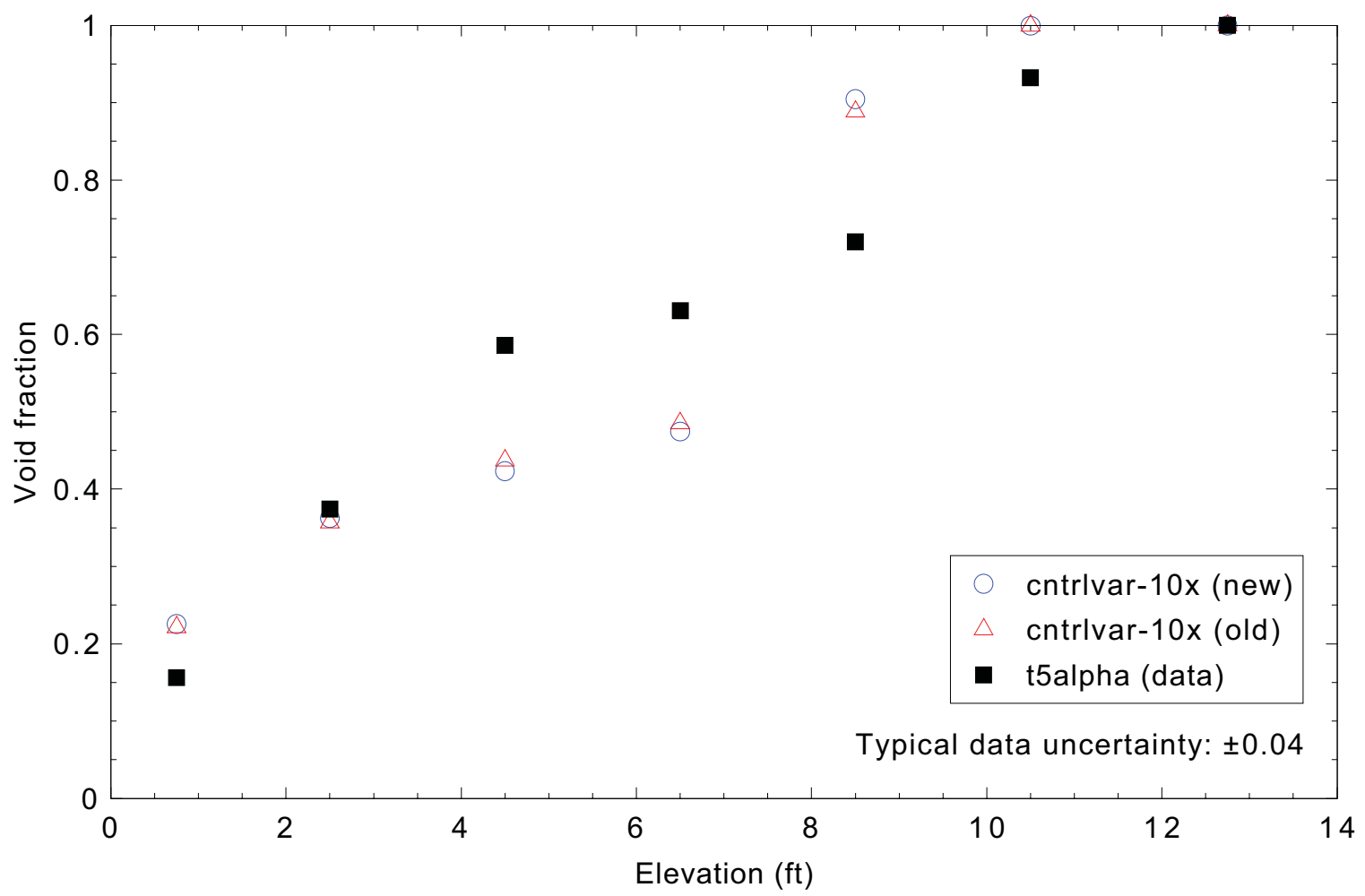

Figure 4.9-5. Measured and calculated void fraction profile in the vessel at $5 \mathrm{~s}$ for GE level swell Test 5801-15.

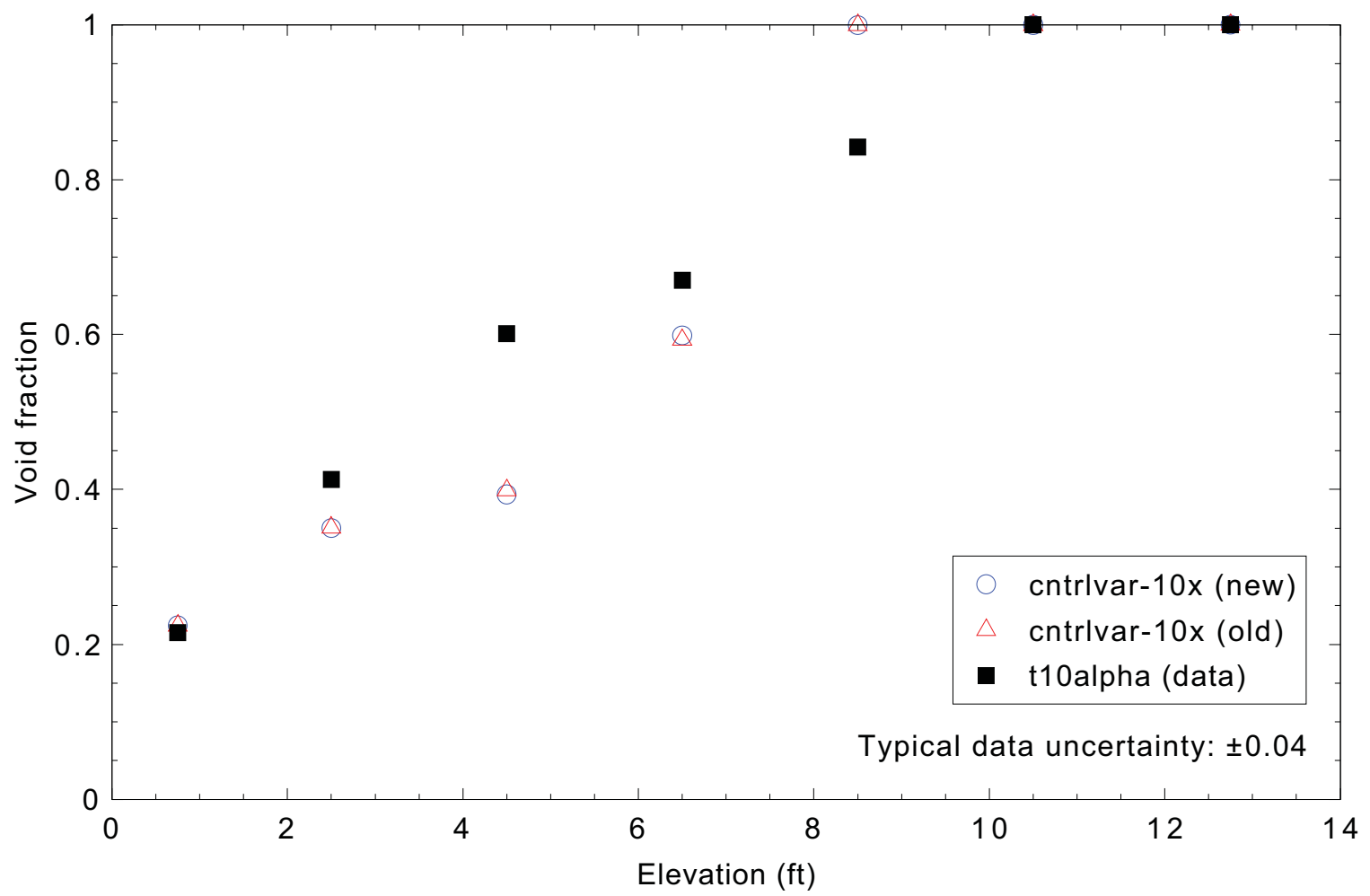

Figure 4.9-6. Measured and calculated void fraction profile in the vessel at $10 \mathrm{~s}$ for GE level swell Test 5801-15. 


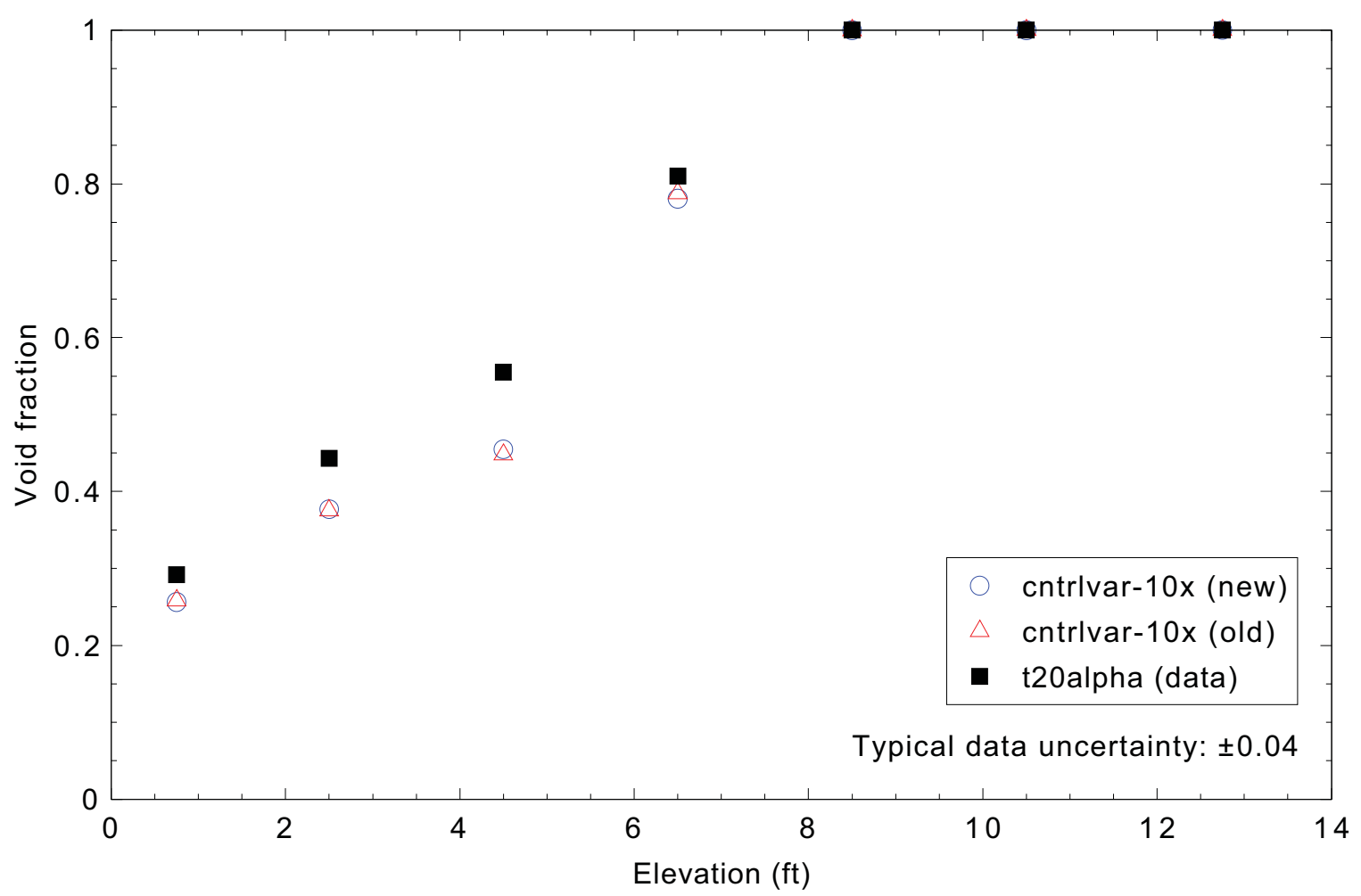

Figure 4.9-7. Measured and calculated void fraction profile in the vessel at $20 \mathrm{~s}$ for GE level swell Test 5801-15.

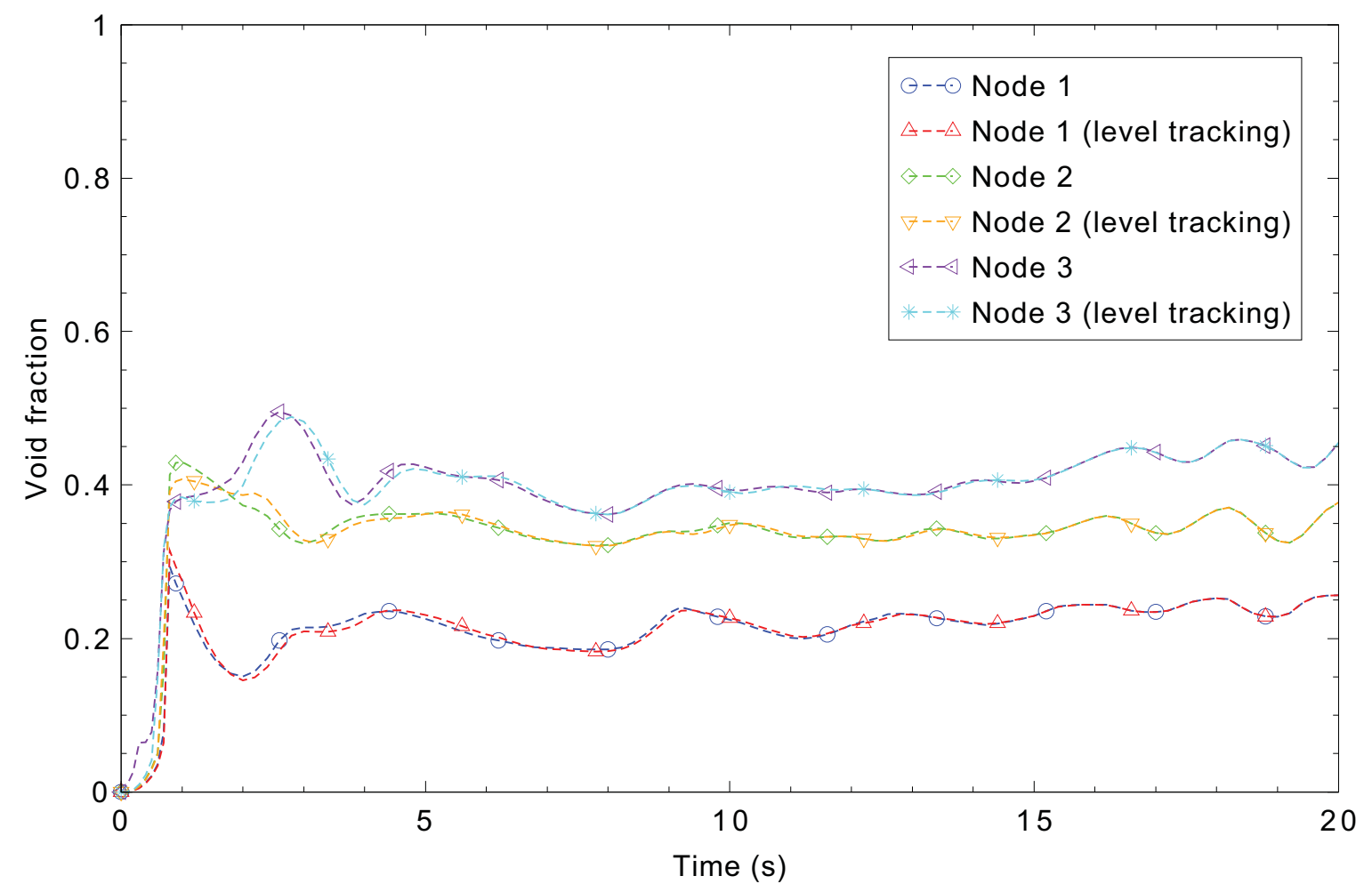

Figure 4.9-8. Effect of level tracking model on calculated void fractions for levels 1-3 using the semi-implicit solution scheme. 


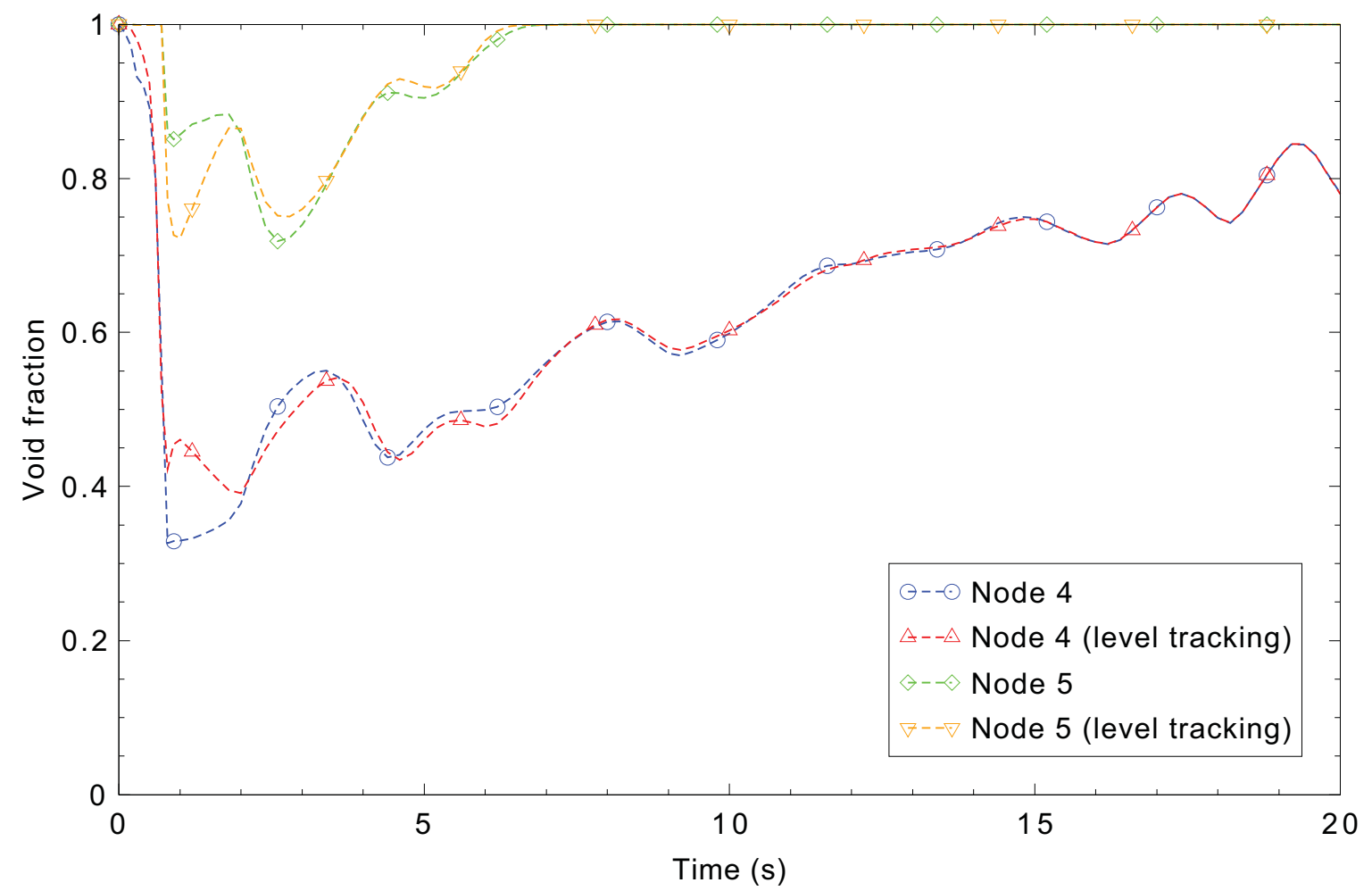

Figure 4.9-9. Effect of level tracking model on calculated void fractions for levels 4 and 5 using the semi-implicit solution scheme.

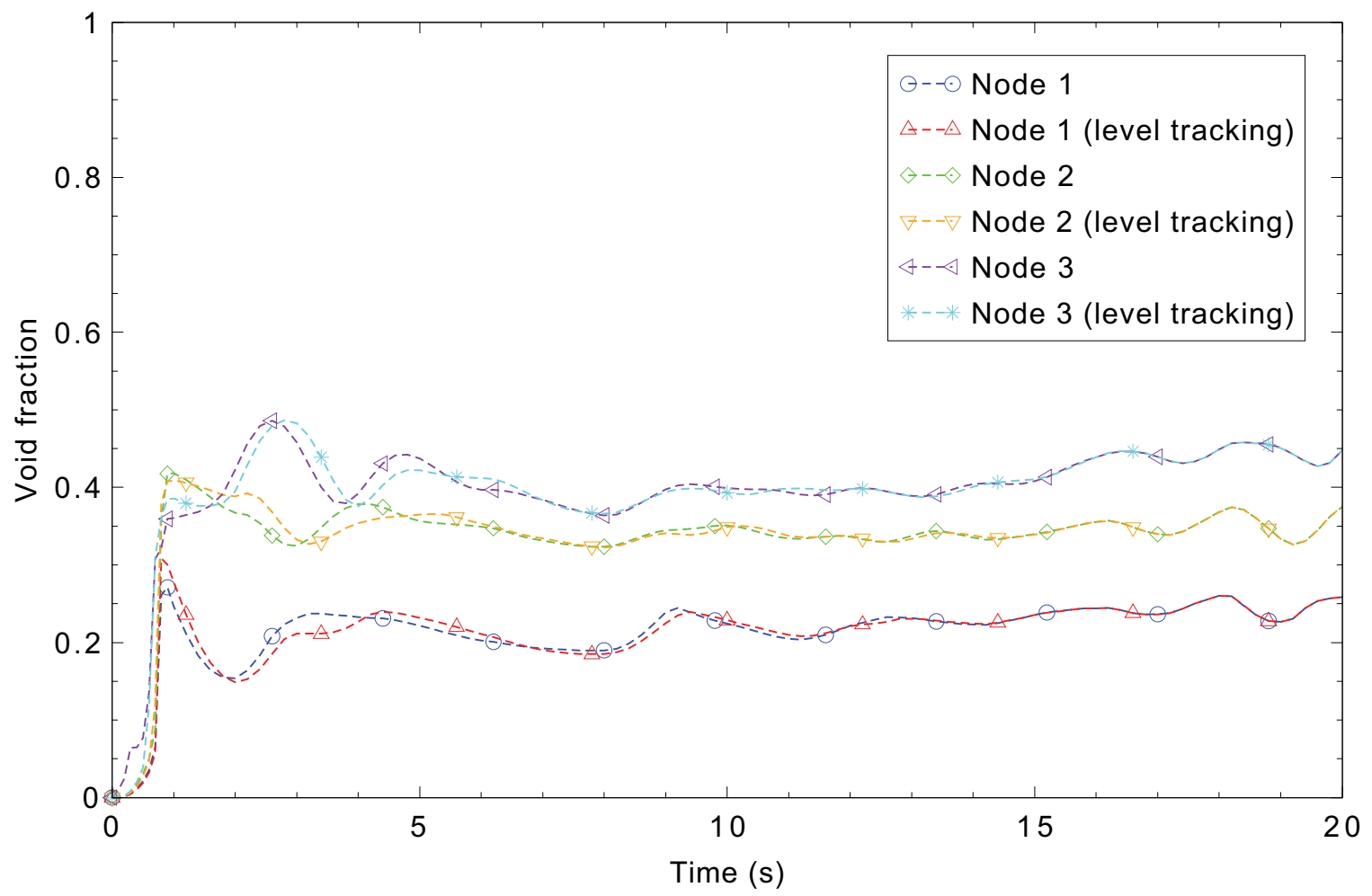

Figure 4.9-10. Effect of level tracking model on calculated void fractions for levels 1-3 using the nearly-implicit solution scheme. 


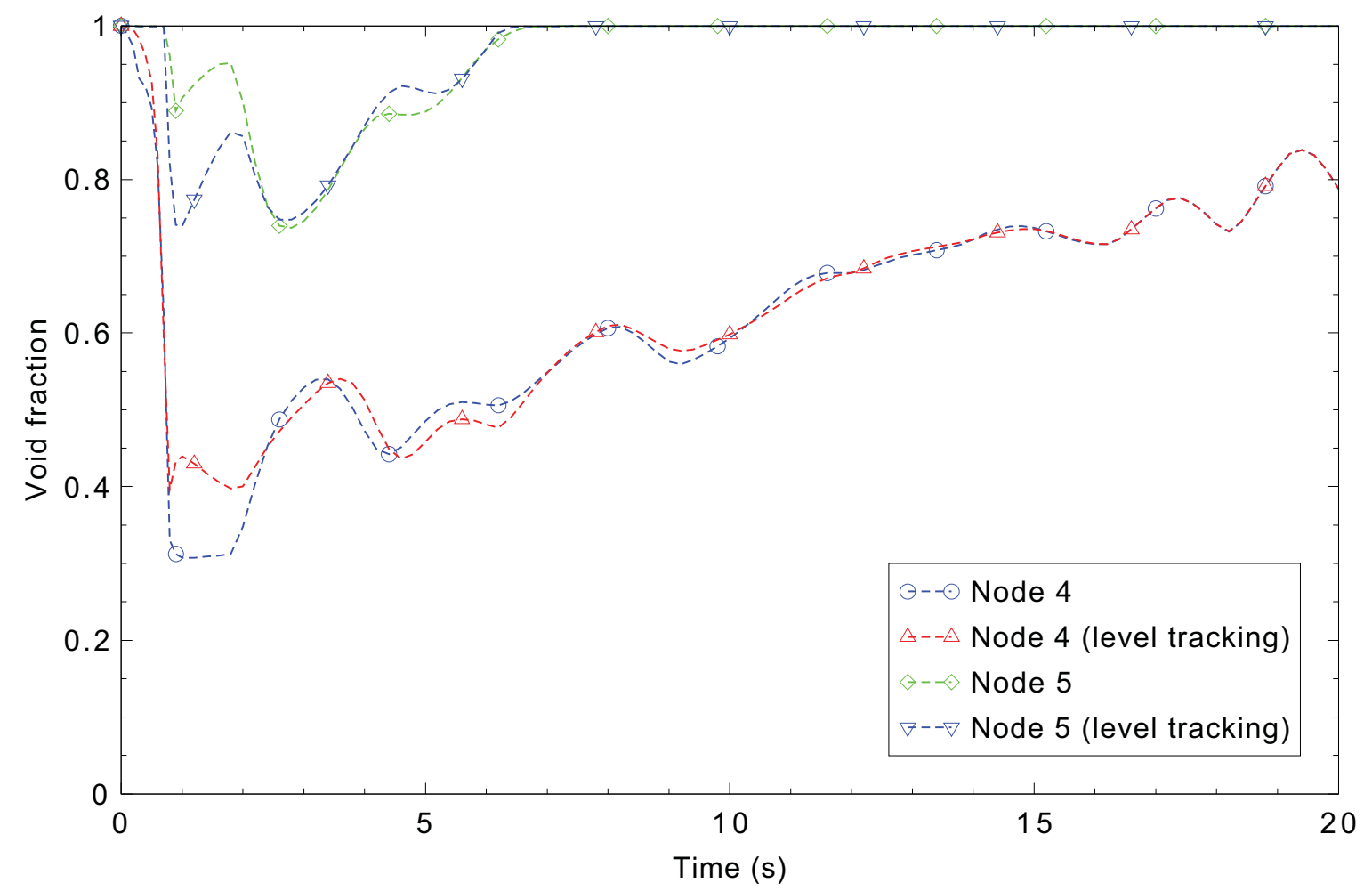

Figure 4.9-11. Effect of level tracking model on calculated void fractions for levels 4 and 5 using the nearly-implicit solution scheme. 


\subsection{Bennett Heated Tube Tests 5358, 5294, and 5394}

Figures comparing simulations using two code versions are presented. Diagrams are included so that the figure numbering is the same as that in Volume III of the RELAP5-3D code manual.A noticeable difference was observed in Figure 4.10-2.

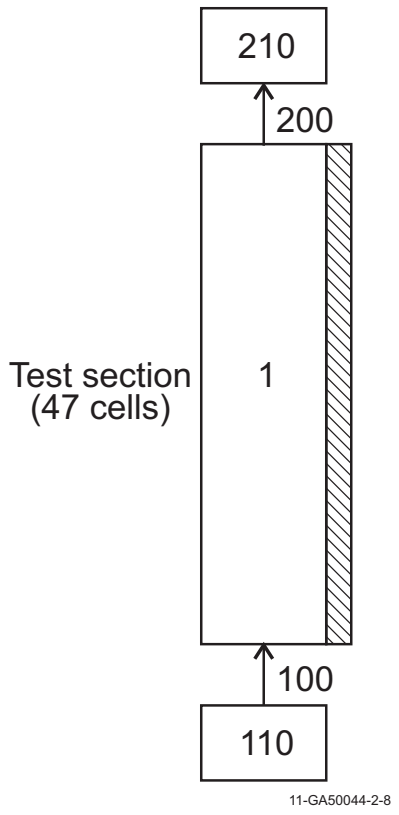

Figure 4.10-1. Nodalization diagram for the Bennett test facility. 


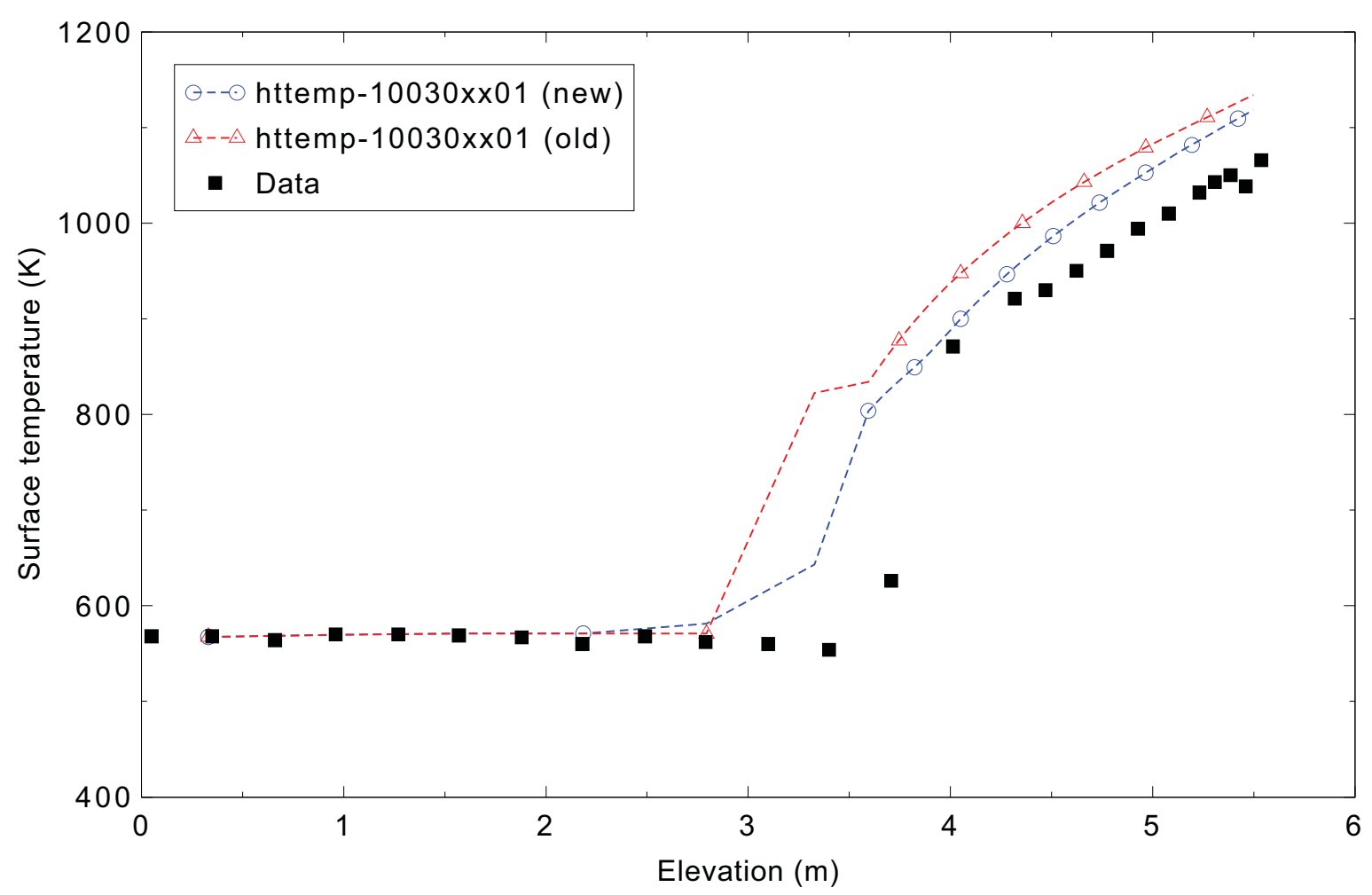

Figure 4.10-2. Measured and calculated axial wall temperatures for Bennett heated tube low mass flux Test 5358.

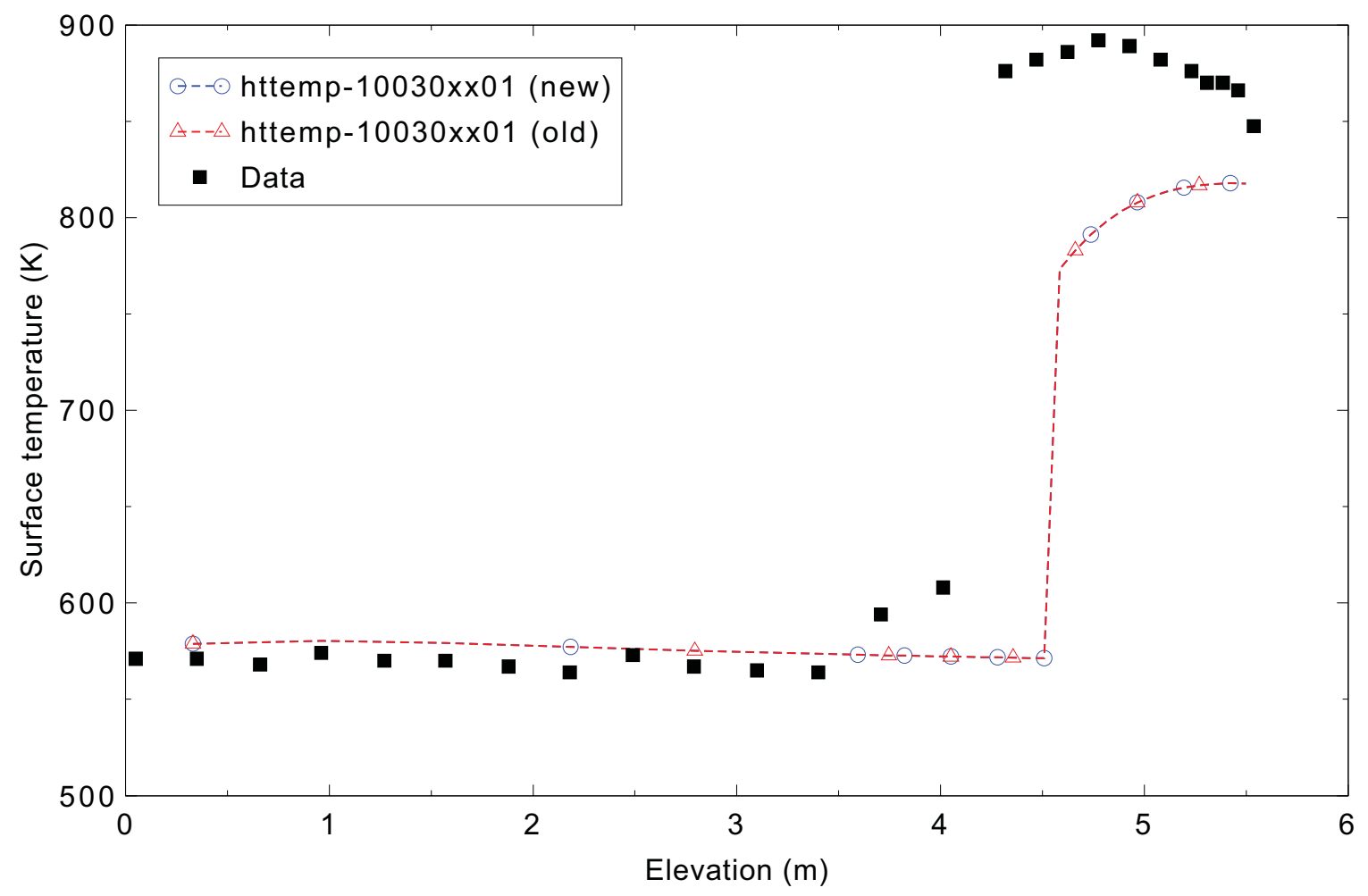

Figure 4.10-3. Measured and calculated axial wall temperatures for Bennett heated tube intermediate mass flux Test 5294 . 


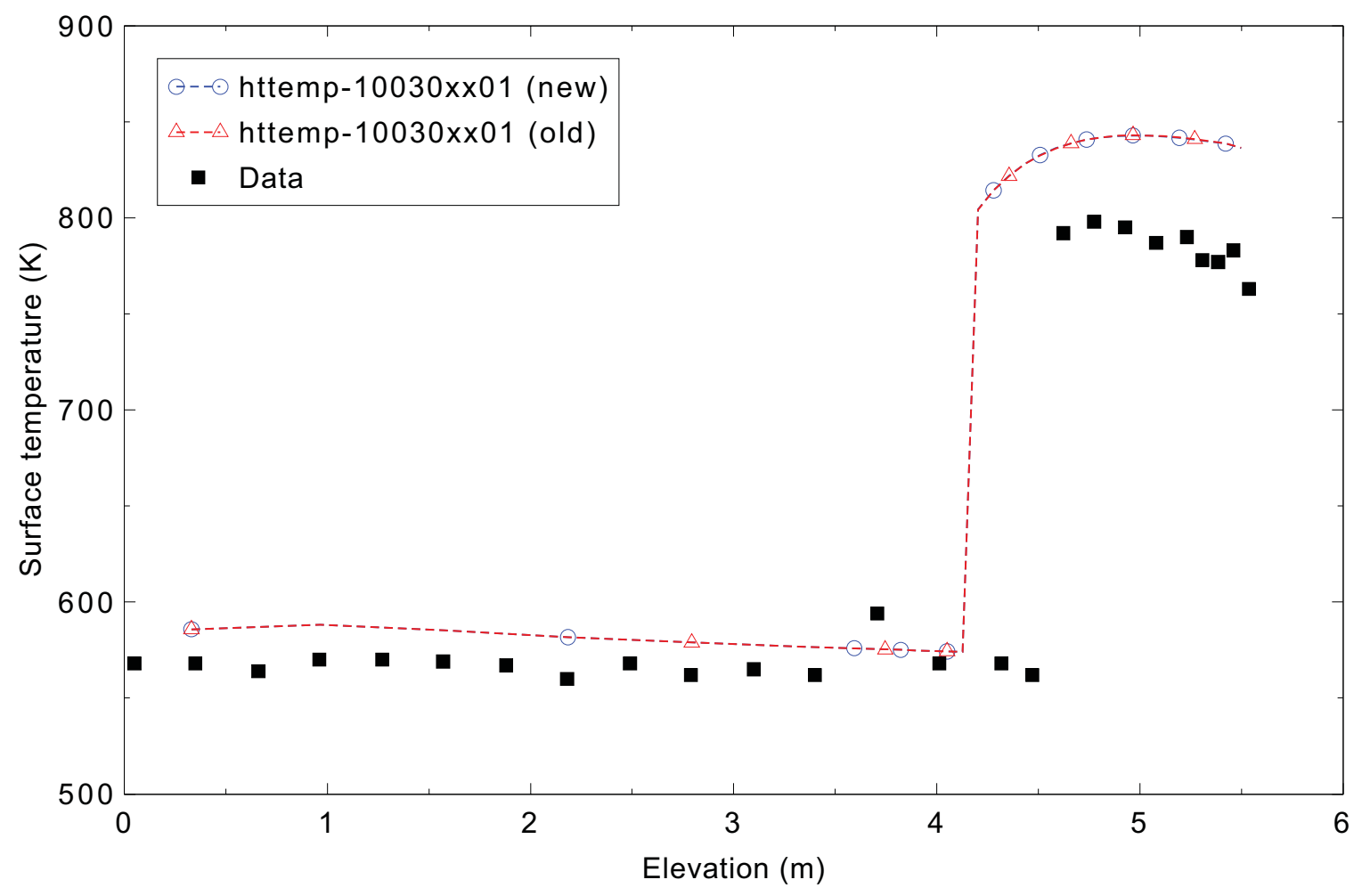

Figure 4.10-4. Measured and calculated axial wall temperatures for Bennett heated tube high mass flux Test 5394. 


\subsection{ORNL THTF Tests 3.07.9B, 3.07.9N, 3.07.9W and 3.09.10I}

Figures comparing simulations using two code versions are presented. Diagrams are included so that the figure numbering is the same as that in Volume III of the RELAP5-3D code manual. Noticeable differences were observed in Figures 4.11-4, 7, and 9.

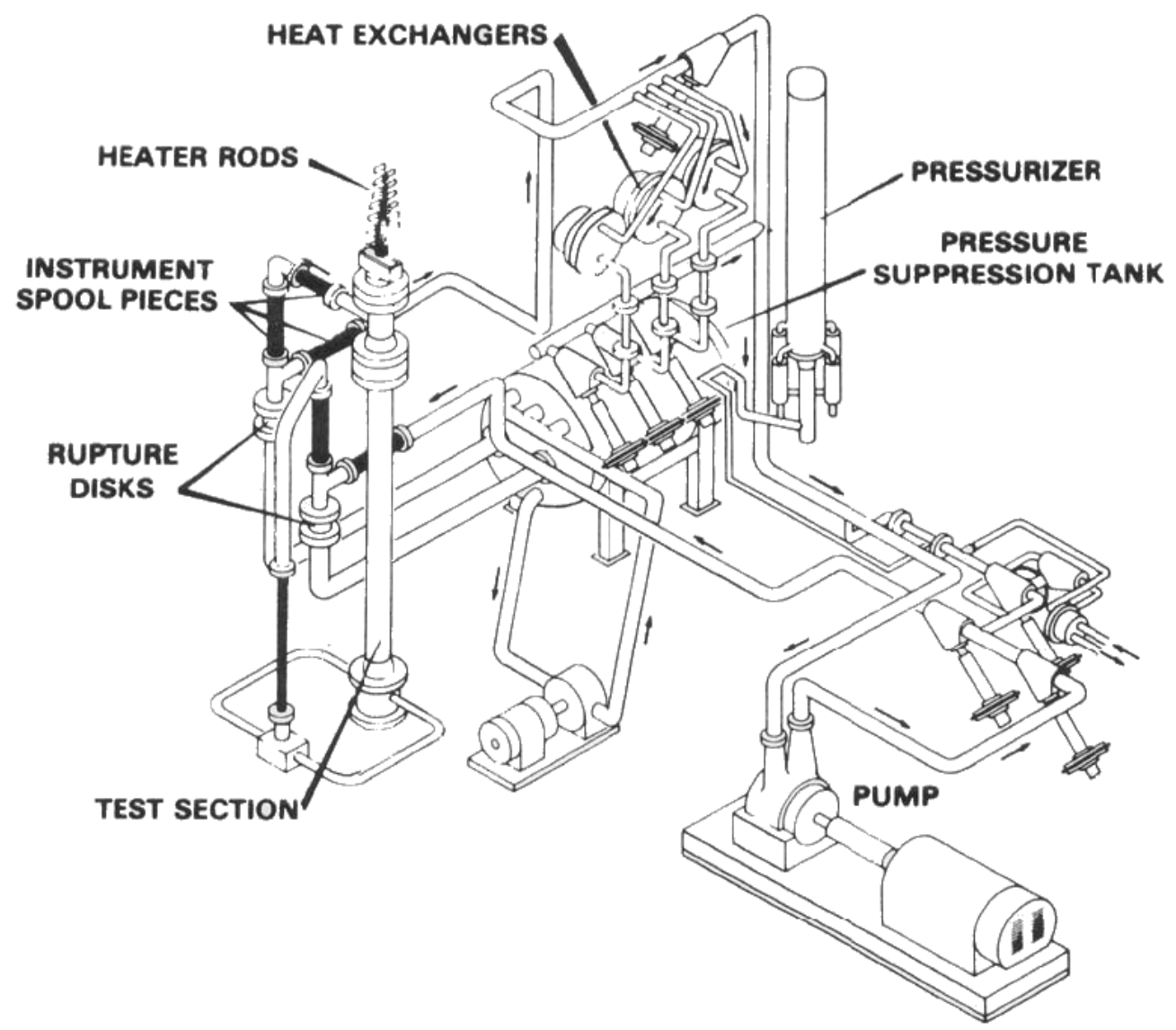

Figure 4.11-1. Experiment setup of the ORNL Thermal Hydraulic Test Facility (THTF) steady state film boiling tests. 
RELAP5-3D/4.0.3

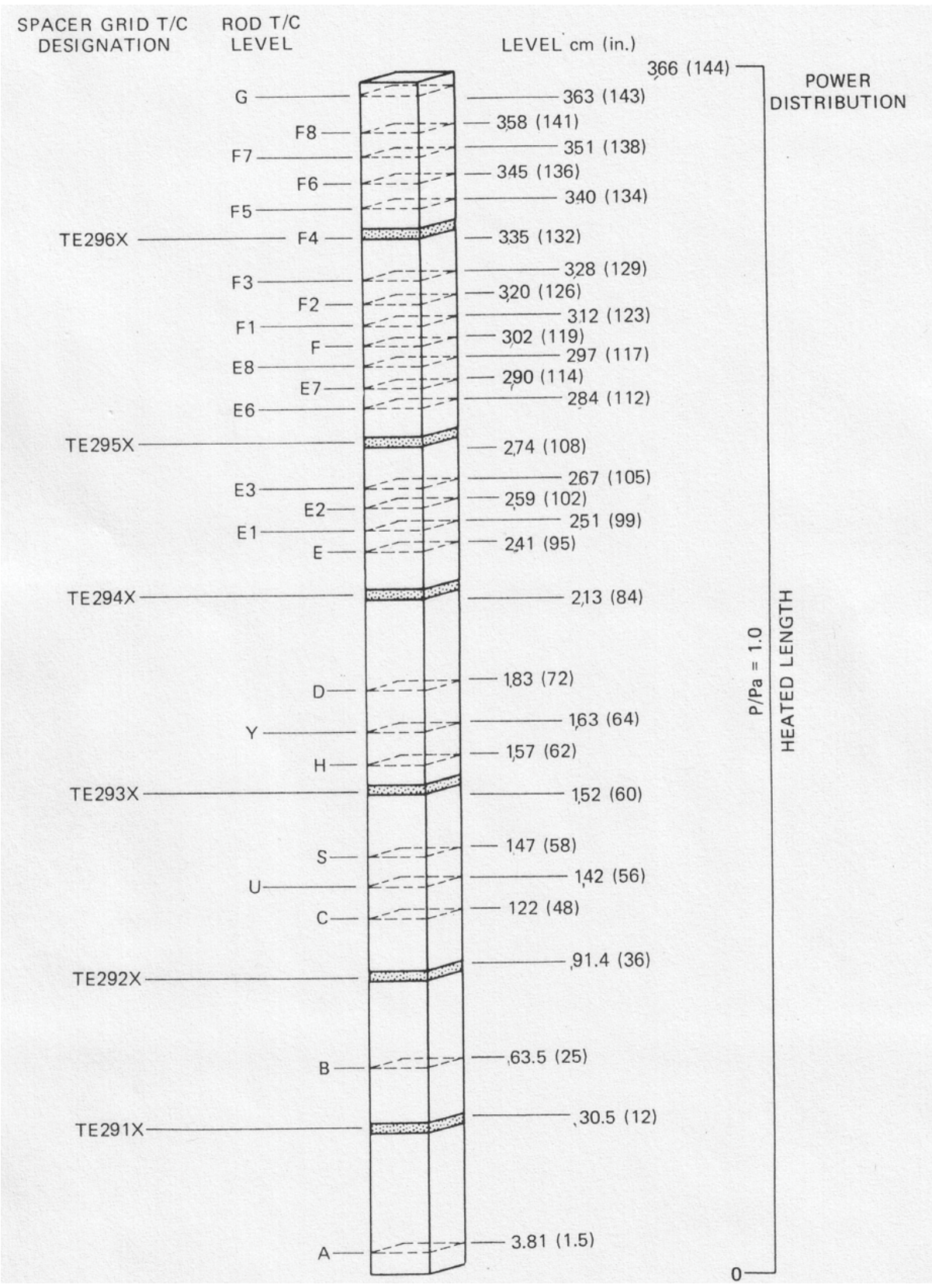

Figure 4.11-2. Test section of the ORNL Thermal Hydraulic Test Facility. 
RELAP5-3D/4.0.3

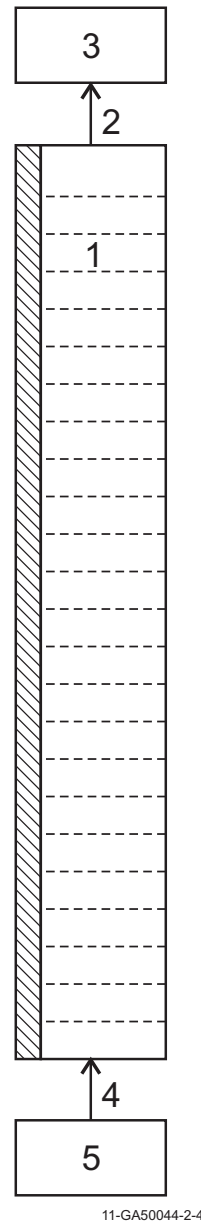

Figure 4.11-3. Nodalization diagram for the ORNL THTF steady state experiments. 


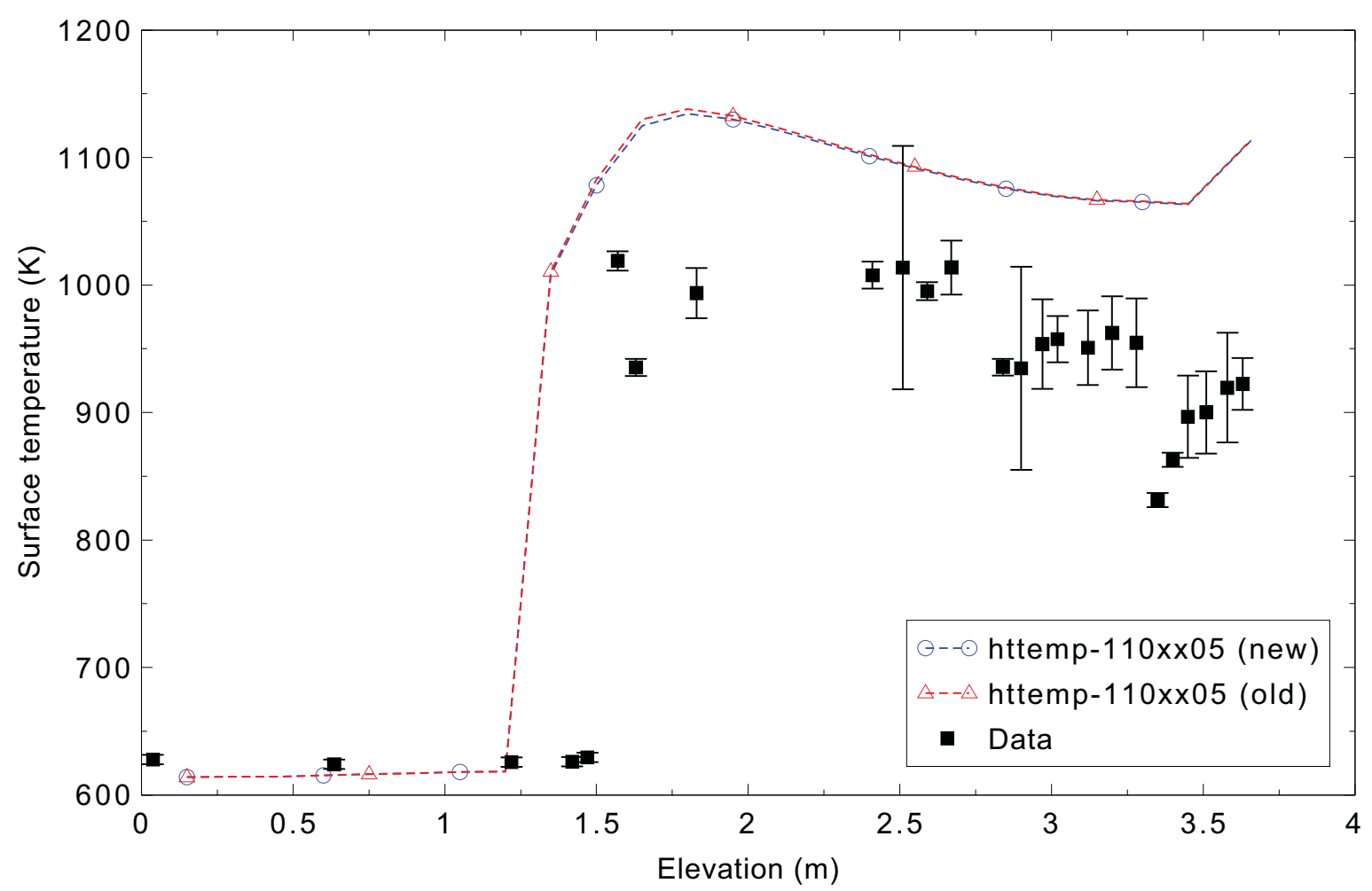

Figure 4.11-4. Measured and calculated steady state rod surface temperatures for ORNL THTF Test 3.07.9B.

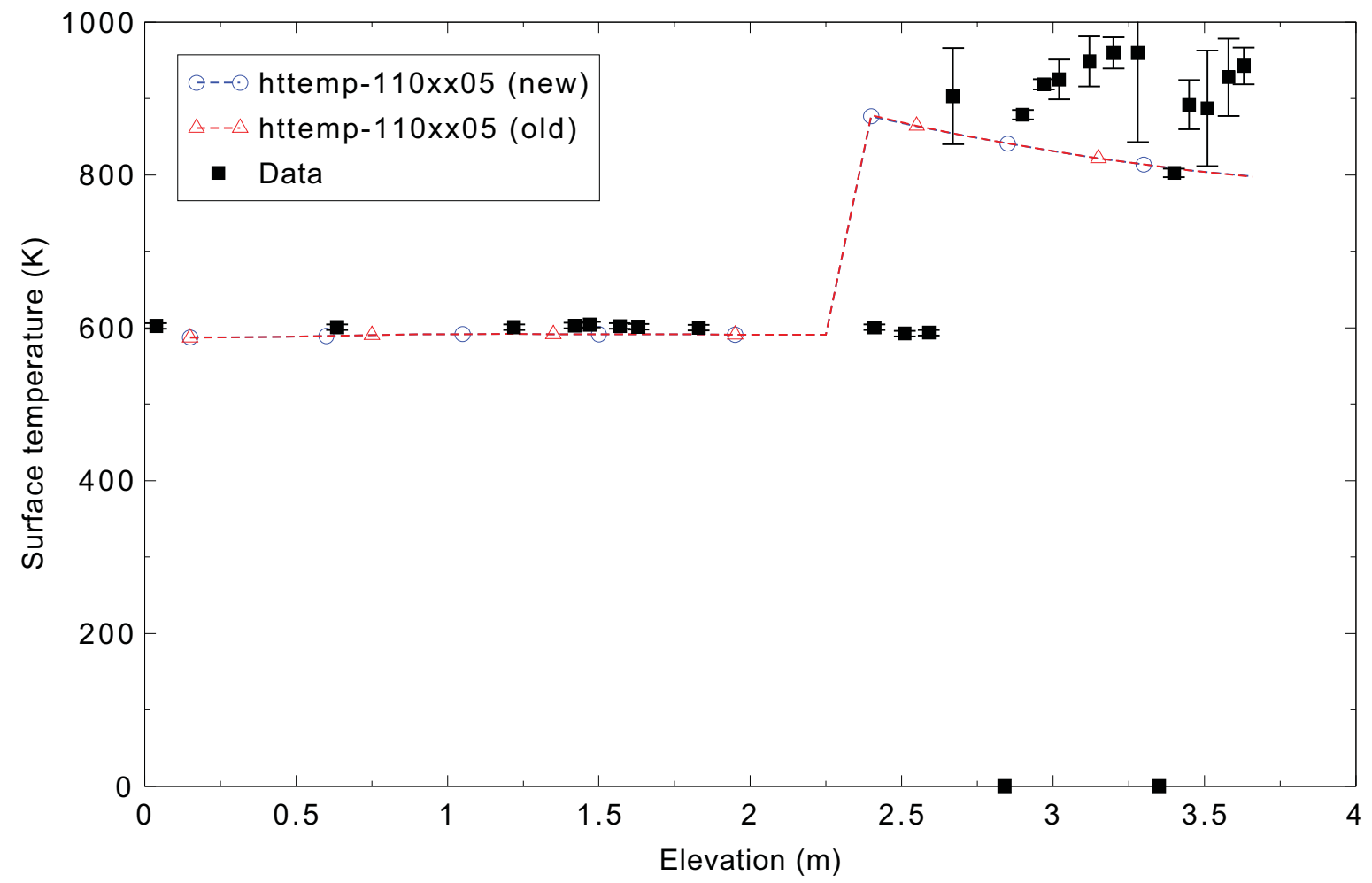

Figure 4.11-5. Measured and calculated steady state rod surface temperatures for ORNL THTF Test $3.07 .9 \mathrm{~N}$. 


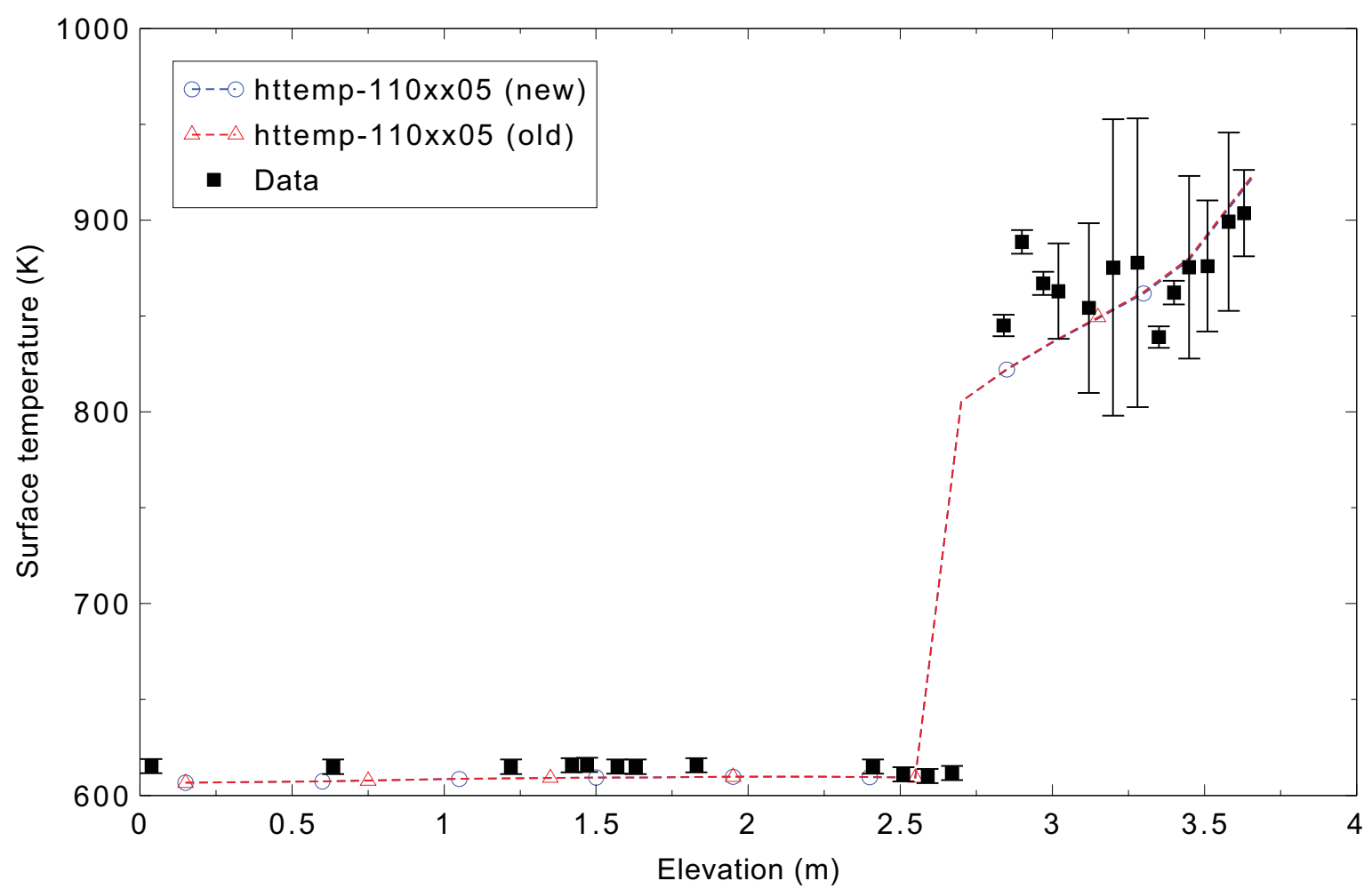

Figure 4.11-6. Measured and calculated steady state rod surface temperatures for ORNL THTF Test 3.07.9W.

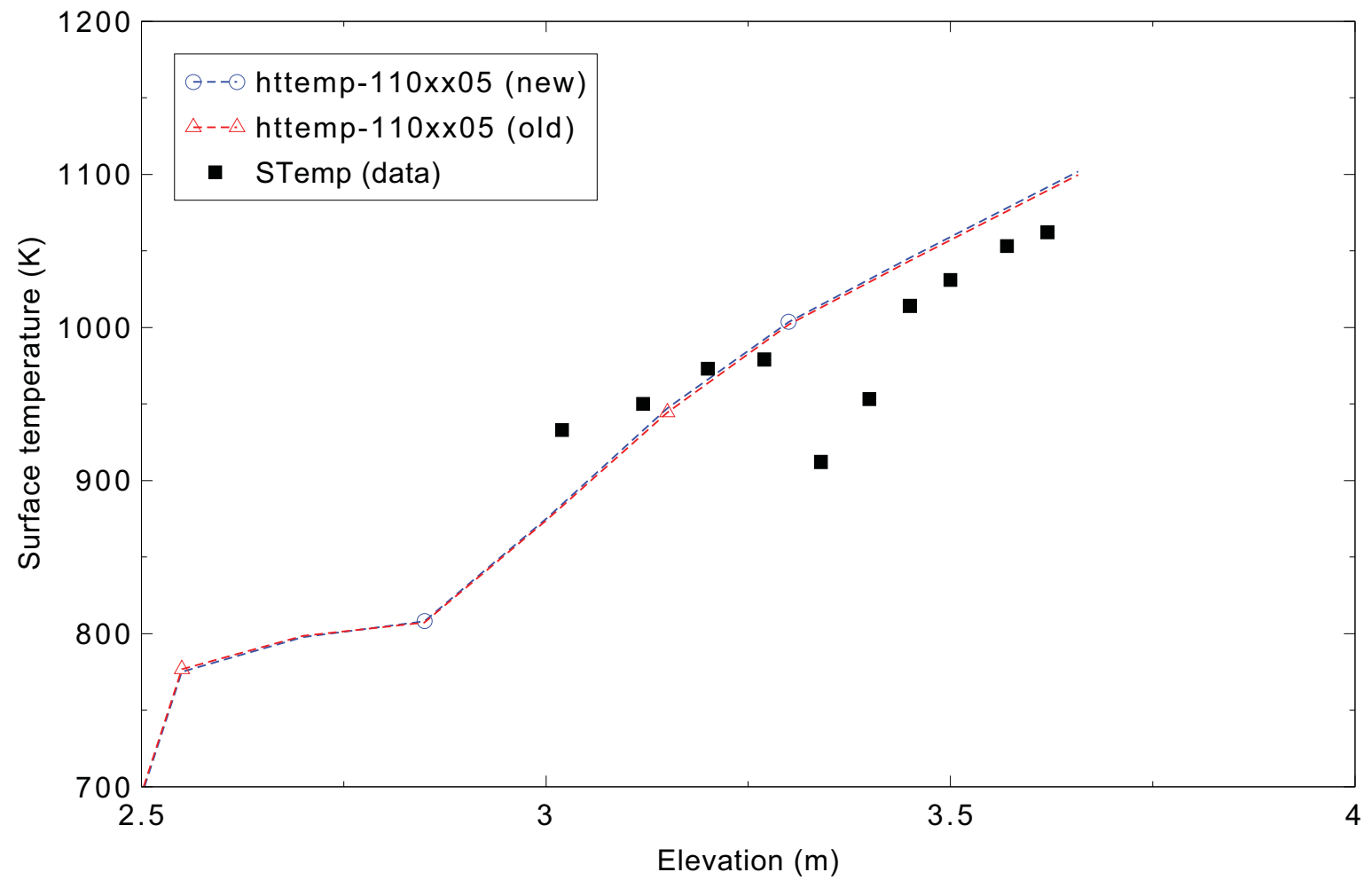

Figure 4.11-7. Measured and calculated steady state axial rod surface temperatures for ORNL THTF Test 3.09.10I. 


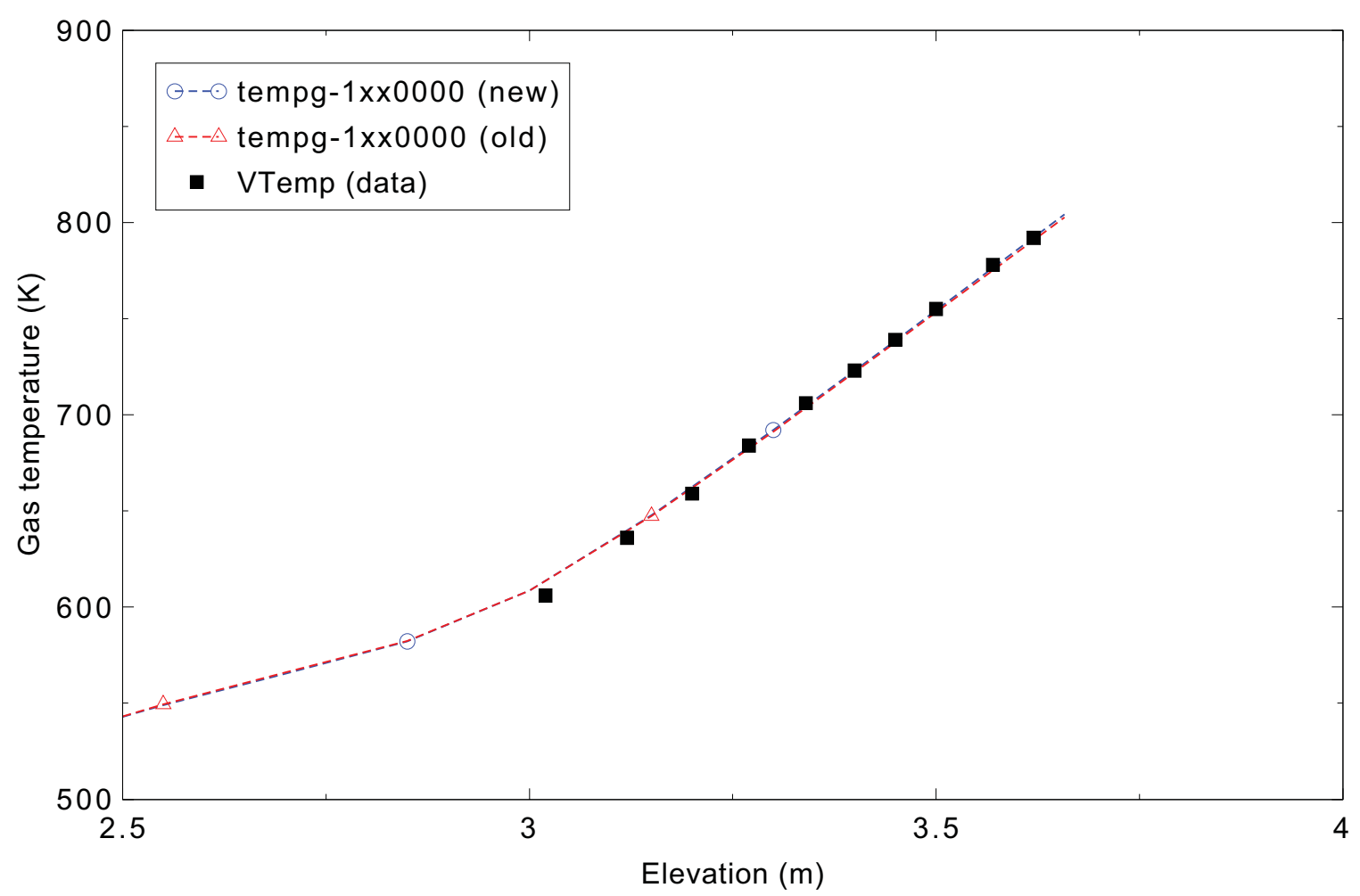

Figure 4.11-8. Measured and calculated steady state axial gas temperatures for ORNL THTF Test 3.09.10I.

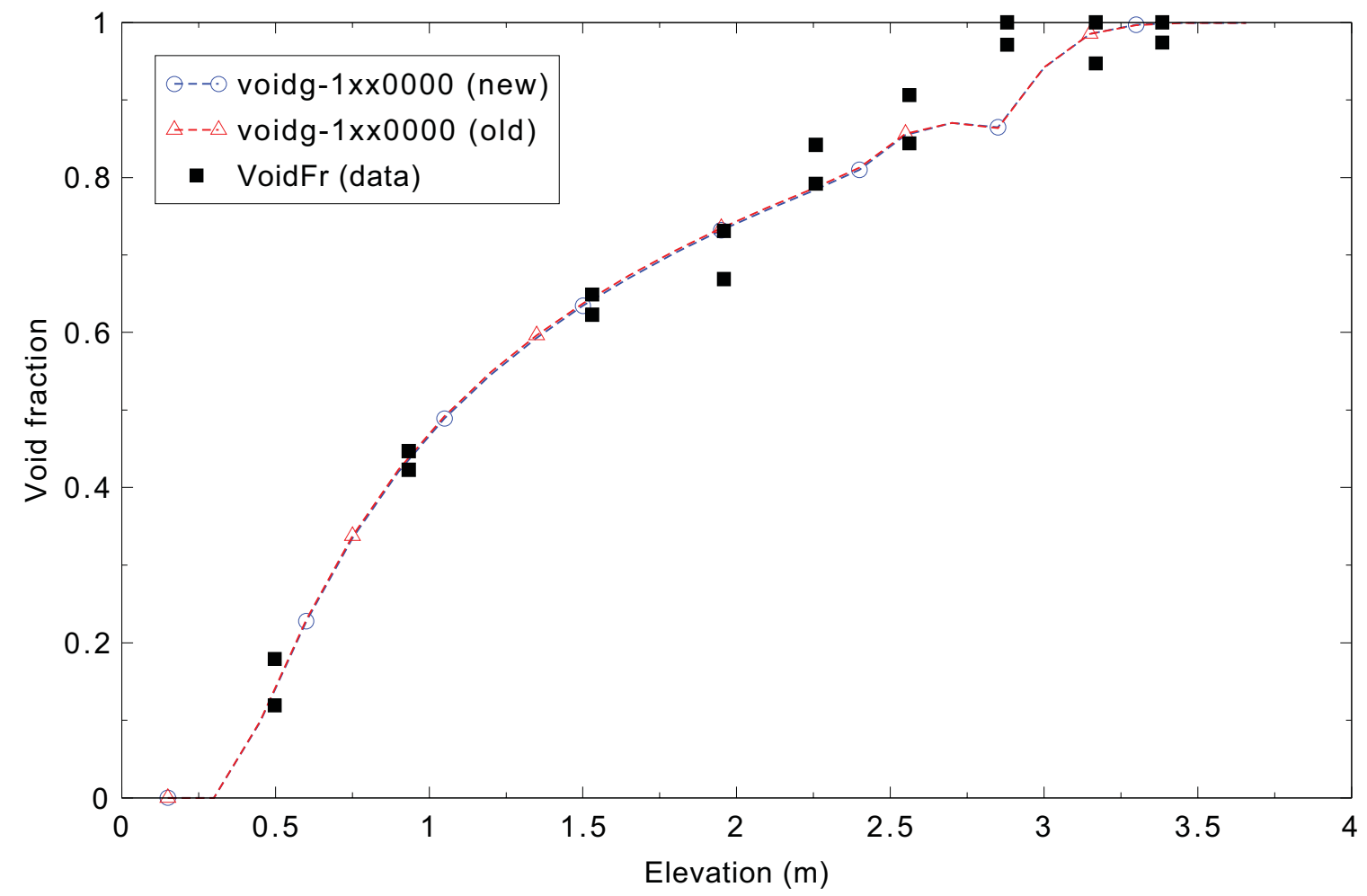

Figure 4.11-9. Measured and calculated steady state axial void fractions for ORNL THTF Test 3.09.10I. 


\subsection{Royal Institute of Technology Tube Test 261}

Figures comparing simulations using two code versions are presented. Diagrams are included so that the figure numbering is the same as that in Volume III of the RELAP5-3D code manual. No differences were observed in the figures.

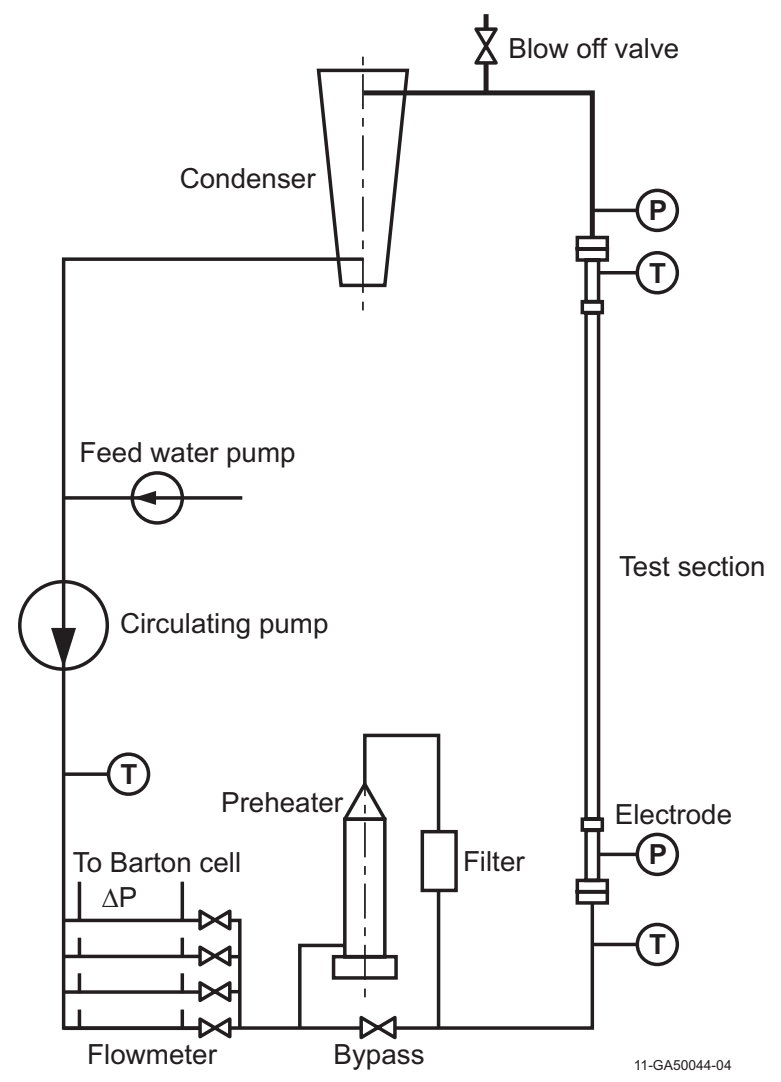

Figure 4.12-1. RIT Tube Test facility diagram. 
RELAP5-3D/4.0.3

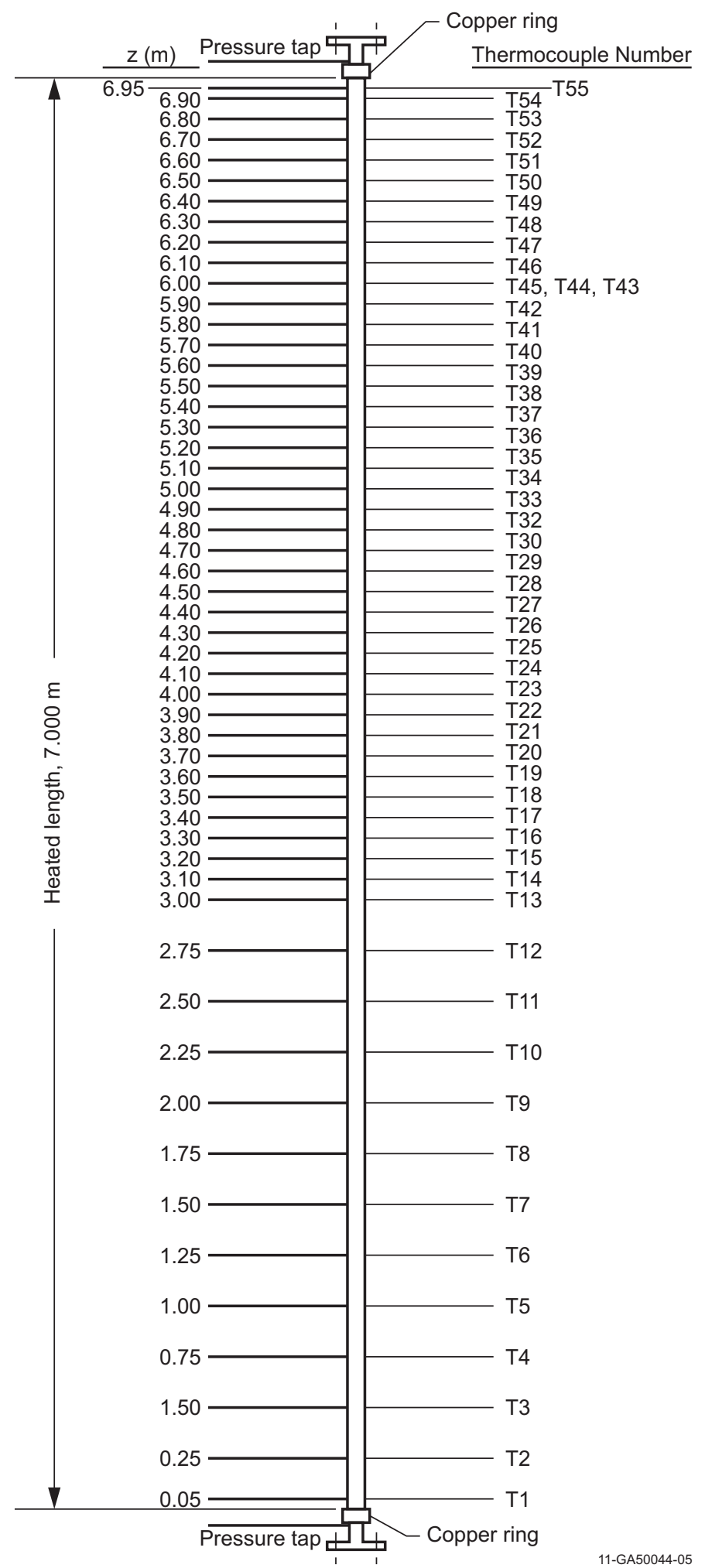

Figure 4.12-2. Locations of temperature measurements for RIT Tube Test 261. 


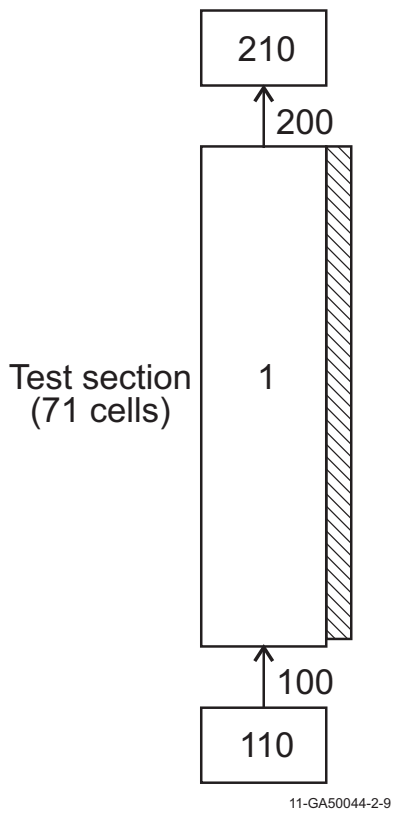

Figure 4.12-3. Nodalization diagram for the RIT test facility.

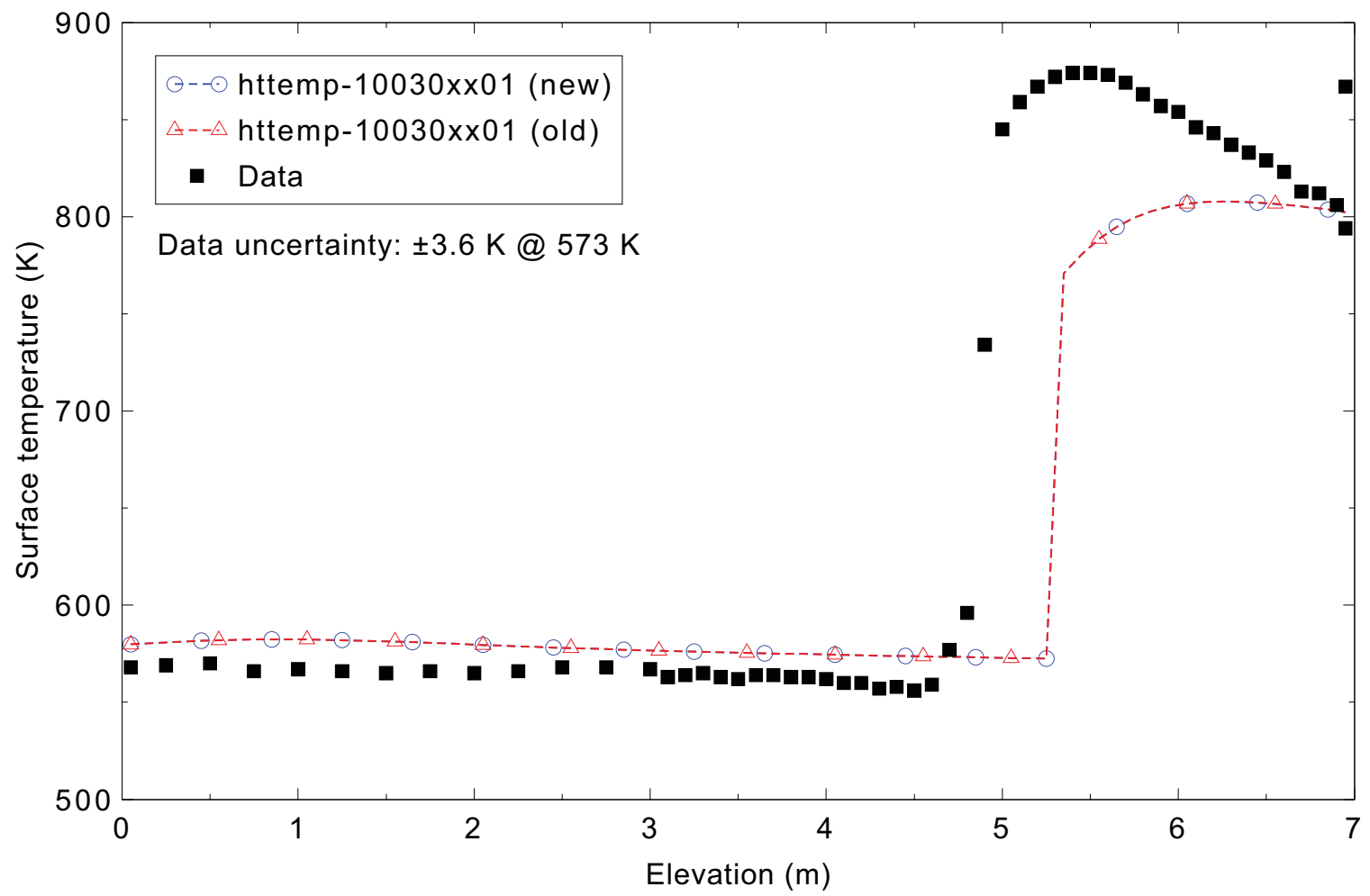

Figure 4.12-4. Measured and calculated tube surface temperatures for RIT Tube Test 261 with the default CHF model. 


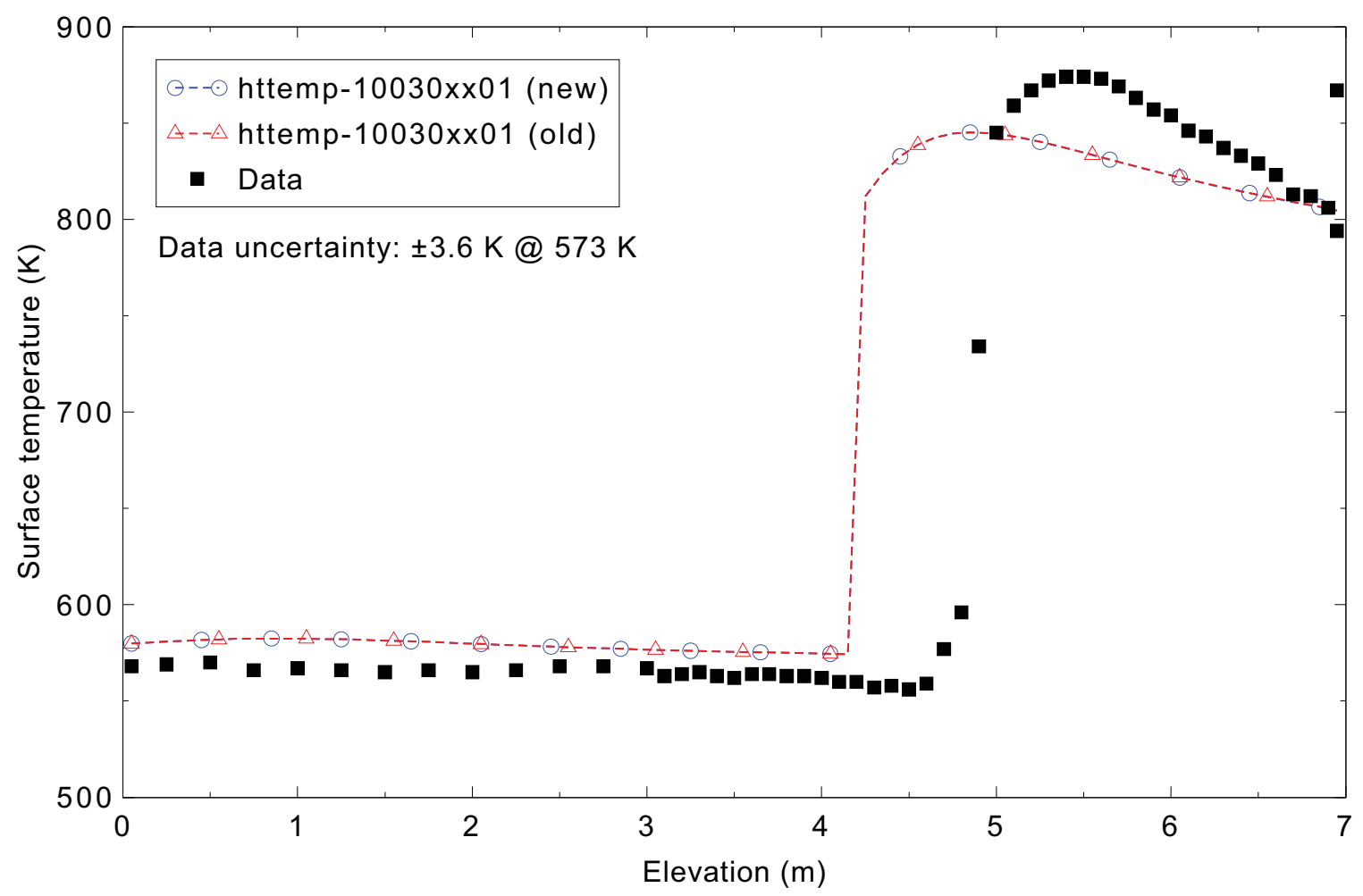

Figure 4.12-5. Measured and calculated tube surface temperatures for RIT Tube Test 261 with the PG-CHF model. 


\subsection{FLECHT SEASET Test 31504}

Figures comparing simulations using two code versions are presented. Diagrams are included so that the figure numbering is the same as that in Volume III of the RELAP5-3D code manual. Significant differences were observed in Figures 4.13-8 and 9; noticeable differences were observed in Figures 4.13-4, $5,6,7,10,11,12,13,14,15,16,17,18,19,20,21,22$, and 23.

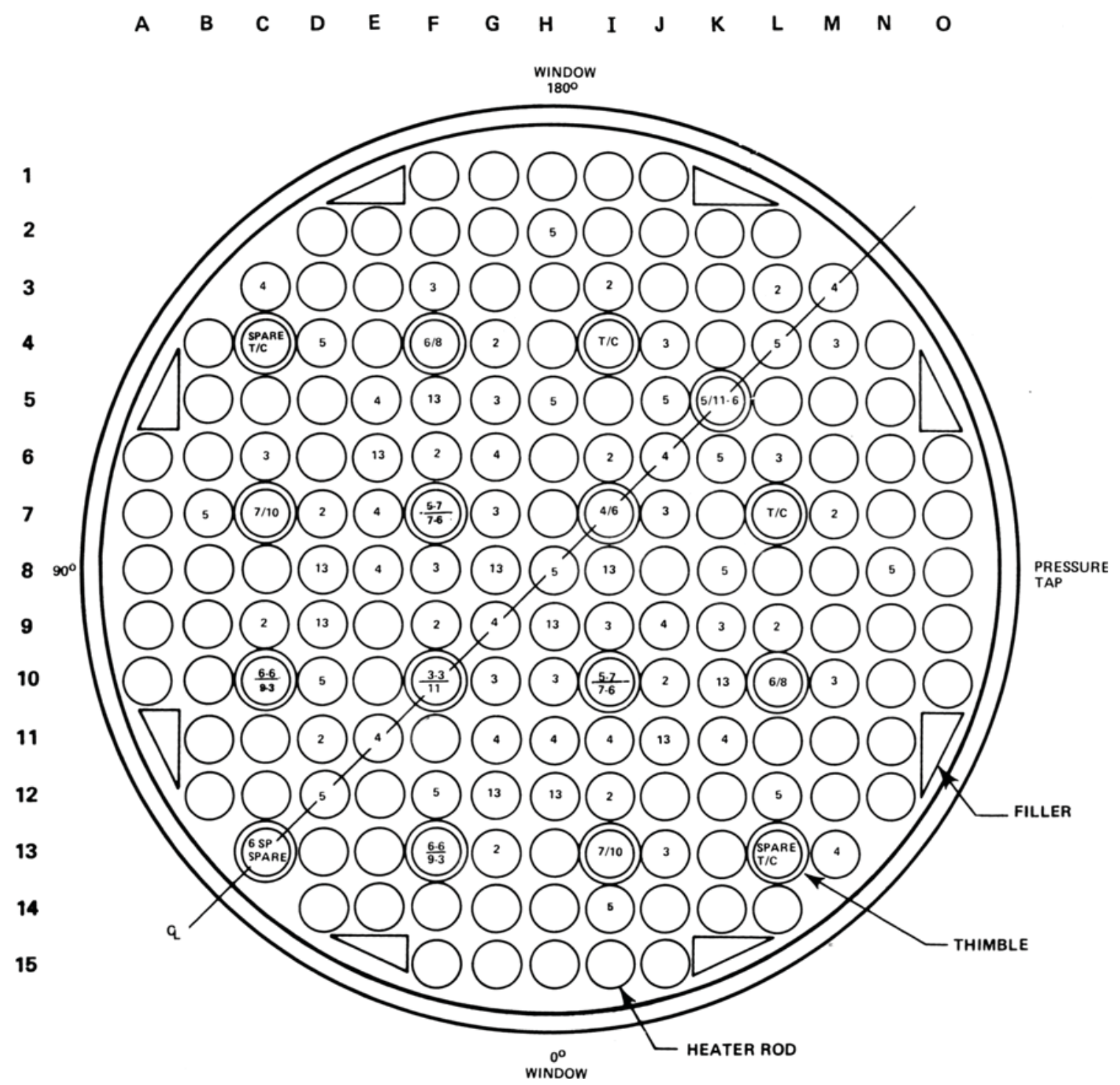

Figure 4.13-2. FLECHT SEASET bundle cross section. 
RELAP5-3D/4.0.3

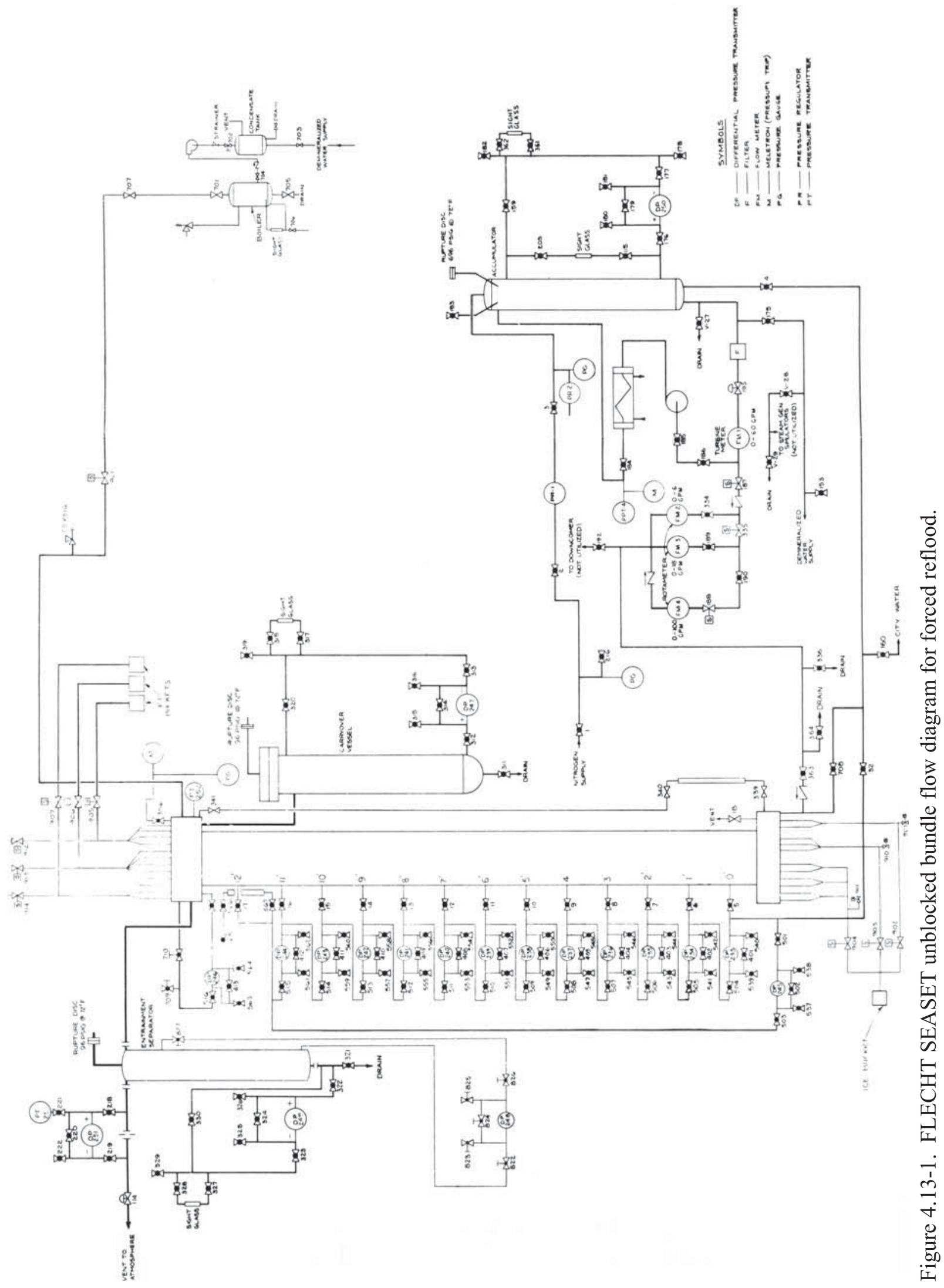




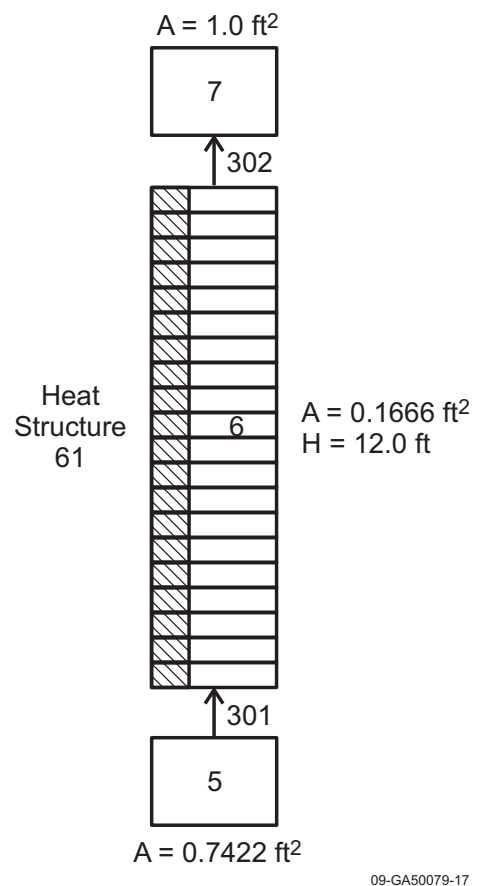

Figure 4.13-3. RELAP5-3D nodalization for the FLECHT SEASET forced reflood experiments.

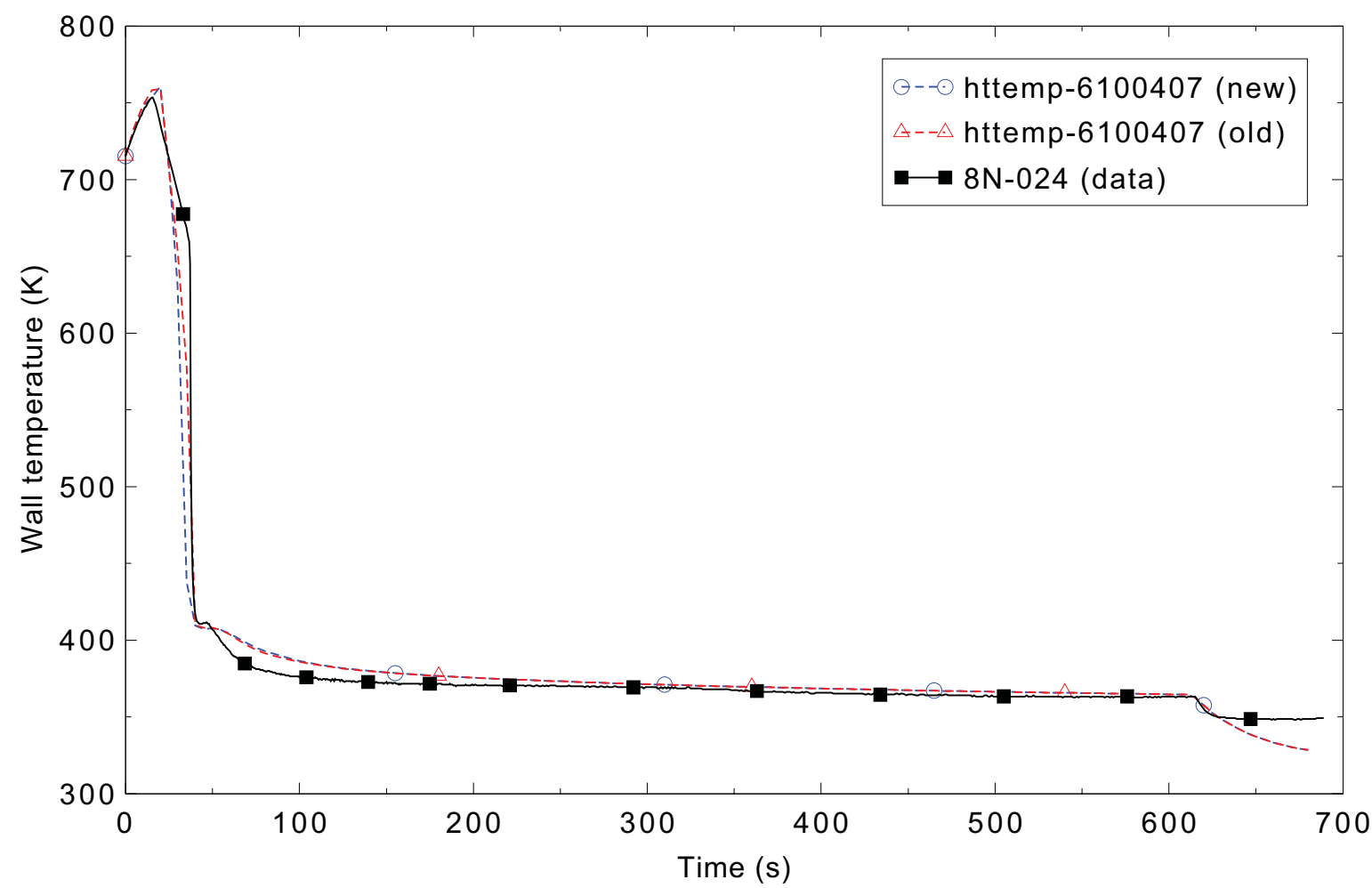

Figure 4.13-4. Measured and calculated rod surface temperatures for FLECHT SEASET forced reflood Test 31504 at the $0.62-\mathrm{m}$ (24-in.) elevation. 


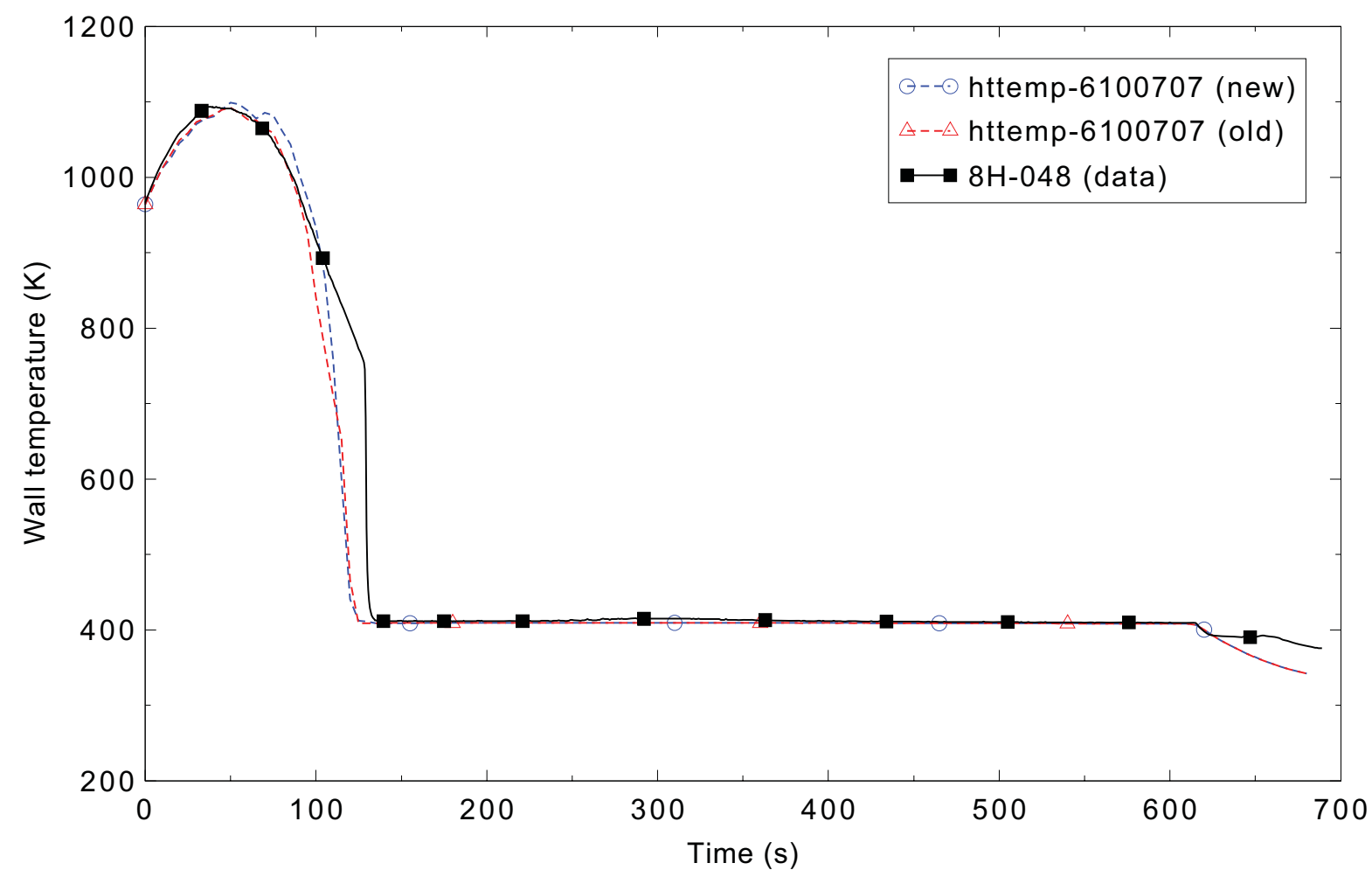

Figure 4.13-5. Measured and calculated rod surface temperatures for FLECHT SEASET forced reflood Test 31504 at the $1.23-\mathrm{m}$ (48-in.) elevation

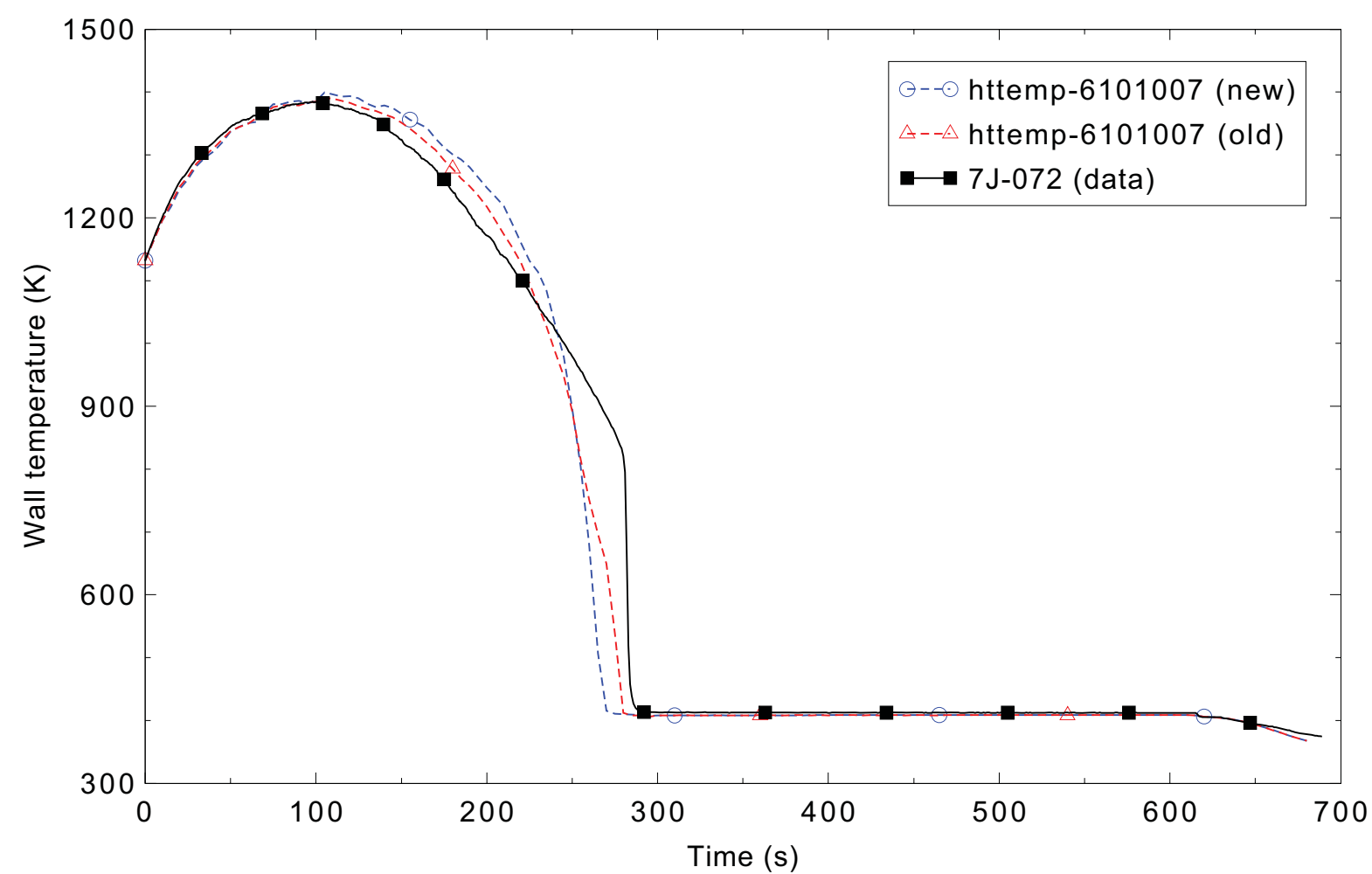

Figure 4.13-6. Measured and calculated rod surface temperatures for FLECHT SEASET forced reflood Test 31504 at the $1.85-\mathrm{m}$ (72-in.) elevation. 


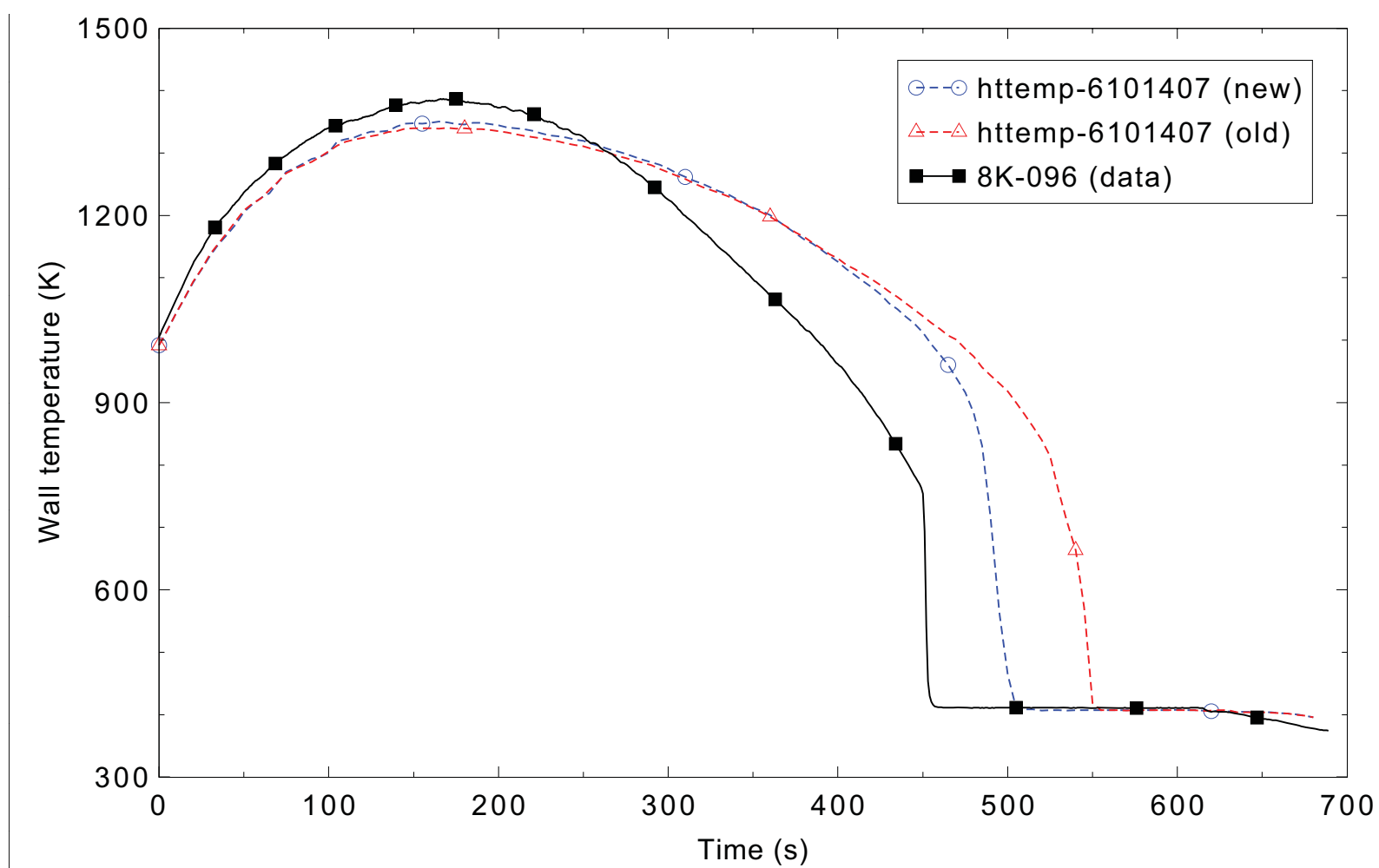

Figure 4.13-7. Measured and calculated rod surface temperatures for FLECHT SEASET forced reflood Test 31504 at the 2.46-m (96-in.) elevation.

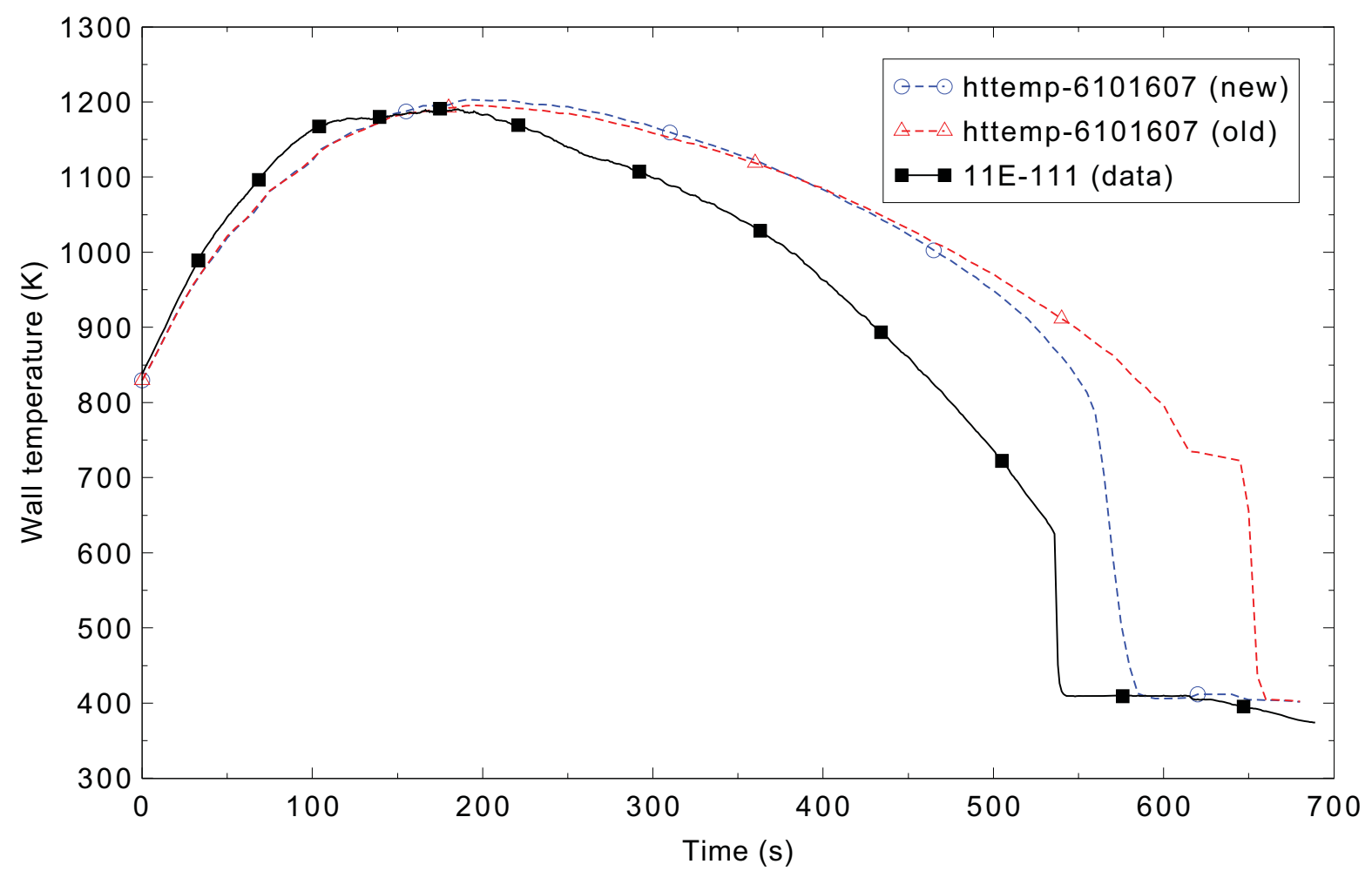

Figure 4.13-8. Measured and calculated rod surface temperatures for FLECHT SEASET forced reflood Test 31504 at the $2.85-\mathrm{m}$ (111-in.) elevation. 


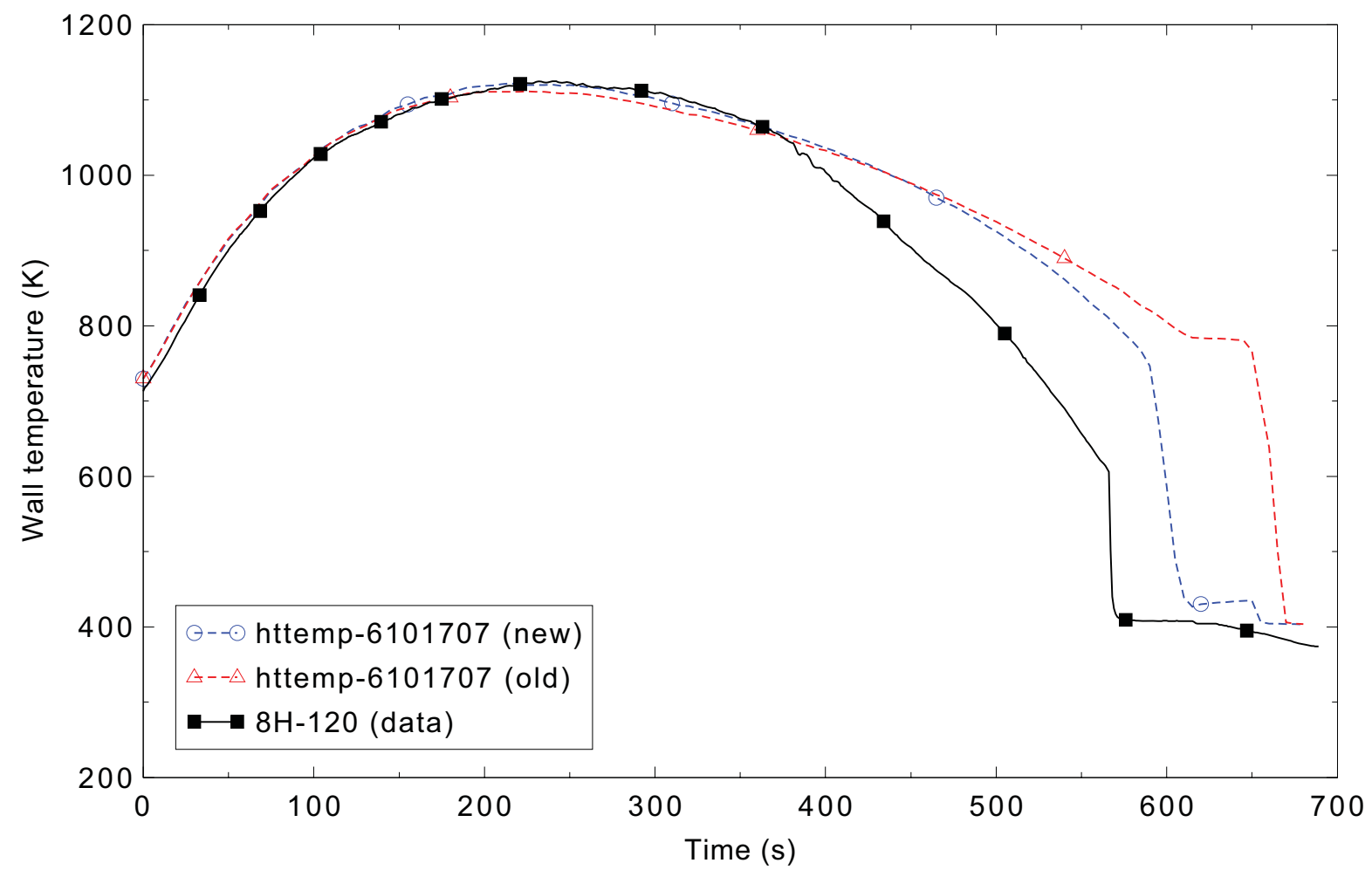

Figure 4.13-9. Measured and calculated rod surface temperatures for FLECHT SEASET forced reflood Test 31504 at the 3.08-m (120-in.) elevation.

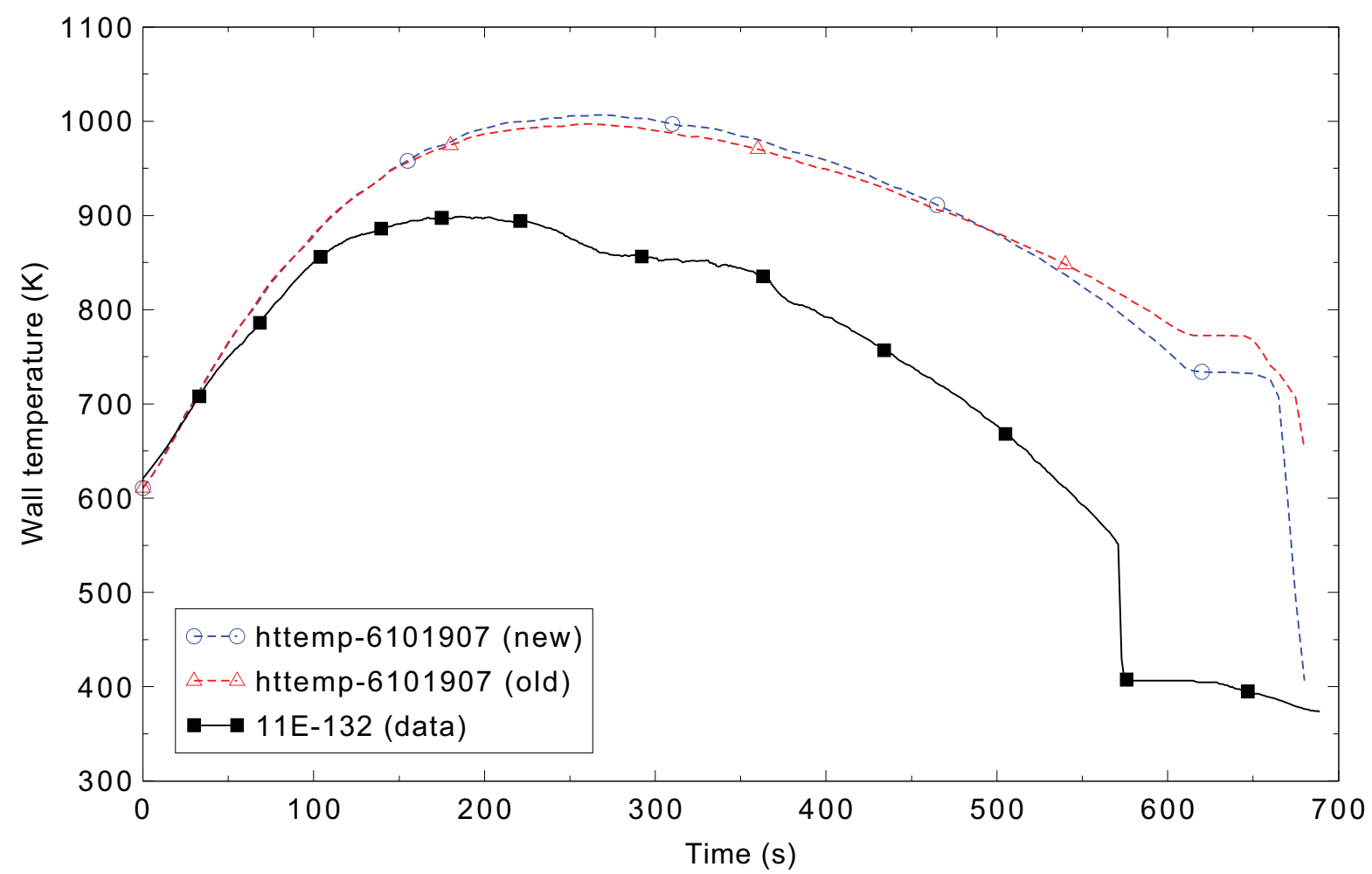

Figure 4.13-10. Measured and calculated rod surface temperatures for FLECHT SEASET forced reflood Test 31504 at the 3.38-m (132-in.) elevation. 


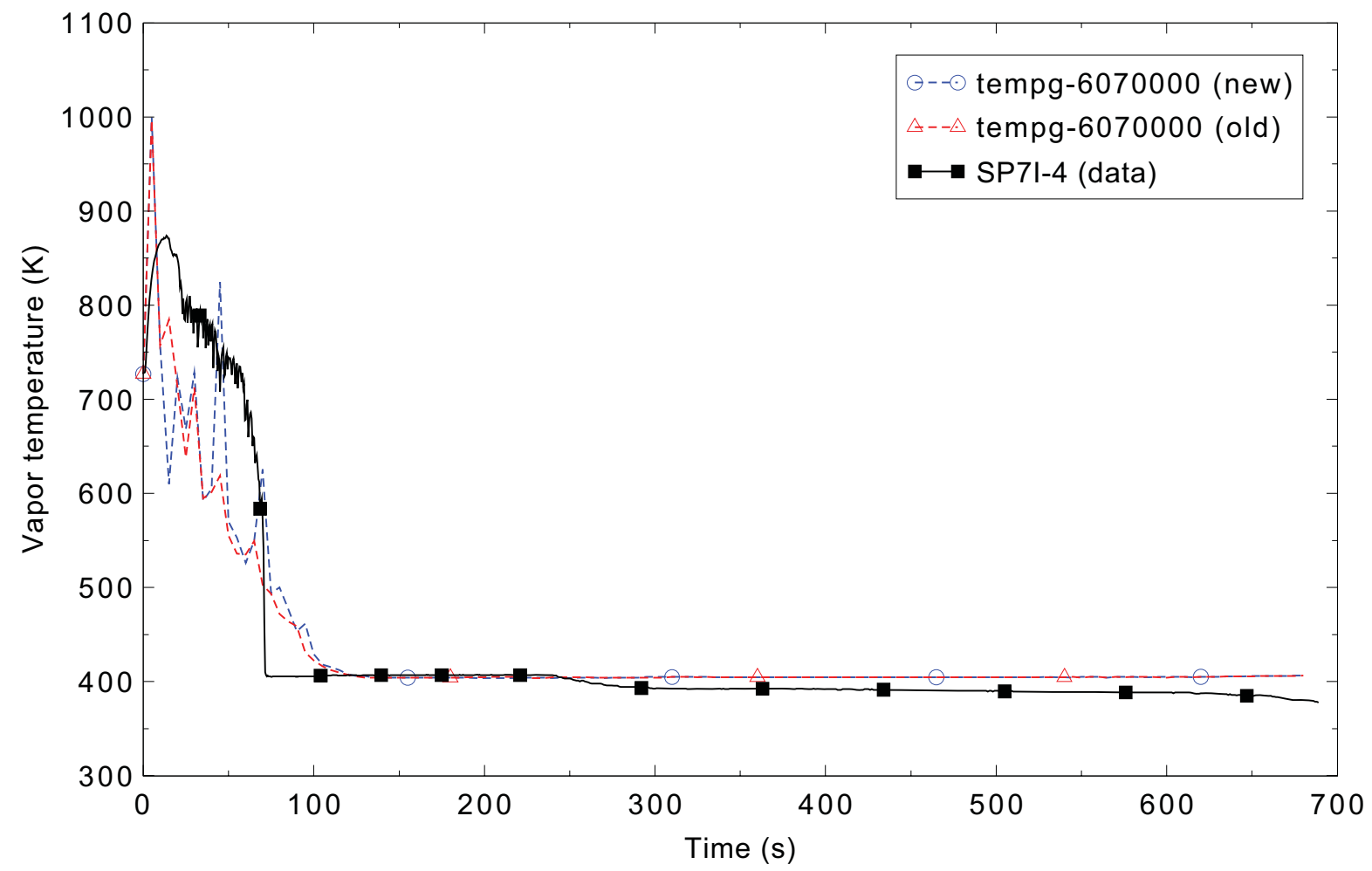

Figure 4.13-11. Measured and calculated steam temperatures for FLECHT SEASET forced reflood Test 31504 at the $1.23-\mathrm{m}$ (4-ft) elevation.

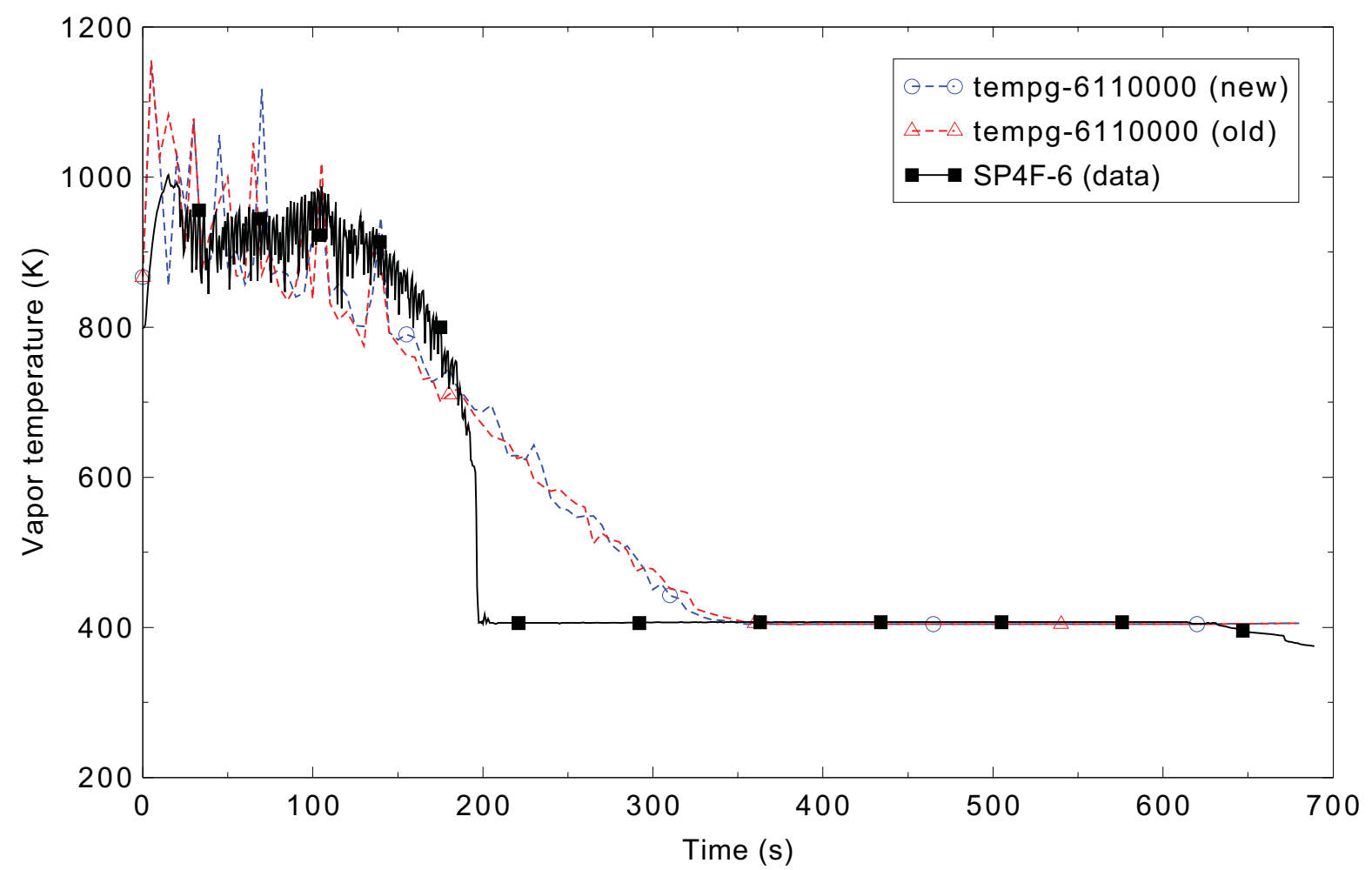

Figure 4.13-12. Measured and calculated steam temperatures for FLECHT SEASET forced reflood Test 31504 at the $1.85-\mathrm{m}(6-\mathrm{ft})$ elevation. 


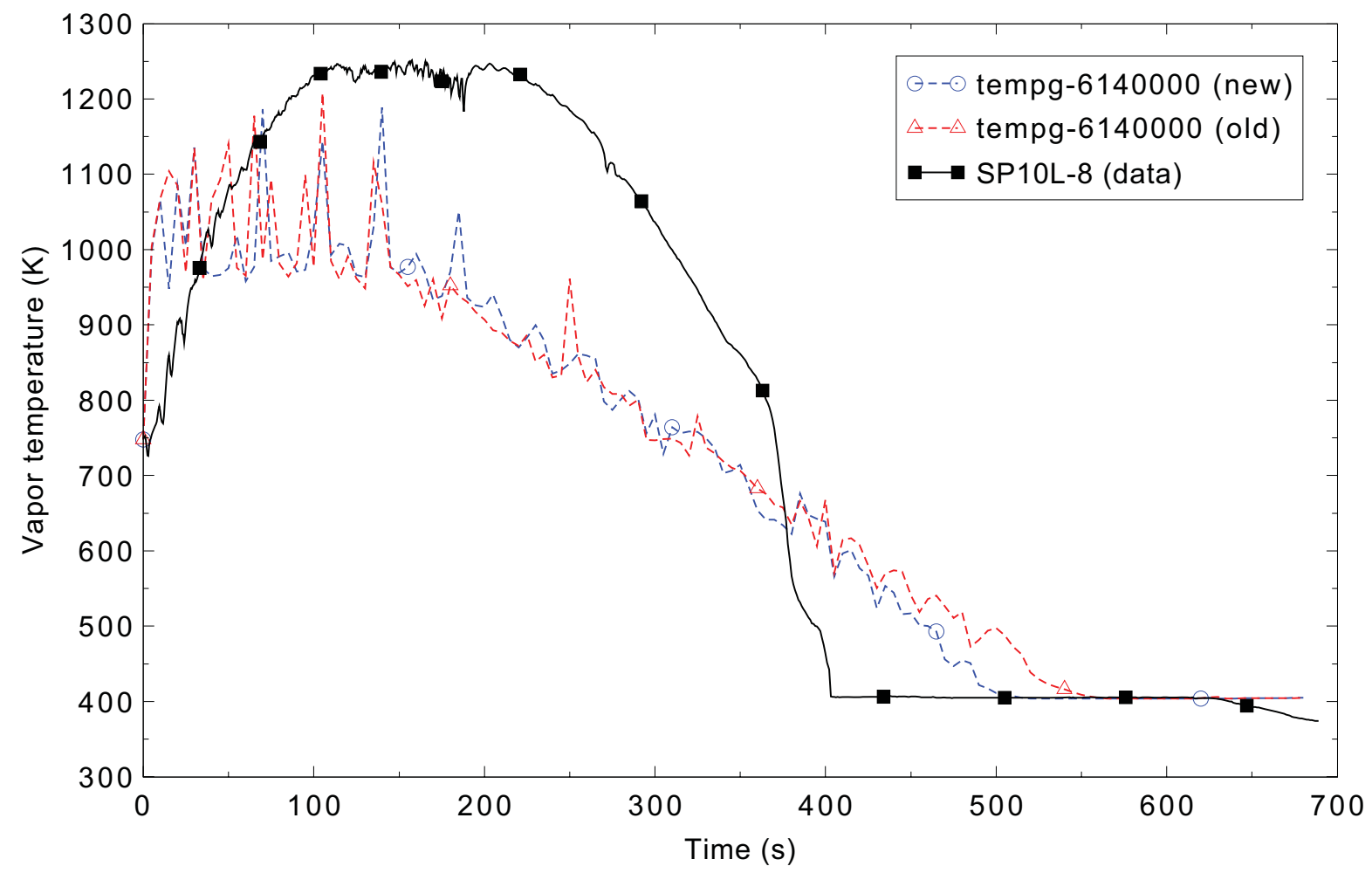

Figure 4.13-13. Measured and calculated steam temperatures for FLECHT SEASET forced reflood Test 31504 at the $2.46-\mathrm{m}$ (8-ft) elevation.

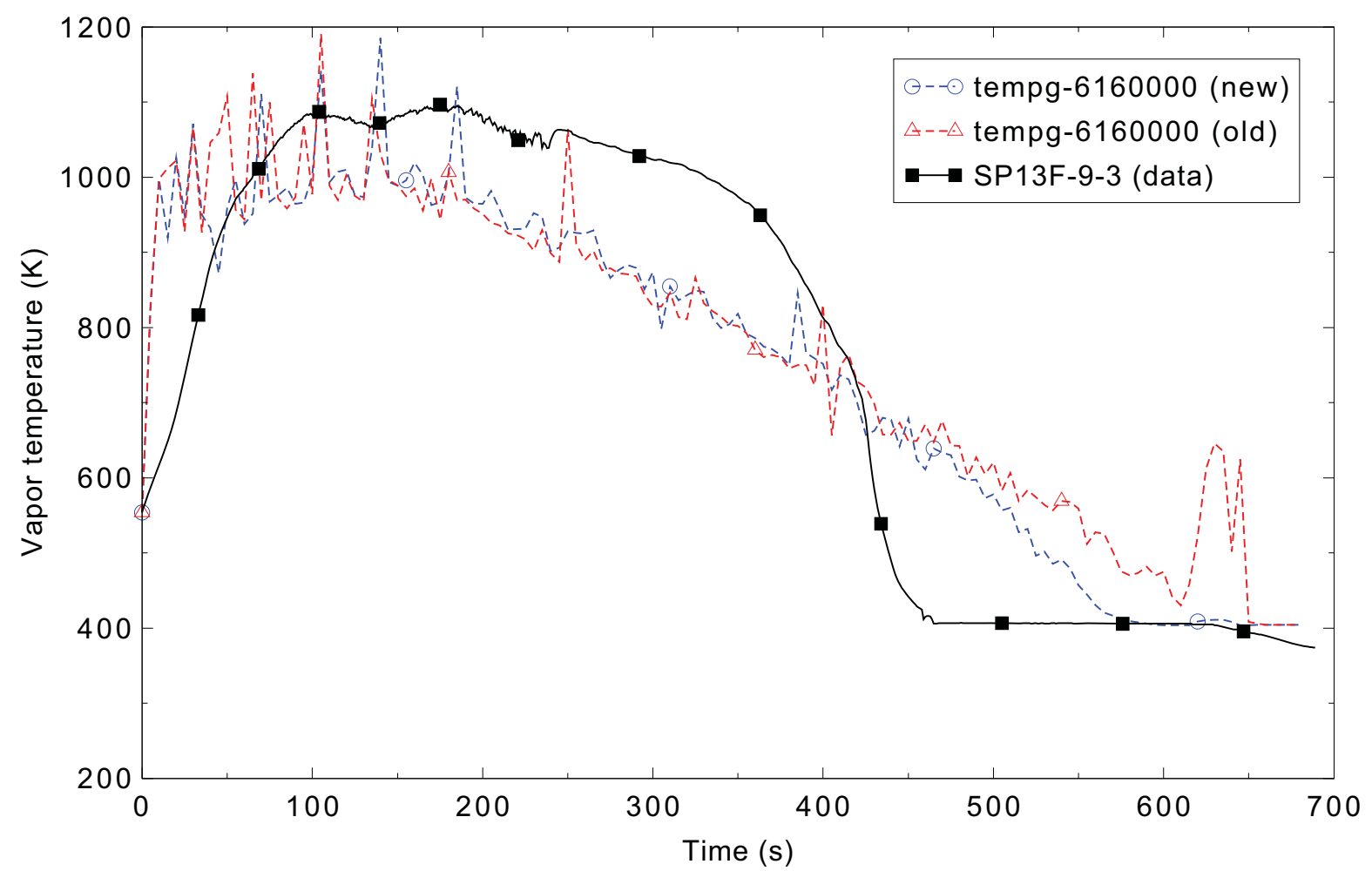

Figure 4.13-14. Measured and calculated steam temperatures for FLECHT SEASET forced reflood Test 31504 at the $2.85-\mathrm{m}(9.25-\mathrm{ft})$ elevation. 


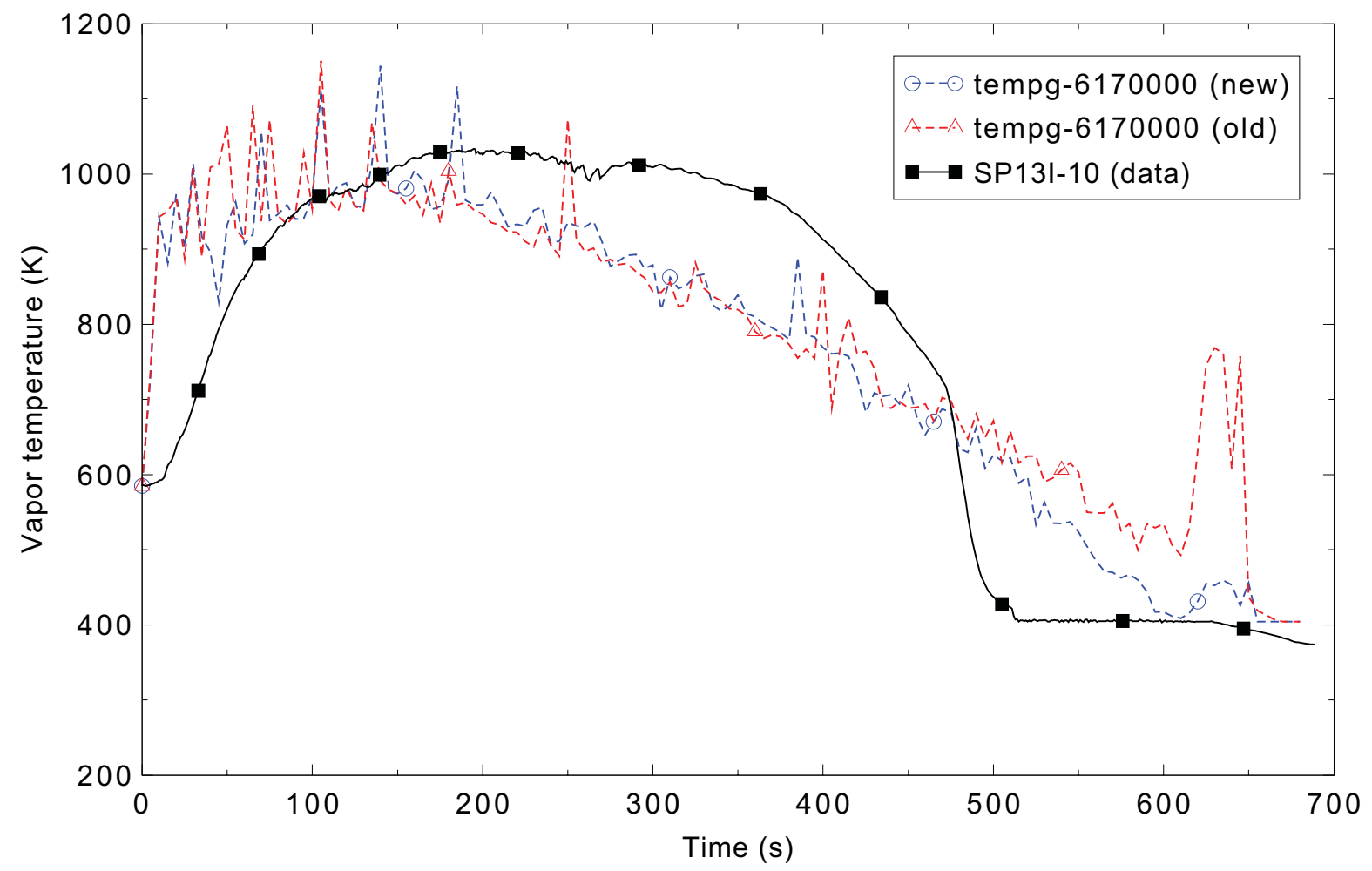

Figure 4.13-15. Measured and calculated steam temperatures for FLECHT SEASET forced reflood Test 31504 at the $3.08-\mathrm{m}(10-\mathrm{ft})$ elevation.

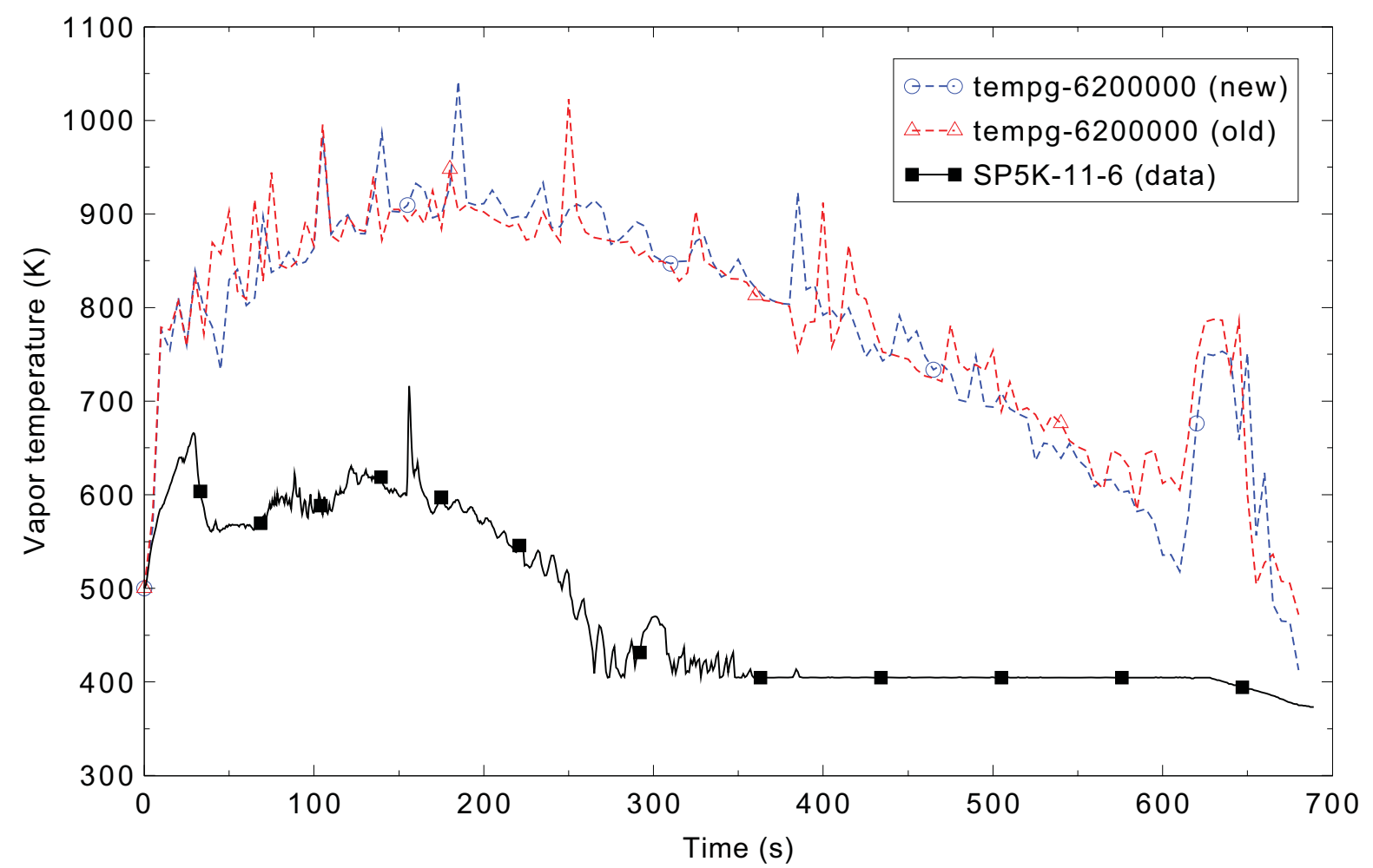

Figure 4.13-16. Measured and calculated steam temperatures for FLECHT SEASET forced reflood Test 31504 at the 3.54-m (11.5-ft) elevation. 


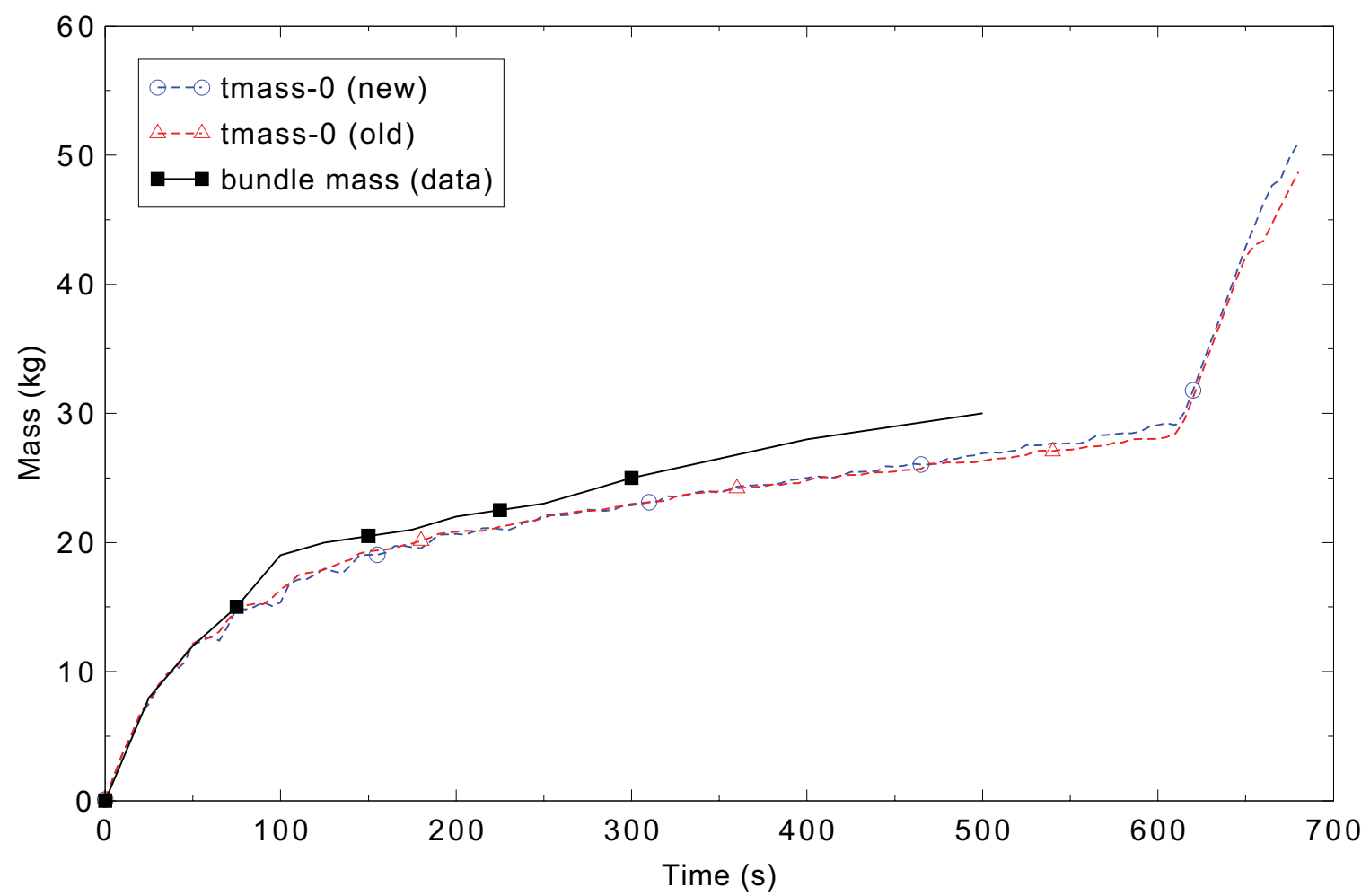

Figure 4.13-17. Measured and calculated total bundle mass inventory for FLECHT SEASET forced reflood Test 31504.

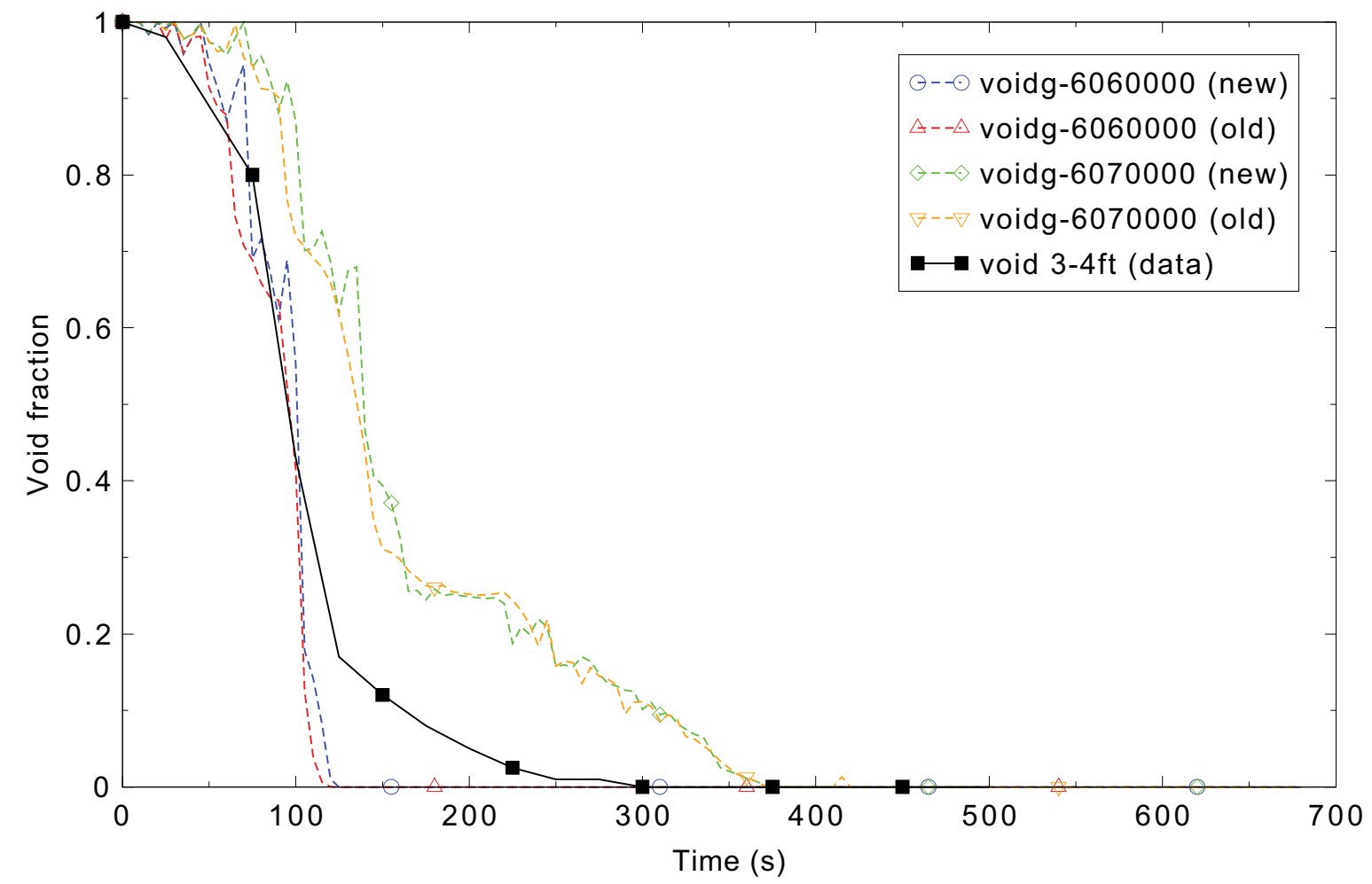

Figure 4.13-18. Measured and calculated void fractions at 0.92 to $1.23-\mathrm{m}$ ( 3 to $4-\mathrm{ft}$ ) elevations for FLECHT SEASET forced reflood Test 31504. 


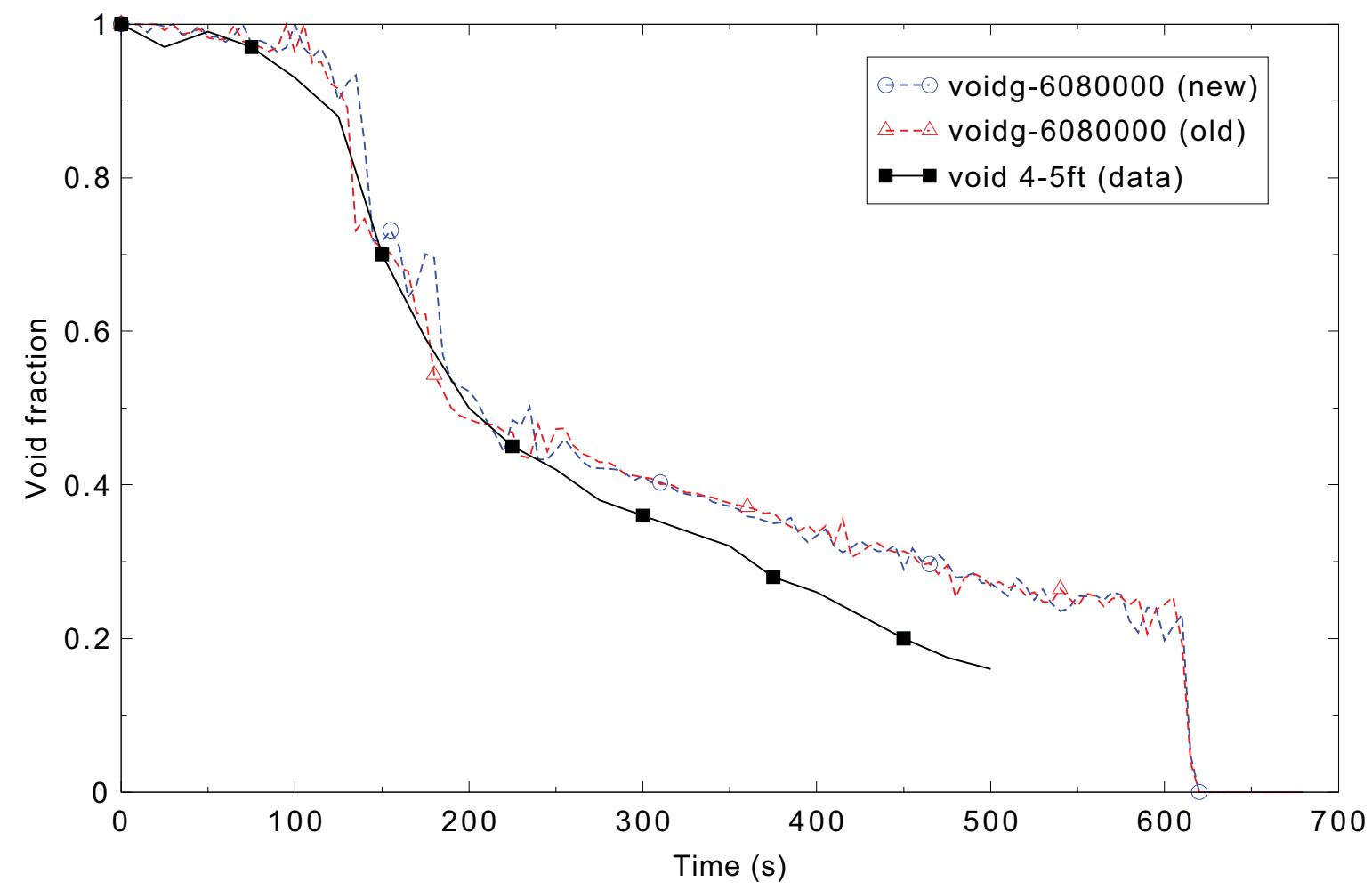

Figure 4.13-19. Measured and calculated void fractions at 1.23 to $1.54-\mathrm{m}$ (4 to 5-ft) elevations for FLECHT SEASET forced reflood Test 31504.

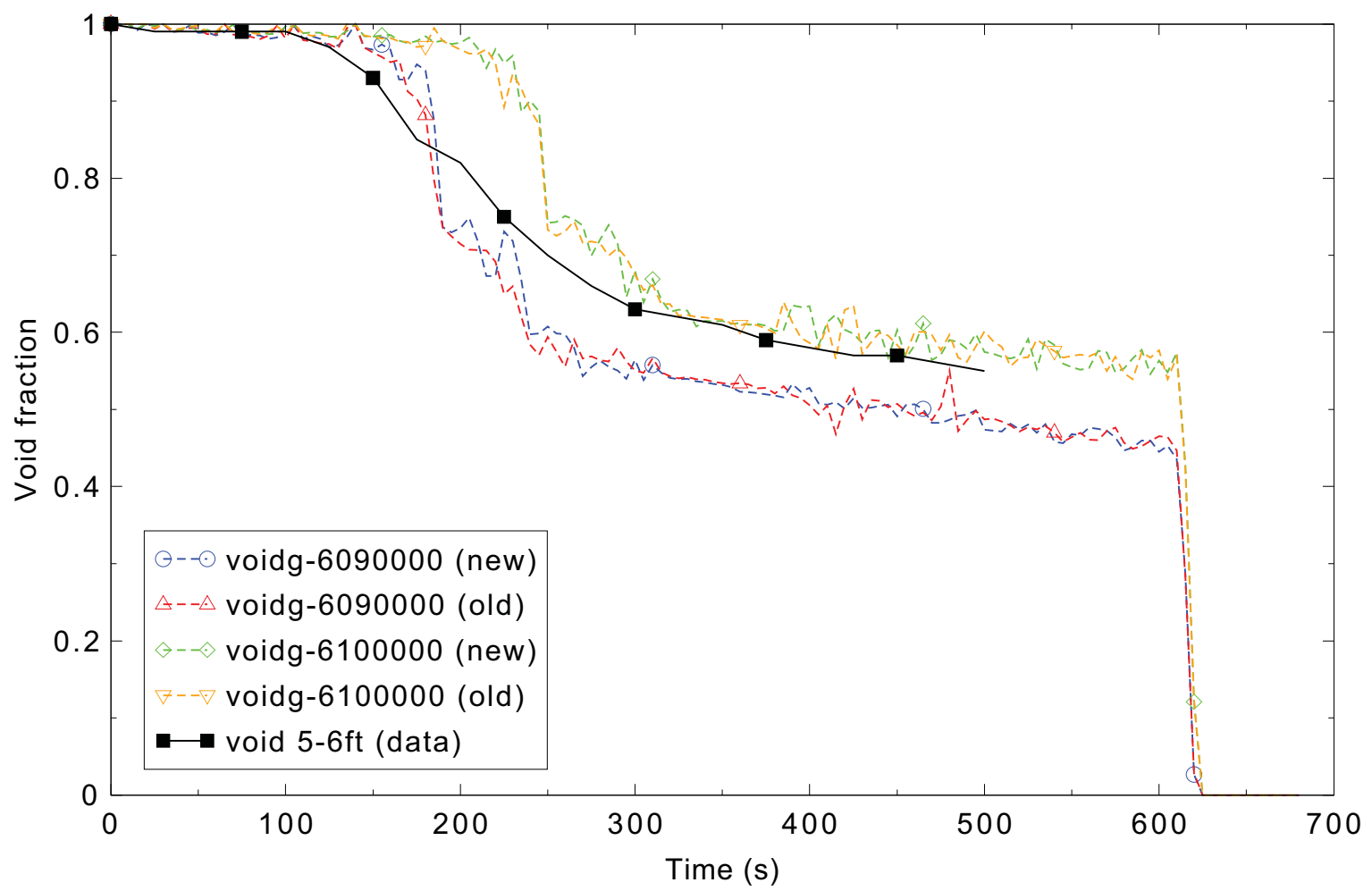

Figure 4.13-20. Measured and calculated void fractions at 1.54 to $1.85-\mathrm{m}$ ( 5 to $6-\mathrm{ft}$ ) elevations for FLECHT SEASET forced reflood Test 31504. 


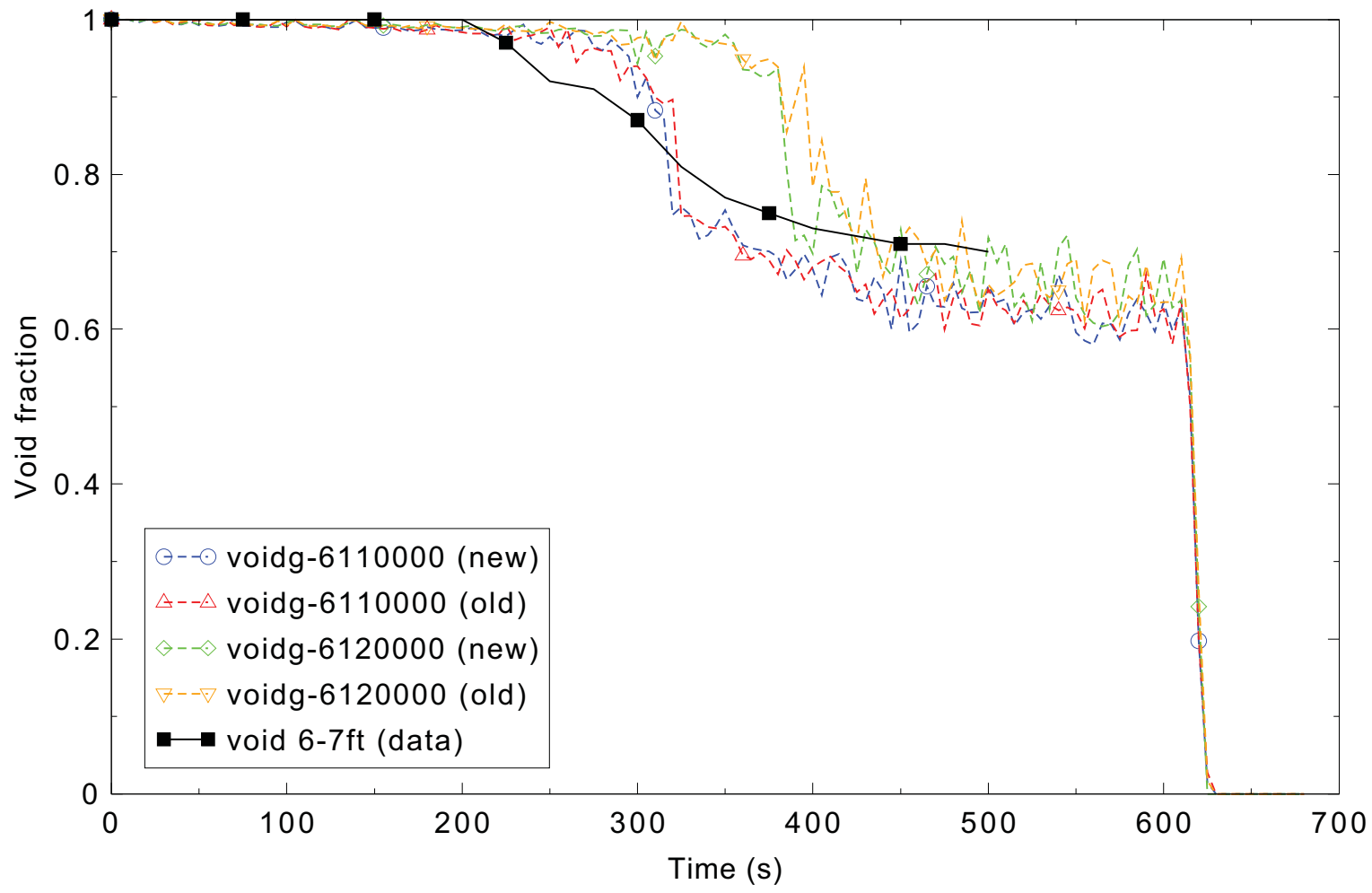

Figure 4.13-21. Measured and calculated void fractions at 1.85 to $2.15-\mathrm{m}$ ( 6 to $7-\mathrm{ft}$ ) elevations for FLECHT SEASET forced reflood Test 31504.

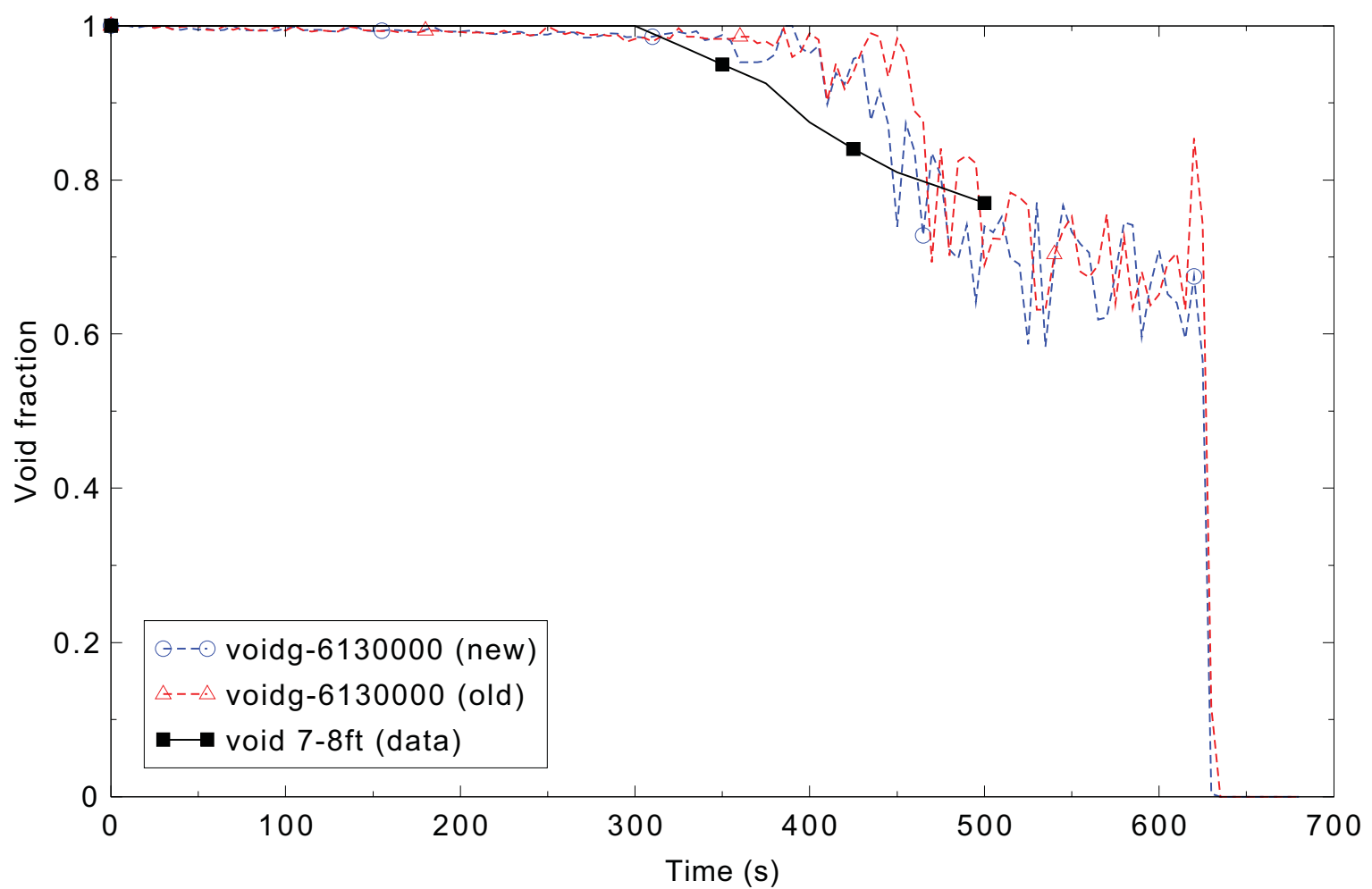

Figure 4.13-22. Measured and calculated void fractions at 2.15 to $2.46-\mathrm{m}$ ( 7 to 8 -ft) elevations for FLECHT SEASET forced reflood Test 31504. 
RELAP5-3D/4.0.3

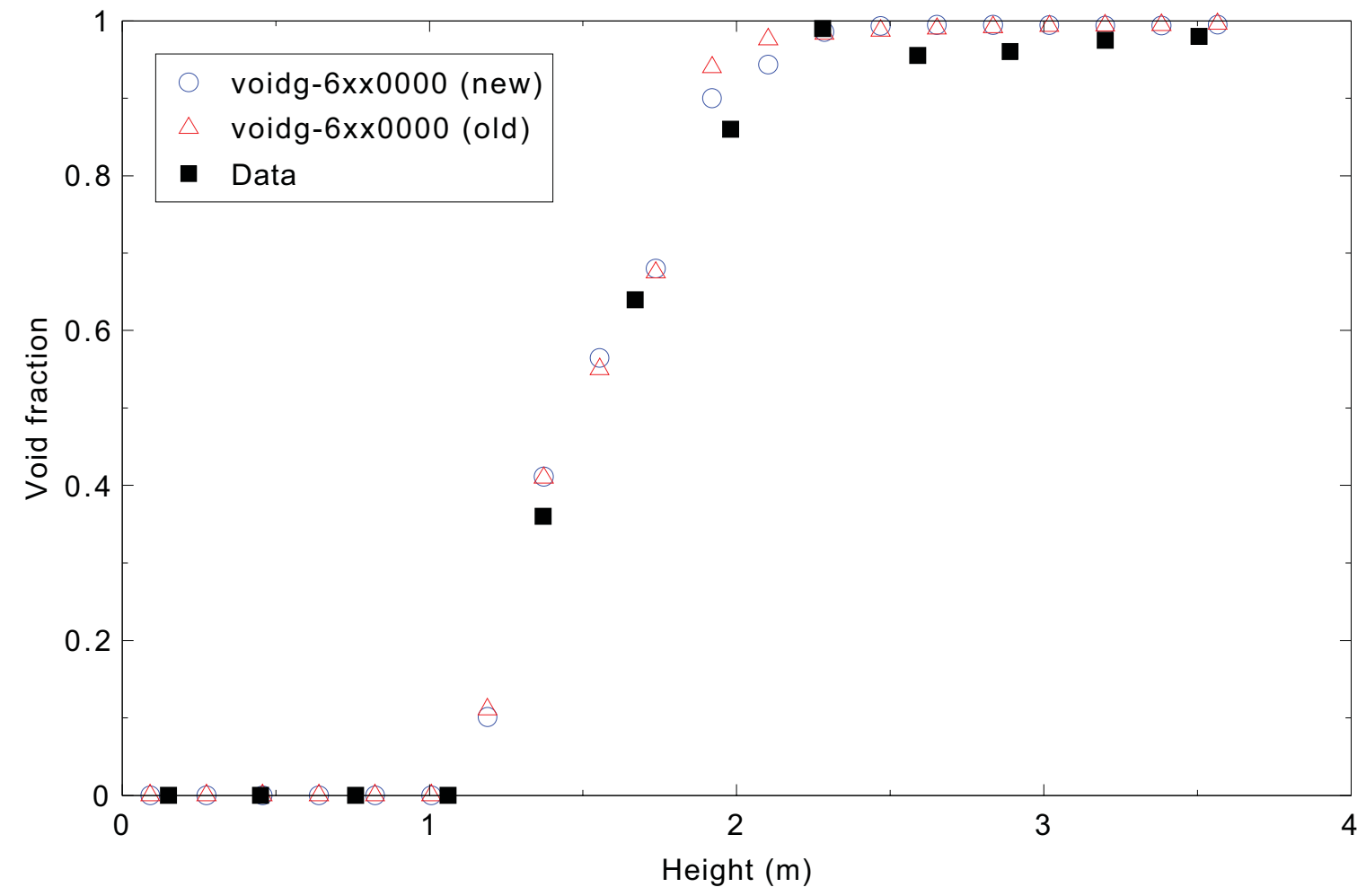

Figure 4.13-23. Measured and calculated axial void profile at $300 \mathrm{~s}$ for FLECHT SEASET forced reflood Test 31504 . 


\subsection{FLECHT SEASET Test 31701}

Figures comparing simulations using two code versions are presented. Diagrams are included so that the figure numbering is the same as that in Volume III of the RELAP5-3D code manual. Significant

differences were observed in Figure 4.14-9; noticeable differences were observed in Figures 4.14-4, 5, 6, $7,8,10,11,12,13,14,15,16,17$, and 18 .

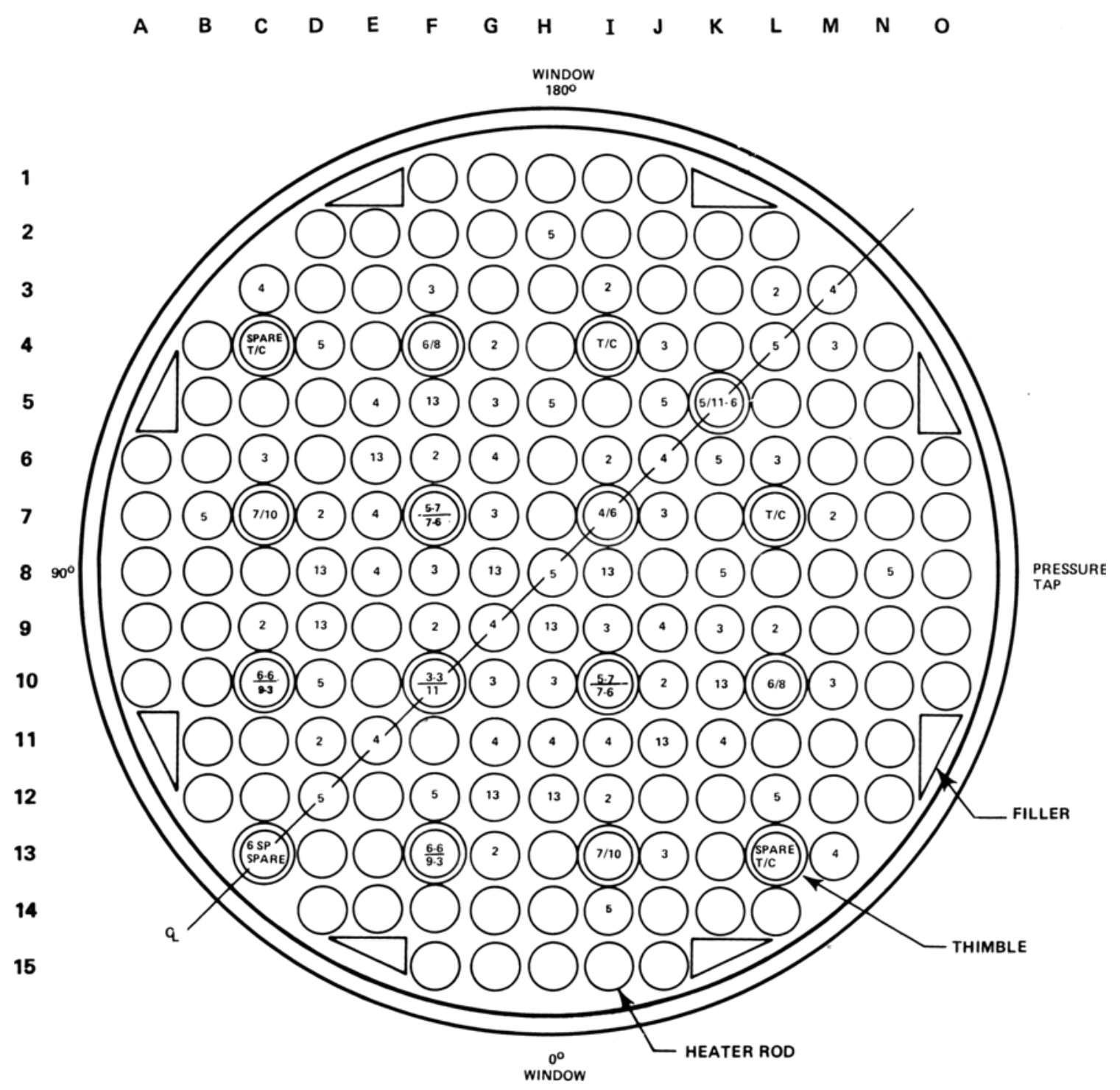

Figure 4.14-2. FLECHT SEASET bundle cross section. 


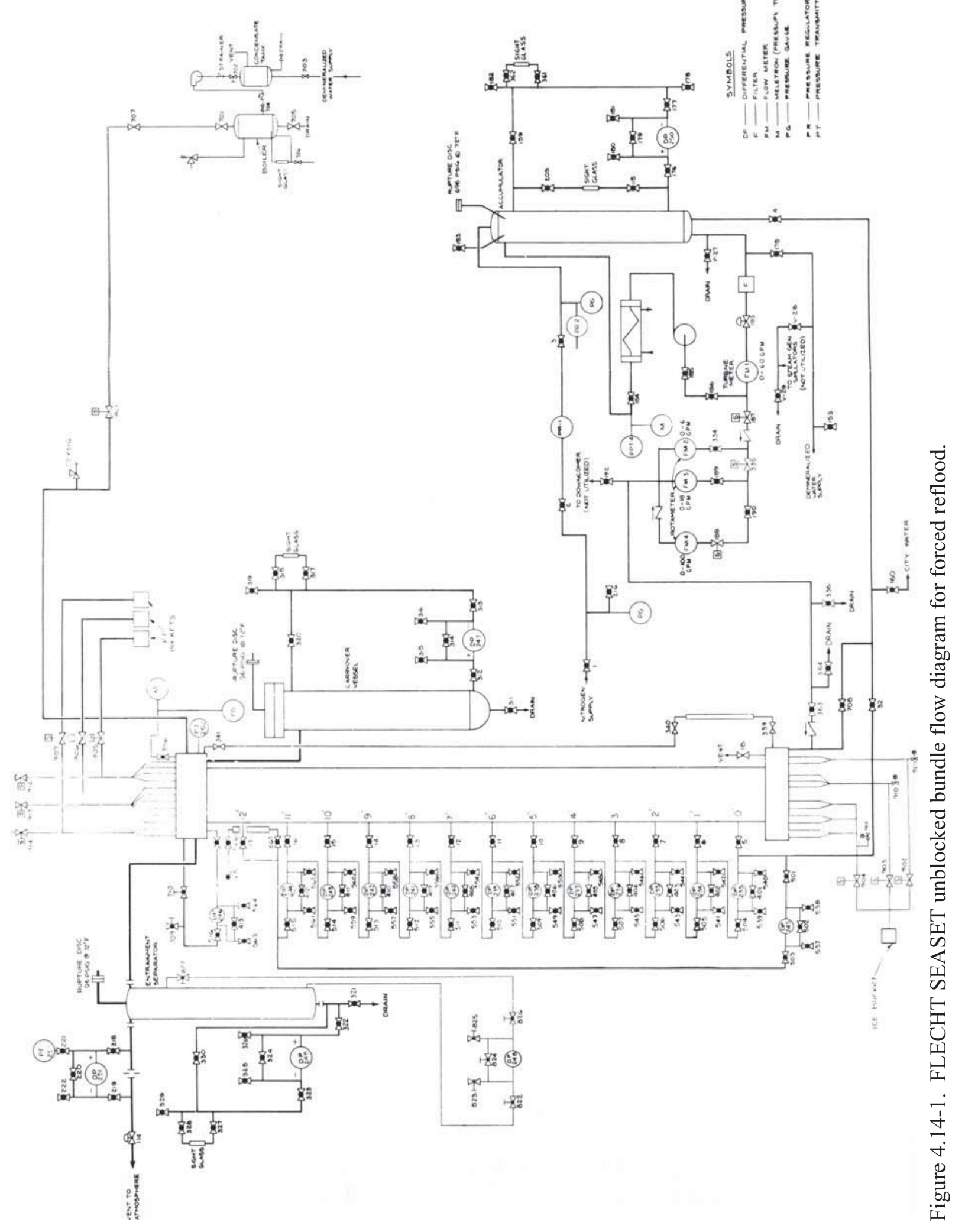




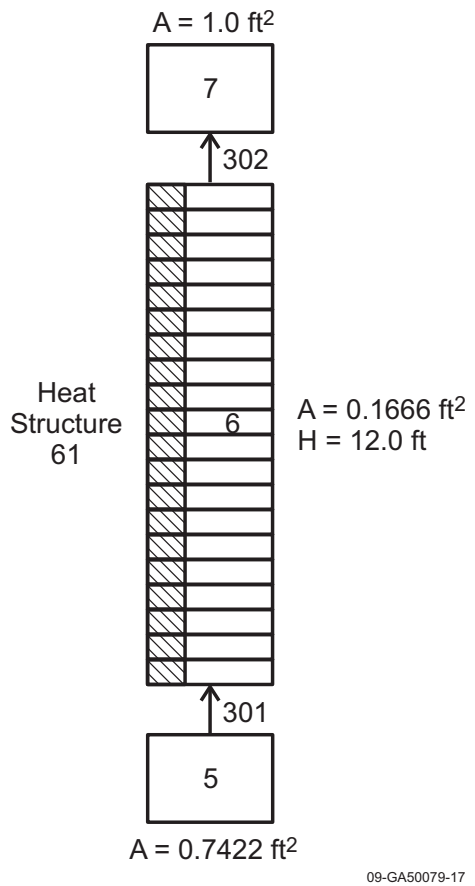

Figure 4.14-3. RELAP5-3D nodalization for the FLECHT SEASET forced reflood experiments.

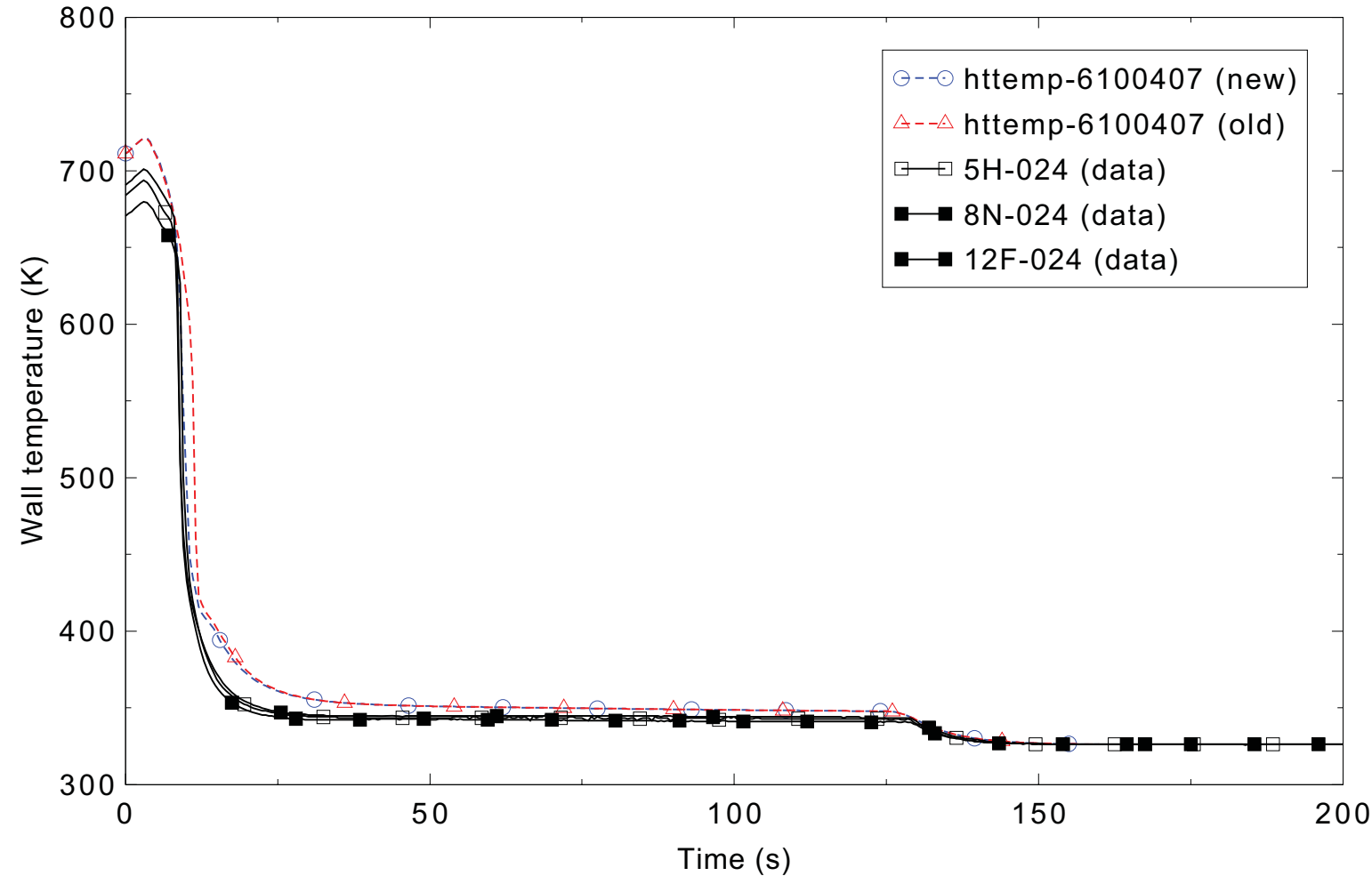

Figure 4.14-4. Measured and calculated rod surface temperatures for FLECHT SEASET forced reflood Test 31701 at the $0.62-\mathrm{m}$ (24-in.) elevation. 


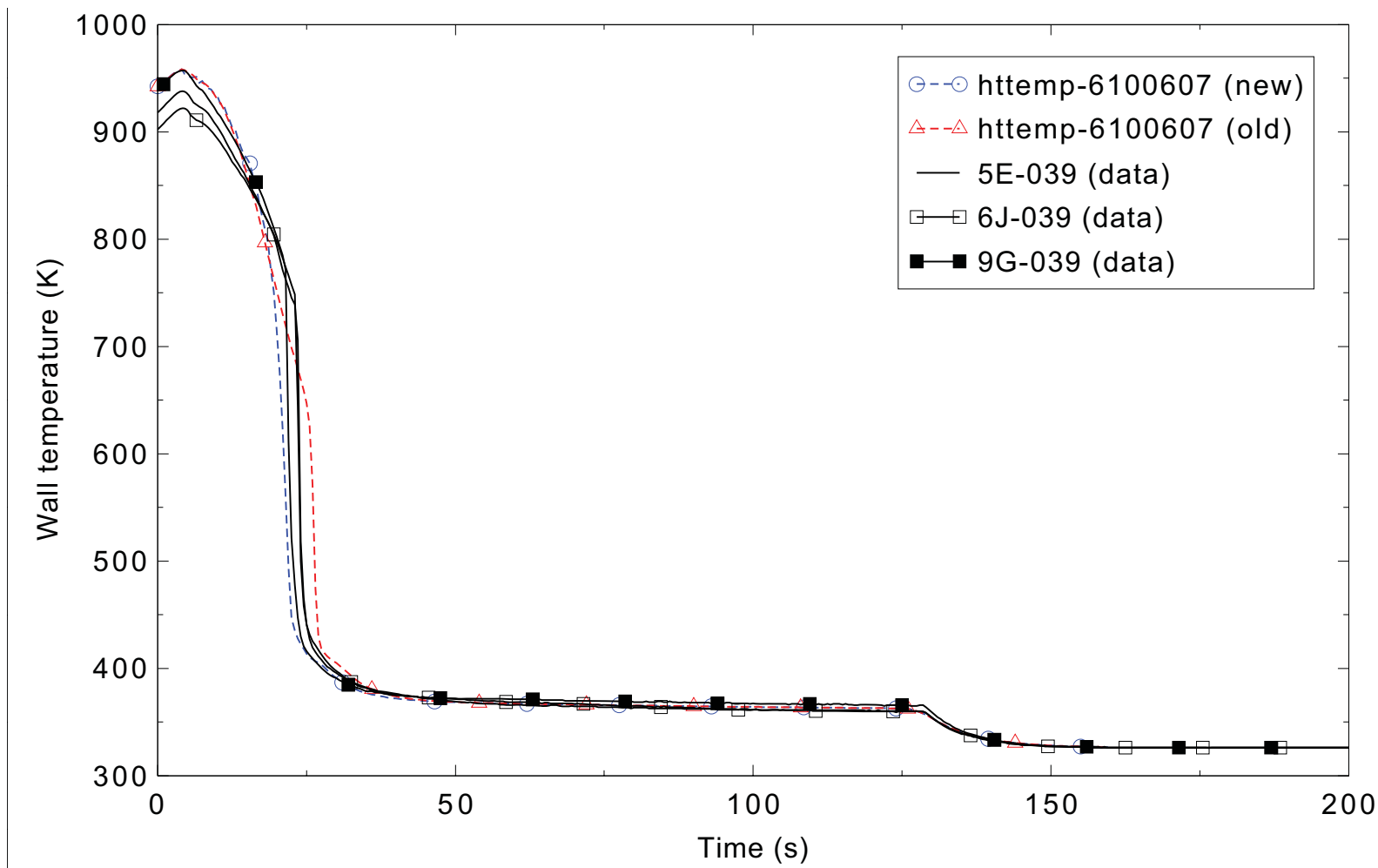

Figure 4.14-5. Measured and calculated rod surface temperatures for FLECHT SEASET forced reflood Test 31701 at the $0.99-\mathrm{m}$ (39-in.) elevation.

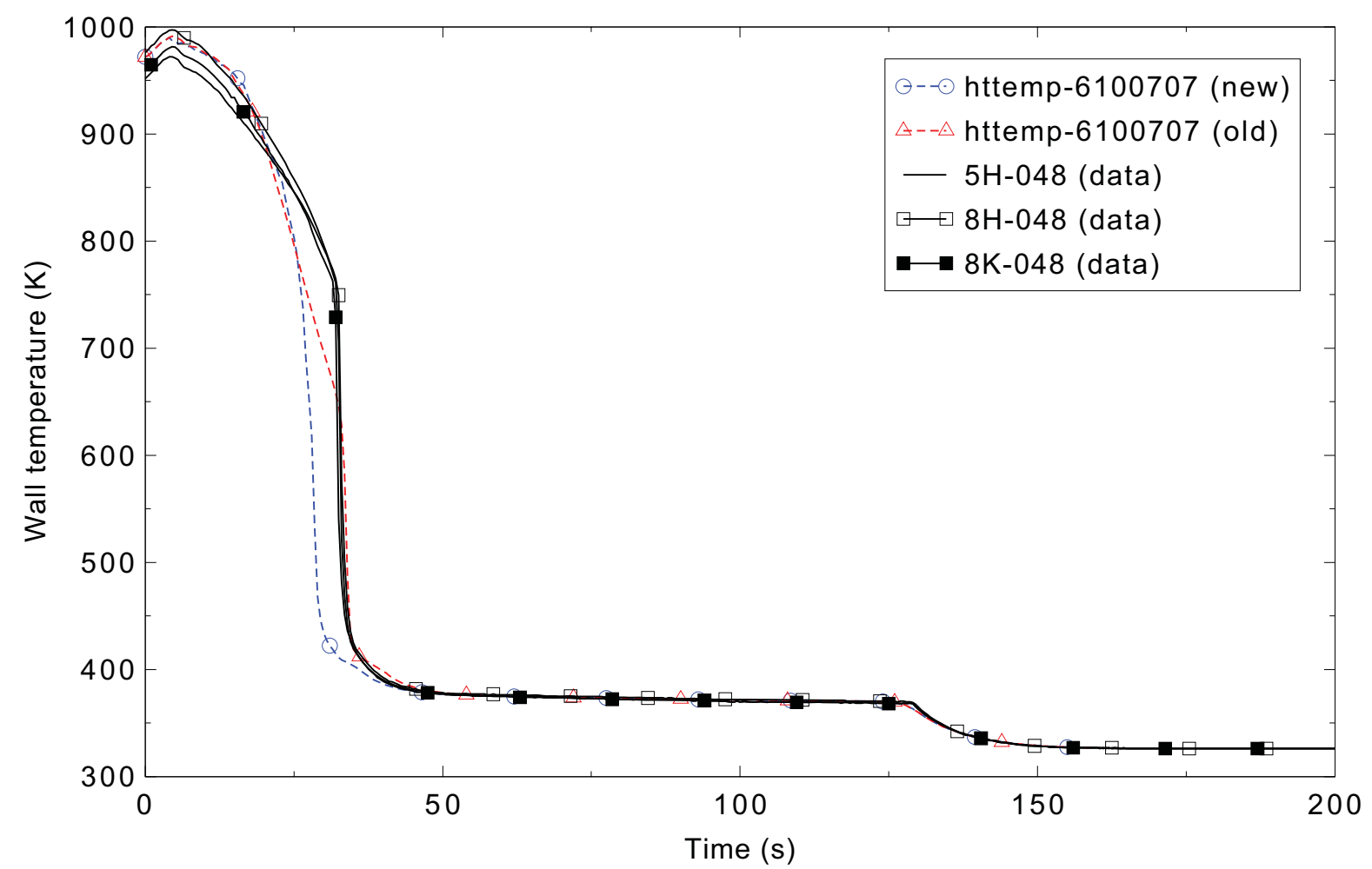

Figure 4.14-6. Measured and calculated rod surface temperatures for FLECHT SEASET forced reflood Test 31701 at the $1.22-\mathrm{m}$ (48-in.) elevation. 


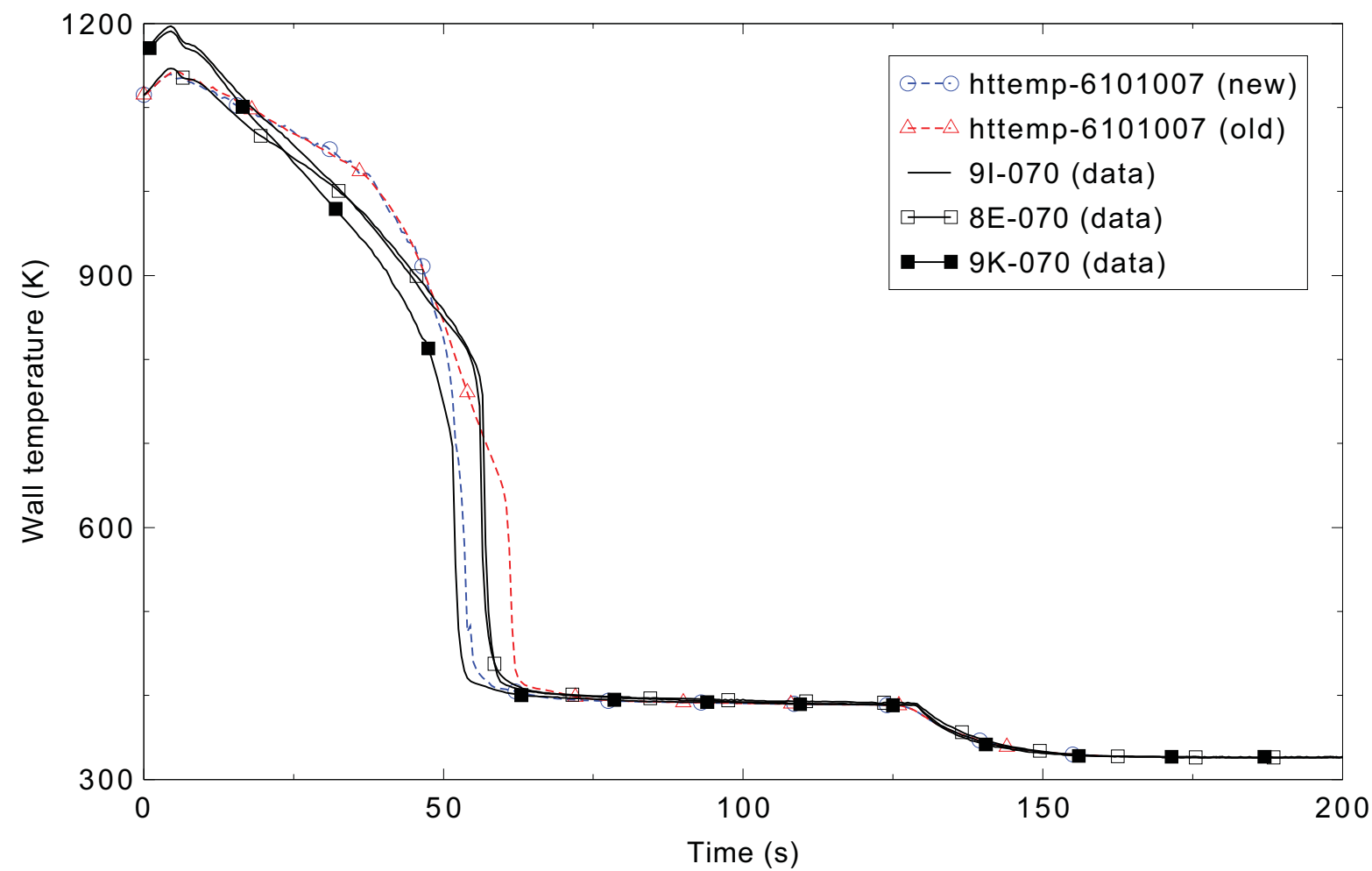

Figure 4.14-7. Measured and calculated rod surface temperatures for FLECHT SEASET forced reflood Test 31701 at the $1.78-\mathrm{m}$ (70-in.) elevation.

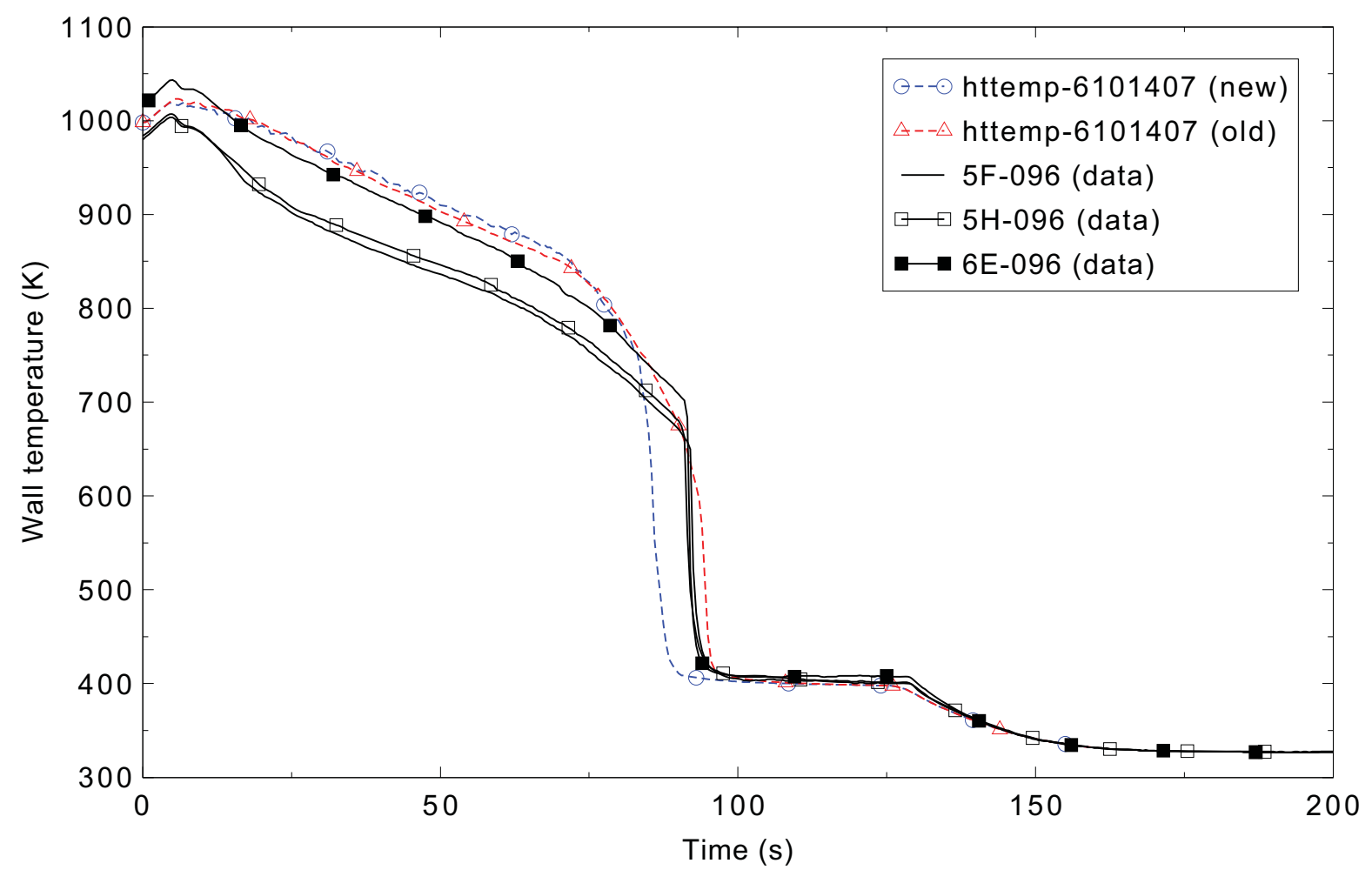

Figure 4.14-8. Measured and calculated rod surface temperatures for FLECHT SEASET forced reflood Test 31701 at the $2.46-\mathrm{m}$ (96-in.) elevation. 


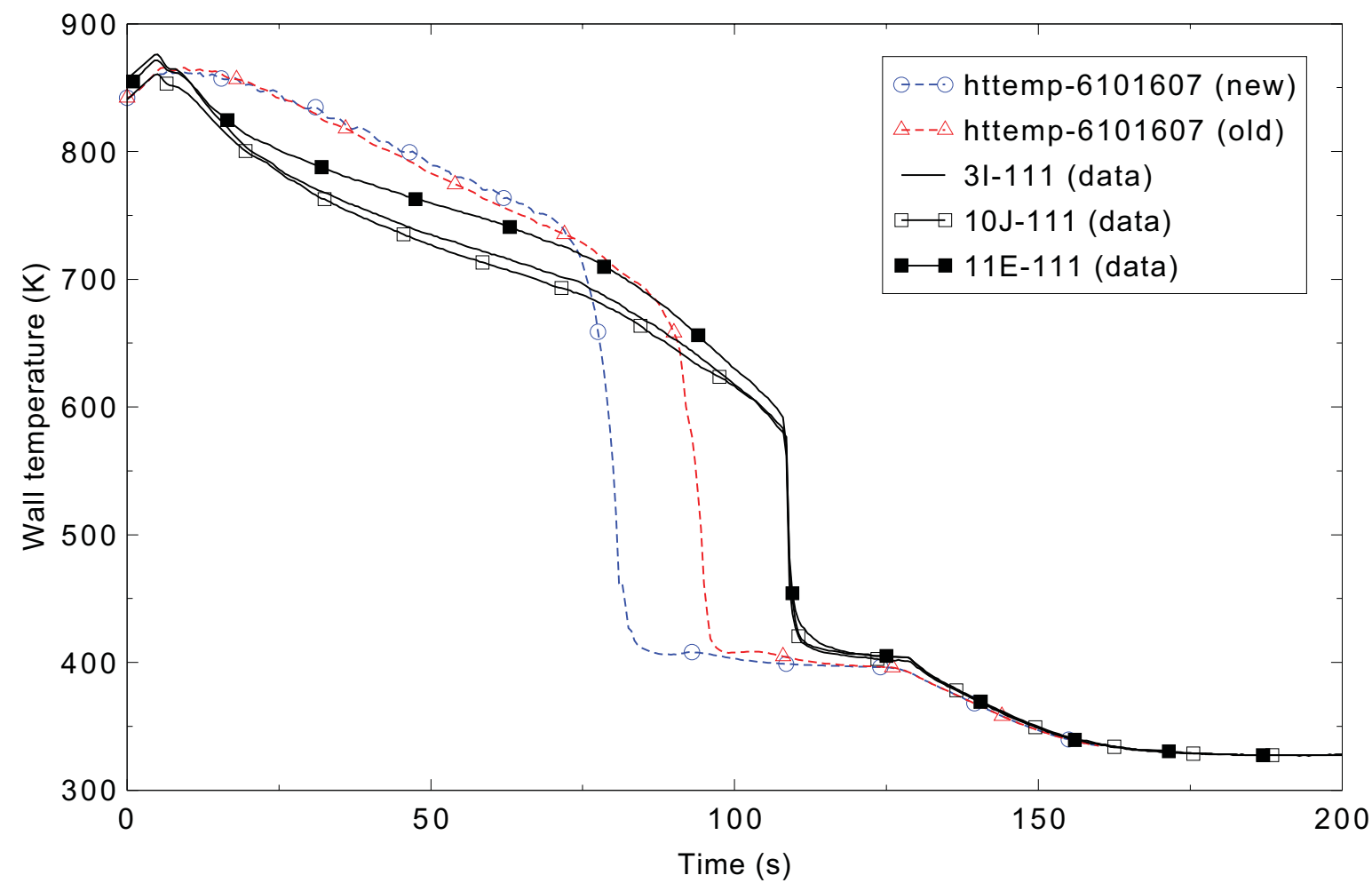

Figure 4.14-9. Measured and calculated rod surface temperatures for FLECHT SEASET forced reflood Test 31701 at the $2.85-\mathrm{m}$ (111-in.) elevation.

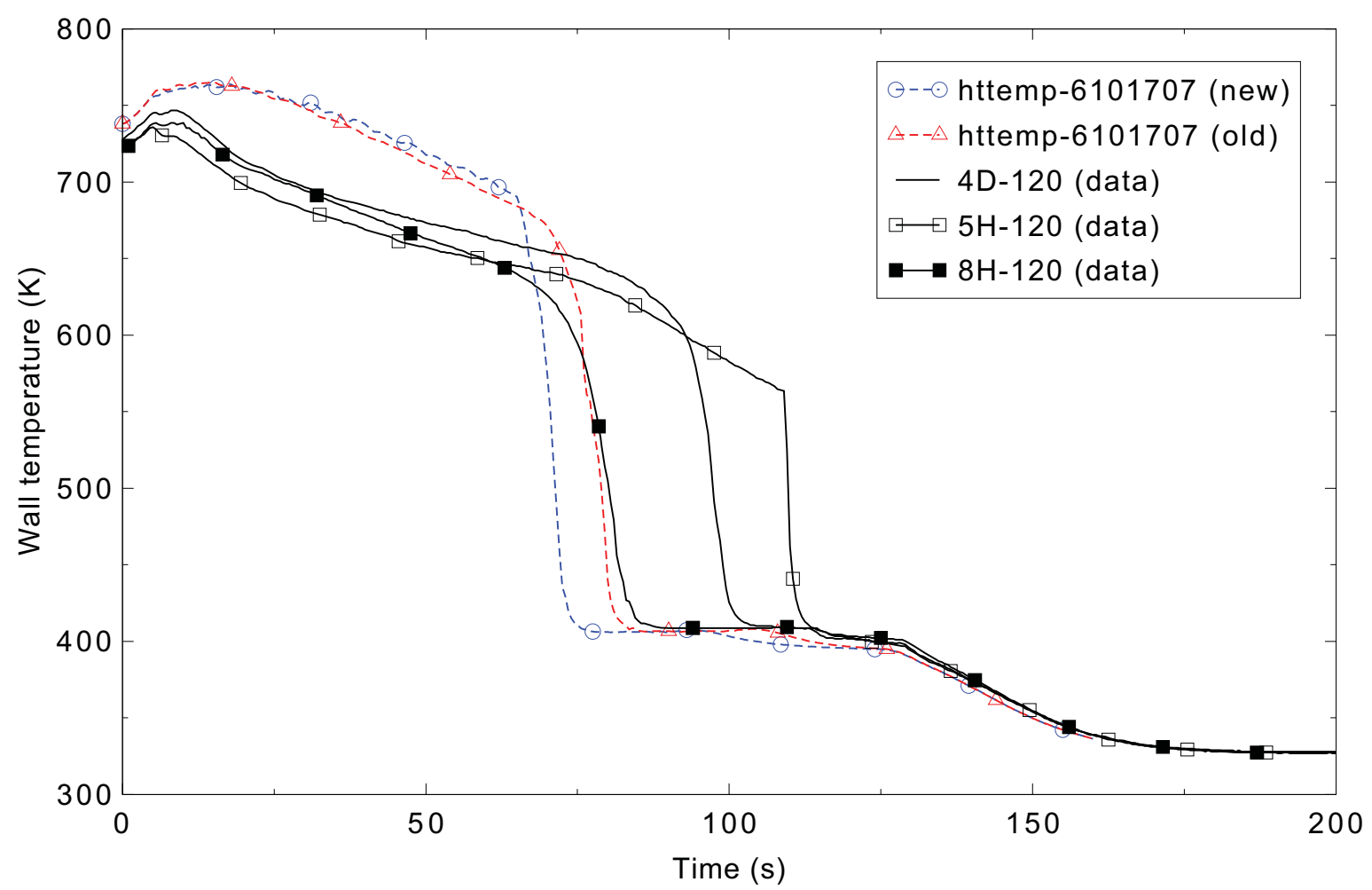

Figure 4.14-10. Measured and calculated rod surface temperatures for FLECHT SEASET forced reflood Test 31701 at the 3.08-m (120-in.) elevation. 


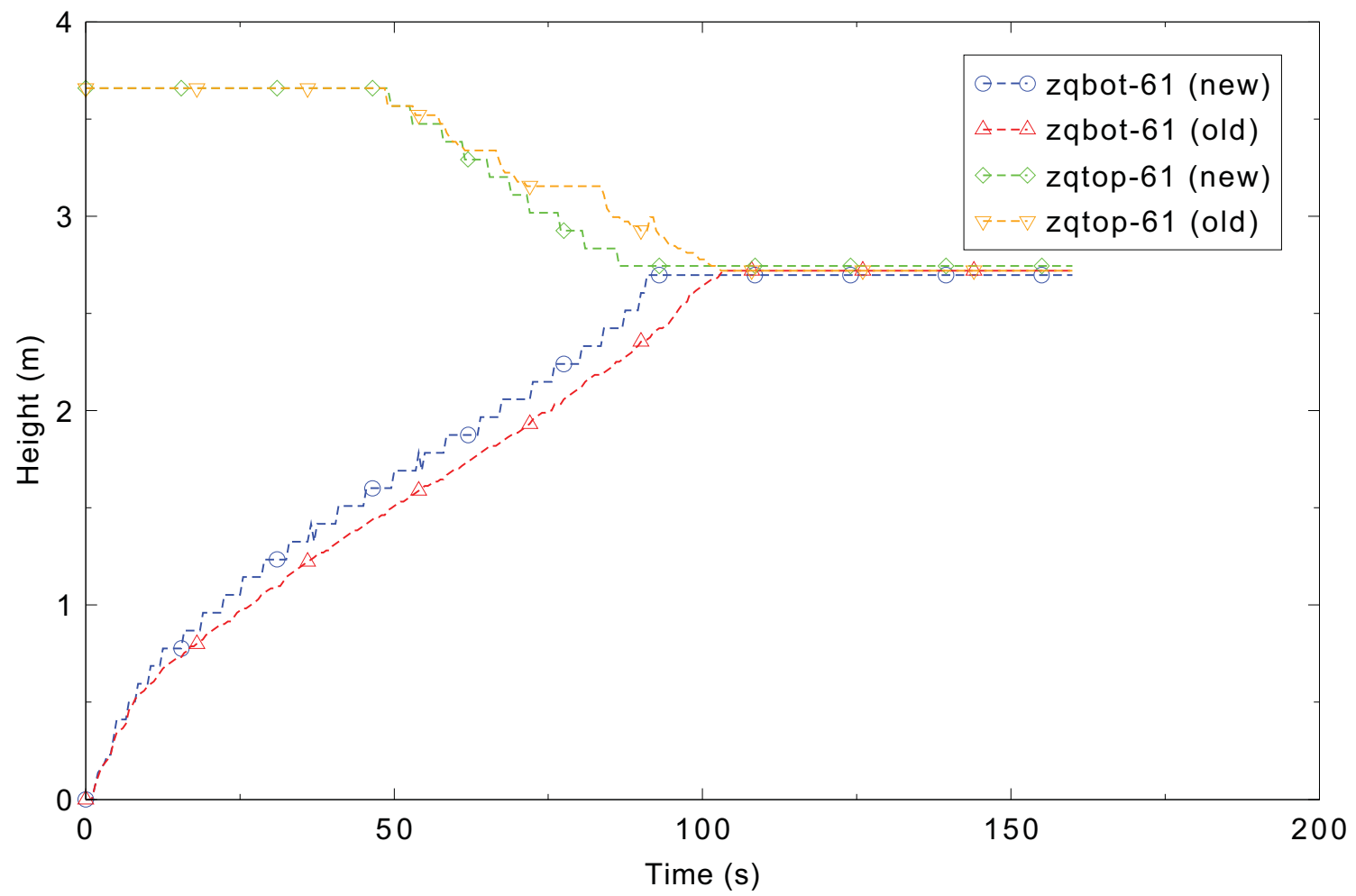

Figure 4.14-11. RELAP5-3D calculated rod bundle bottom and top quench behavior for FLECHT SEASET forced reflood Test 31701.

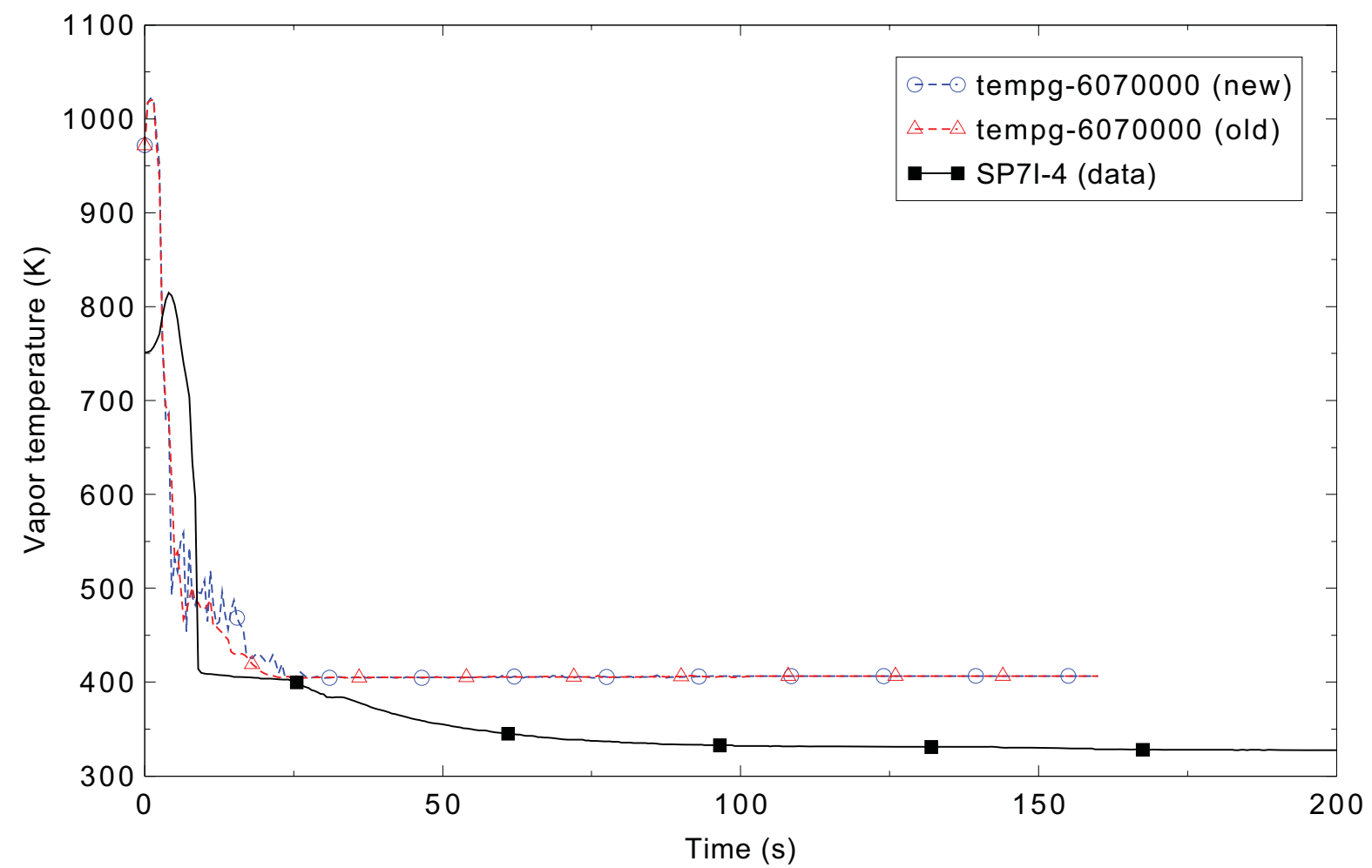

Figure 4.14-12. Measured and calculated steam temperatures for FLECHT SEASET forced reflood Test 31701 at the $1.23-\mathrm{m}(4-\mathrm{ft})$ elevation. 


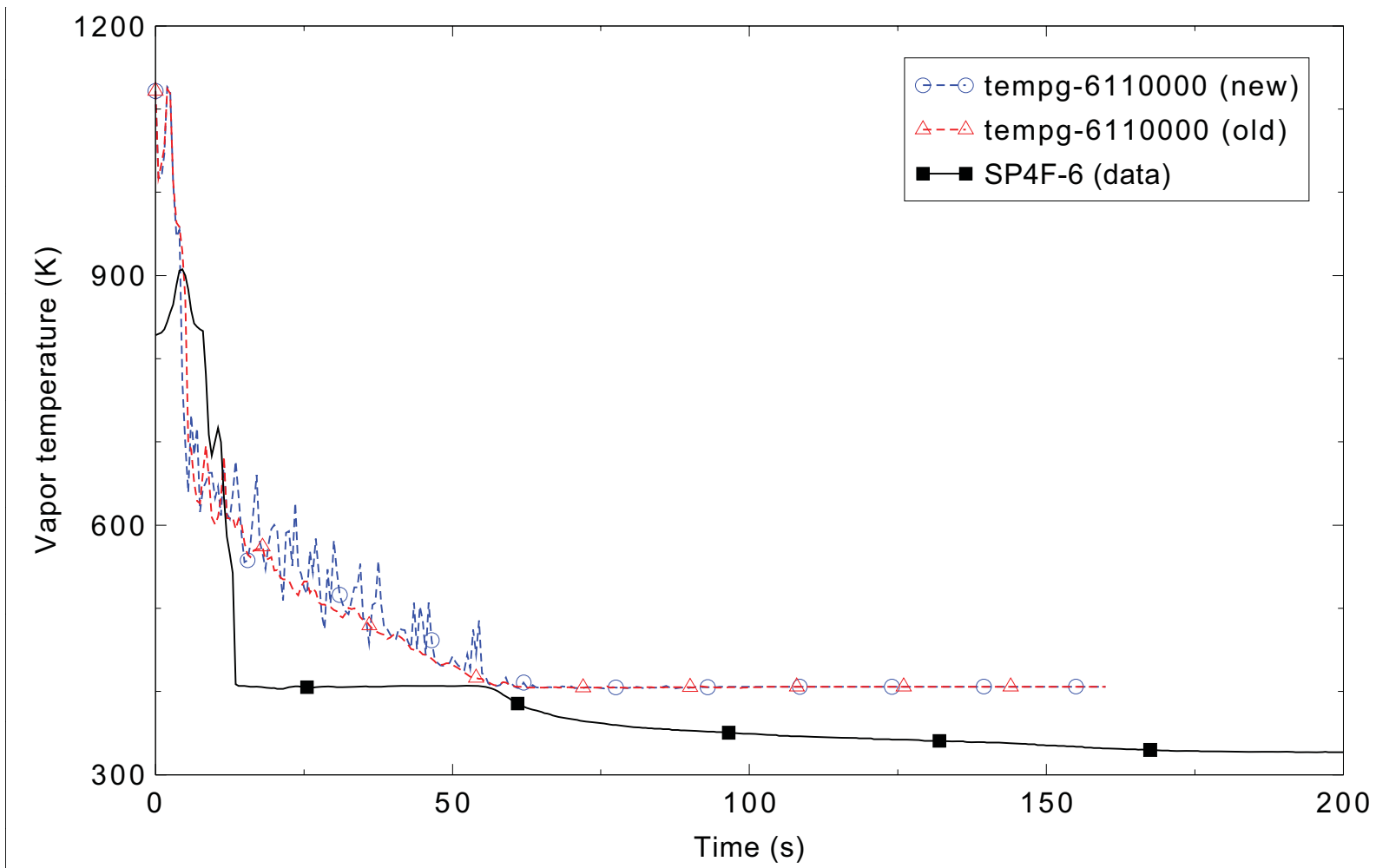

Figure 4.14-13. Measured and calculated steam temperatures for FLECHT SEASET forced reflood Test 31701 at the $1.85-\mathrm{m}(6-\mathrm{ft})$ elevation.

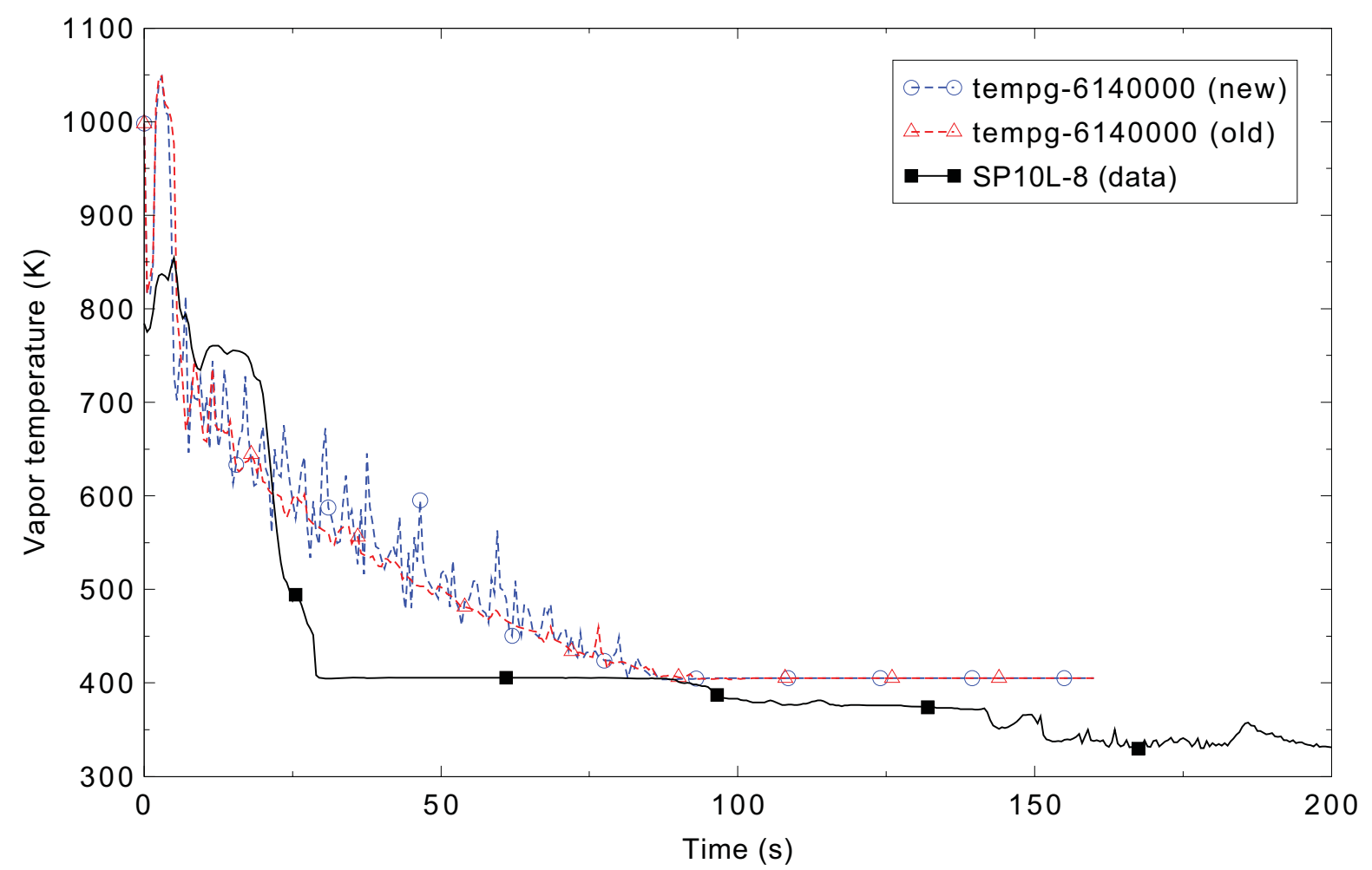

Figure 4.14-14. Measured and calculated steam temperatures for FLECHT SEASET forced reflood Test 31701 at the $2.46-\mathrm{m}(8-\mathrm{ft})$ elevation. 


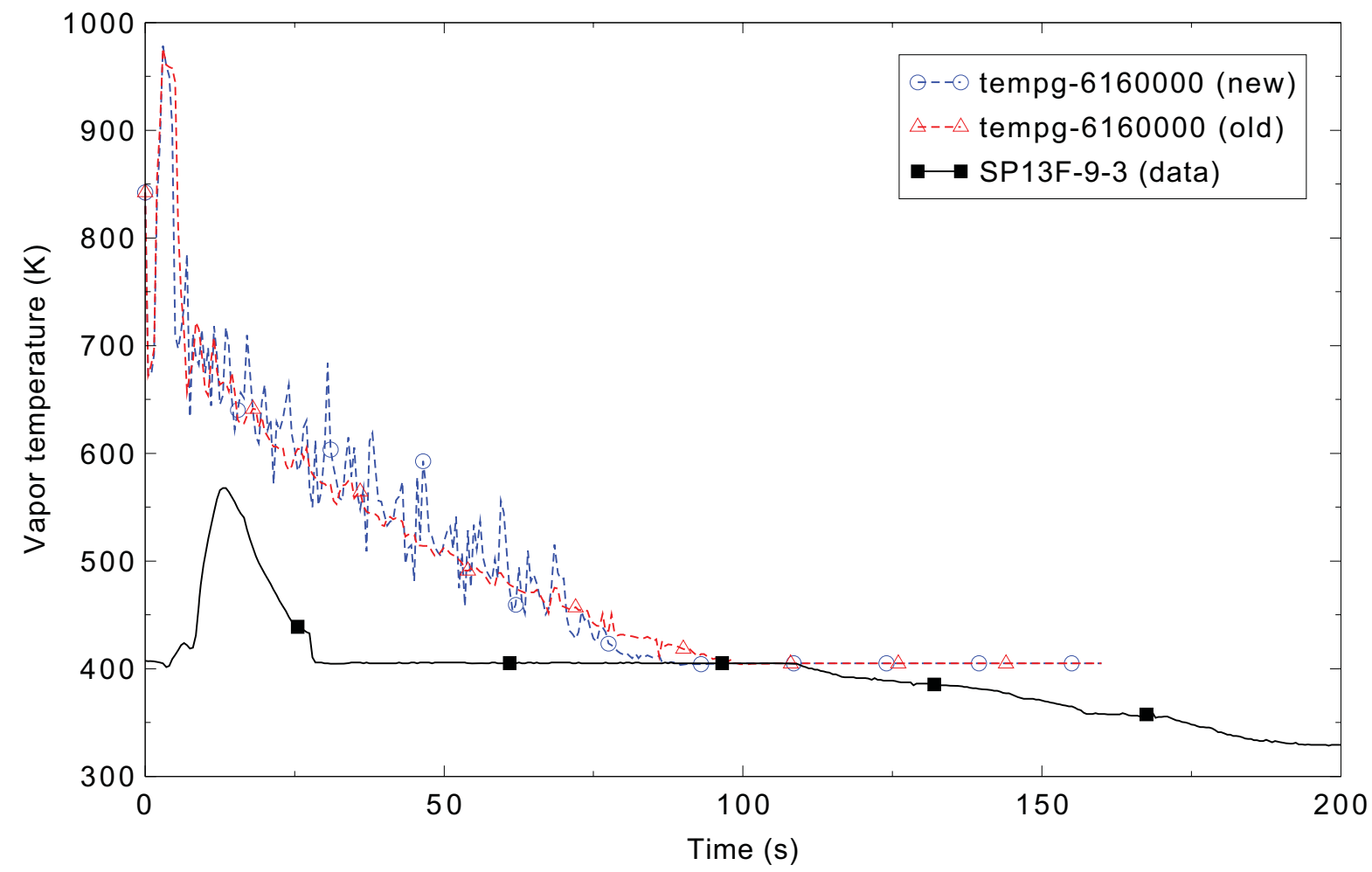

Figure 4.14-15. Measured and calculated steam temperatures for FLECHT SEASET forced reflood Test 31701 at the $2.85-\mathrm{m}(9.25-\mathrm{ft})$ elevation.

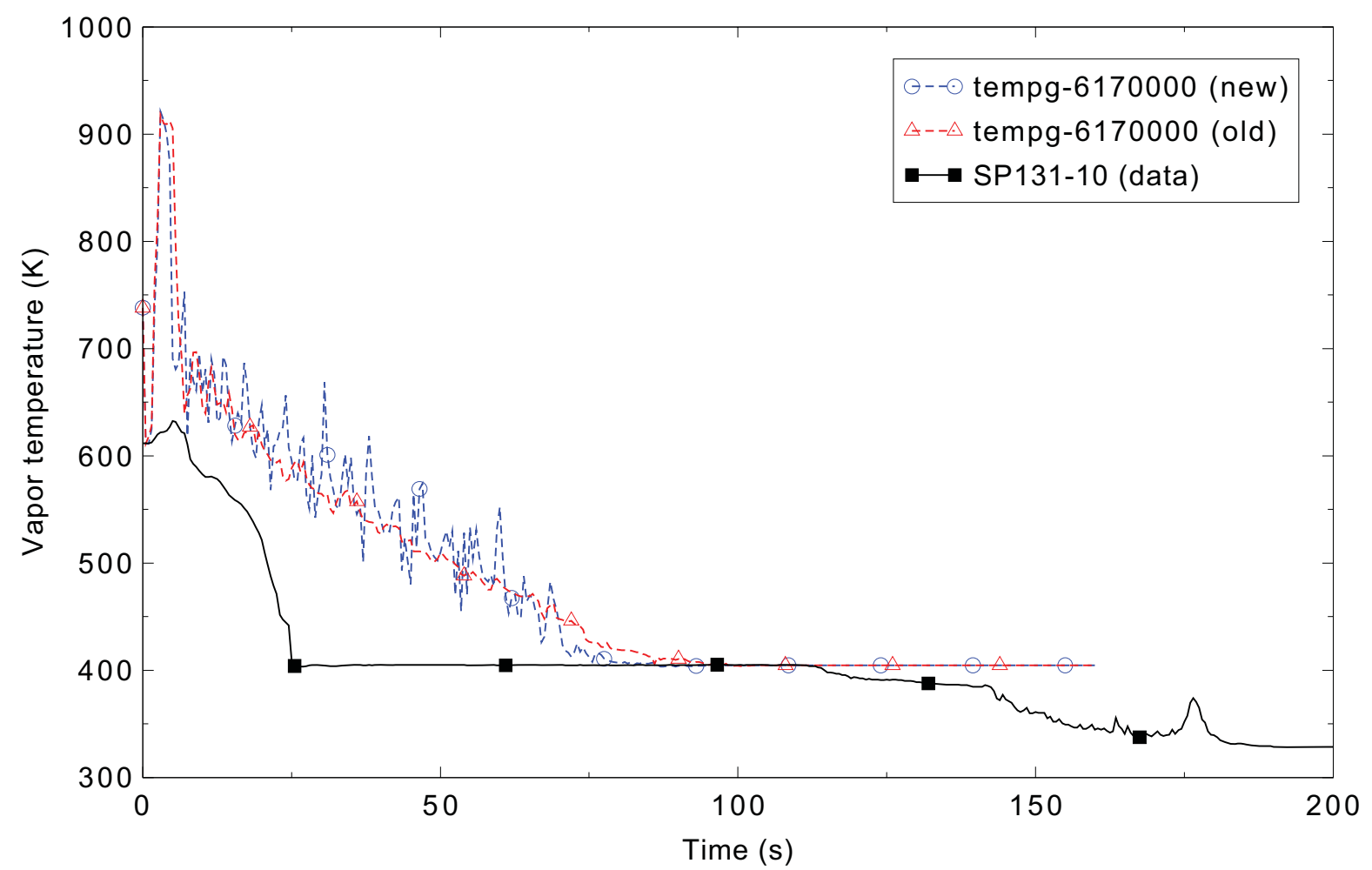

Figure 4.14-16. Measured and calculated steam temperatures for FLECHT SEASET forced reflood Test 31701 at the $3.08-\mathrm{m}(10-\mathrm{ft})$ elevation. 


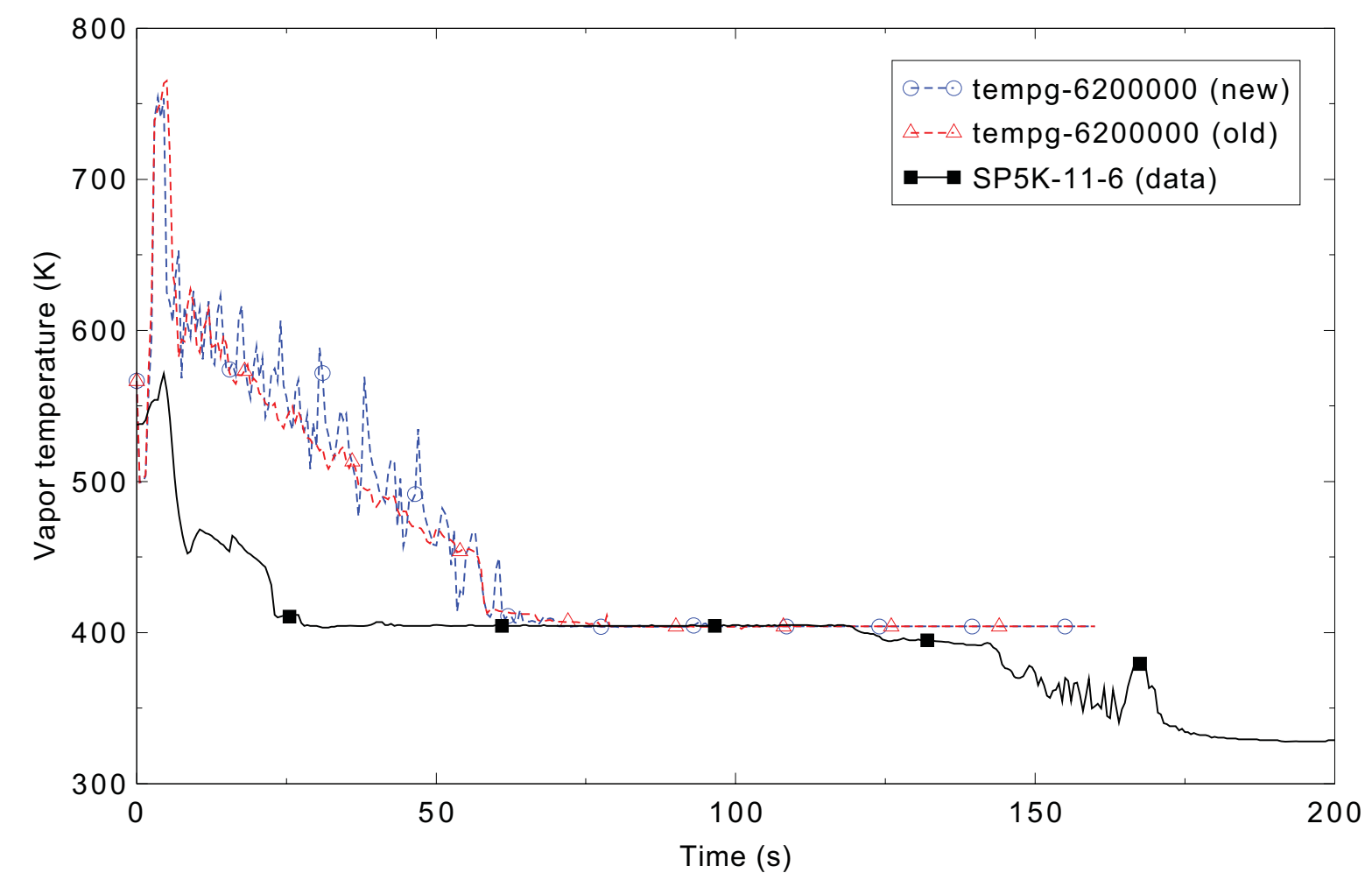

Figure 4.14-17. Measured and calculated steam temperatures for FLECHT SEASET forced reflood Test 31701 at the 3.54-m (11.5-ft) elevation.

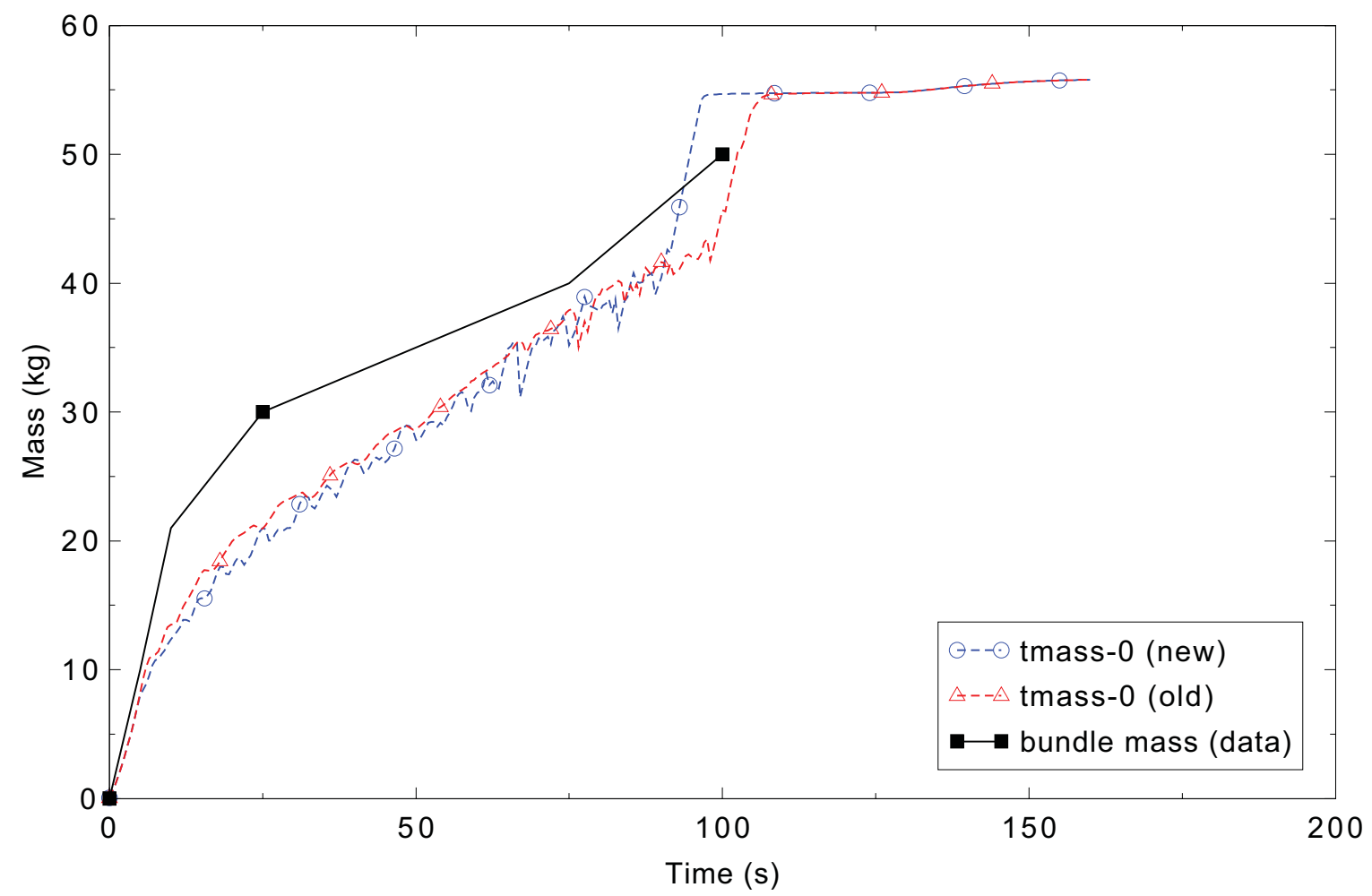

Figure 4.14-18. Measured and calculated total bundle mass inventory for FLECHT SEASET forced reflood Test 31701. 


\subsection{Dukler-Smith Air-Water Flooding}

Figures comparing simulations using two code versions are presented. Diagrams are included so that the figure numbering is the same as that in Volume III of the RELAP5-3D code manual. No differences were observed in the figures.

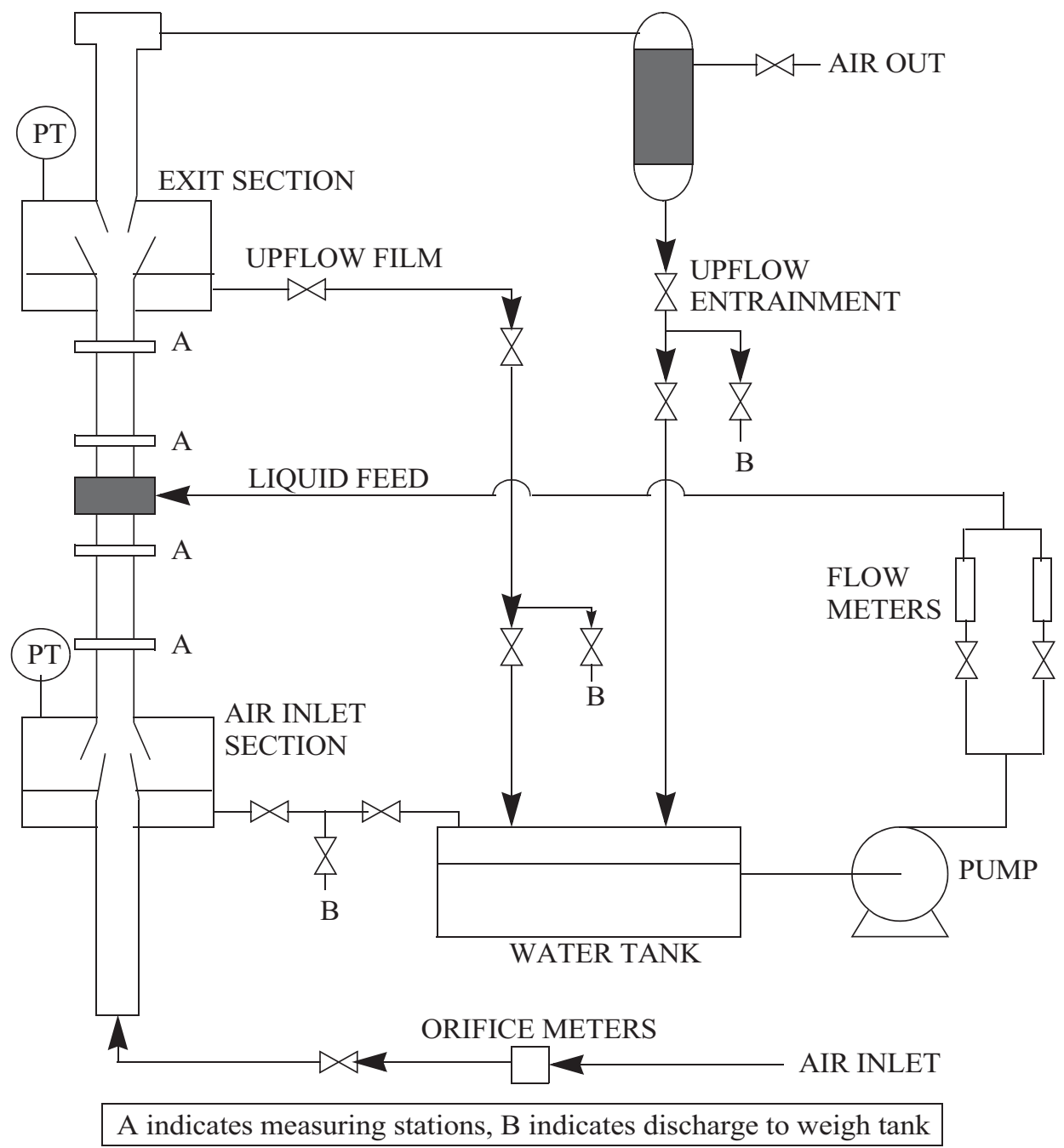

Figure 4.15-1. Schematic of the Dukler-Smith Air-Water Test Facility (from Reference 4.15-3). 
RELAP5-3D/4.0.3

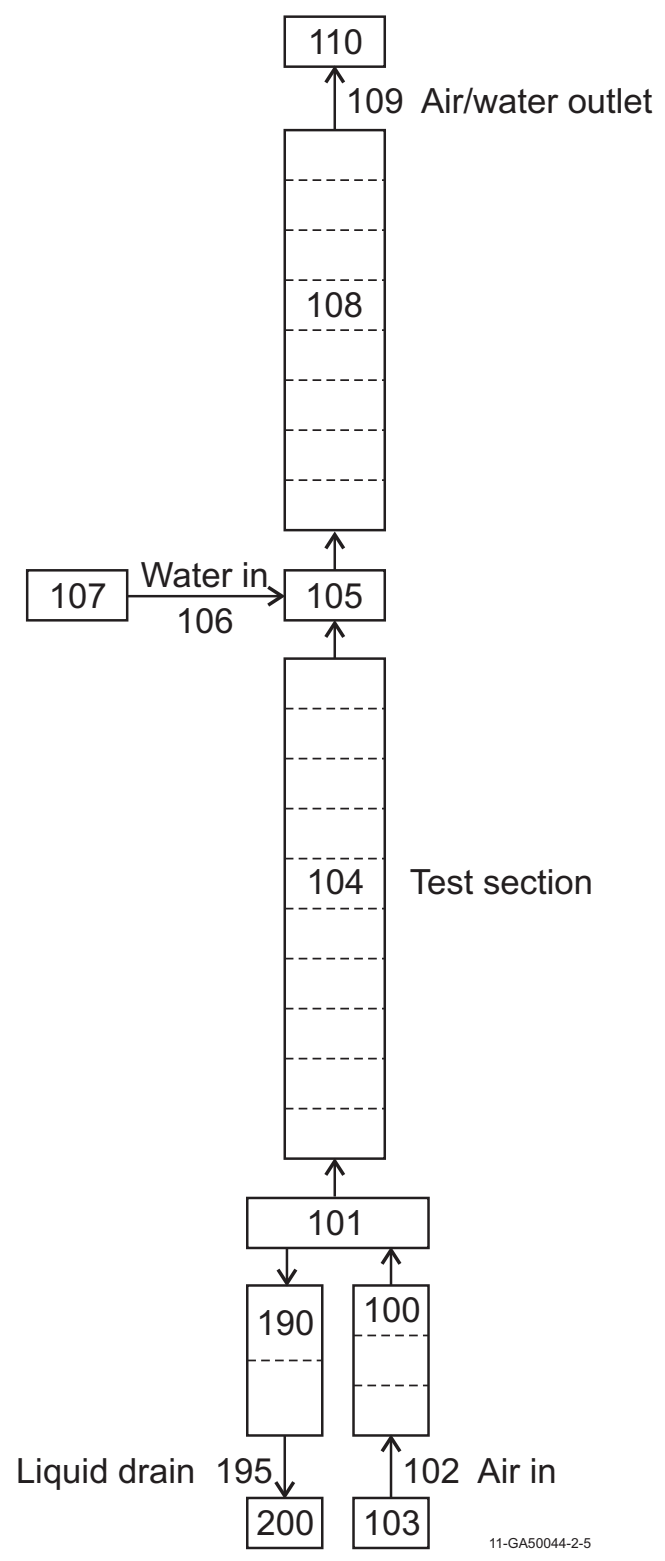

Figure 4.15-2. Nodalization diagram for the Dukler-Smith test facility. 


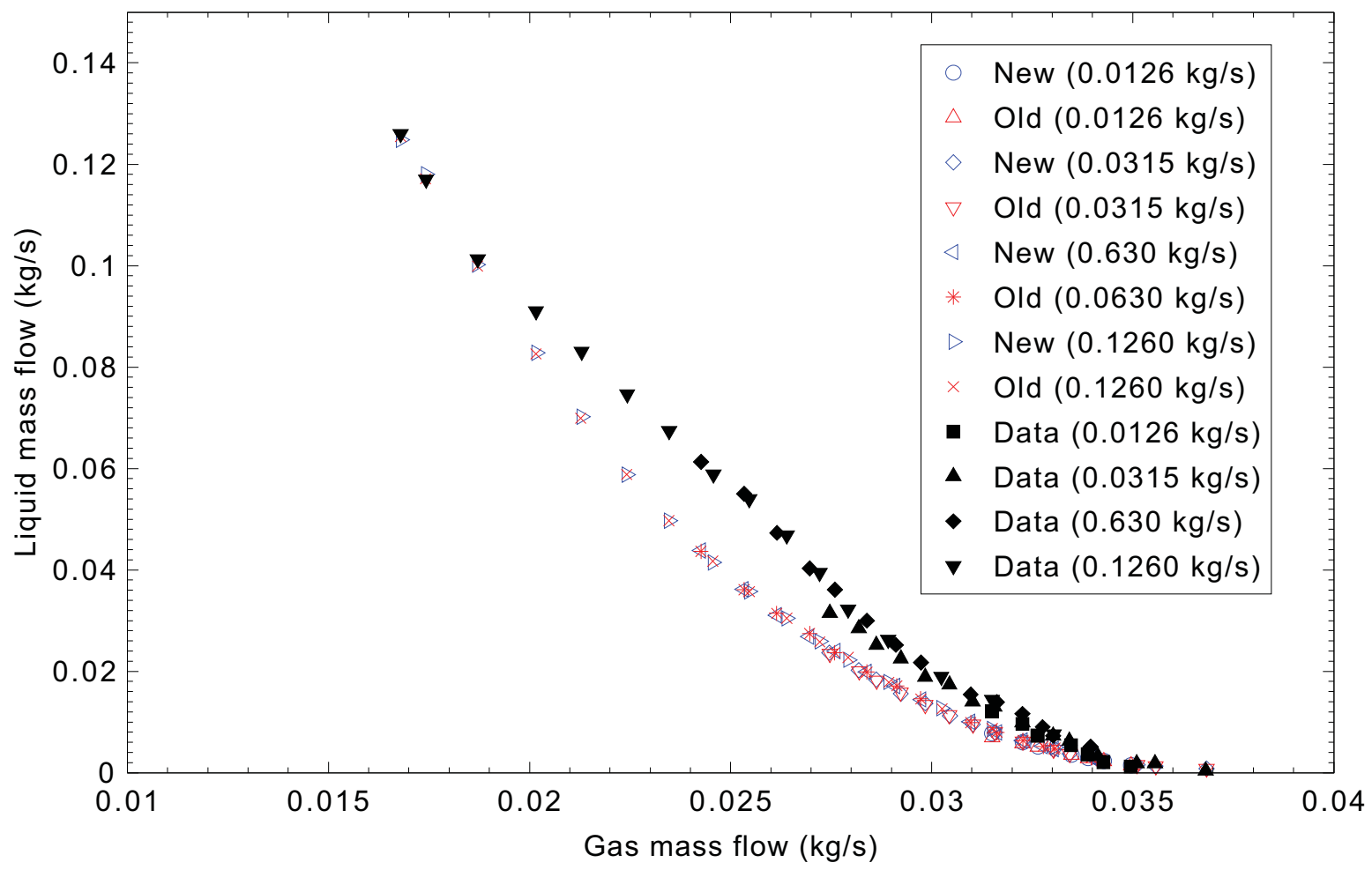

Figure 4.15-3. Comparison of RELAP5-3D predictions to Dukler-Smith data.

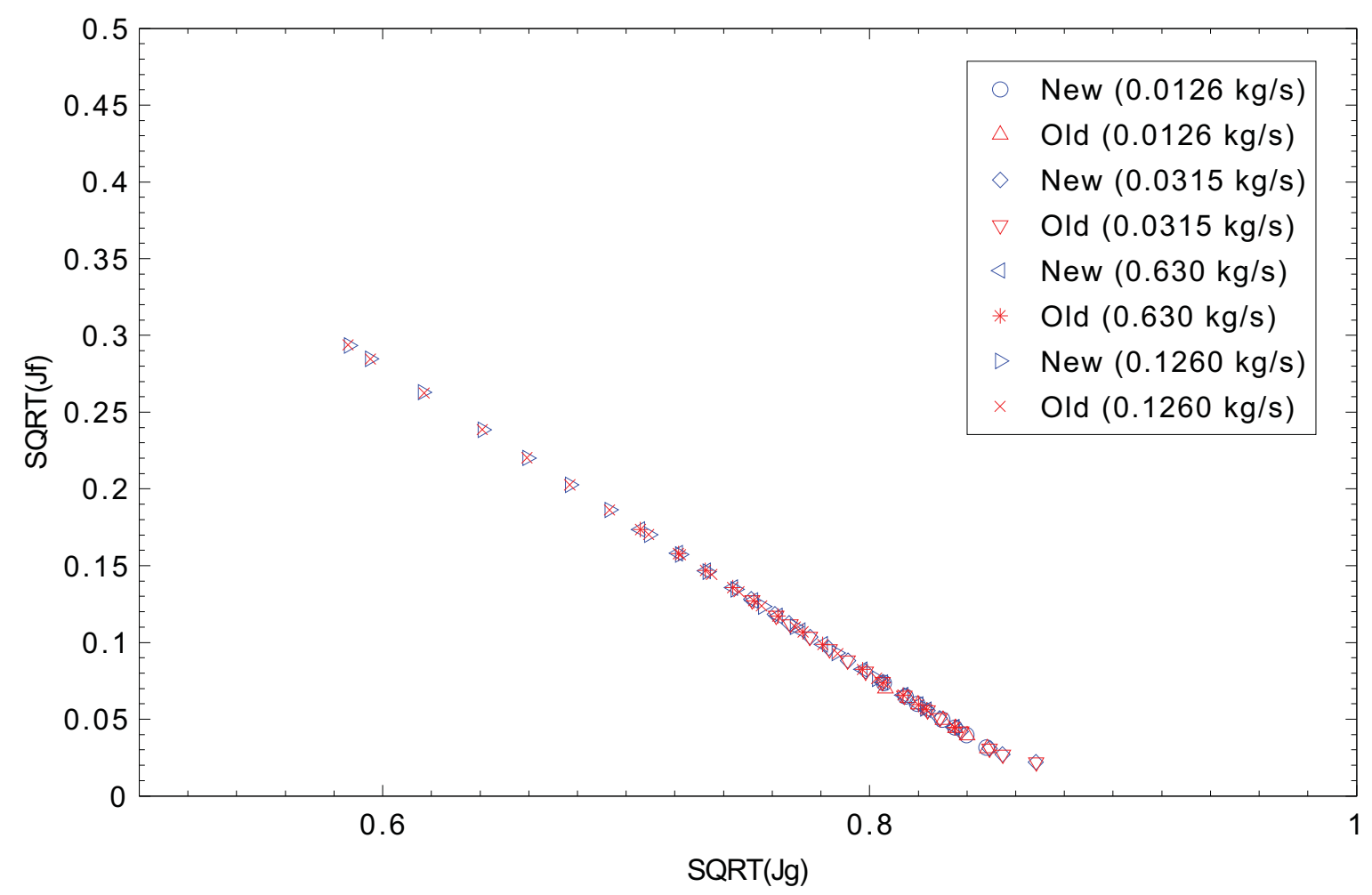

Figure 4.15-4. RELAP5-3D calculated superficial liquid velocity versus superficial gas velocity for the Dukler-Smith test. 


\subsection{UPTF Downcomer CCFL Test 6, Run 131}

Figures comparing simulations using two code versions are presented. Diagrams are included so that the figure numbering is the same as that in Volume III of the RELAP5-3D code manual. Noticeable differences were observed in Figures 4.16-5, 6, 7, 8, and 9.

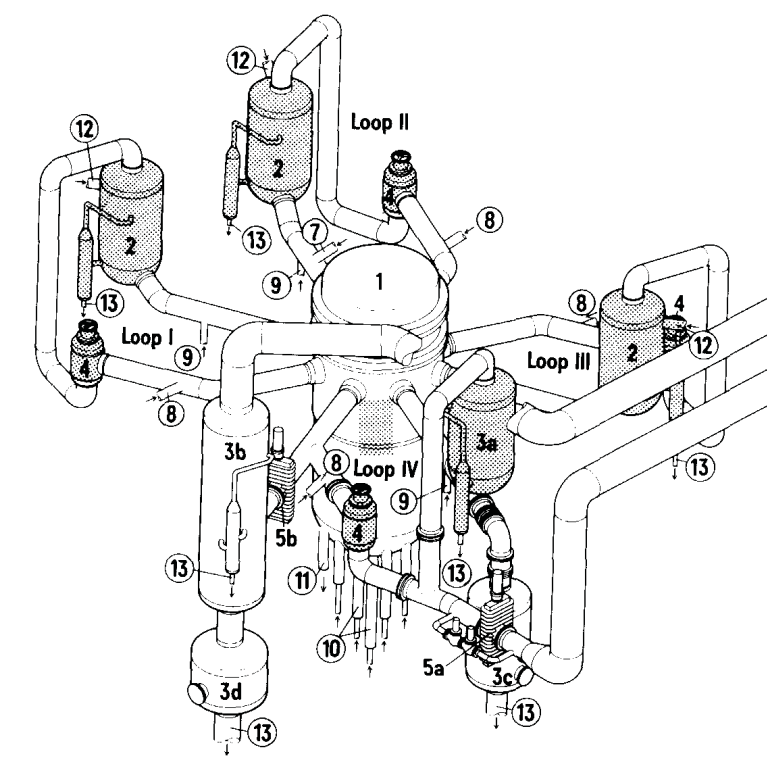
1 Test Vessel
2 Steam Generator Simulator (Intact Loop)
3 a Steam Generator Simulator/ Water Separator
(Broken Loop Hot Leg)
$3 \mathrm{~b}$ Water Separator (Broken Loop Cold Leg)
$3 c$ Drainage Vessel for Hot Leg
3d Drainage Vessel for Cold Leg
4 Pump Simulator
5 a Break Valve (Hot Leg)
5 b Break Valve (Cold Leg)
6 Containment Simulator
(7) Surgeline-Nozzle
(8) ECC-Injection Nozzles (Cold Leg)
(9) ECC-Injection Nozzles (Hot Leg)
(10) Core Simulator Injection Nozzle
(11) TV.Drainage Nozzle
(12) Steam Injection Nozzle
(13) Drainage Nozzle

Simulator

Figure 4.16-1. Schematic of the UPTF. 


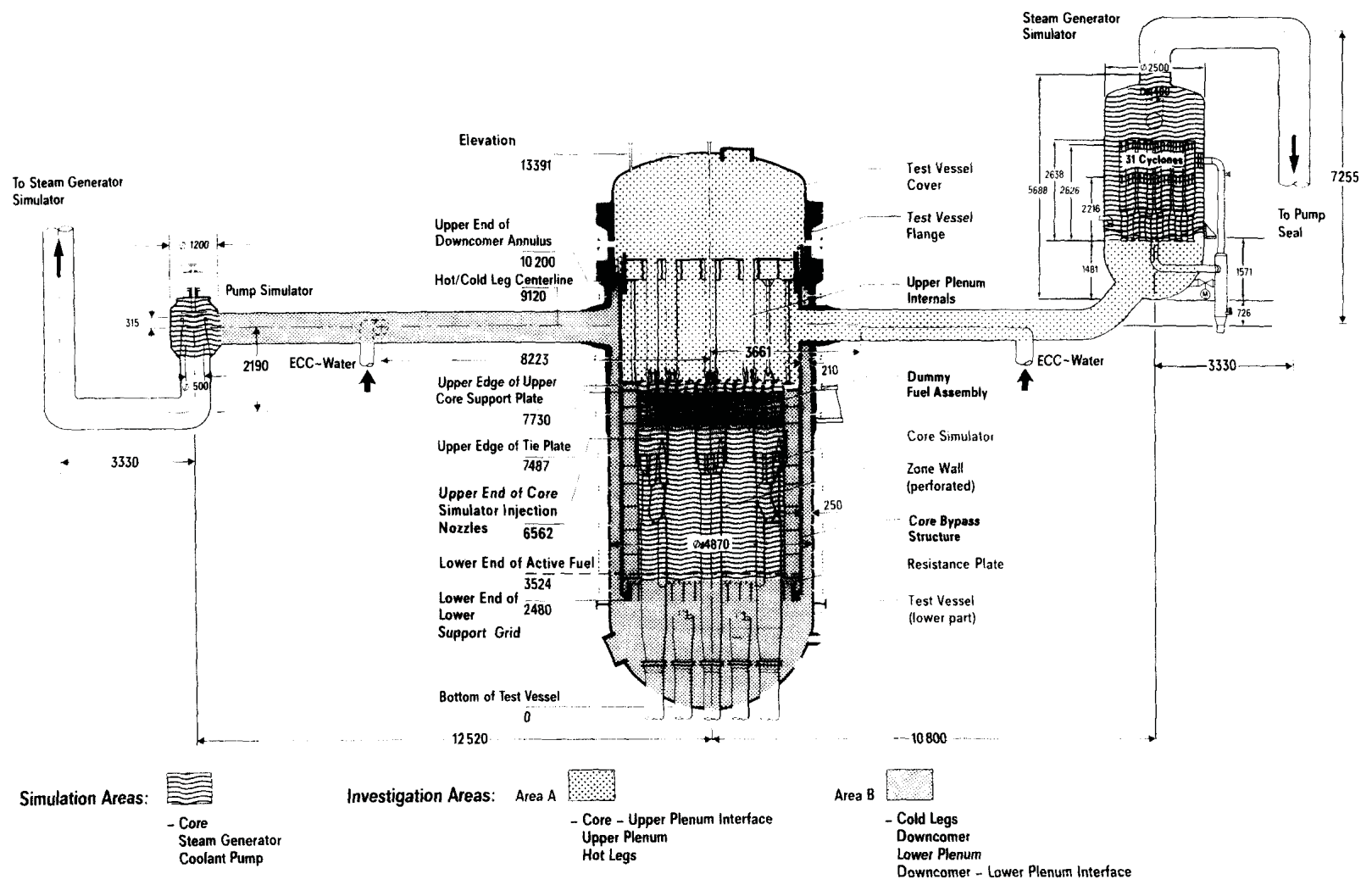

Figure 4.16-2. Key dimensions of the UPTF.

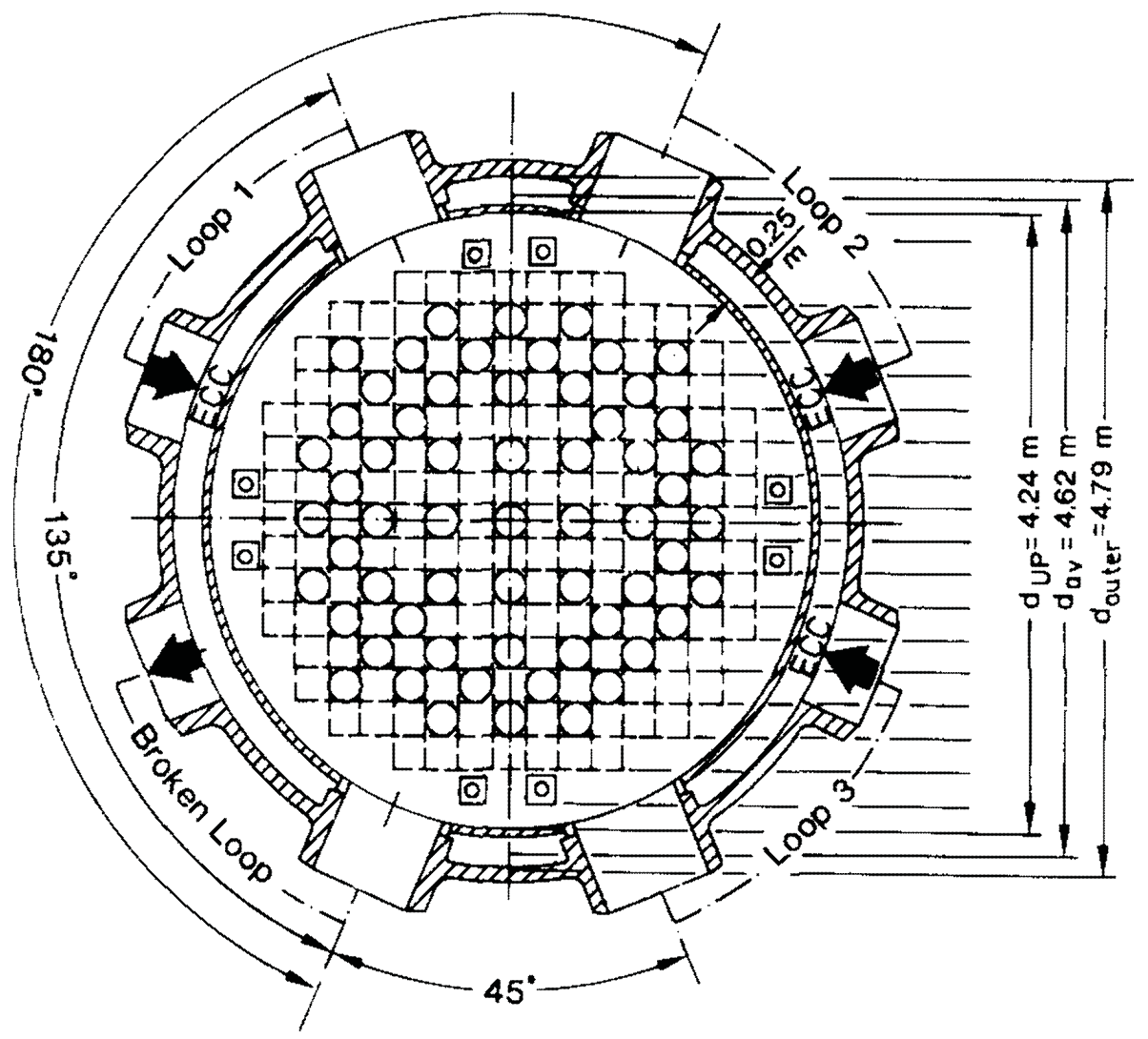

Figure 4.16-3. Cross-section of the UPTF reactor vessel. 


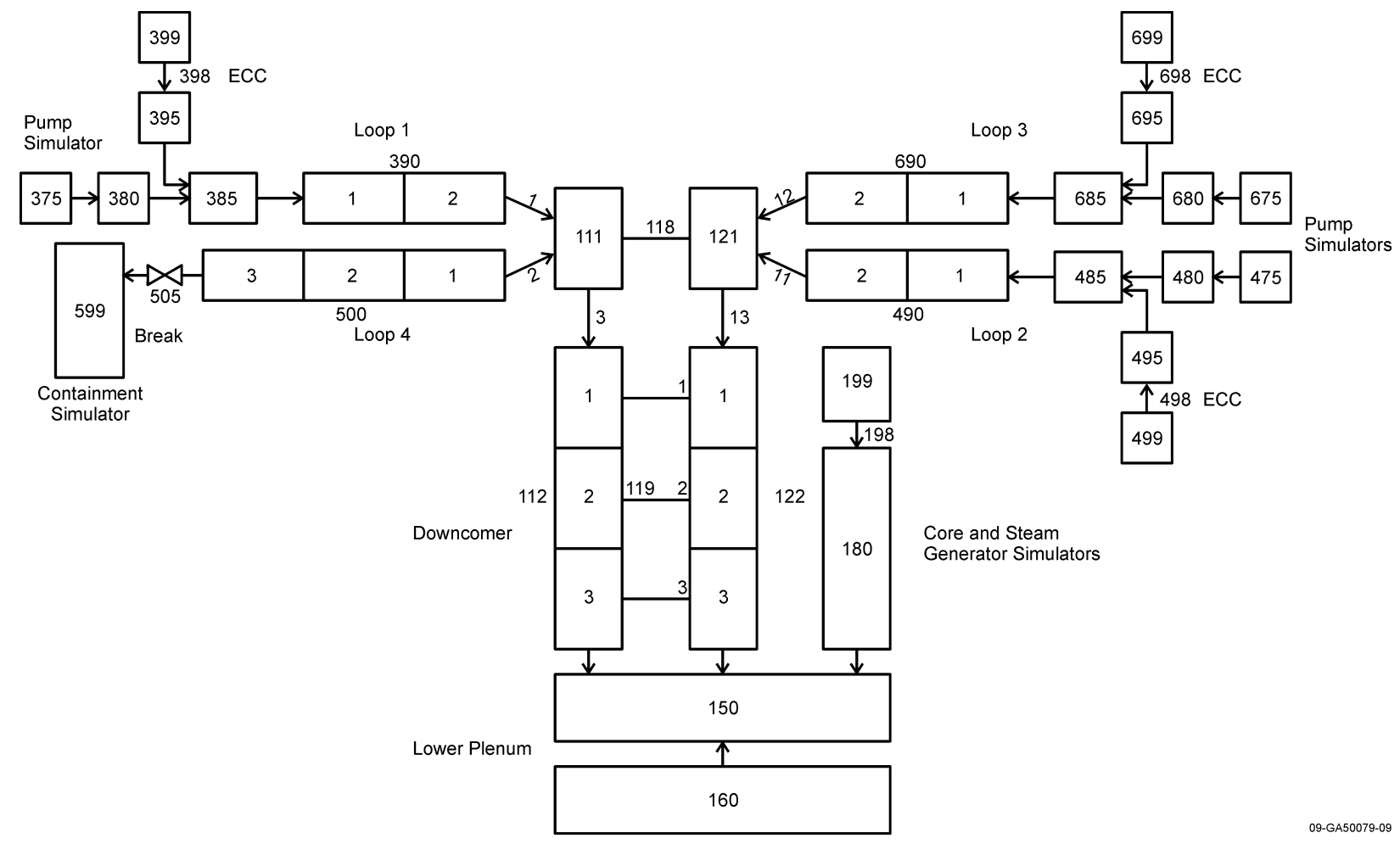

Figure 4.16-4. RELAP5-3D nodalization for UPTF Test 6.

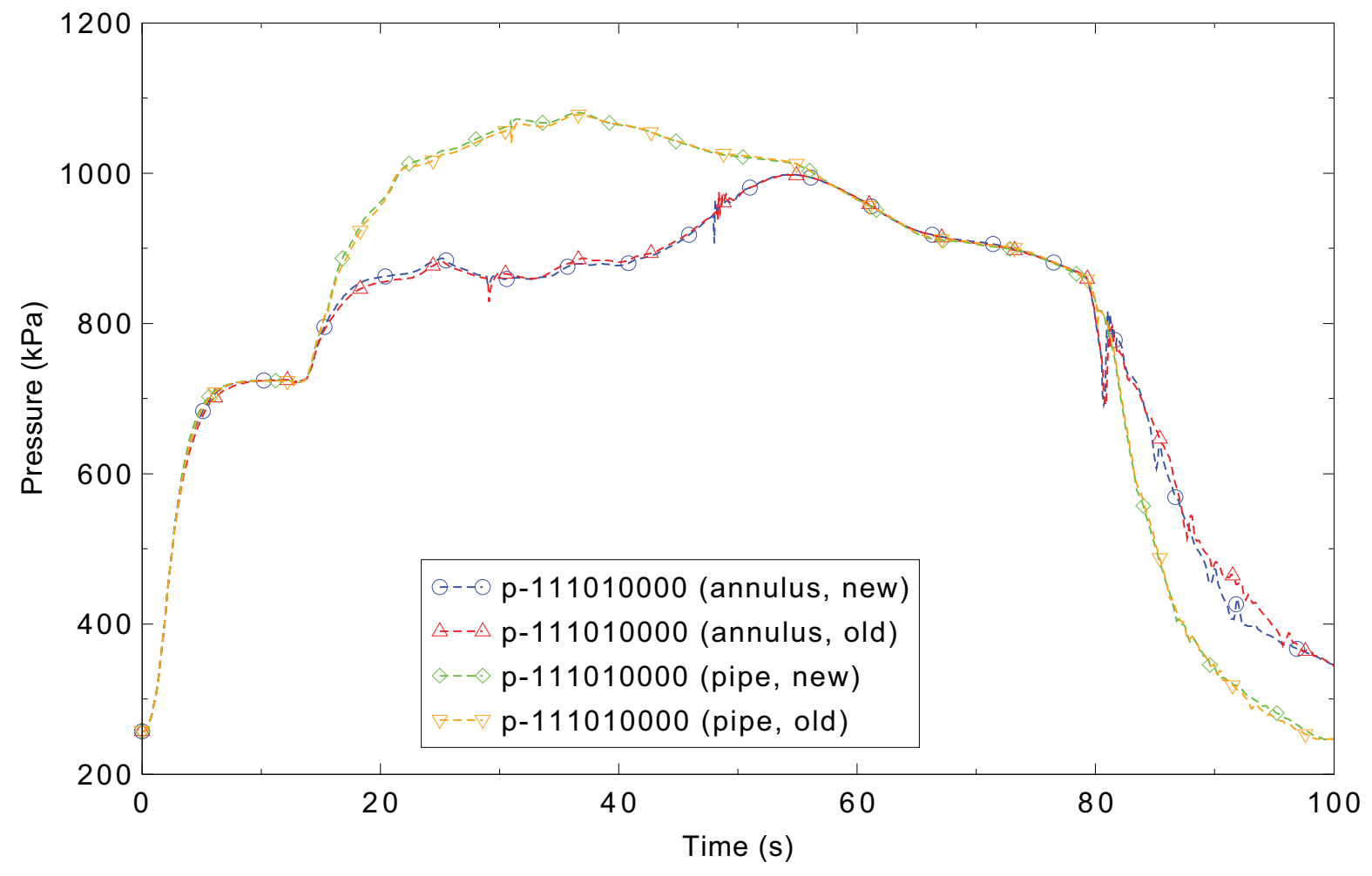

Figure 4.16-5. Downcomer pressure in UPTF Test 6, Run 131. 


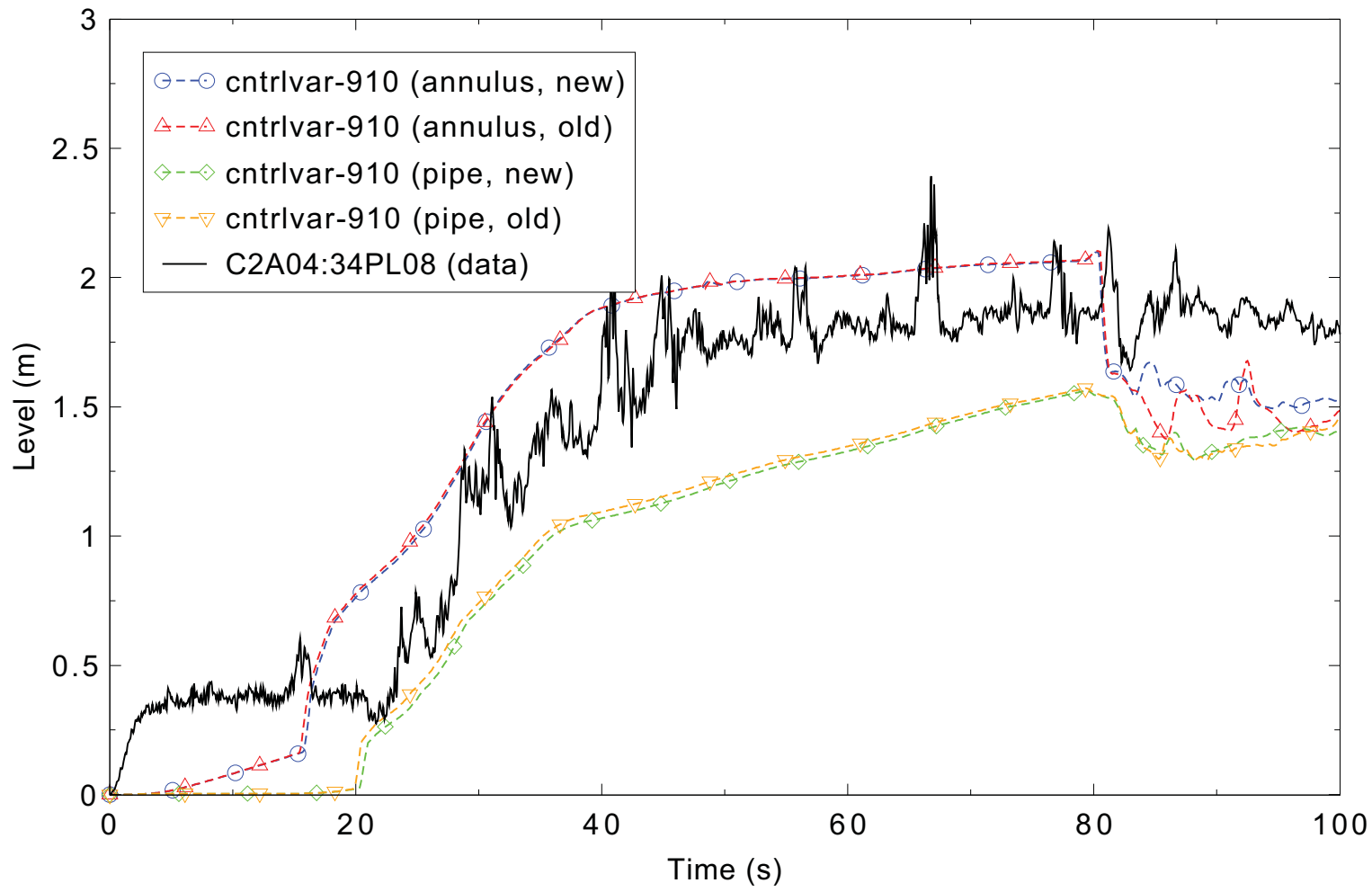

Figure 4.16-6. Collapsed liquid level in the lower plenum in UPTF Test 6, Run 131.

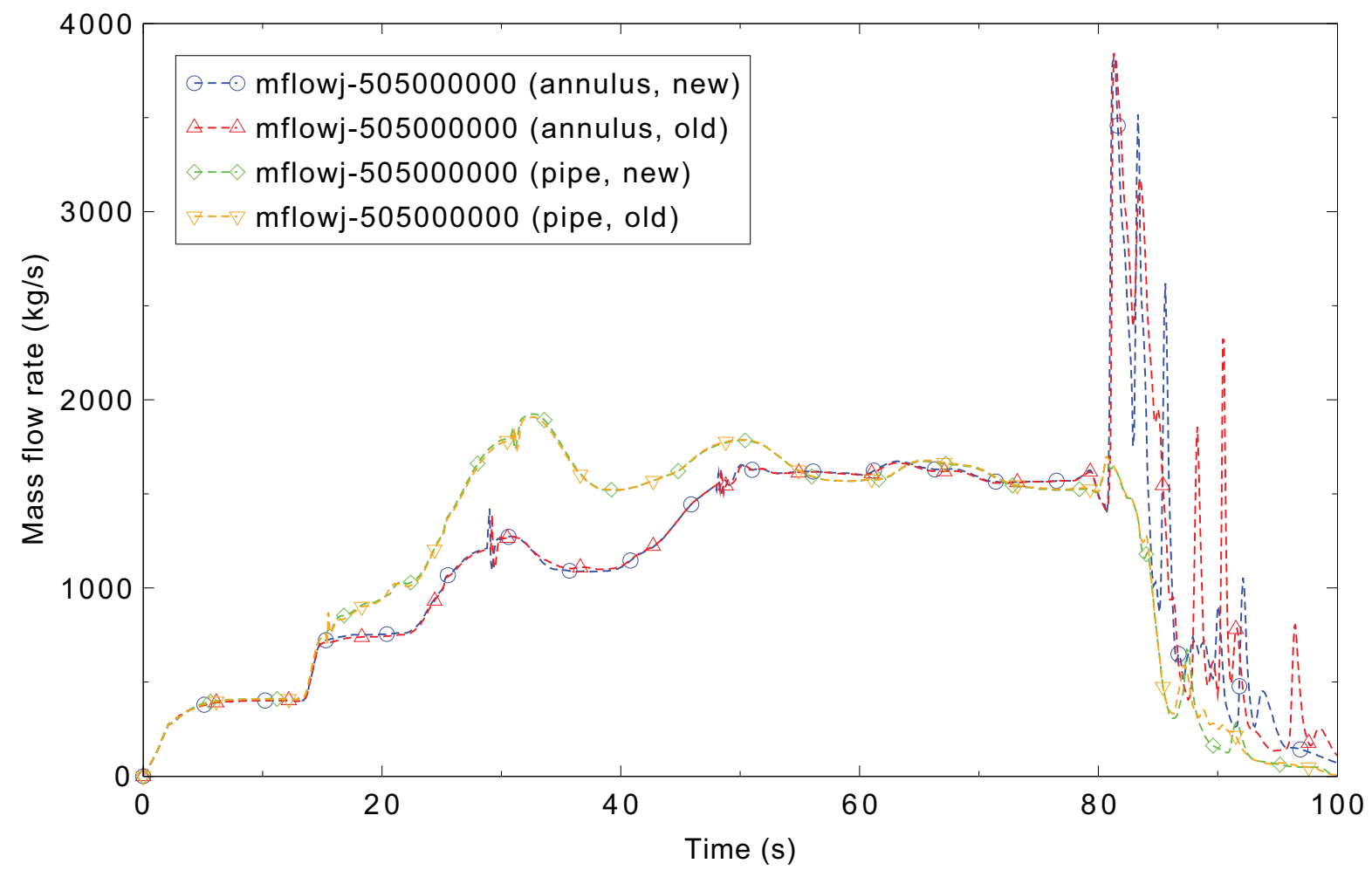

Figure 4.16-7. Break mass flow in UPTF Test 6, Run 131. 


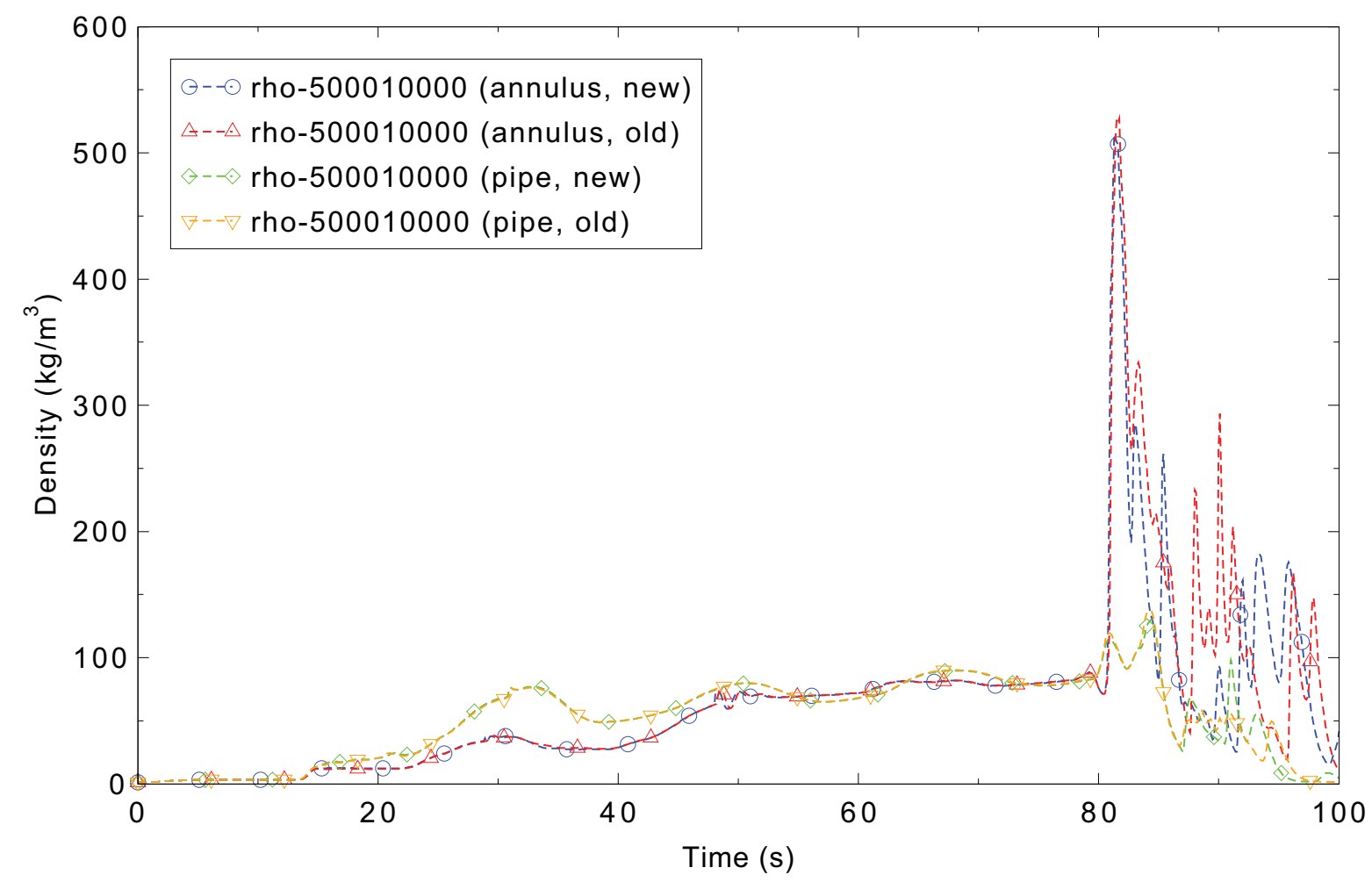

Figure 4.16-8. Fluid density in the broken cold leg in UPTF Test 6, Run 131.

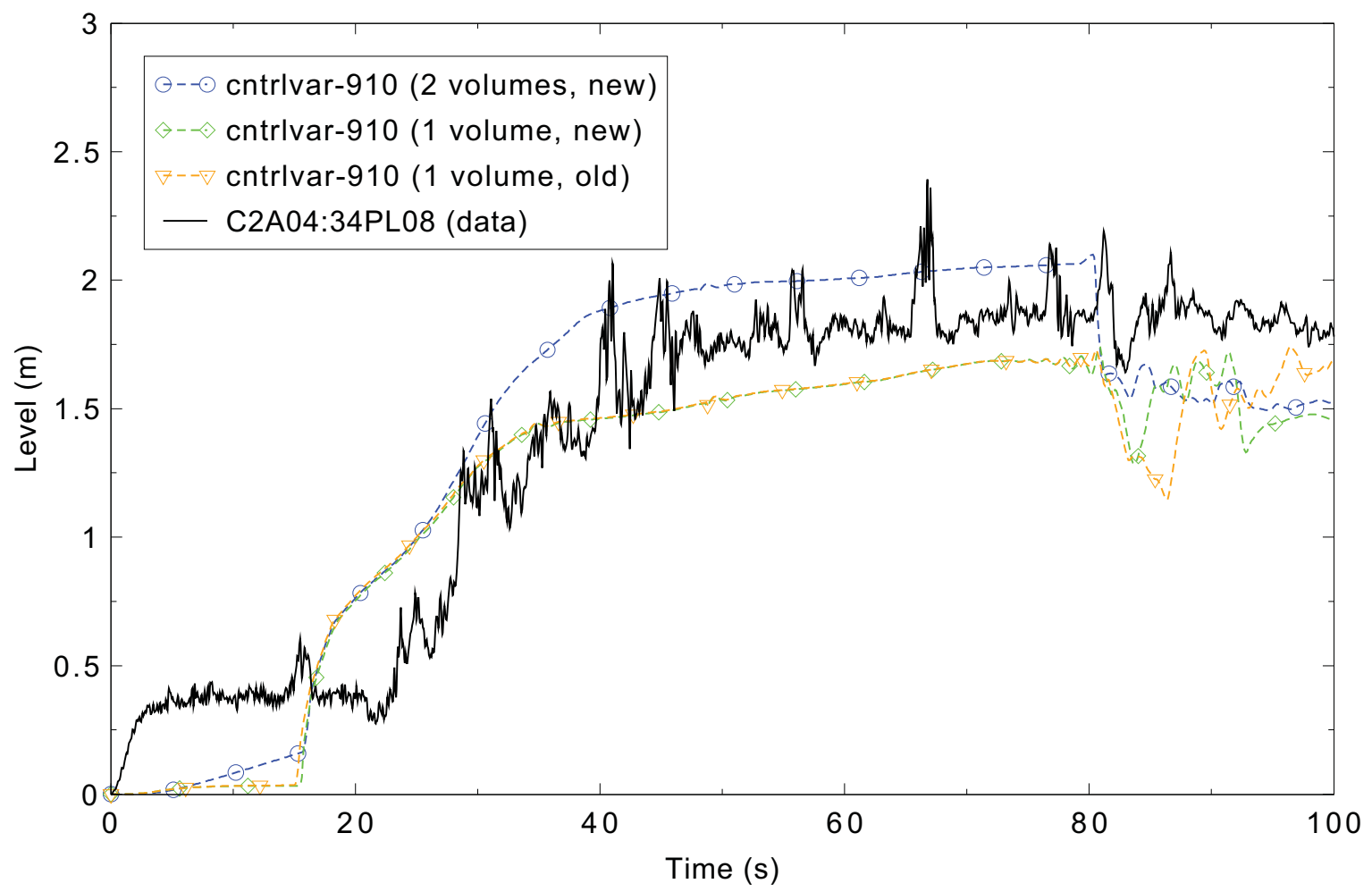

Figure 4.16-9. The effect of nodalization on collapsed liquid level in UPTF Test 6, Run 131. 


\subsection{MIT Pressurizer Test ST4}

Figures comparing simulations using two code versions are presented. Diagrams are included so that the figure numbering is the same as that in Volume III of the RELAP5-3D code manual. Significant differences were observed in Figures 4.17-4 and 5; noticeable differences were observed in Figures 4.17-3 and 6.

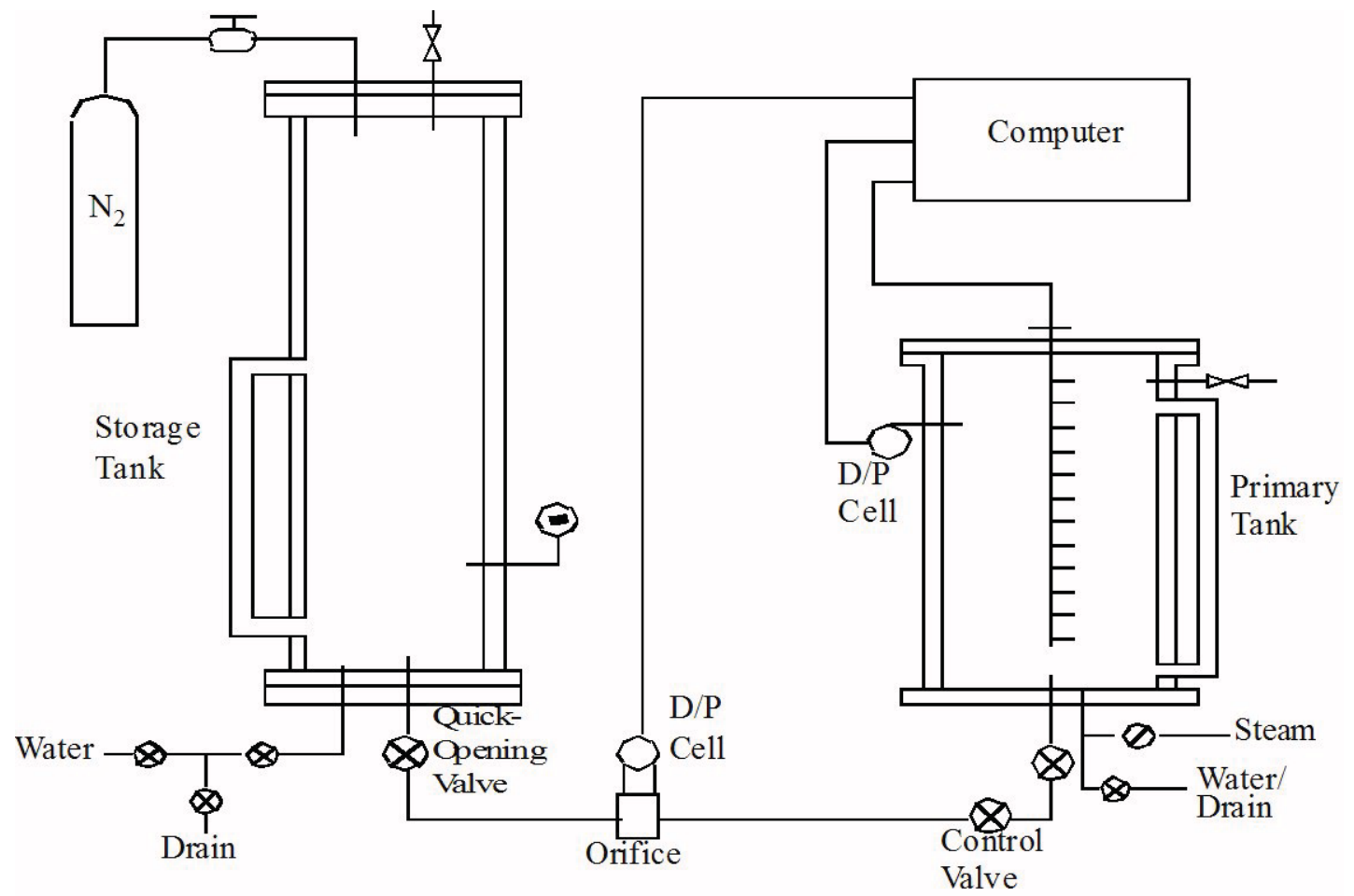

Figure 4.17-1. Schematic of MIT Pressurizer test facility. 


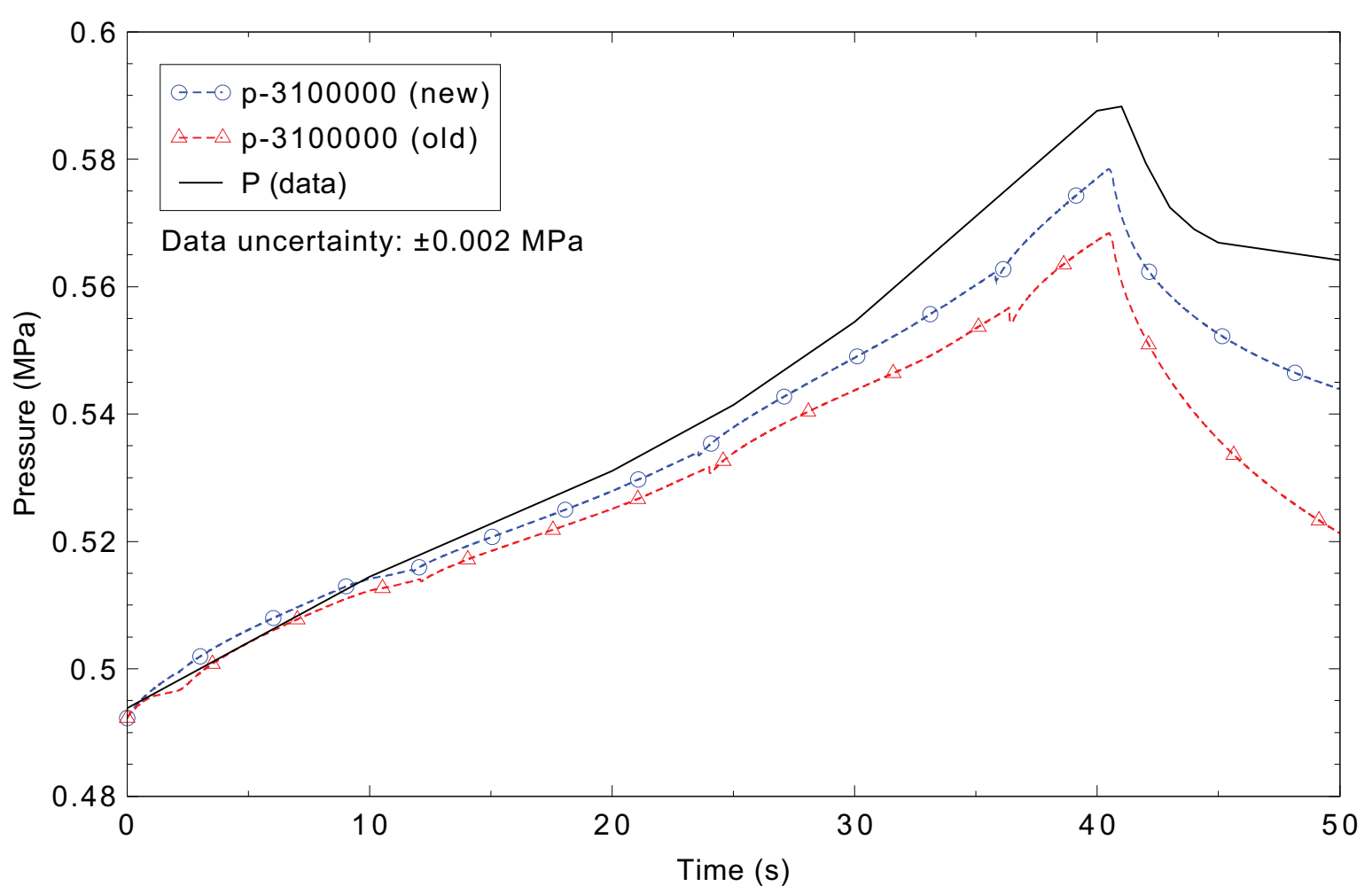

Figure 4.17-3. Measured and calculated pressure at the top of the tank for MIT pressurizer Test ST4.

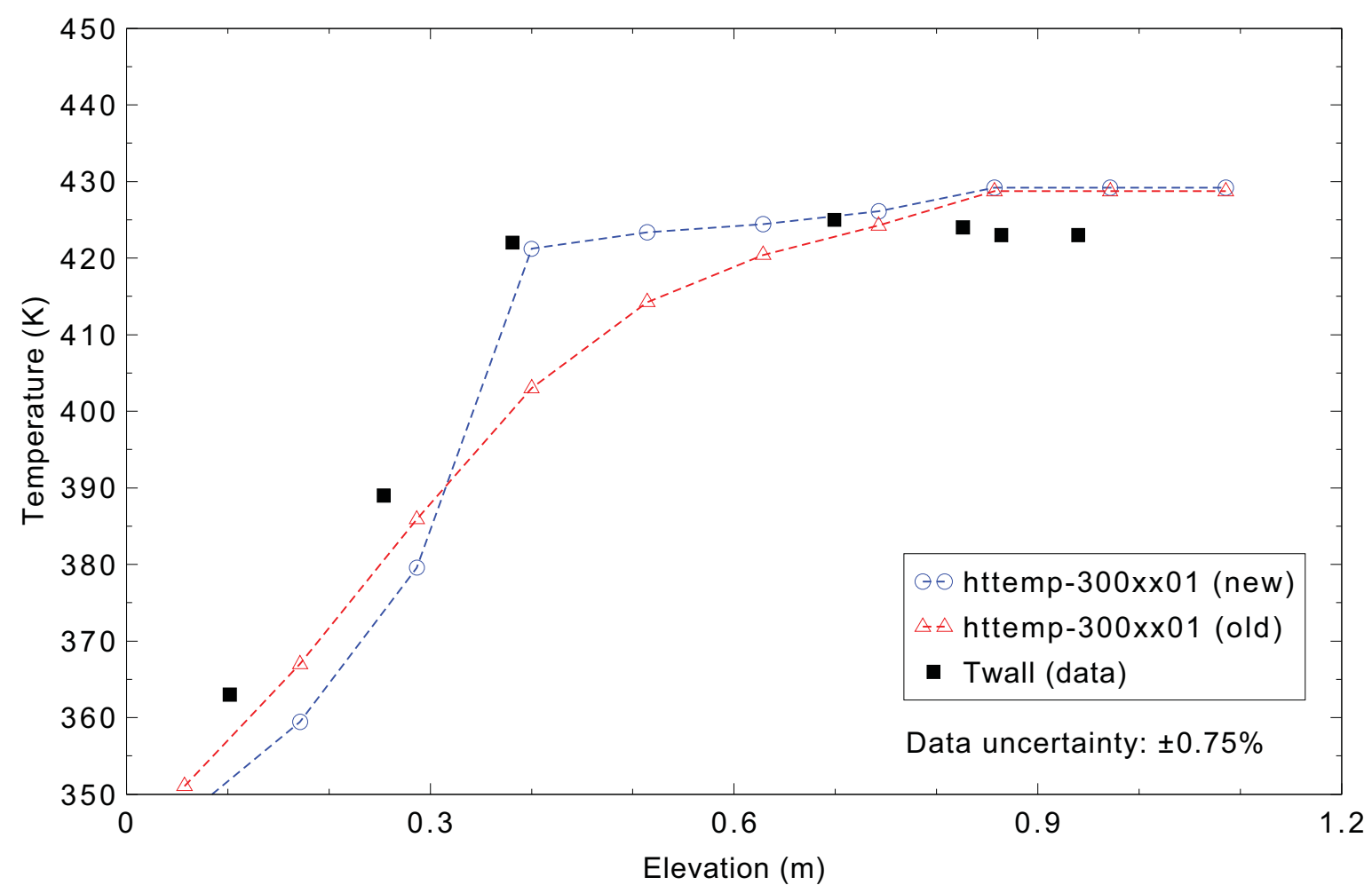

Figure 4.17-4. Measured and calculated wall temperature profile at $35 \mathrm{~s}$ for MIT pressurizer Test ST4. 


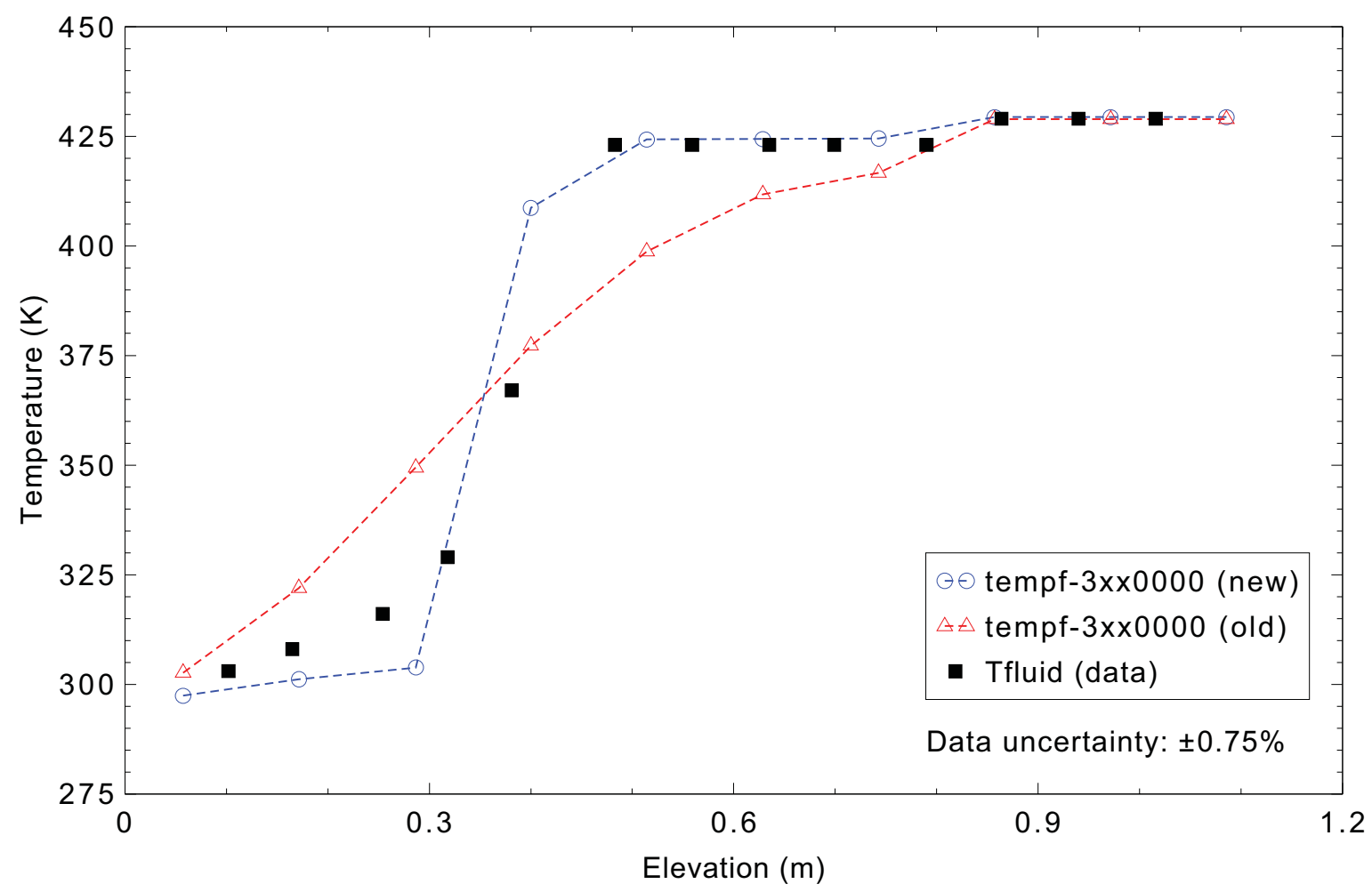

Figure 4.17-5. Measured and calculated fluid temperature profile at $35 \mathrm{~s}$ for MIT pressurizer Test ST4.

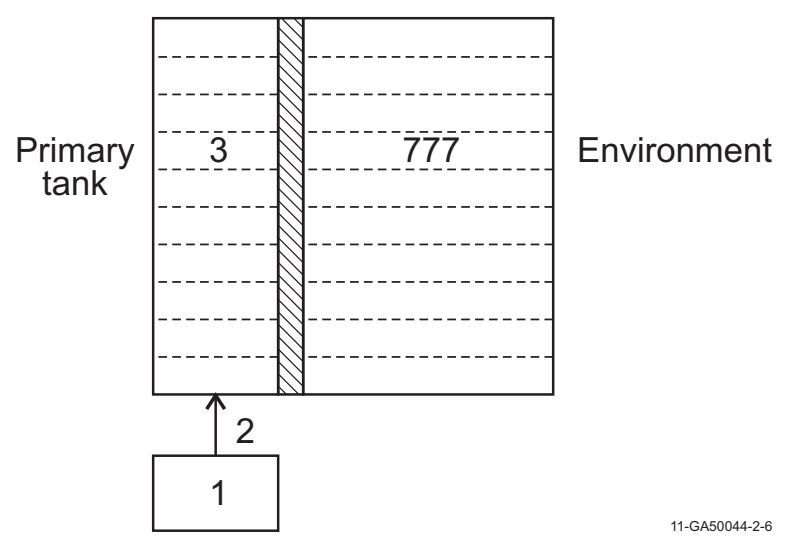

Figure 4.17-2. RELAP5-3D nodalization of MIT pressurizer. 


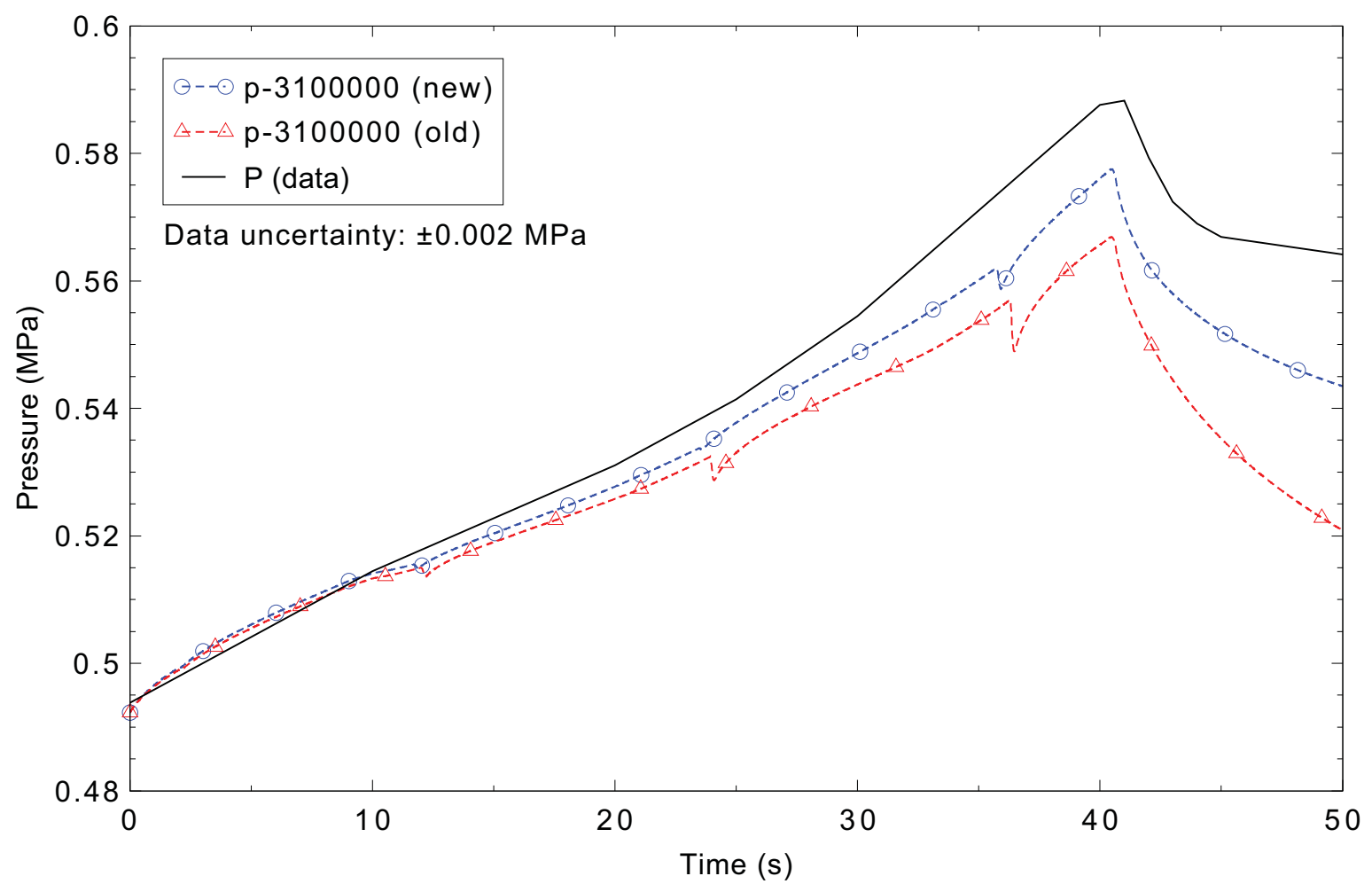

Figure 4.17-6. Measured and calculated pressure at the top of the tank for MIT pressurizer Test ST4 with the mixture level tracking turned off. 


\subsection{Neptunus Test Y05}

TFigures comparing simulations using two code versions are presented. Diagrams are included so that the figure numbering is the same as that in Volume III of the RELAP5-3D code manual. Noticeable differences were observed in Figures 4.18-5 and 6.

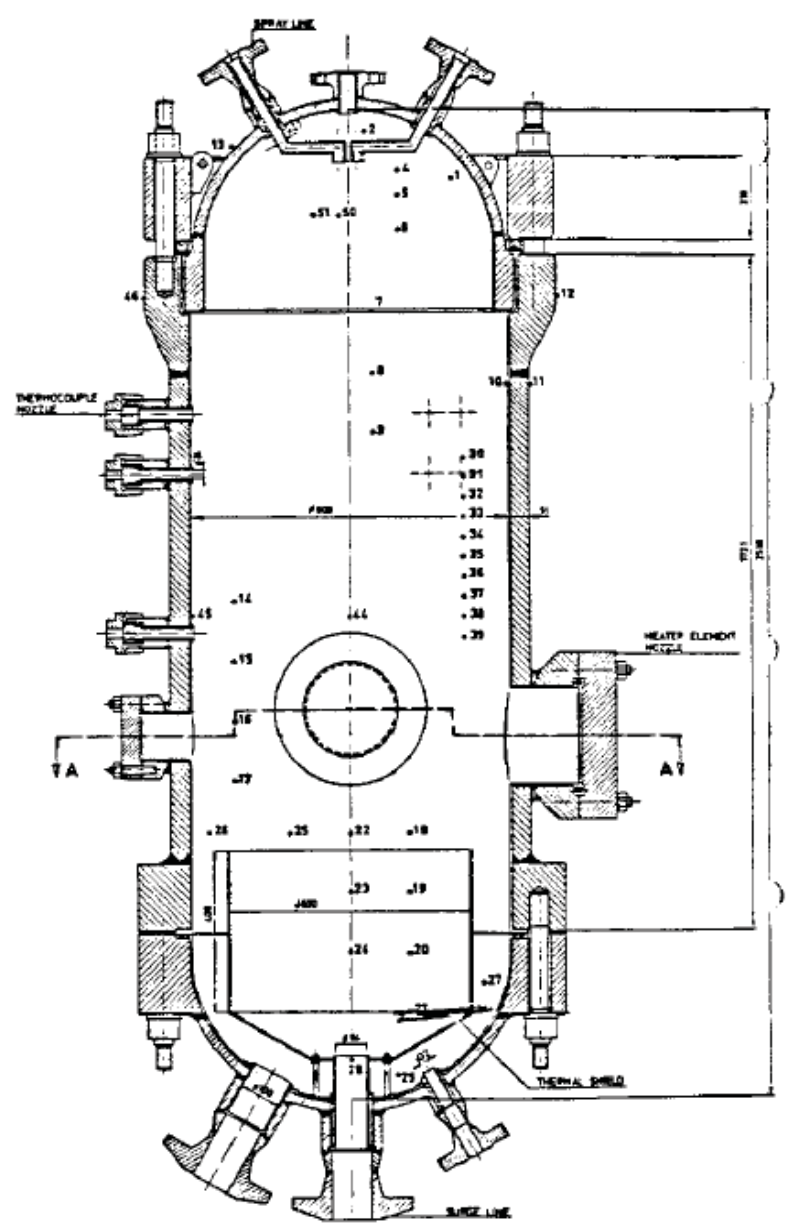

Figure 4.18-1. Neptunus test facility pressurizer. 


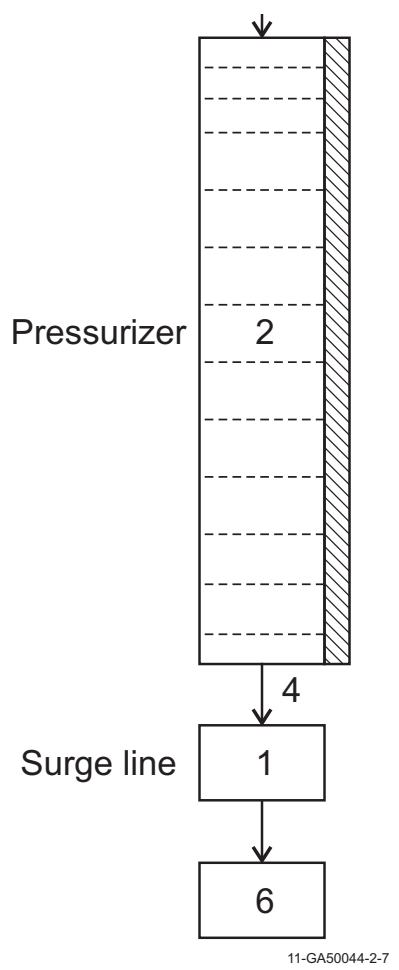

Figure 4.18-2. Nodalization diagram for the Neptunus pressurizer model.

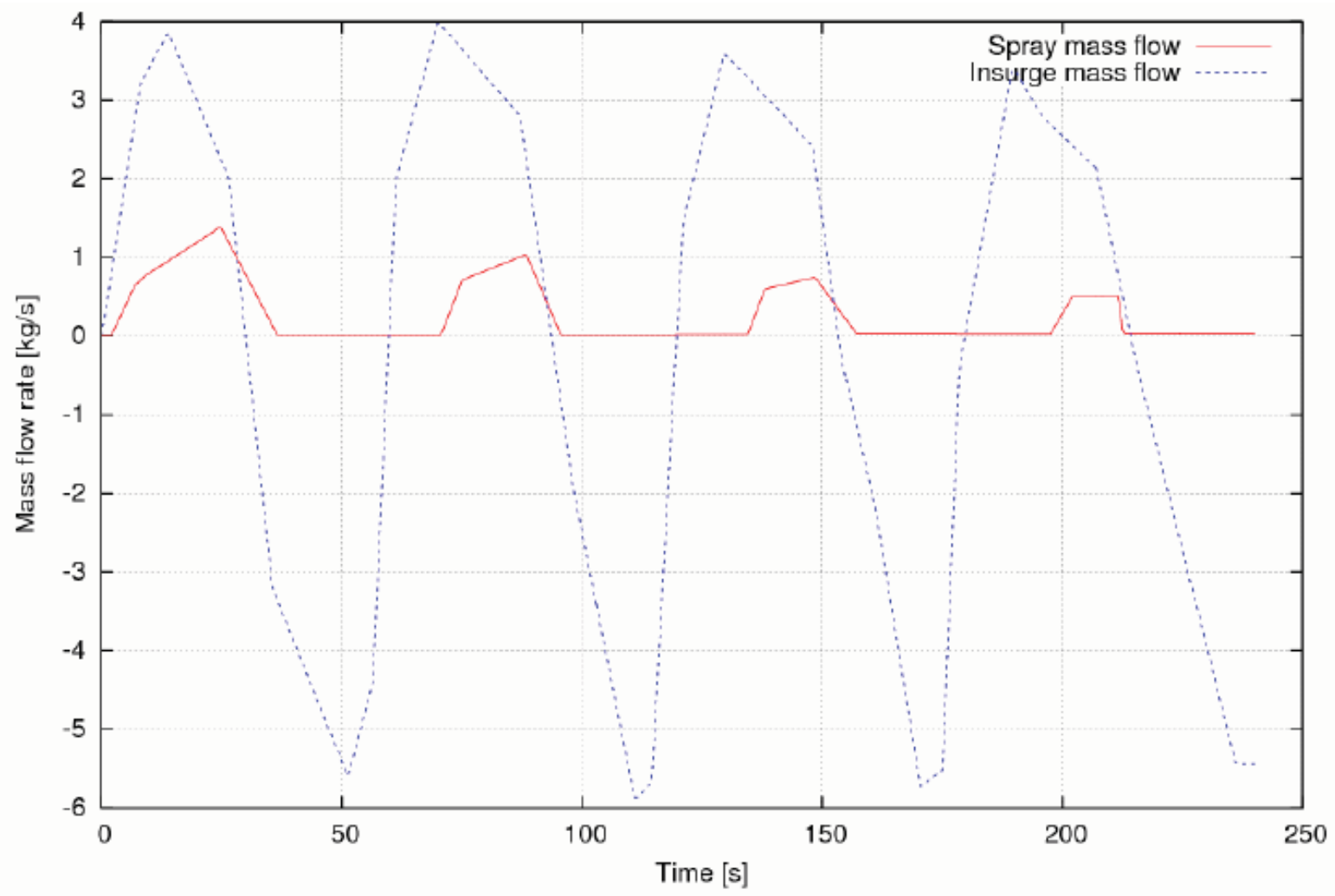

Figure 4.18-3. Transient boundary condition flow rates for Neptunus Test Y05. 


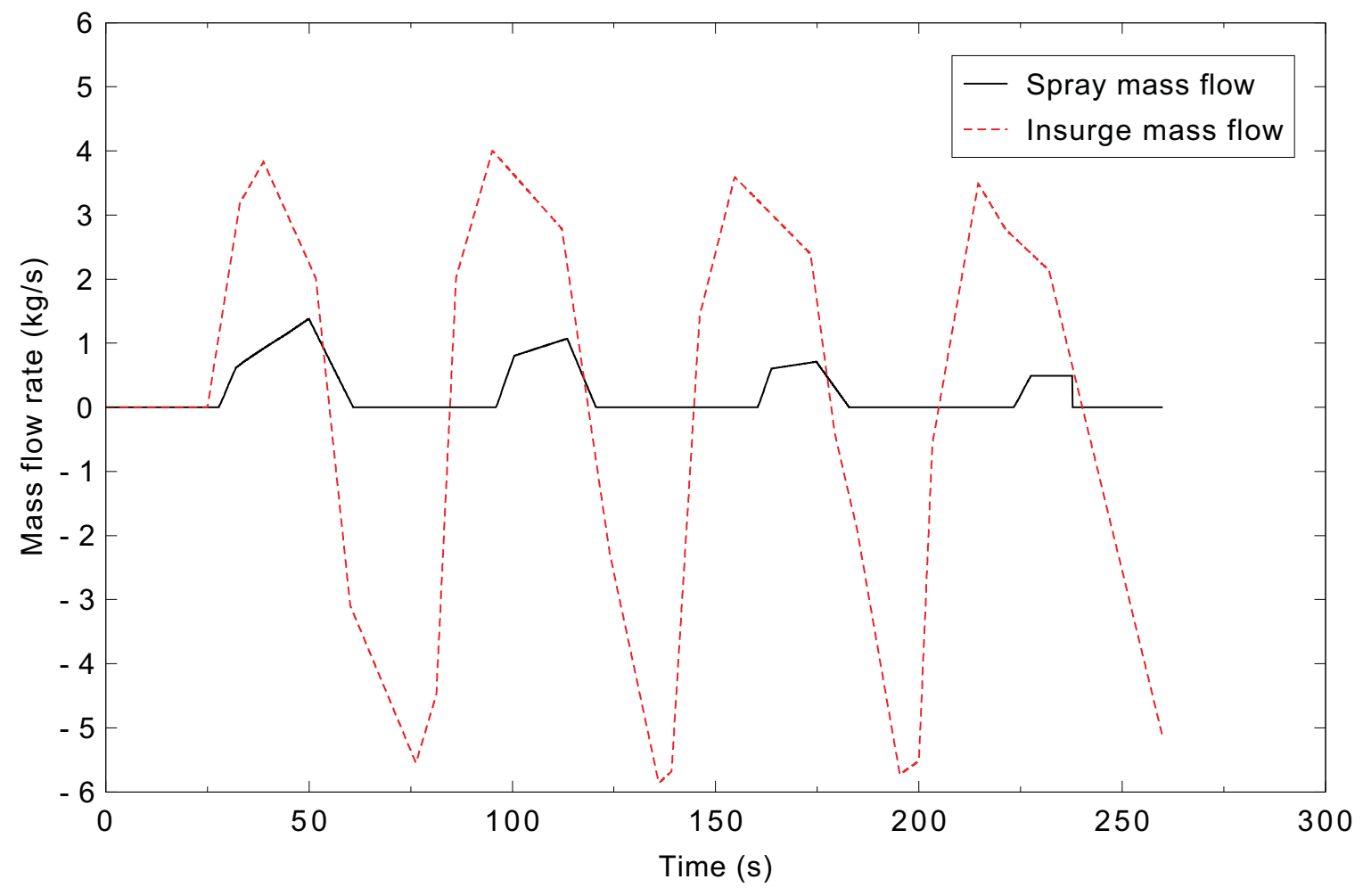

Figure 4.18-4. RELAP5-3D model input boundary flows for Neptunus Test Y05. 
RELAP5-3D/4.0.3

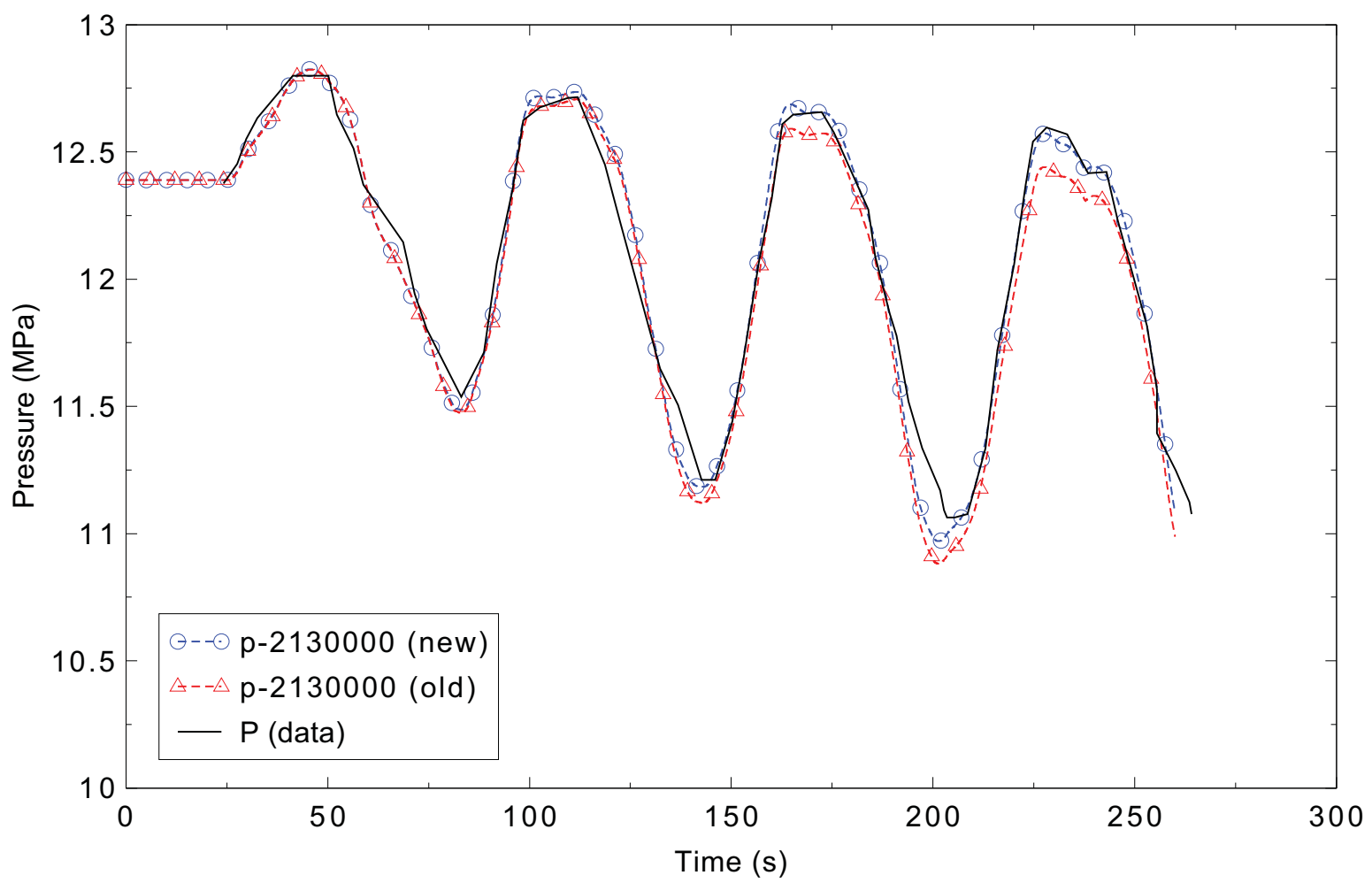

Figure 4.18-5. Measured and calculated pressurizer dome pressure for Neptunus Test Y05.

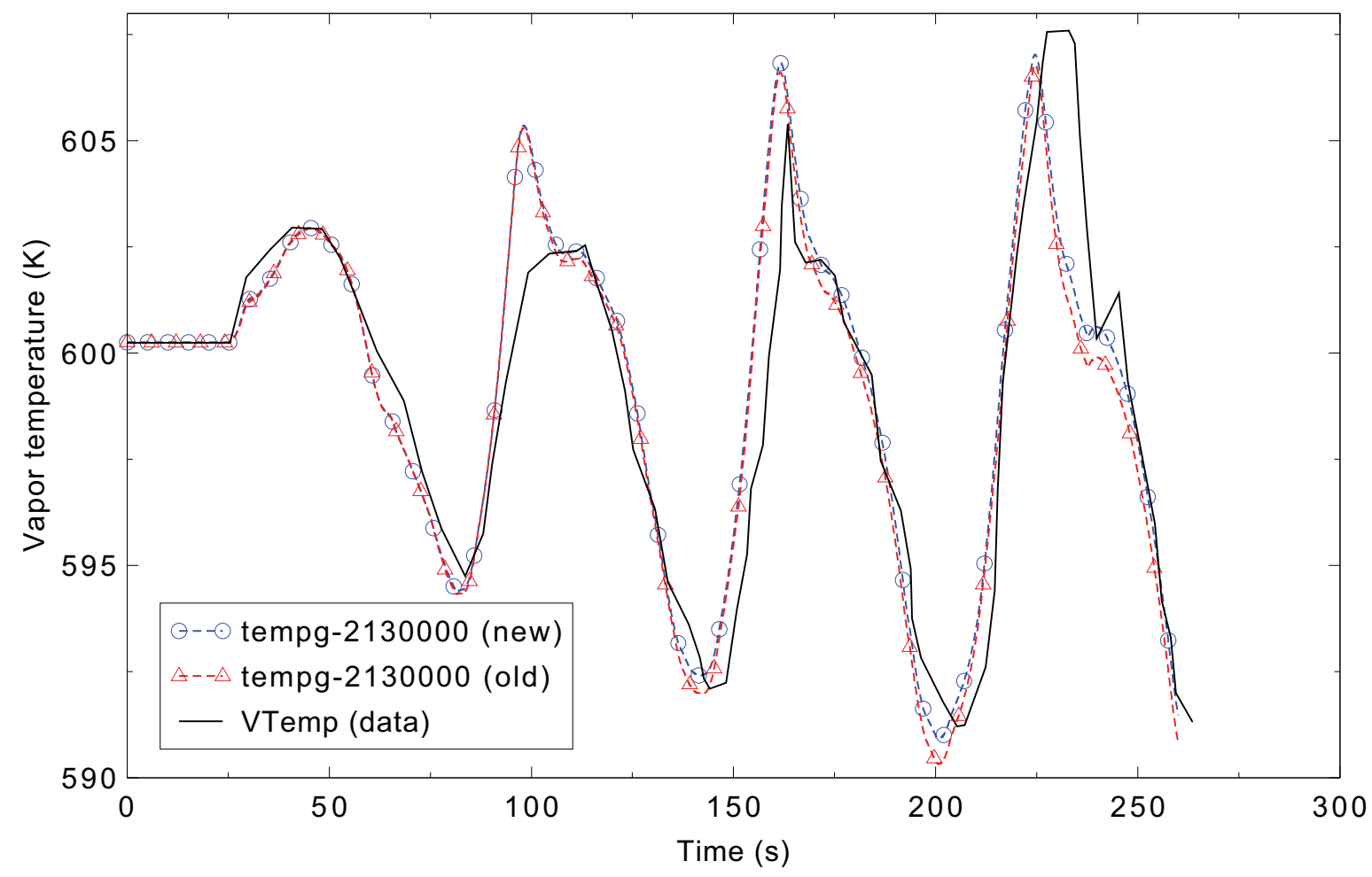

Figure 4.18-6. Measured and calculated pressurizer steam temperature for Neptunus Test Y05. 


\subsection{MB2 Test 1712}

Figures comparing simulations using two code versions are presented. Diagrams are included so that the figure numbering is the same as that in Volume III of the RELAP5-3D code manual. Noticeable differences were observed in Figures 4.19-6, 7, 8, and 9. 


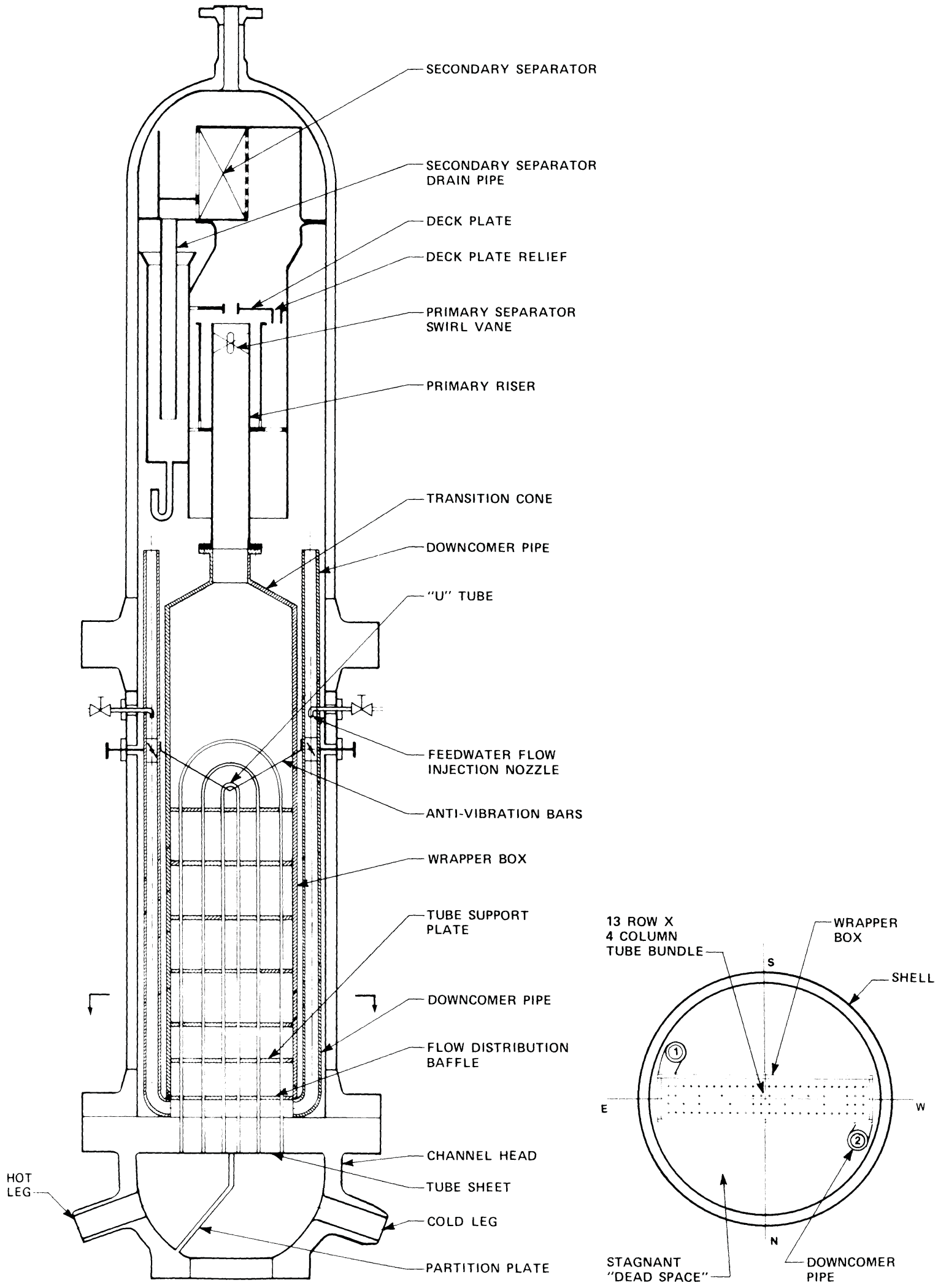

Figure 4.19-1. MB-2 schematic diagram. 


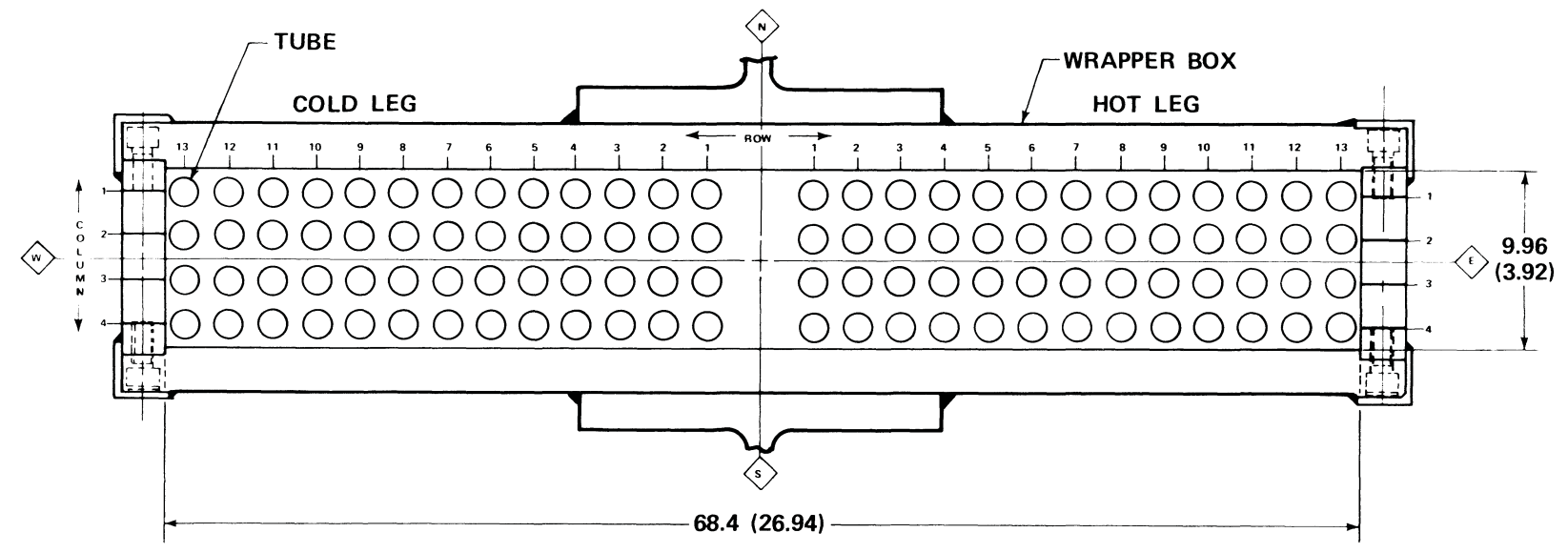

ALL DIMENSIONS IN cm (in.)

Figure 4.19-2. MB-2 tube bundle cross section. 


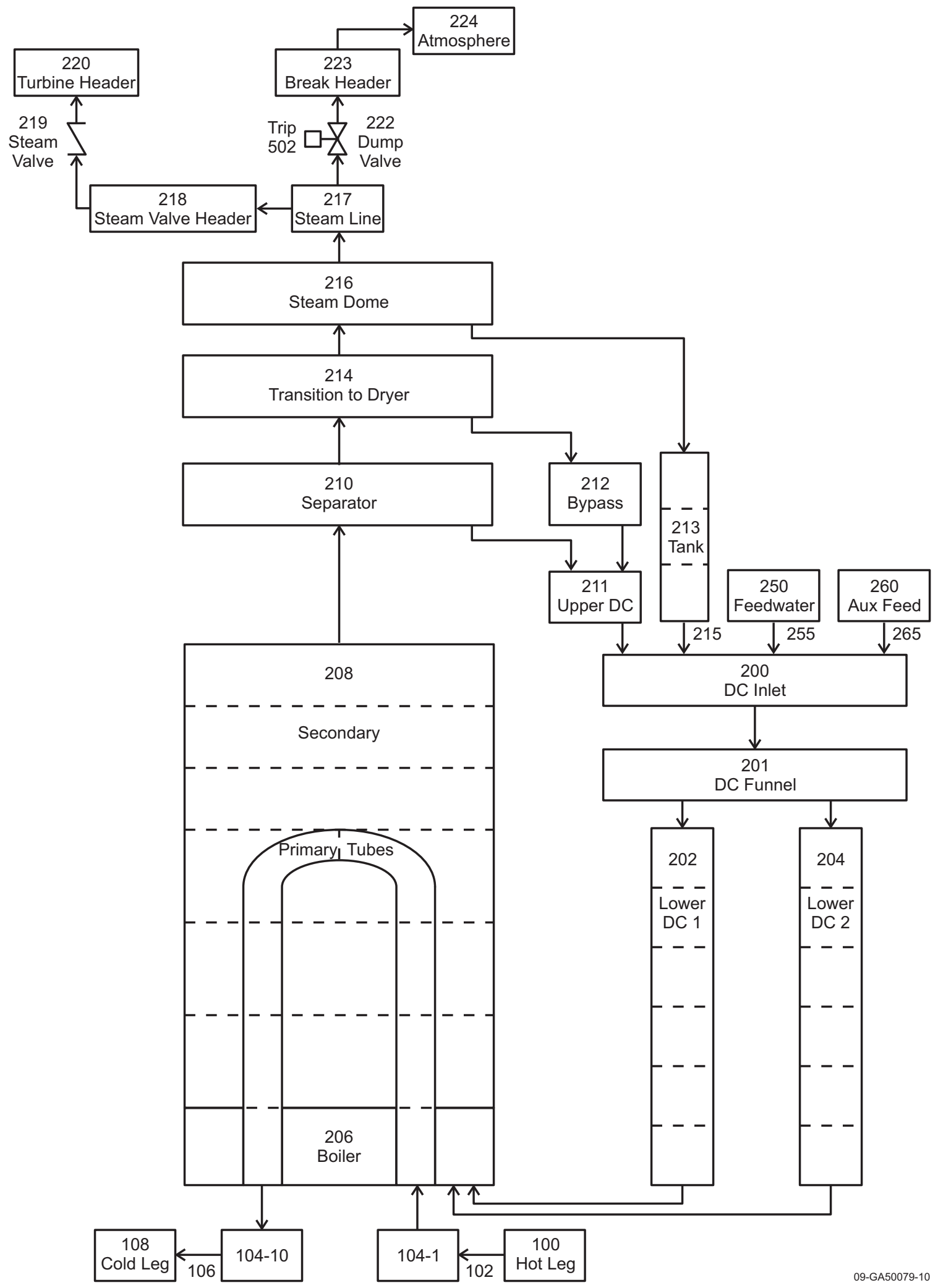

Figure 4.19-3. Nodalization diagram for MB-2 LOF Test 1712. 


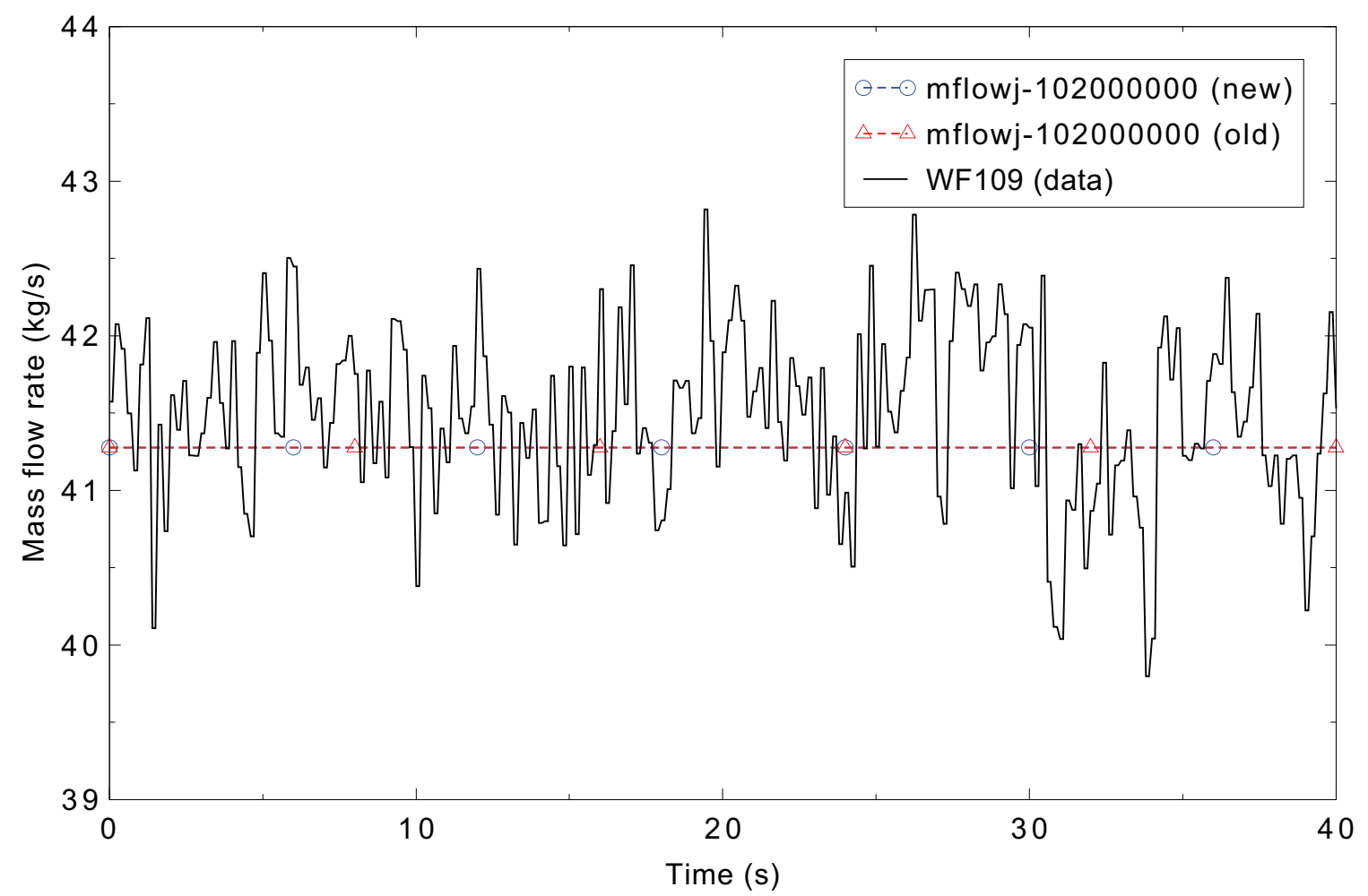

Figure 4.19-4. Measured and RELAP5-3D primary flow rate during MB-2 steady state Test 1712.

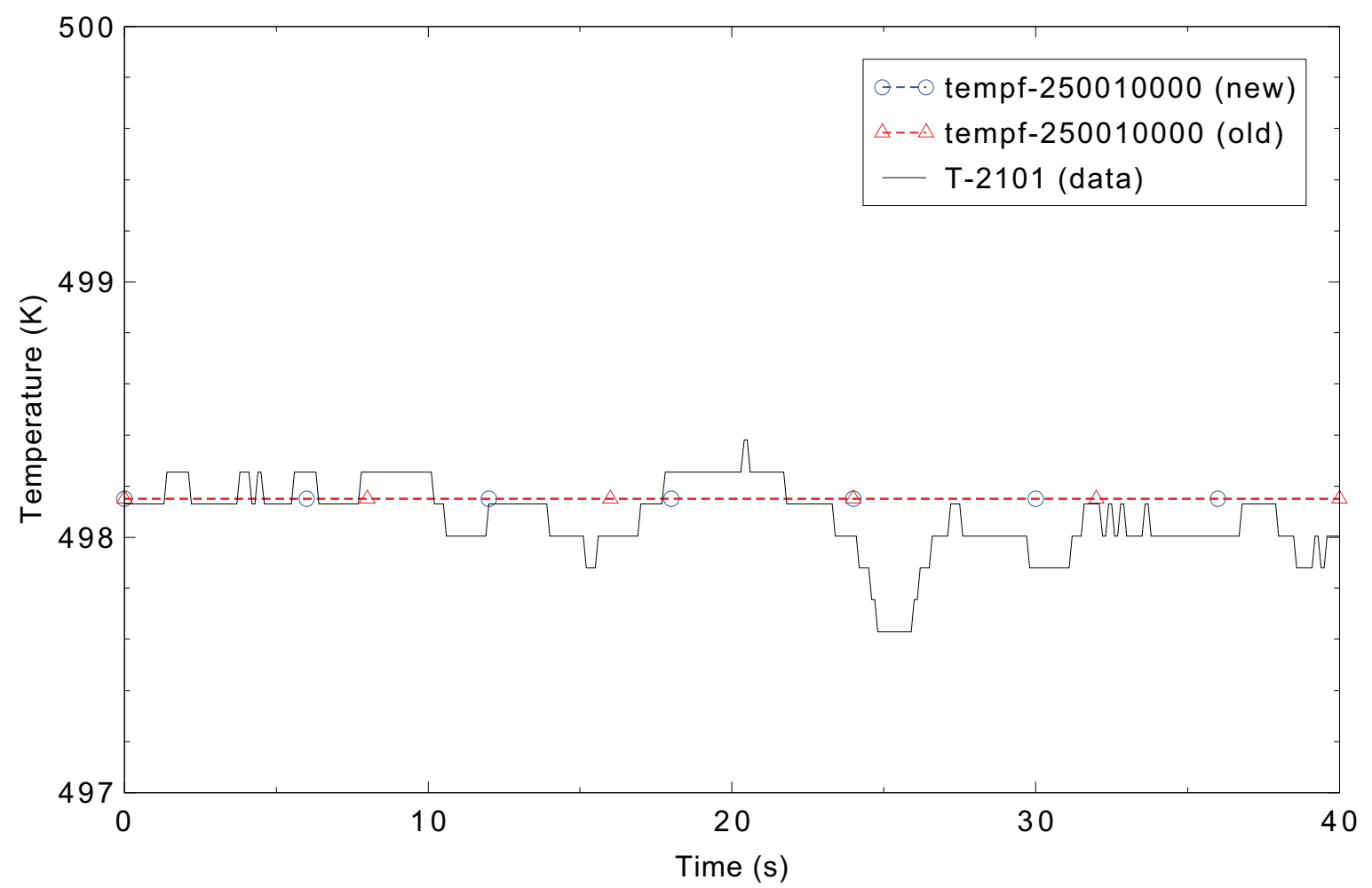

Figure 4.19-5. Measured and RELAP5-3D main feed water temperature during MB-2 steady state Test 1712 . 
RELAP5-3D/4.0.3

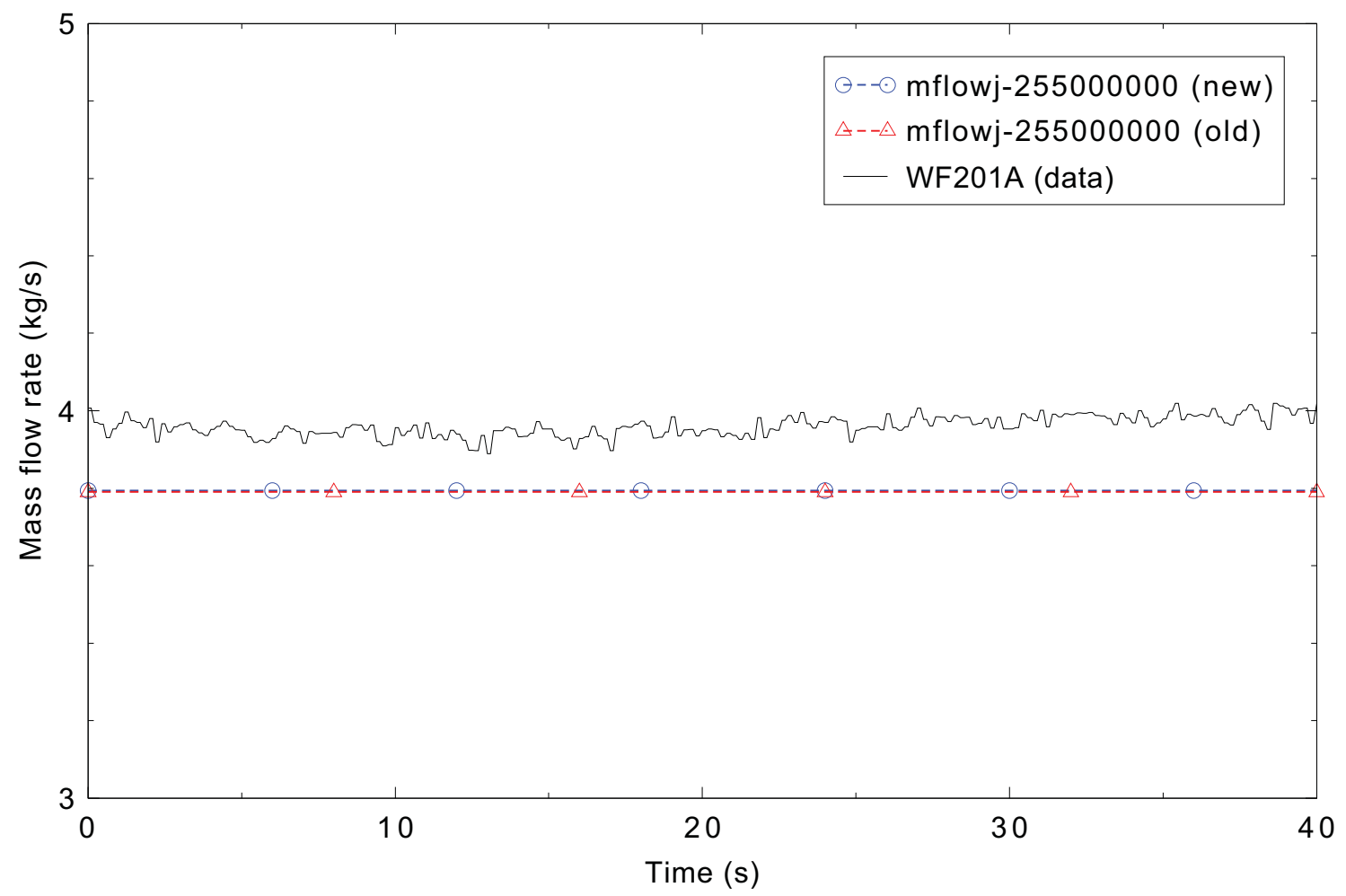

Figure 4.19-6. Measured and calculated main feed water flow rate during MB-2 steady state Test 1712 .

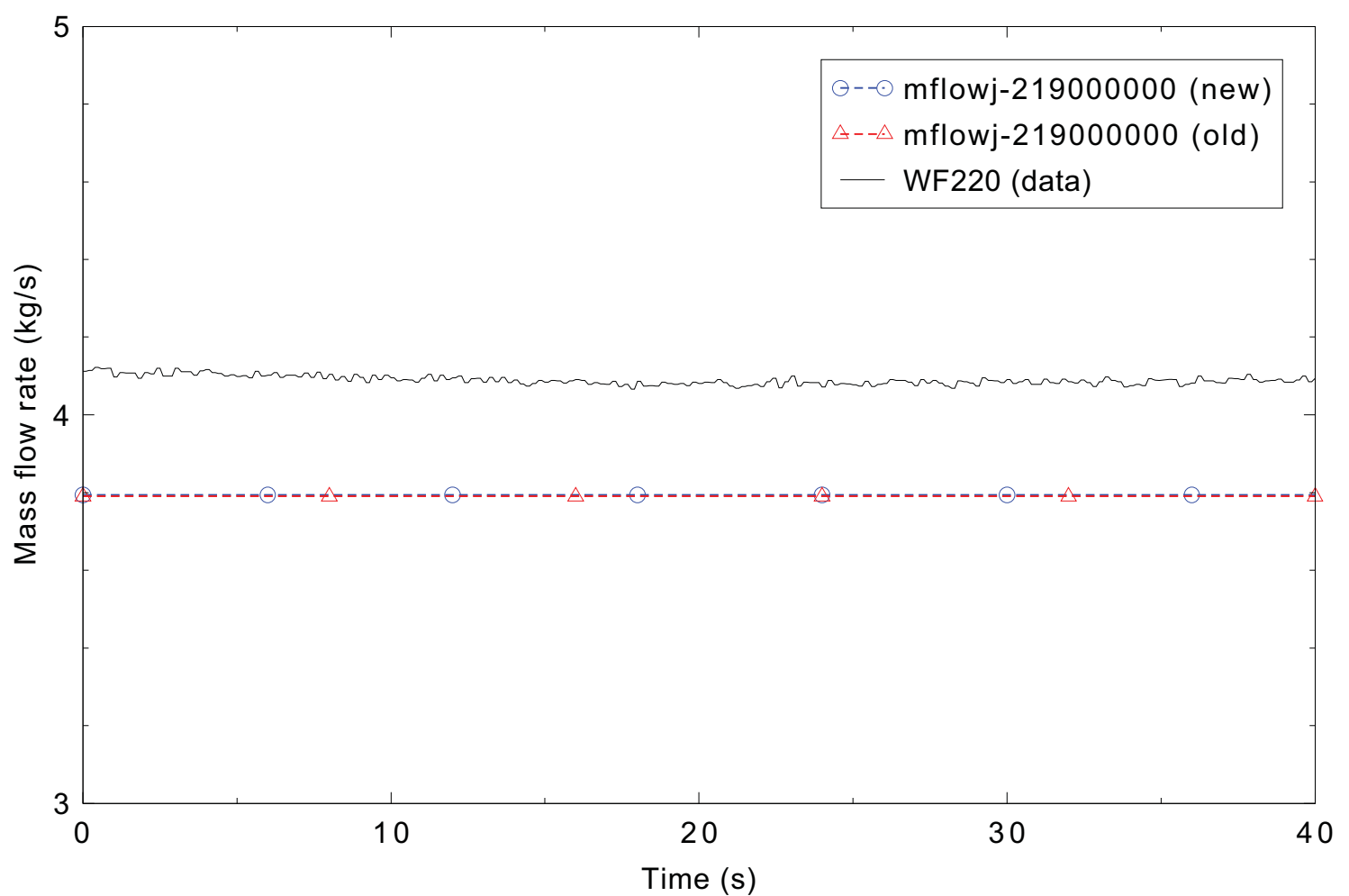

Figure 4.19-7. Measured and calculated steam flow rate during MB-2 steady state Test 1712. 


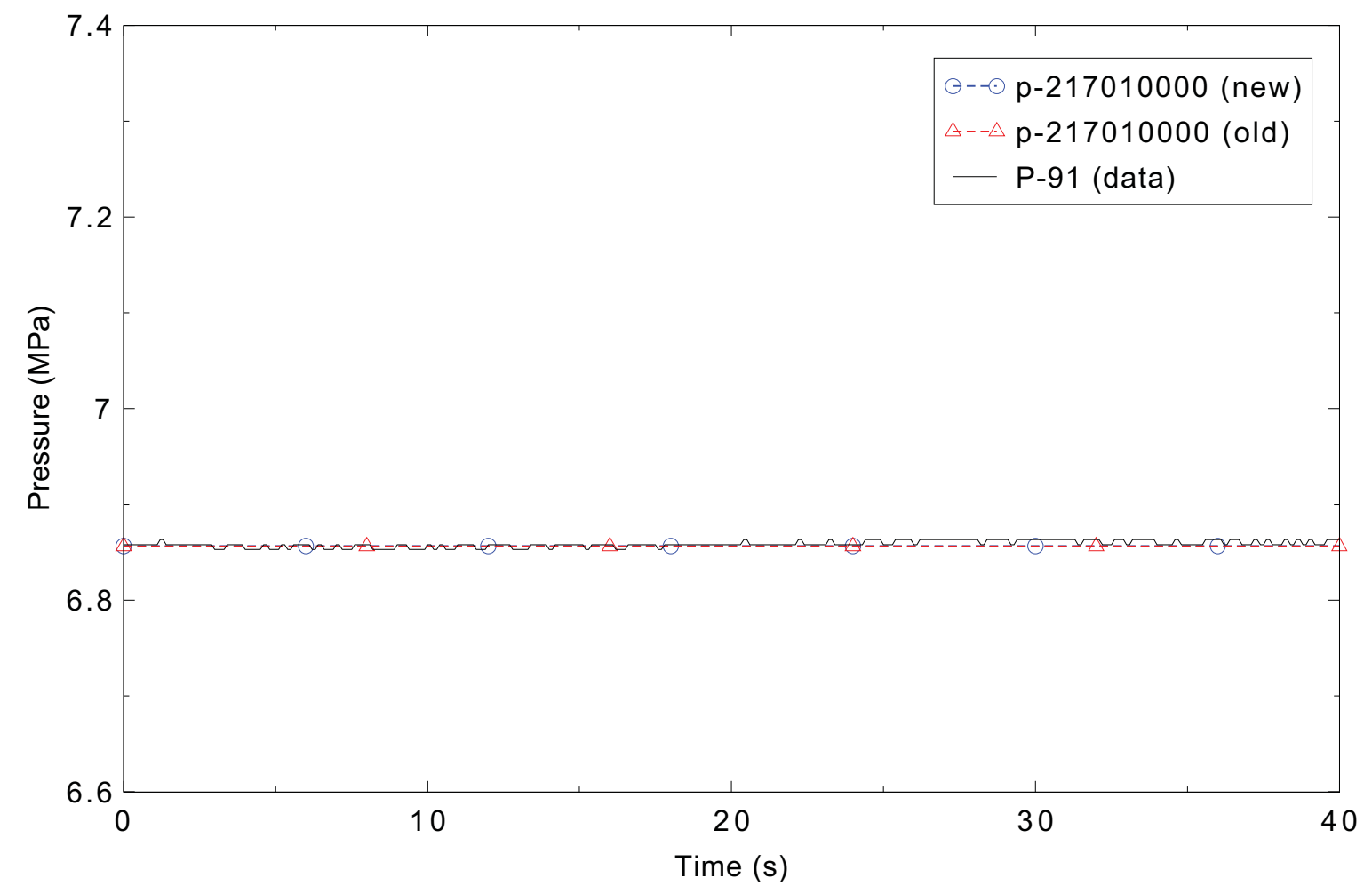

Figure 4.19-8. Measured and calculated steam line pressure during MB-2 steady state Test 1712.

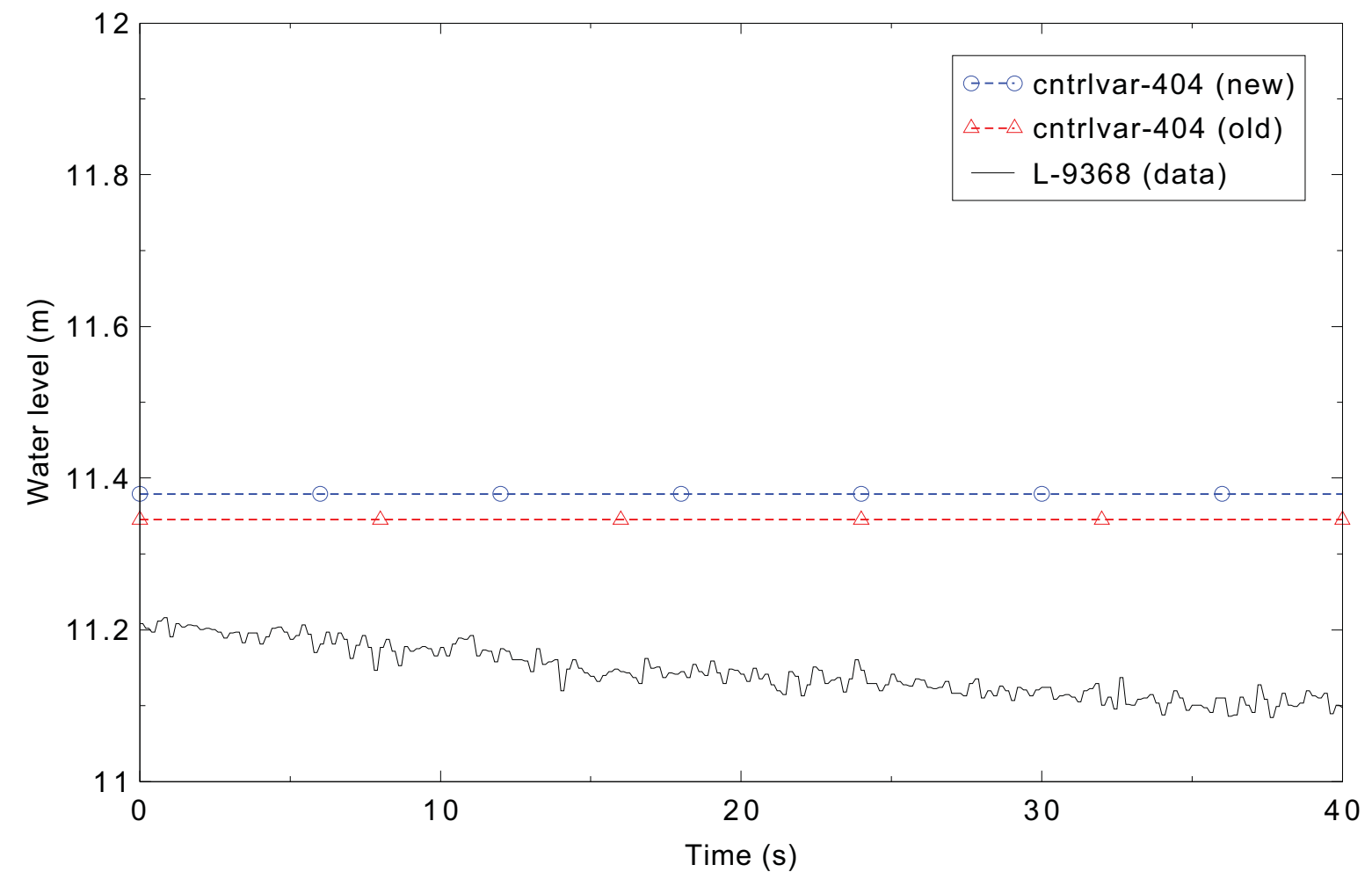

Figure 4.19-9. Measured and calculated narrow range water level during MB-2 steady state Test 1712. 


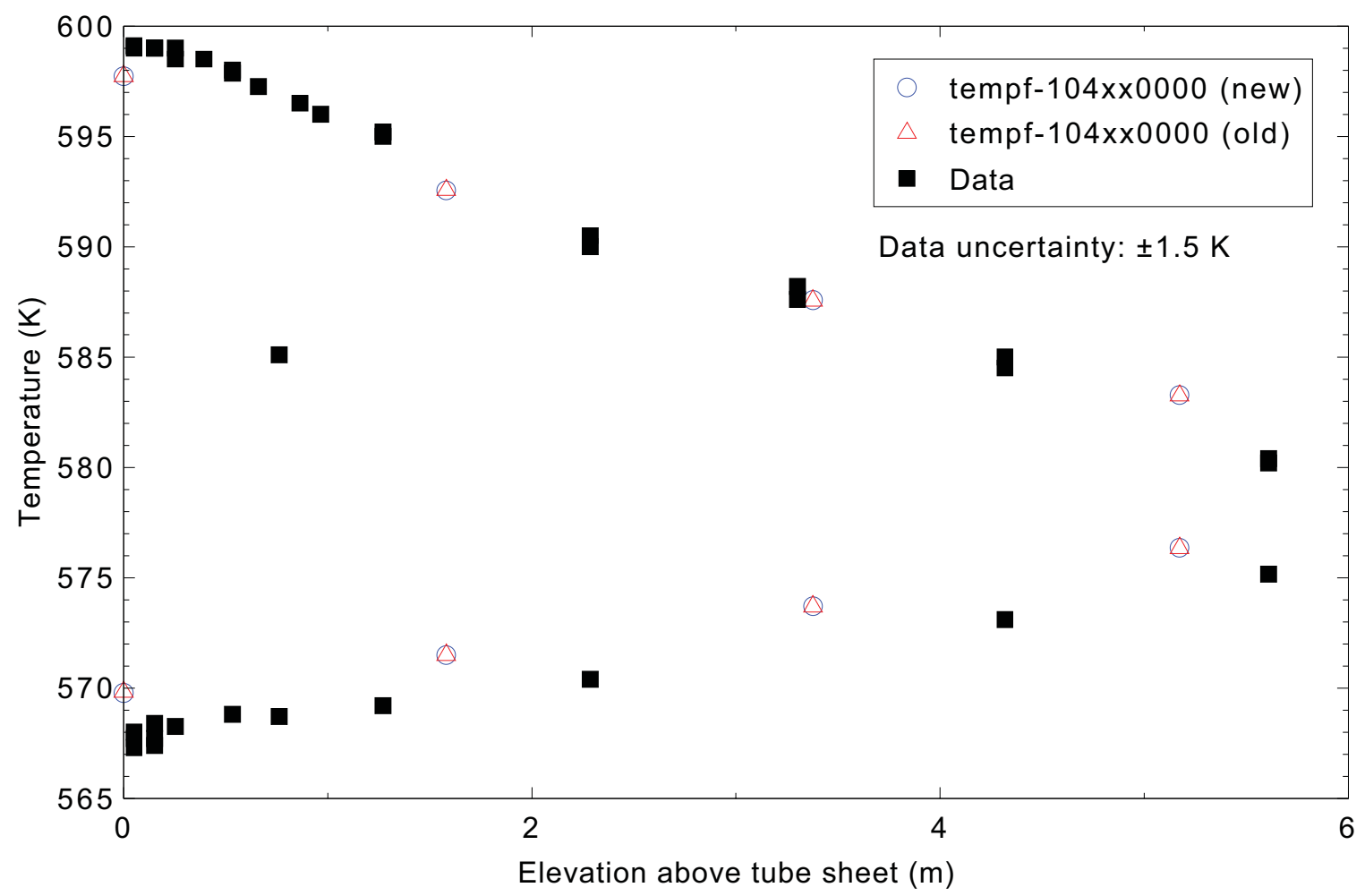

Figure 4.19-10. Measured and calculated primary side fluid temperatures during MB-2 steady state Test 1712. 


\subsection{LOFT L3-1}

Figures comparing simulations using two code versions are presented. Diagrams are included so that the figure numbering is the same as that in Volume III of the RELAP5-3D code manual. No differences were observed in the figures.

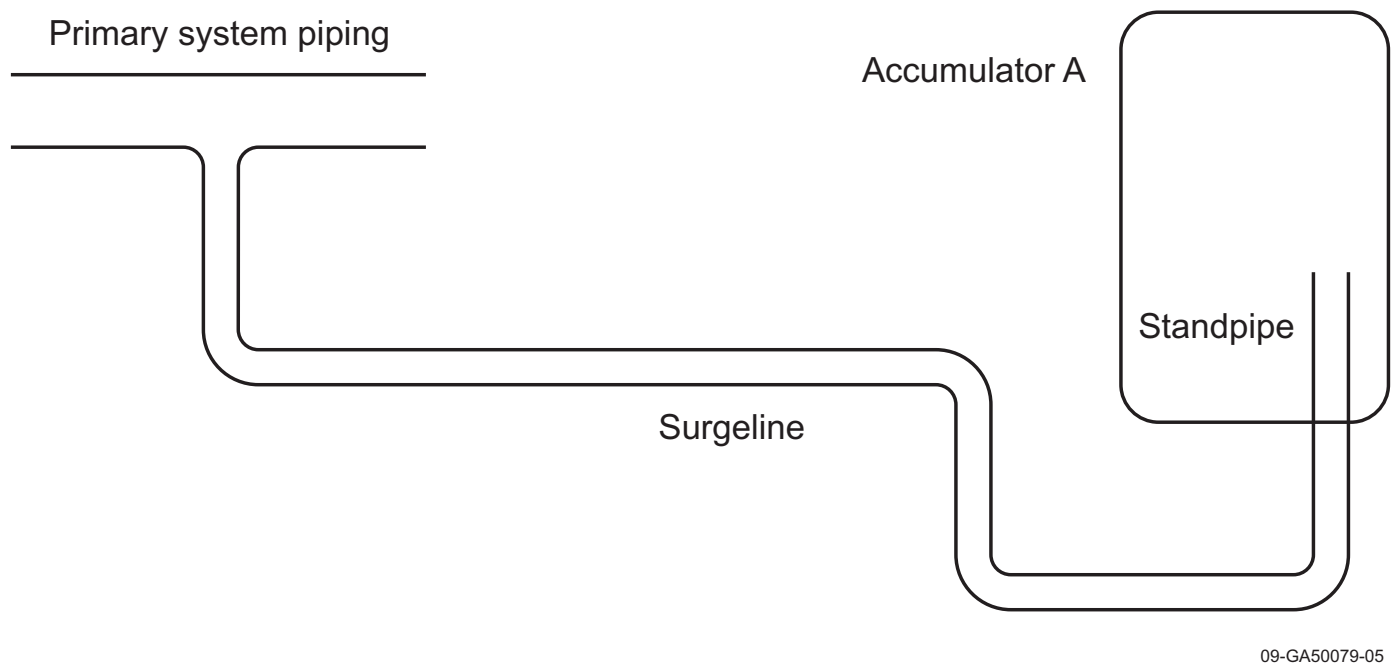

Figure 4.20-1. LOFT L3-1 Accumulator A and surgeline schematic.

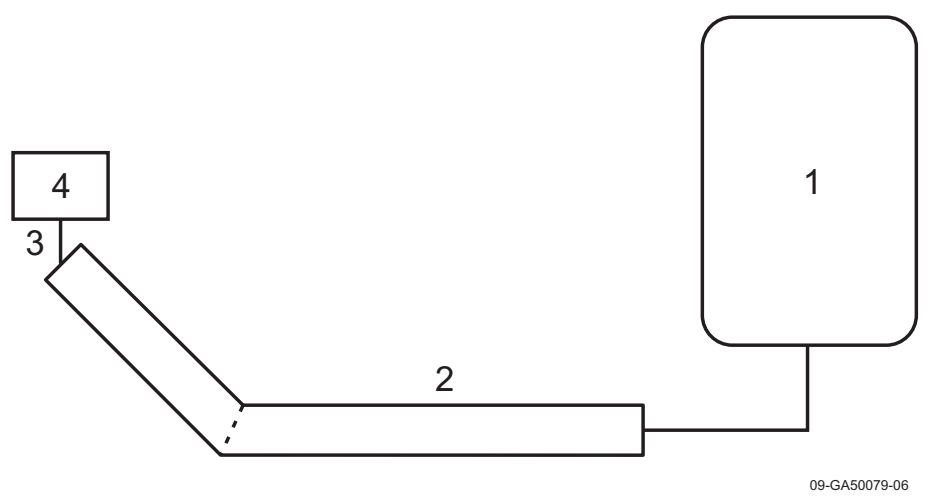

Figure 4.20-2. RELAP5 LOFT L3-1 accumulator model nodalization. 


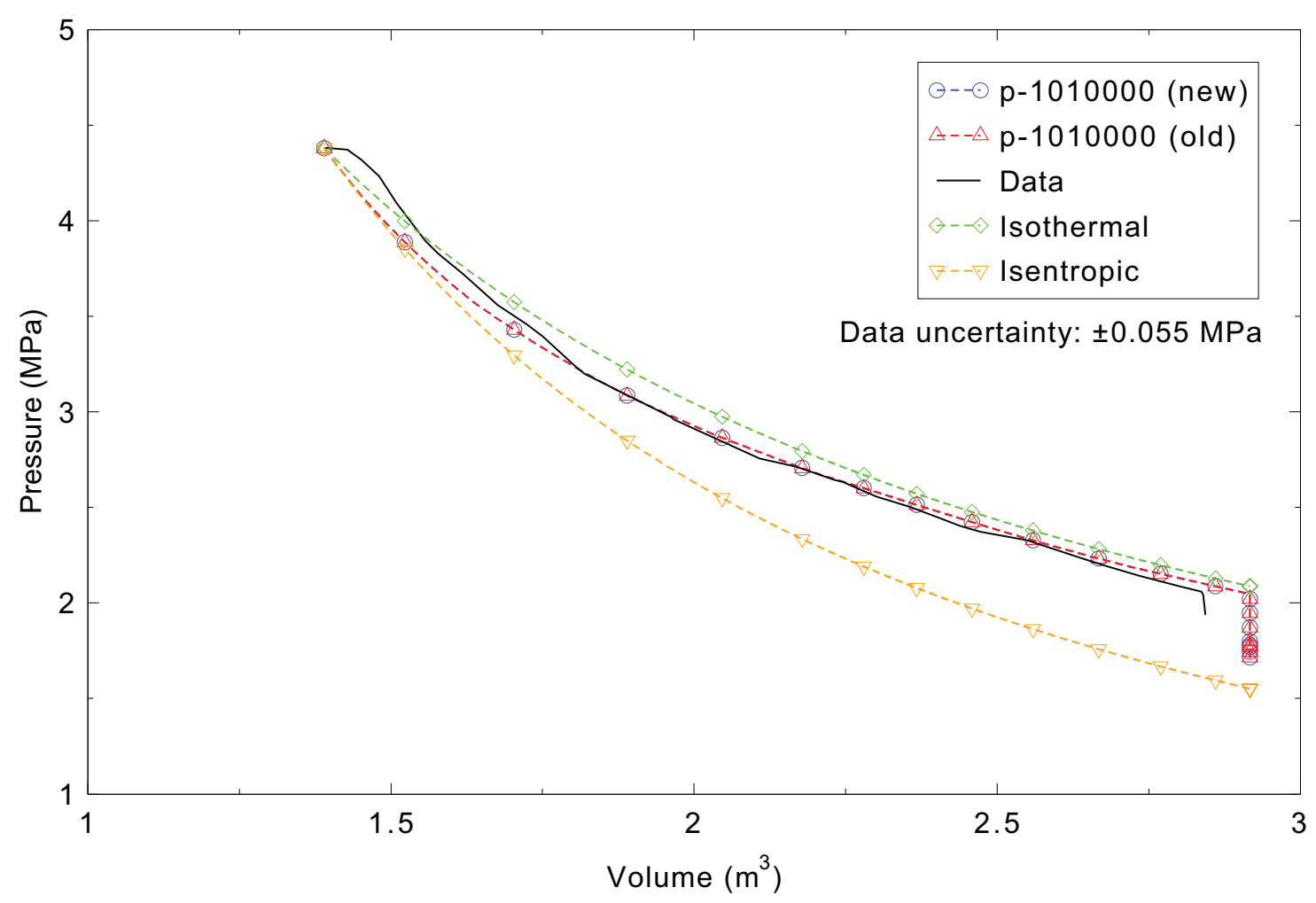

Figure 4.20-3. Measured and calculated accumulator gas dome pressure versus volume for LOFT Test L3-1.

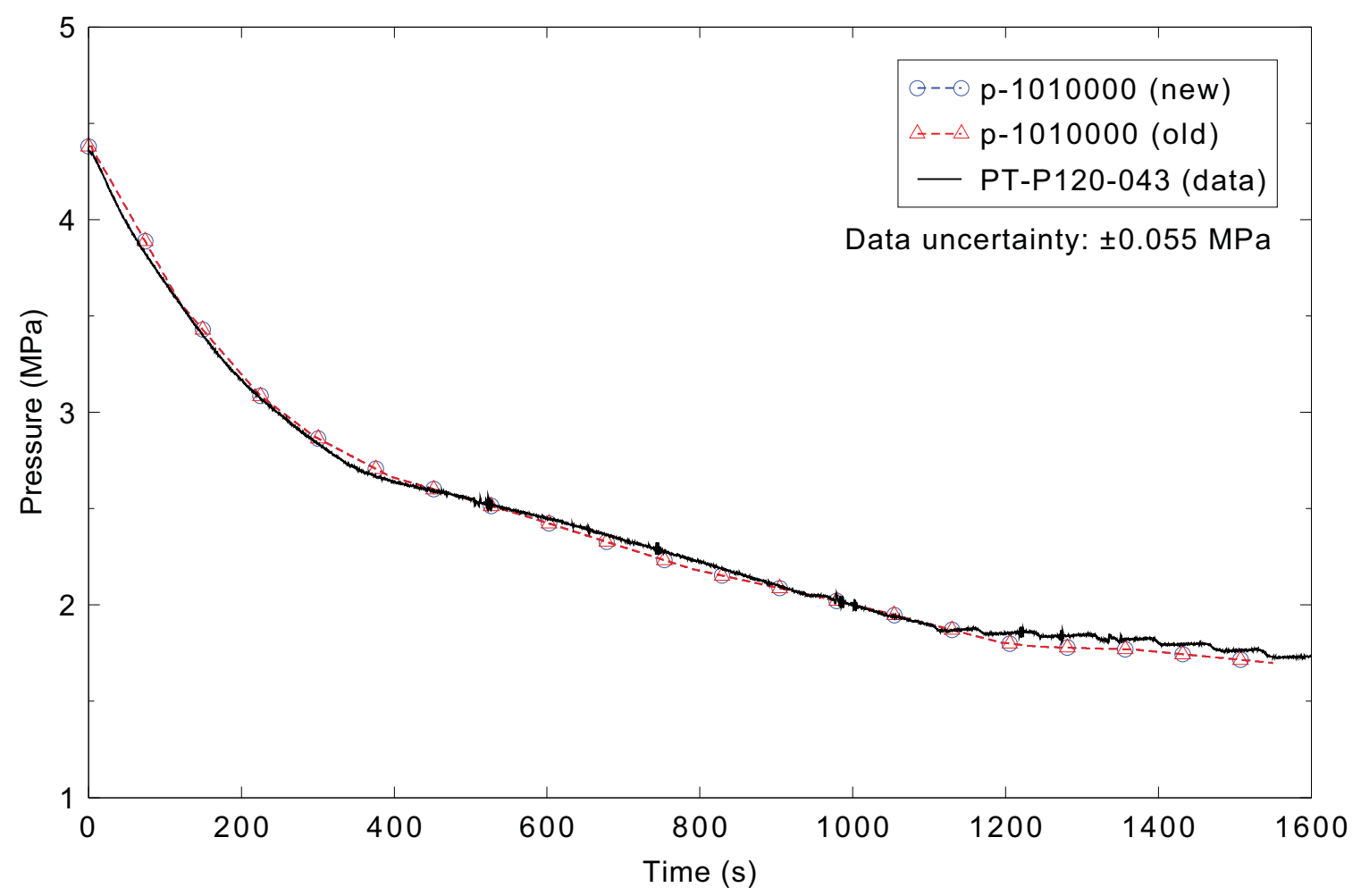

Figure 4.20-4. Measured and calculated accumulator gas dome pressure for LOFT Test L3-1. 


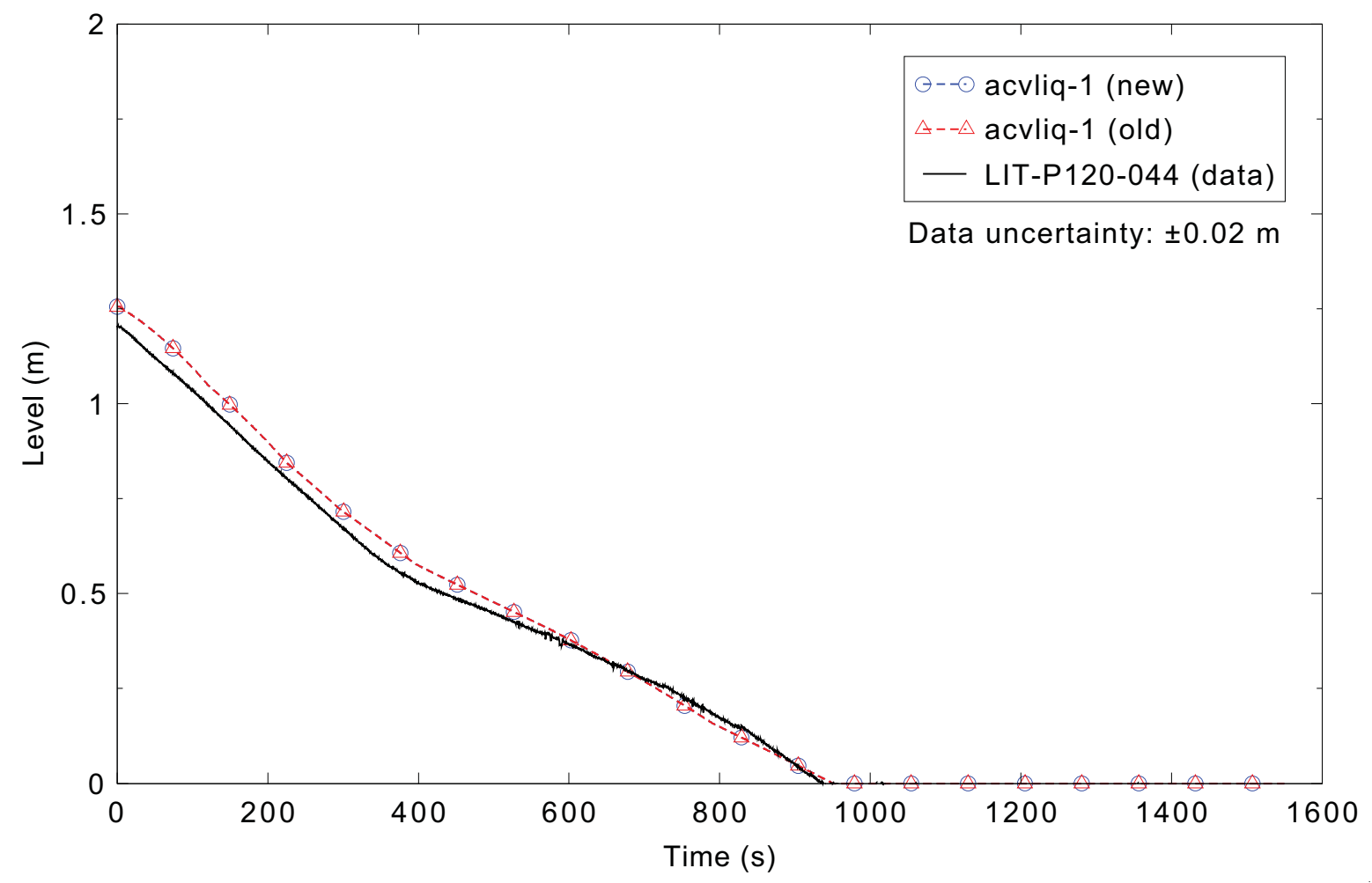

Figure 4.20-5. Measured and calculated accumulator liquid level for LOFT Test L3-1. 


\subsection{Full-Scale Reactor Coolant Pump}

Figures comparing simulations using two code versions are presented. Diagrams are included so that the figure numbering is the same as that in Volume III of the RELAP5-3D code manual. This capability was not available in Version 2.4.2, so these plots should be ignored.

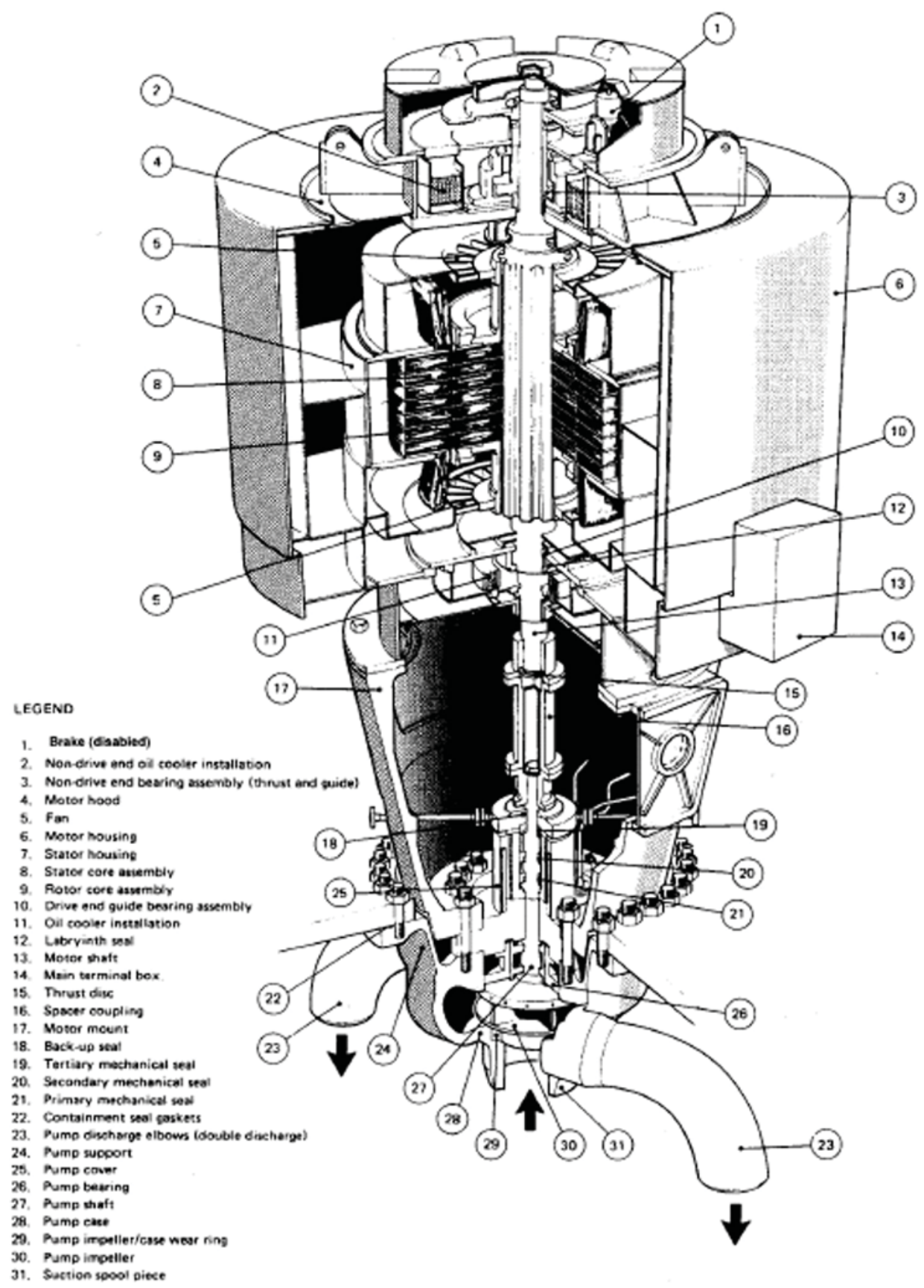

Figure 4.21-1. Full-size reactor coolant pump. 


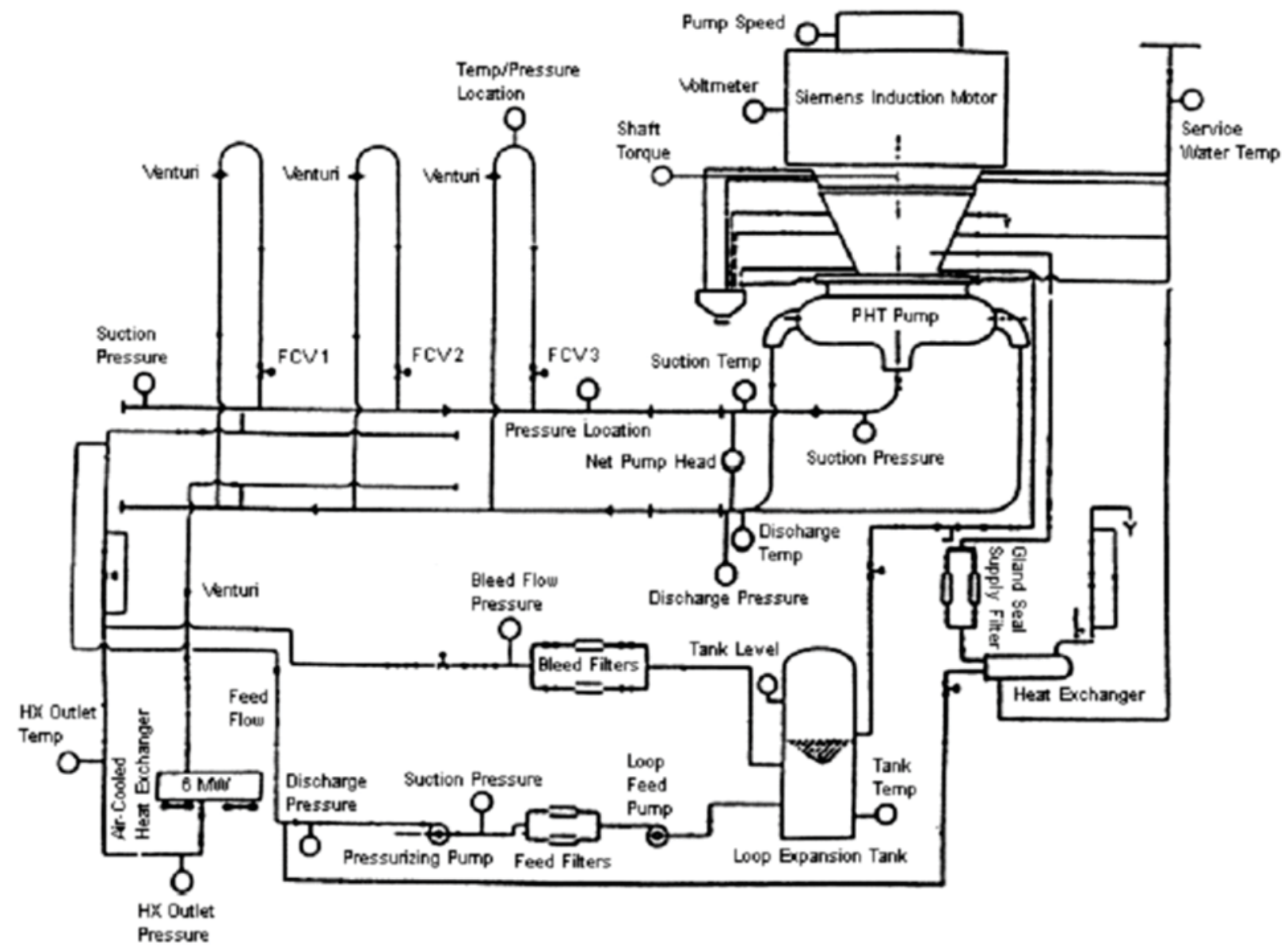

Figure 4.21-2. Schematic of the OHT test loop.

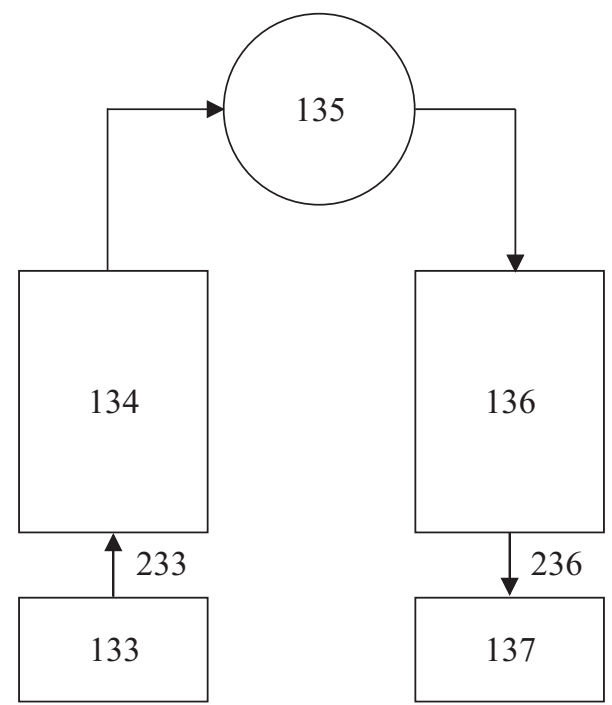

Figure 4.21-3. RELAP5-3D nodalization for the OHT pump tests. 


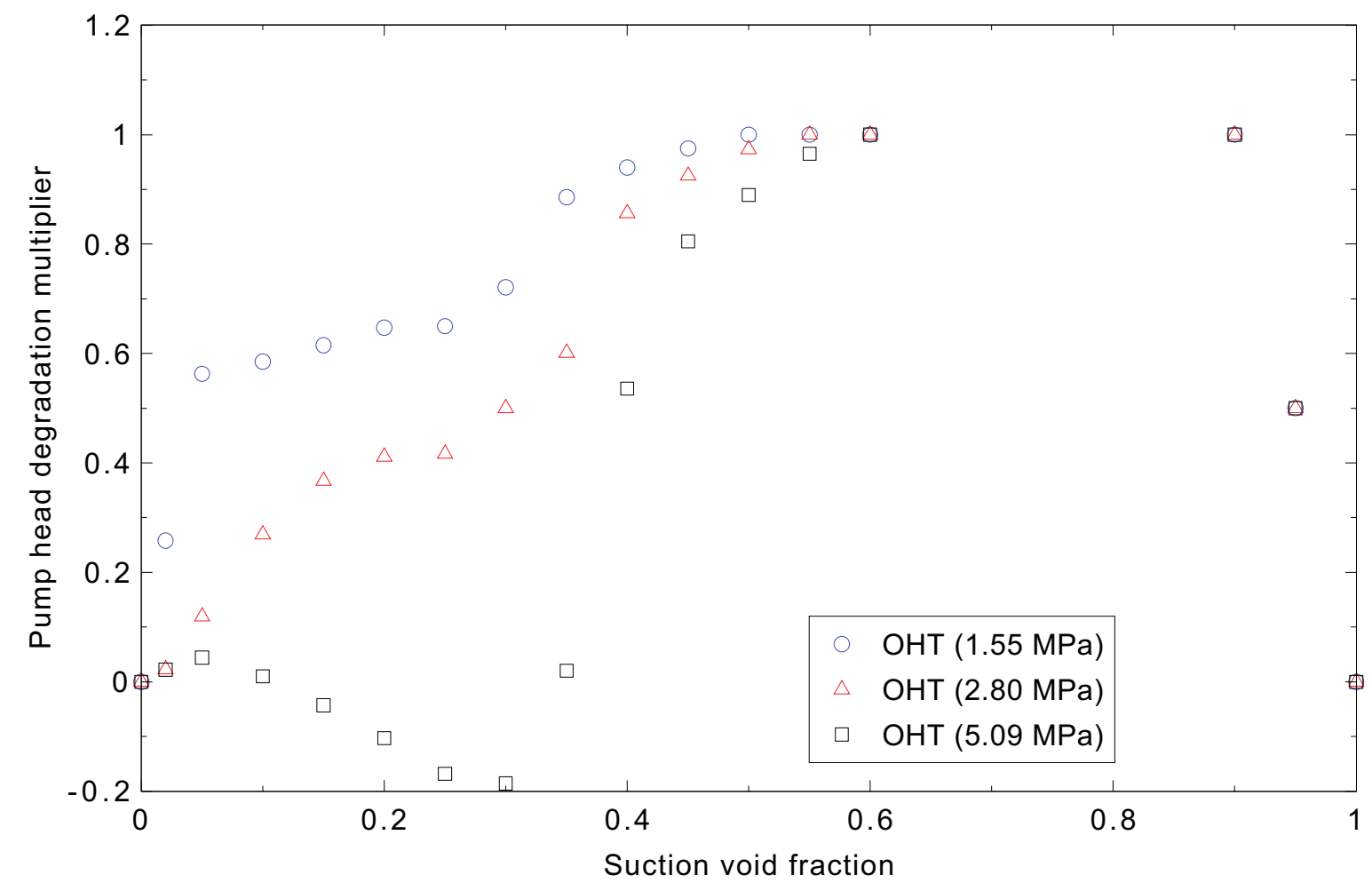

Figure 4.21-4. OHT pump head degradation multipliers.

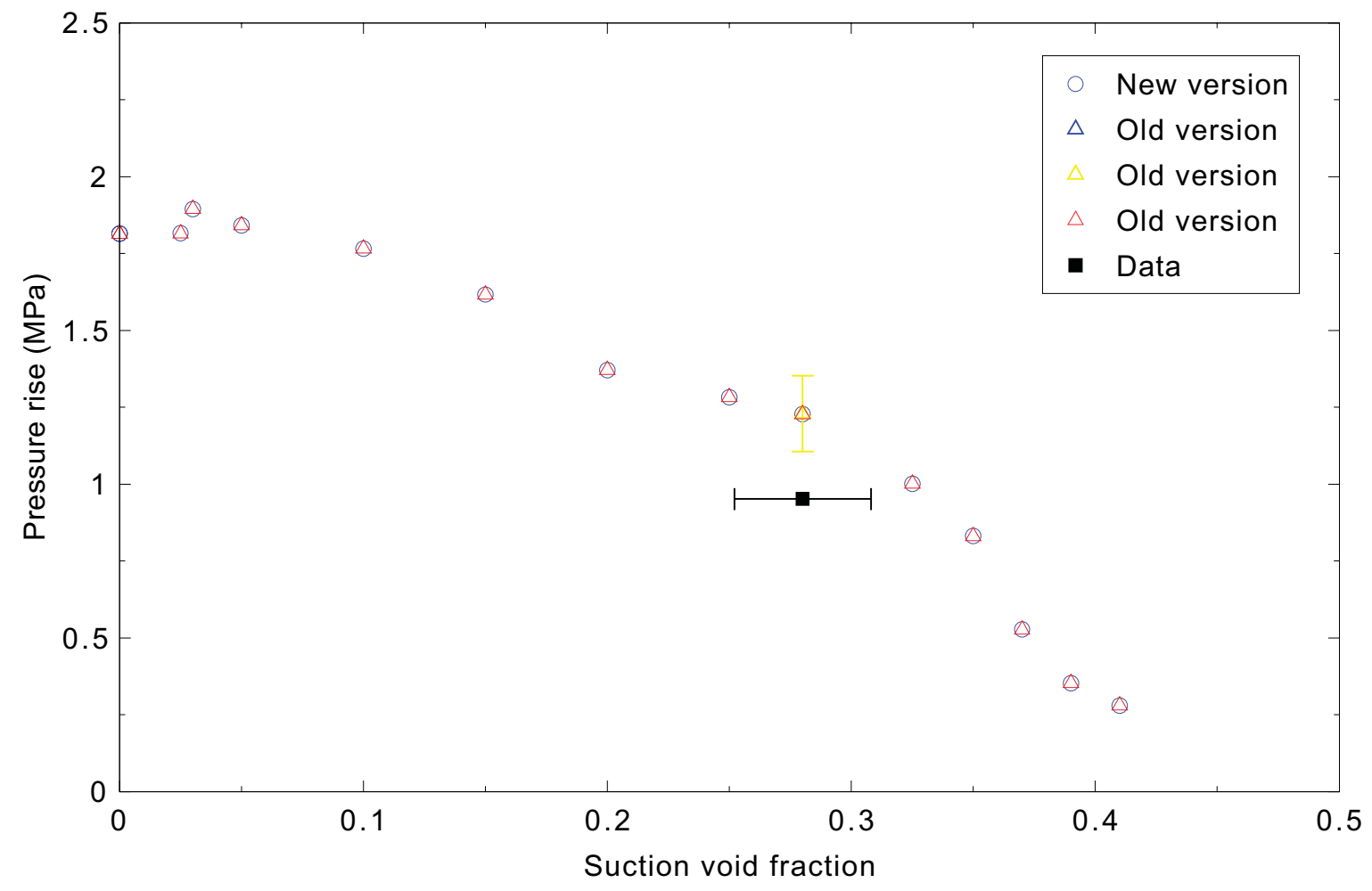

Figure 4.21-5. Pump differential pressures for a suction pressure of $2.80 \mathrm{MPa}$ for the reactor coolant pump case. 


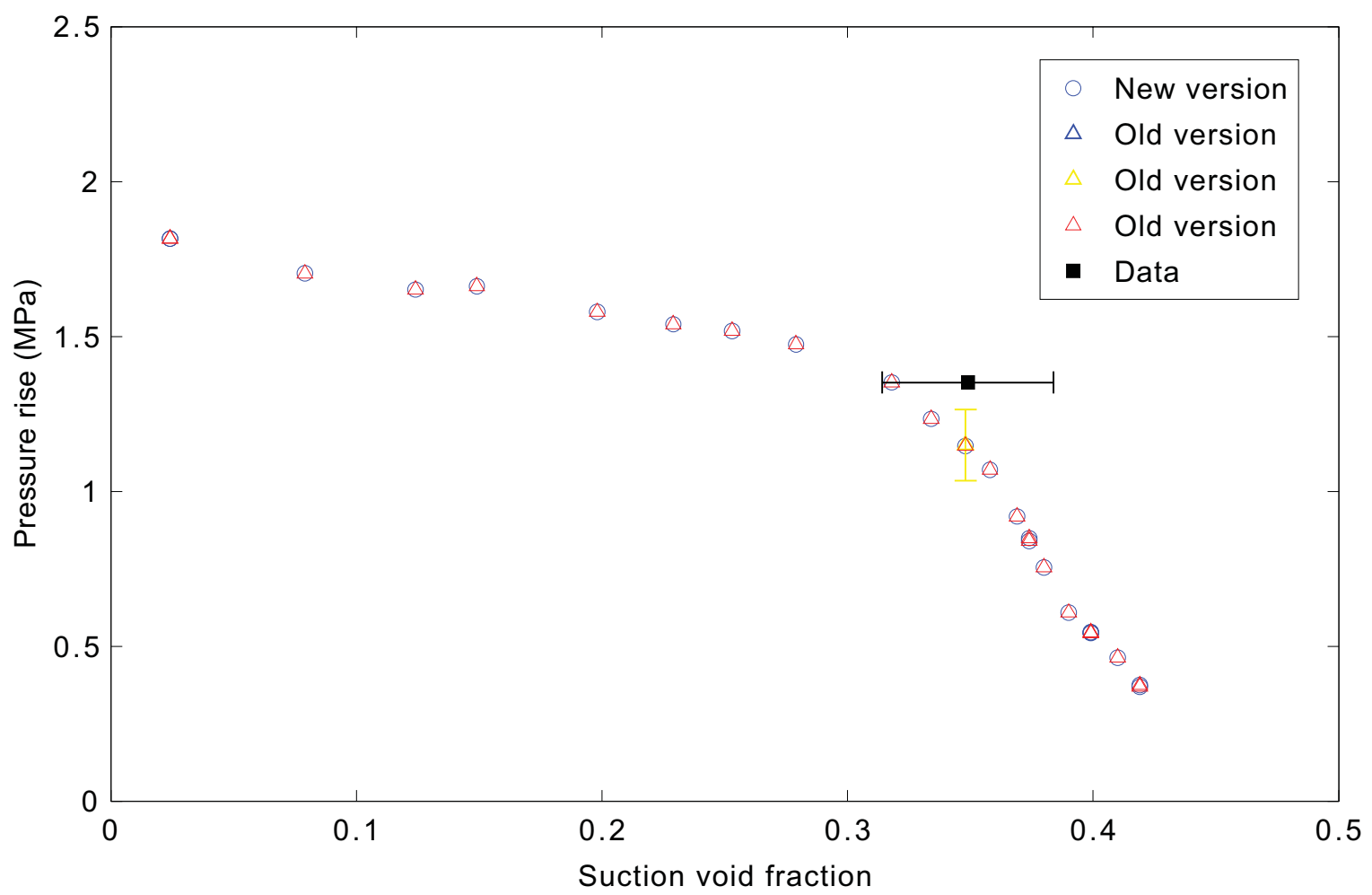

Figure 4.21-6. Pump differential pressures for a suction pressure of 4.69 MPa for the reactor coolant pump case.

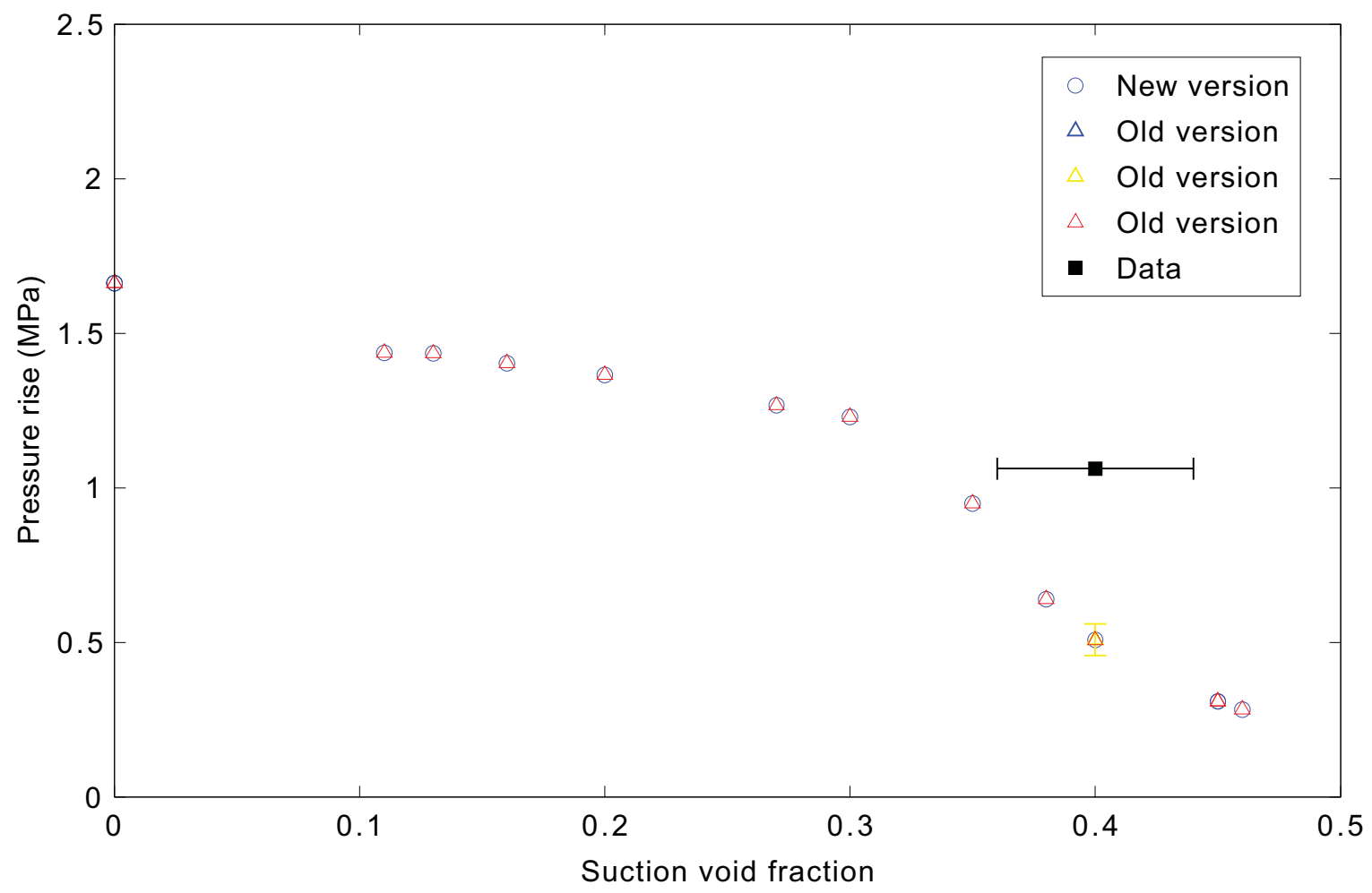

Figure 4.21-7. Pump differential pressures for a suction pressure of $6.42 \mathrm{MPa}$ for the reactor coolant pump case. 
RELAP5-3D/4.0.3 


\subsection{GE 1/6-Scale Jet Pump}

Figures comparing simulations using two code versions are presented. Diagrams are included so that the figure numbering is the same as that in Volume III of the RELAP5-3D code manual. No differences were observed in the figures.

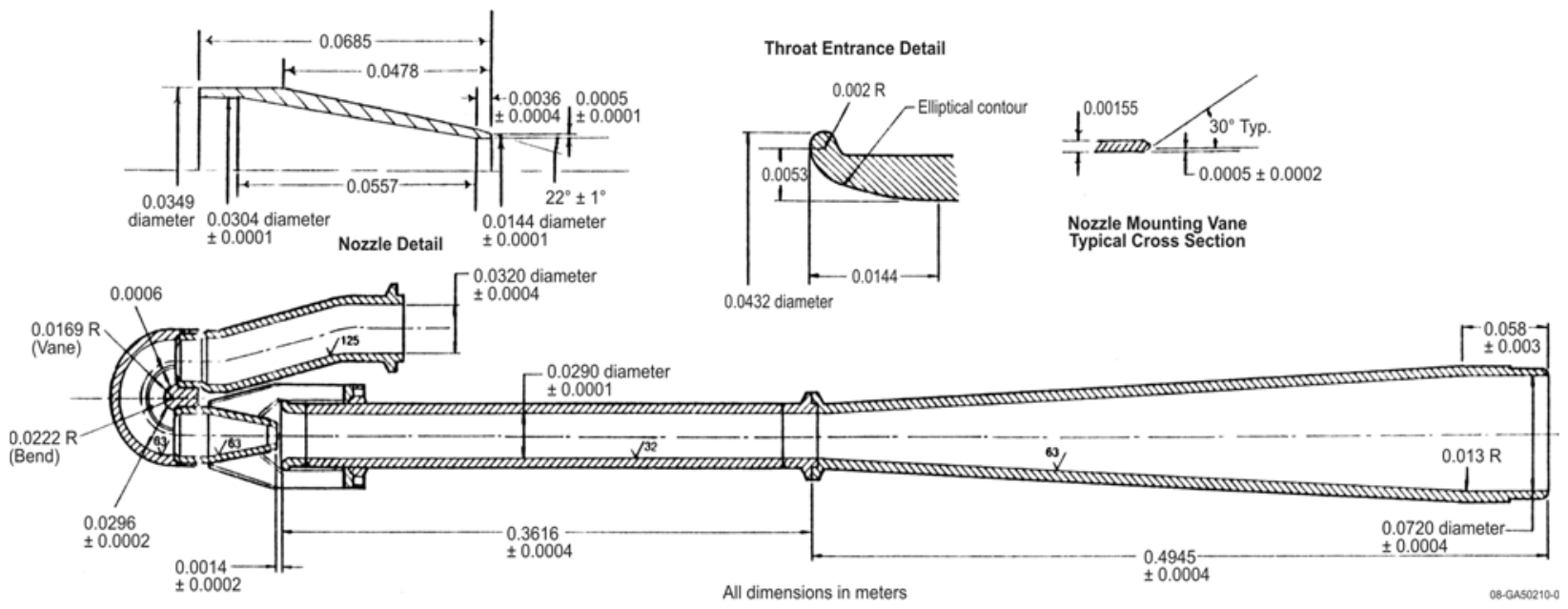

Figure 4.22-1. 1/6-scale model jet pump. 


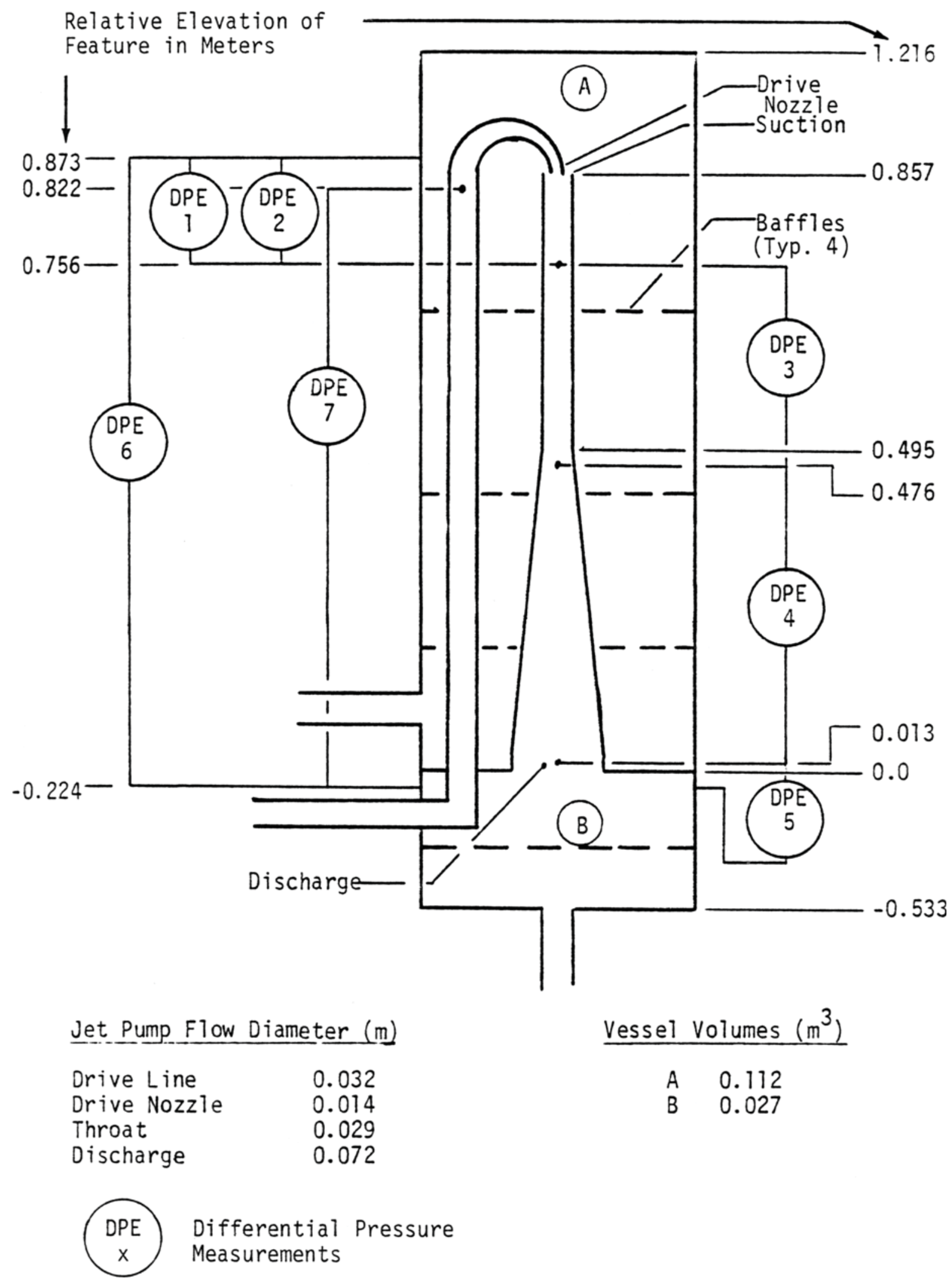

Figure 4.22-2. Schematic of the jet pump and vessel. 
Orifice and Densitometer use:

(a) Transient Test 1

(b) Transient Test 2
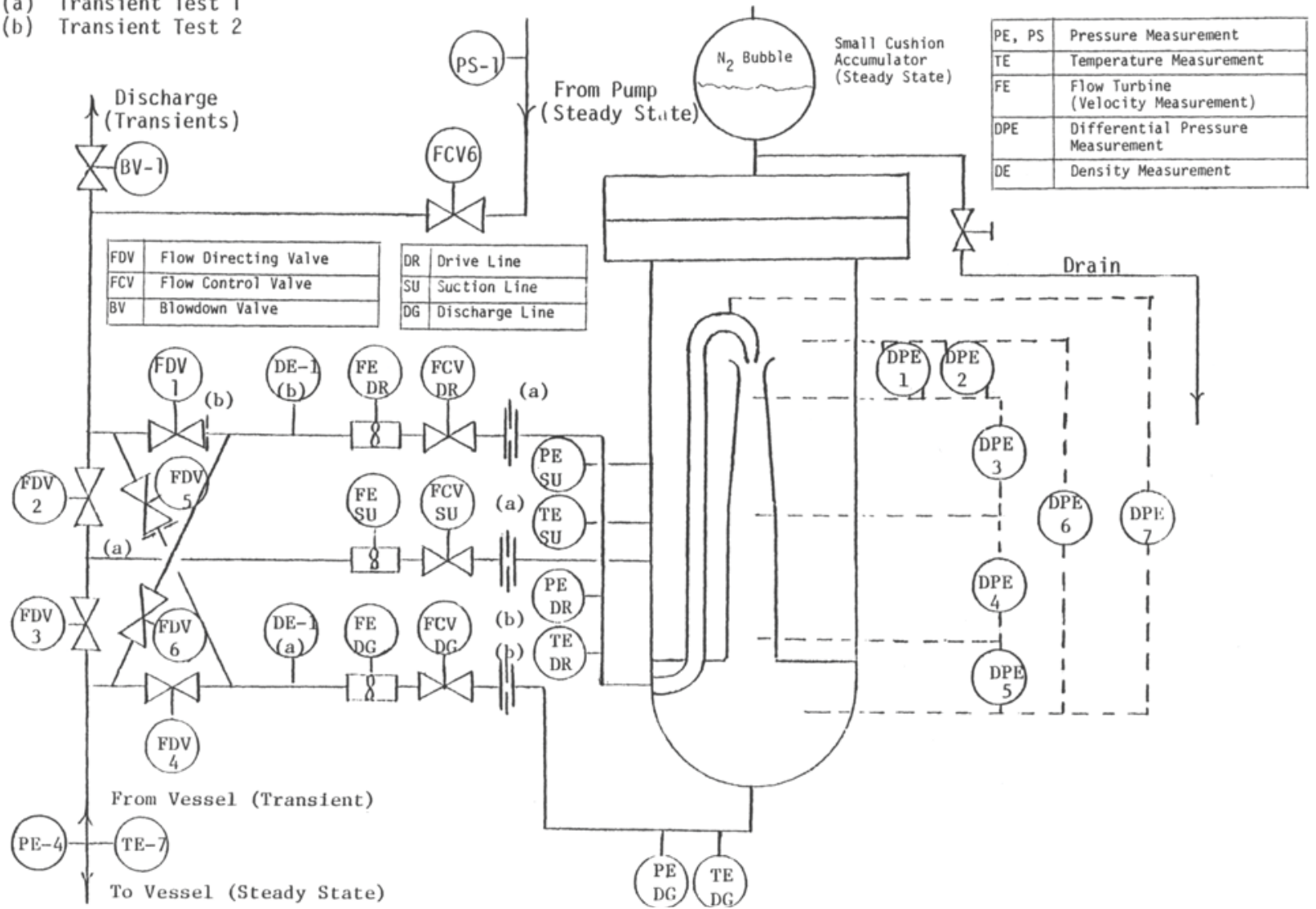

Figure 4.22-3. Jet pump test assembly and instrumentation. 


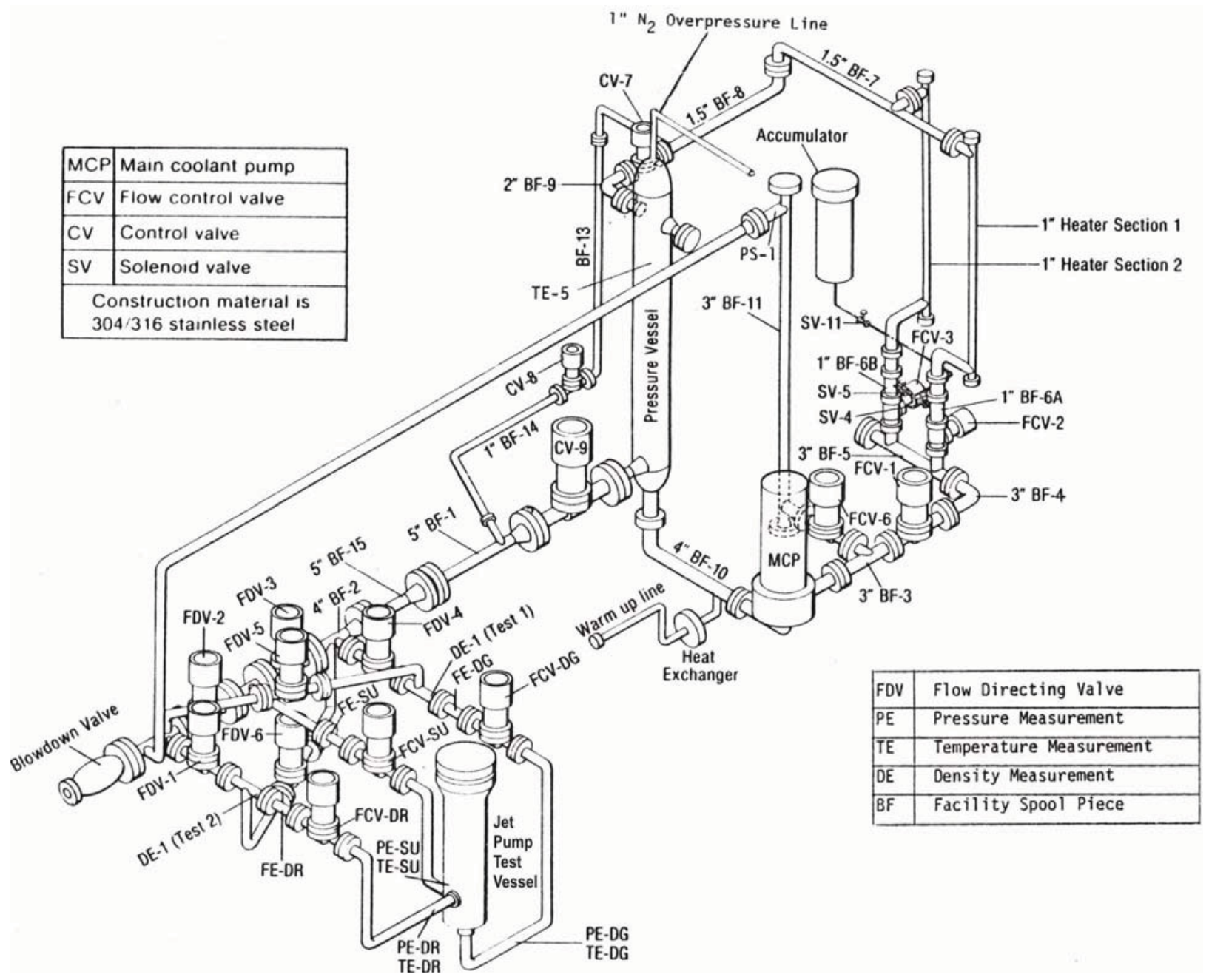

Figure 4.22-4. Jet pump assembly and blowdown facility schematic. 


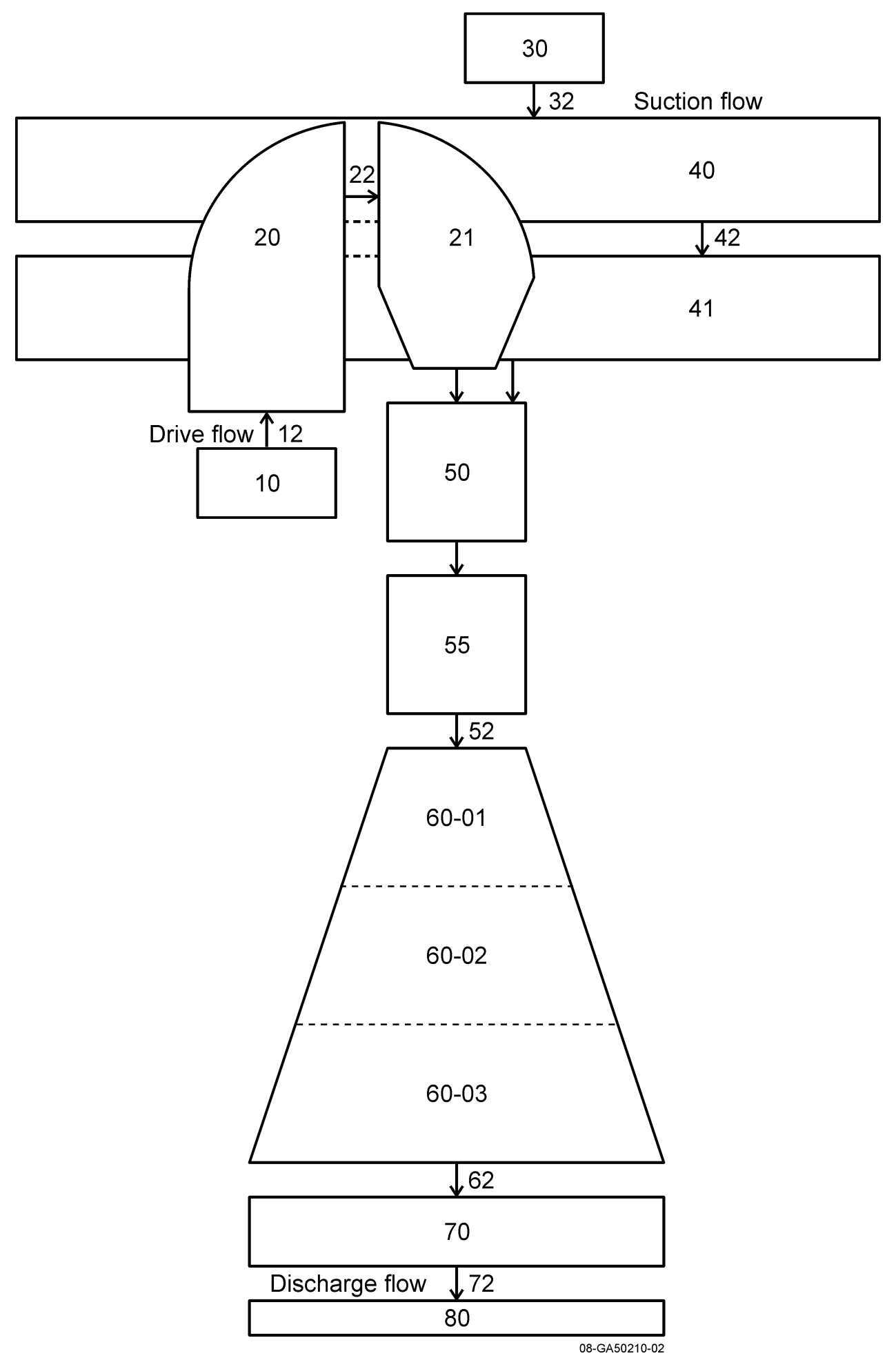

Figure 4.22-5. RELAP5-3D nodalization for the 1/6-scale jet pump test. 


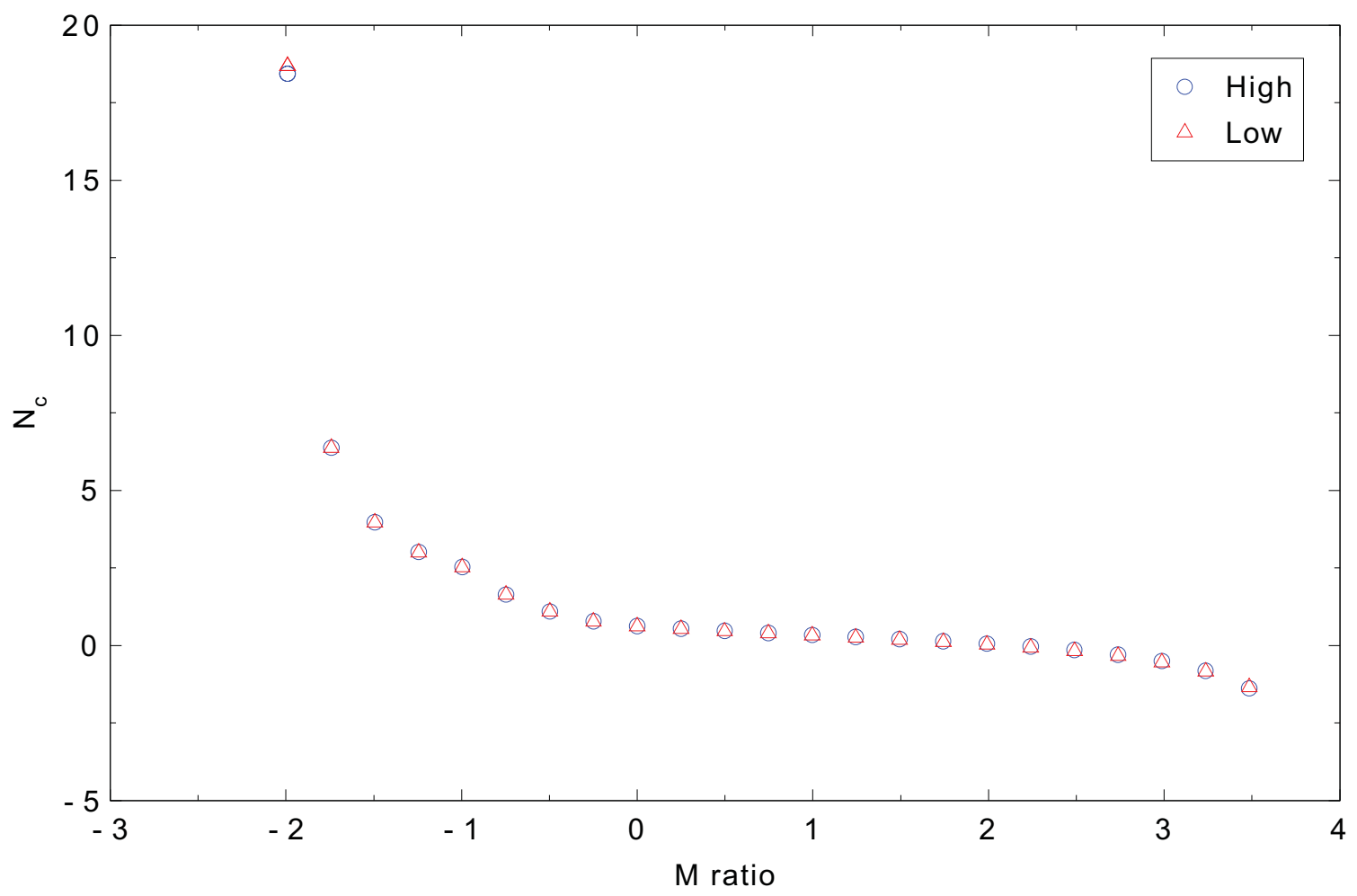

Figure 4.22-6. Calculated flow parameters for forward drive flows at high and low pressure and temperature for the $1 / 6$-scale jet pump case.

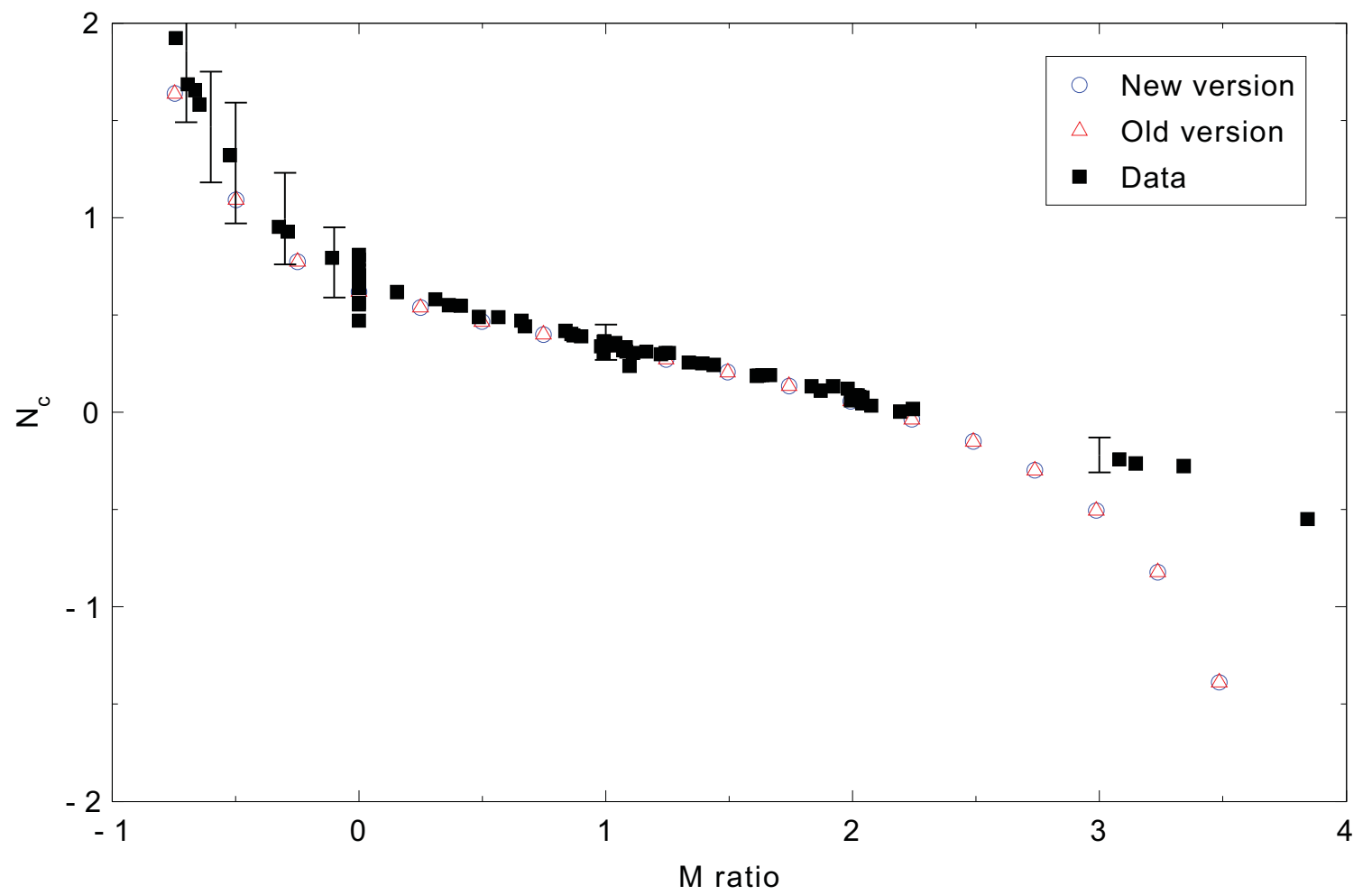

Figure 4.22-7. Measured and calculated flow parameters for forward drive flows for the $1 / 6$-scale jet pump case. 


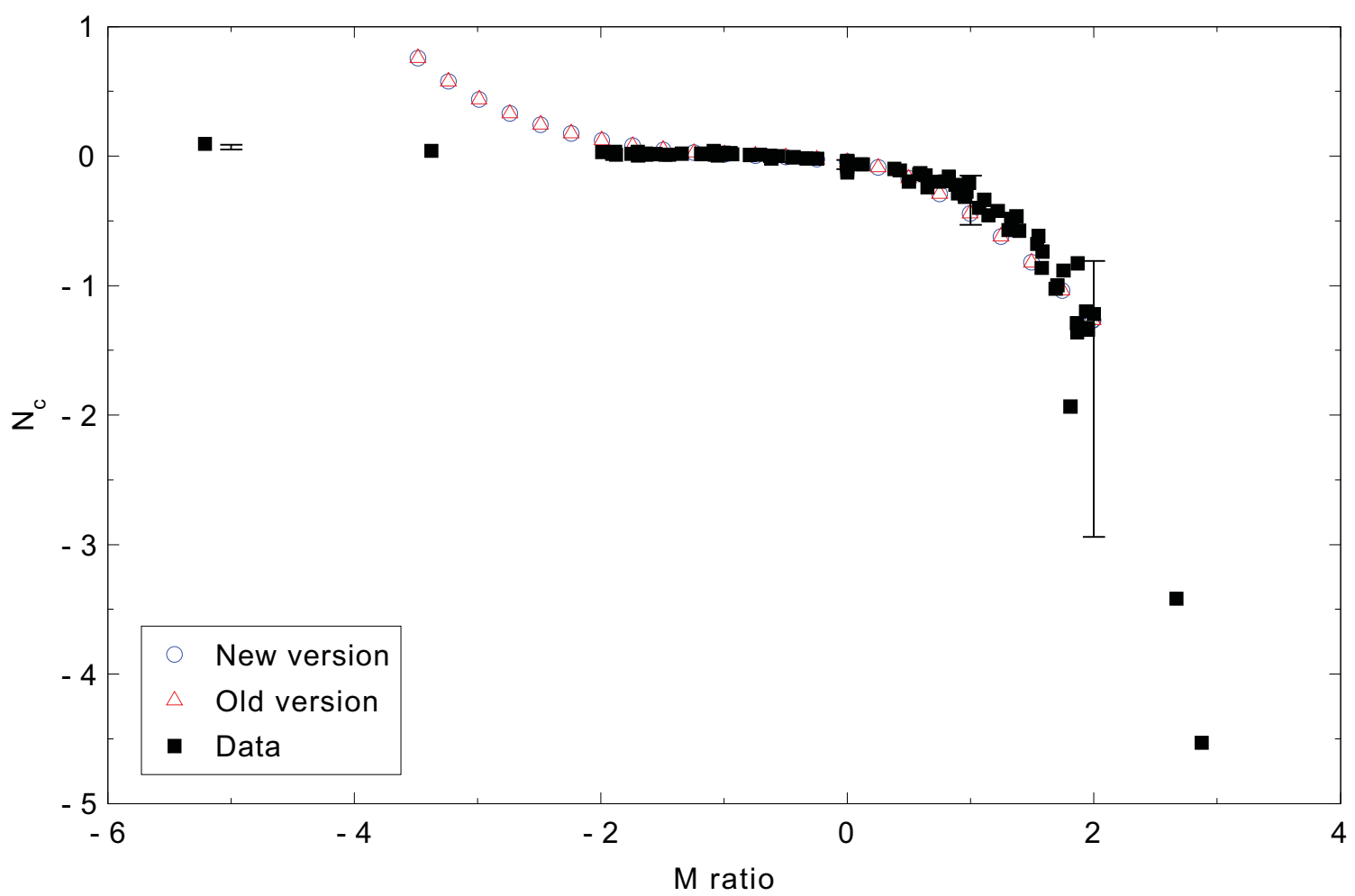

Figure 4.22-8. Measured and calculated flow parameters for reverse drive flows for the 1/6-scale jet pump case. 
RELAP5-3D/4.0.3 


\section{INTEGRAL EFFECTS CASES}

This chapter presents the integral effects assessment case results. 


\subsection{LOFT Experiment L3-7}

Figures comparing simulations using two code versions are presented. Diagrams are included so that the figure numbering is the same as that in Volume III of the RELAP5-3D code manual. Noticeable differences were observed in Figures 5.1-3, 4, 5, 6, 7, 9, 10, 11, 12, 13, 14, 15, 16, 17, and 19.

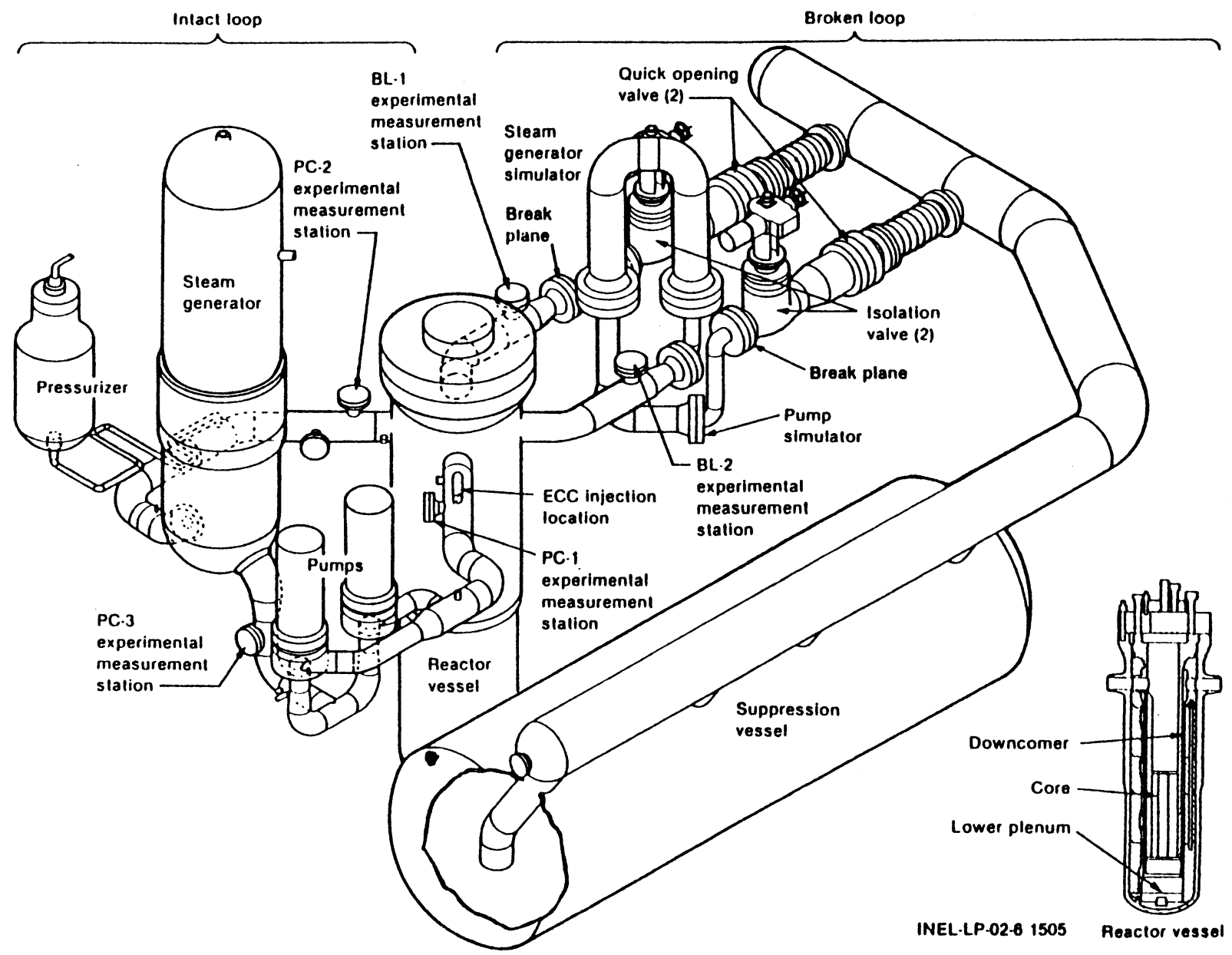

Figure 5.1-1. Schematic of the LOFT facility. 


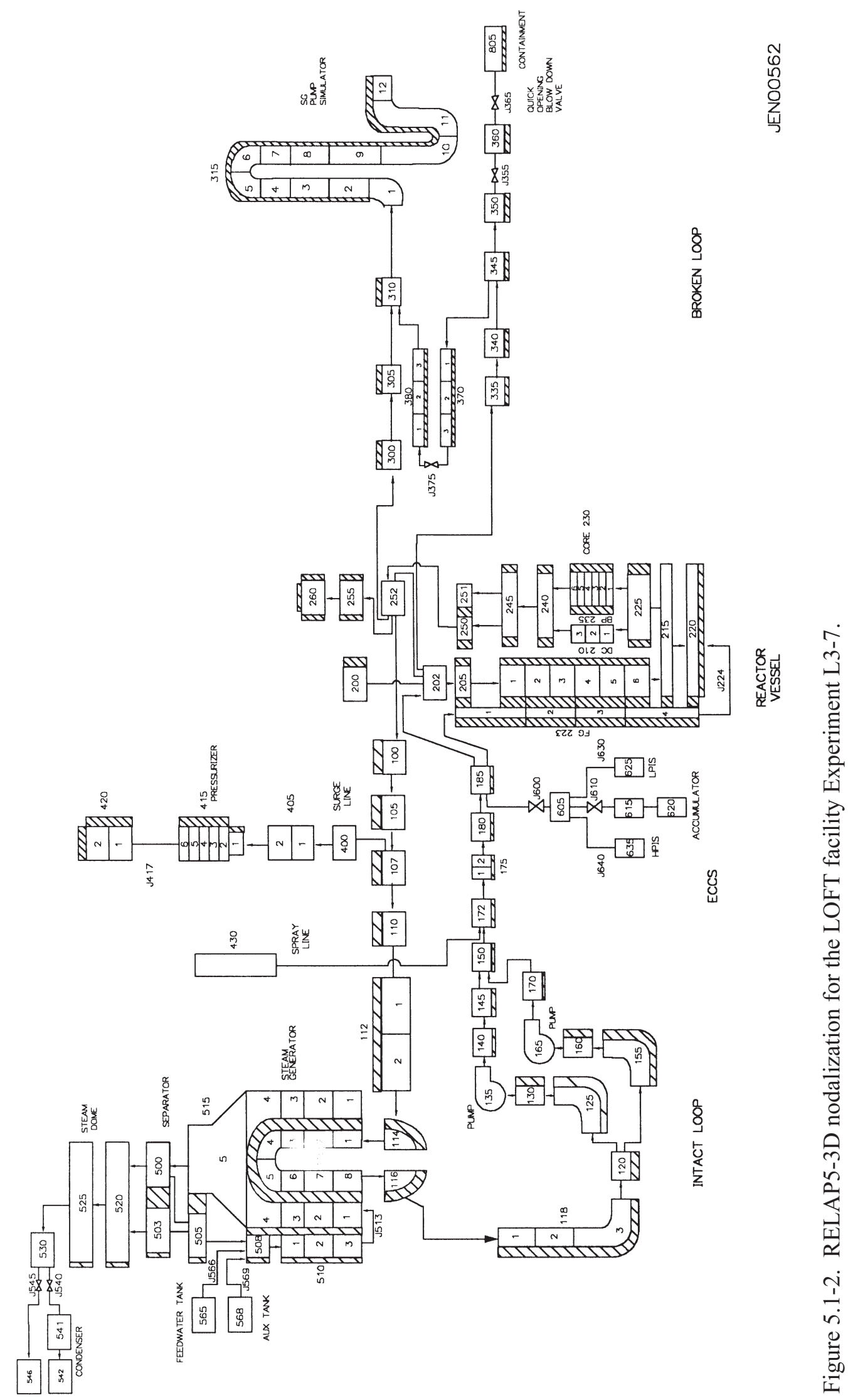




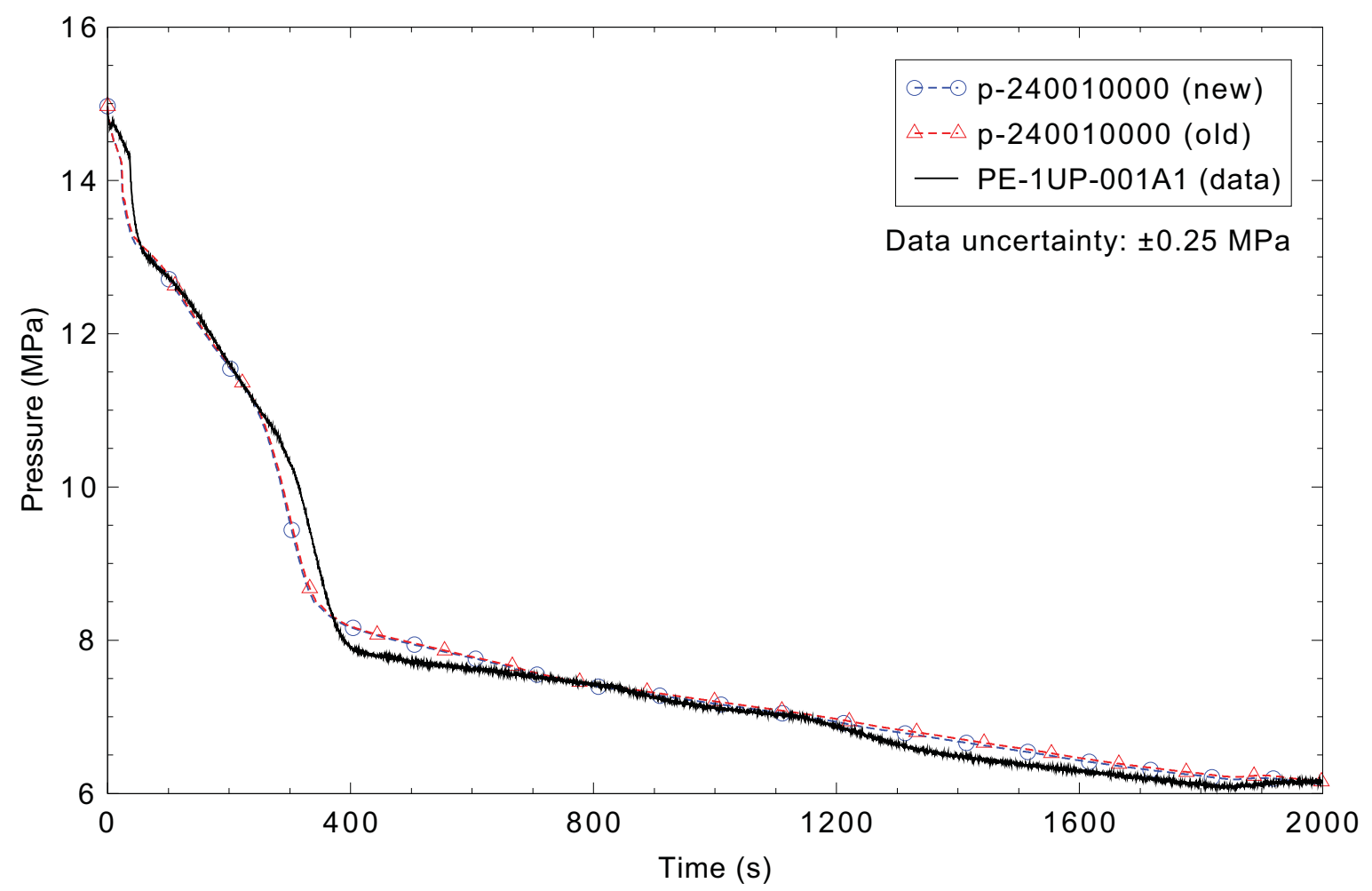

Figure 5.1-3. Measured and calculated reactor vessel upper plenum pressure for LOFT Experiment L3-7.

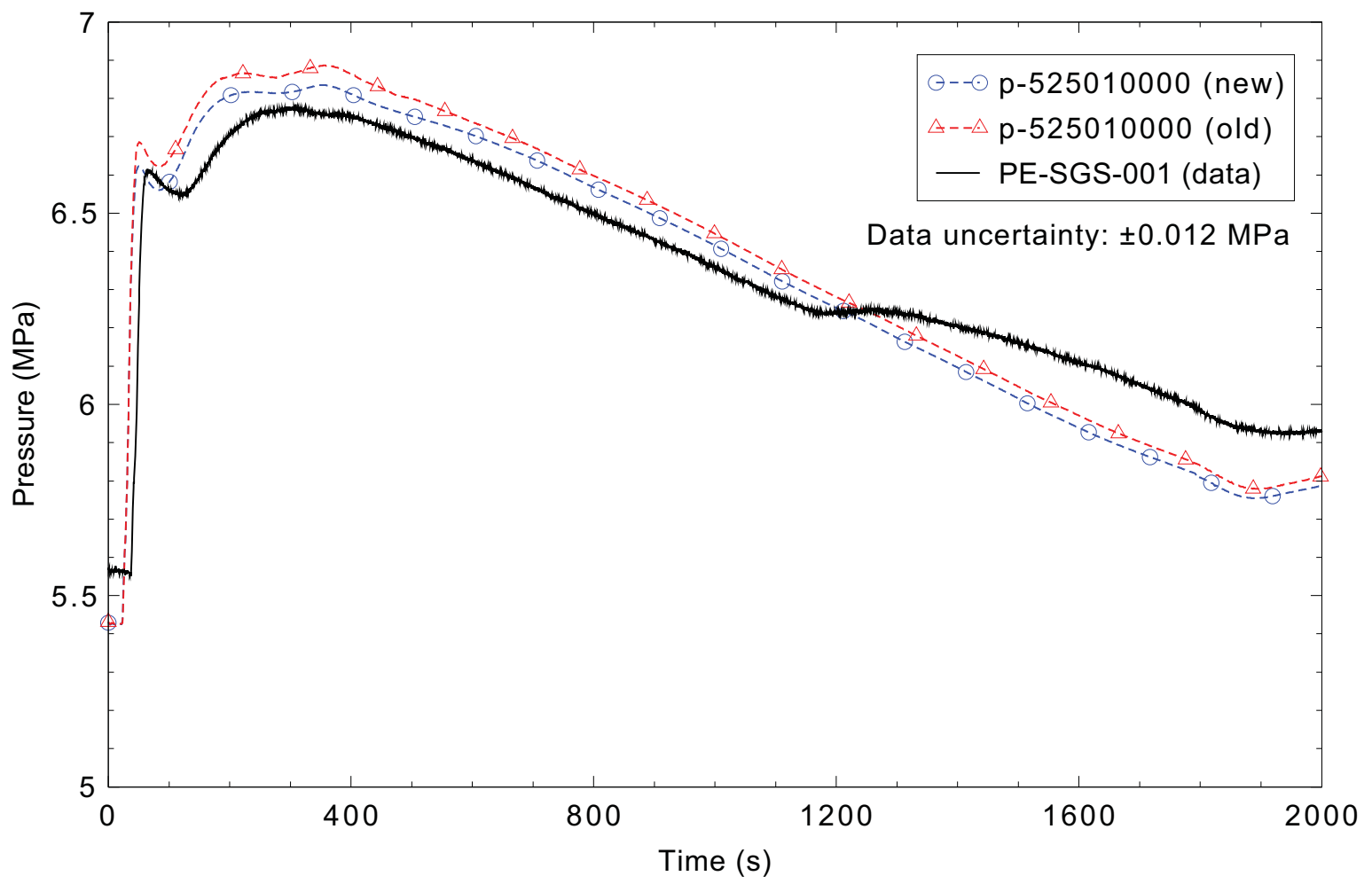

Figure 5.1-4. Measured and calculated steam generator secondary pressure for LOFT Experiment L3-7. 


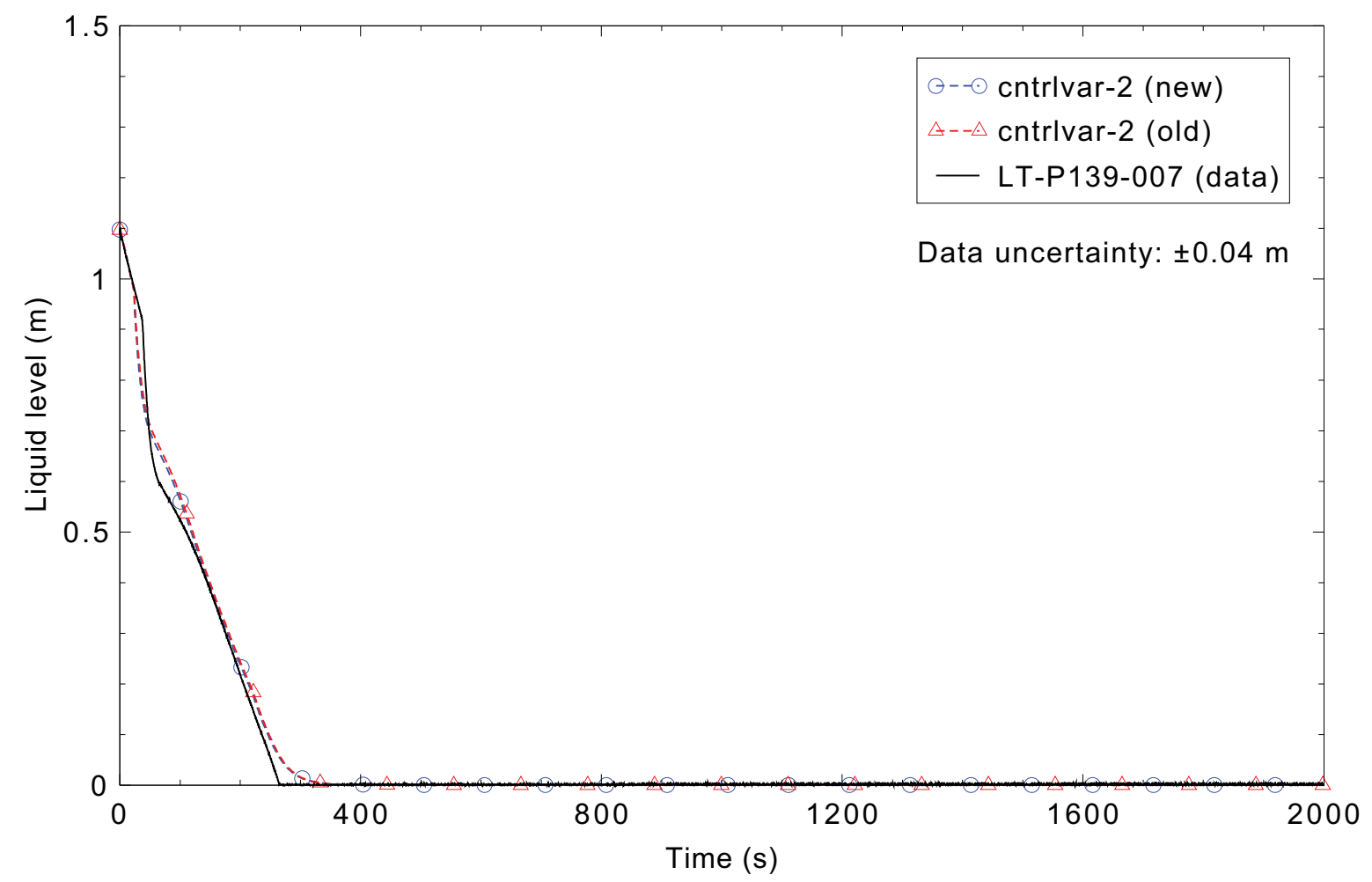

Figure 5.1-5. Measured and calculated pressurizer liquid level for LOFT Experiment L3-7.

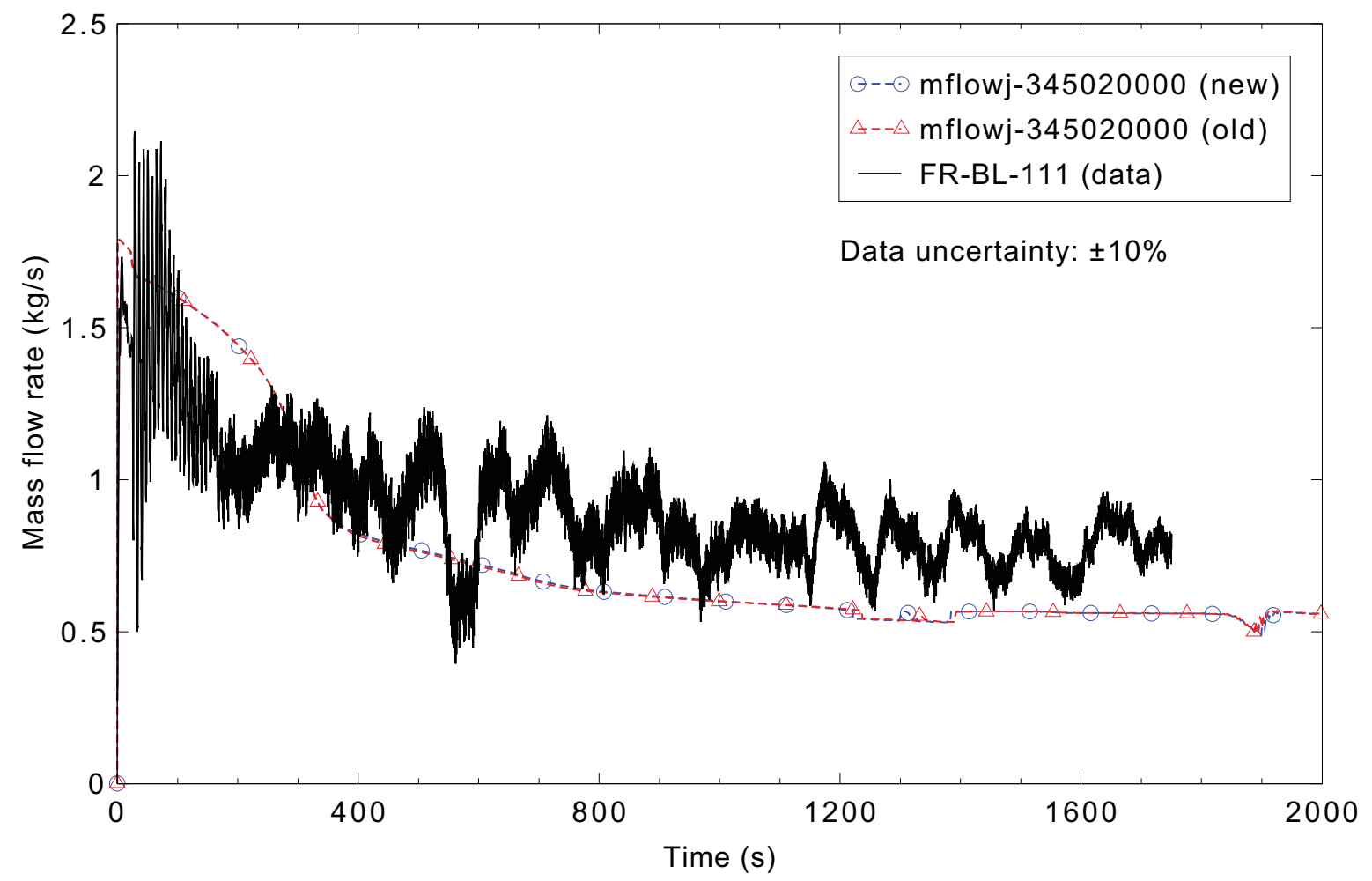

Figure 5.1-6. Measured and calculated break flow rate for LOFT Experiment L3-7. 


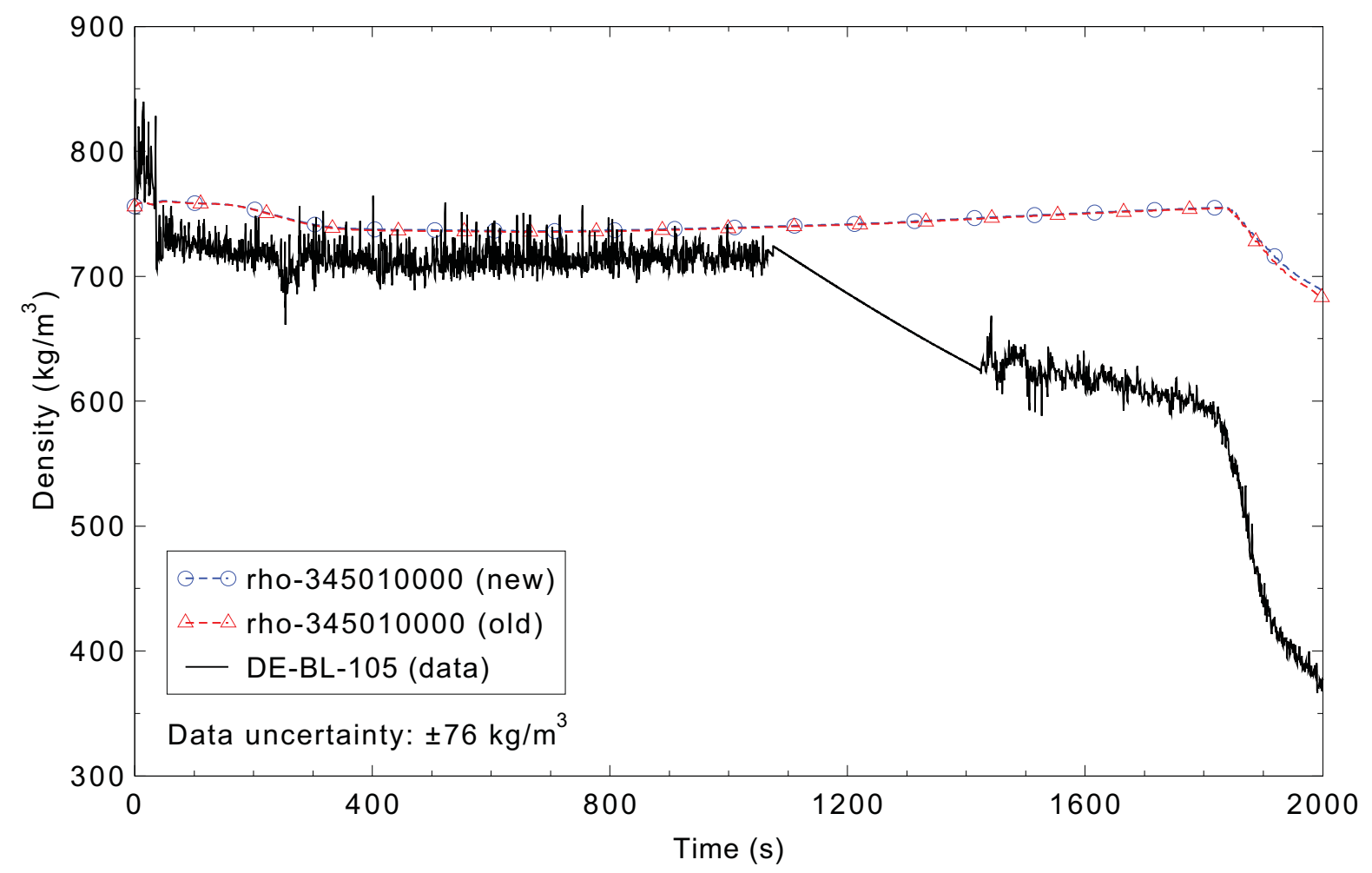

Figure 5.1-7. Measured and calculated broken loop cold leg fluid density for LOFT Experiment L3-7.

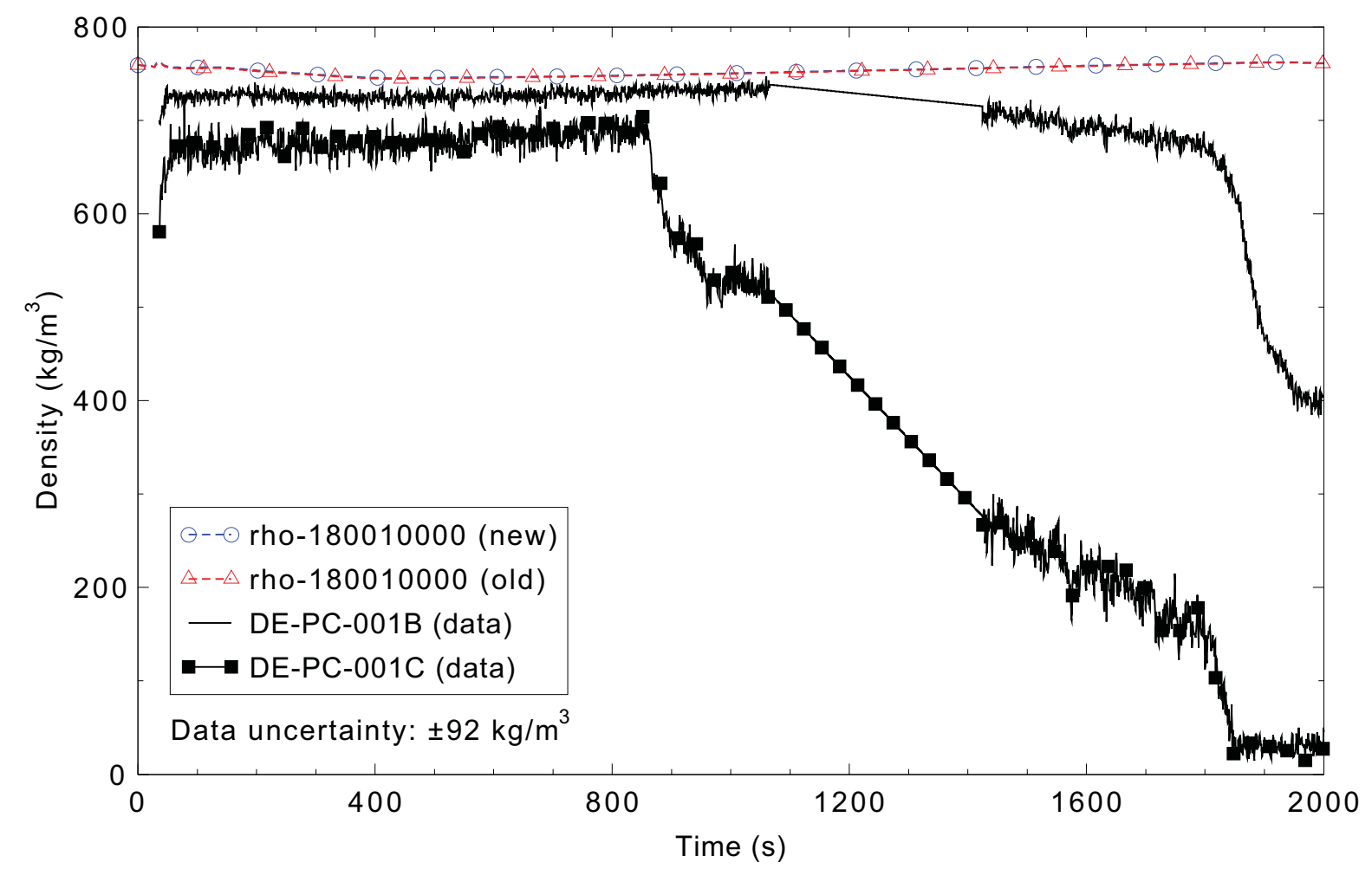

Figure 5.1-8. Measured and calculated intact loop cold leg fluid density for LOFT Experiment L3-7. 


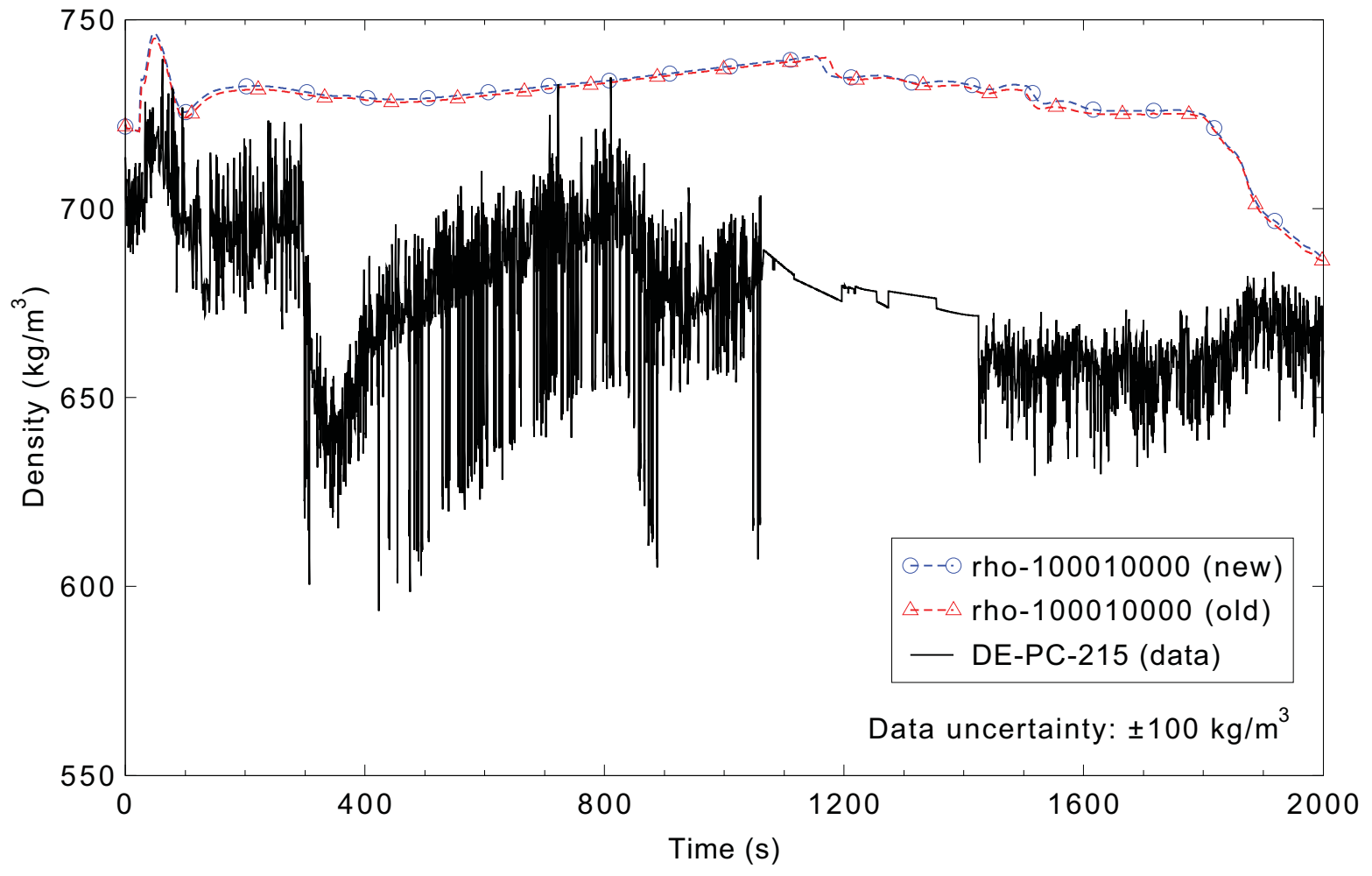

Figure 5.1-9. Measured and calculated intact loop hot leg fluid density for LOFT Experiment L3-7.

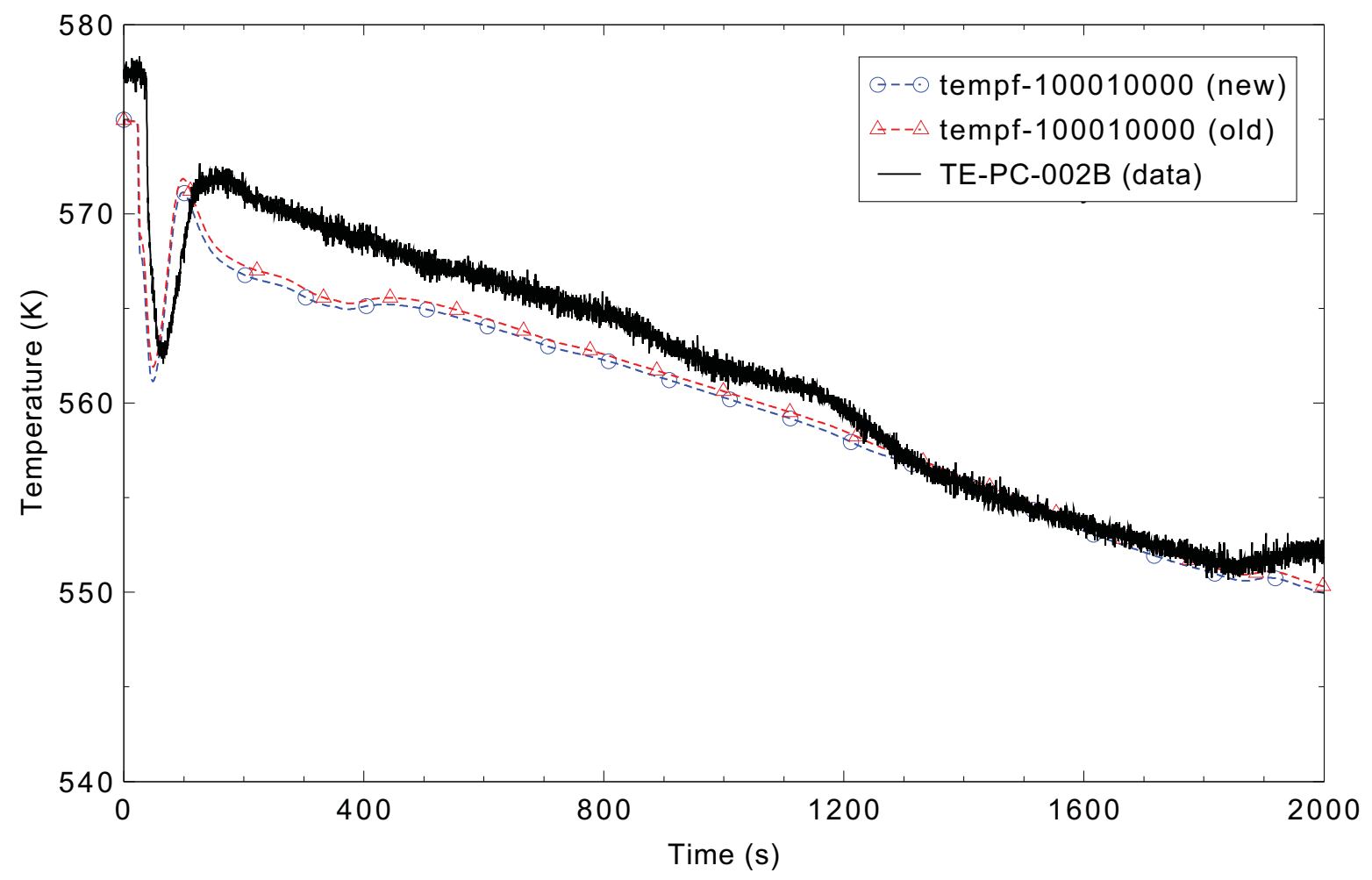

Figure 5.1-10. Measured and calculated intact loop hot leg fluid temperature for LOFT Experiment L3-7. 


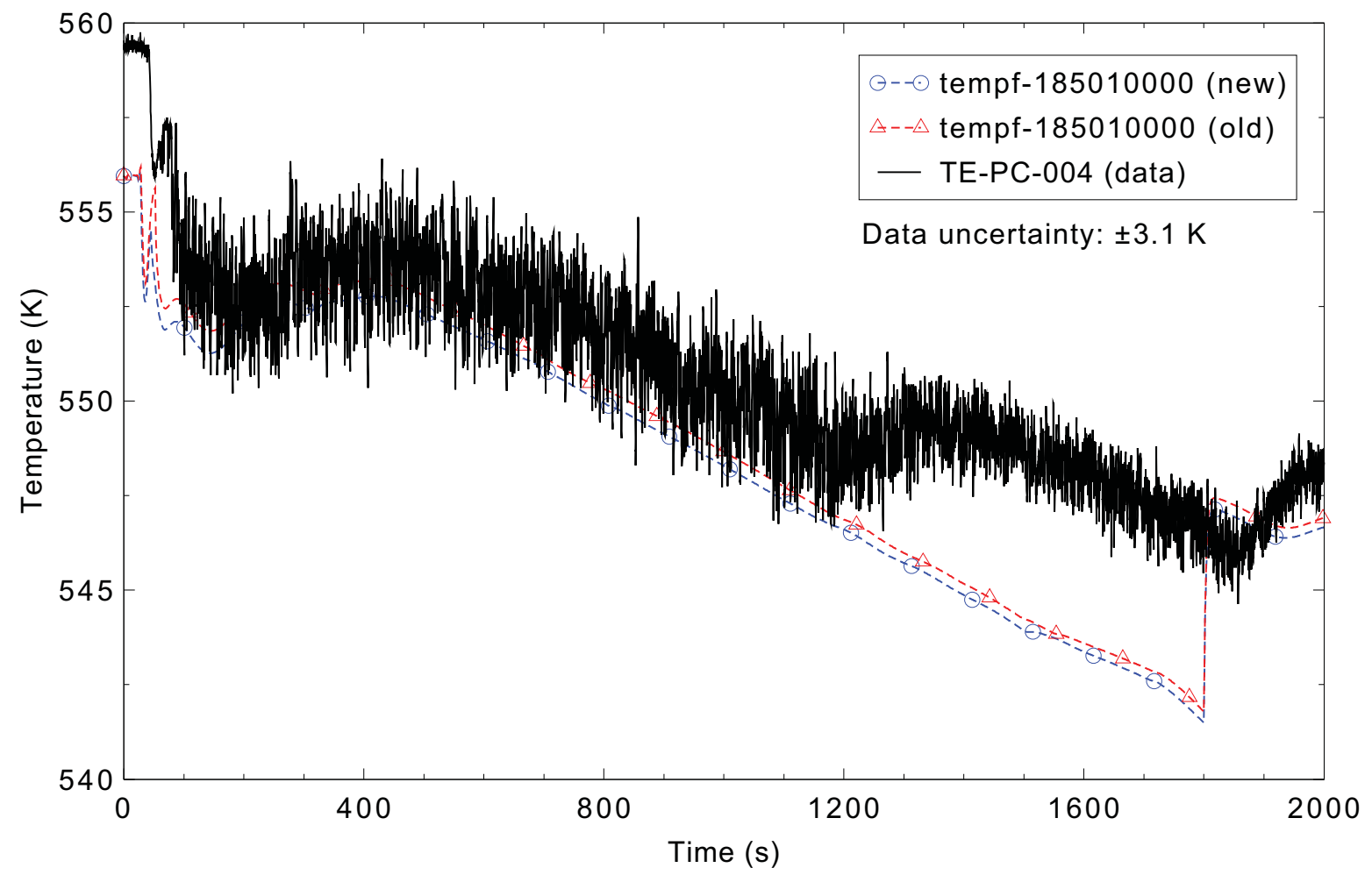

Figure 5.1-11. Measured and calculated intact loop cold leg fluid temperature for LOFT Experiment L3-7.

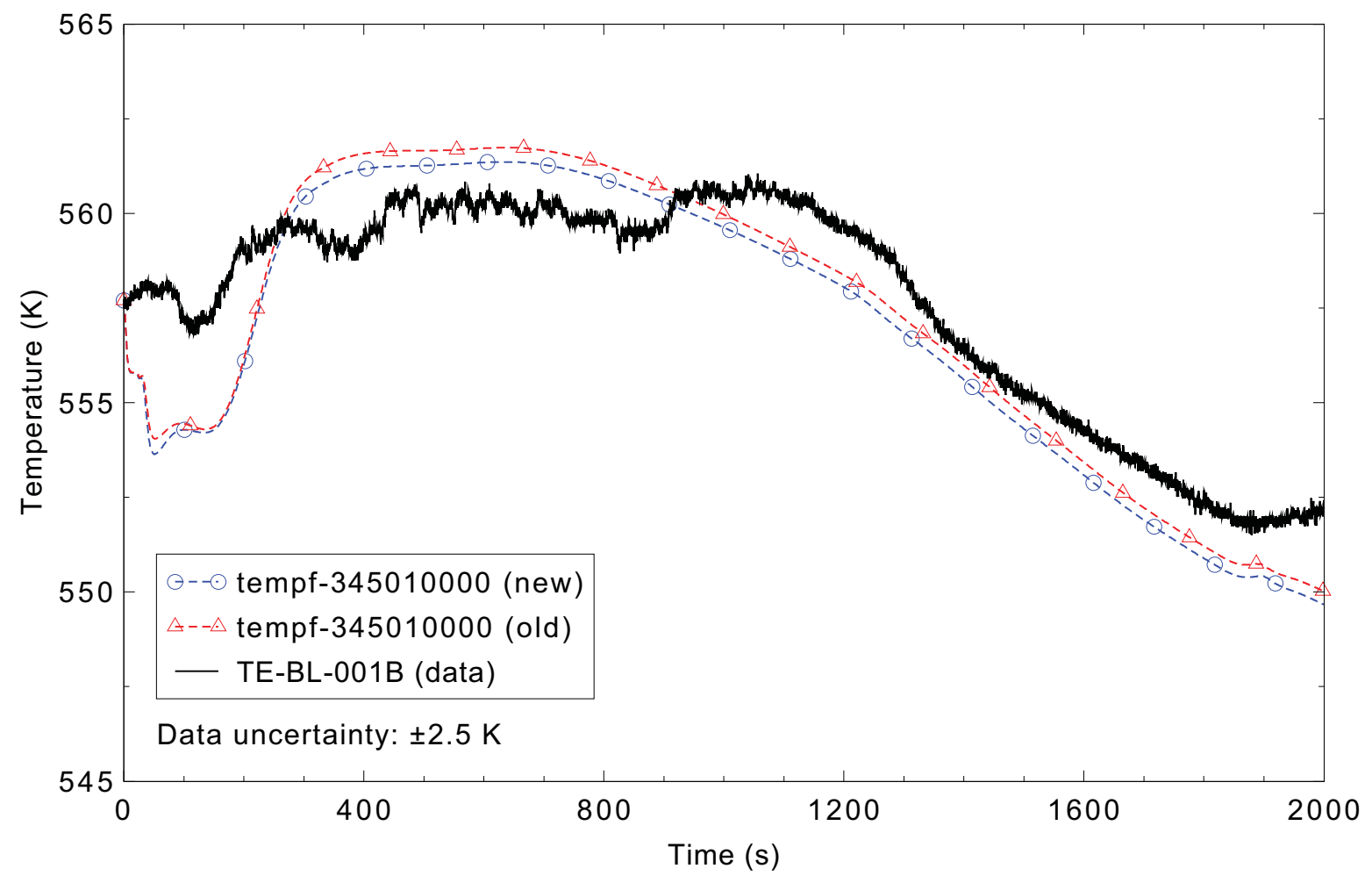

Figure 5.1-12. Measured and calculated broken loop cold leg fluid temperature for LOFT Experiment L3-7. 


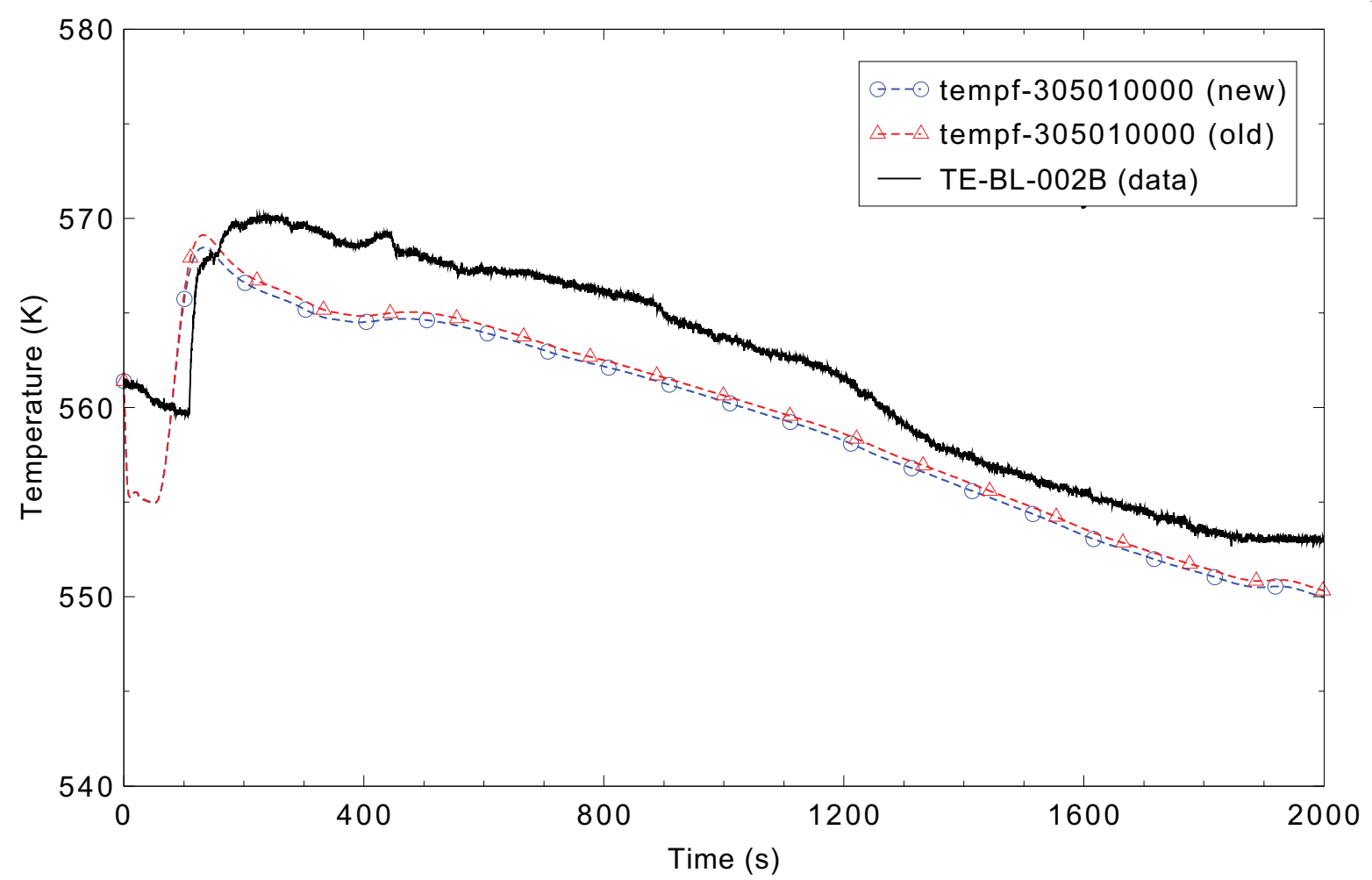

Figure 5.1-13. Measured and calculated broken loop hot leg fluid temperature for LOFT Experiment L3-7.

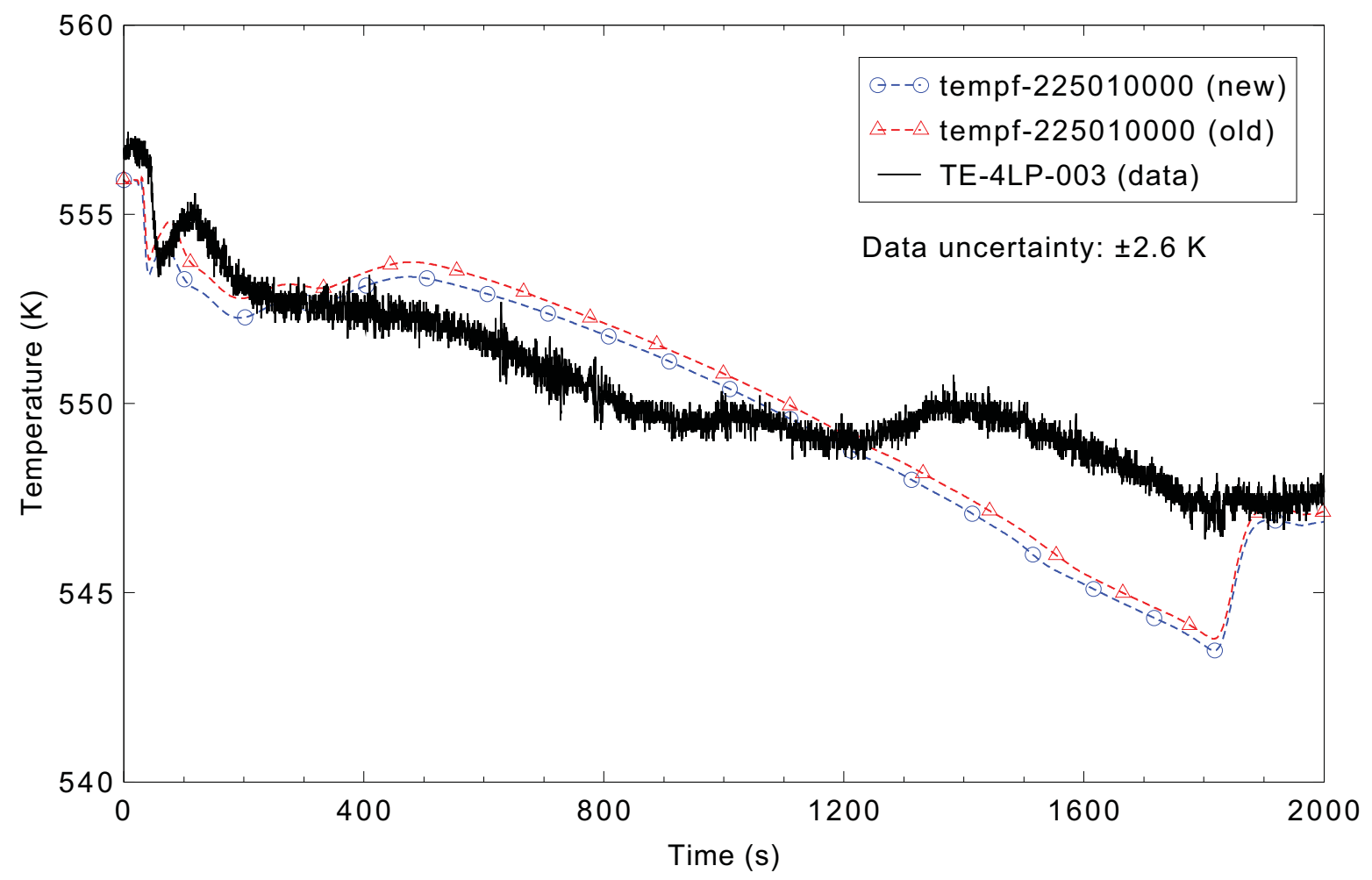

Figure 5.1-14. Measured and calculated core inlet fluid temperature for LOFT Experiment L3-7. 


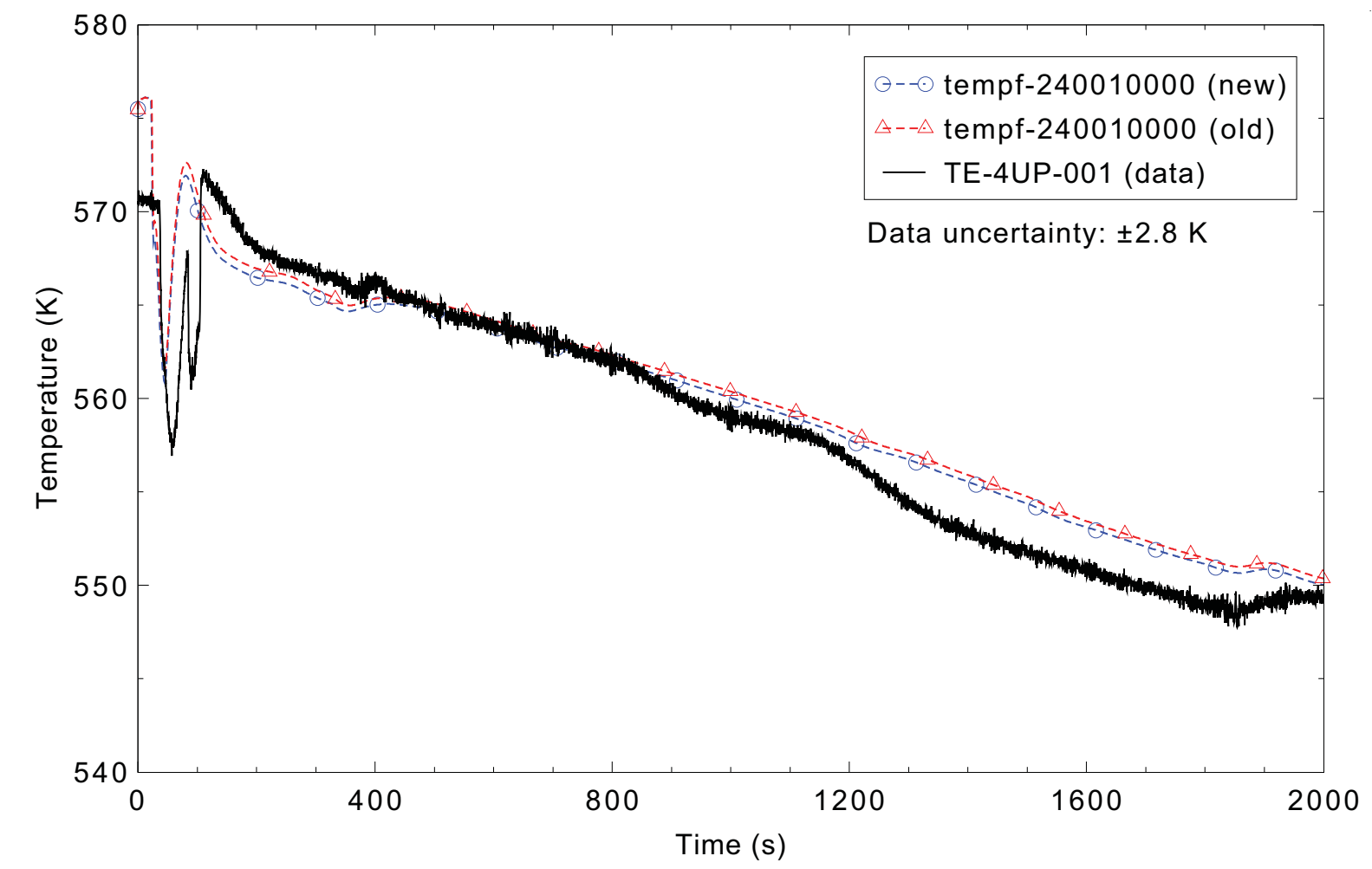

Figure 5.1-15. Measured and calculated reactor vessel upper plenum fluid temperature for LOFT Experiment L3-7.

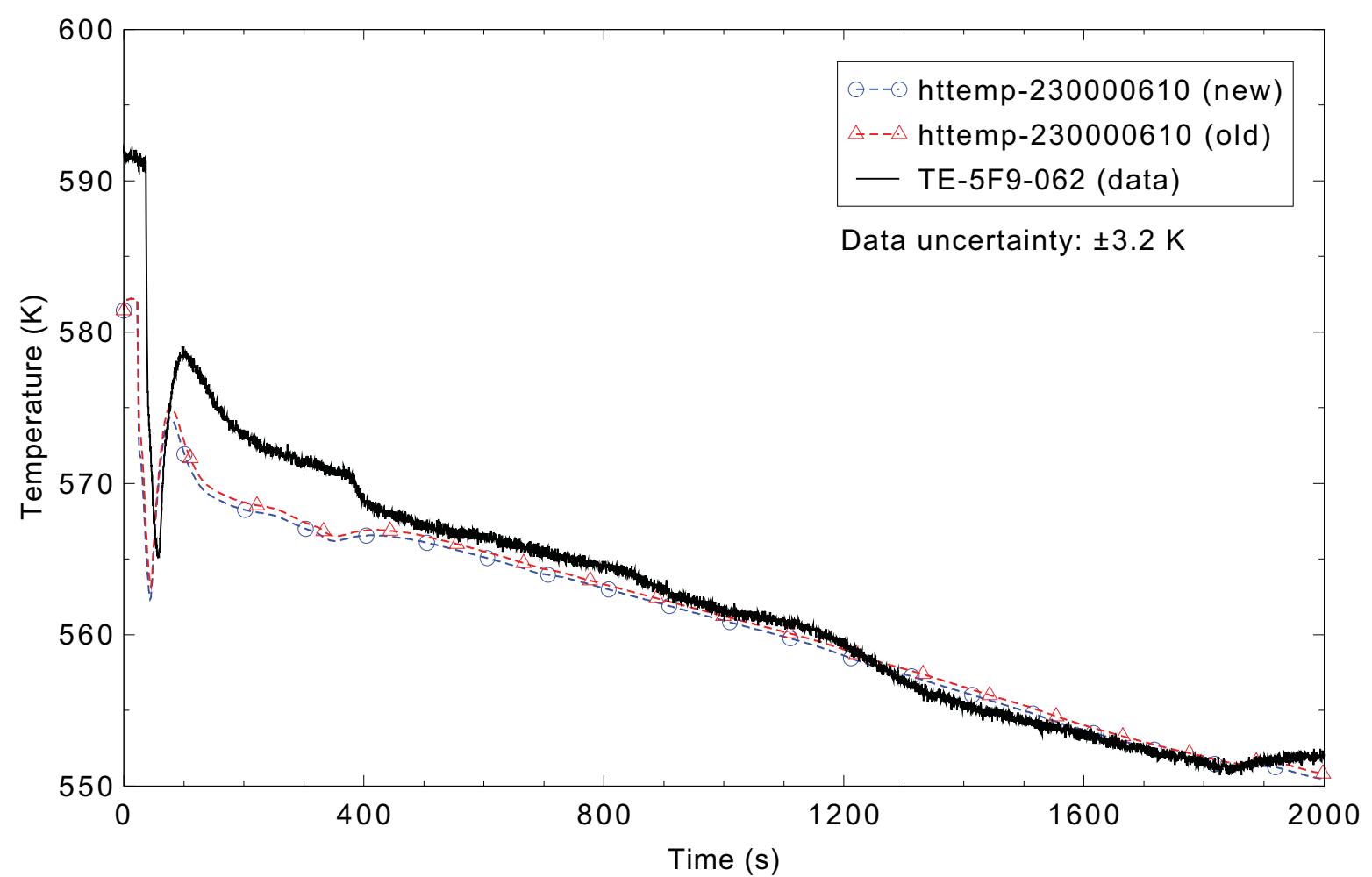

Figure 5.1-16. Measured and calculated fuel cladding surface temperature $1.57 \mathrm{~m}$ above the bottom of the fuel for LOFT Experiment L3-7. 


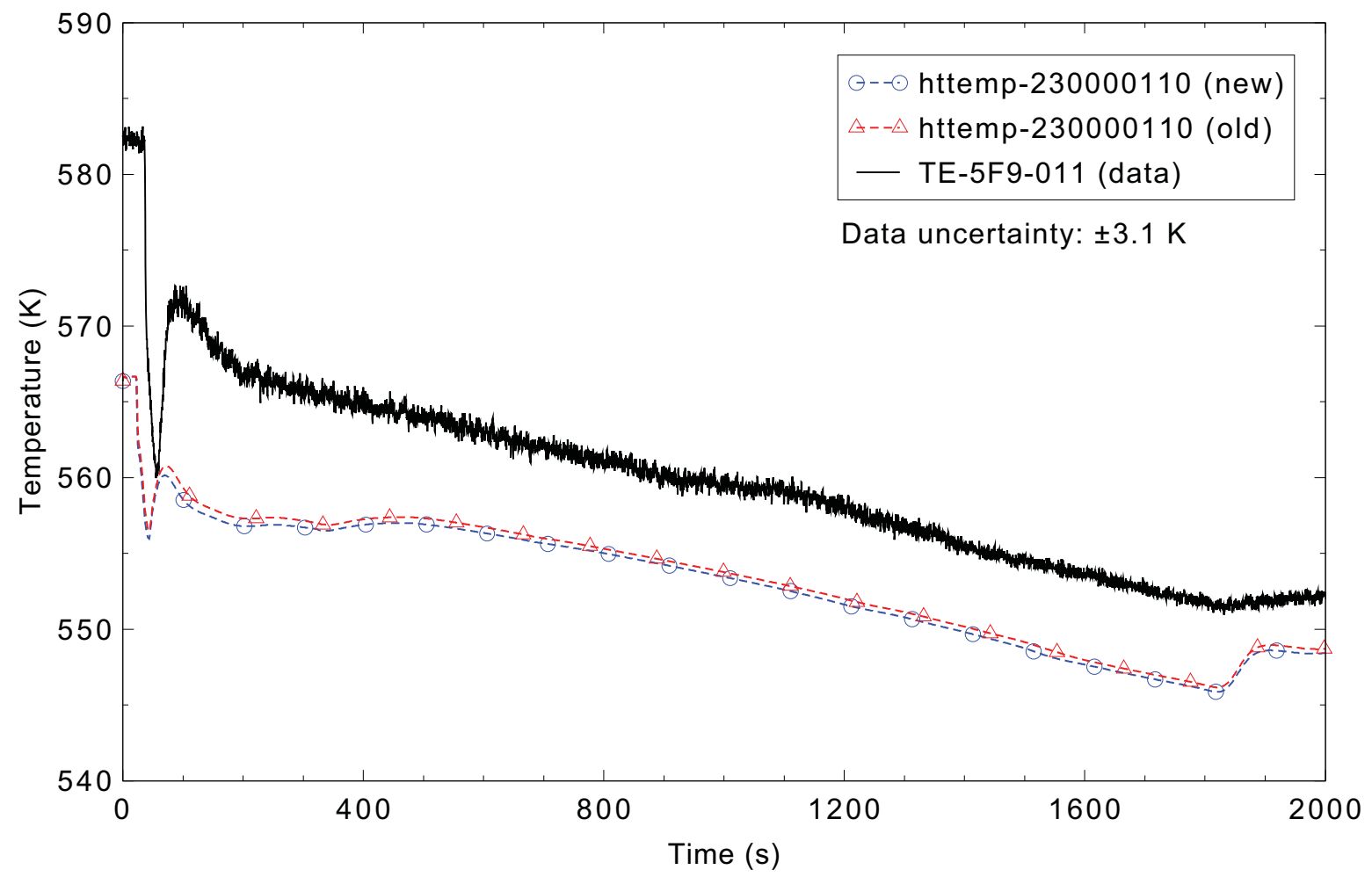

Figure 5.1-17. Measured and calculated fuel cladding surface temperature $0.28 \mathrm{~m}$ above the bottom of the fuel for LOFT Experiment L3-7.

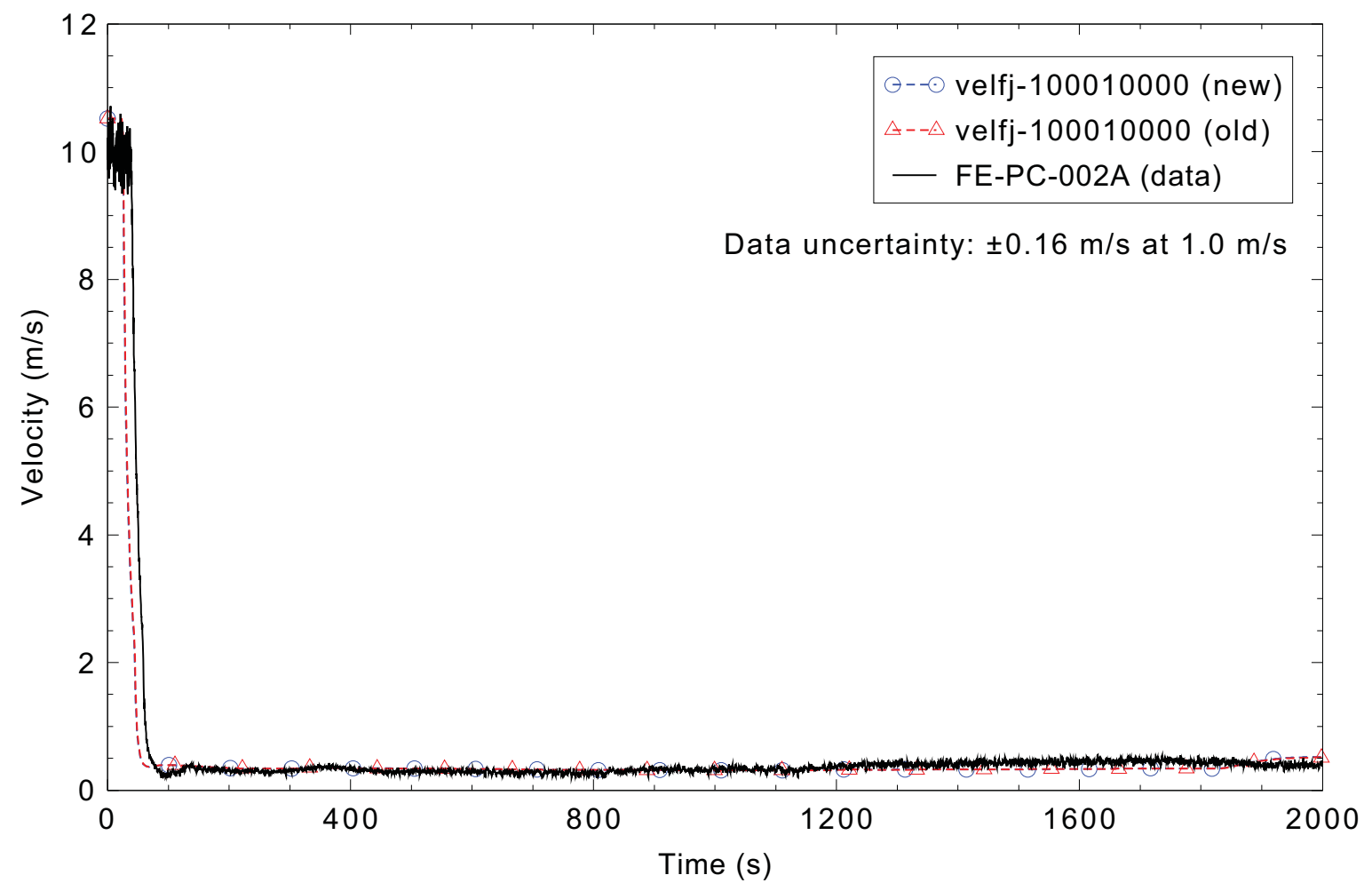

Figure 5.1-18. Measured and calculated hot leg fluid velocity for LOFT Experiment L3-7. 
RELAP5-3D/4.0.3

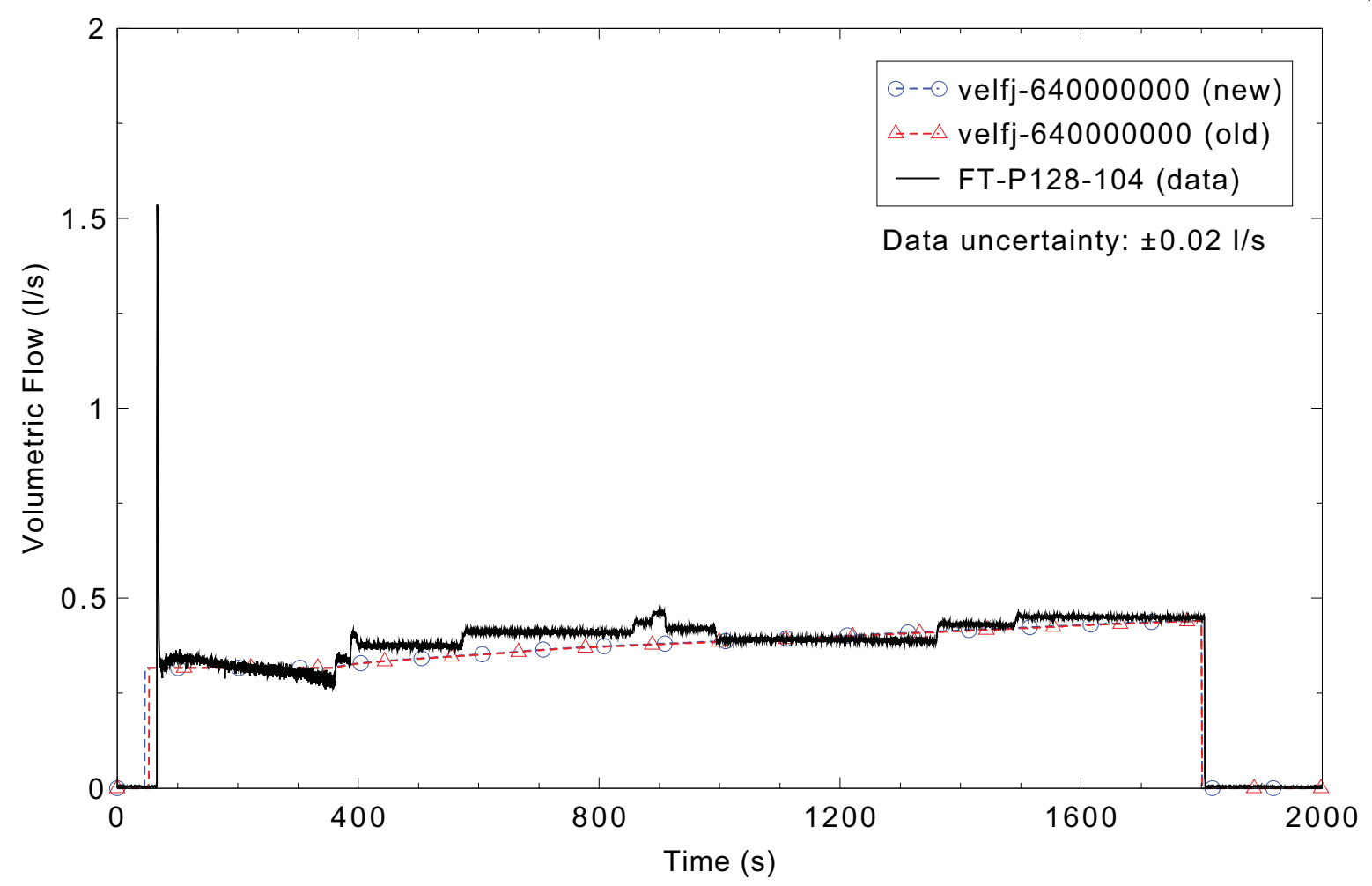

Figure 5.1-19. Measured and calculated HPIS volumetric flow for LOFT Experiment L3-7. 


\subsection{ROSA-IV Test SB-CL-18}

Figures comparing simulations using two code versions are presented. Diagrams are included so that the figure numbering is the same as that in Volume III of the RELAP5-3D code manual. Significant differences were observed in Figures 5.2-23 and 24; noticeable differences were observed in Figures 5.2-4, $5,6,8,9,10,11,12,13,14,15,16,17,18,19,20,21$, and 22 .

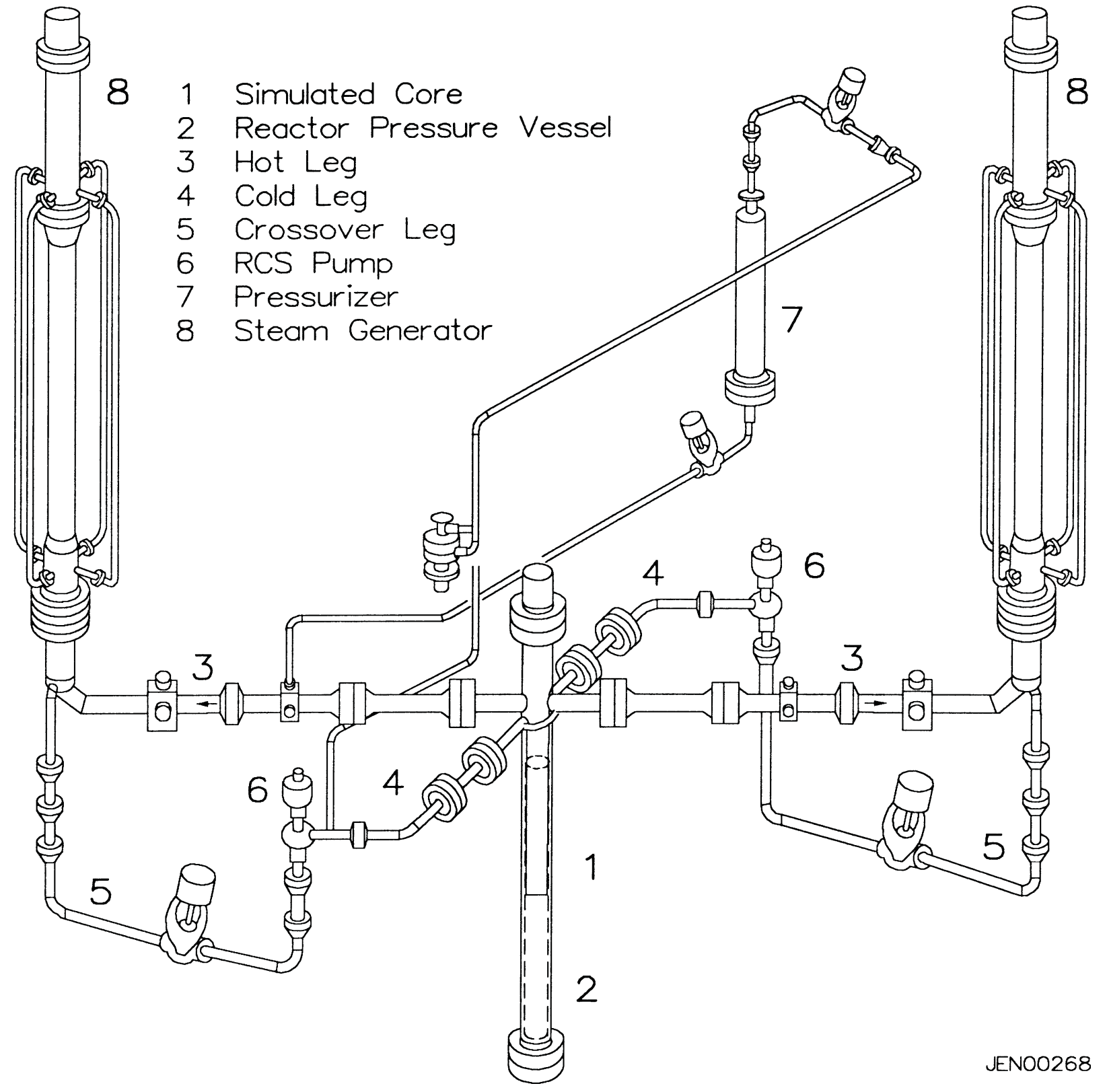

Figure 5.2-1. Schematic of the ROSA-IV large scale test facility (LSTF). 


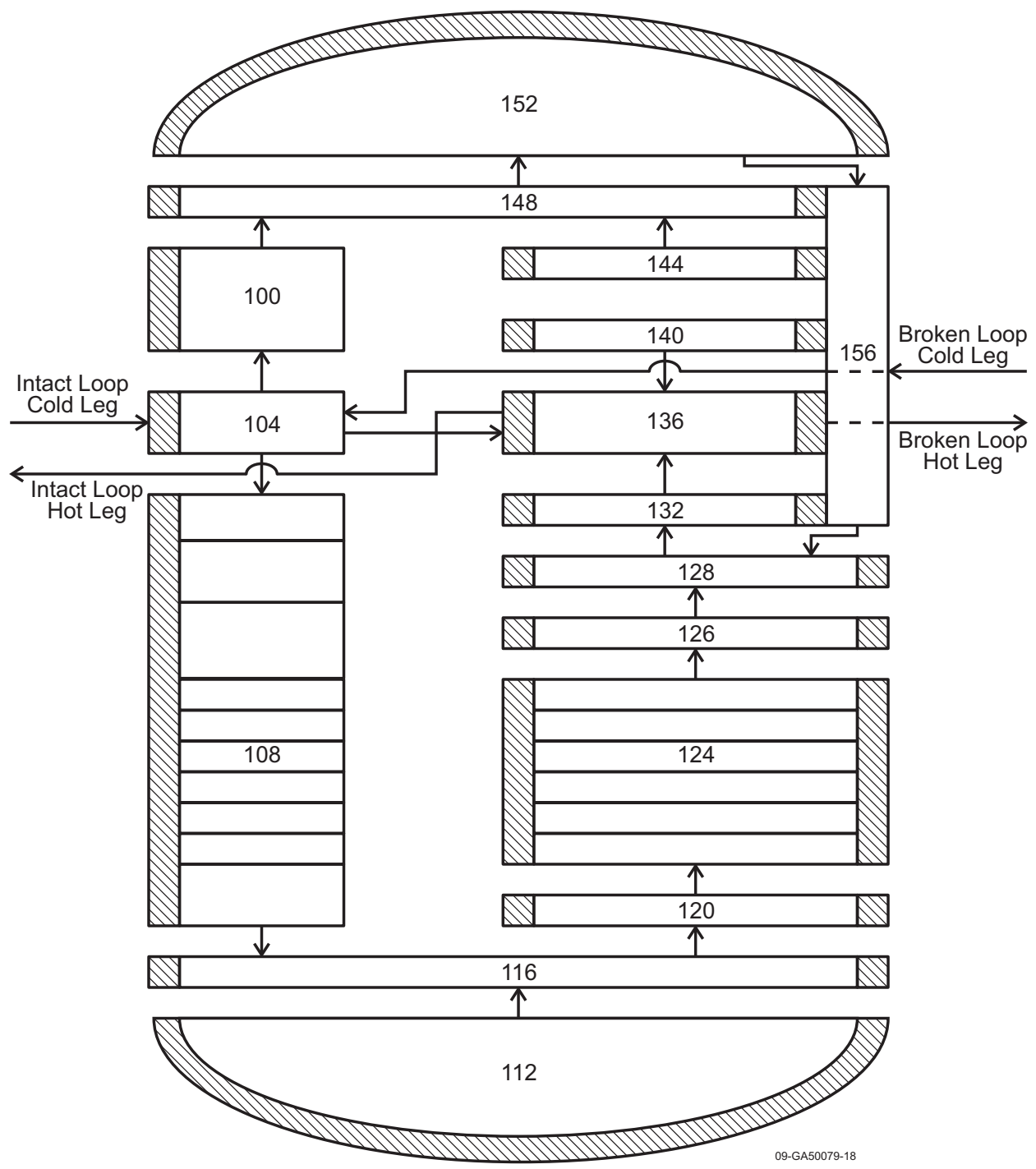

Figure 5.2-2. RELAP5 input model reactor vessel nodalization for ROSA-IV SB-CL-18 test. 


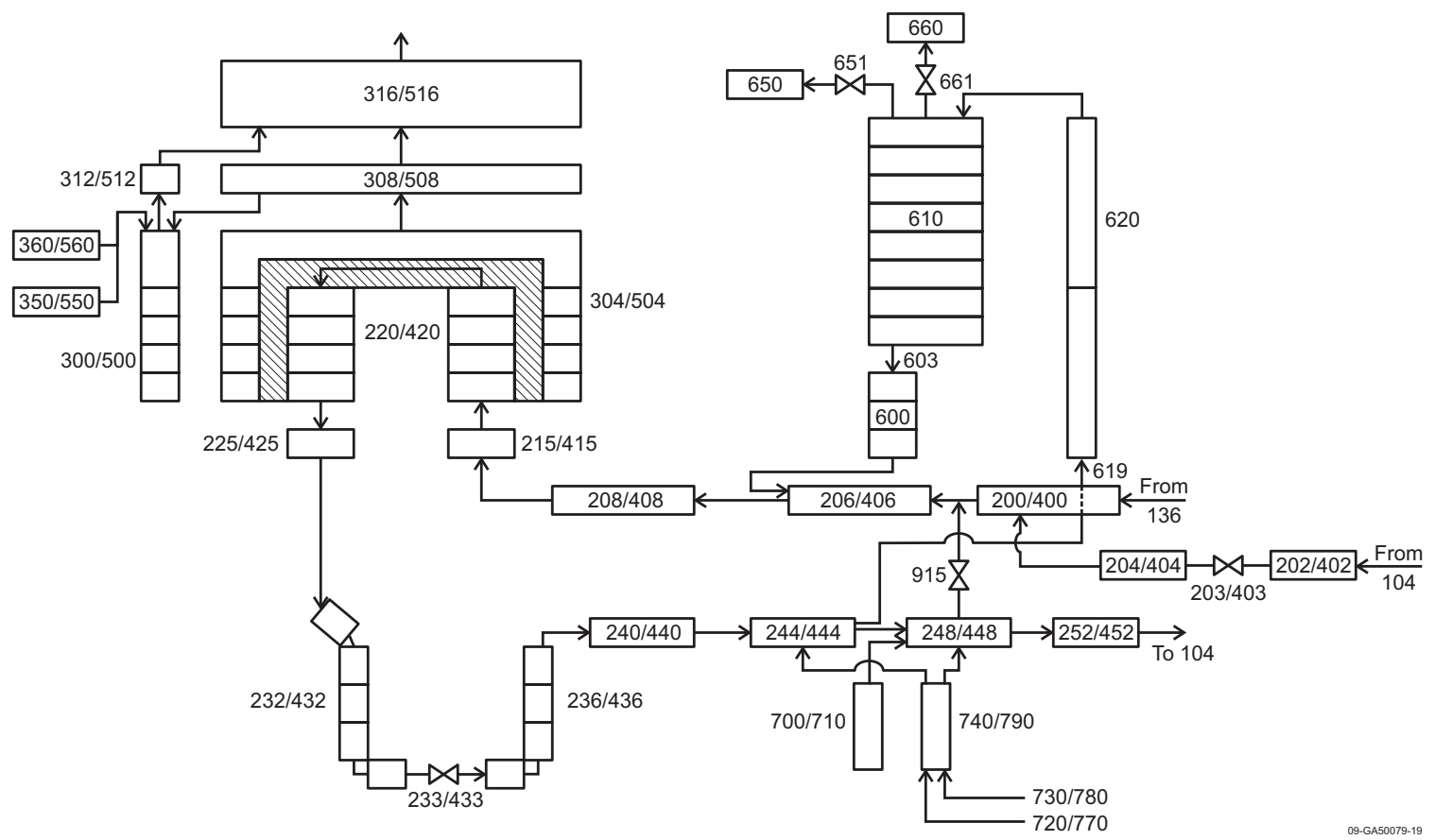

Figure 5.2-3. RELAP5-3D input model loop nodalization for ROSA-IV SB-CL-18 test.

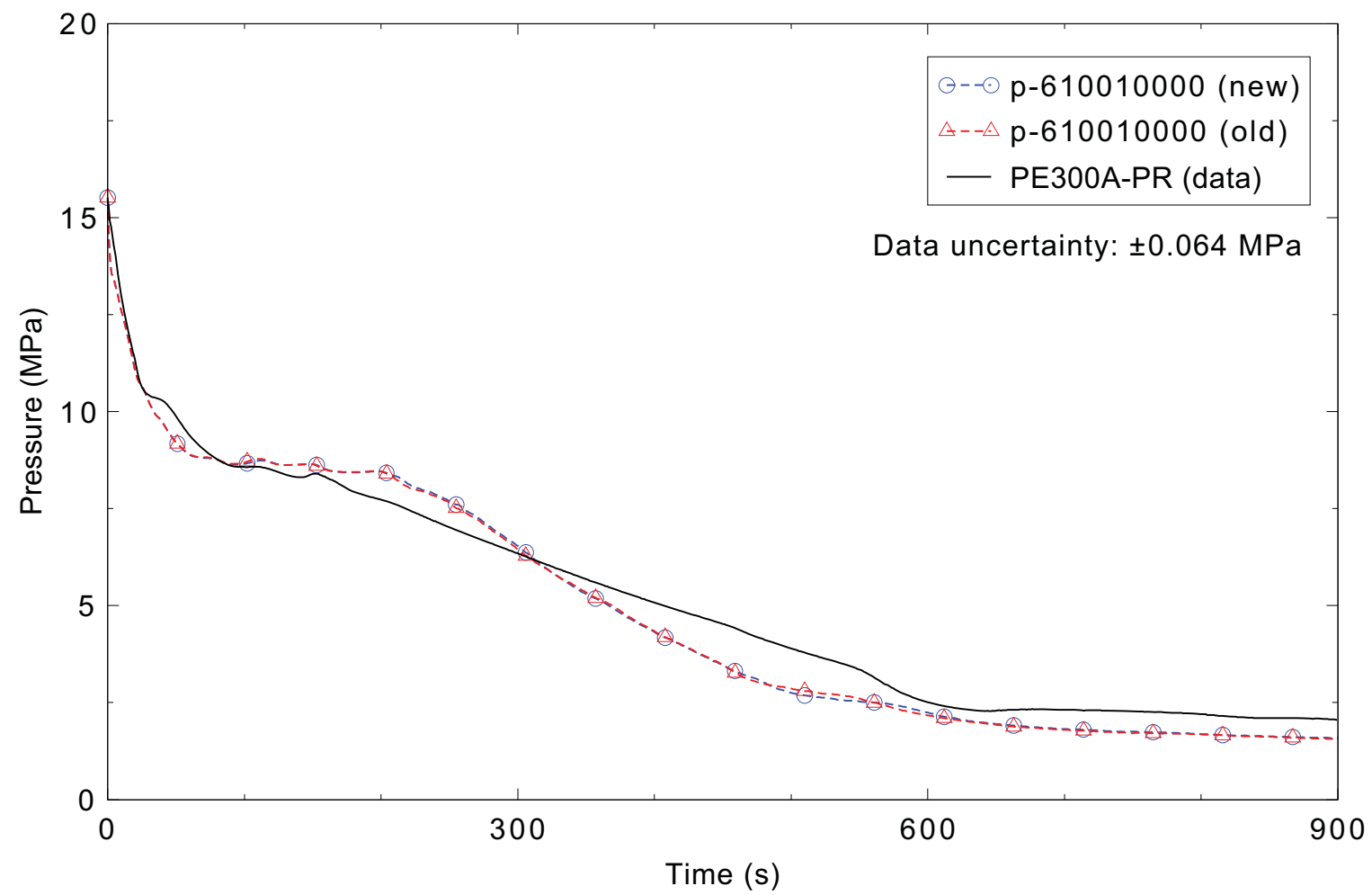

Figure 5.2-4. Measured and calculated pressurizer pressure, ROSA-IV Test SB-CL-18. 


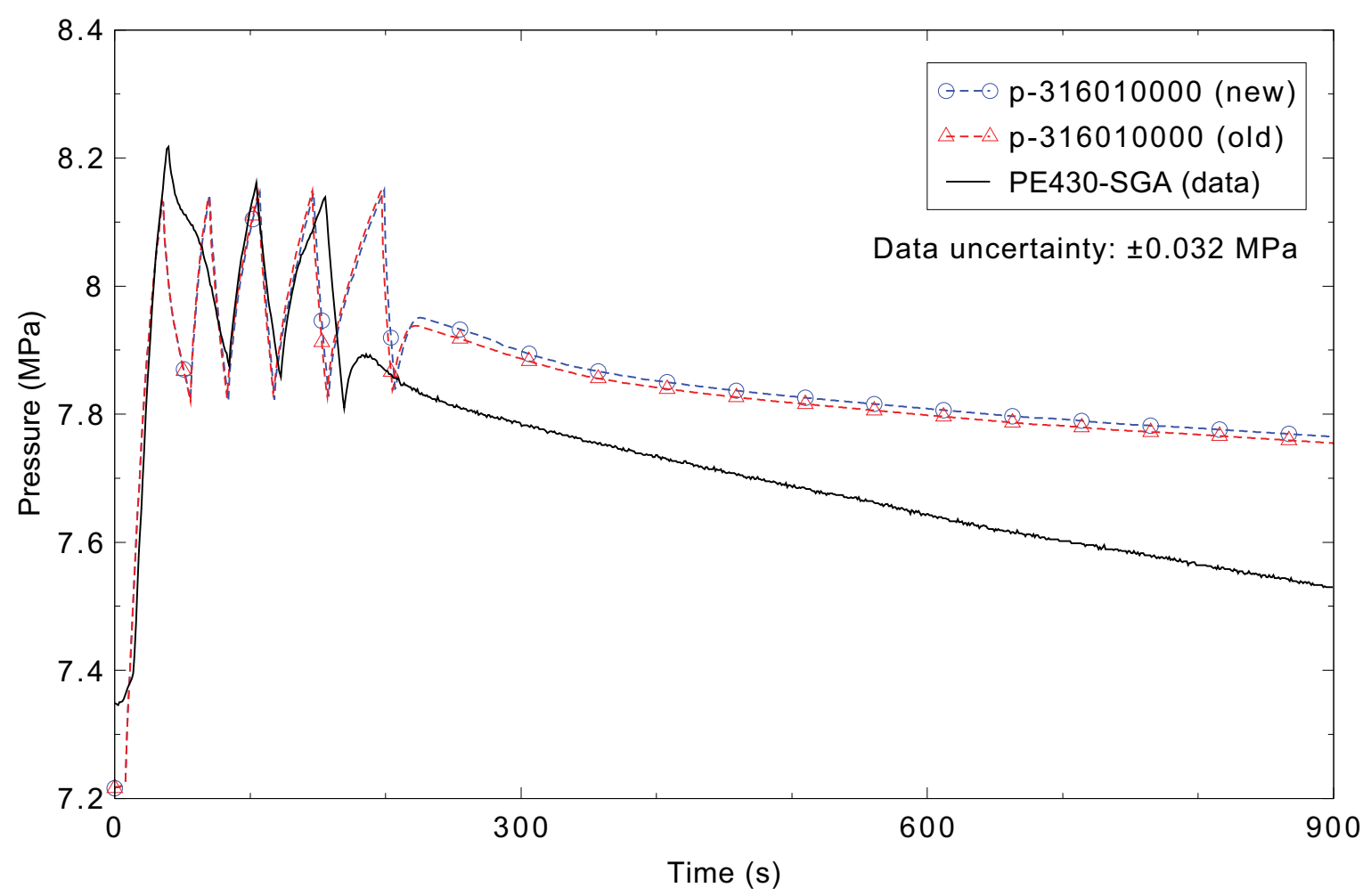

Figure 5.2-5. Measured and calculated pressure of steam generator A, ROSA-IV Test SB-CL-18.

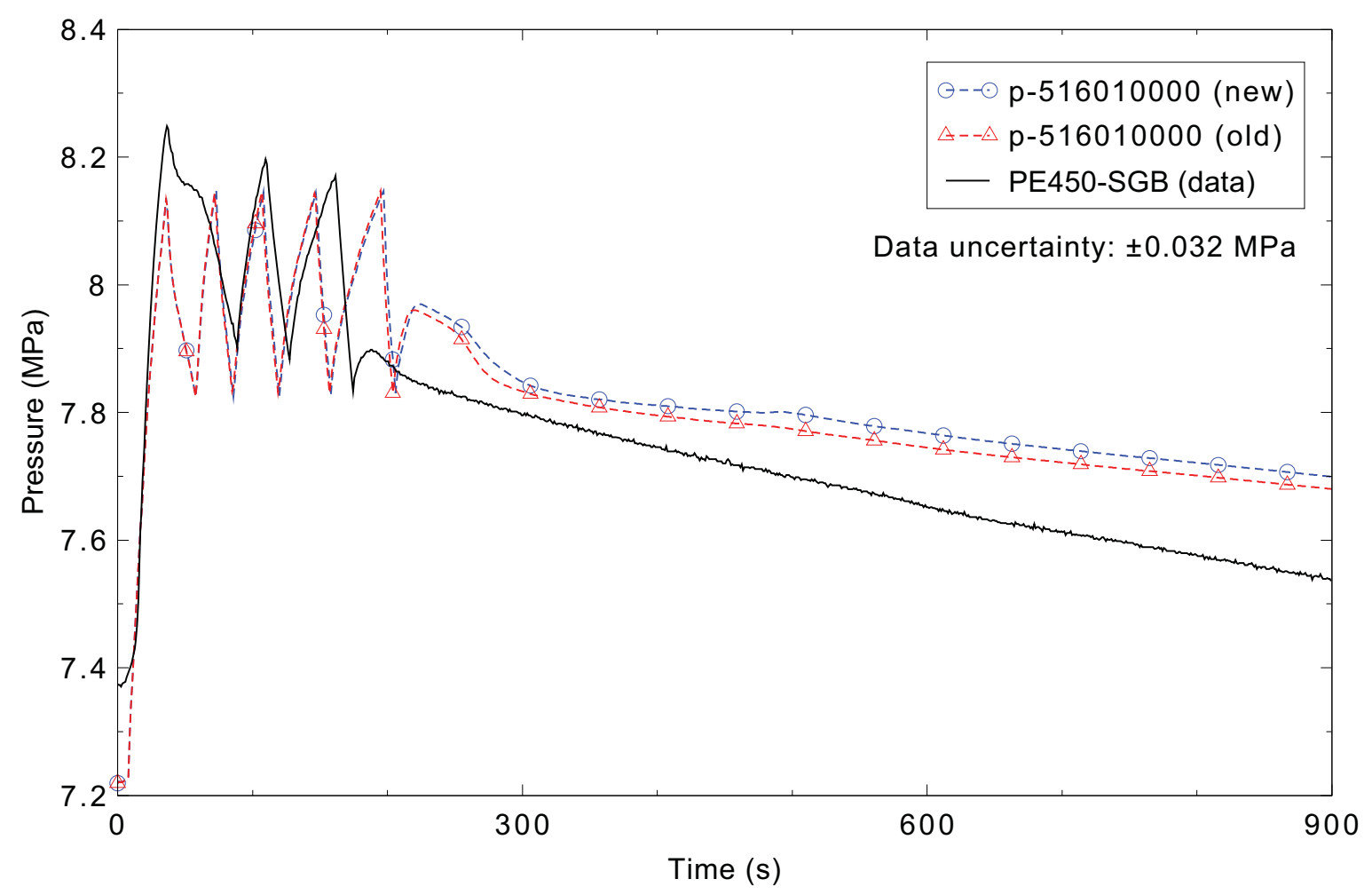

Figure 5.2-6. Measured and calculated pressure of steam generator B, ROSA-IV Test SB-CL-18. 


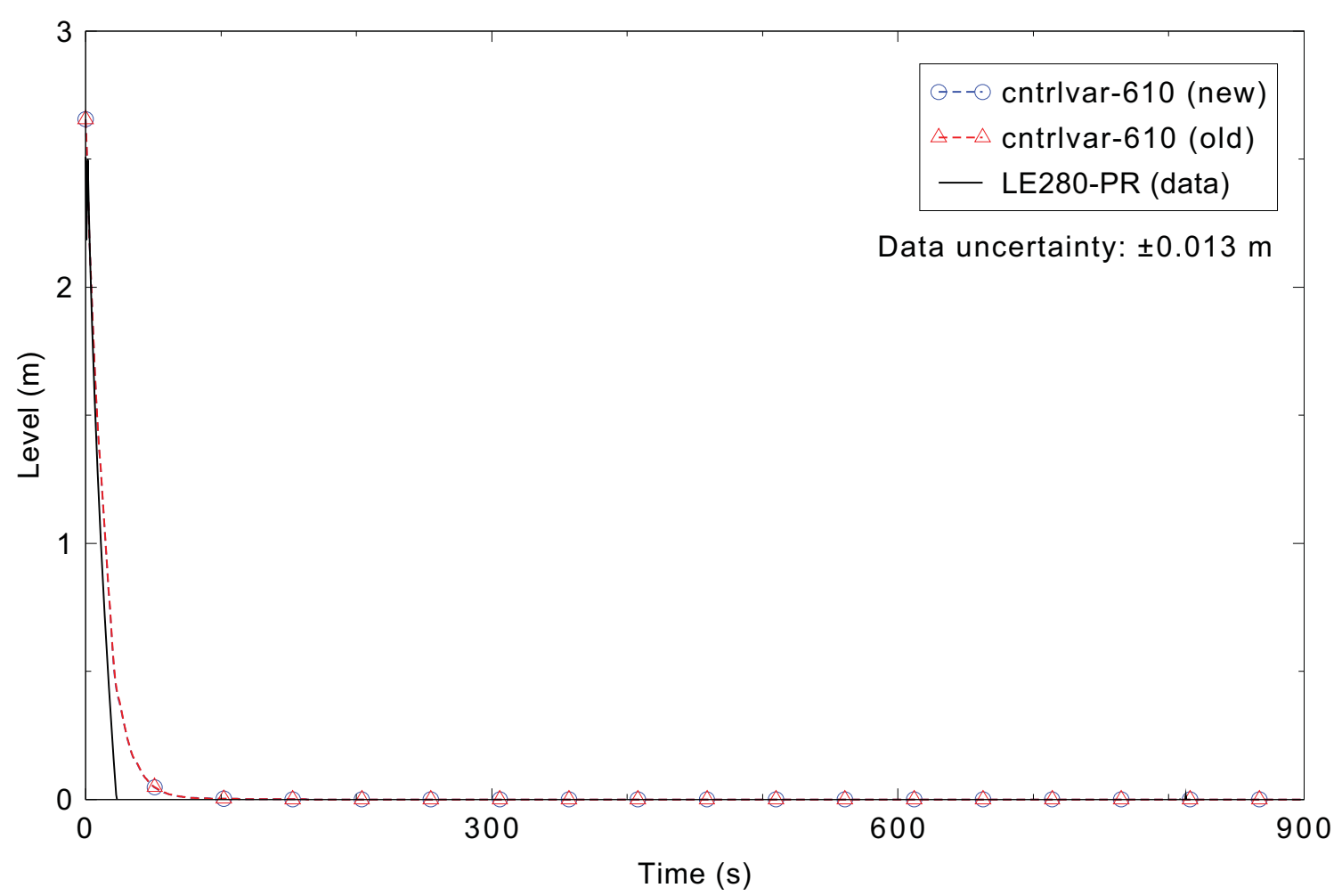

Figure 5.2-7. Measured and calculated pressurizer liquid level, ROSA-IV Test SB-CL-18.

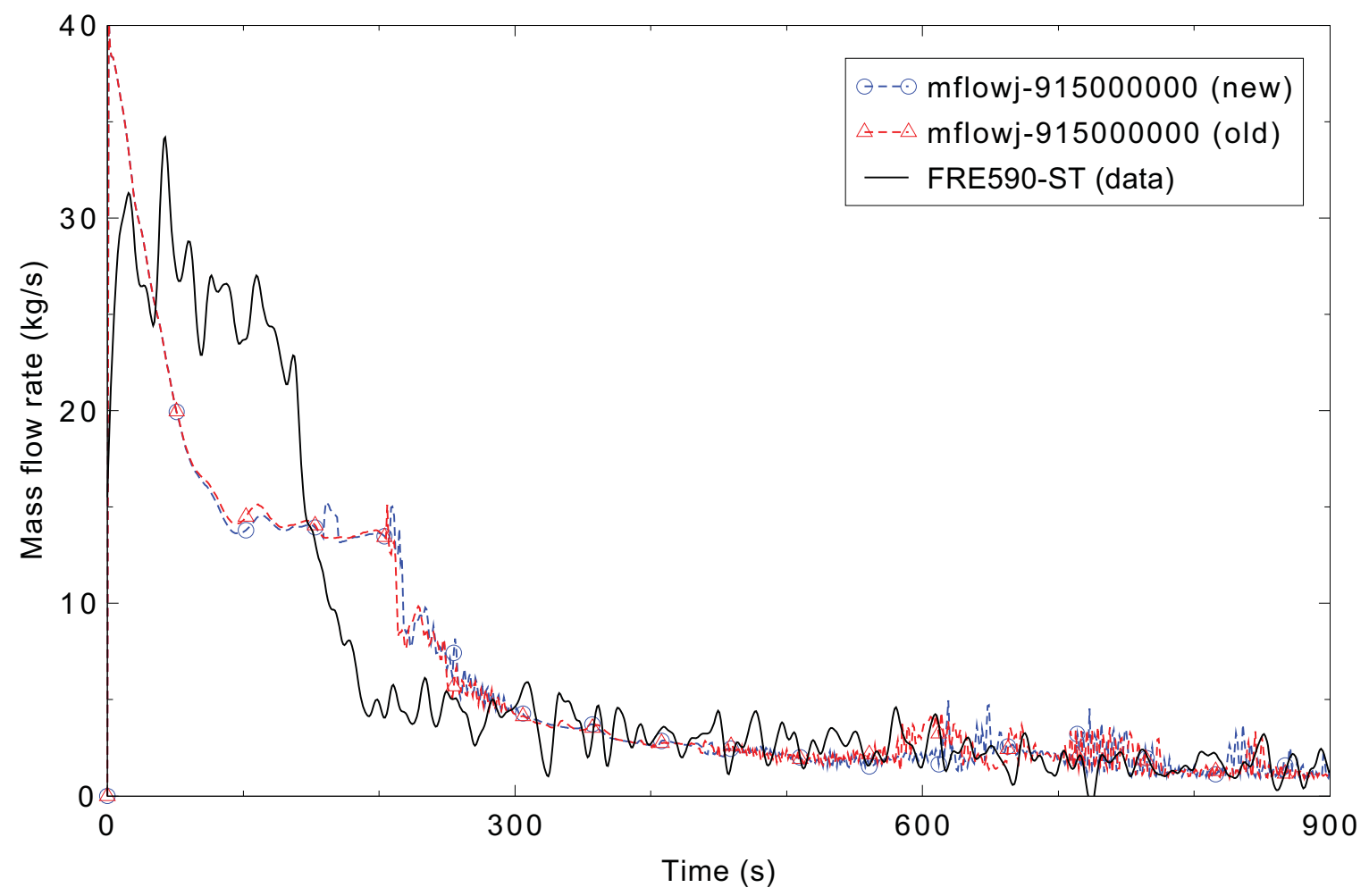

Figure 5.2-8. Measured and calculated break mass flow rate, ROSA-IV Test SB-CL-18. 


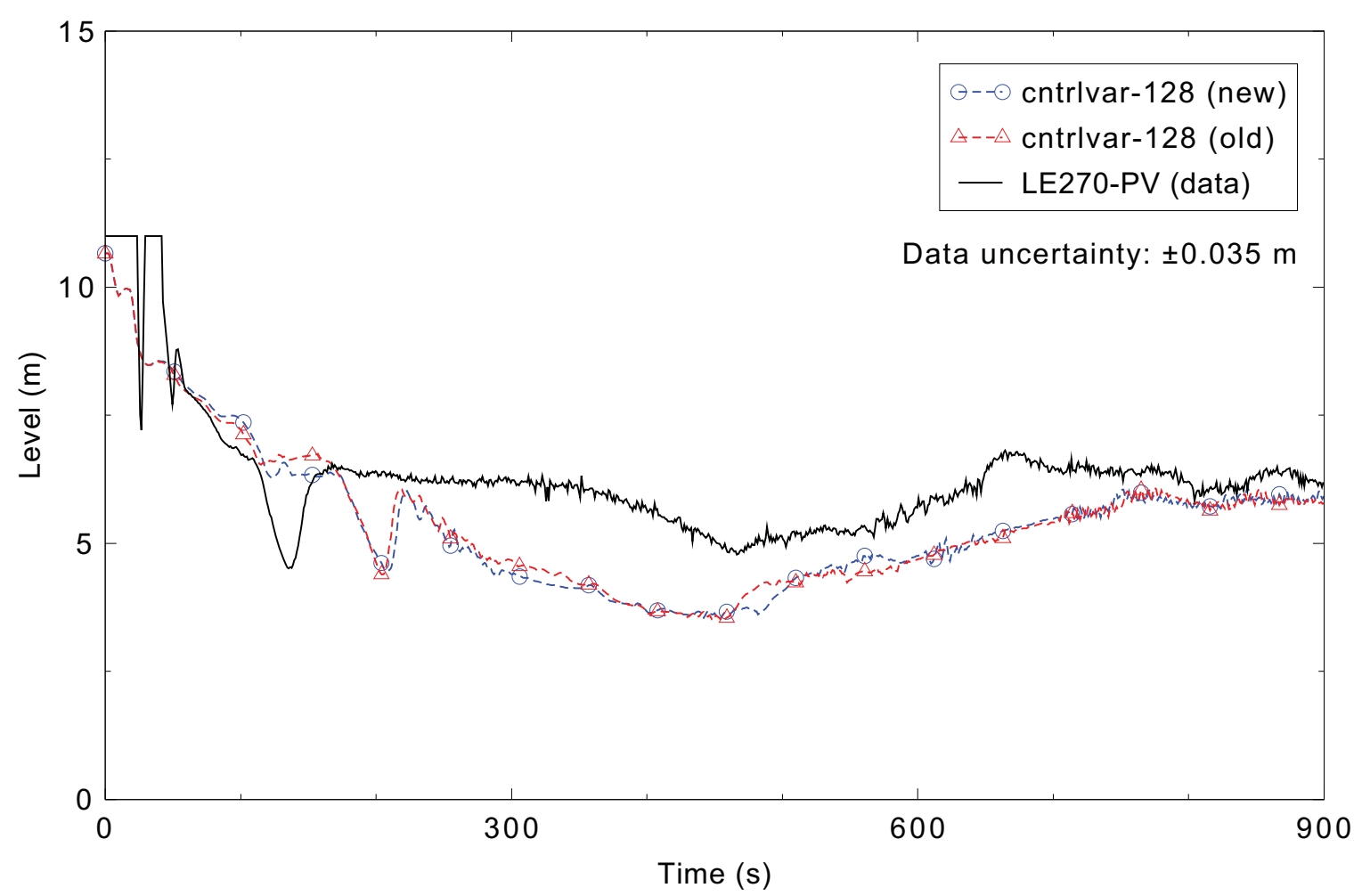

Figure 5.2-9. Measured and calculated vessel liquid level, ROSA-IV Test SB-CL-18.

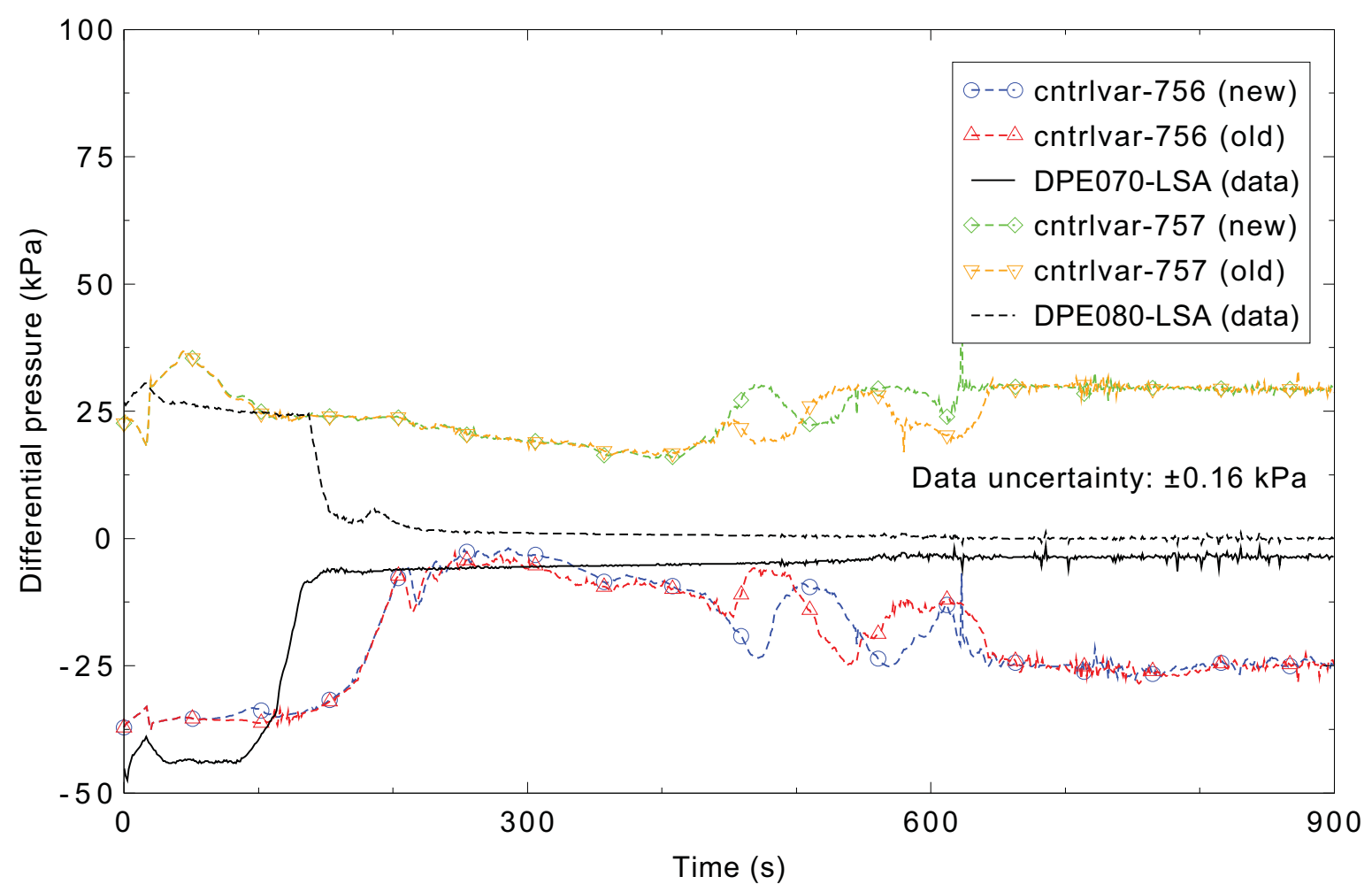

Figure 5.2-10. Measured and calculated differential pressures across loop seal A, ROSA-IV Test SB-CL-18. 


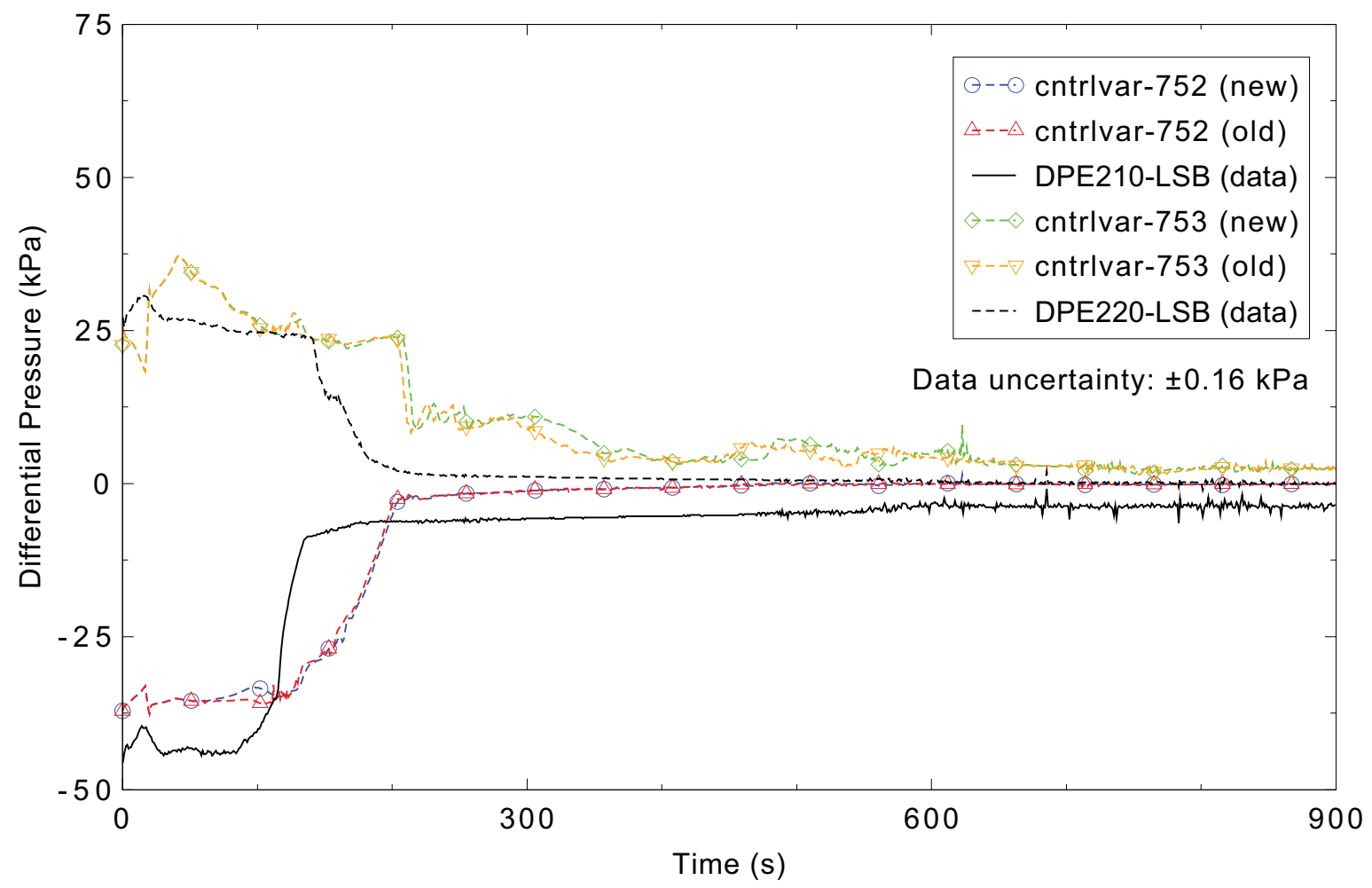

Figure 5.2-11. Measured and calculated differential pressures across loop seal B, ROSA-IV Test SB-CL-18.

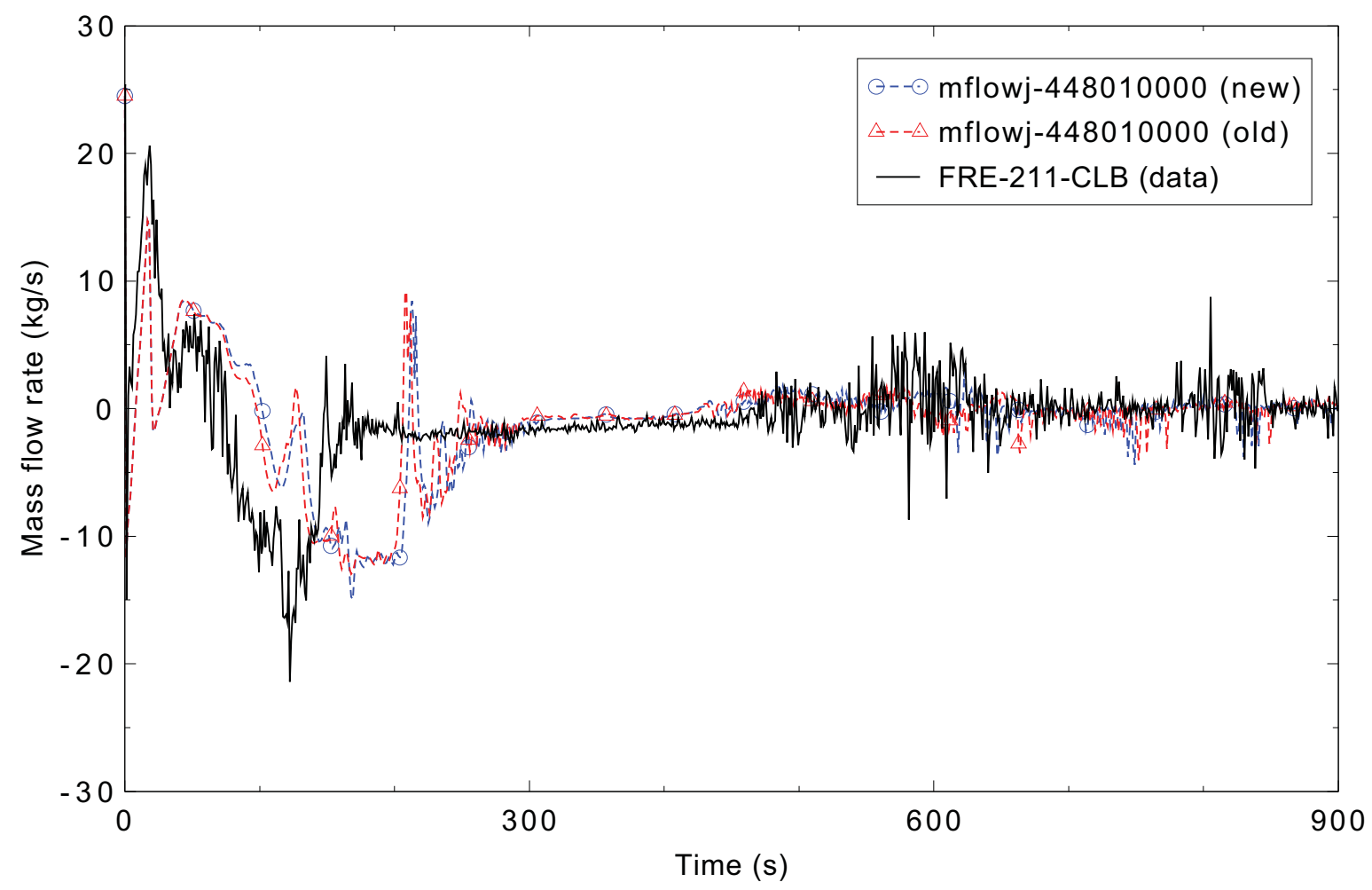

Figure 5.2-12. Measured and calculated mass flow rate in the broken loop cold leg, ROSA-IV Test SB-CL-18. 


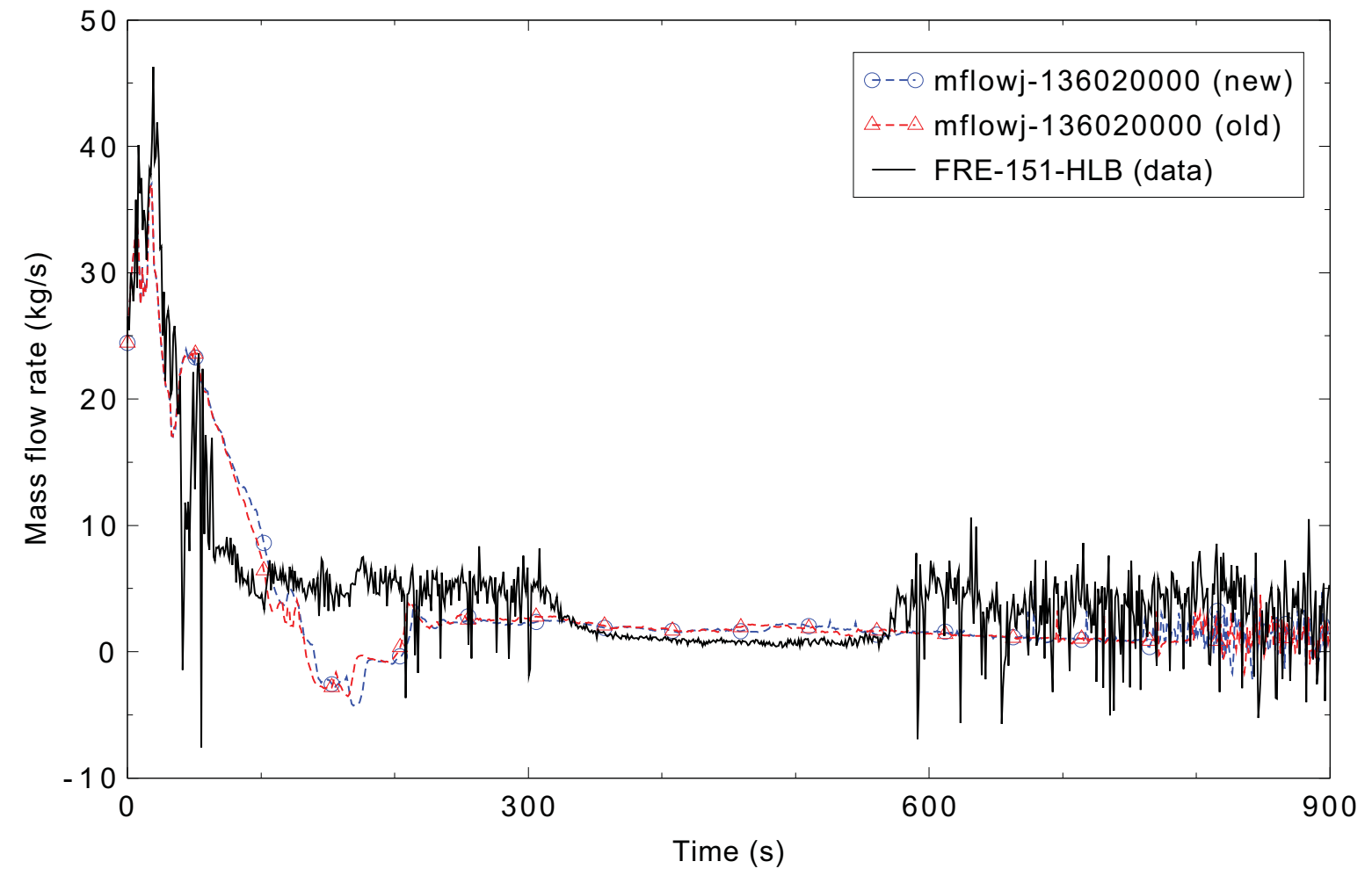

Figure 5.2-13. Measured and calculated mass flow rate in the broken loop hot leg, ROSA-IV Test SB-CL-18.

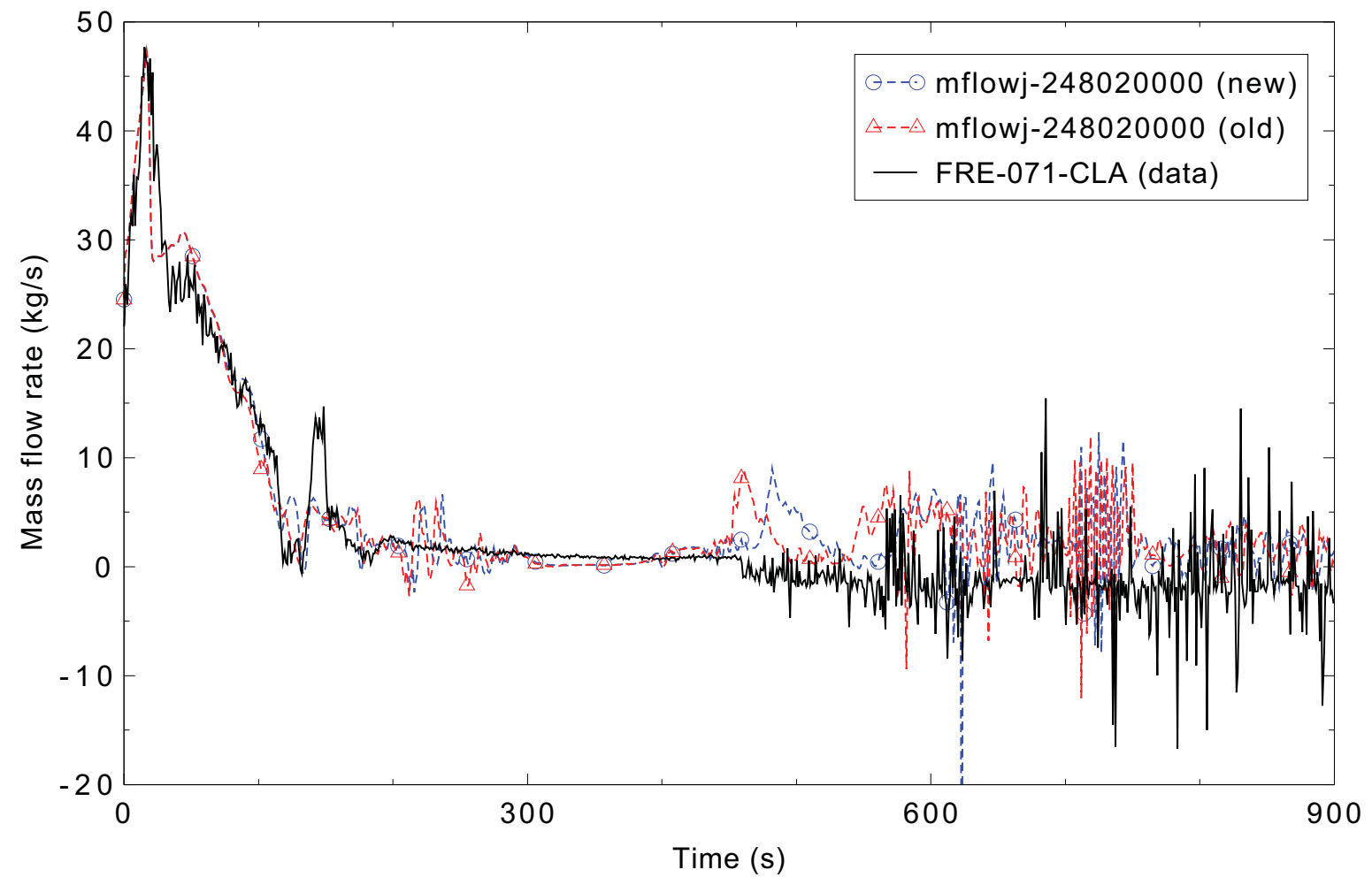

Figure 5.2-14. Measured and calculated mass flow rate in the intact loop cold leg, ROSA-IV Test SB-CL-18. 


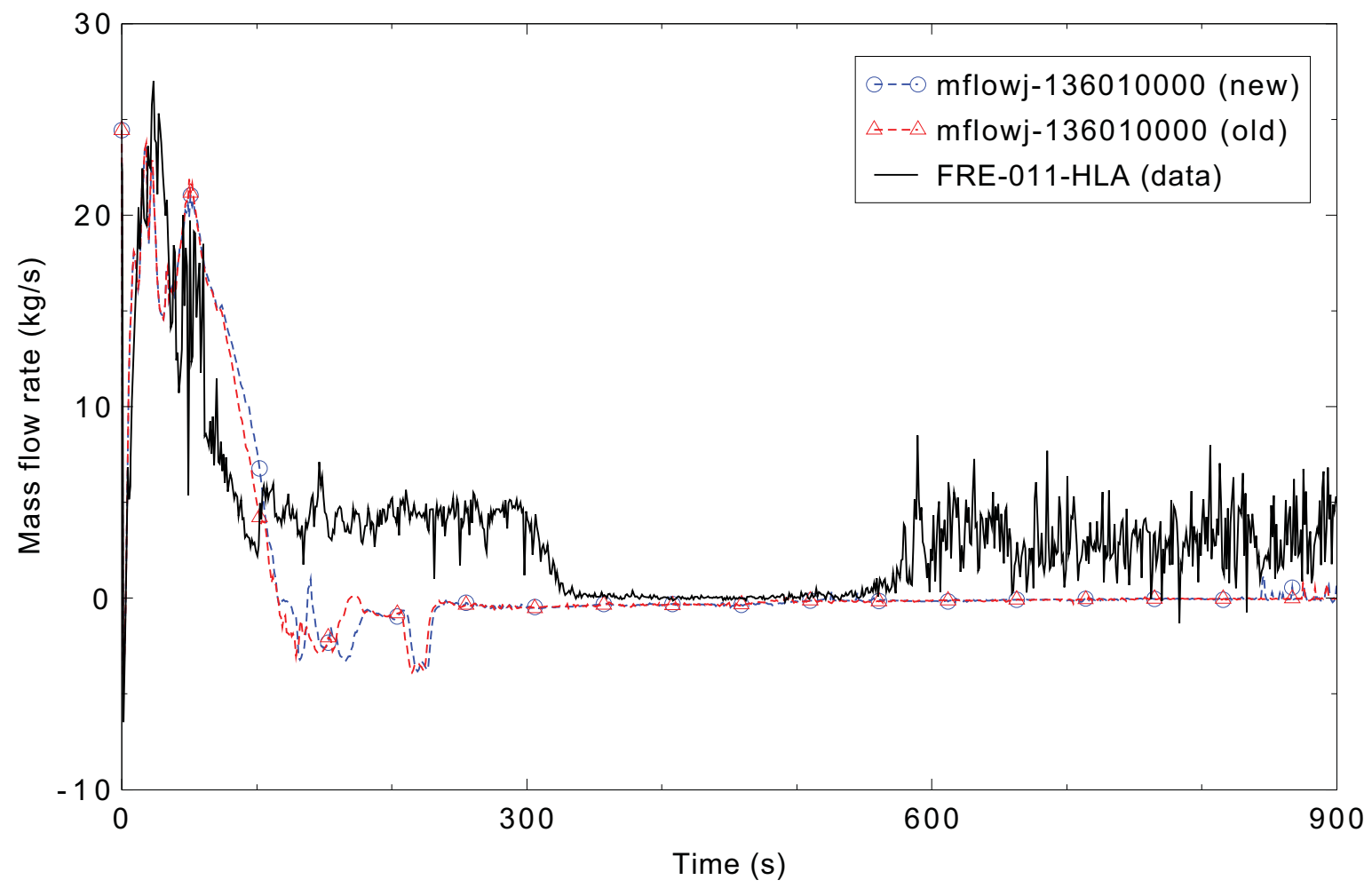

Figure 5.2-15. Measured and calculated mass flow rate in the intact loop hot leg, ROSA-IV Test SB-CL-18.

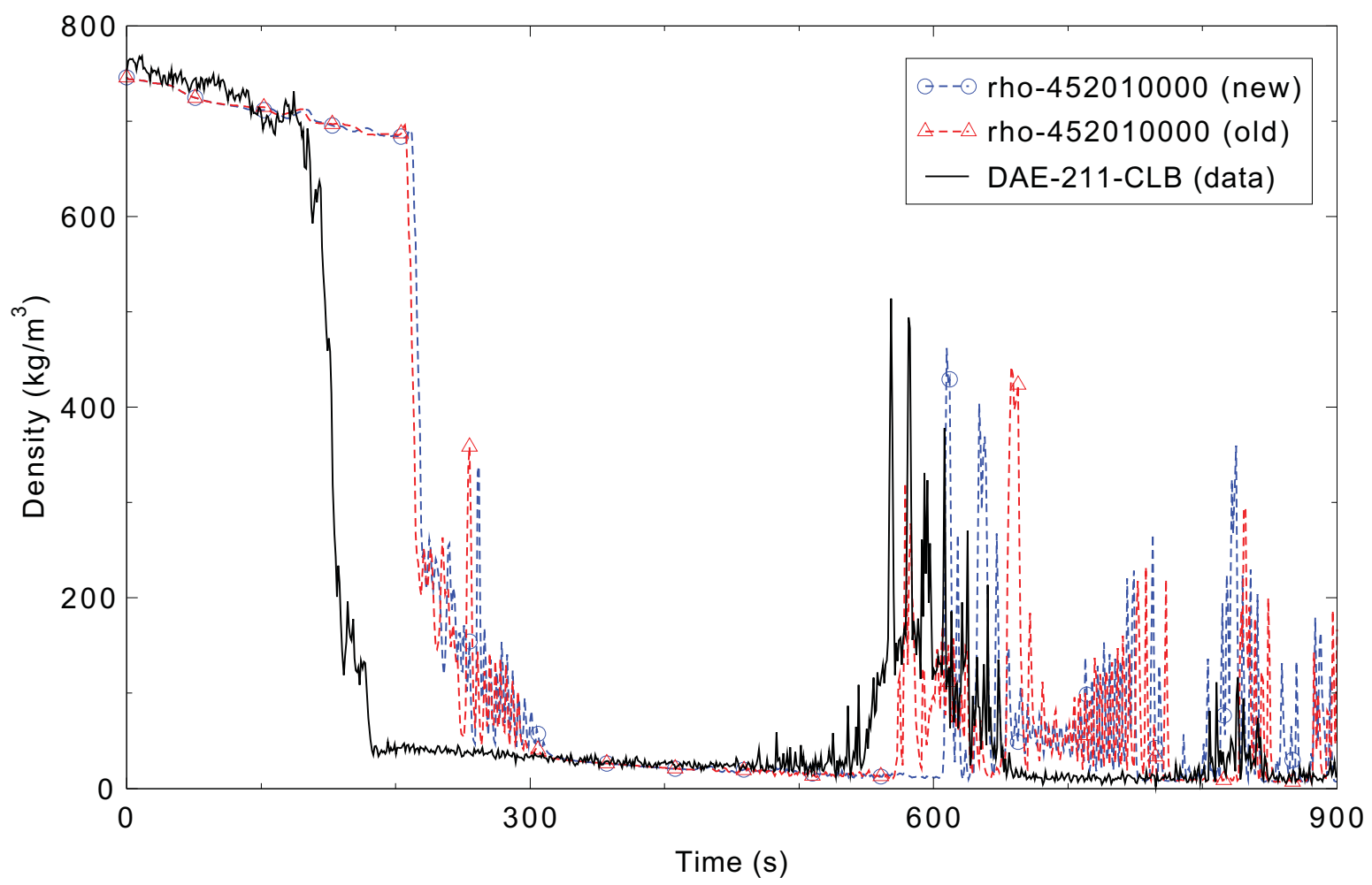

Figure 5.2-16. Measured and calculated density in the broken loop cold leg, ROSA-IV Test SB-CL-18. 


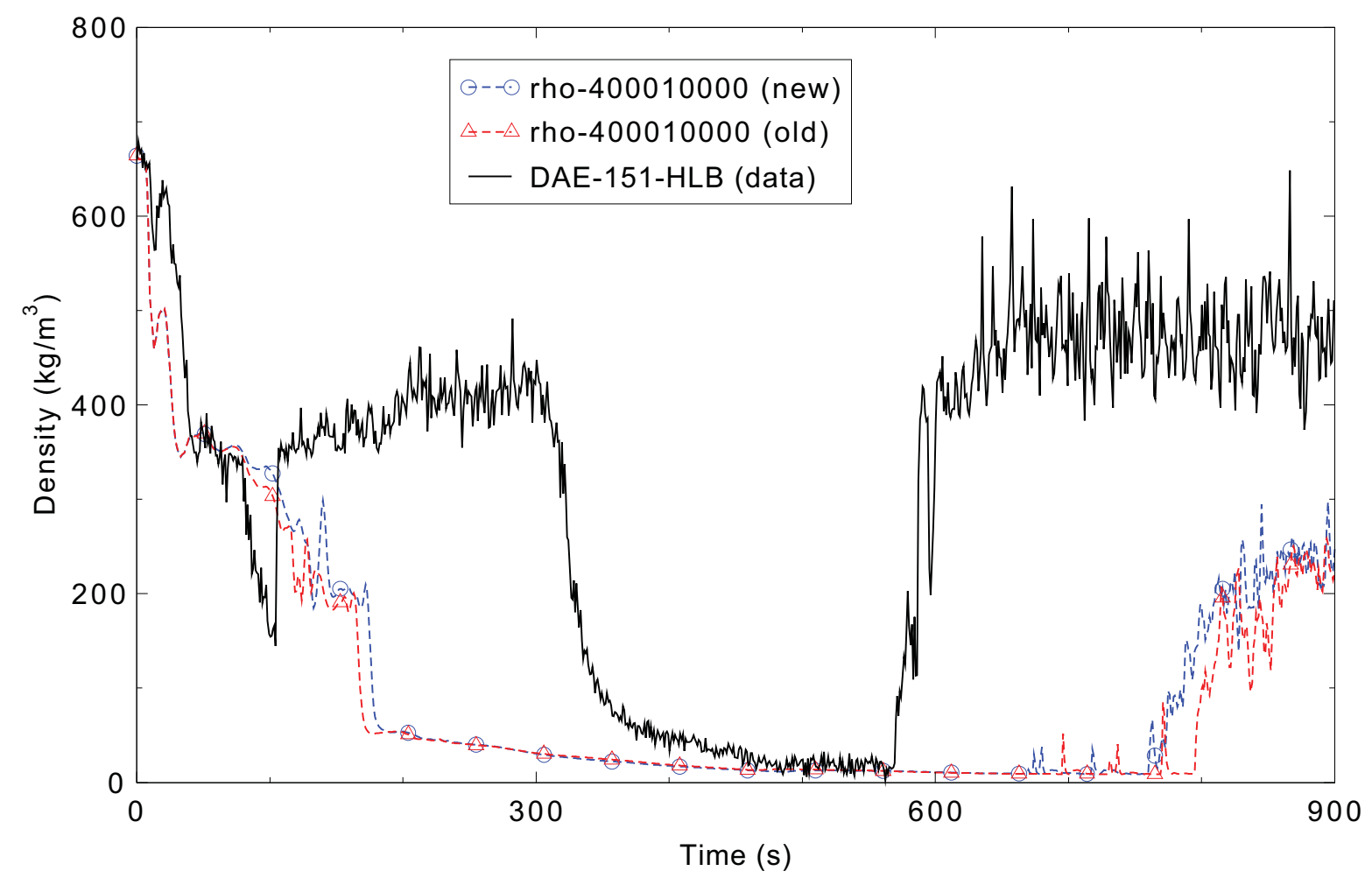

Figure 5.2-17. Measured and calculated density in the broken loop hot leg, ROSA-IV Test SB-CL-18.

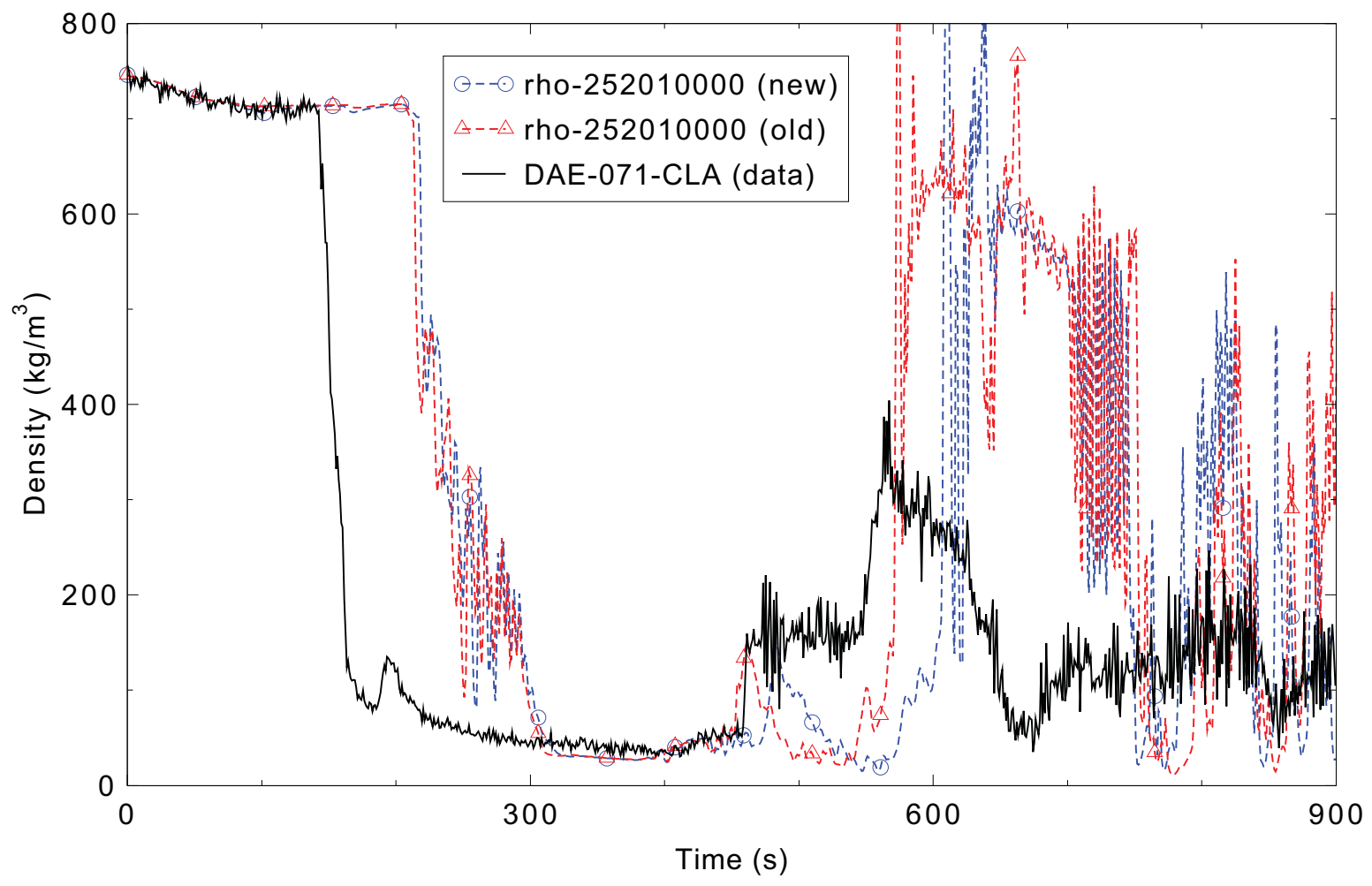

Figure 5.2-18. Measured and calculated density in the intact loop cold leg, ROSA-IV Test SB-CL-18. 


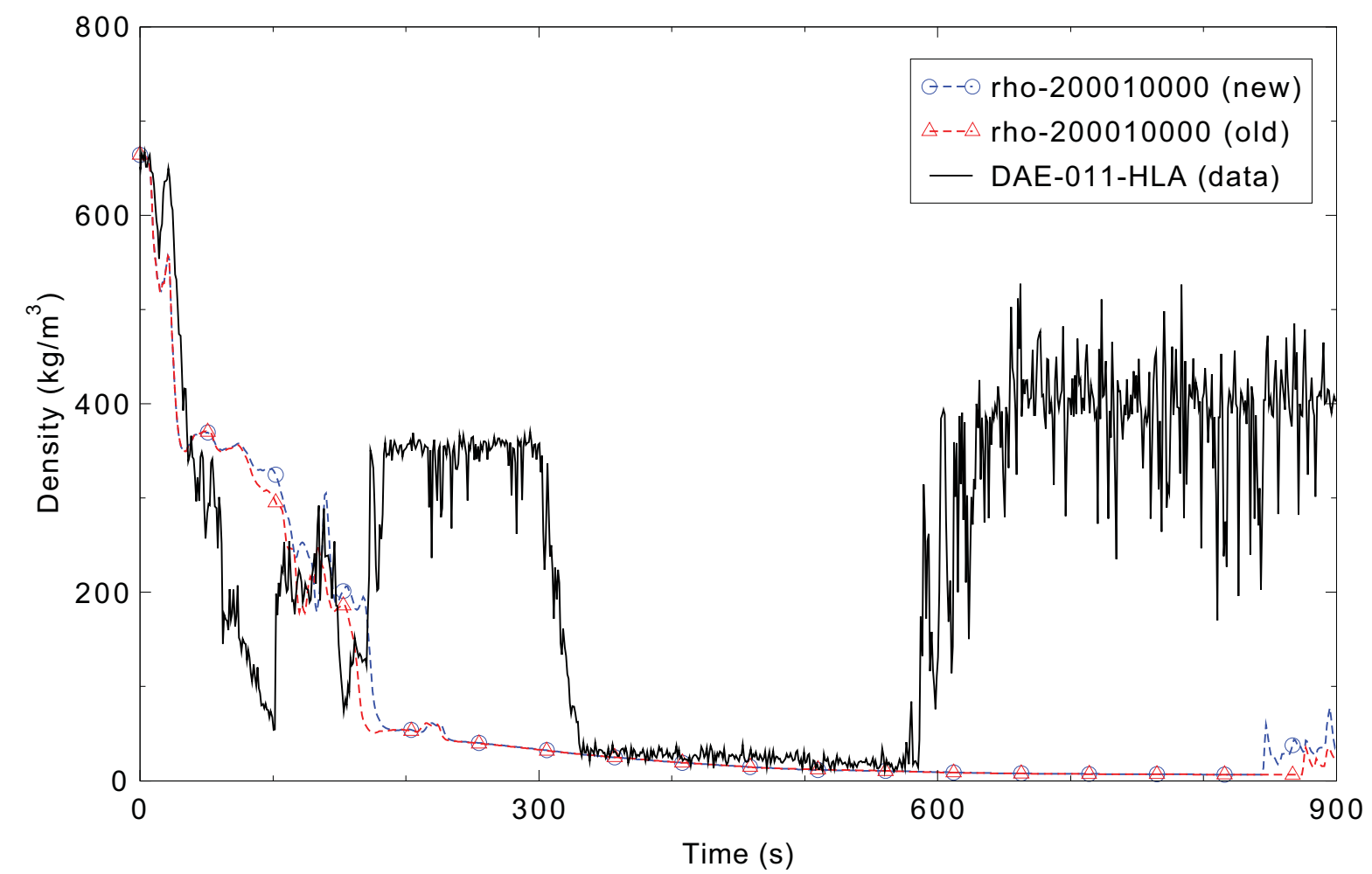

Figure 5.2-19. Measured and calculated density in the intact loop hot leg, ROSA-IV Test SB-CL-18.

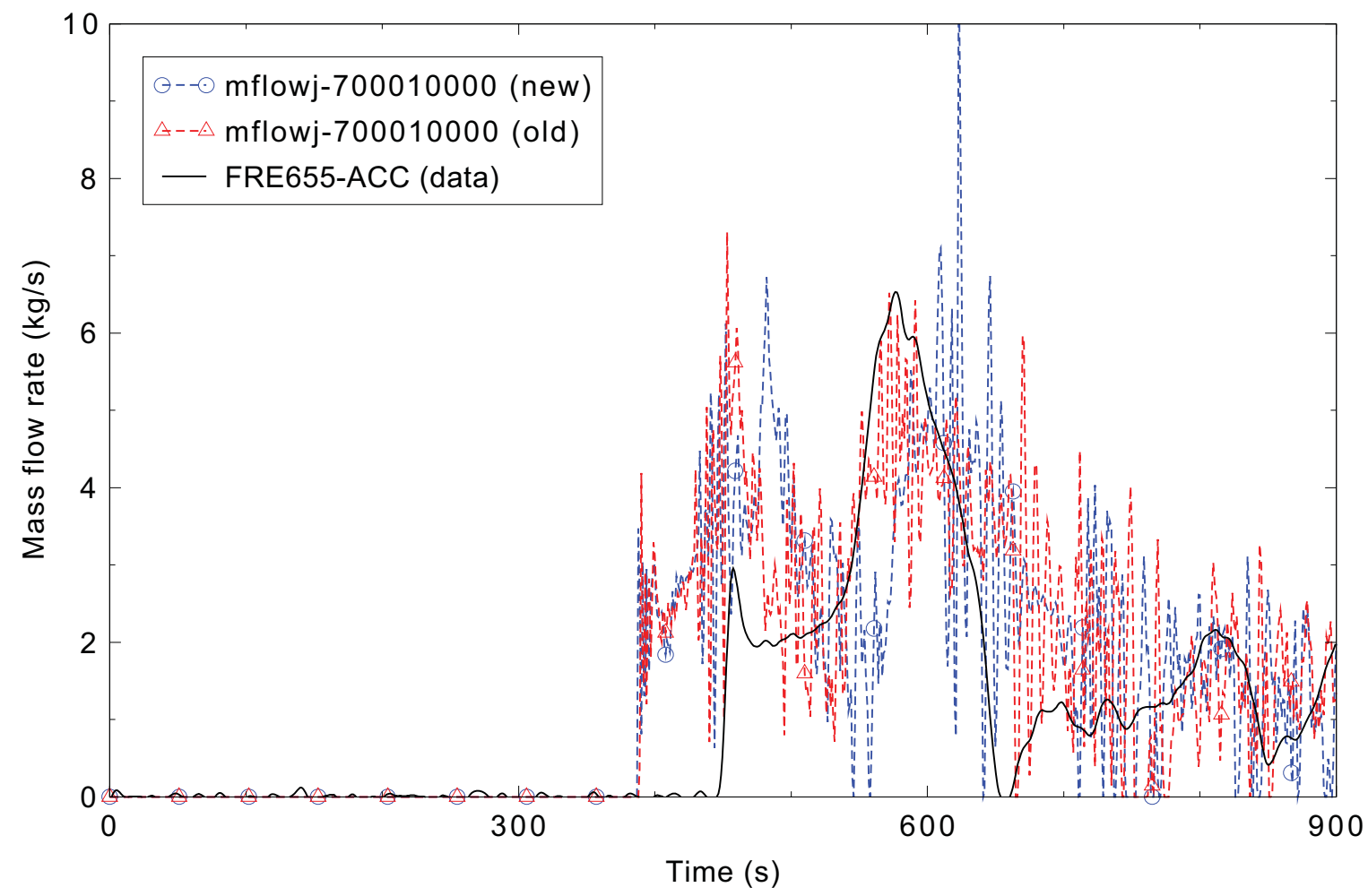

Figure 5.2-20. Measured and calculated mass flow rate accumulator-cold, ROSA-IV Test SB-CL-18. 


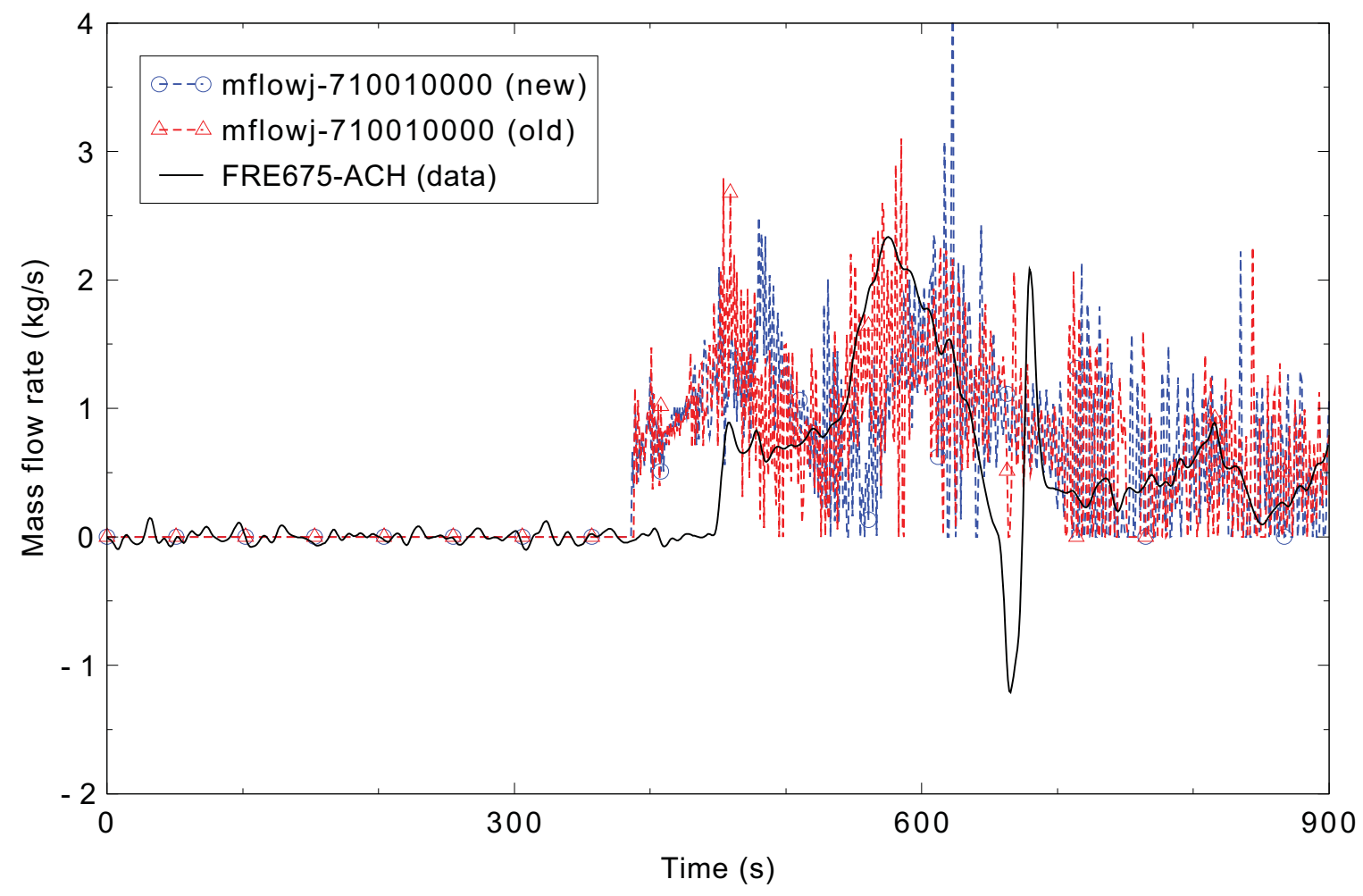

Figure 5.2-21. Measured and calculated mass flow rate accumulator-hot, ROSA-IV Test SB-CL-18.

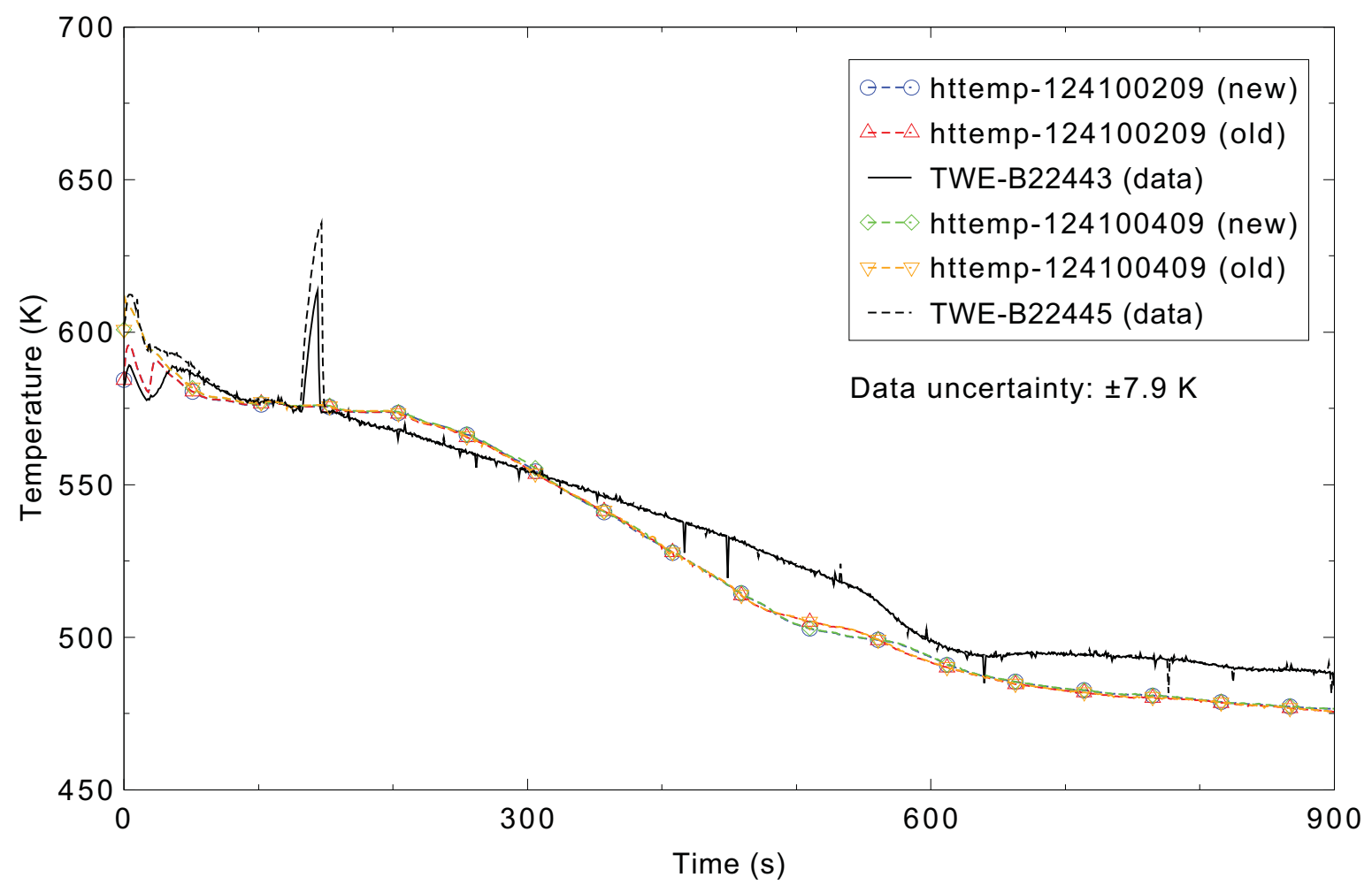

Figure 5.2-22. Measured and calculated heater rod surface temperature for axial levels $3(1.018 \mathrm{~m})$ and 5 (1.830 m), ROSA-IV Test SB-CL-18. 


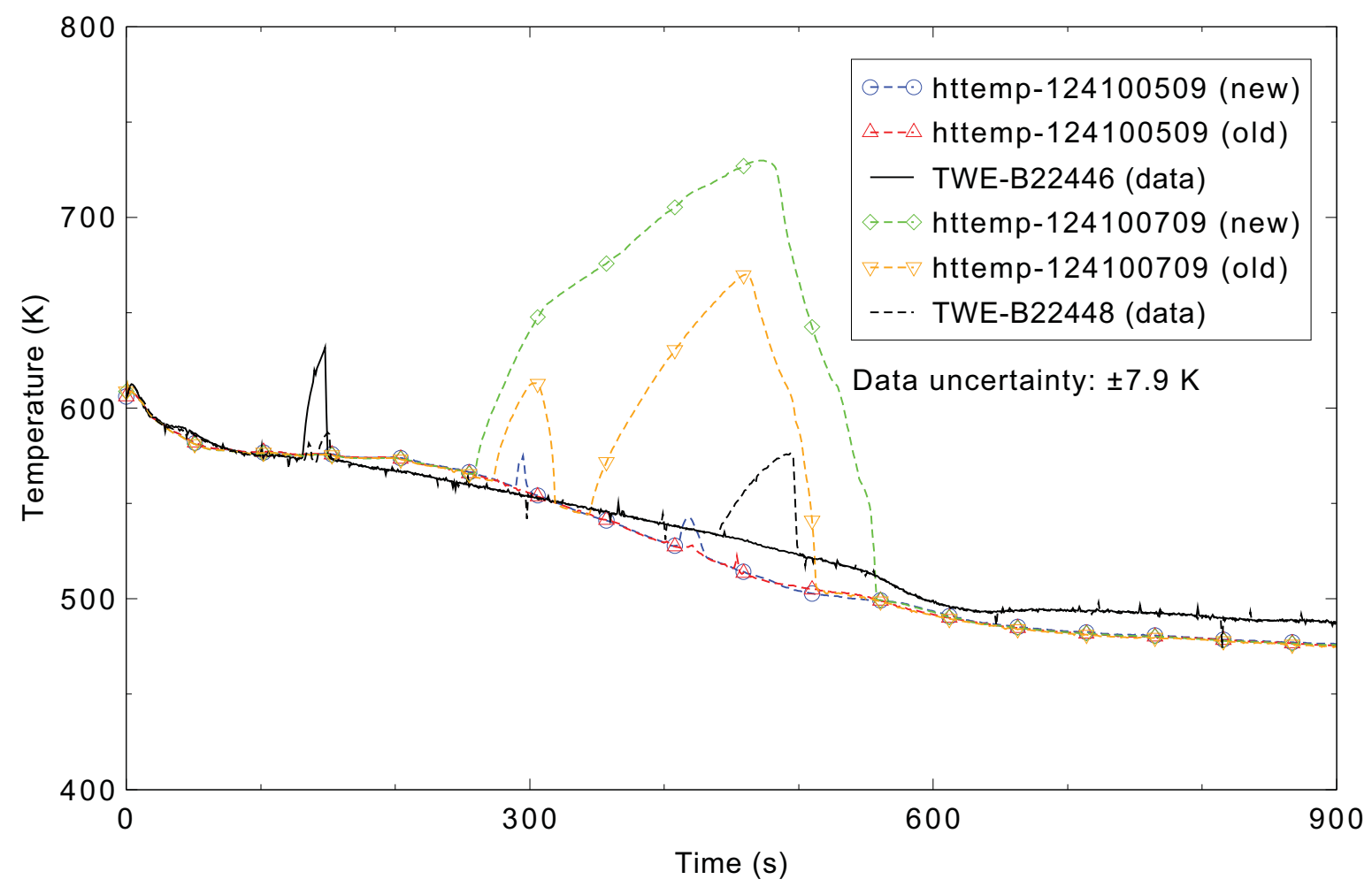

Figure 5.2-23. Measured and calculated heater rod surface temperature for axial levels $6(2.236 \mathrm{~m})$ and 8 (3.048 m), ROSA-IV Test SB-CL-18.

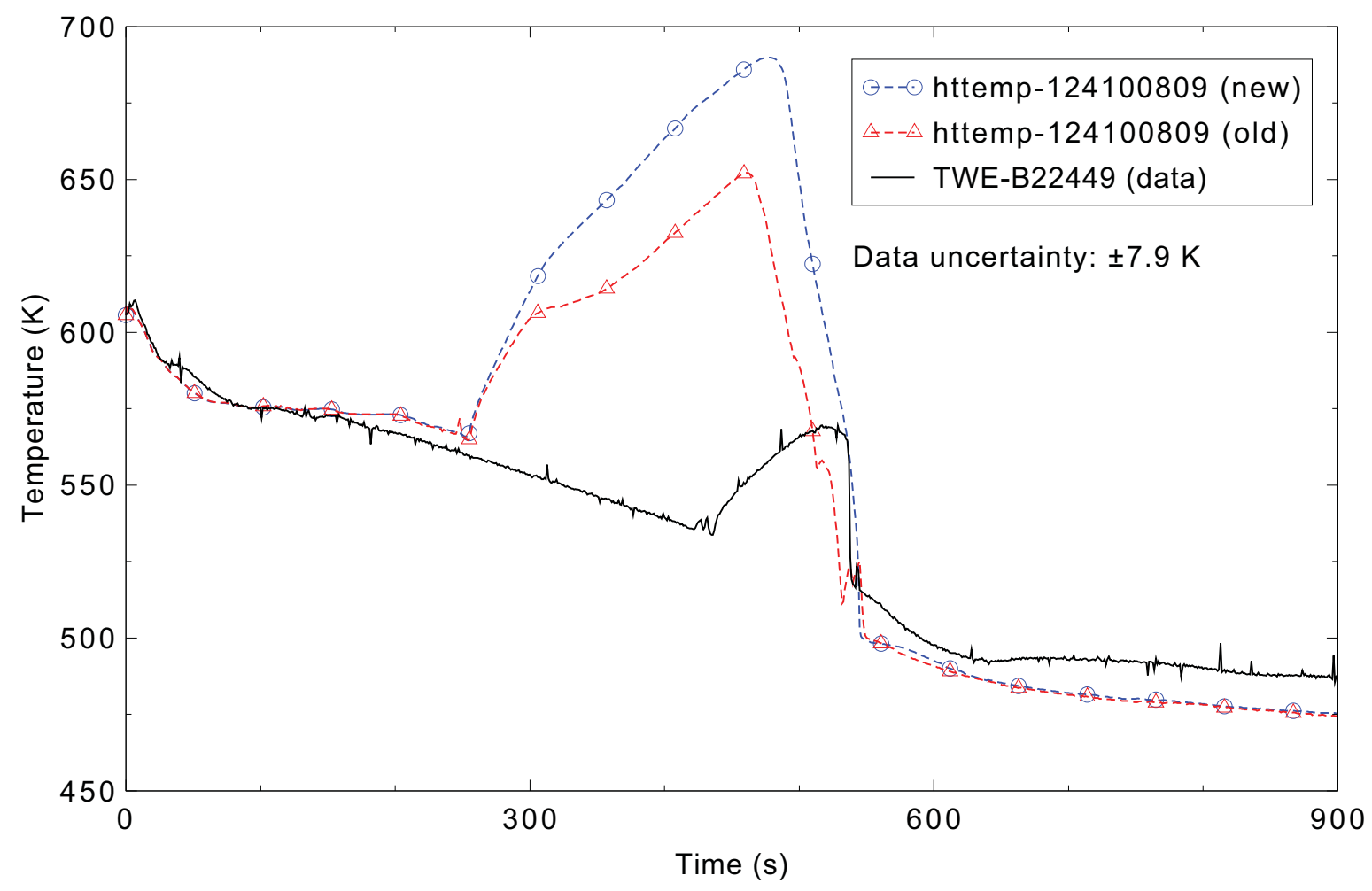

Figure 5.2-24. Measured and calculated heater rod surface temperature for axial level $9(3.610 \mathrm{~m})$, ROSA-IV Test SB-CL-18. 


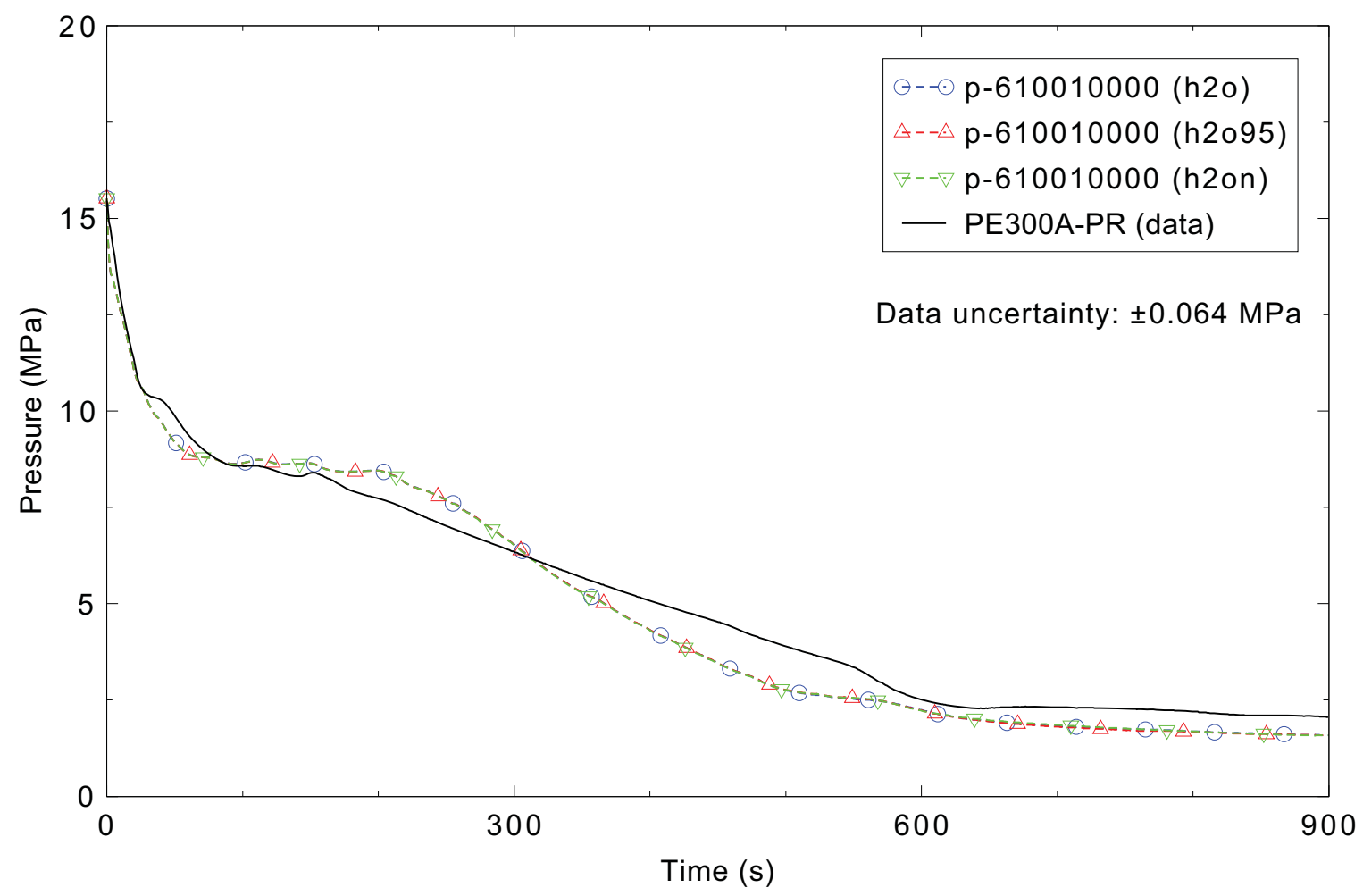

Figure 5.2-25. Measured and calculated pressurizer pressure for different water properties, ROSA-IV Test SB-CL-18.

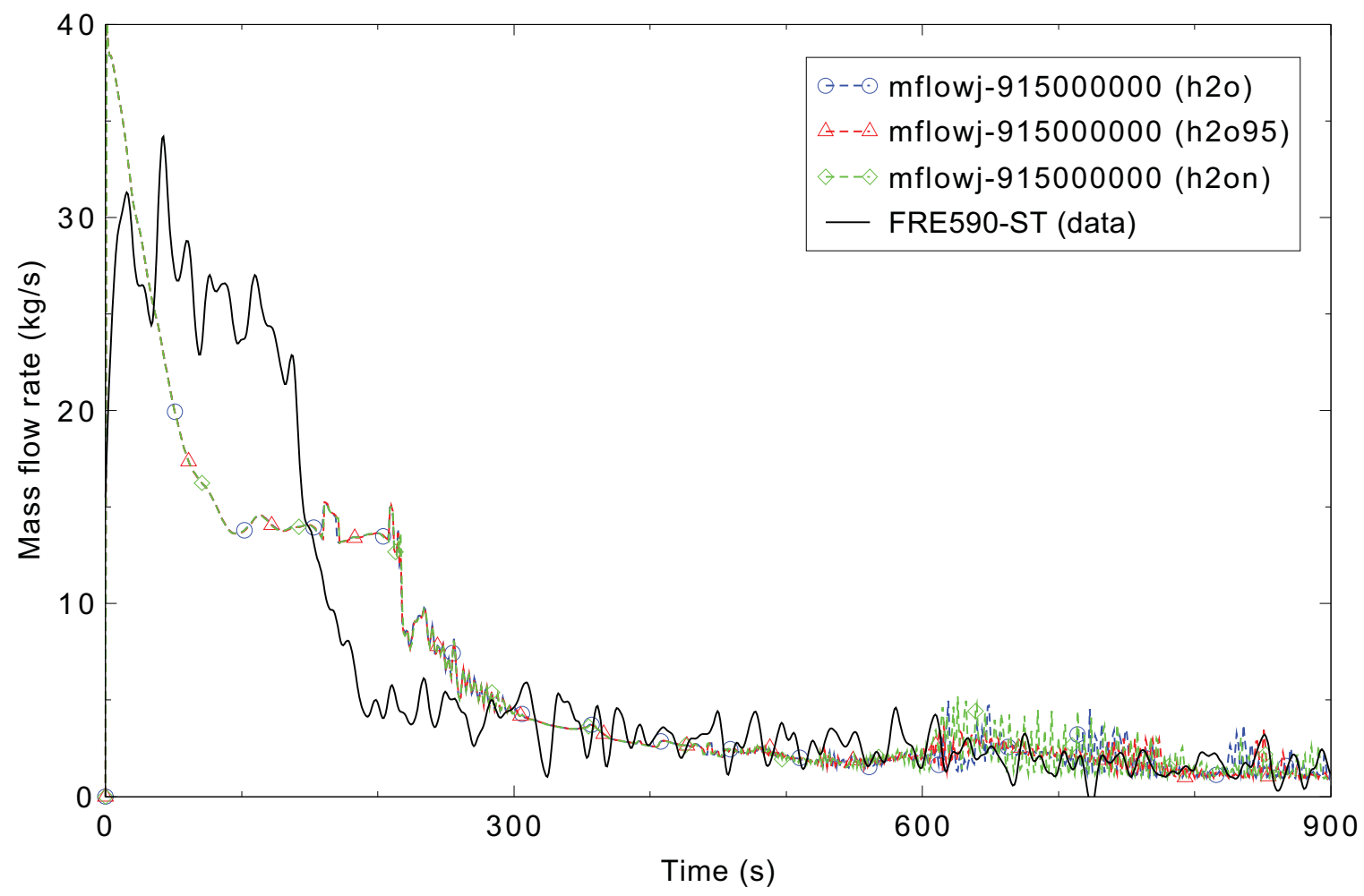

Figure 5.2-26. Measured and calculated break mass flow rate for different water properties, ROSA-IV Test SB-CL-18. 


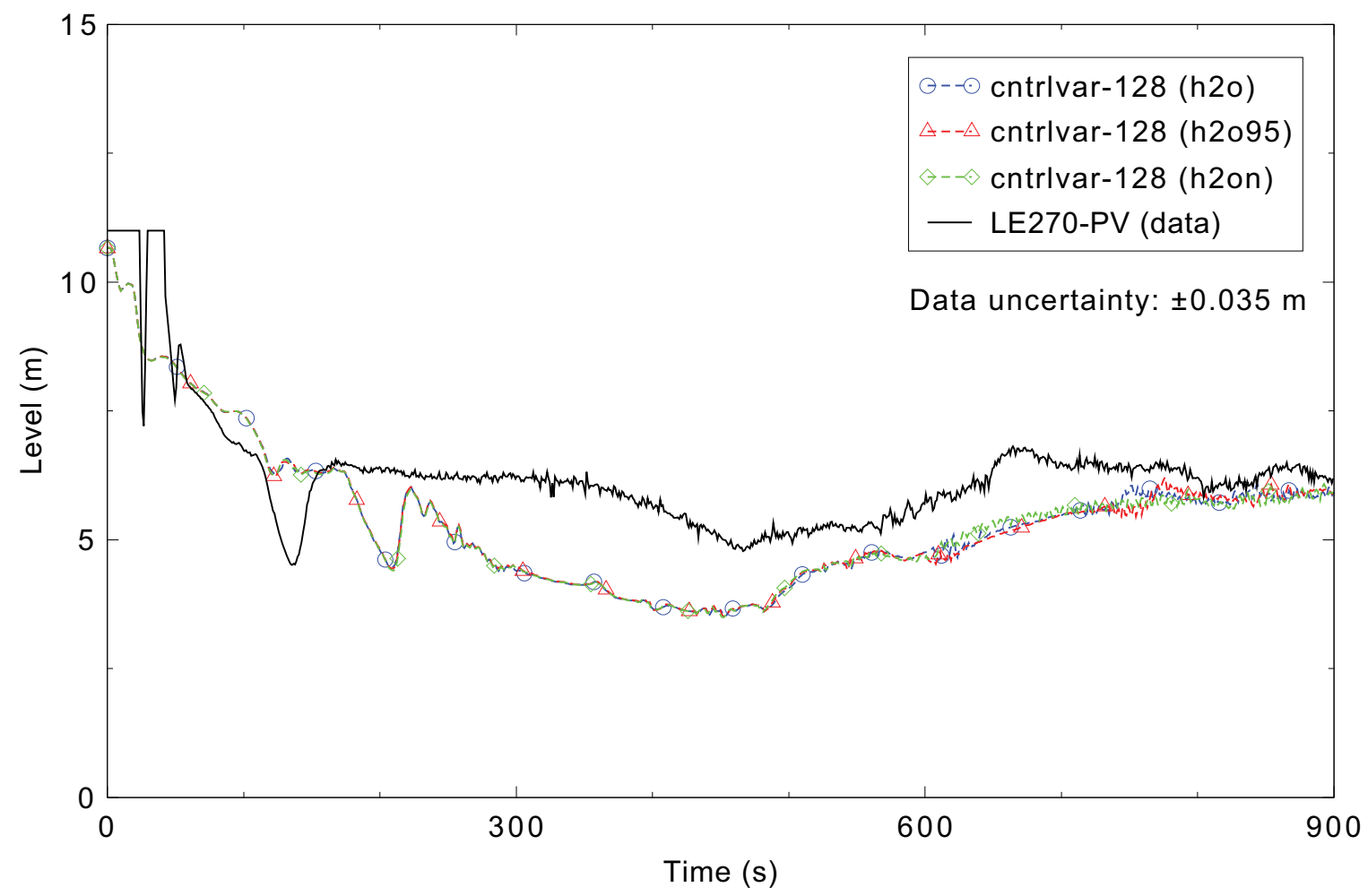

Figure 5.2-27. Measured and calculated vessel liquid level for different water properties, ROSA-IV Test SB-CL-18.

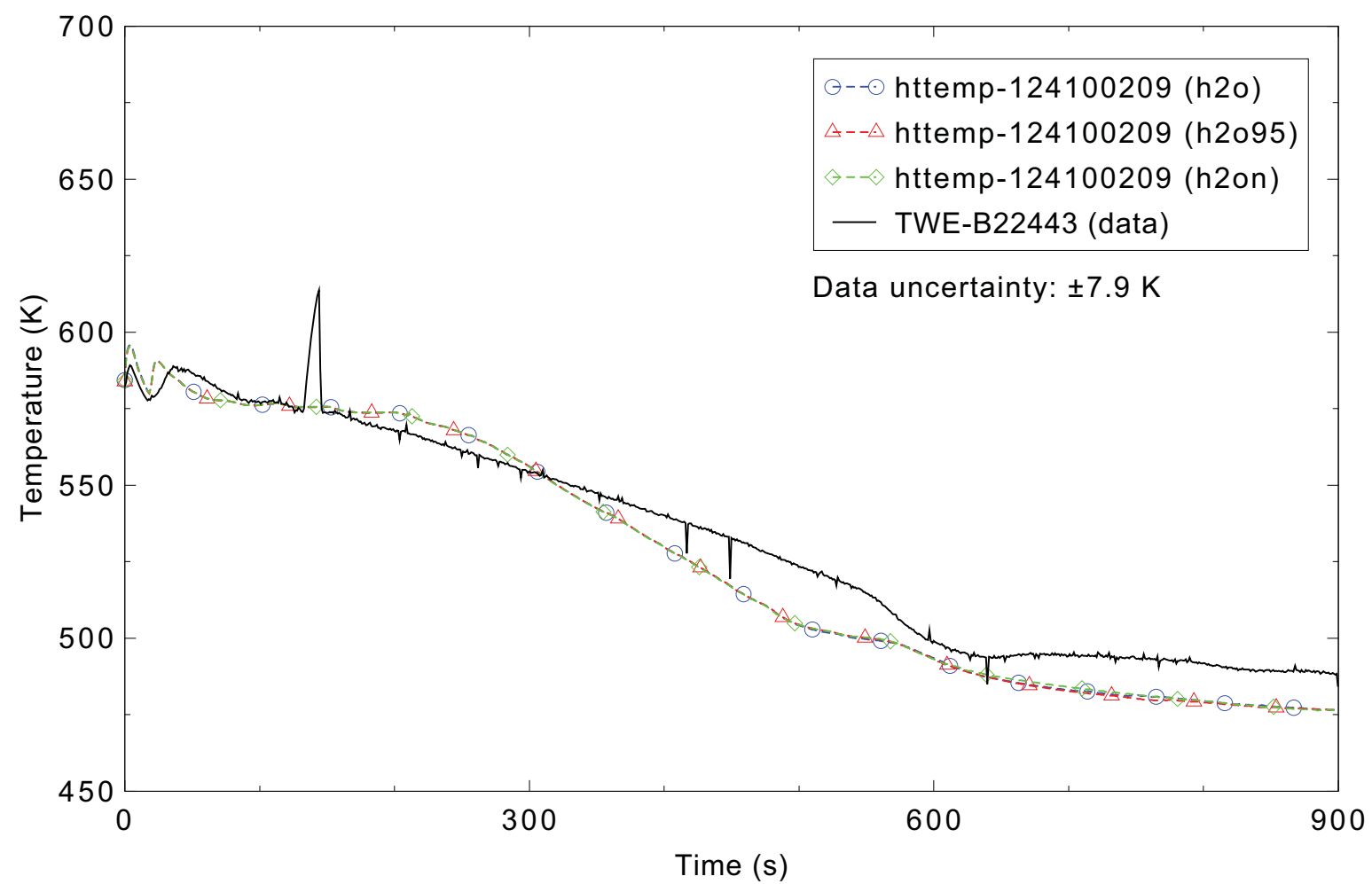

Figure 5.2-28. Measured and calculated heater rod surface temperature for axial level $3(1.018 \mathrm{~m})$ and different water properties, ROSA-IV Test SB-CL-18. 


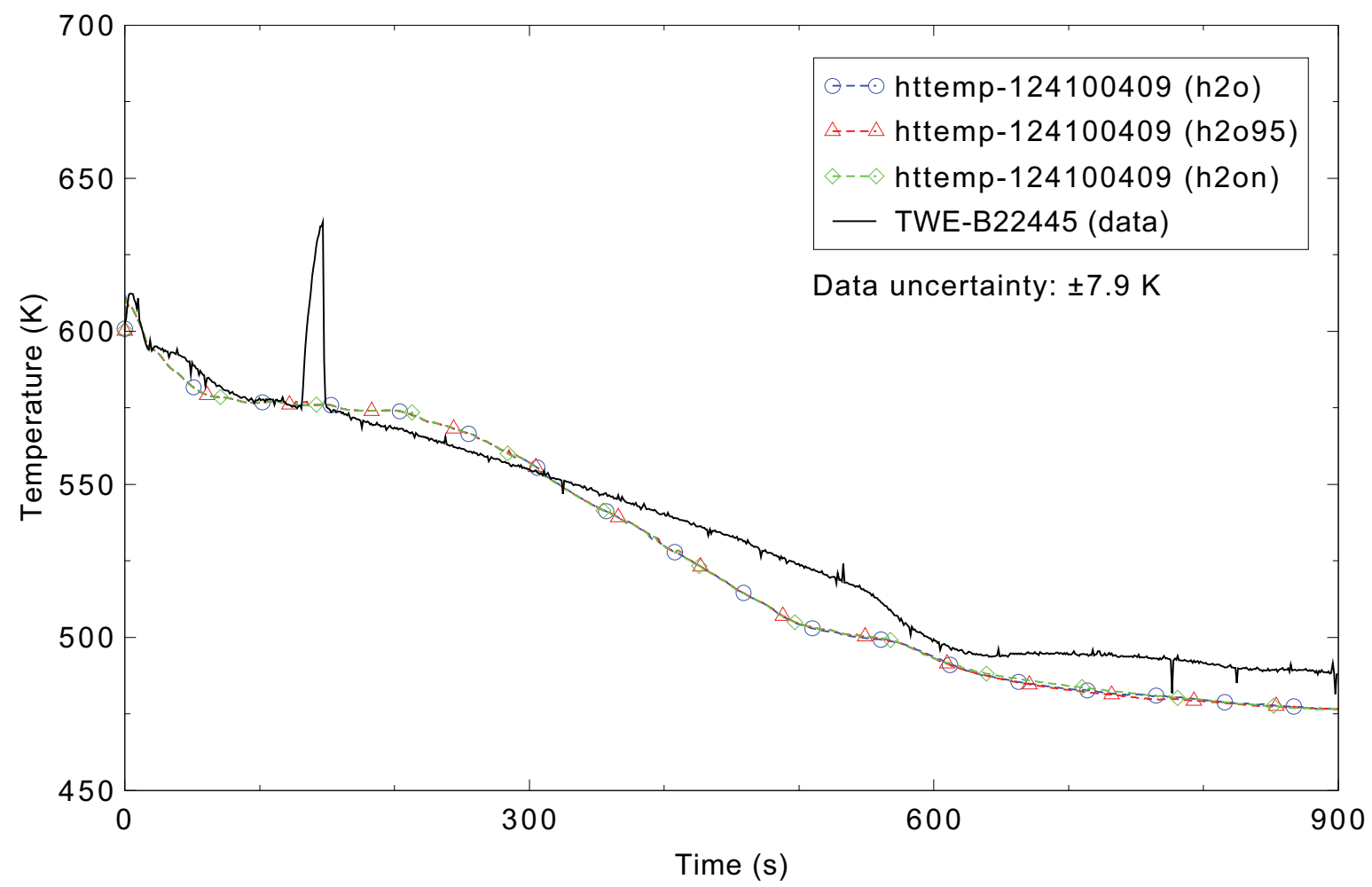

Figure 5.2-29. Measured and calculated heater rod surface temperature for axial level $5(1.830 \mathrm{~m})$ and different water properties, ROSA-IV Test SB-CL-18.

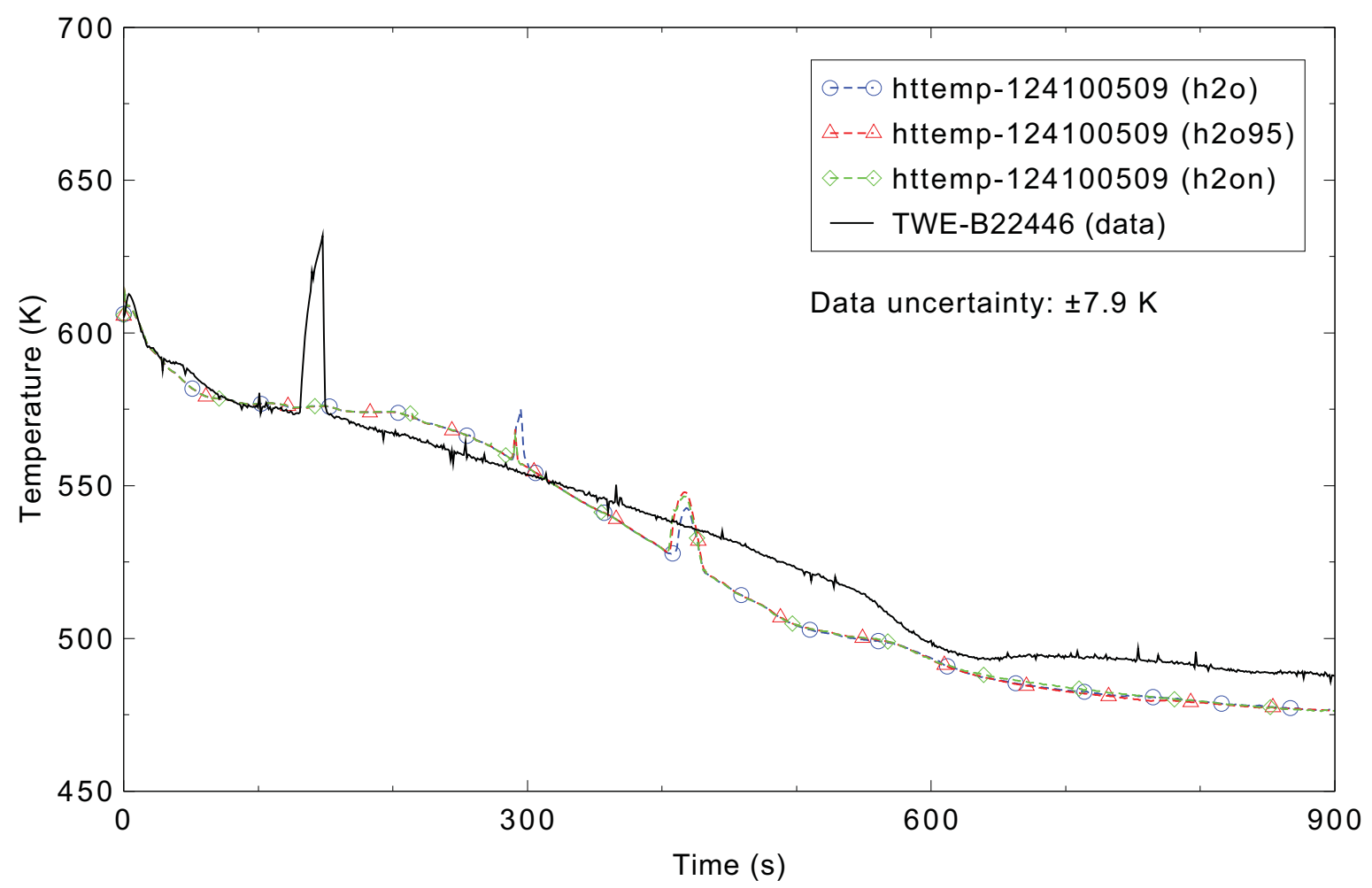

Figure 5.2-30. Measured and calculated heater rod surface temperature for axial level $6(2.236 \mathrm{~m})$ and different water properties, ROSA-IV Test SB-CL-18. 


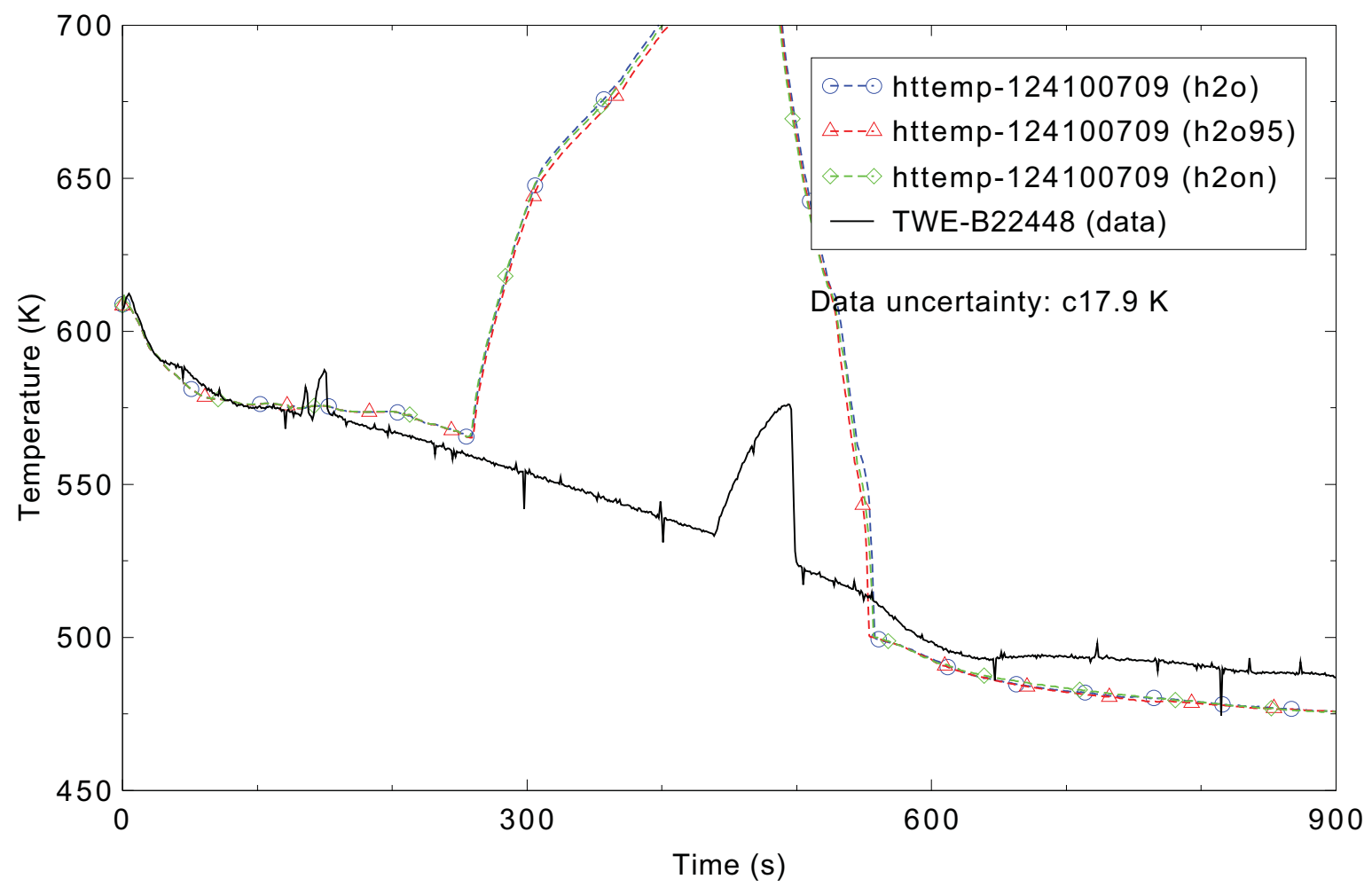

Figure 5.2-31. Measured and calculated heater rod surface temperature for axial level $8(3.048 \mathrm{~m})$ and different water properties, ROSA-IV Test SB-CL-18.

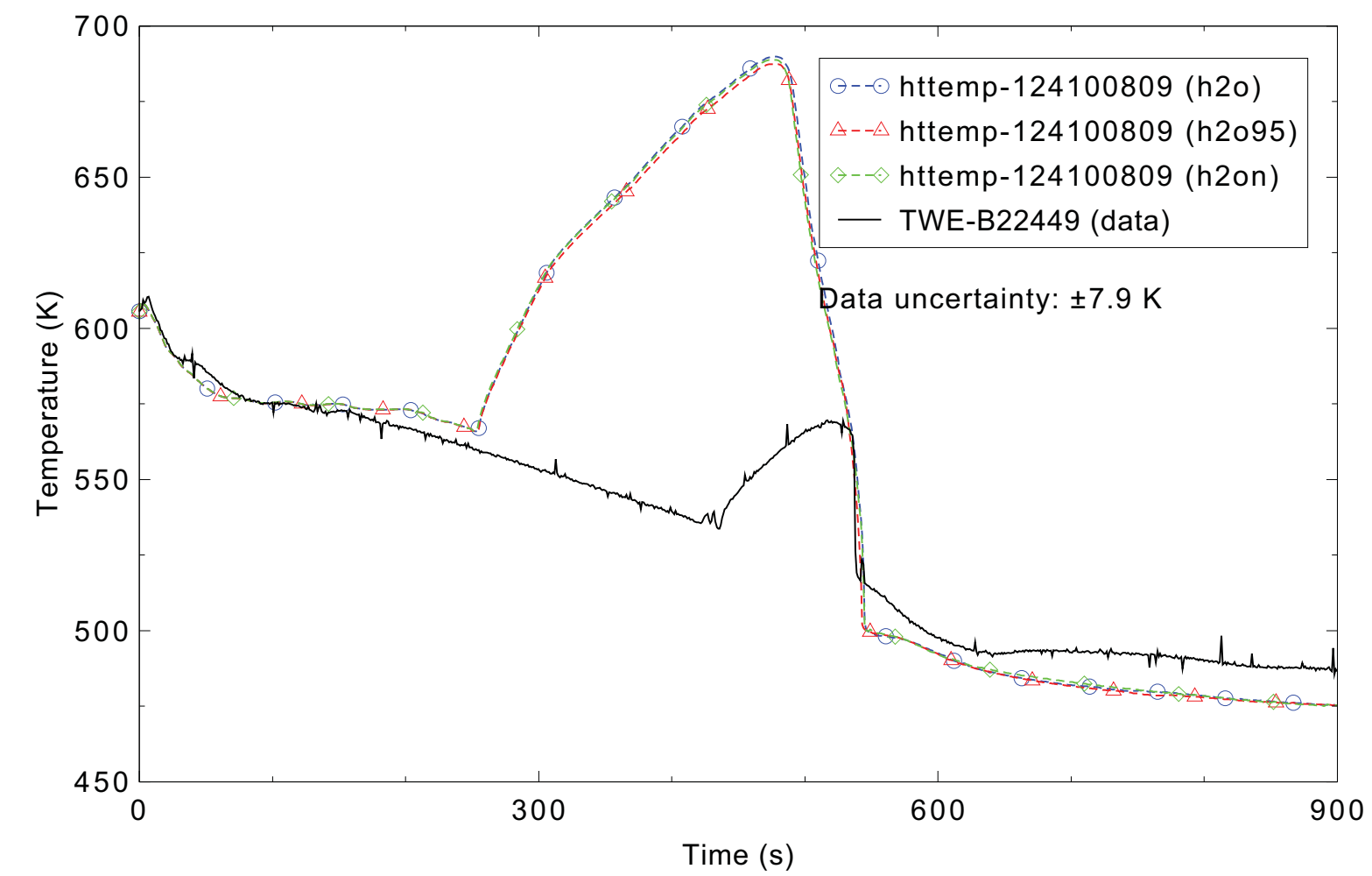

Figure 5.2-32. Measured and calculated heater rod surface temperature for axial level $9(3.610 \mathrm{~m})$ and different water properties, ROSA-IV Test SB-CL-18. 


\subsection{Semiscale NC Tests 1, 2, 3, and 10}

Figures comparing simulations using two coe versions are presented. Diagrams are included so that the figure numbering is the same as that in Volume III of he RELAP5-3D code manual. Noticeable differences were observed in Figures 5.3-3, 4, 5, 7, 9, 10, 11, 12, 13, 14, 15, 16, 17, 18, 19, 20, 21, 22, 23, 24, 25, 26, 27 , and 28.

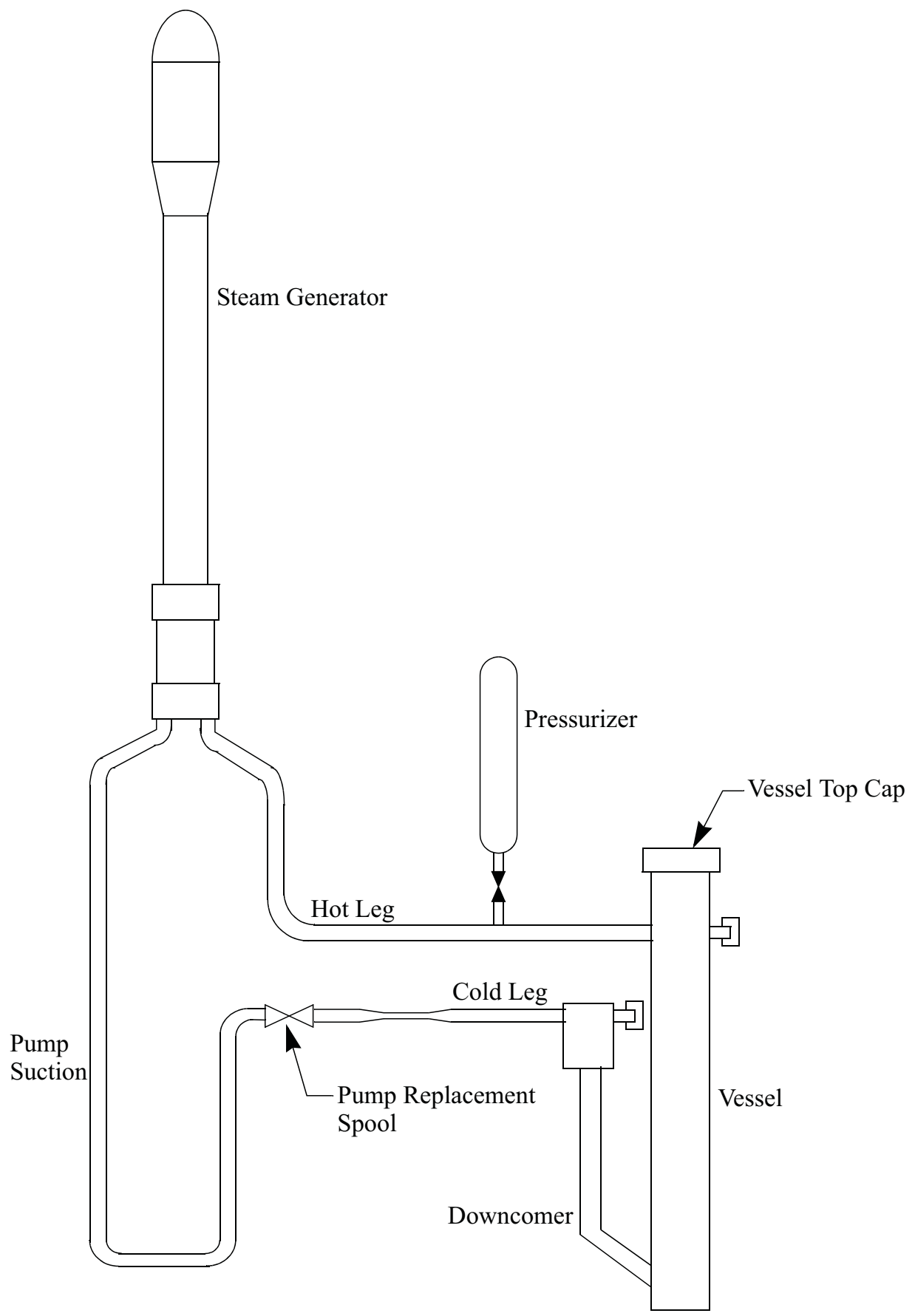

Figure 5.3-1. Semiscale Mod-2A single-loop configuration. 


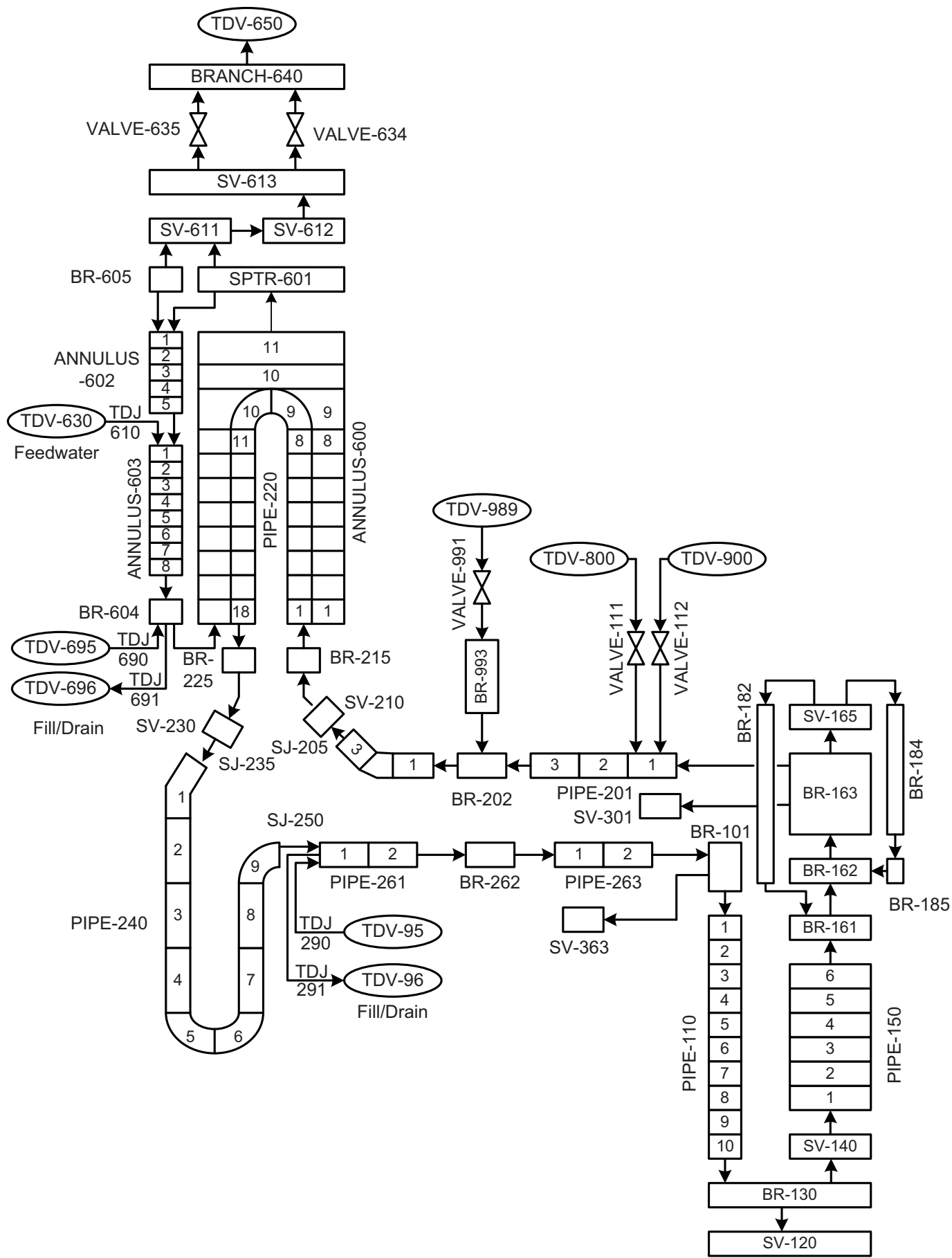

Figure 5.3-2. Nodalization of RELAP5-3D Semiscale natural circulation test model. 


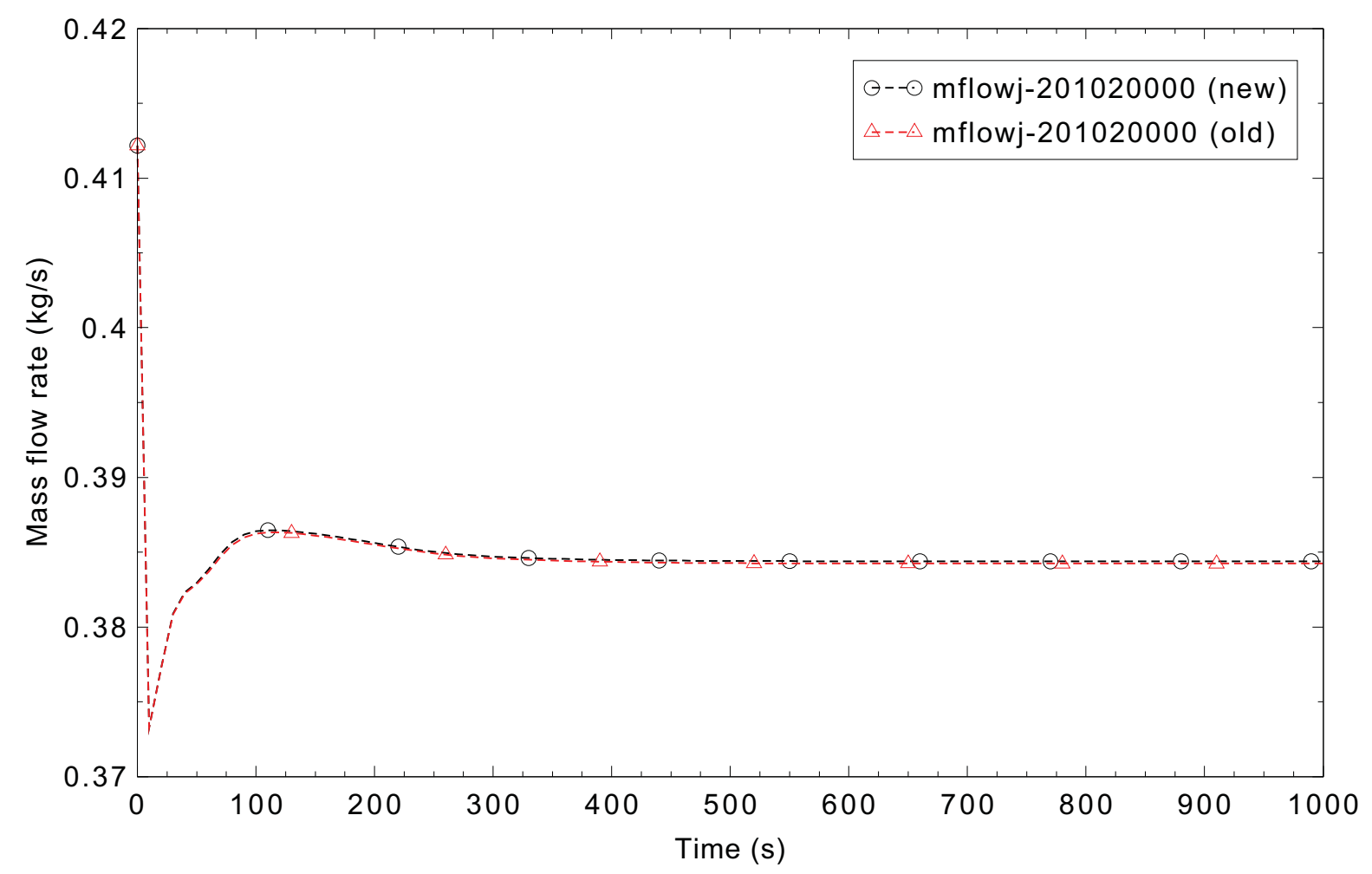

Figure 5.3-3. Calculated primary system mass flow rate at $60 \mathrm{~kW}$ core power for Semiscale Test S-NC-1.

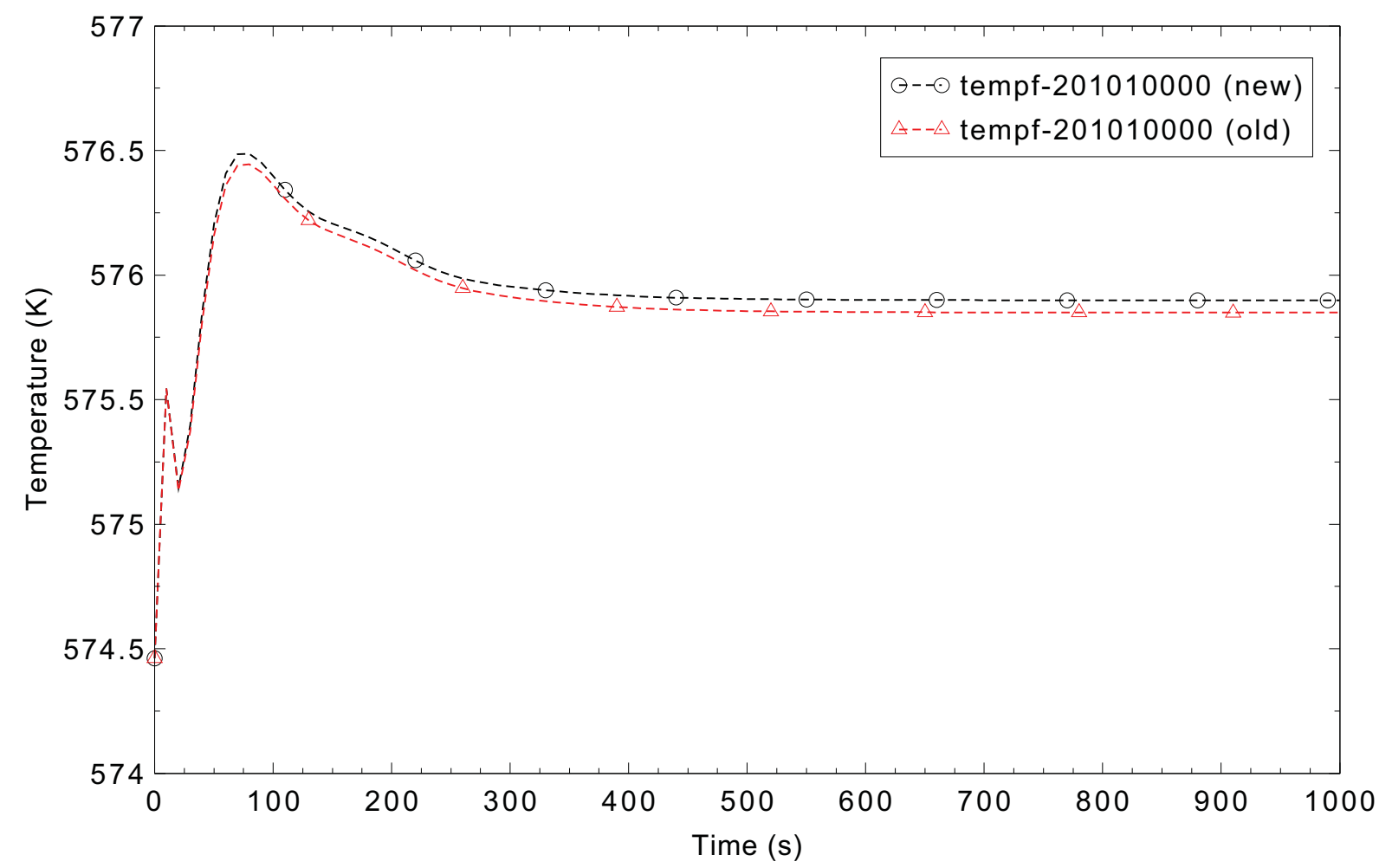

Figure 5.3-4. Calculated hot leg liquid temperature at $60 \mathrm{~kW}$ core power for Semiscale Test S-NC-1. 


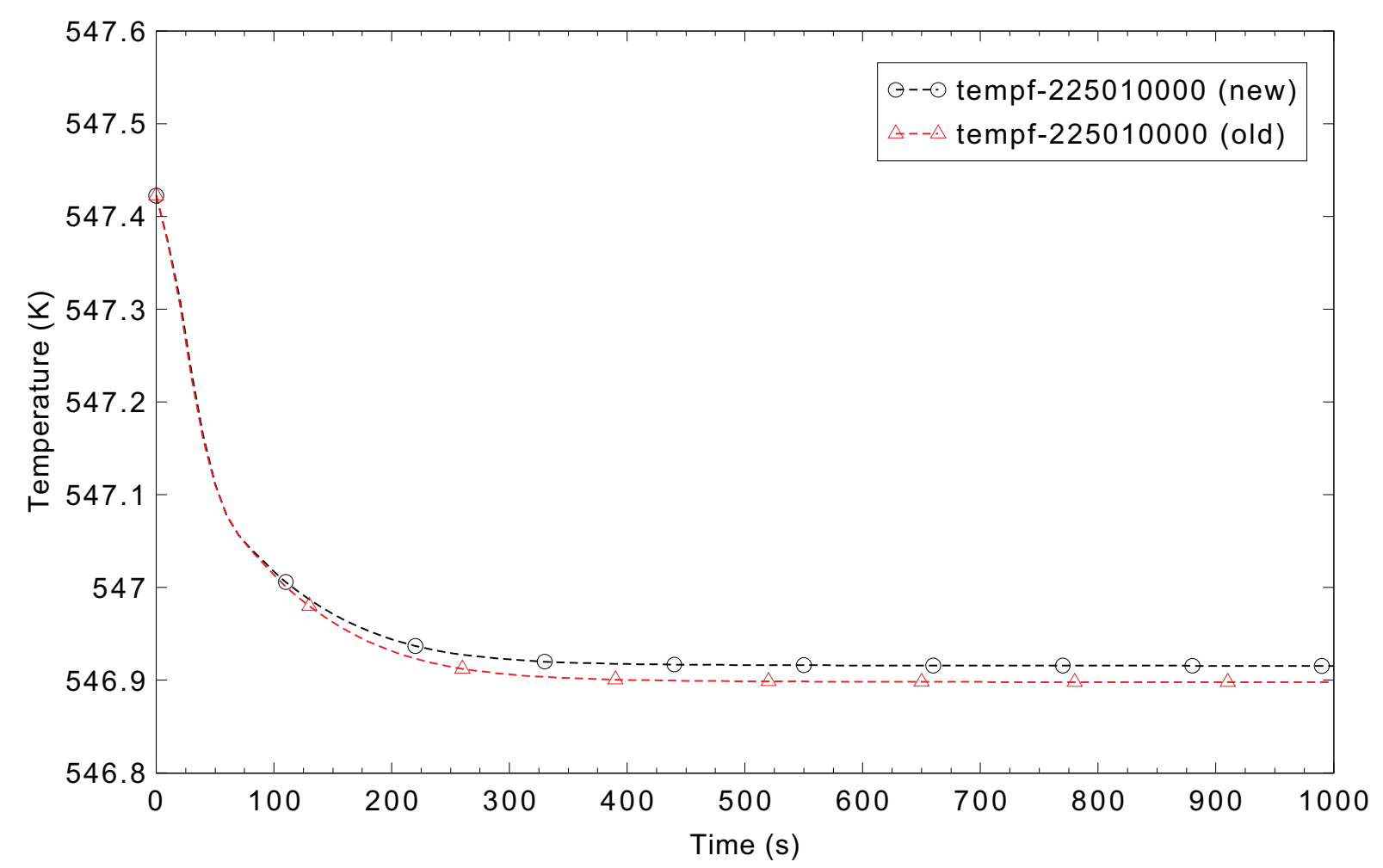

Figure 5.3-5. Calculated cold leg liquid temperature at $60 \mathrm{~kW}$ core power for Semiscale Test S-NC-1.

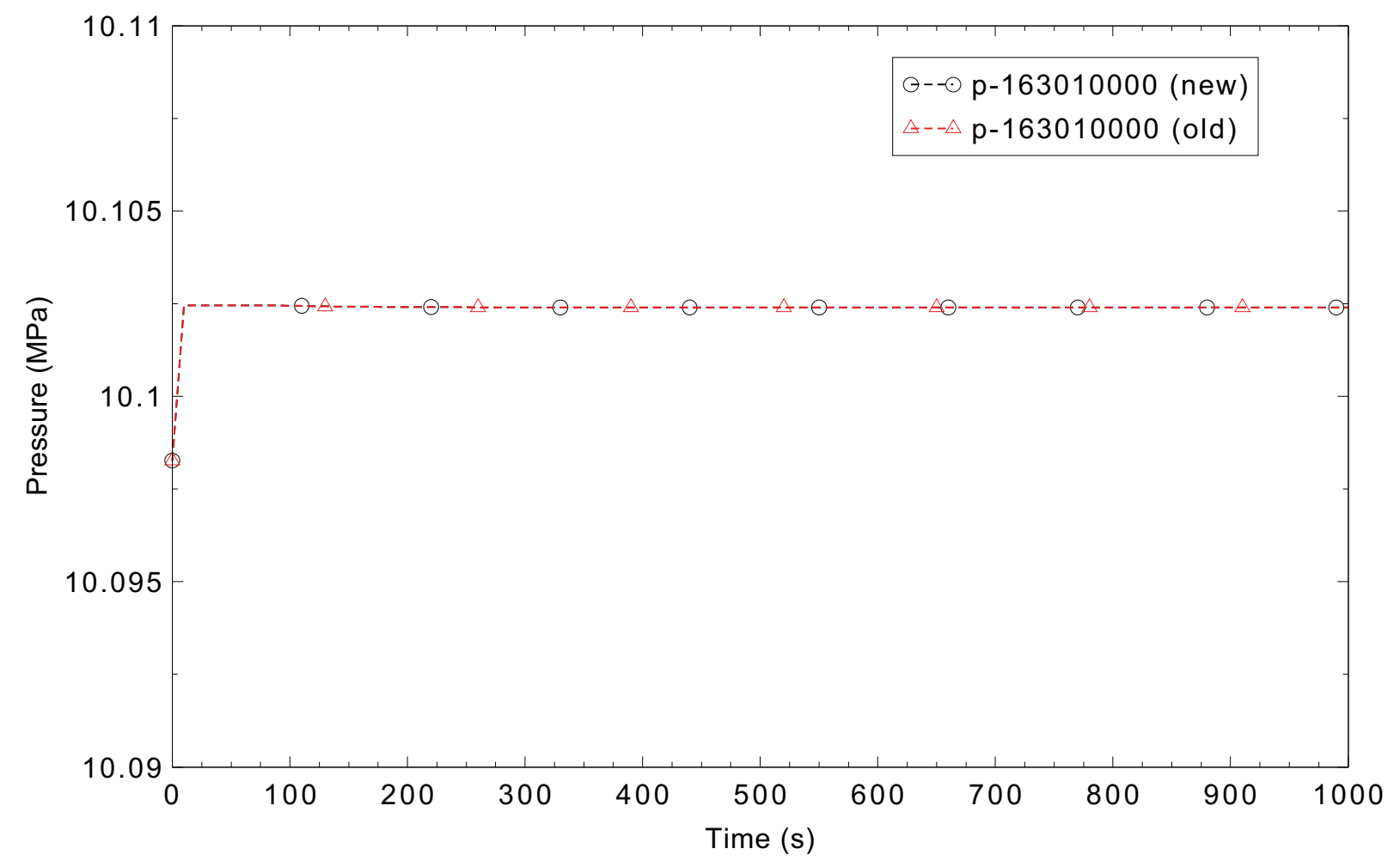

Figure 5.3-6. Calculated primary system pressure at $60 \mathrm{~kW}$ core power for Semiscale Test S-NC-1. 


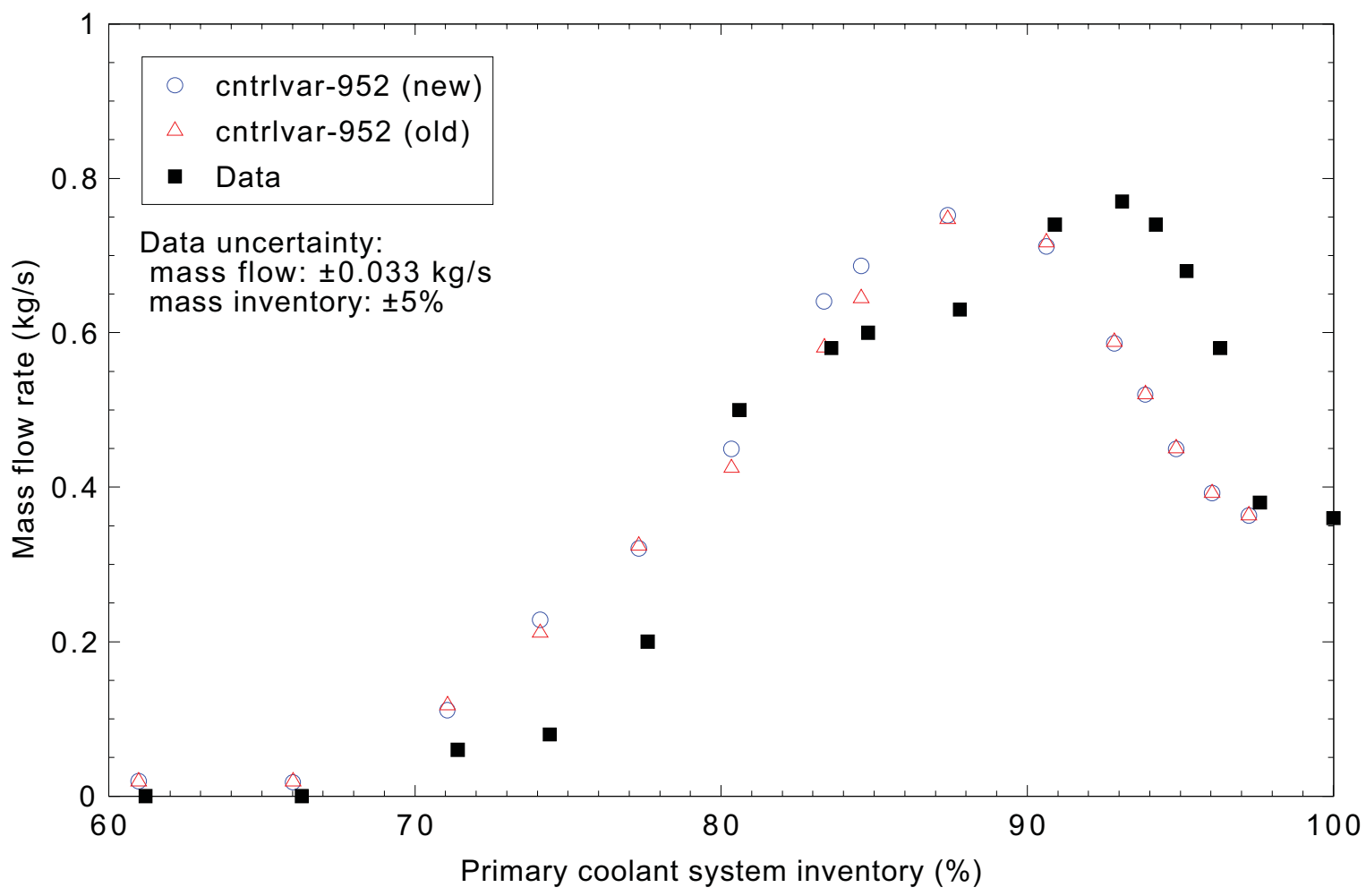

Figure 5.3-7. Measured and calculated primary system mass flow rate at $60 \mathrm{~kW}$ core power for Semiscale Test S-NC-2.

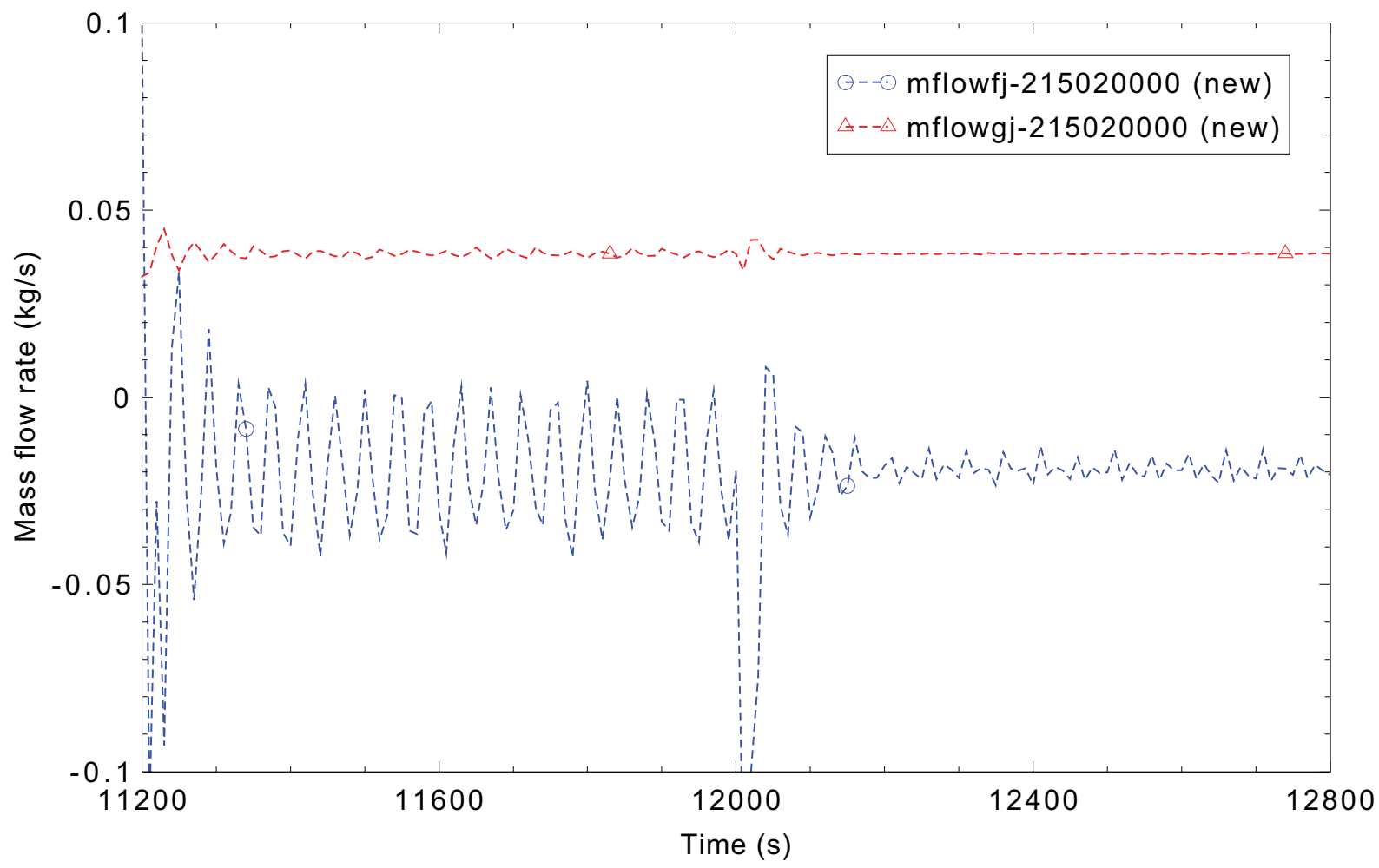

Figure 5.3-8. Calculated primary system liquid and vapor mass flow rates at $60 \mathrm{~kW}$ core power for Semiscale Test S-NC-2. 


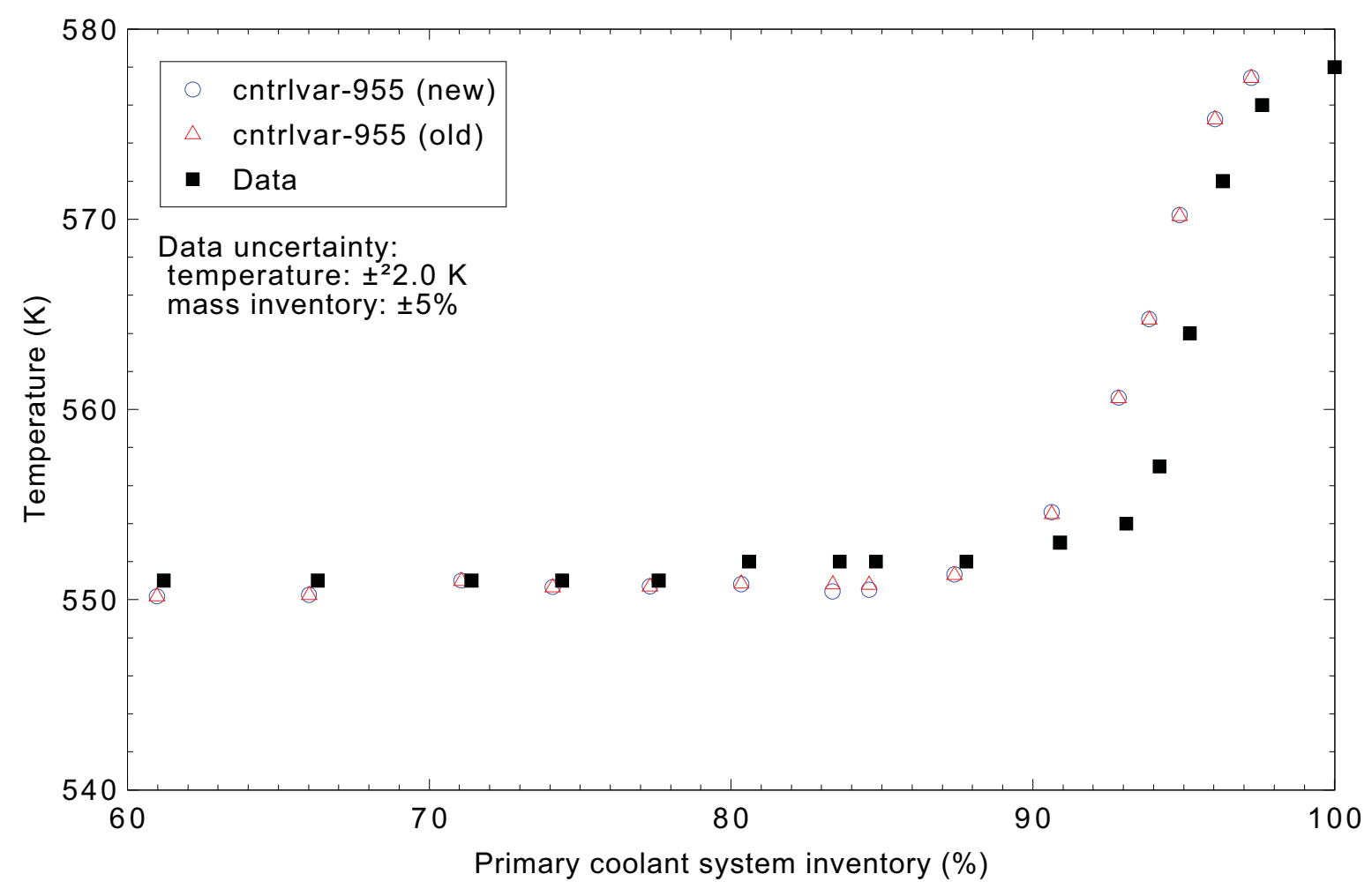

Figure 5.3-9. Measured and calculated hot leg liquid temperature at $60 \mathrm{~kW}$ core power for Semiscale Test S-NC-2.

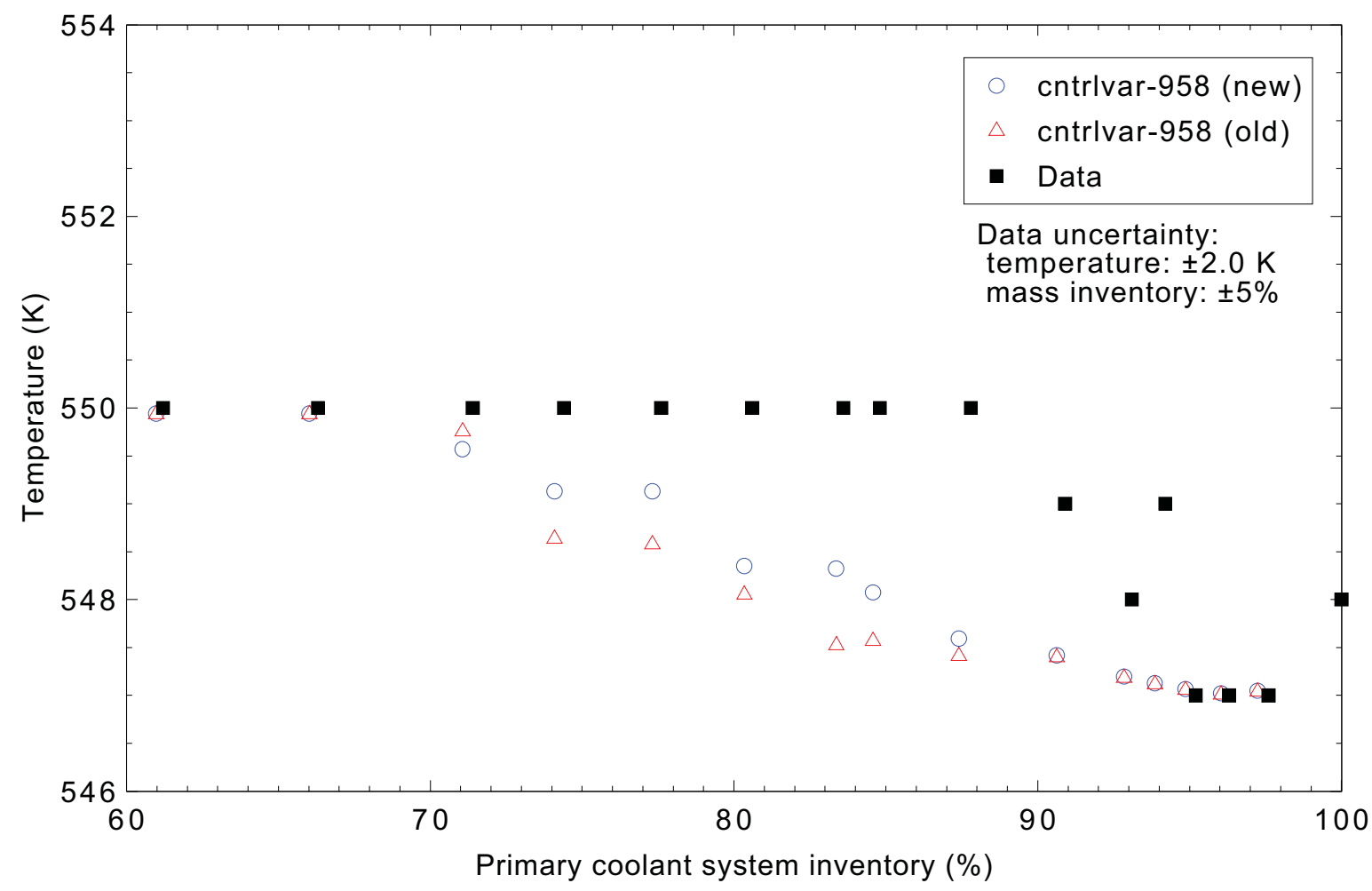

Figure 5.3-10. Measured and calculated cold leg liquid temperature at $60 \mathrm{~kW}$ core power for Semiscale Test S-NC-2. 


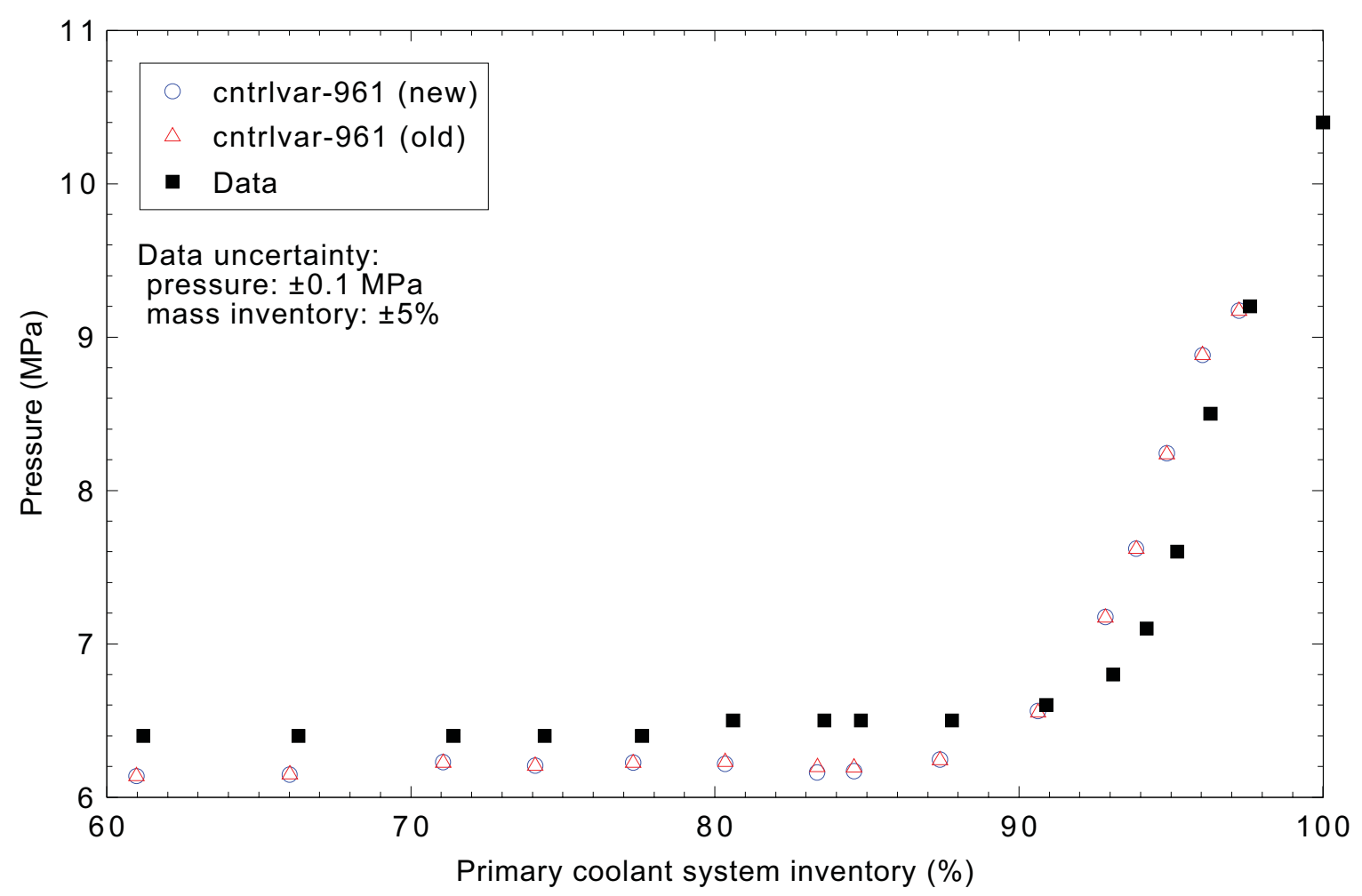

Figure 5.3-11. Measured and calculated reactor vessel upper plenum pressure at $60 \mathrm{~kW}$ core power for Semiscale Test S-NC-2.

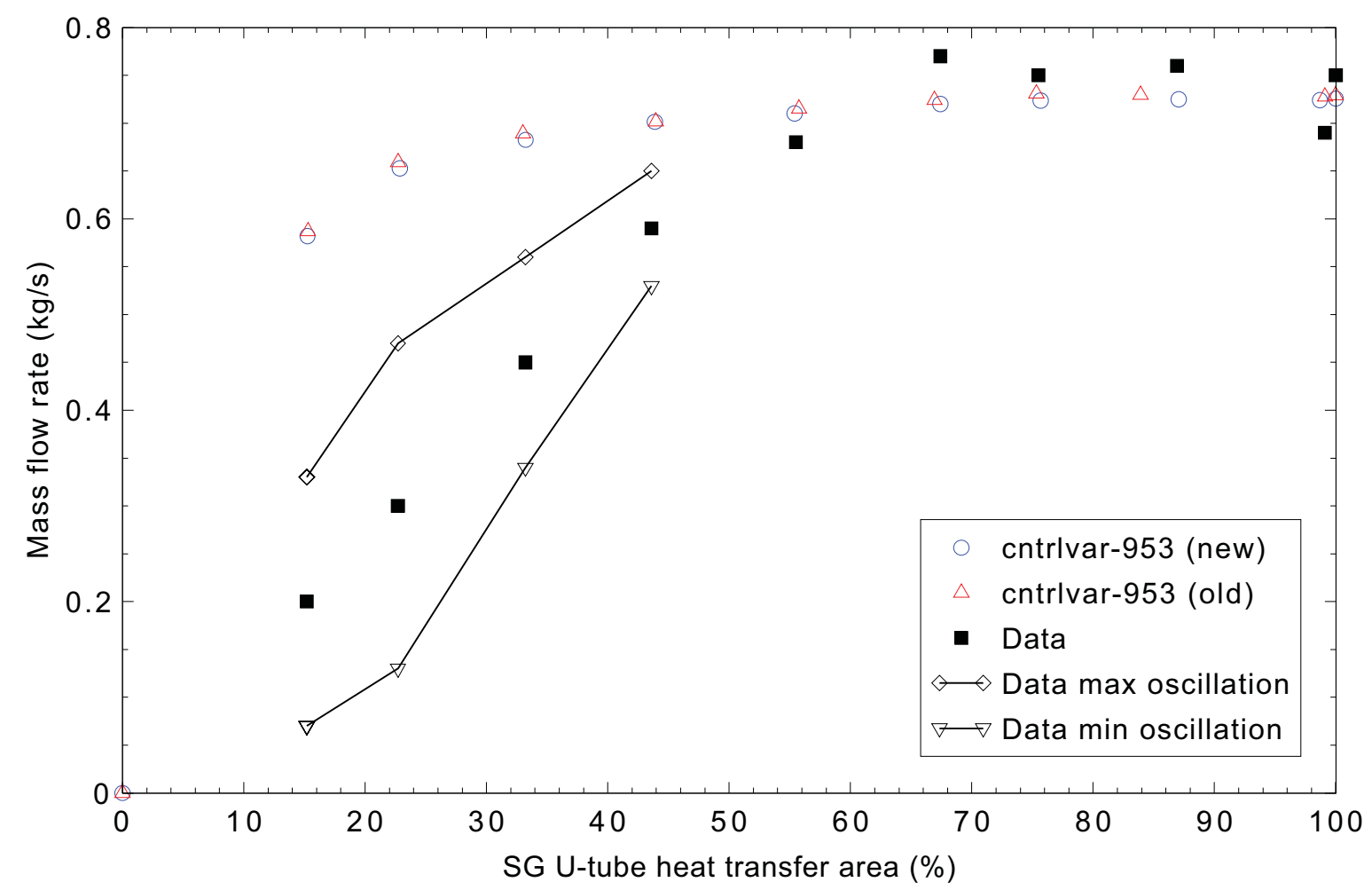

Figure 5.3-12. Measured and calculated primary system mass flow rate for Semiscale Test S-NC-3. 


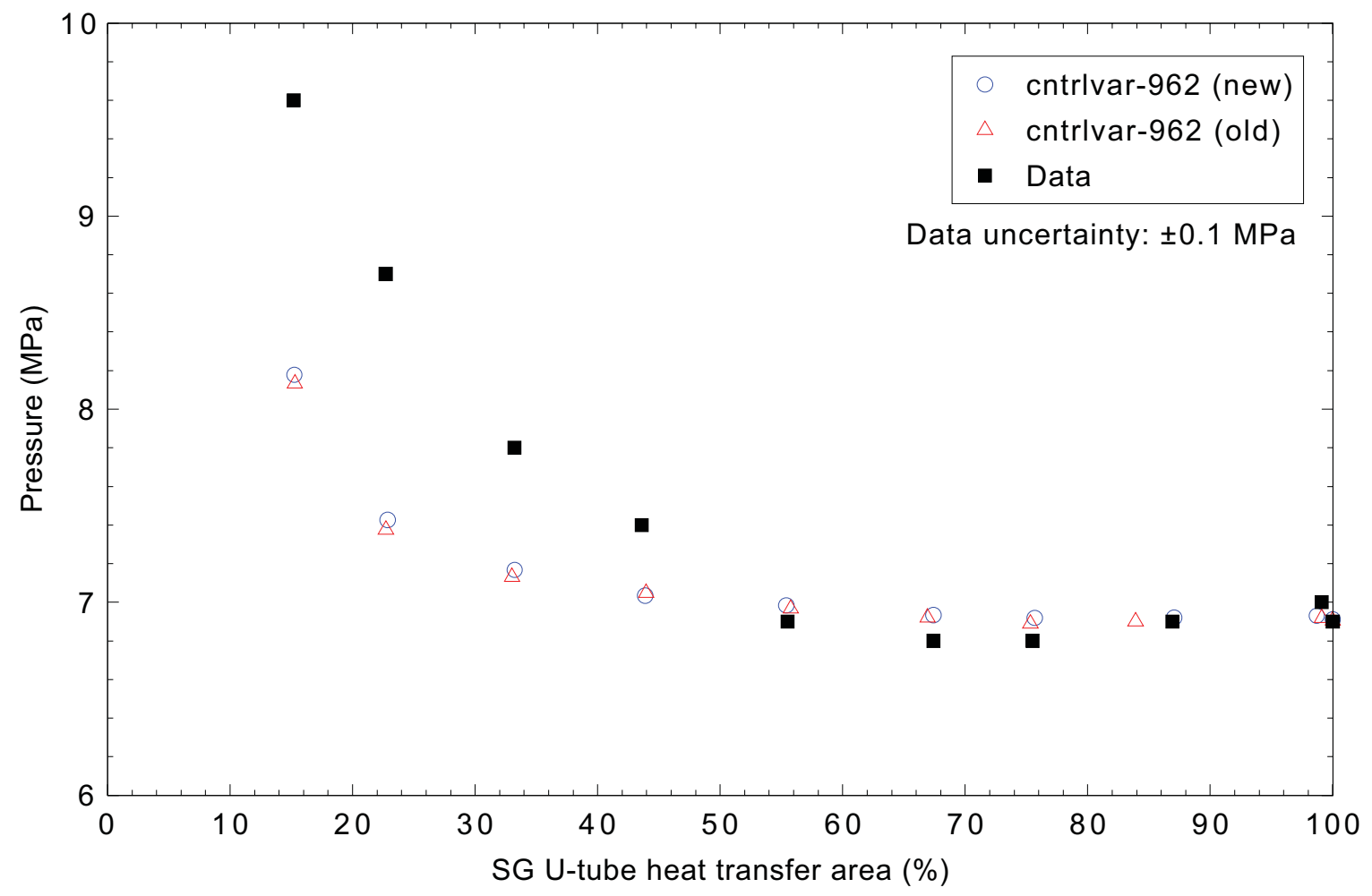

Figure 5.3-13. Measured and calculated primary system pressure for Semiscale Test S=NC-3.

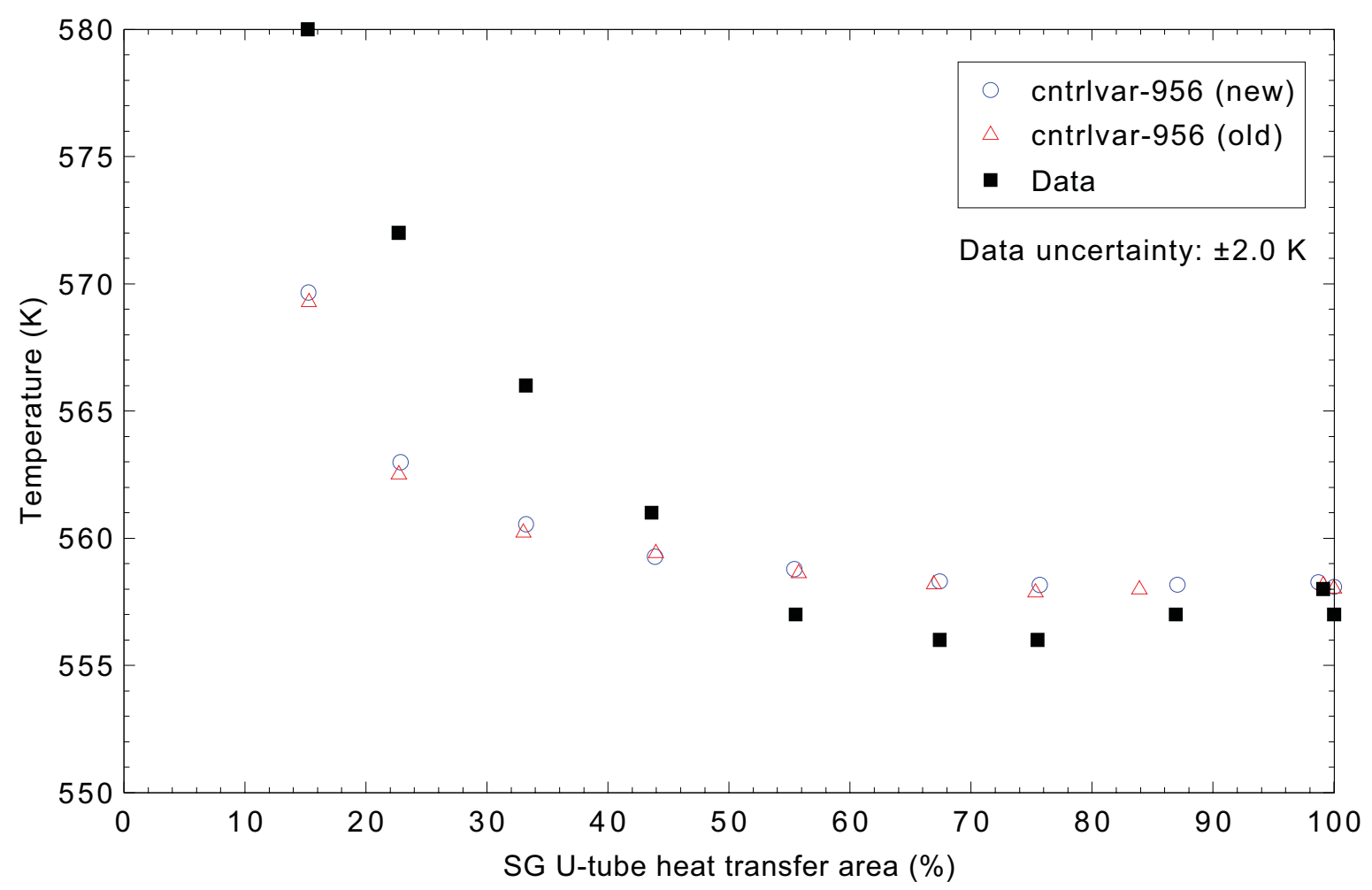

Figure 5.3-14. Measured and calculated hot leg liquid temperature for Semiscale Test S=NC-3. 


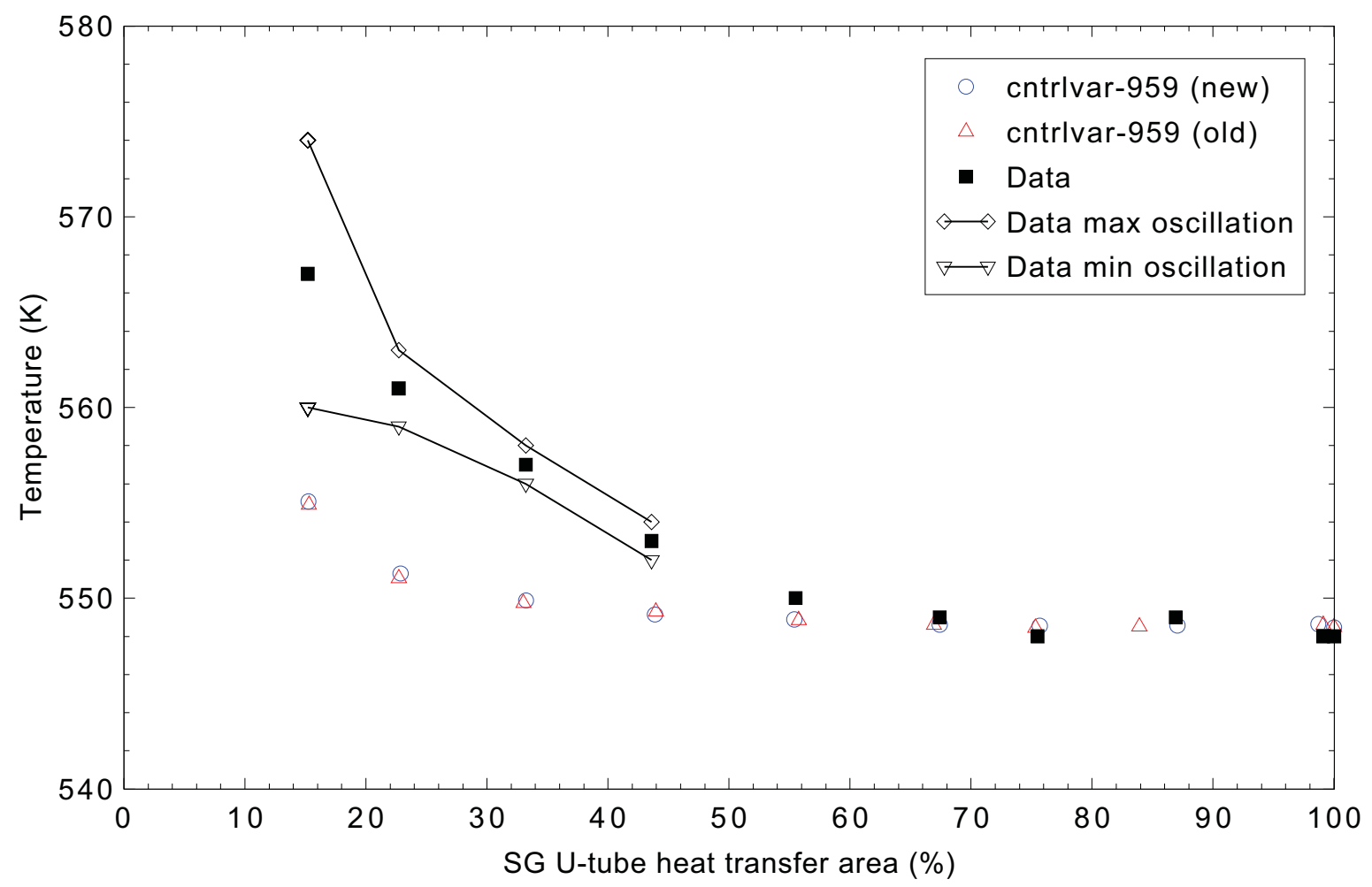

Figure 5.3-15. Measured and calculated cold leg liquid temperarture for Semiscale Test S-NC-3.

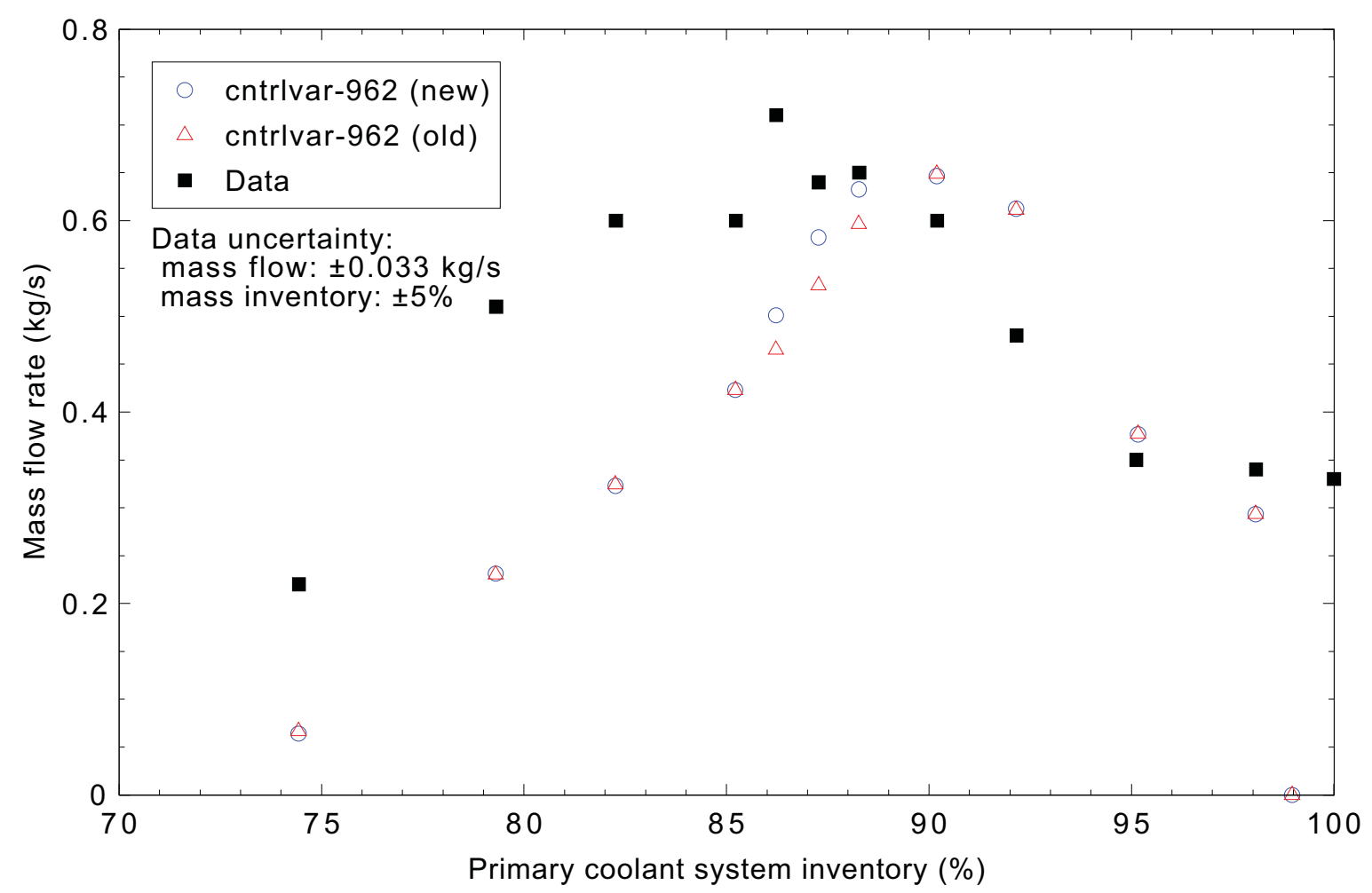

Figure 5.3-16. Measured and calculated primary system mass flow rate for Seimscale Test S-NC-10 Part 2. 


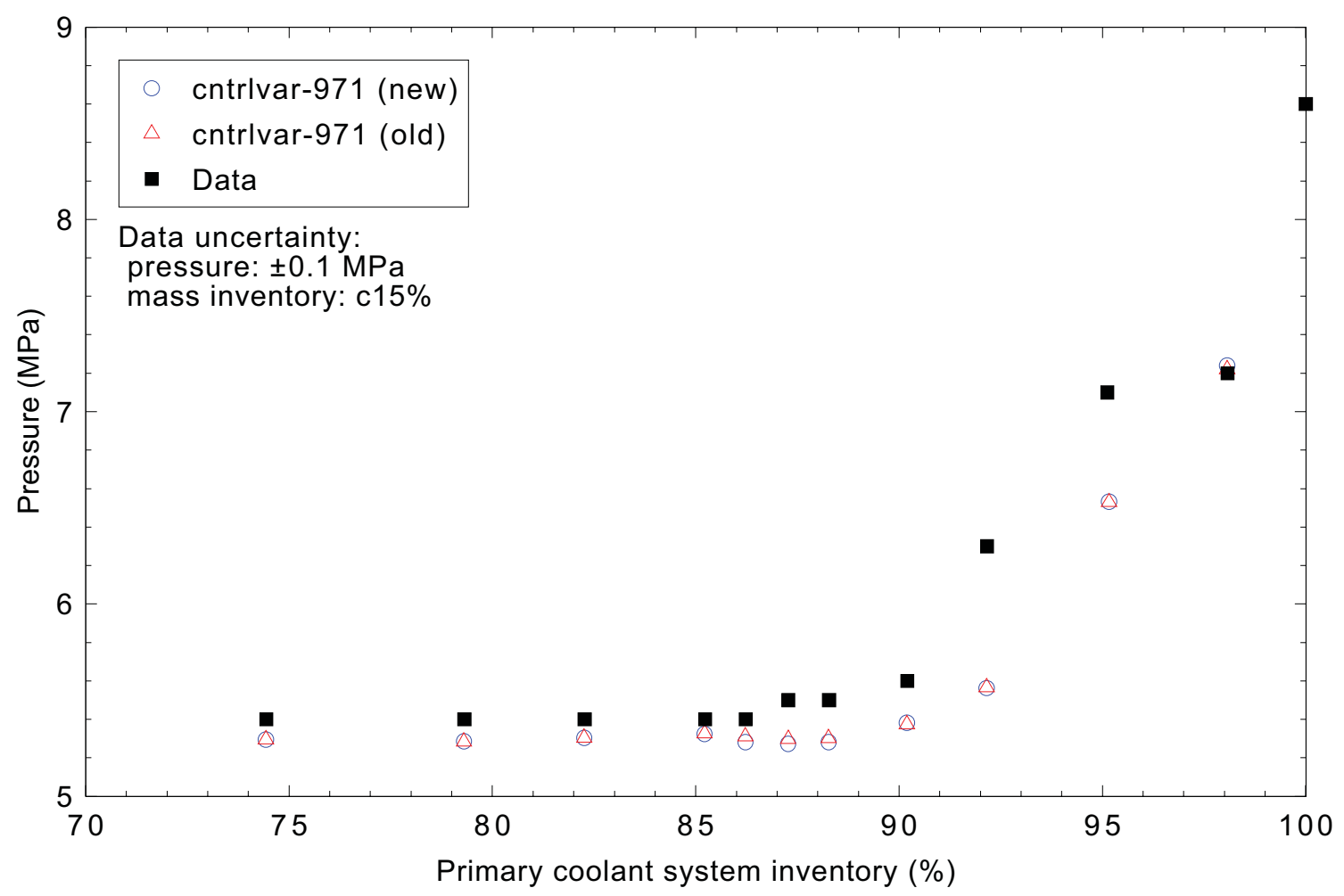

Figure 5.3-17. Measured and calculated primary system pressures for Semiscale Test S-NC-10 Part 2.

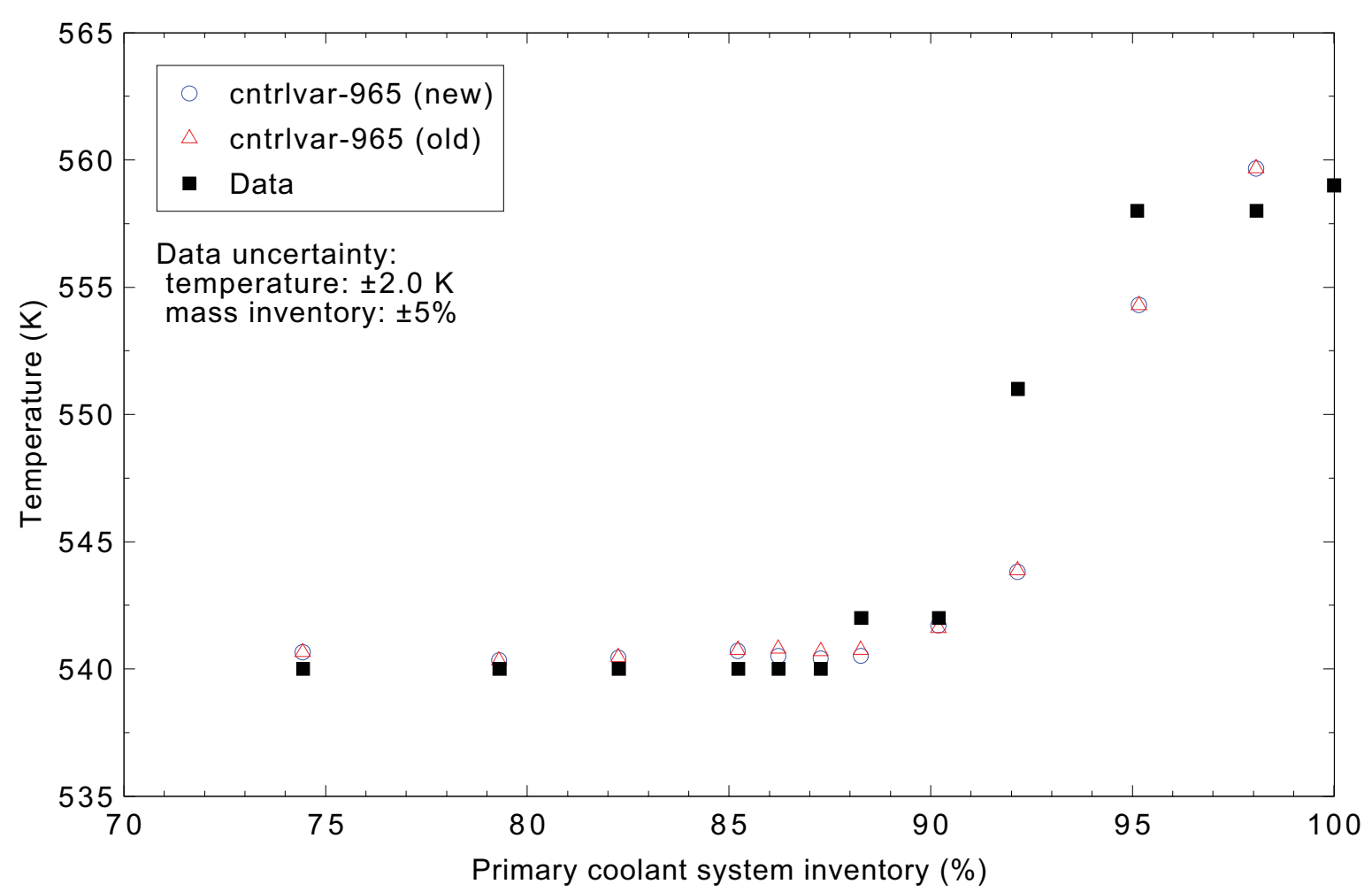

Figure 5.3-18. Measured and calculated hot leg liquid temperatures for Semiscale Test S-NC-10 Part 2. 


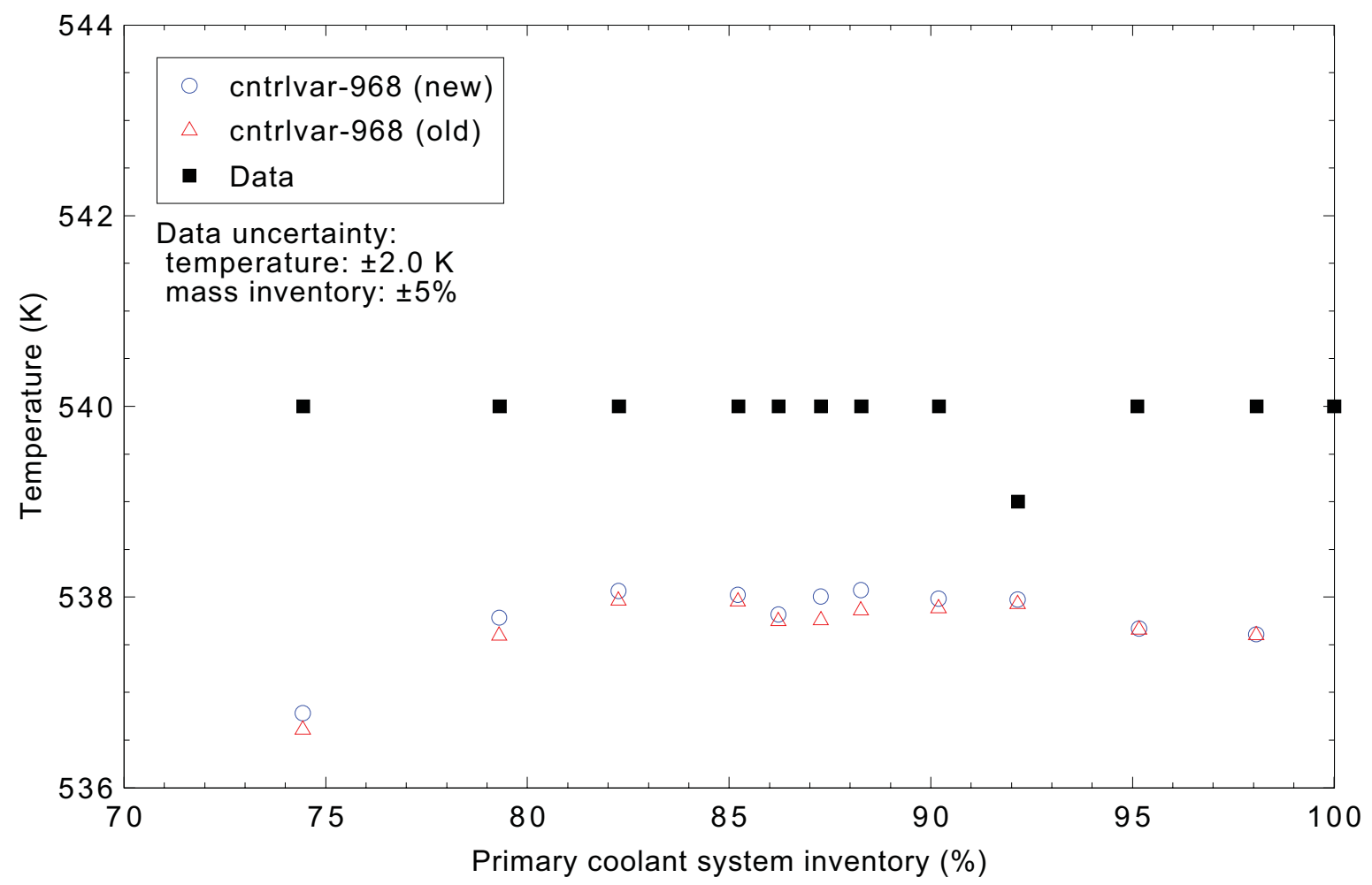

Figure 5.3-19. Measured and calculated cold leg liquid temperatures for Semiscale Test S-NC-10 Part 2.

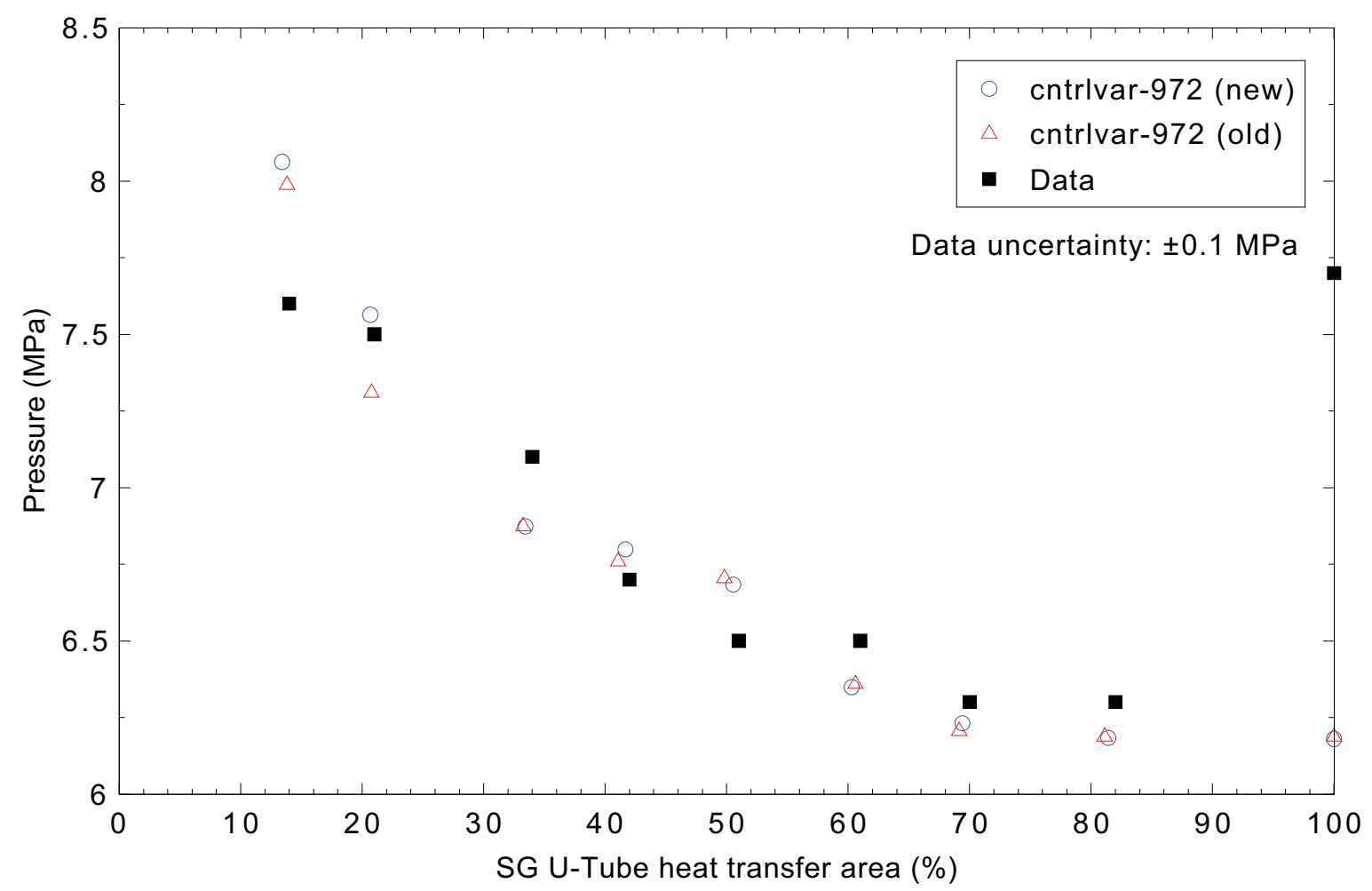

Figure 5.3-20. Measured and calculated primary system pressure for Semiscale Test S-NC-10 Part 3. 


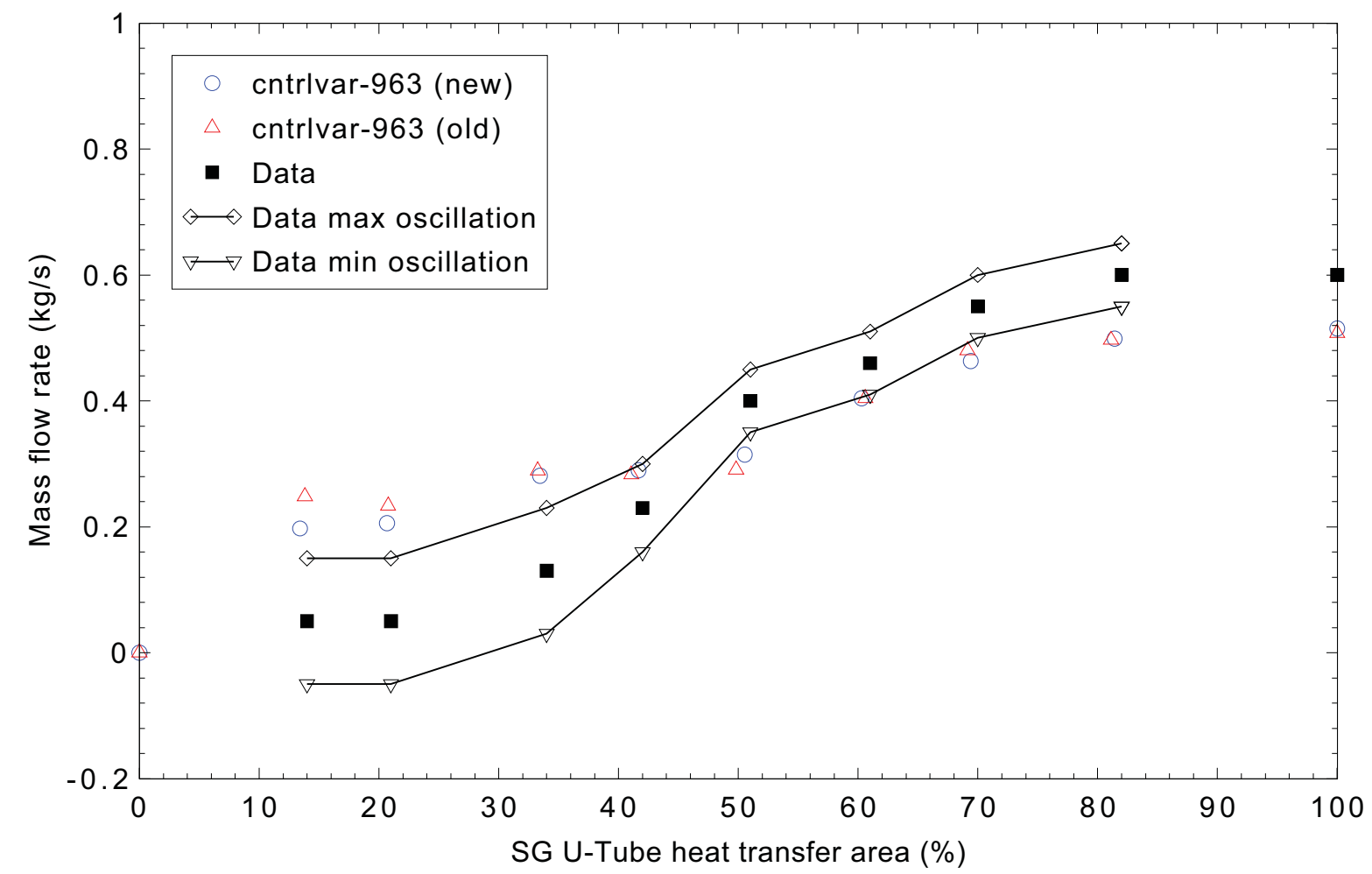

Figure 5.3-21. Measured and calculated primary system mass flow rate for Semiscale Test S-NC-10 Part 3.

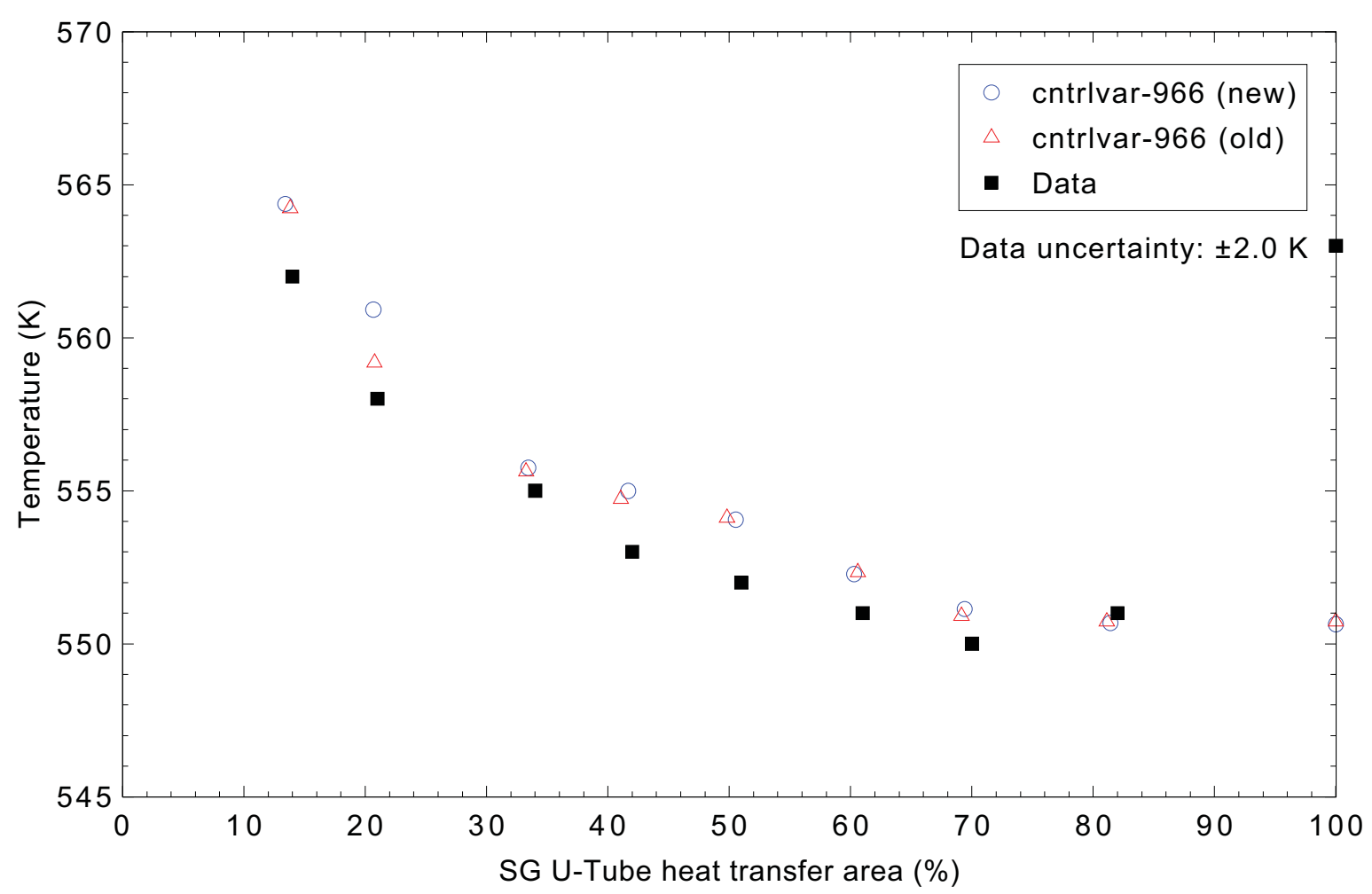

Figure 5.3-22. Measured and calculated hot leg liquid temperature for Semiscale Test S-NC-10 Part 3. 


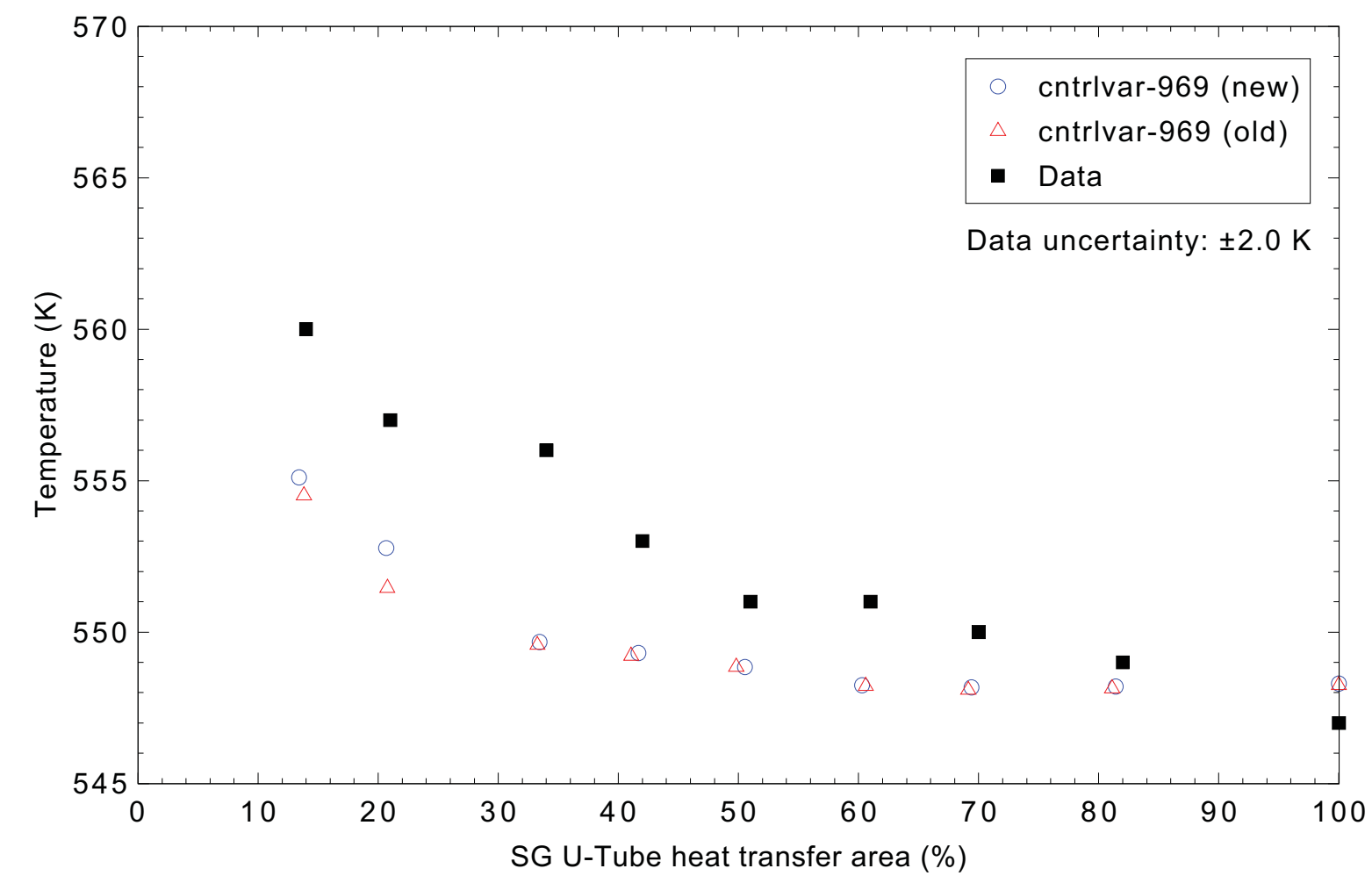

Figure 5.3-23. Measured and calculated cold leg liquid temperature for Semiscale Test S-NC-10 Part 3.

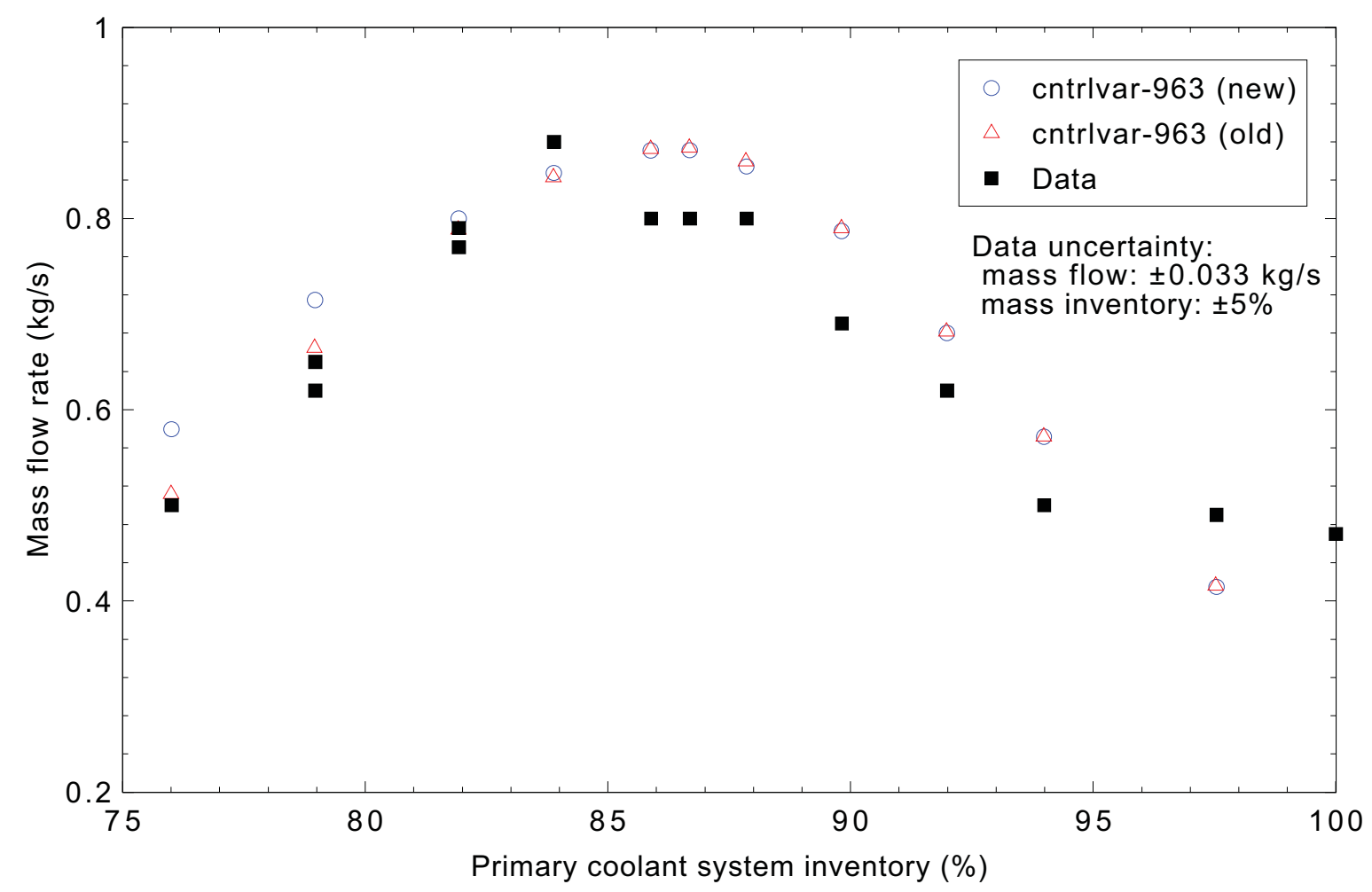

Figure 5.3-24. Measured and calculated primary system mass flow rate for Semiscale Test S-NC-10 Part 4 with core power of $100 \mathrm{~kW}$. 


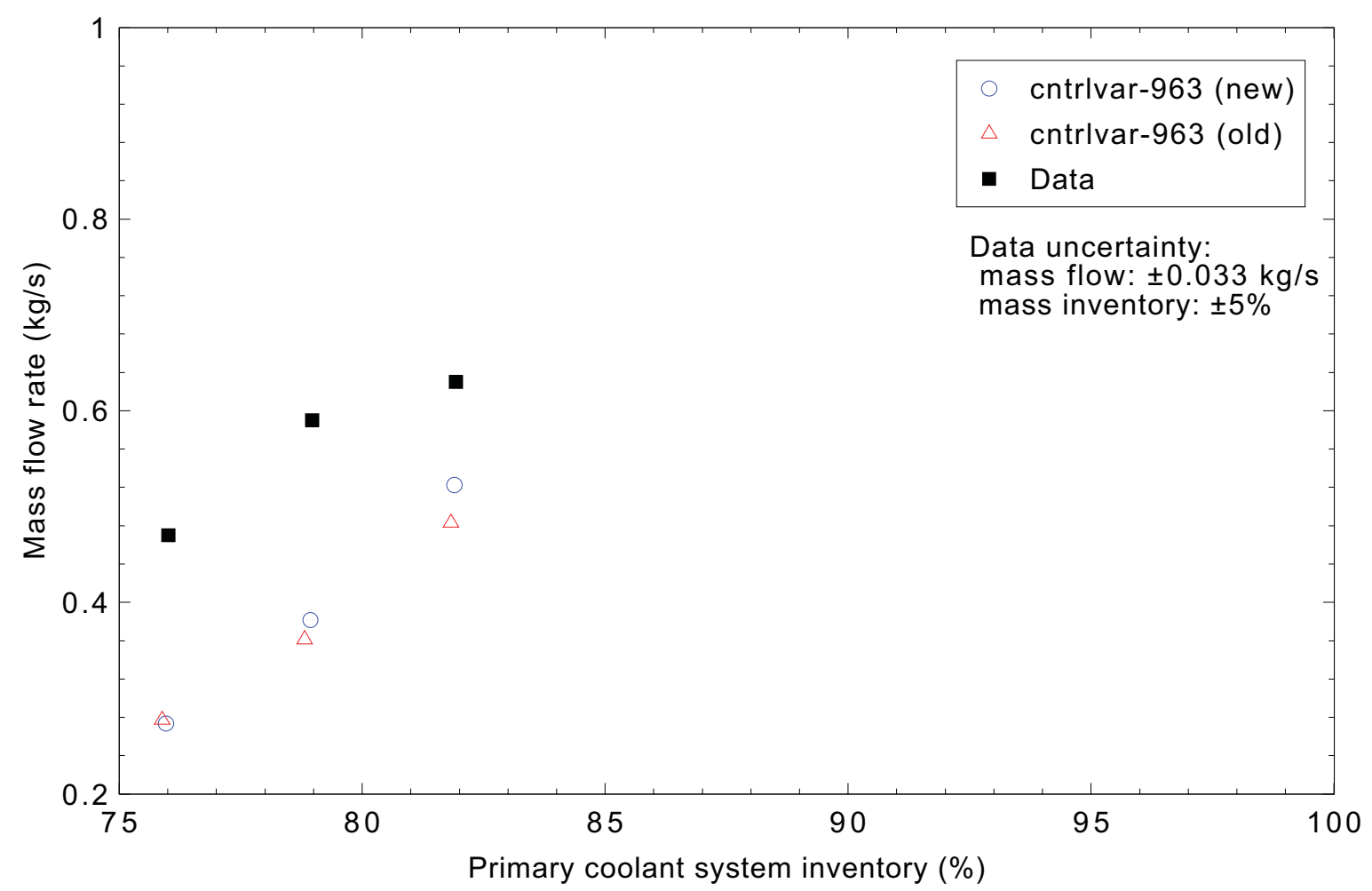

Figure 5.3-25. Measured and calculated primary system mass flow rate for Semiscale Test S-NC-10 Part 4 with core power of $60 \mathrm{~kW}$.

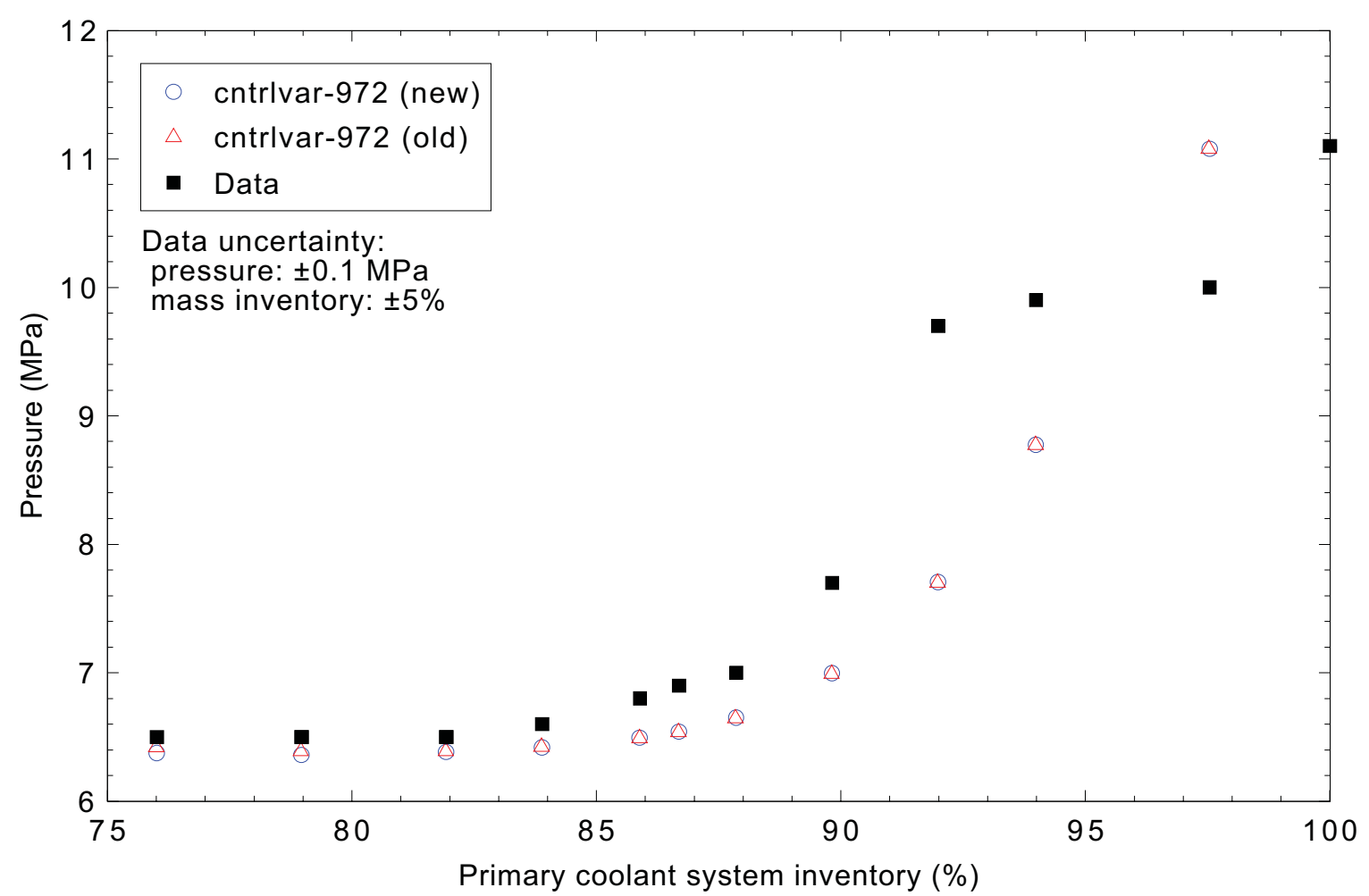

Figure 5.3-26. Measured and calculated primary system pressures for Semiscale Test S-NC-10 Part 4 with core power of $100 \mathrm{~kW}$. 


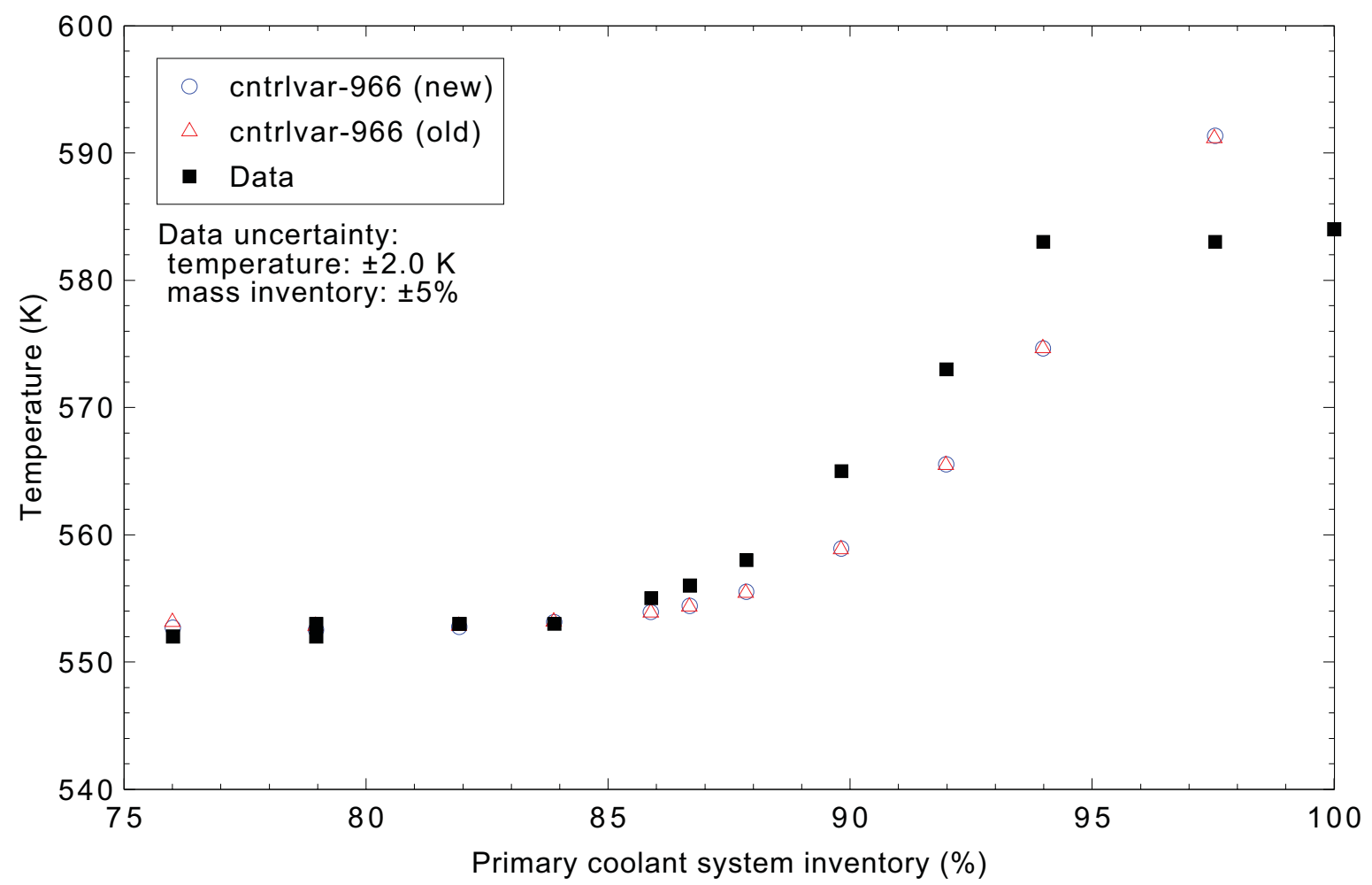

Figure 5.3-27. Measured and calculated hot leg liquid temperatures for Semiscale Test S-NC-10 Part 4 with core power of $100 \mathrm{~kW}$.

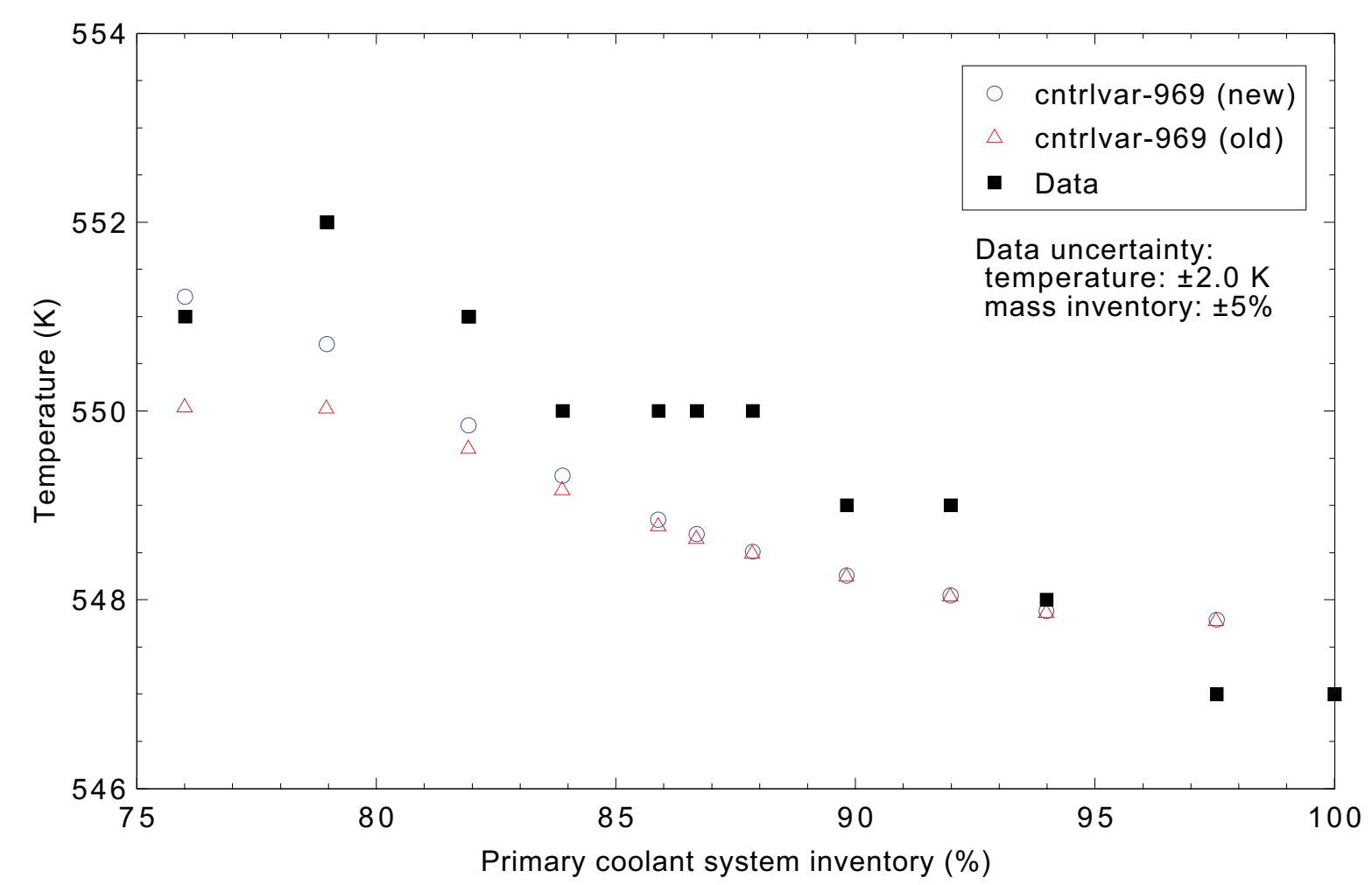

Figure 5.3-28. Measured and calculated cold leg liquid temperatures for Semiscale Test S-NC-10 Part 4 with core power of $100 \mathrm{~kW}$. 


\subsection{LOBI Test A1-04R (Large Break)}

Figures comparing simulations using two code versions are presented. Diagrams are included so that the figure numbering is the same as that in Volume III of the RELAP5-3D code manual. A significant difference was observed in Figure 5.4-20; noticeable differences were observed in Figures 5.4-5, 6, 7, 8, 9, $10,11,12,13,14,15,16,17,18$, and 19. 


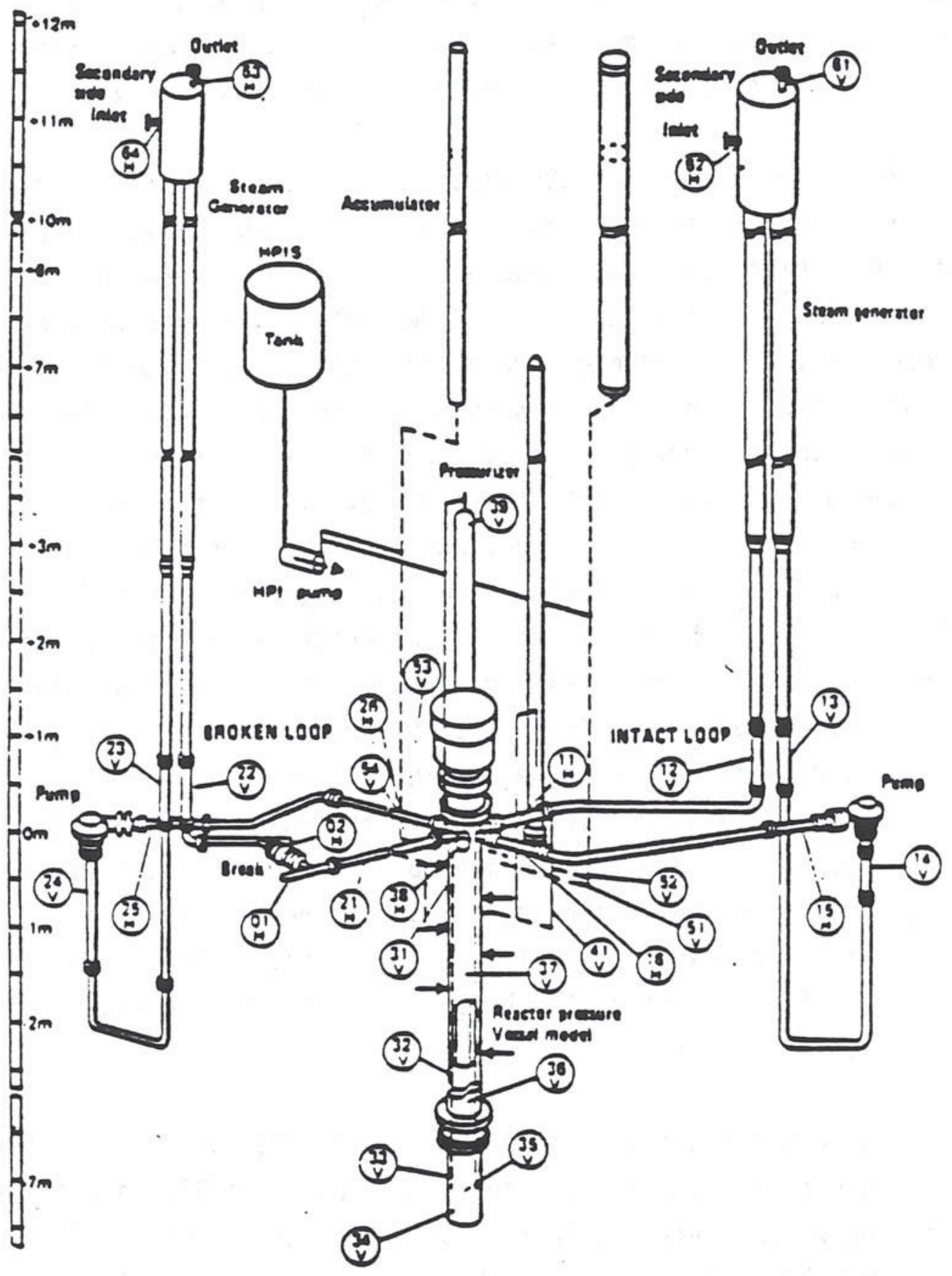

Figure 5.4-1. Schematic of LOBI facility. 
RELAP5-3D/4.0.3

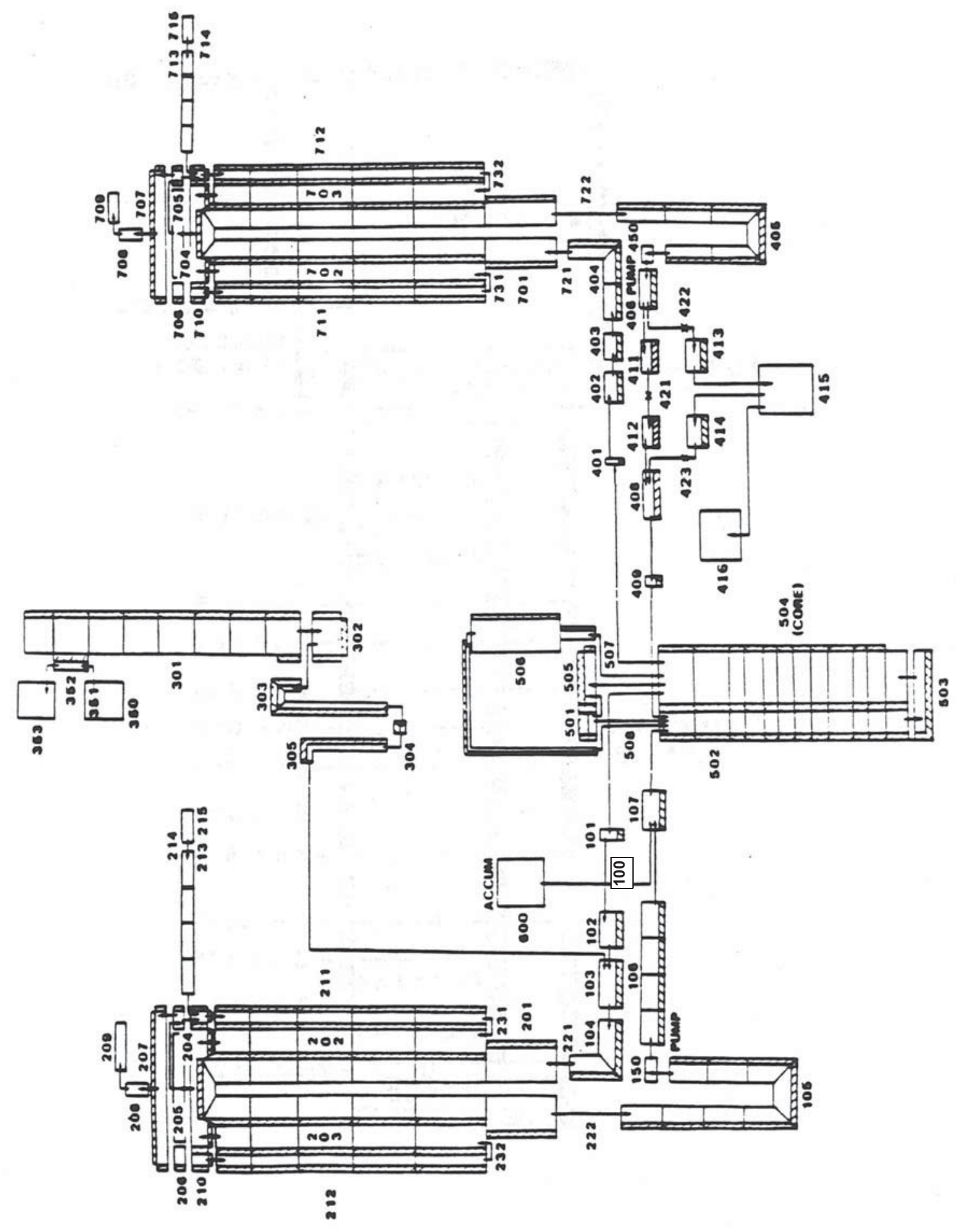

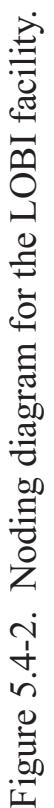




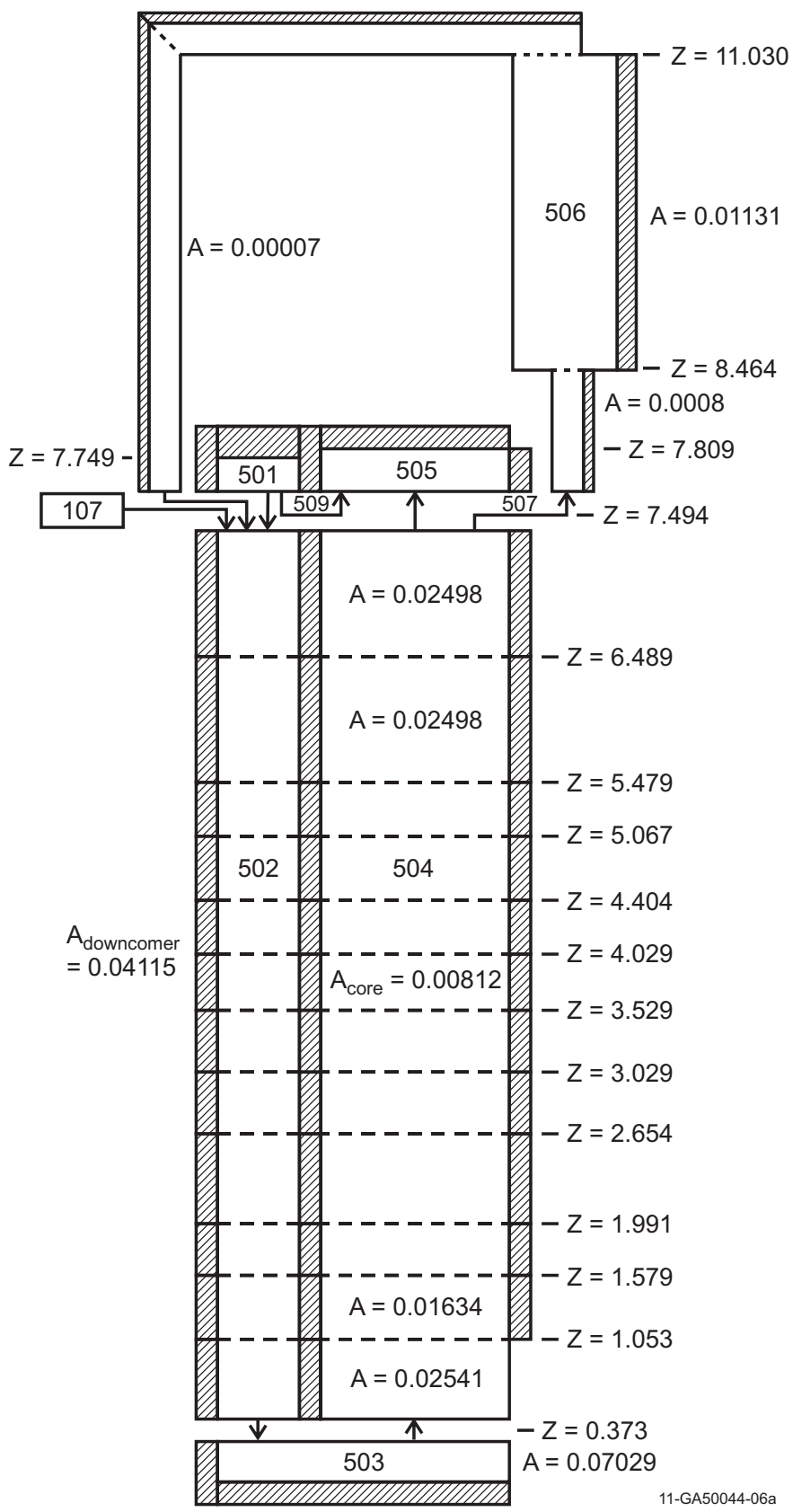

Figure 5.4-3. LOBI reactor vessel nodalization. 
RELAP5-3D/4.0.3

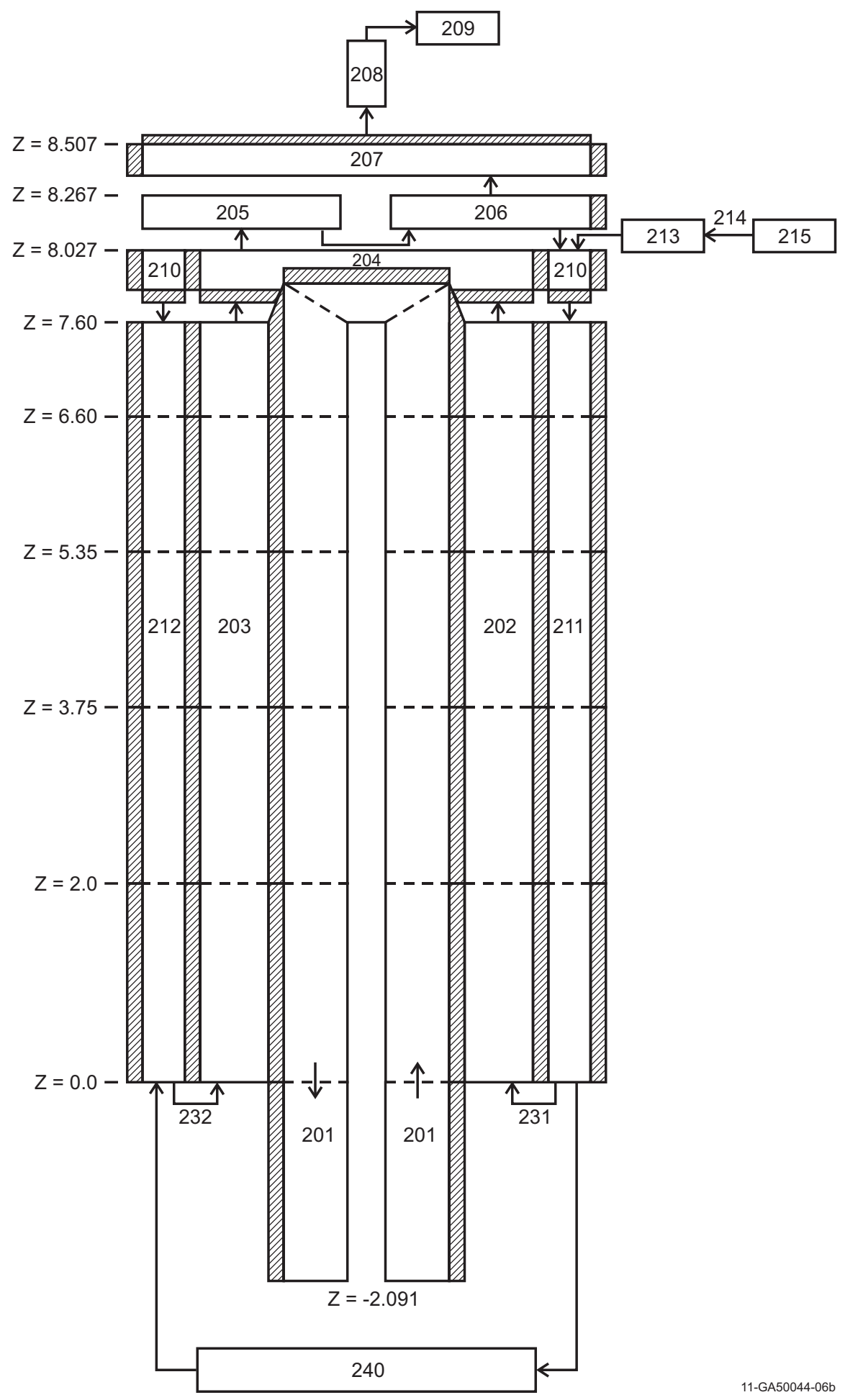

Figure 5.4-4. LOBI steam generator nodalization. 
RELAP5-3D/4.0.3

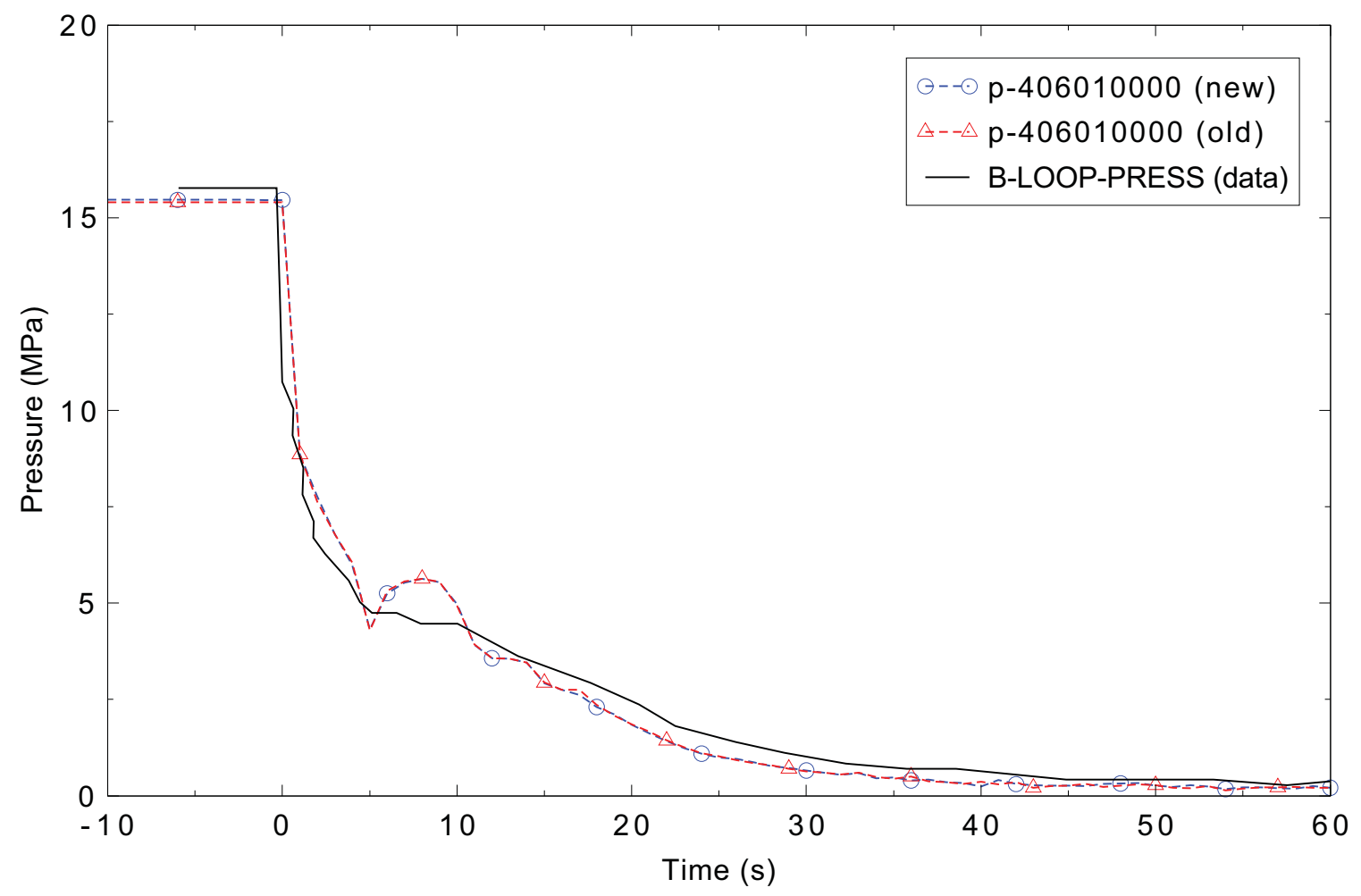

Figure 5.4-5. Broken loop pressure behavior for LOBI Test A1-04R. 


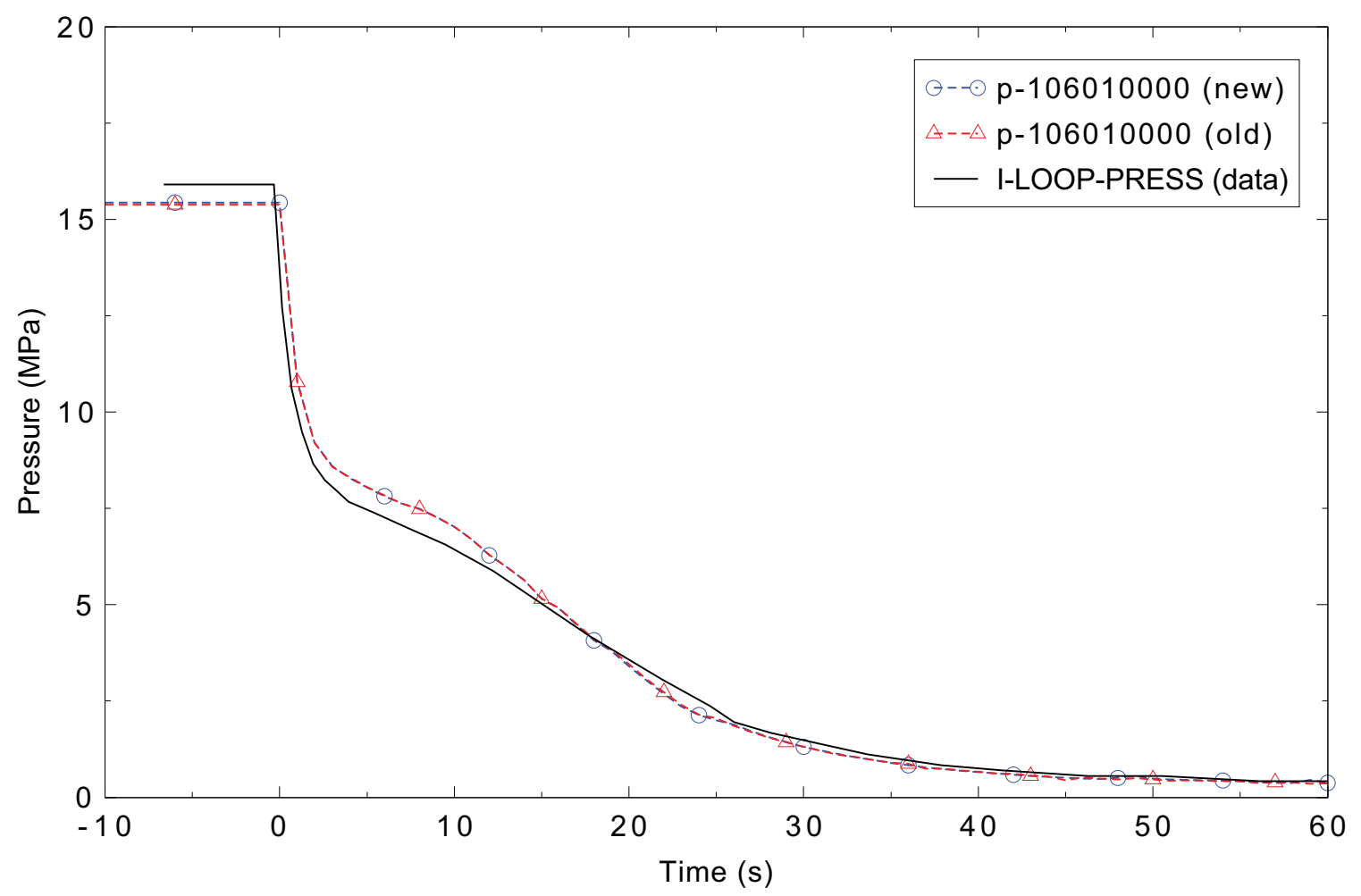

Figure 5.4-6. Intact loop pressure behavior for LOBI Test A1-04R.

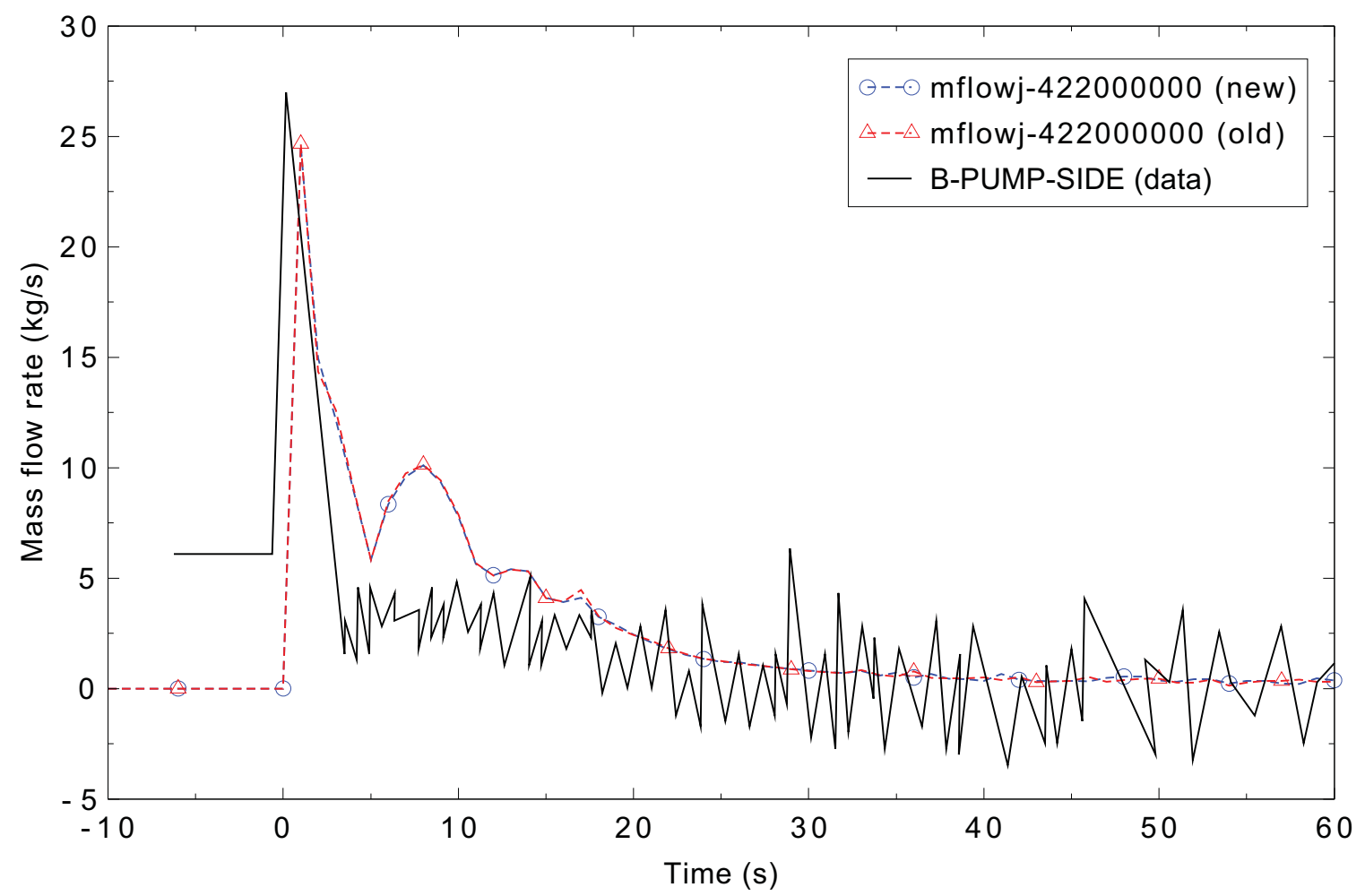

Figure 5.4-7. Broken loop mass flow rate (pump side) for LOBI Test A1-04R. 


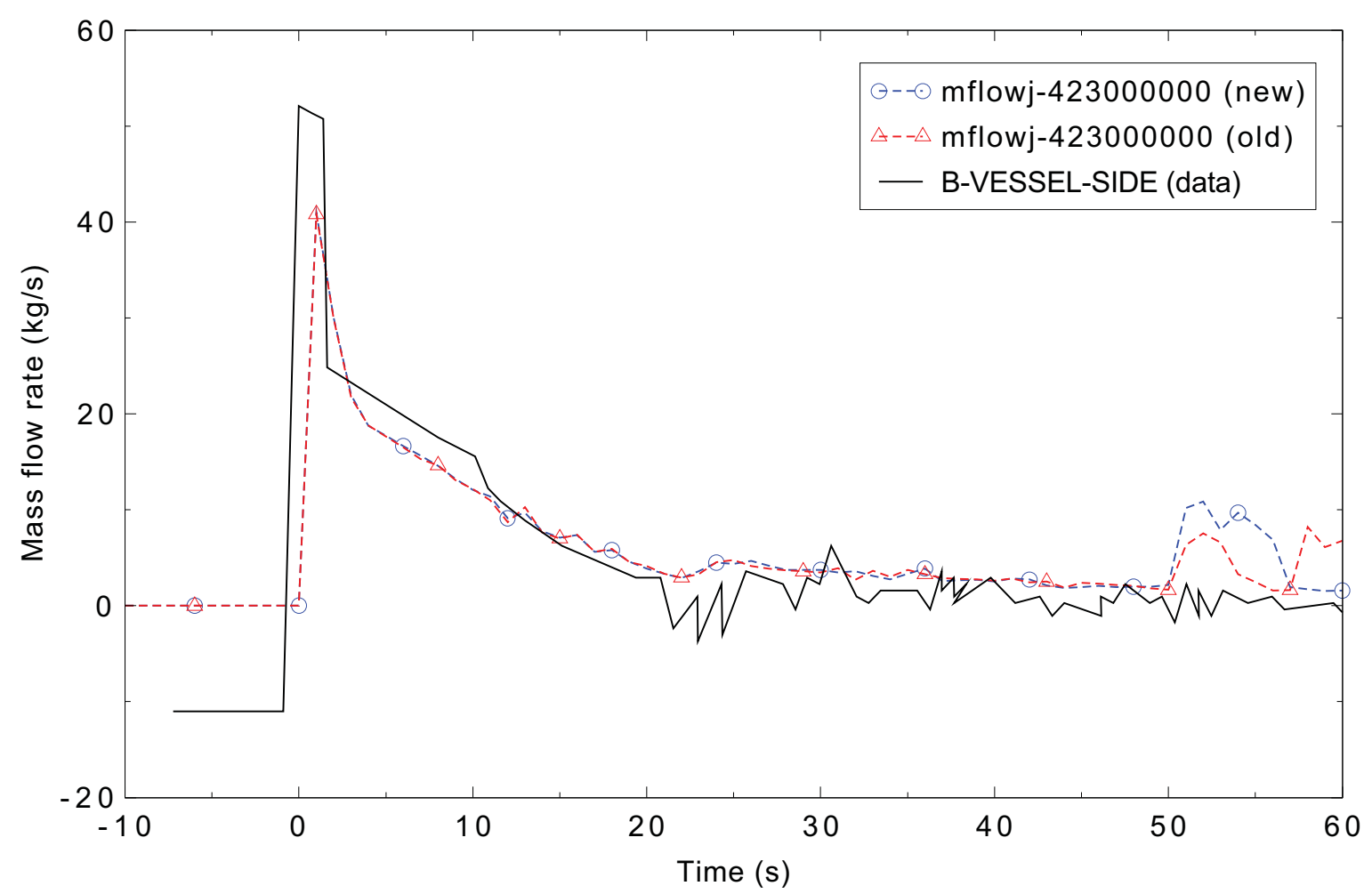

Figure 5.4-8. Broken loop mass flow rate (vessel side) for LOBI Test A1-04R.

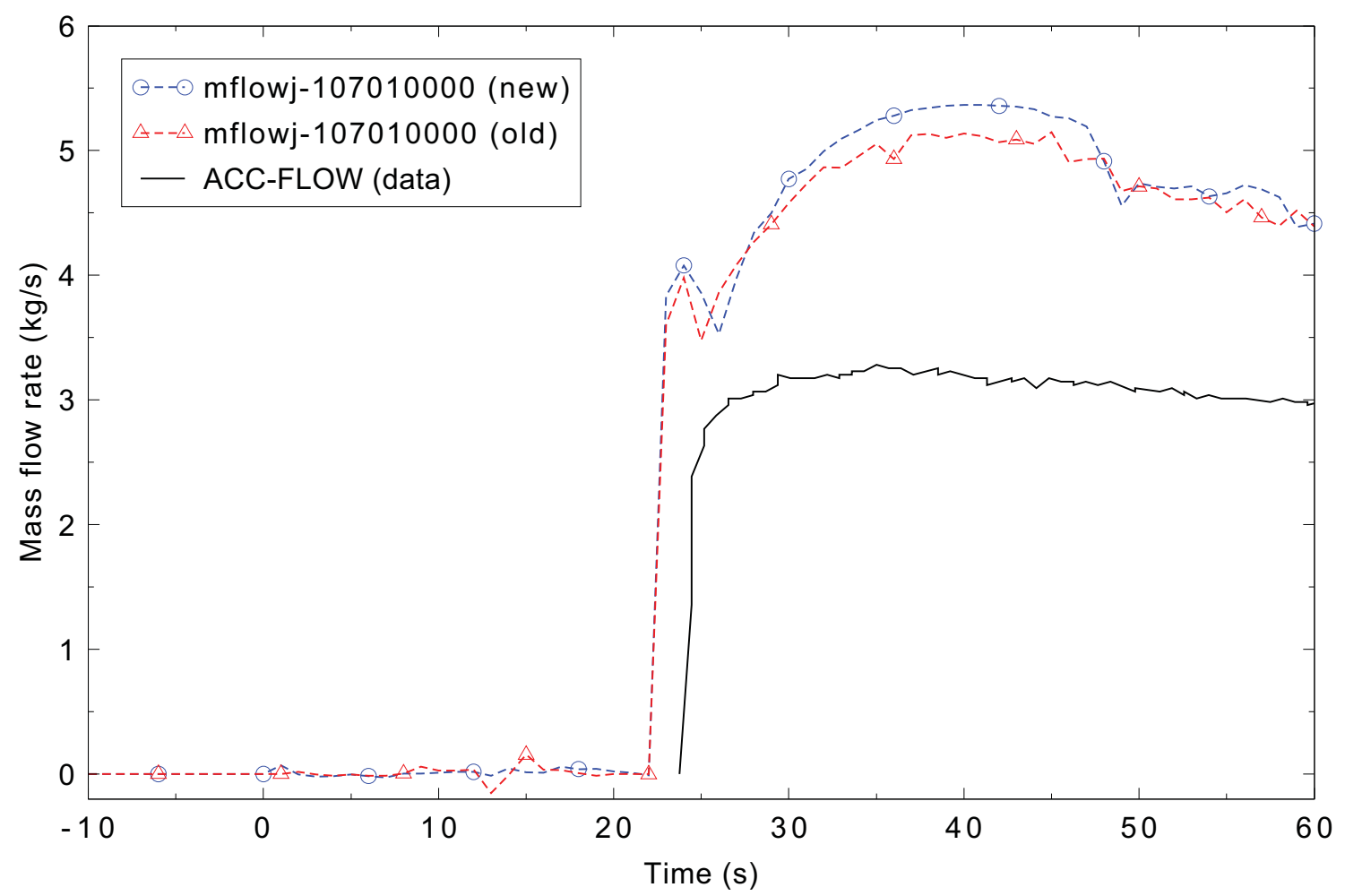

Figure 5.4-9. Accumulator discharge flow rate for LOBI Test A1-04R. 


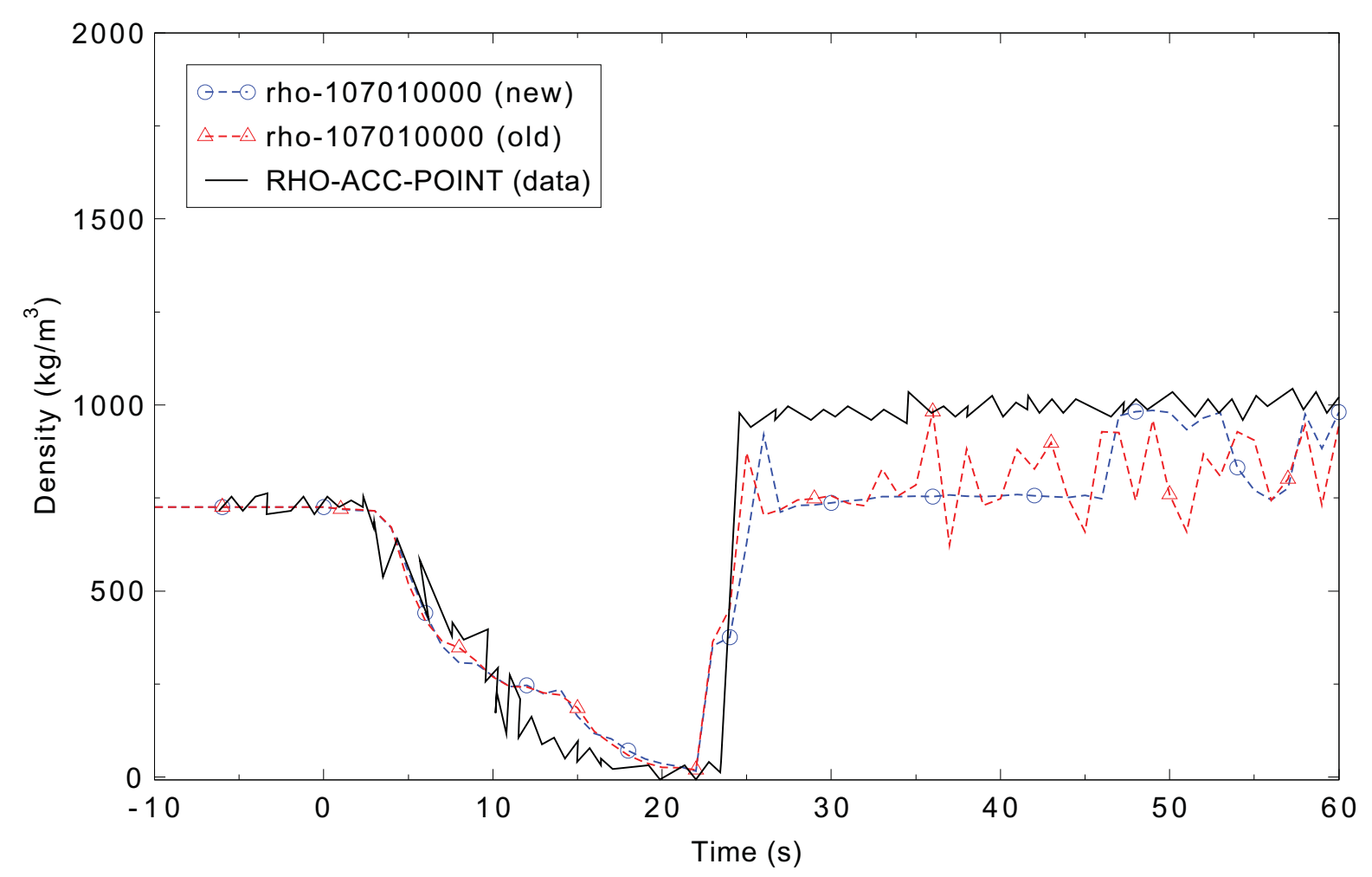

Figure 5.4-10. Fluid density at the accumulator injection point for LOBI Test A1-04R.

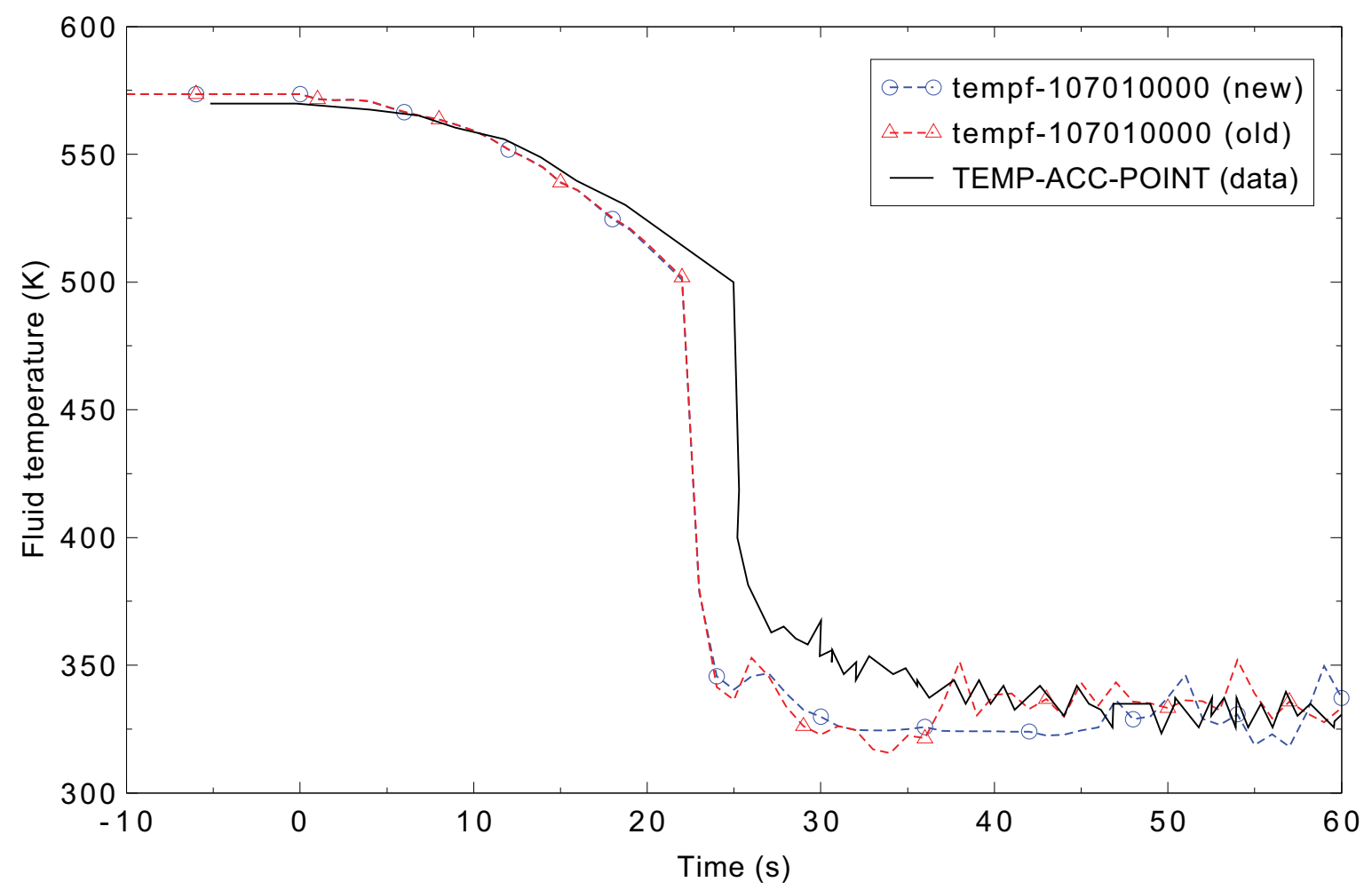

Figure 5.4-11. Measured and calculated fluid temperature at the accumulator injection point for LOBI Test A1-04R. 


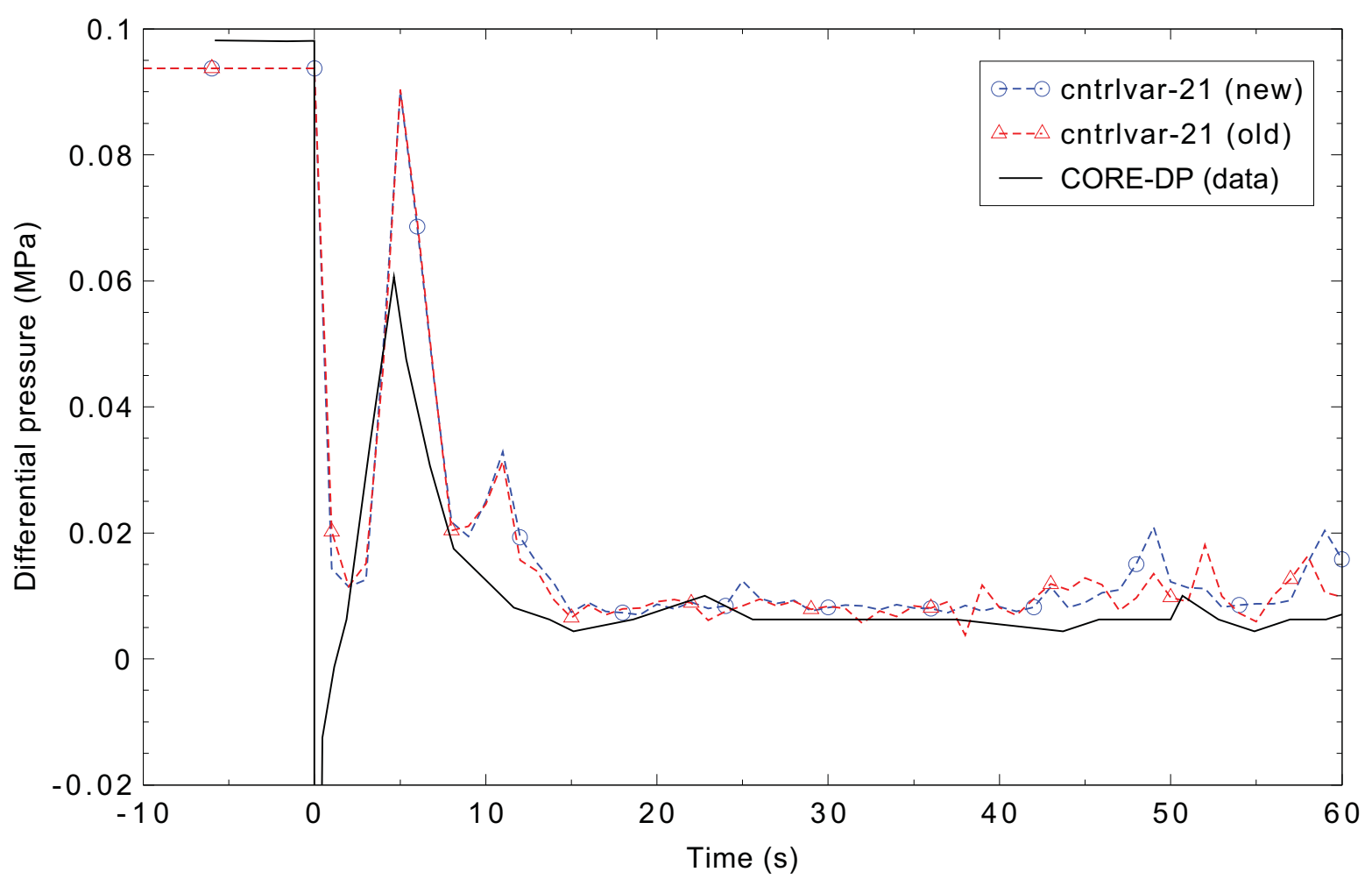

Figure 5.4-12. Measured and calculated core differential pressure for LOBI Test A1-04R.

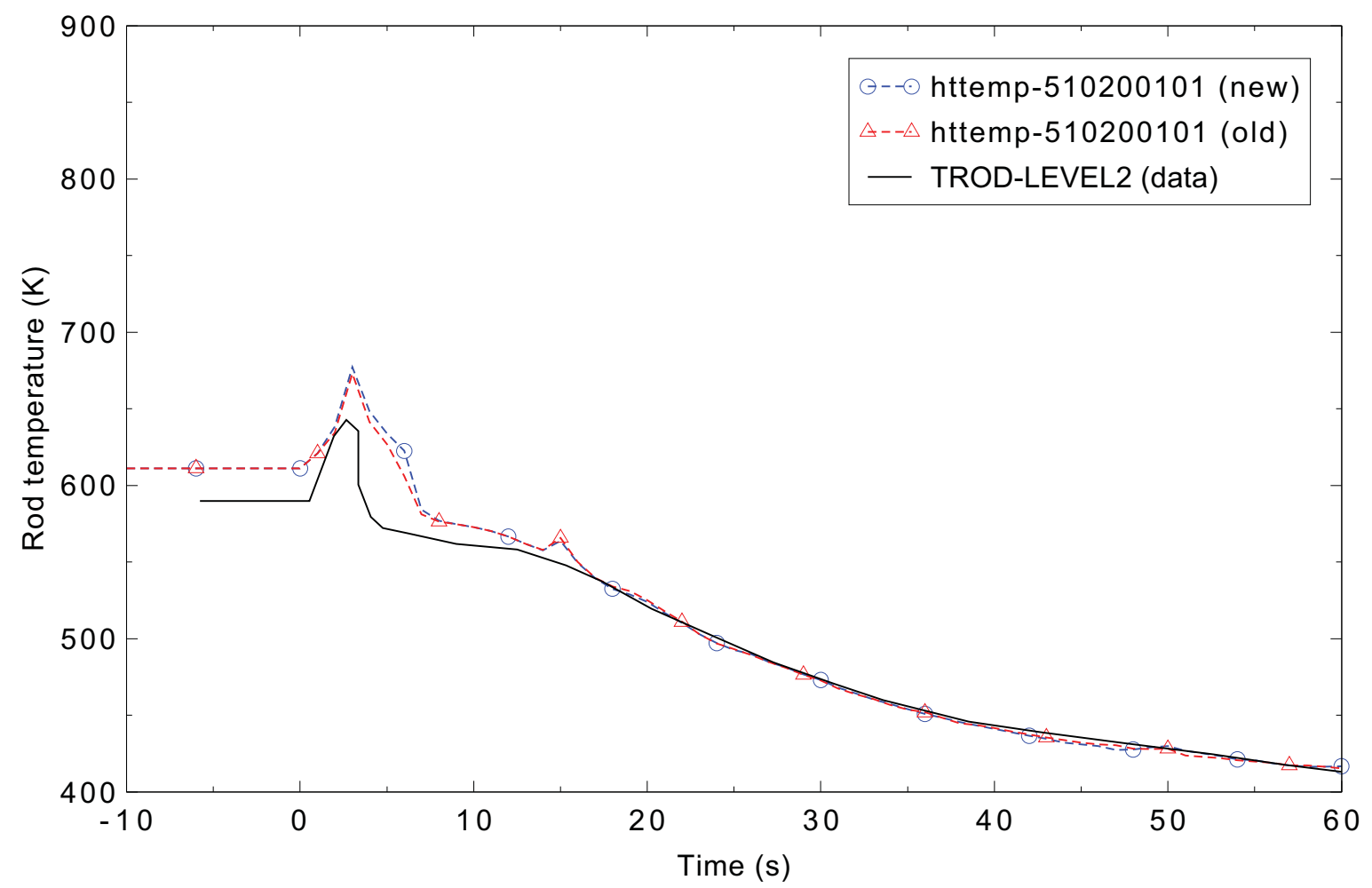

Figure 5.4-13. Measured and calculated lower core heater rod temperature (Level 2) for LOBI Test A1-04R. 


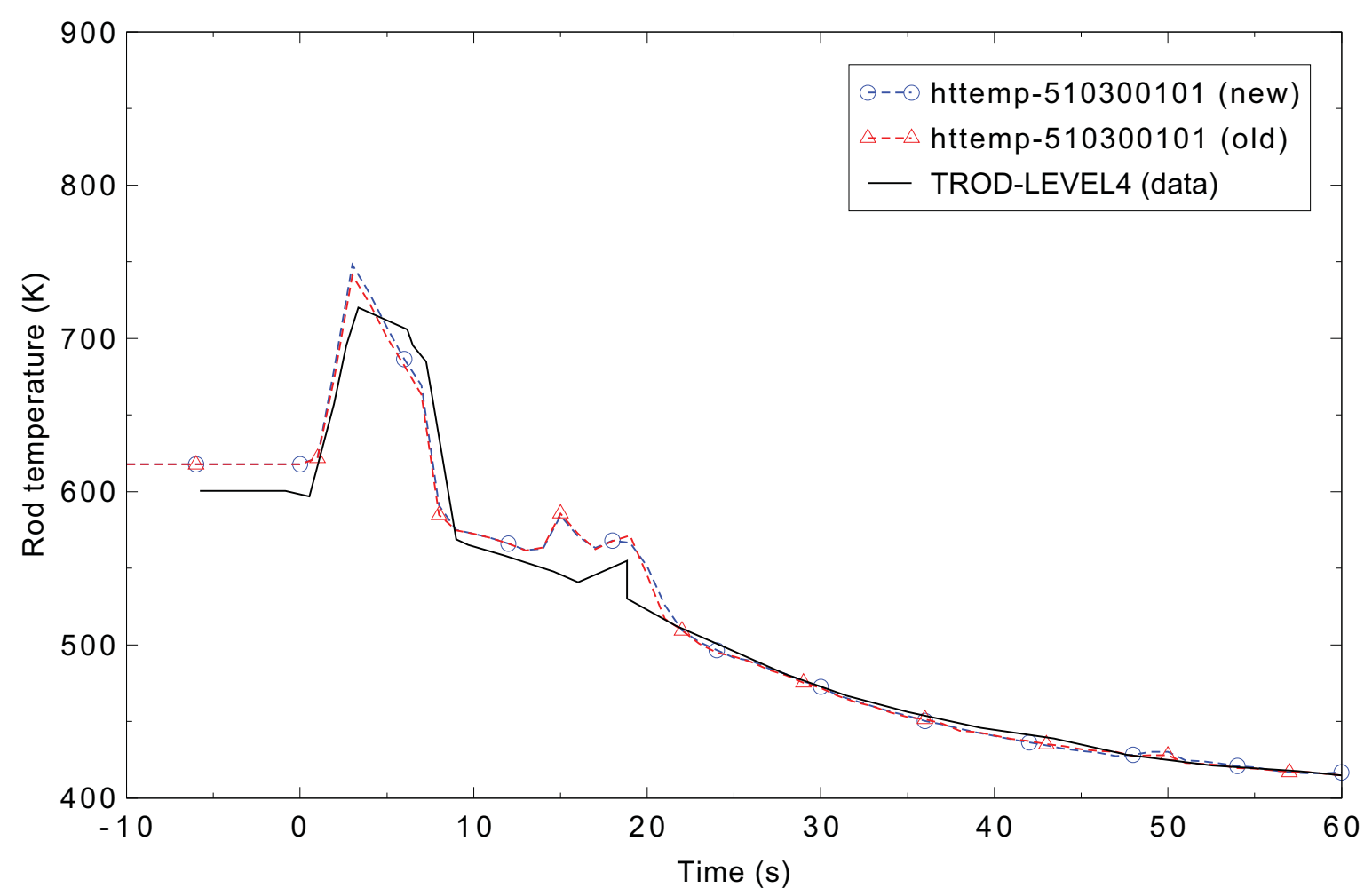

Figure 5.4-14. Measured and calculated lower core heater rod temperature (Level 4) for LOBI Test A1-04R.

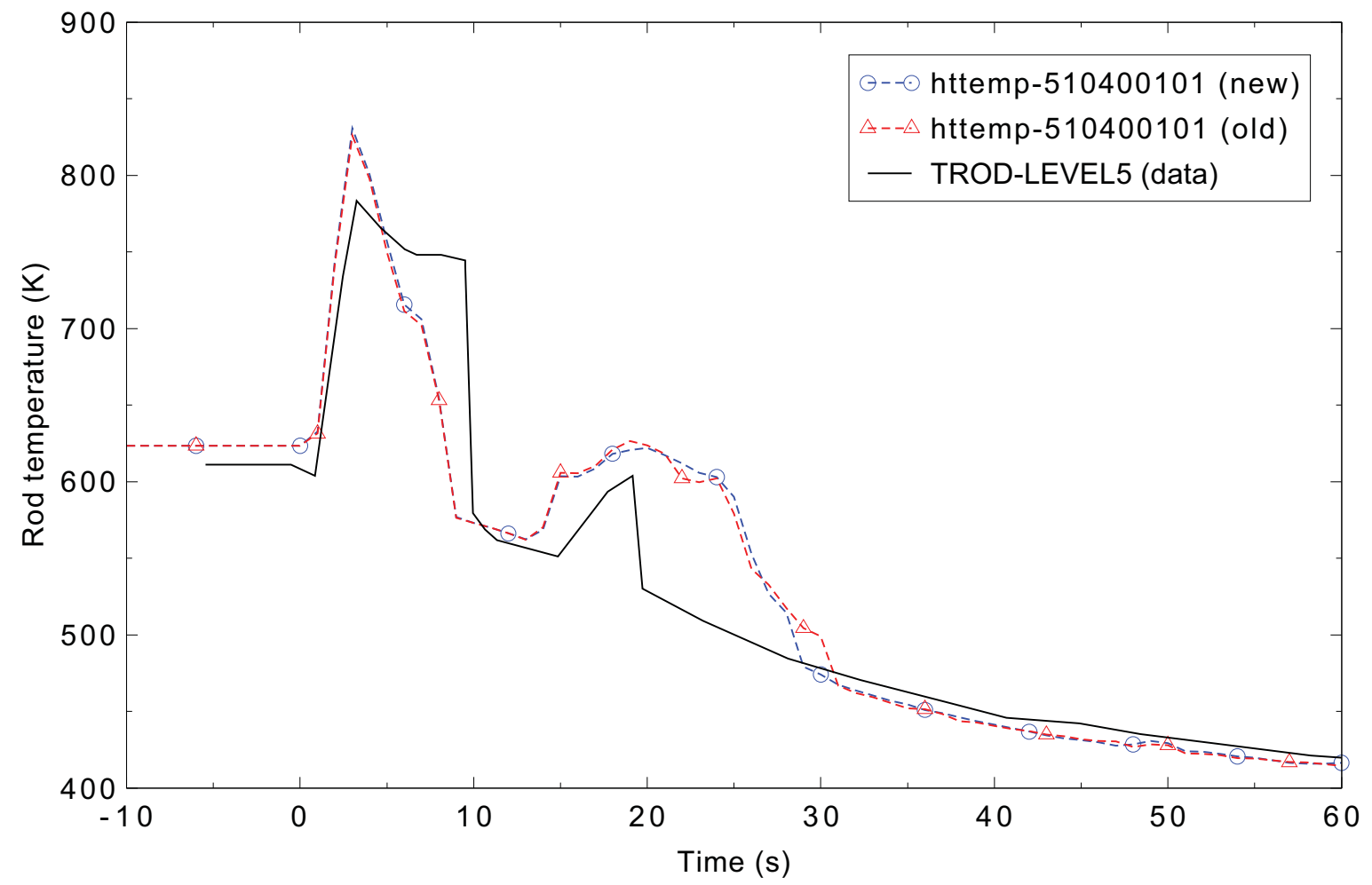

Figure 5.4-15. Measured and calculated mid-core heater rod temperature (Level 5) for LOBI Test A1-04R. 


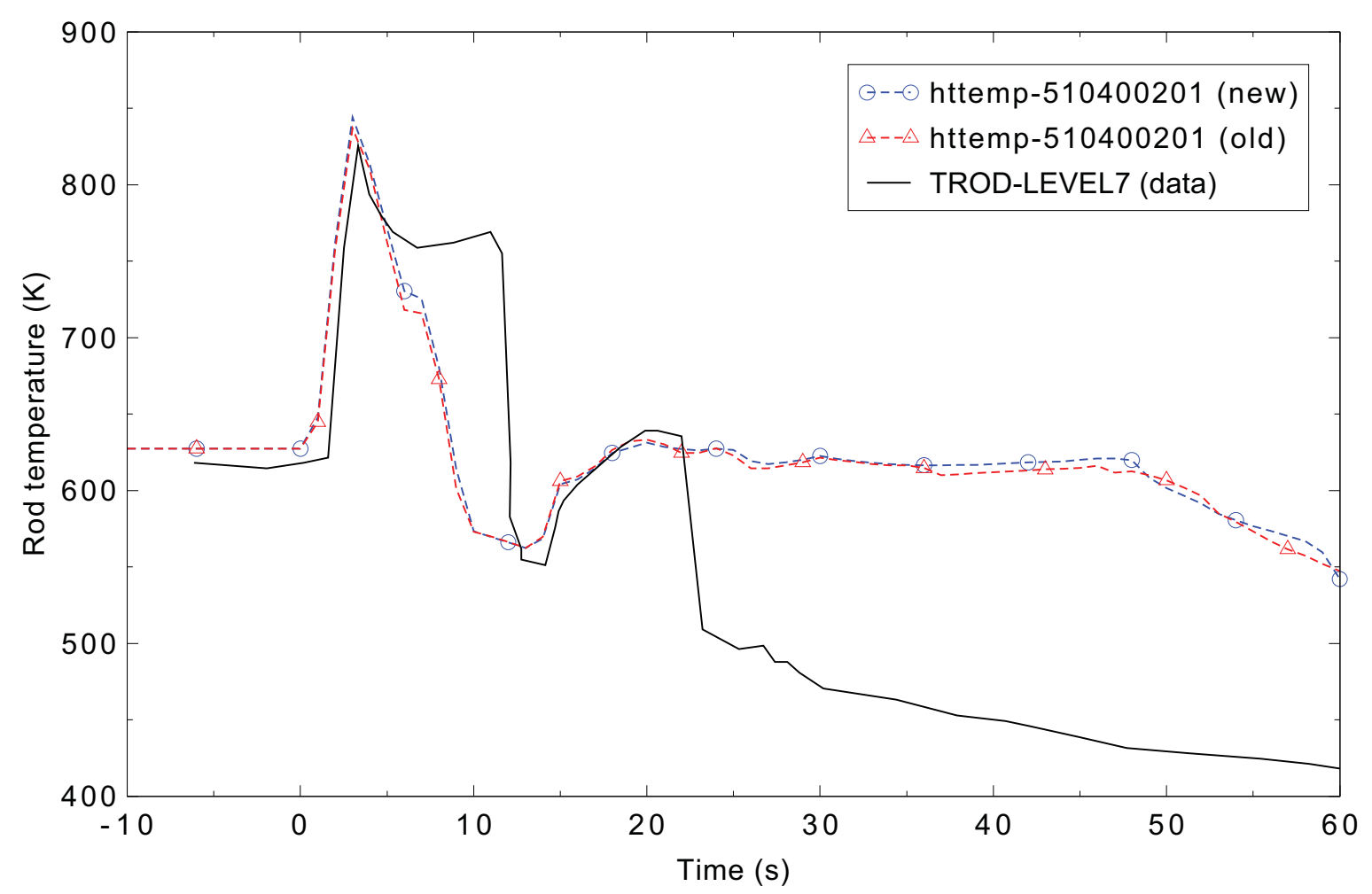

Figure 5.4-16. Measured and calculated mid-core heater rod temperature (Level 6) for LOBI Test A1-04R.

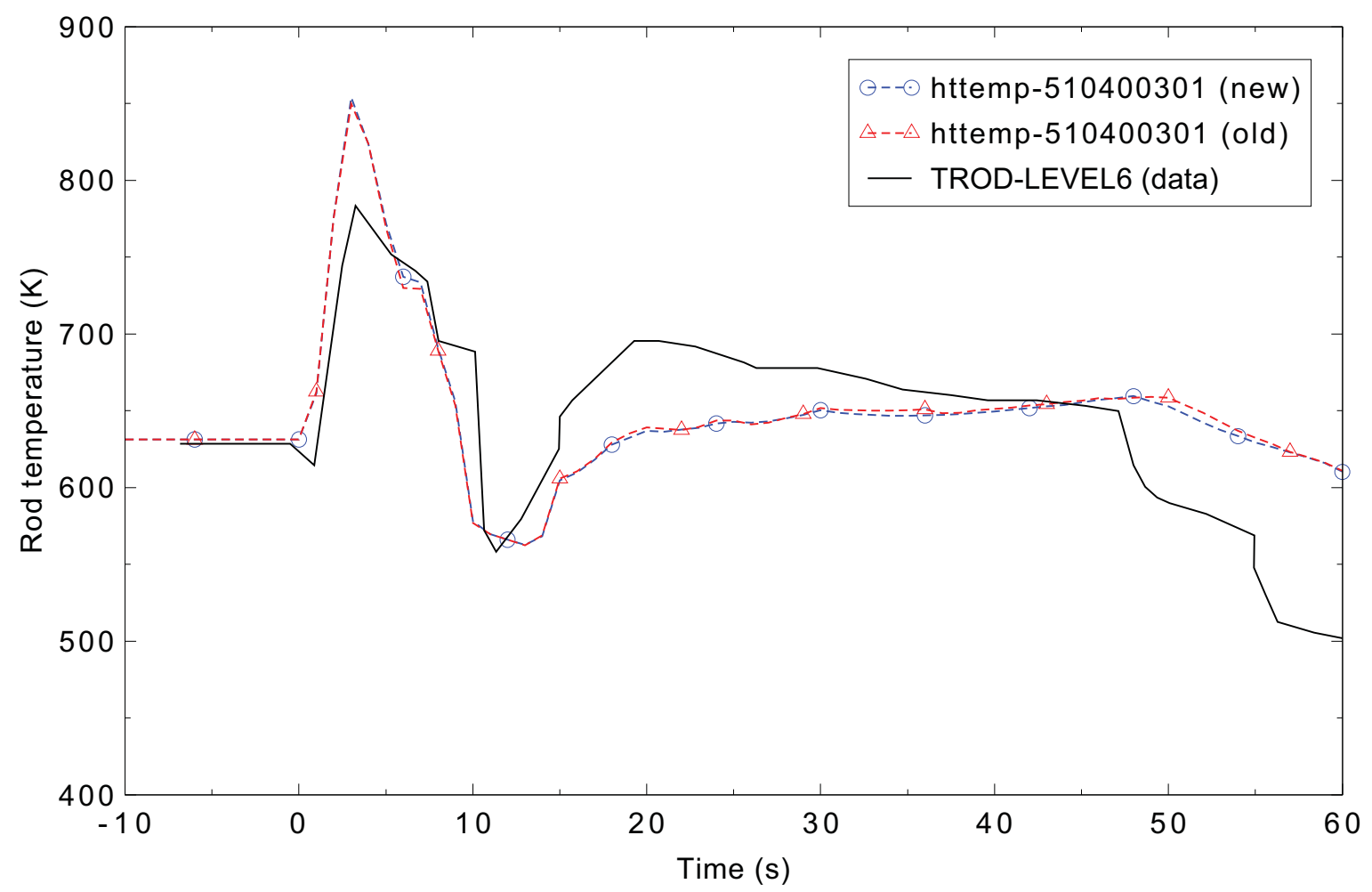

Figure 5.4-17. Measured and calculated mid-core heater rod temperature (Level 7) for LOBI Test A1-04R. 


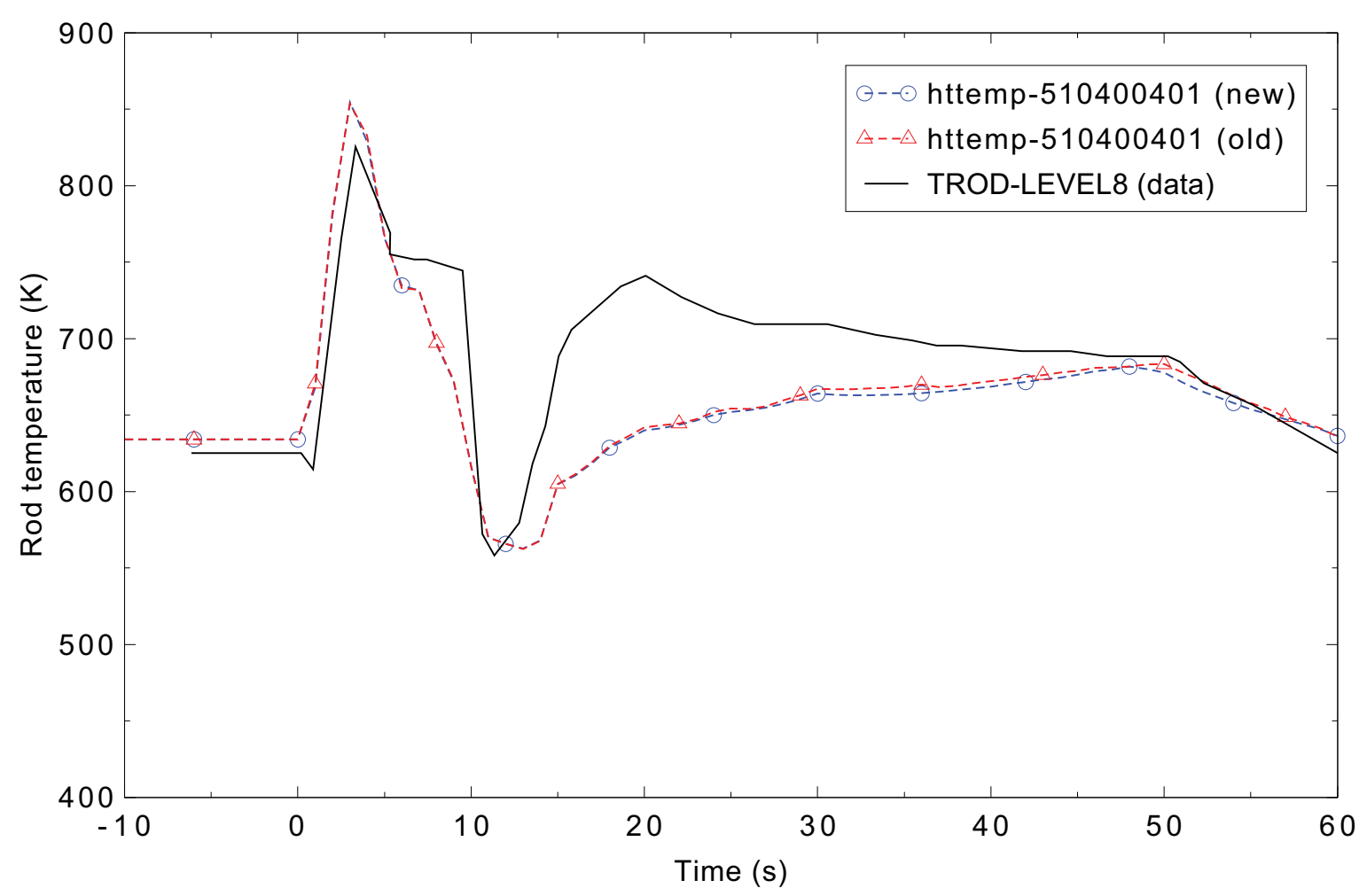

Figure 5.4-18. Measured and calculated mid-core heater temperature (Level 8) for LOBI Test A1-04R.

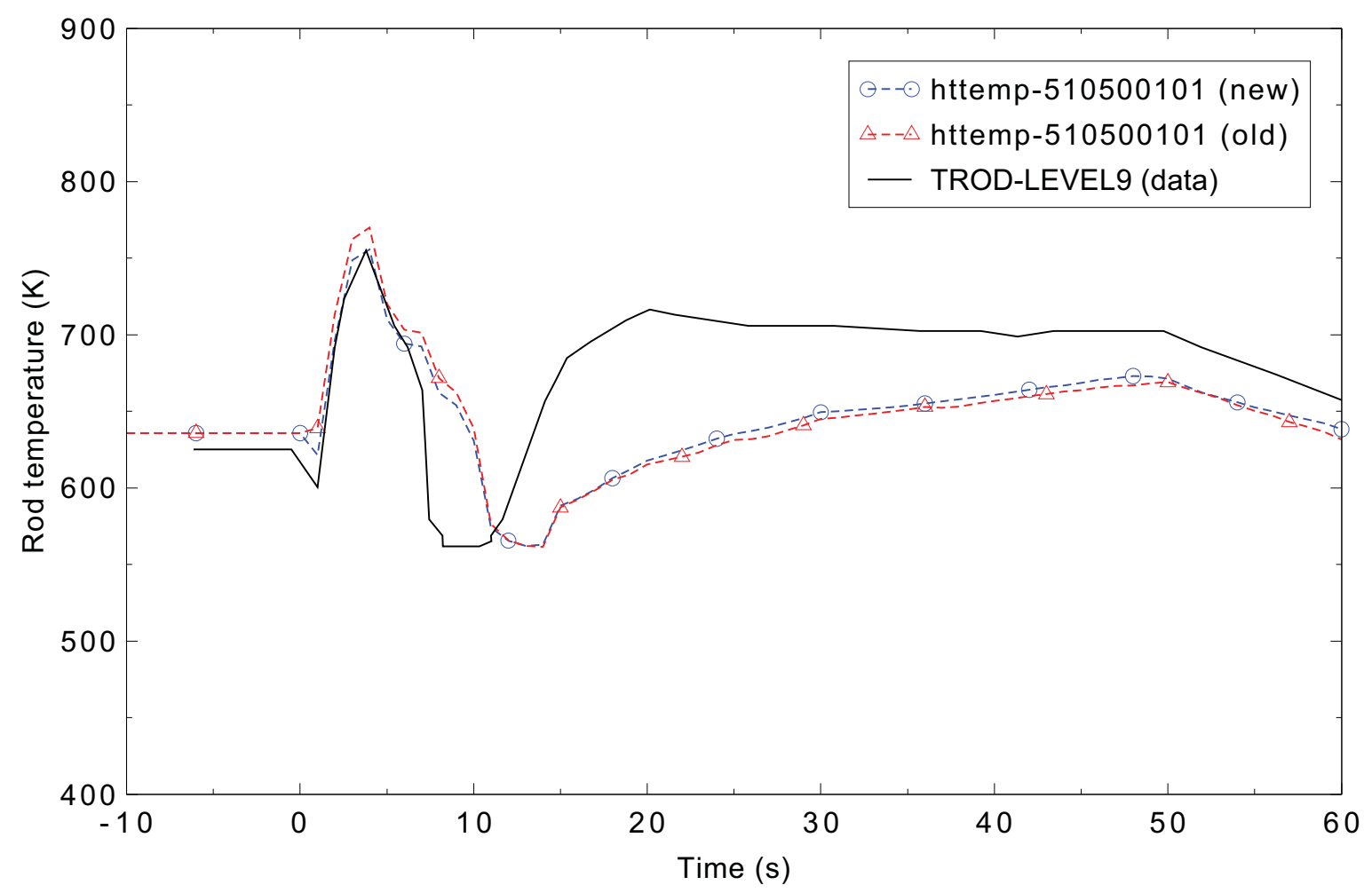

Figure 5.4-19. Measured and calculated upper core heater rod temperature (Level 9) for LOBI Test A1-04R. 
RELAP5-3D/4.0.3

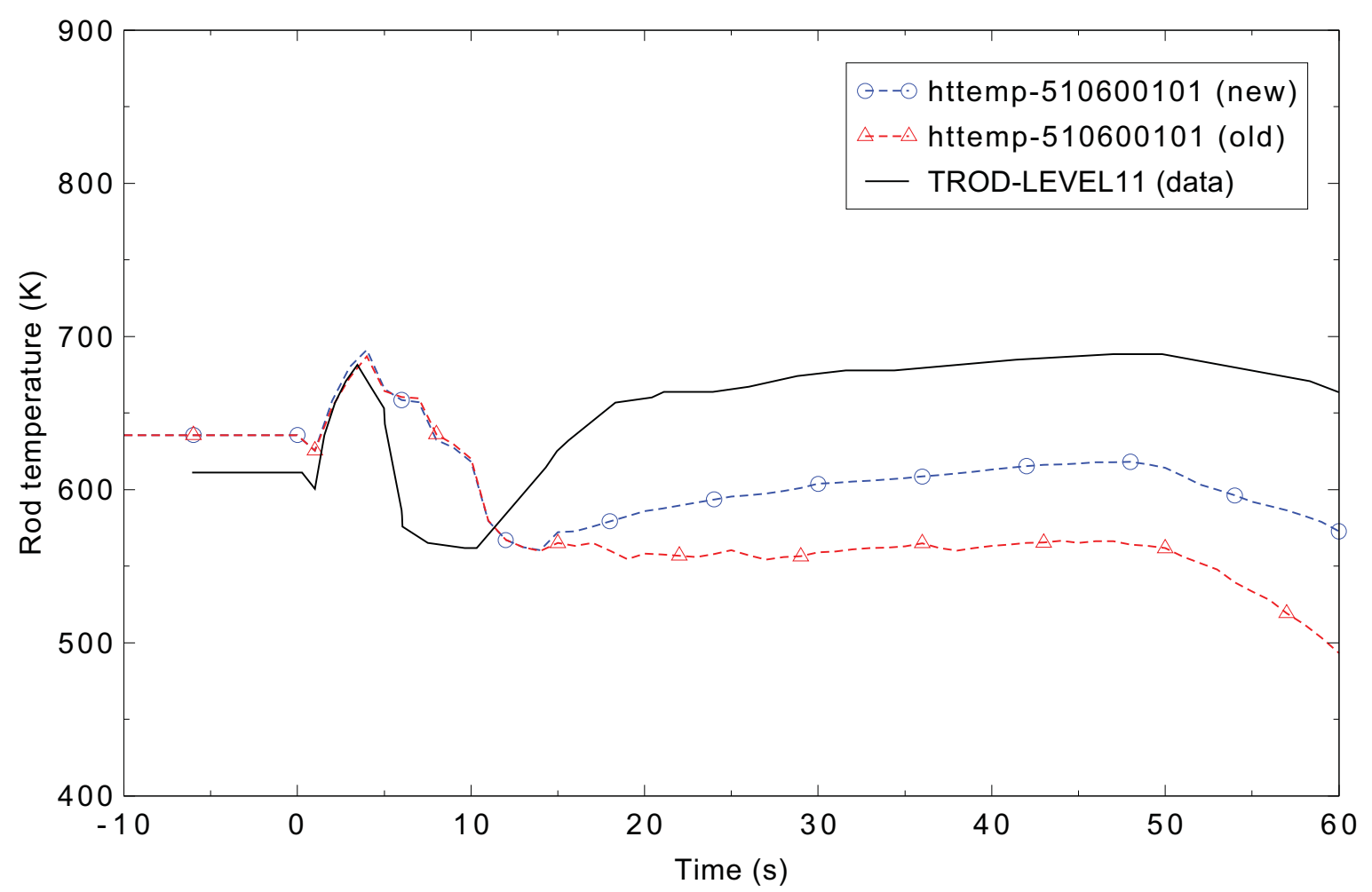

Figure 5.4-20. Measured and calculated upper core heater rod temperature (Level 11) for LOBI Test A1-04R. 


\subsection{LOFT Experiment L2-5 (1-D)}

Figures comparing simulations using two code versions are presented. Diagrams are included so that the figure numbering is the same as that in Volume III of the RELAP5-3D code manual. Significant differences were observed in Figures 5.5-21, 27, 28, 29, and 30; noticeable differences were observed in Figures 5.5-4, 5, 6, 7, 8, 9, 10, 11, 12, 13, 14, 17, 18, 19, 20, 22, 23, 24, 25, 26, 31, and 32.

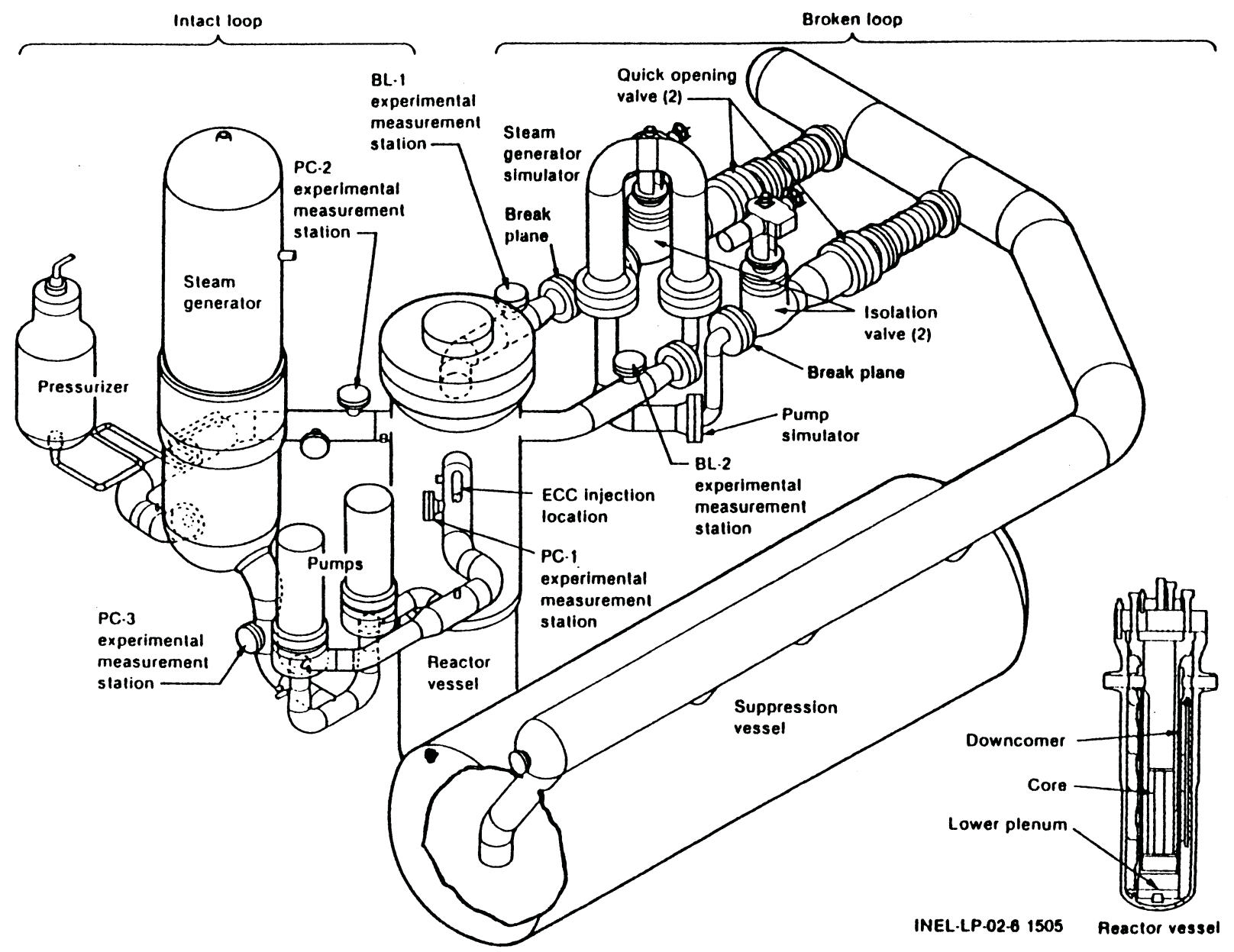

Figure 5.5-1. Schematic of the LOFT facility. 


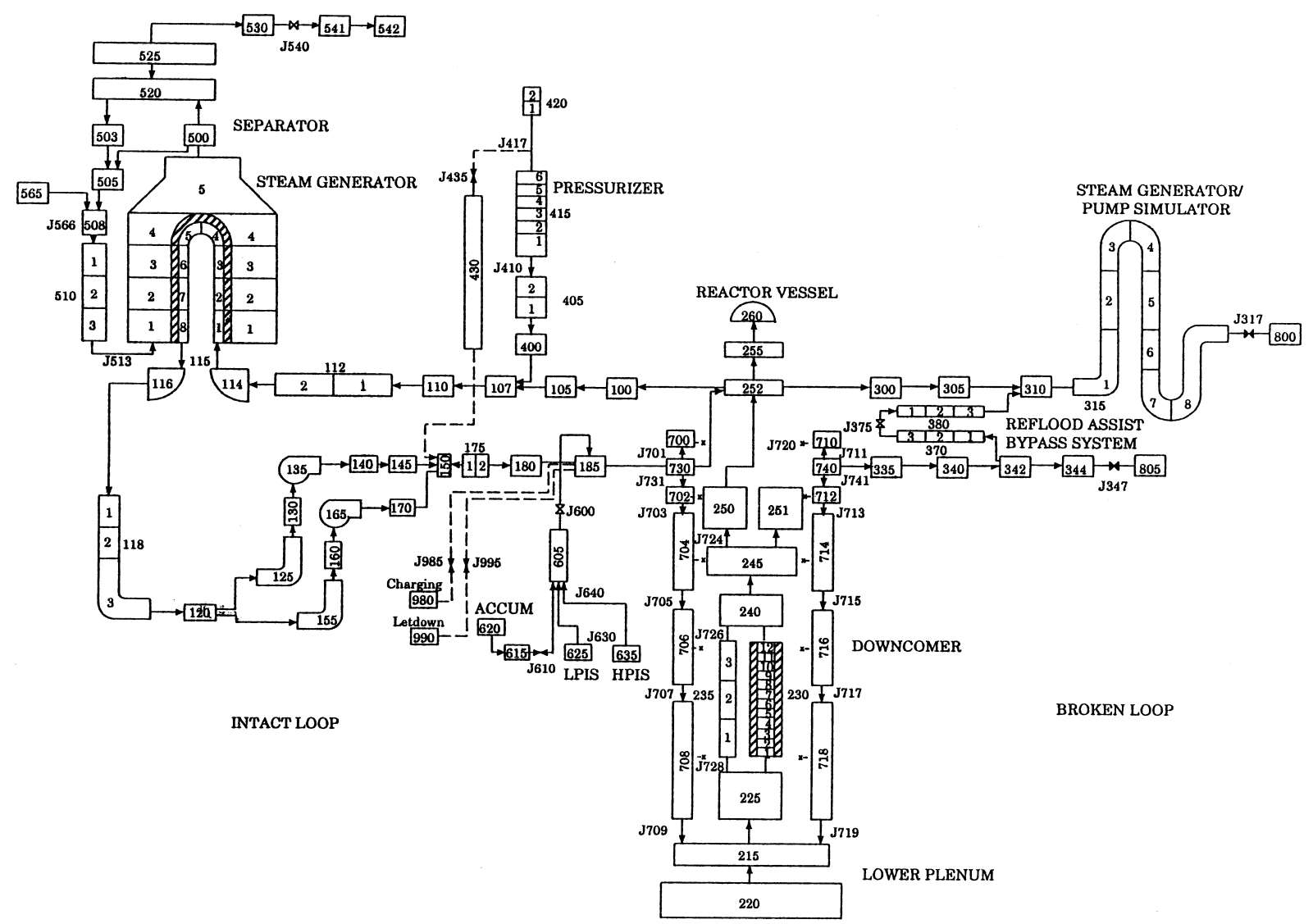

Figure 5.5-2. RELAP5-3D nodalization for the LOFT facility Experiment L2-5 (1-D vessel). 


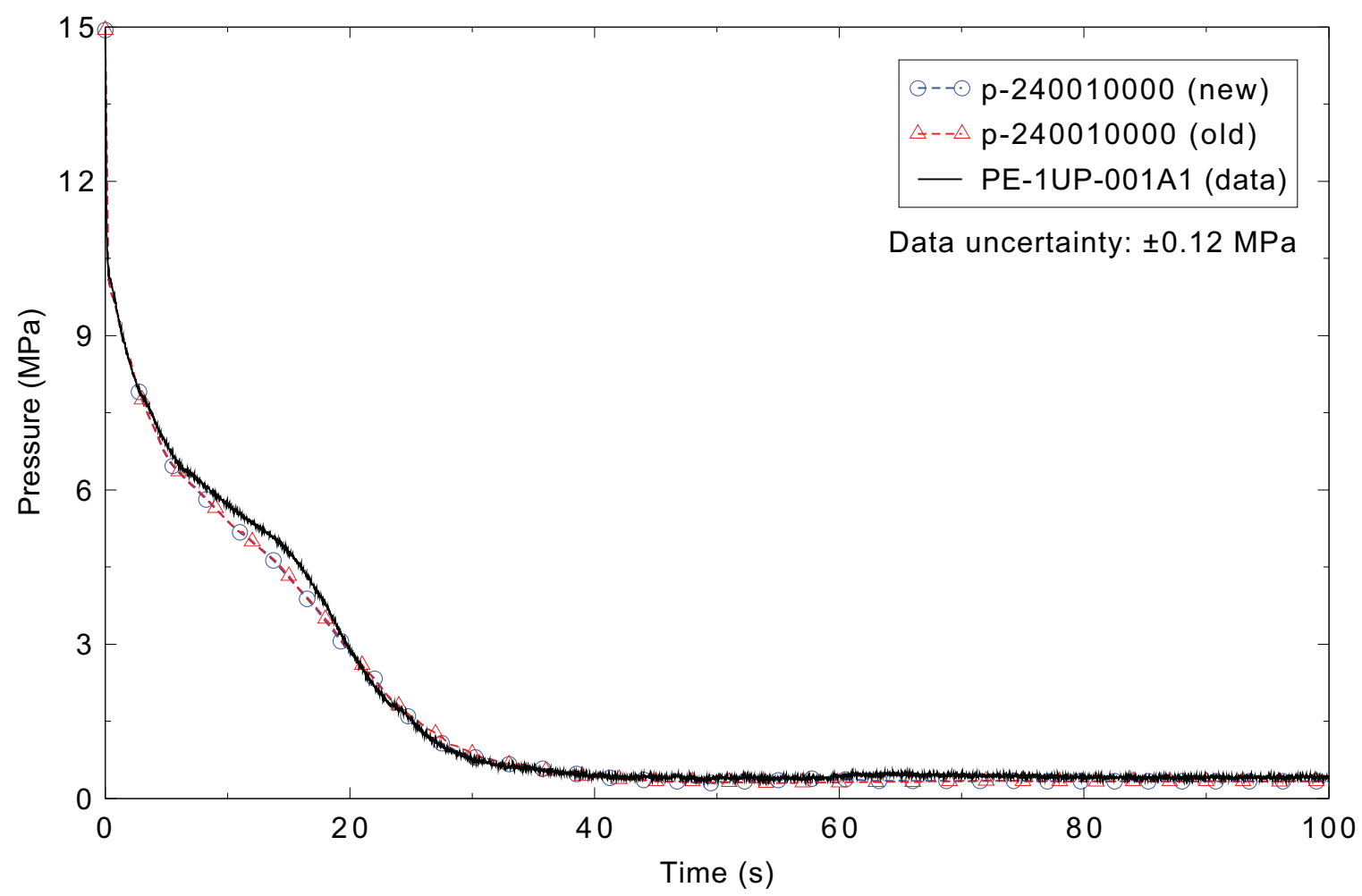

Figure 5.5-3. Measured and calculated reactor vessel upper plenum pressure for the LOFT L2-5 1-D case.

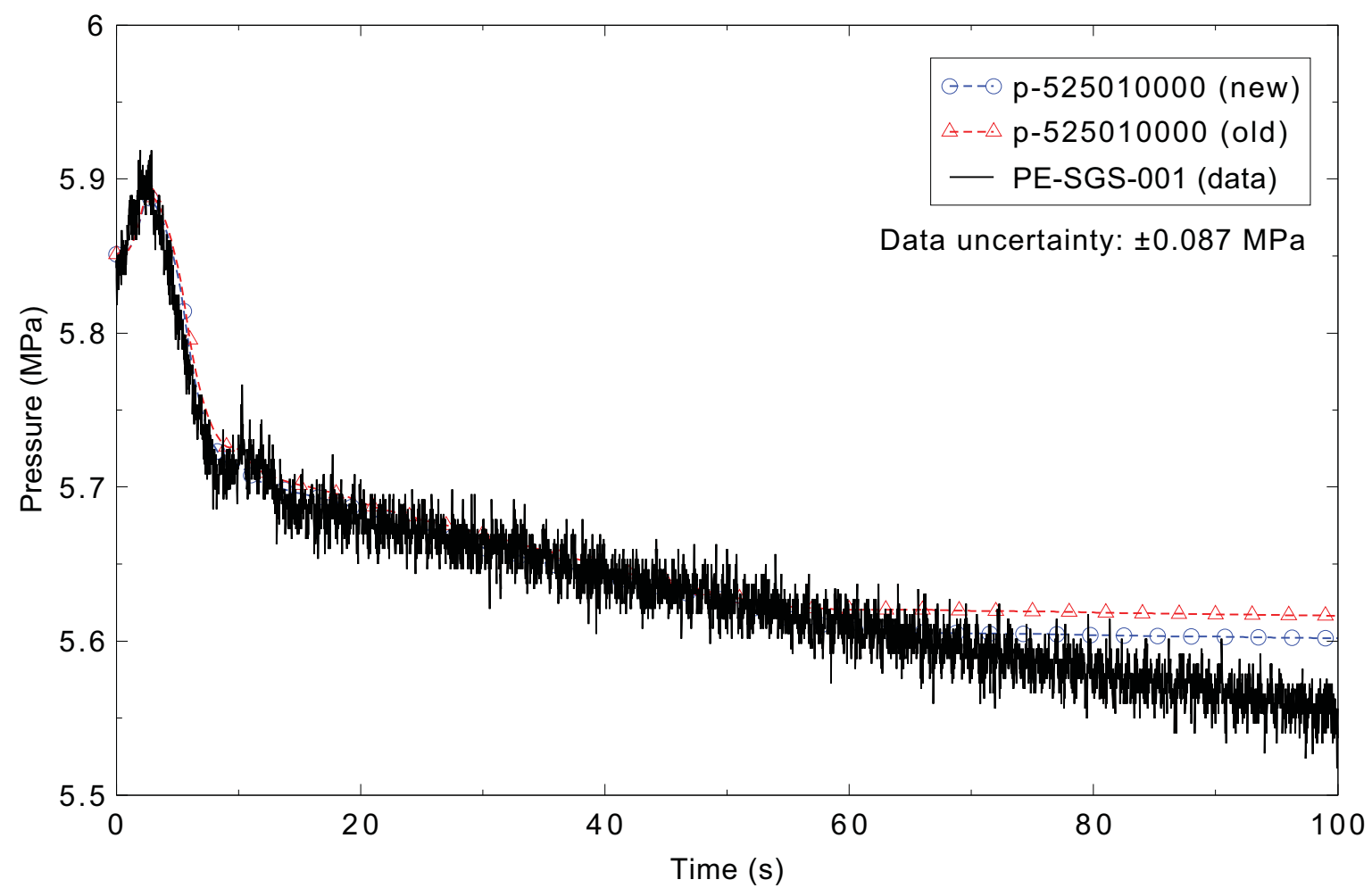

Figure 5.5-4. Measured and calculated steam generator pressure for the LOFT L2-5 1-D case. 


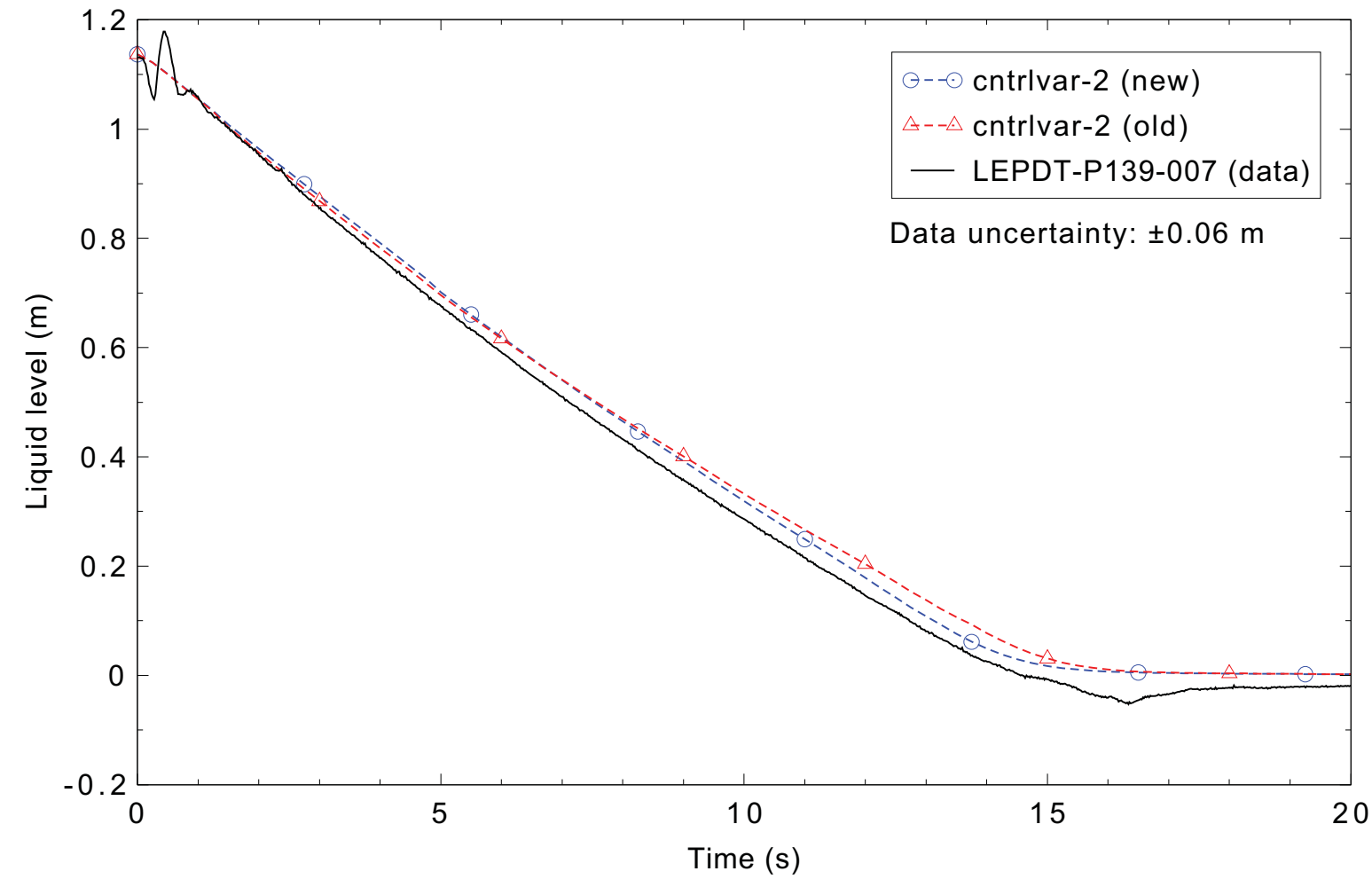

Figure 5.5-5. Measured and calculated pressurizer liquid level for the LOFT L2-5 1-D case.

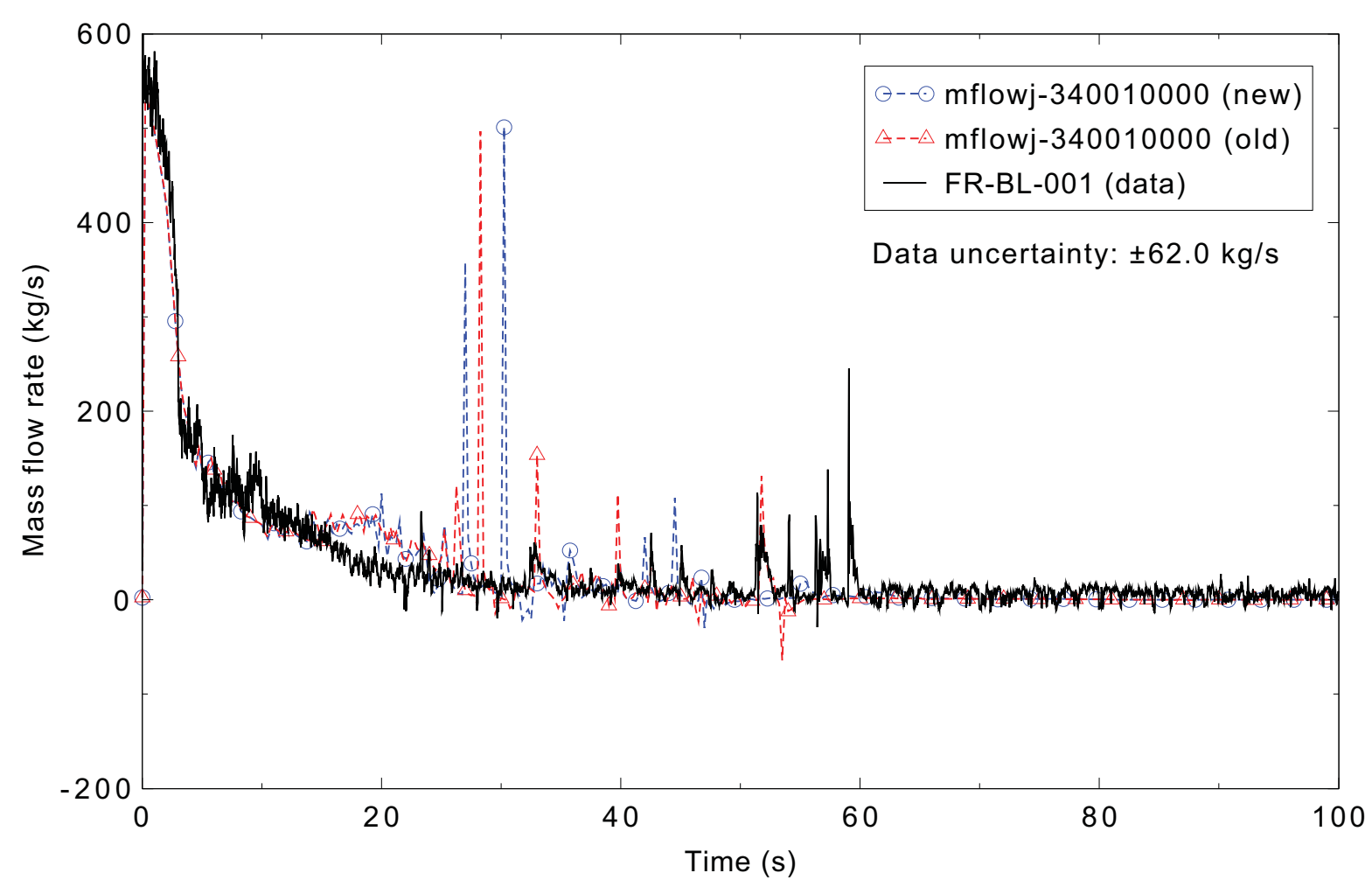

Figure 5.5-6. Measured and calculated mass flow rate in the broken loop cold leg for the LOFT L2-5 1-D case. 


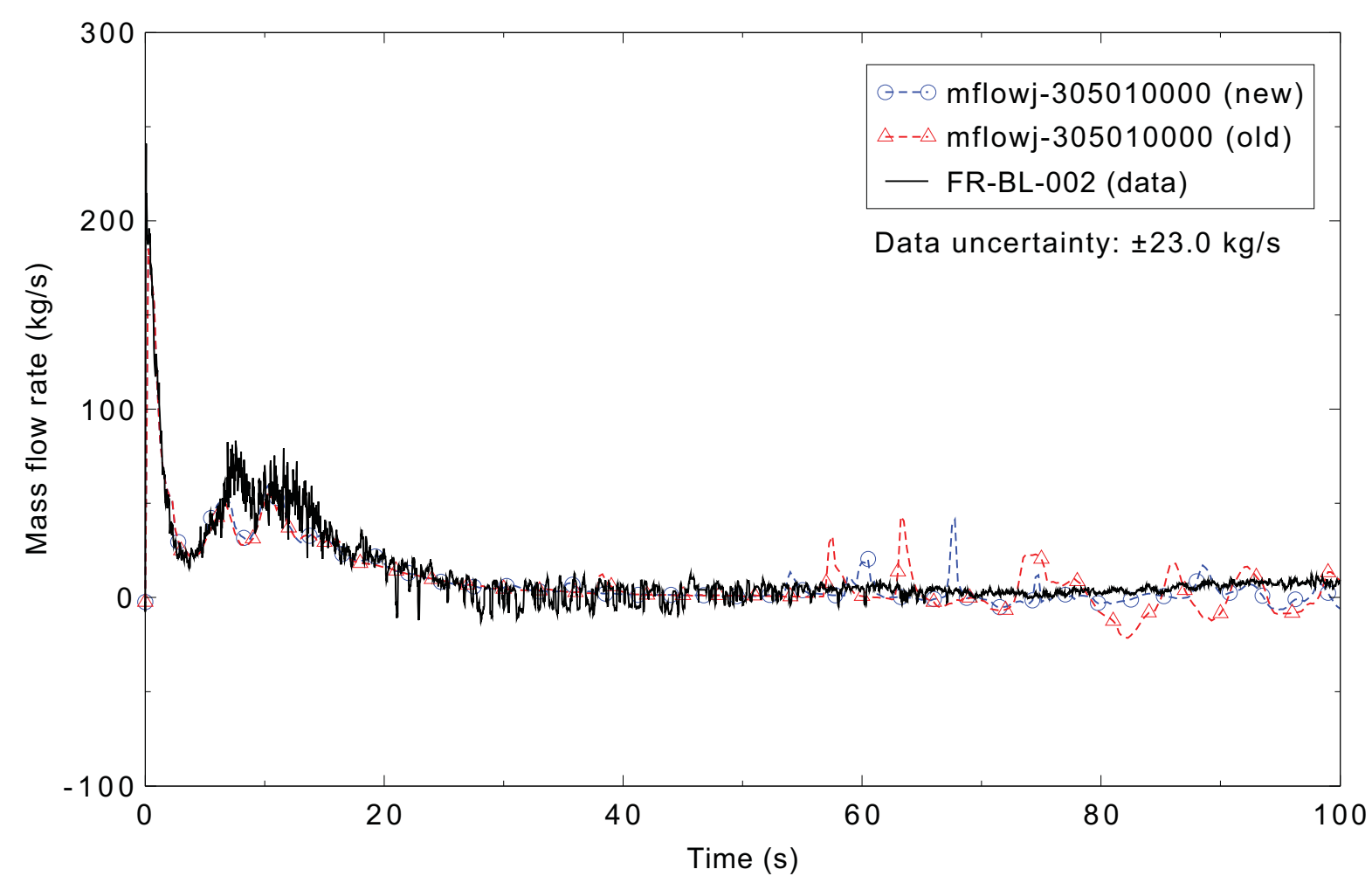

Figure 5.5-7. Measured and calculated mass flow rate in the broken loop hot leg for the LOFT L2-5 1-D case.

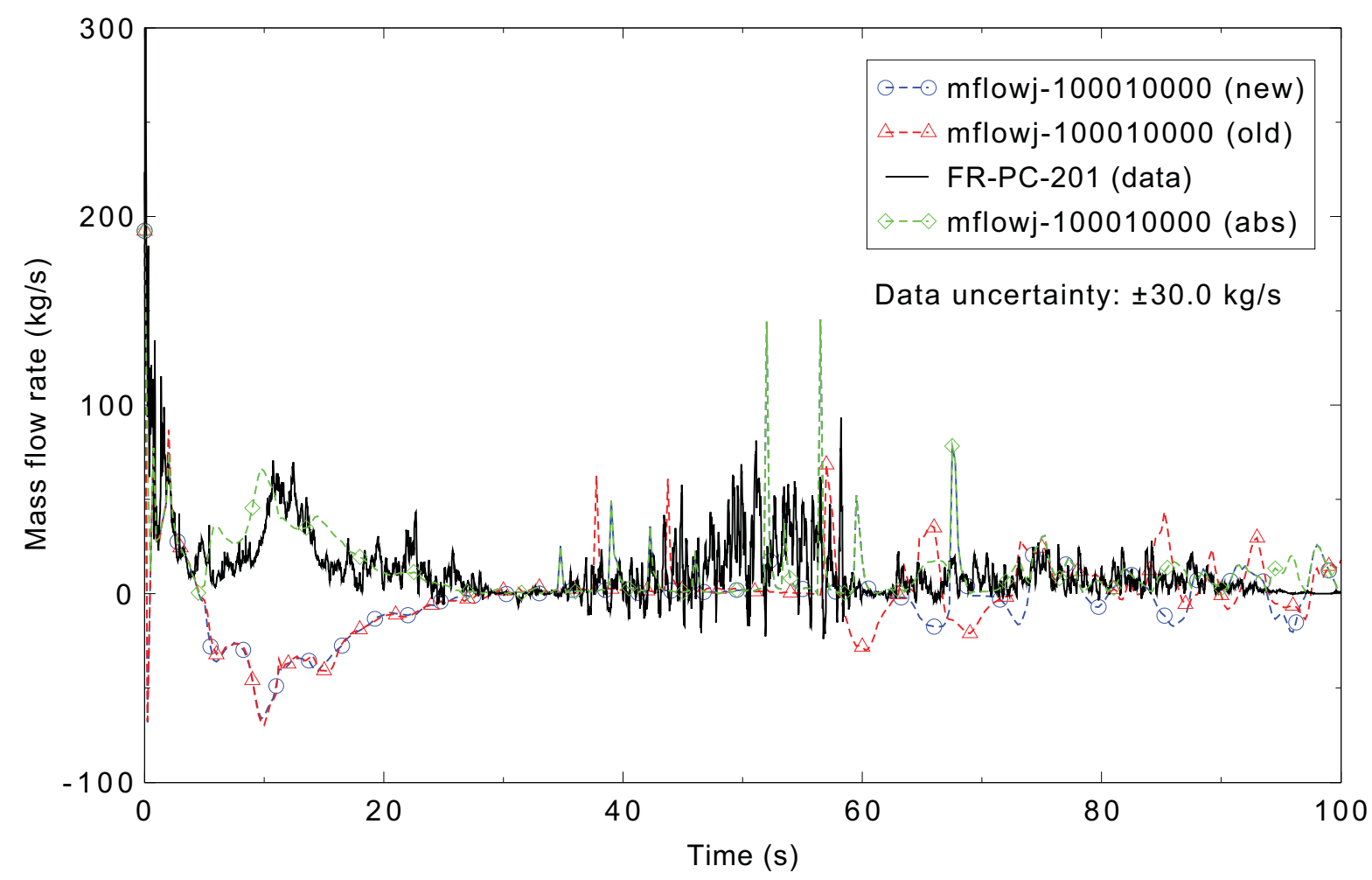

Figure 5.5-8. Measured and calculated mass flow rate in the intact loop hot leg for the LOFT L2-5 1-D case. 


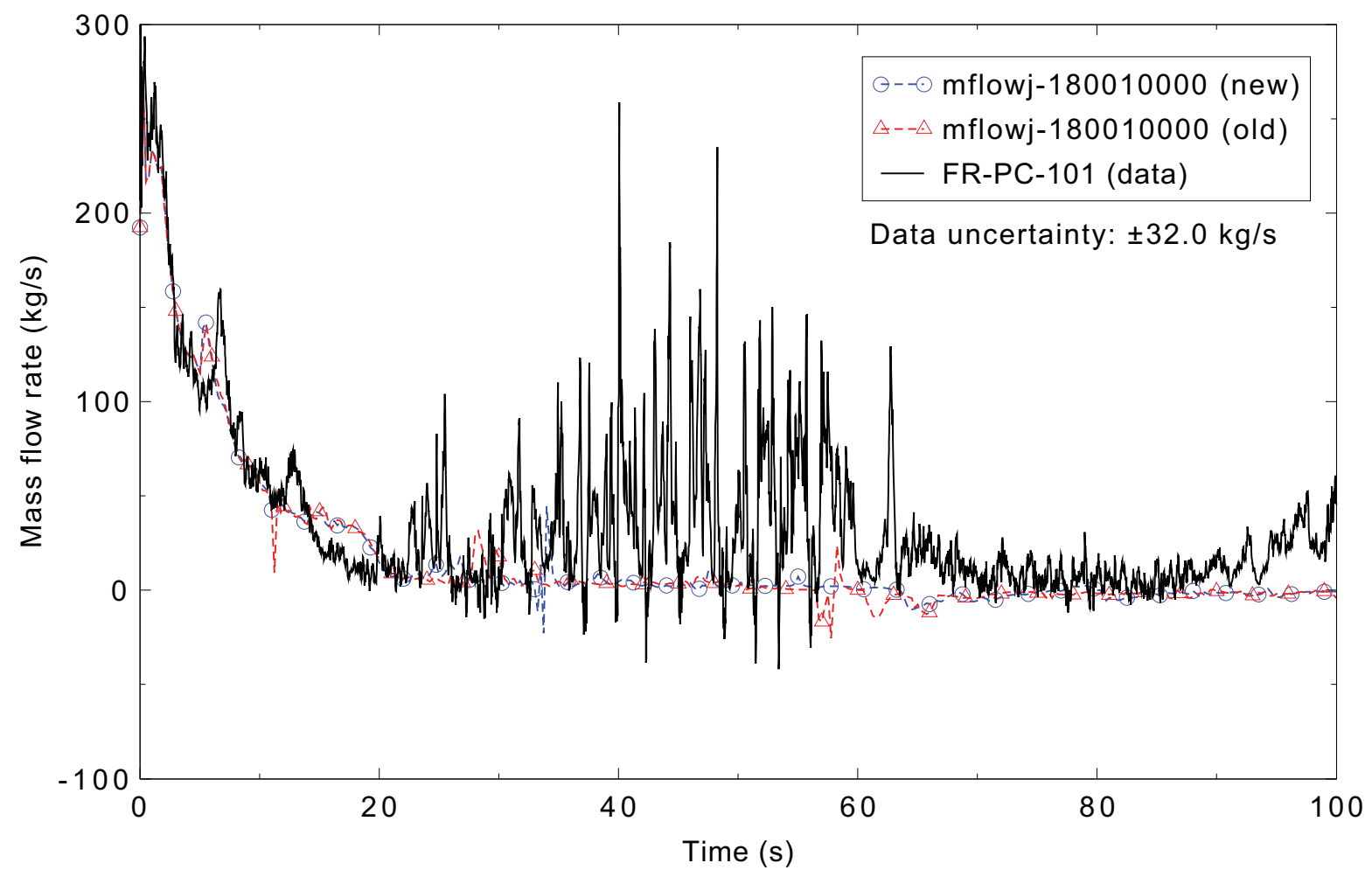

Figure 5.5-9. Measured and calculated mass flow rate in the intact loop cold leg for the LOFT L2-5 1-D case.

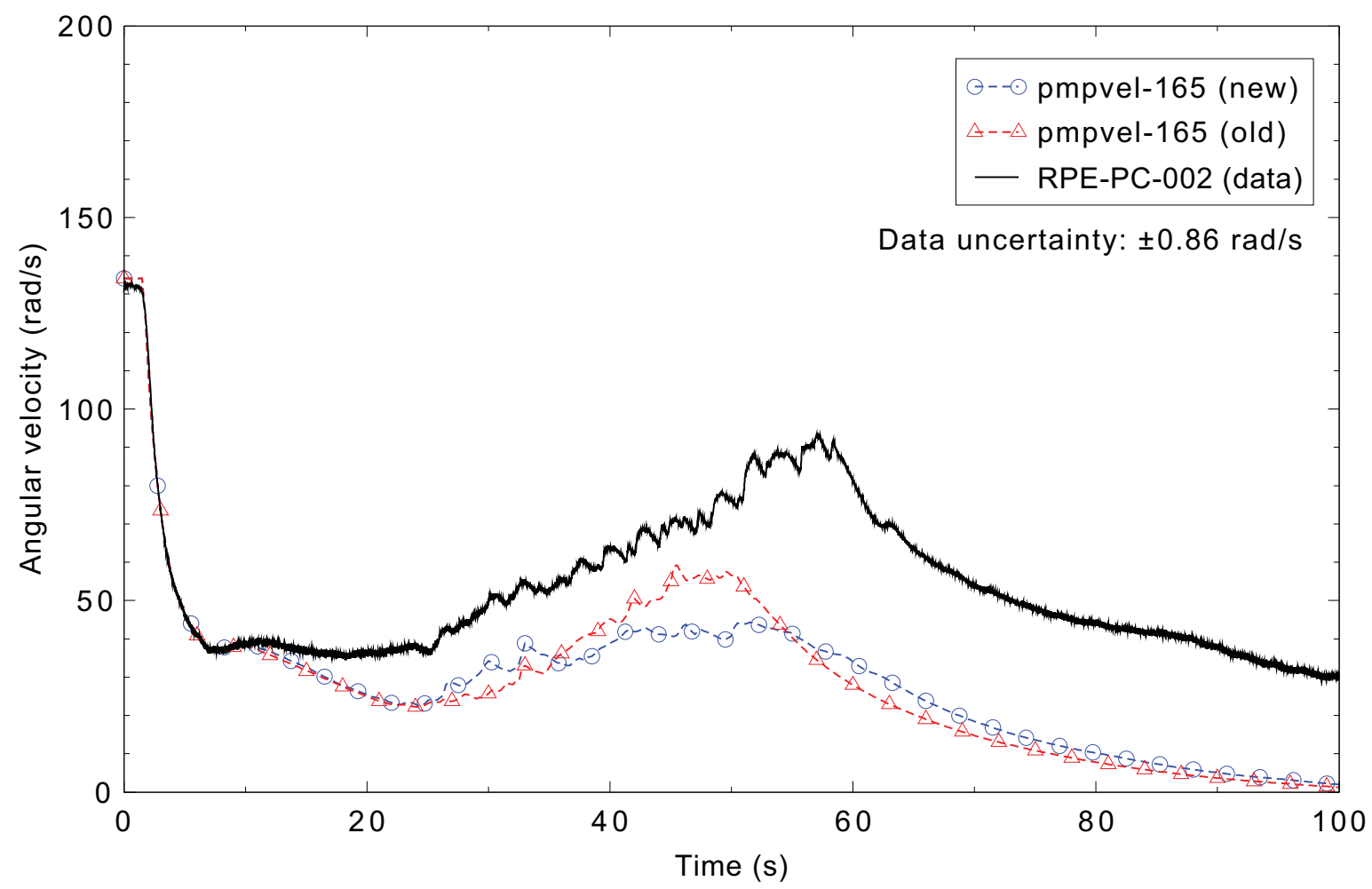

Figure 5.5-10. Measured and calculated speed for primary coolant pump 2 for the LOFT L2-5 1-D case. 


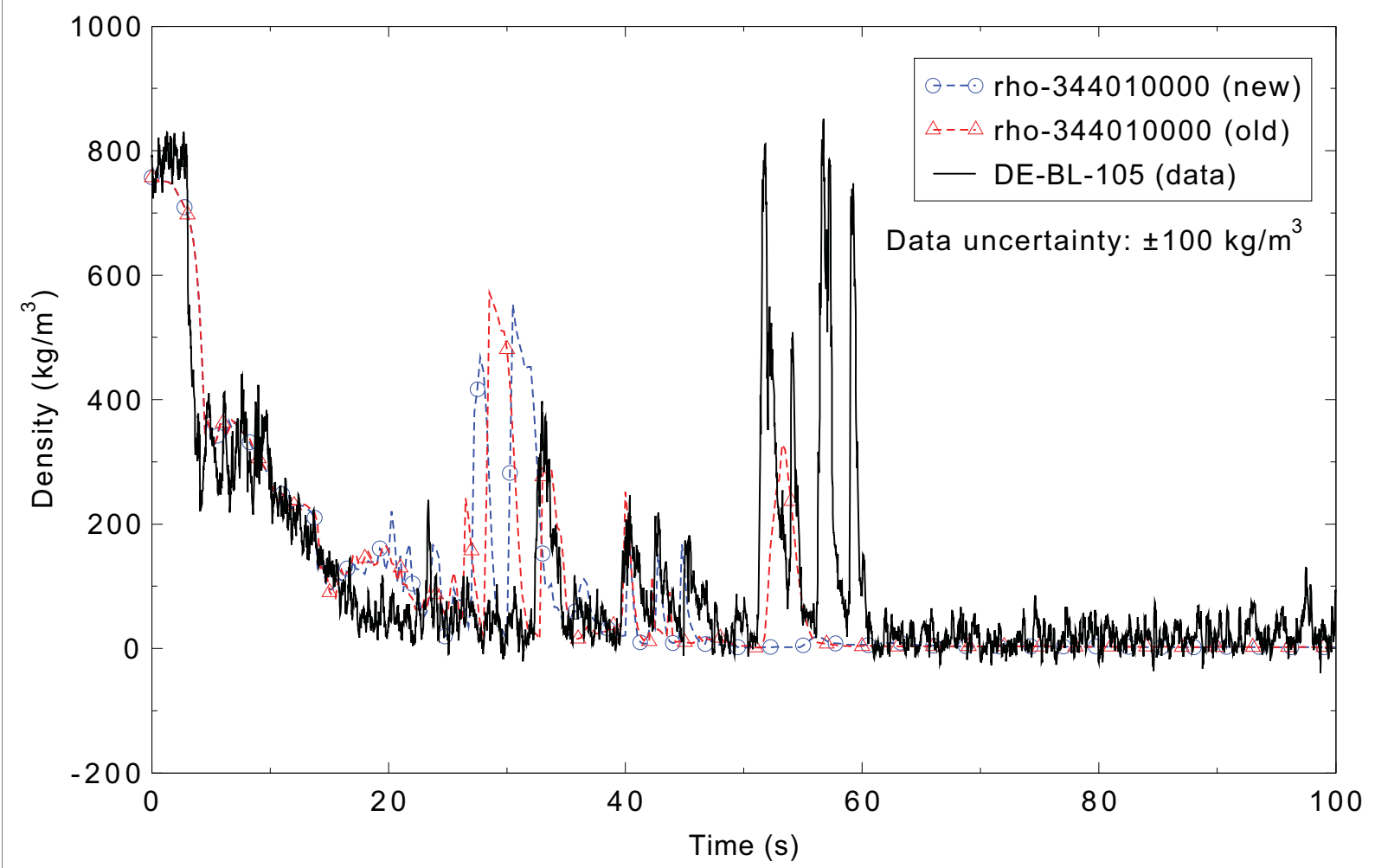

Figure 5.5-11. Measured and calculated density in the broken loop cold leg for the LOFT L2-5 1-D case.

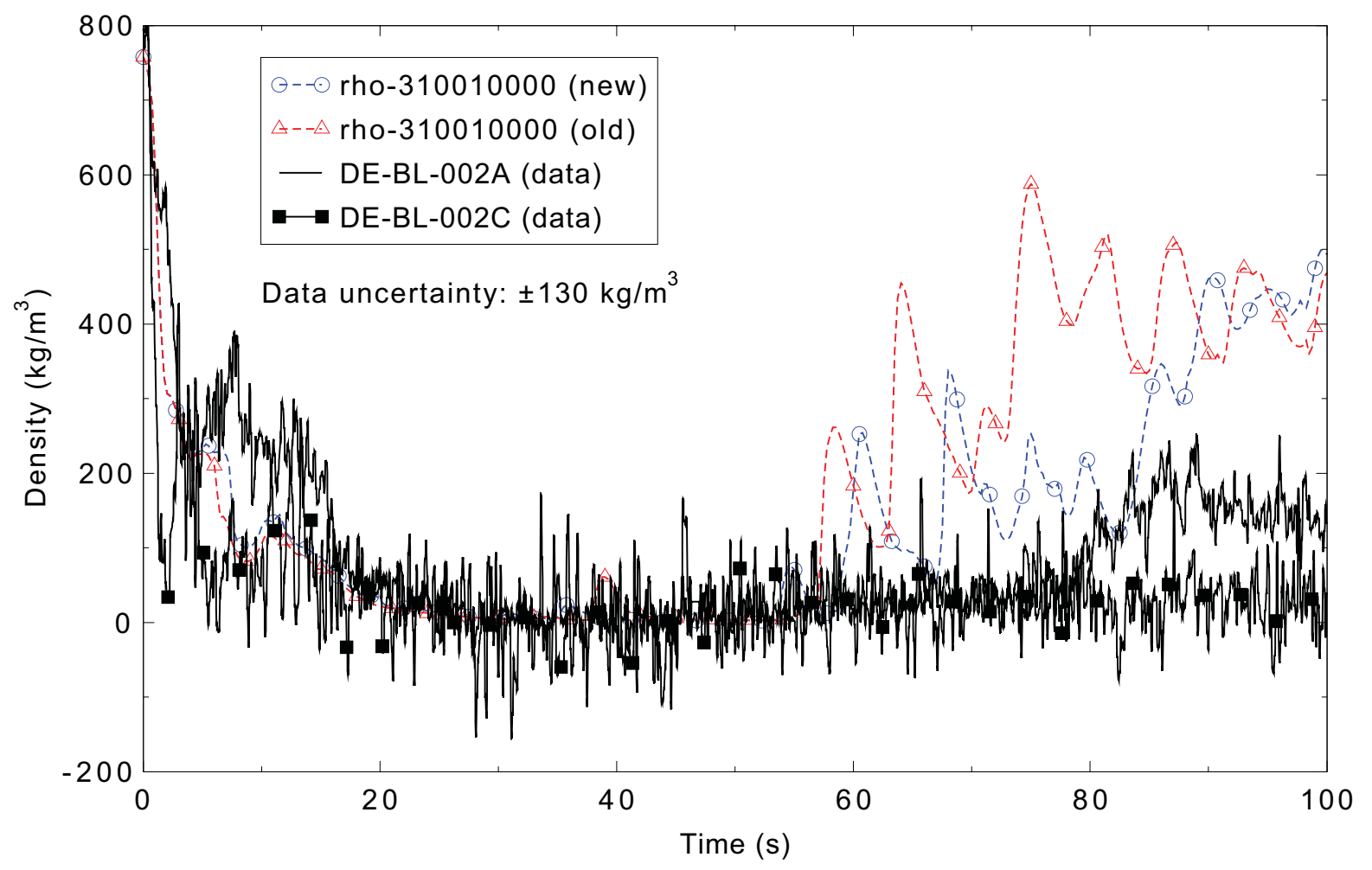

Figure 5.5-12. Measured and calculated density in the broken loop hot leg for the LOFT L2-5 1-D case. 


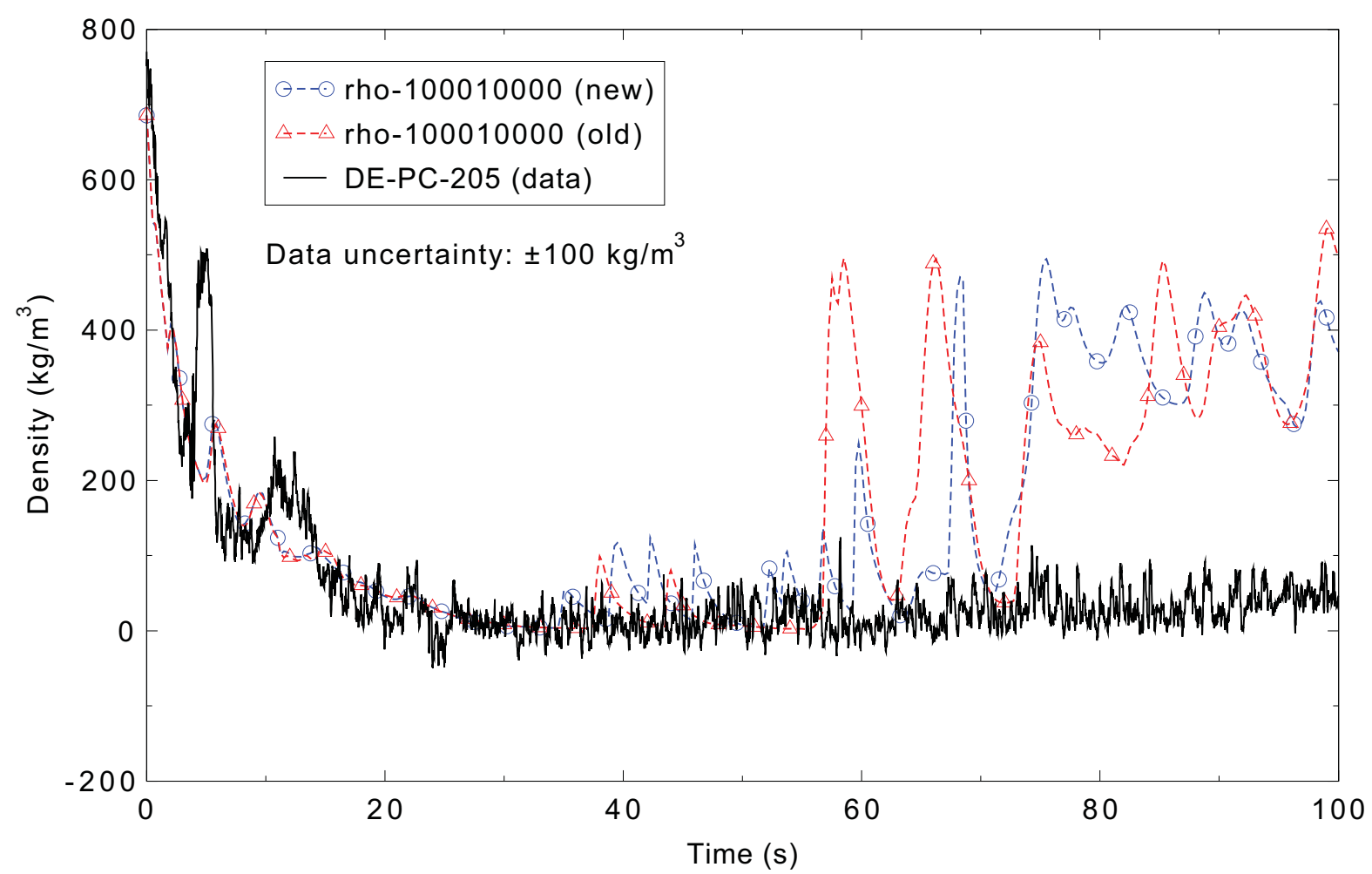

Figure 5.5-13. Measured and calculated density in the intact loop hot leg for the LOFT L2-5 1-D case.

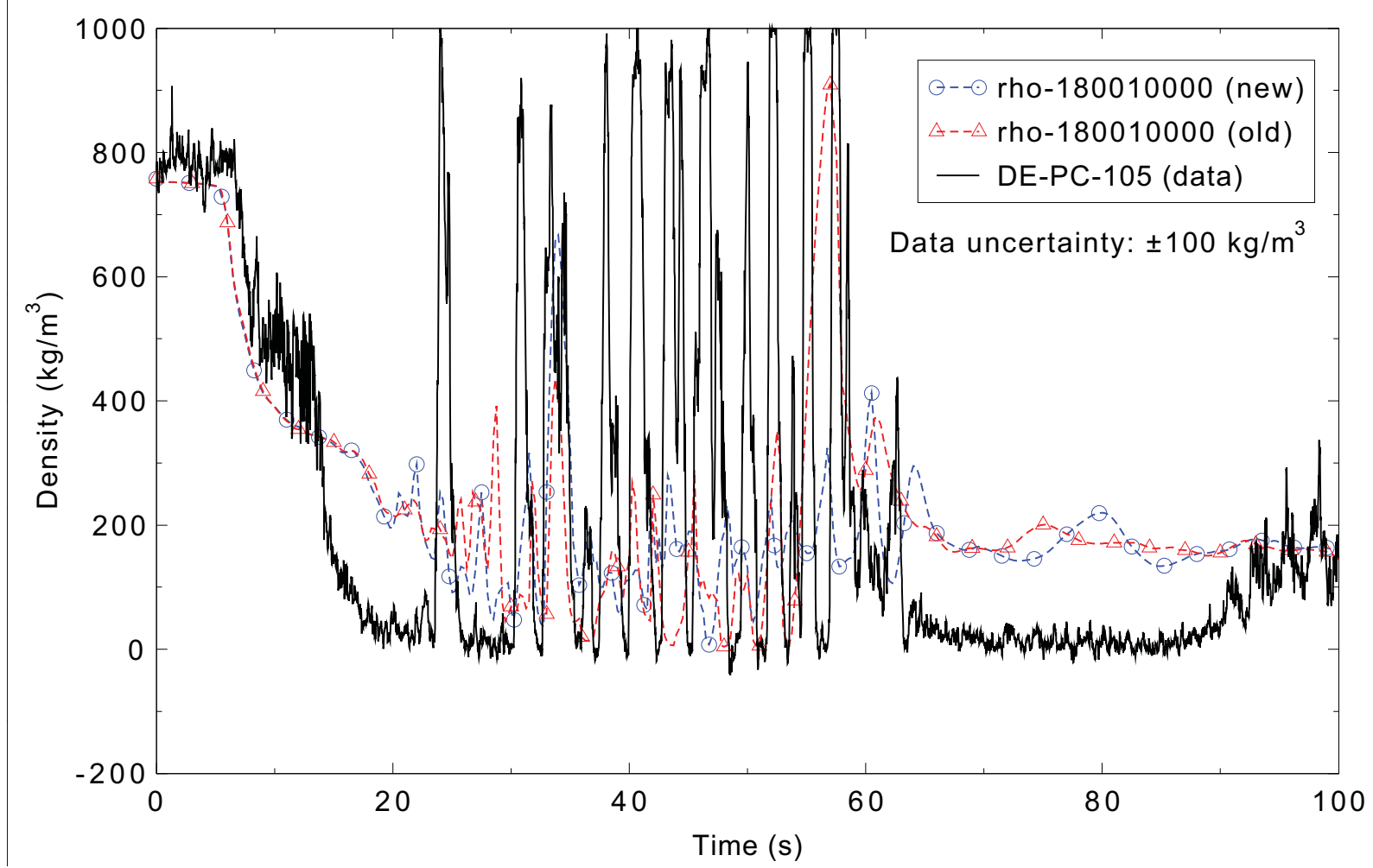

Figure 5.5-14. Measured and calculated density in the intact loop cold leg for the LOFT L2-5 1-D case. 


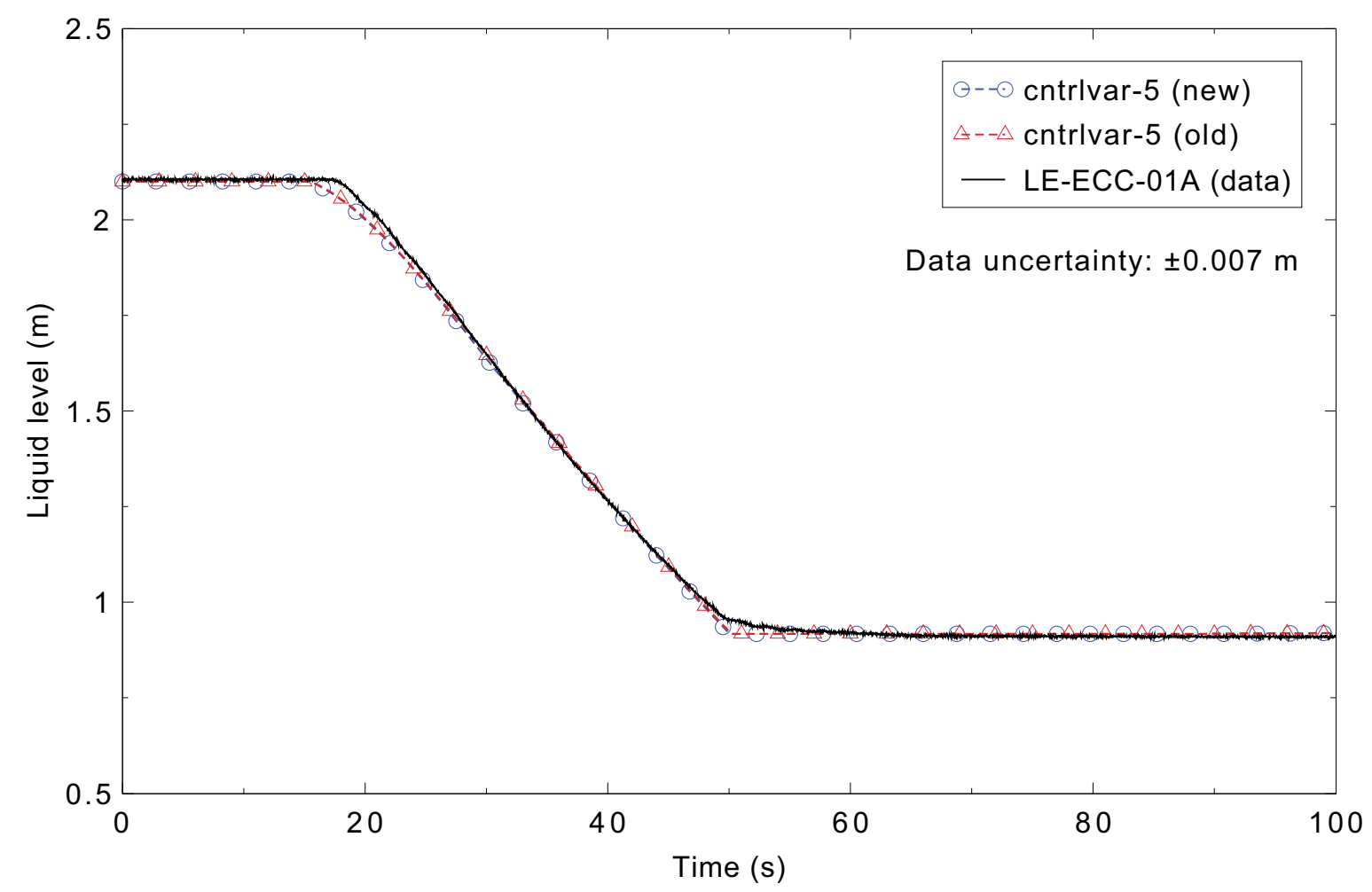

Figure 5.5-15. Measured and calculated accumulator liquid level for the LOFT L2-5 1-D case.

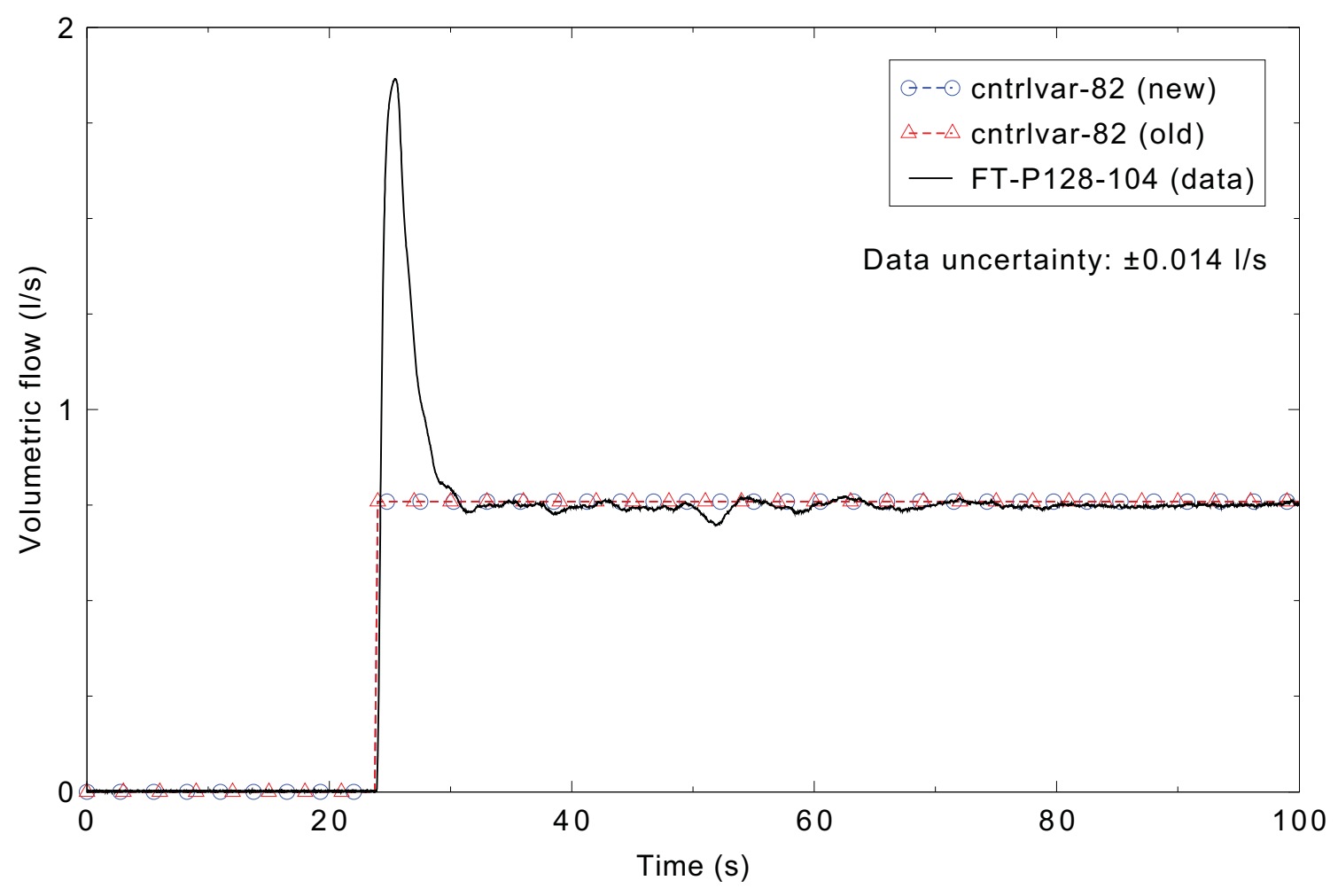

Figure 5.5-16. Measured and calculated HPIS flow for the LOFT L2-5 1-D case. 


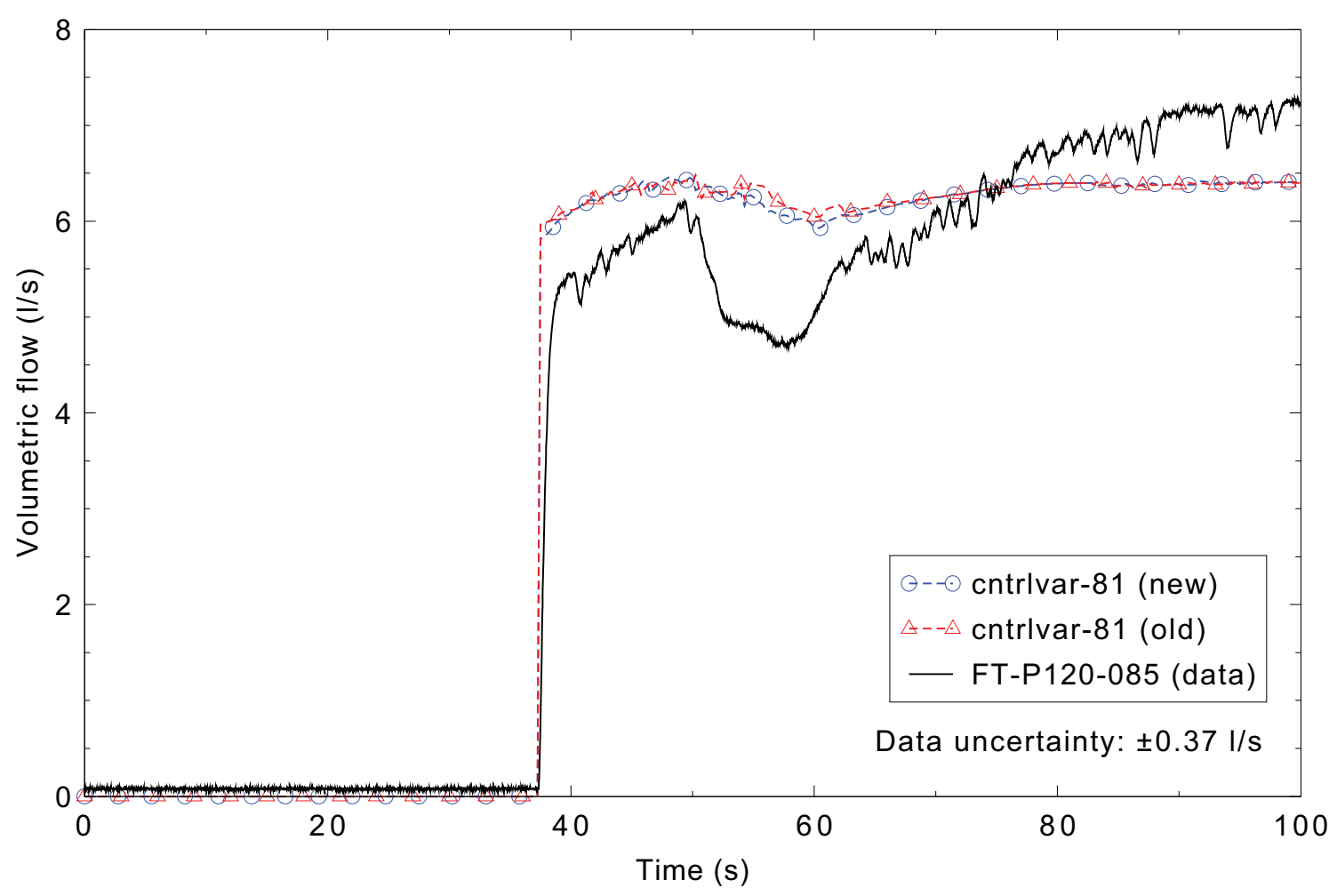

Figure 5.5-17. Measured and calculated LPIS flow for the LOFT L2-5 1-D case.

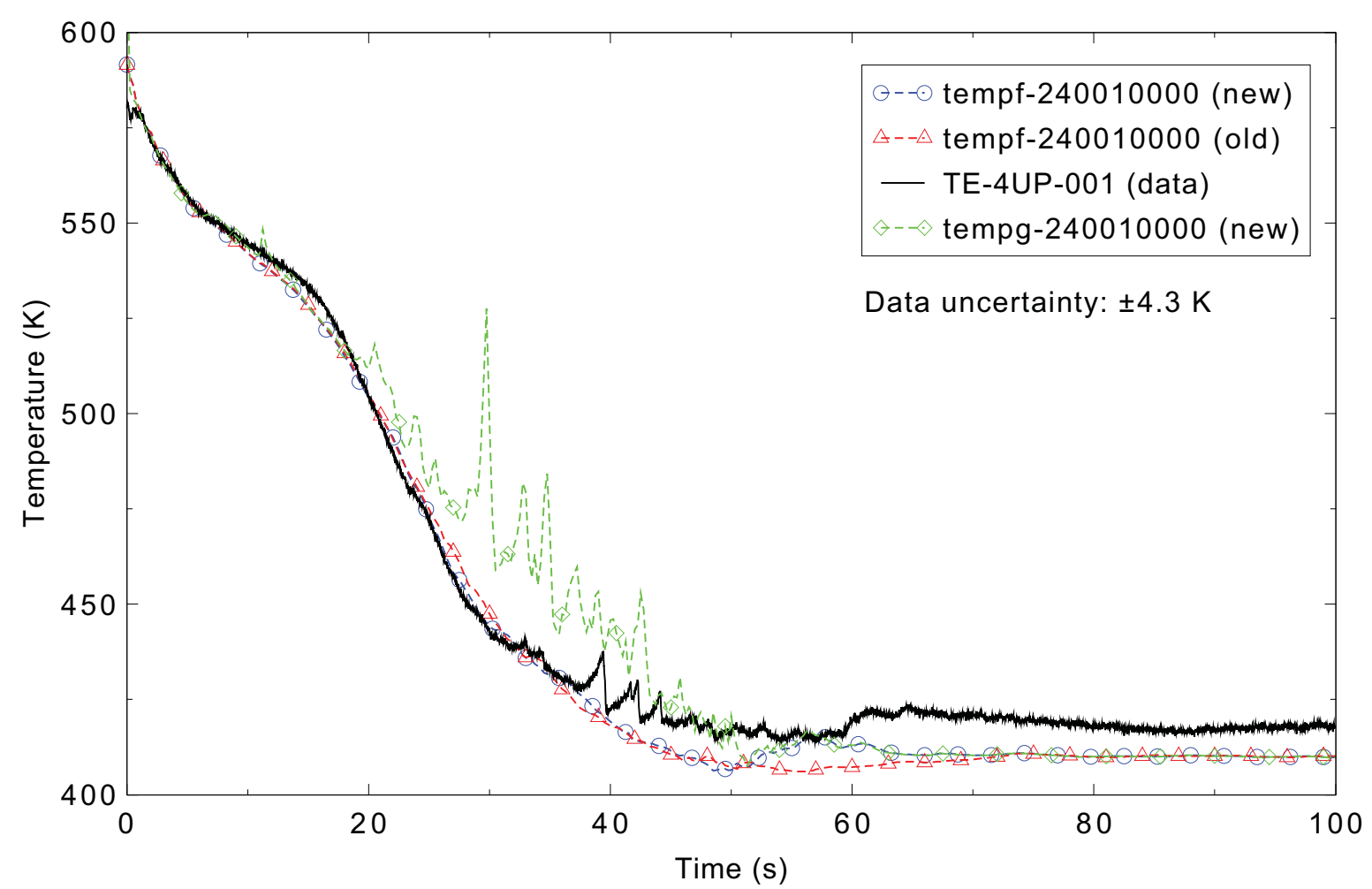

Figure 5.5-18. Measured and calculated reactor vessel upper plenum coolant temperature for the LOFT L2-5 1-D case. 


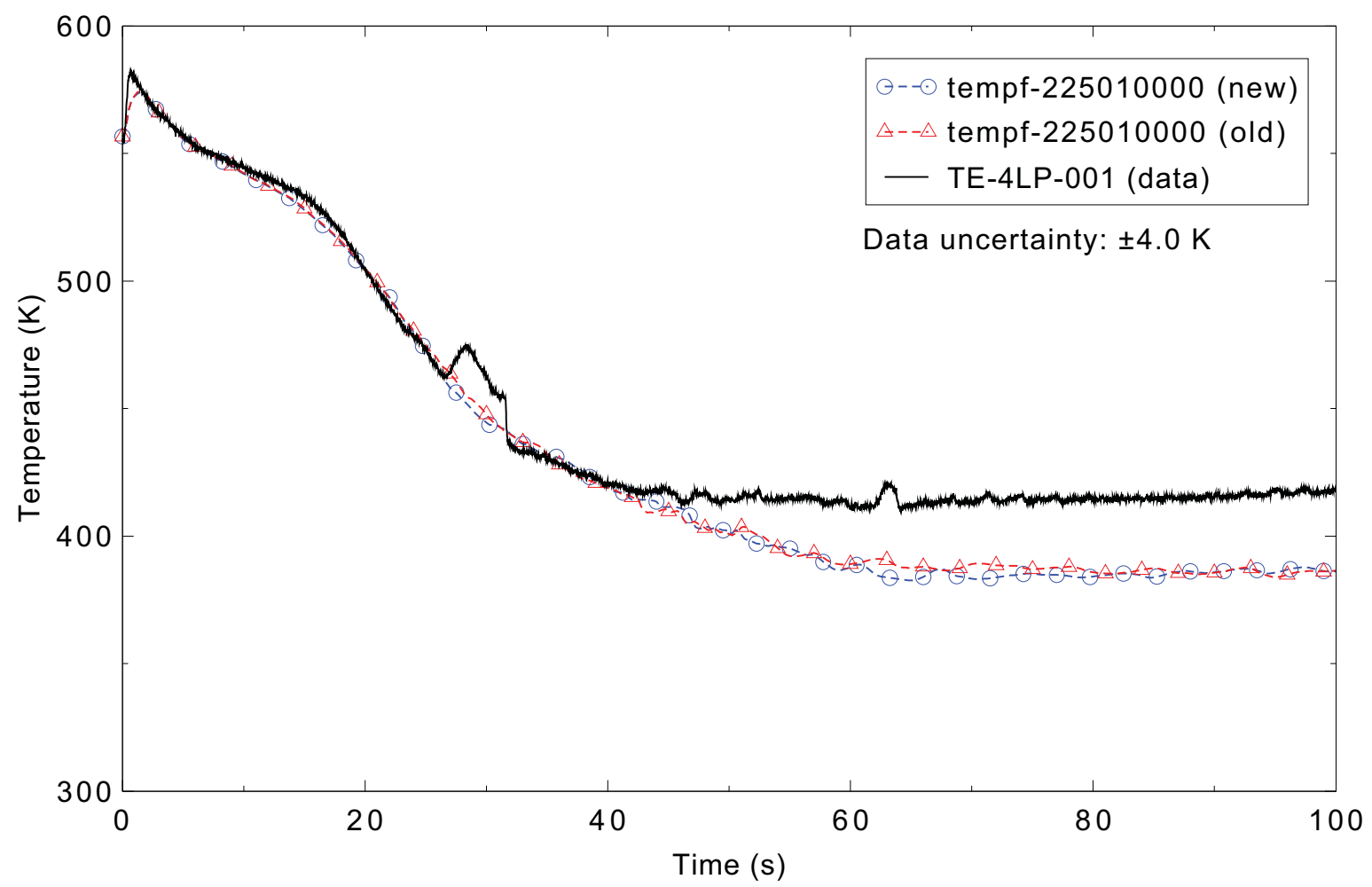

Figure 5.5-19. Measured and calculated reactor vessel lower plenum coolant temperature for the LOFT L2-5 1-D case.

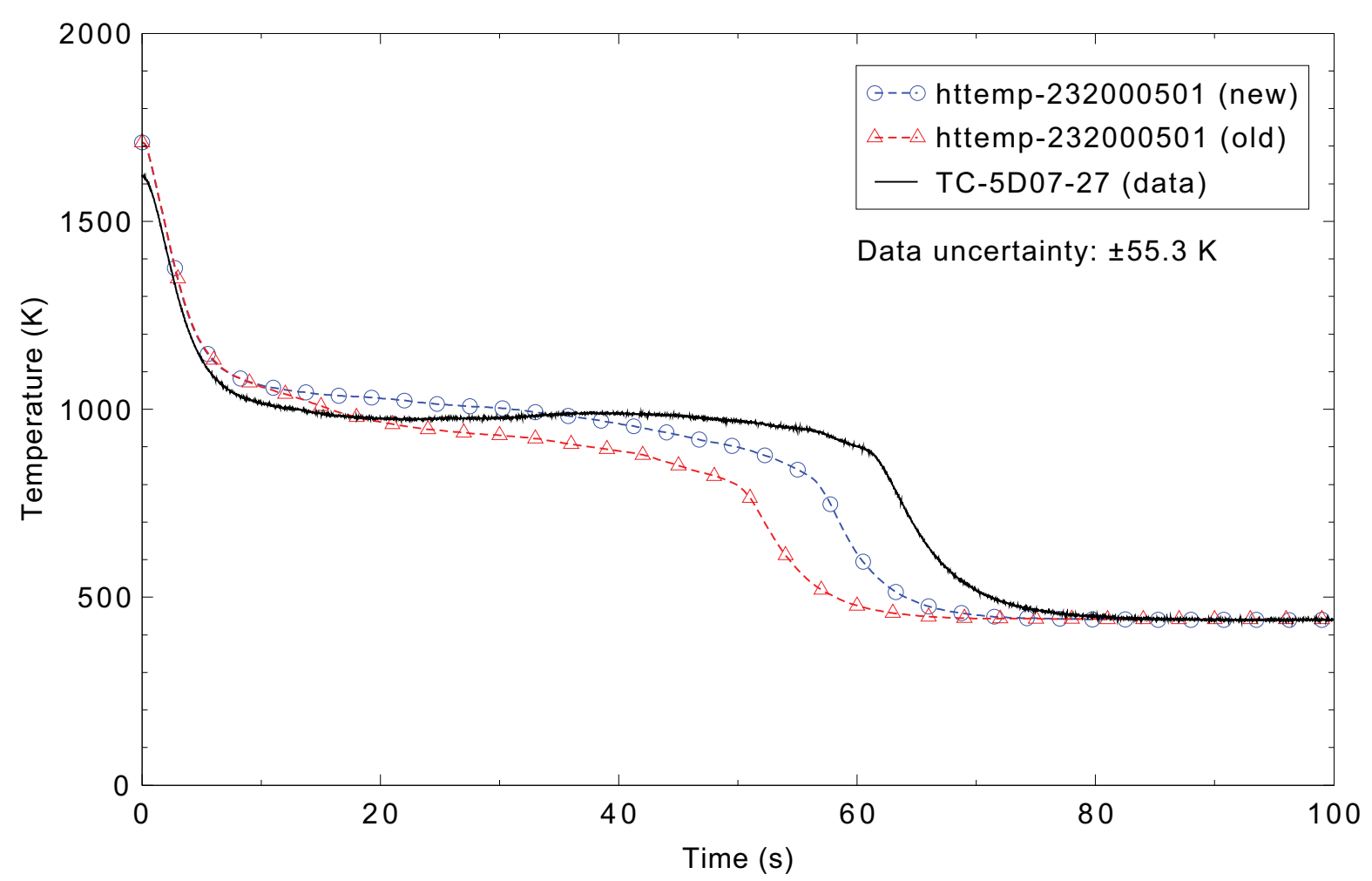

Figure 5.5-20. Measured and calculated fuel centerline temperature $0.69 \mathrm{~m}$ above the bottom of the fuel rod for the LOFT L2-5 1-D case. 


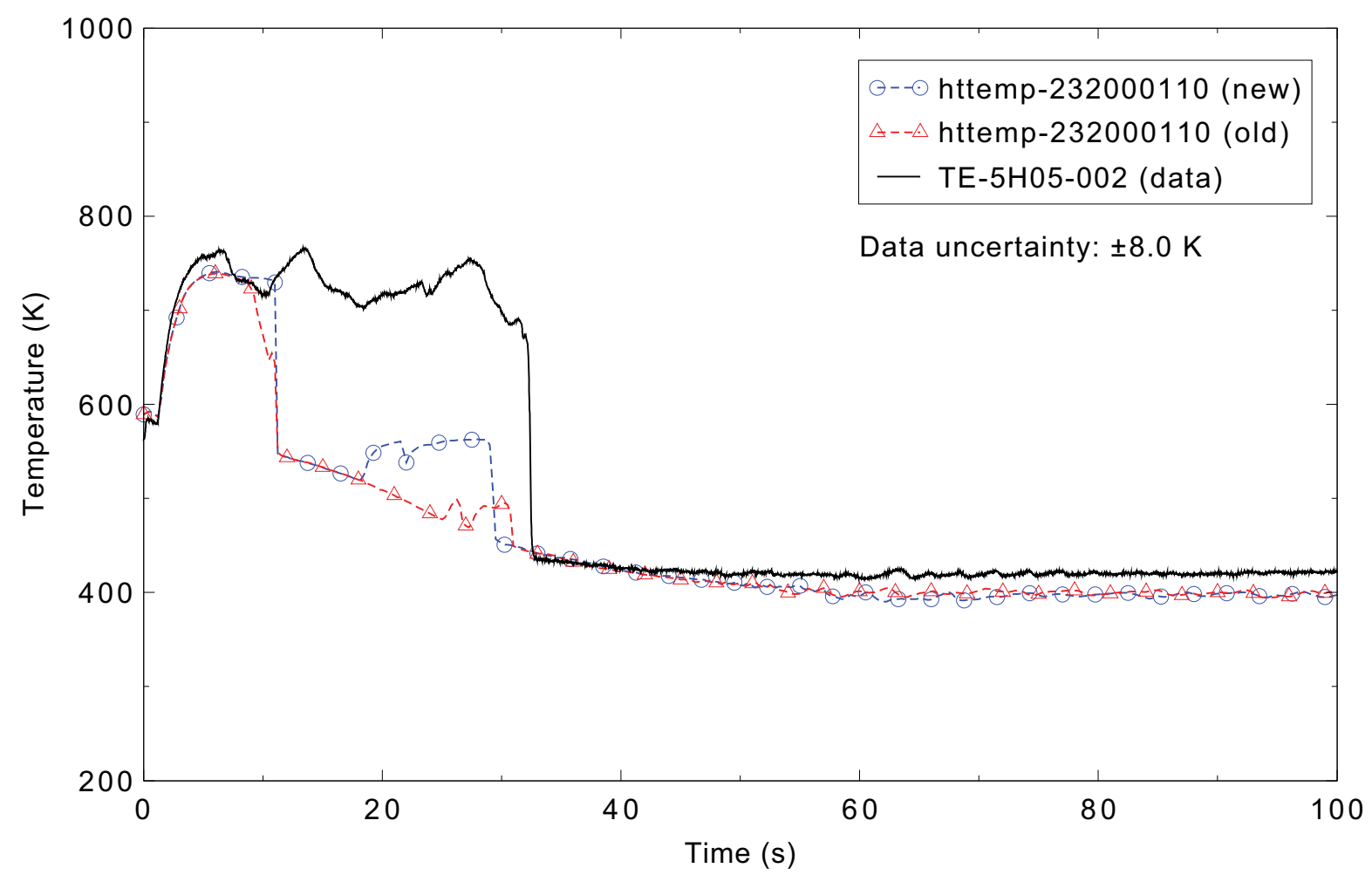

Figure 5.5-21. Measured and calculated fuel cladding surface temperature $0.05 \mathrm{~m}$ above the bottom of the fuel rod for the LOFT L2-5 1-D case.

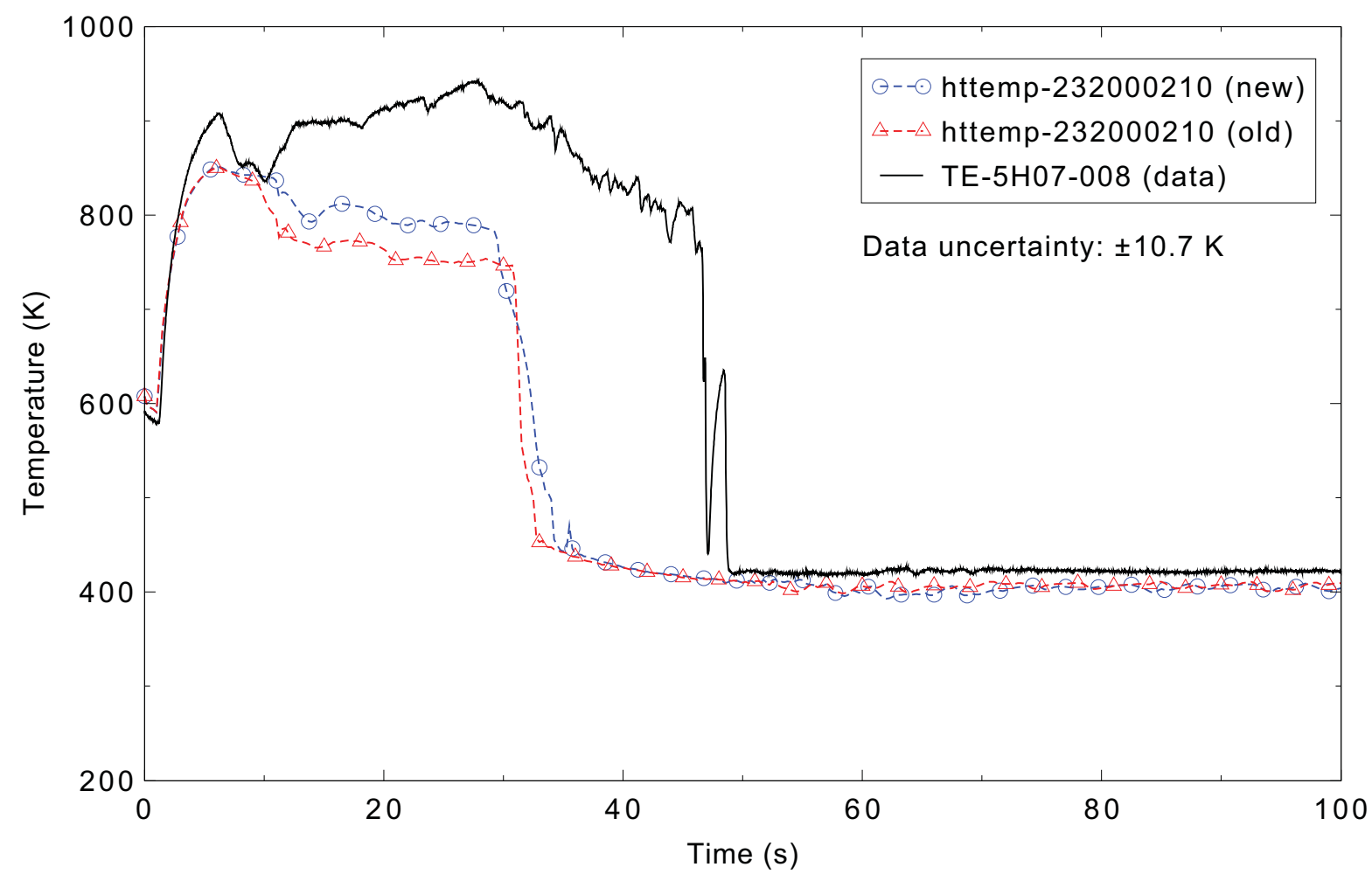

Figure 5.5-22. Measured and calculated fuel cladding surface temperature $0.20 \mathrm{~m}$ above the bottom of the fuel rod for the LOFT L2-5 1-D case. 


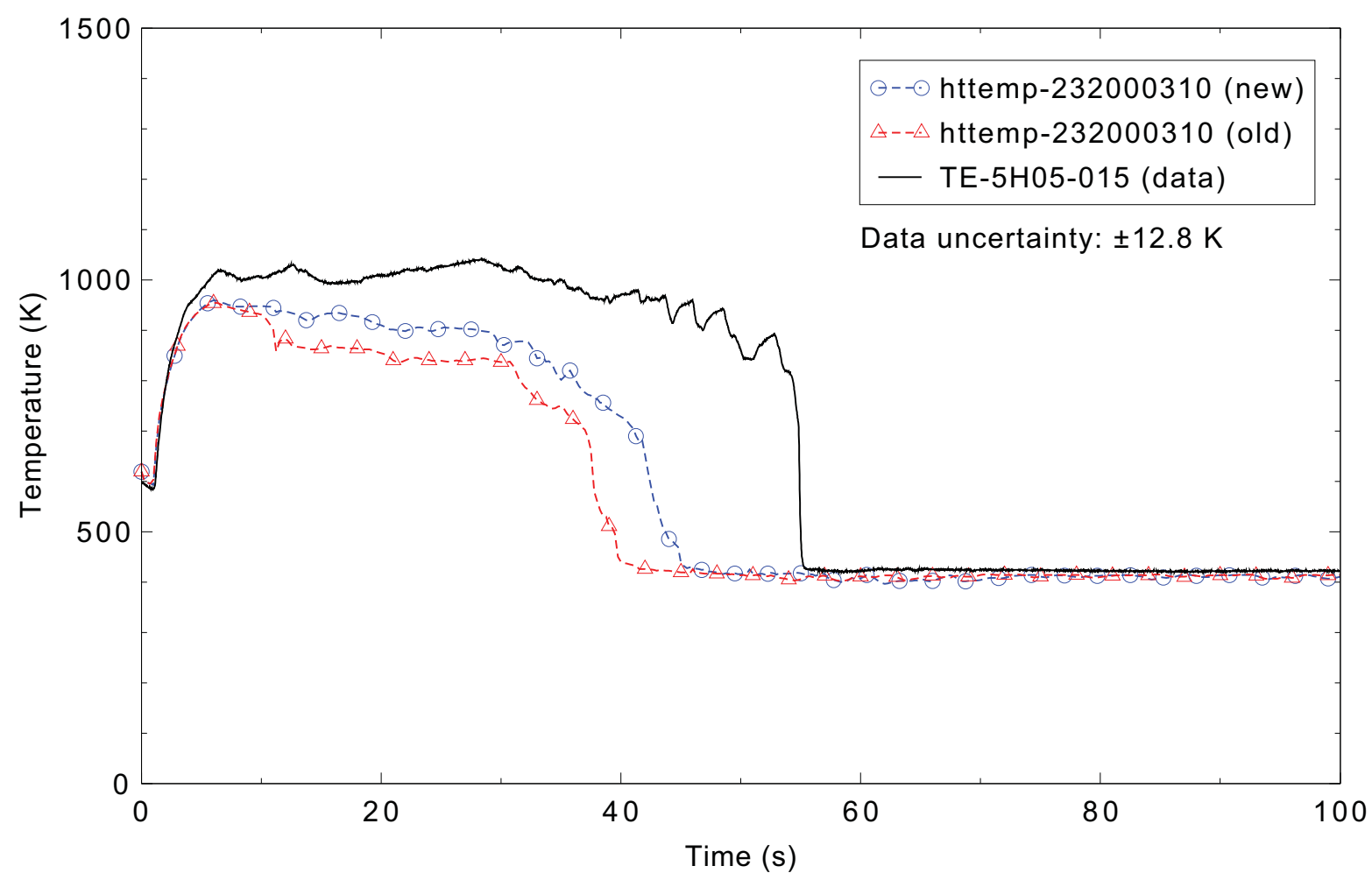

Figure 5.5-23. Measured and calculated fuel cladding surface temperature $0.38 \mathrm{~m}$ above the bottom of the fuel rod for the LOFT L2-5 1-D case.

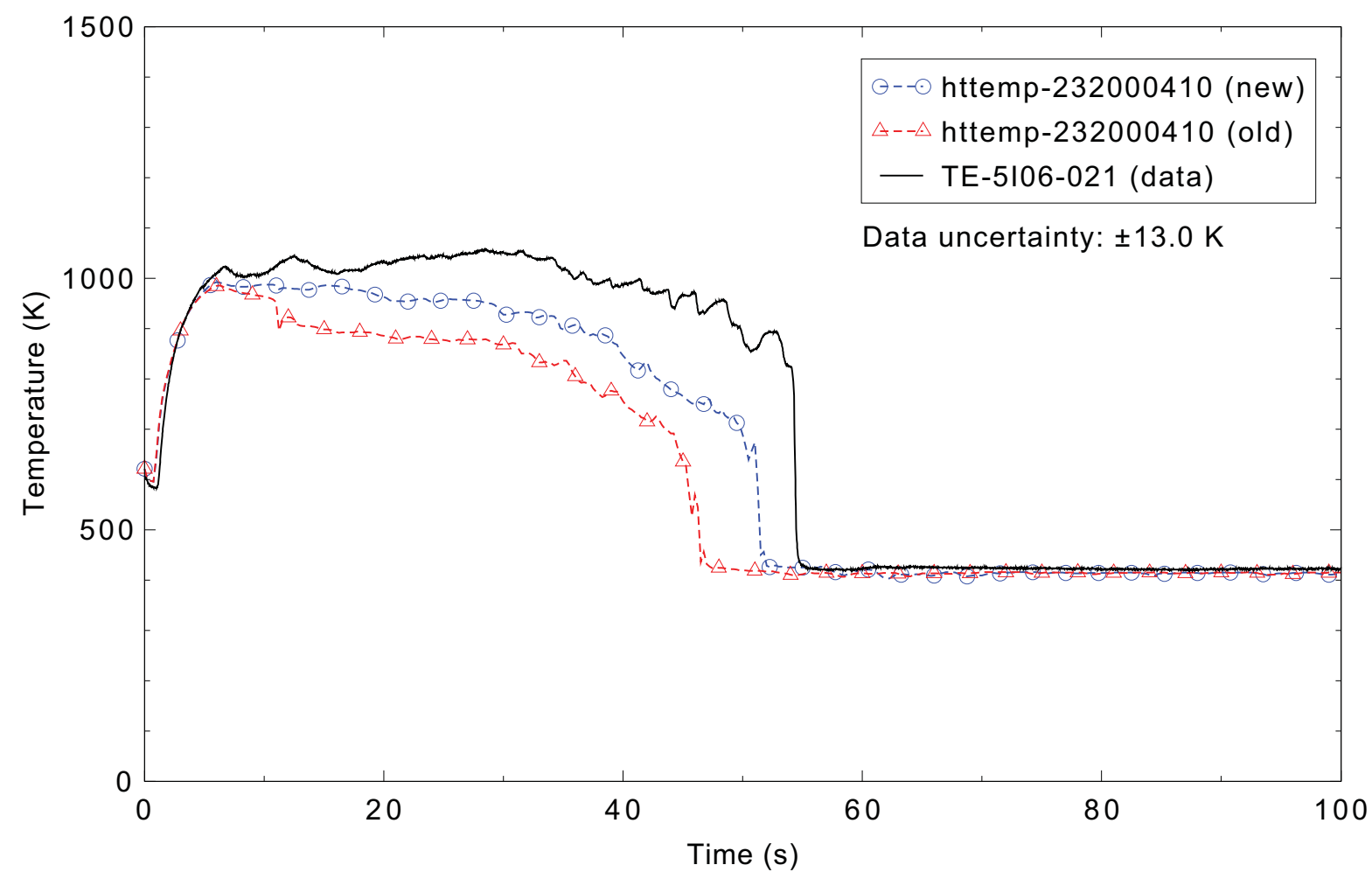

Figure 5.5-24. Measured and calculated fuel cladding surface temperature $0.53 \mathrm{~m}$ above the bottom of the fuel rod for the LOFT L2-5 1-D case. 


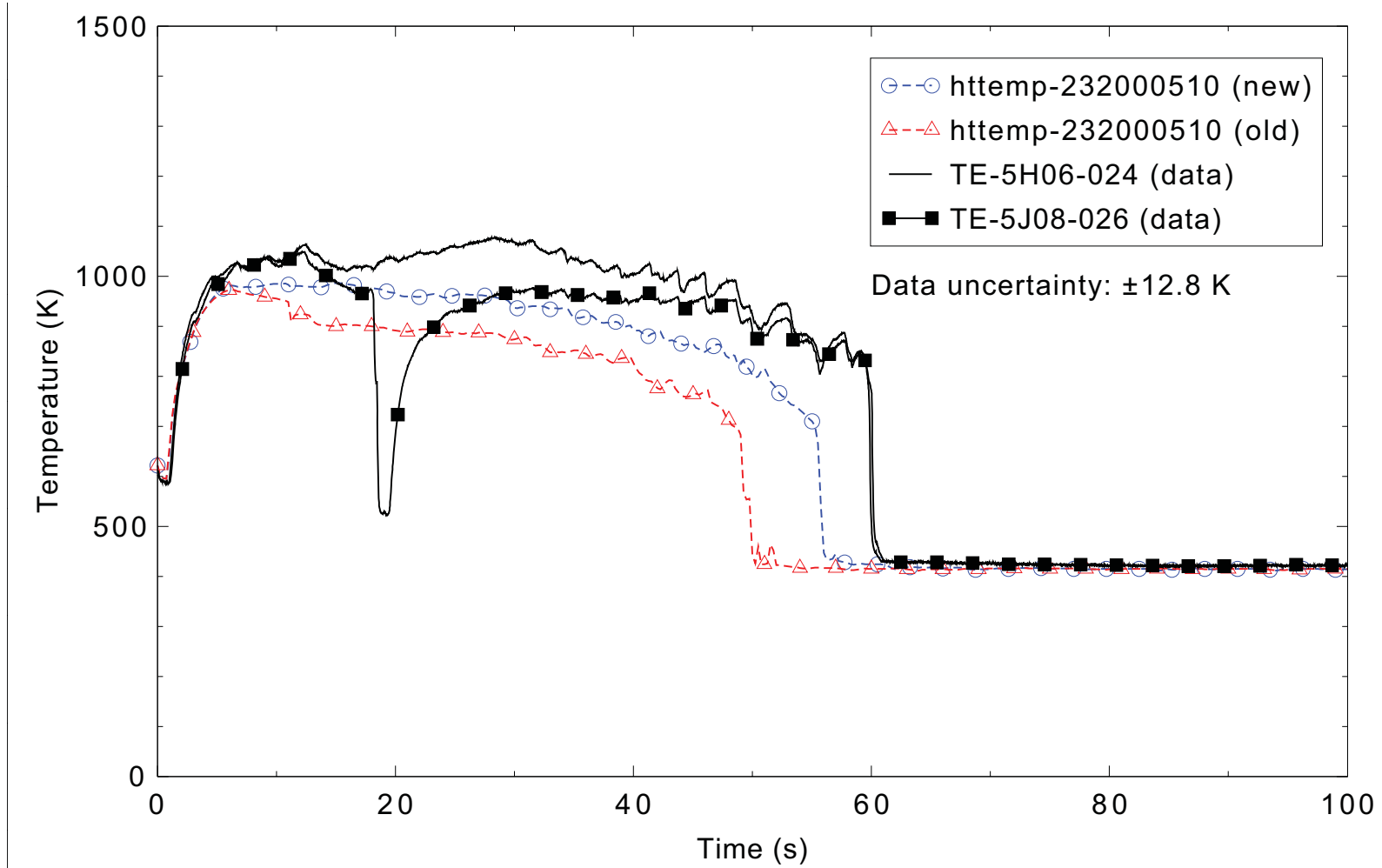

Figure 5.5-25. Measured and calculated fuel cladding surface temperature $0.64 \mathrm{~m}$ above the bottom of the fuel rod for the LOFT L2-5 1-D case.

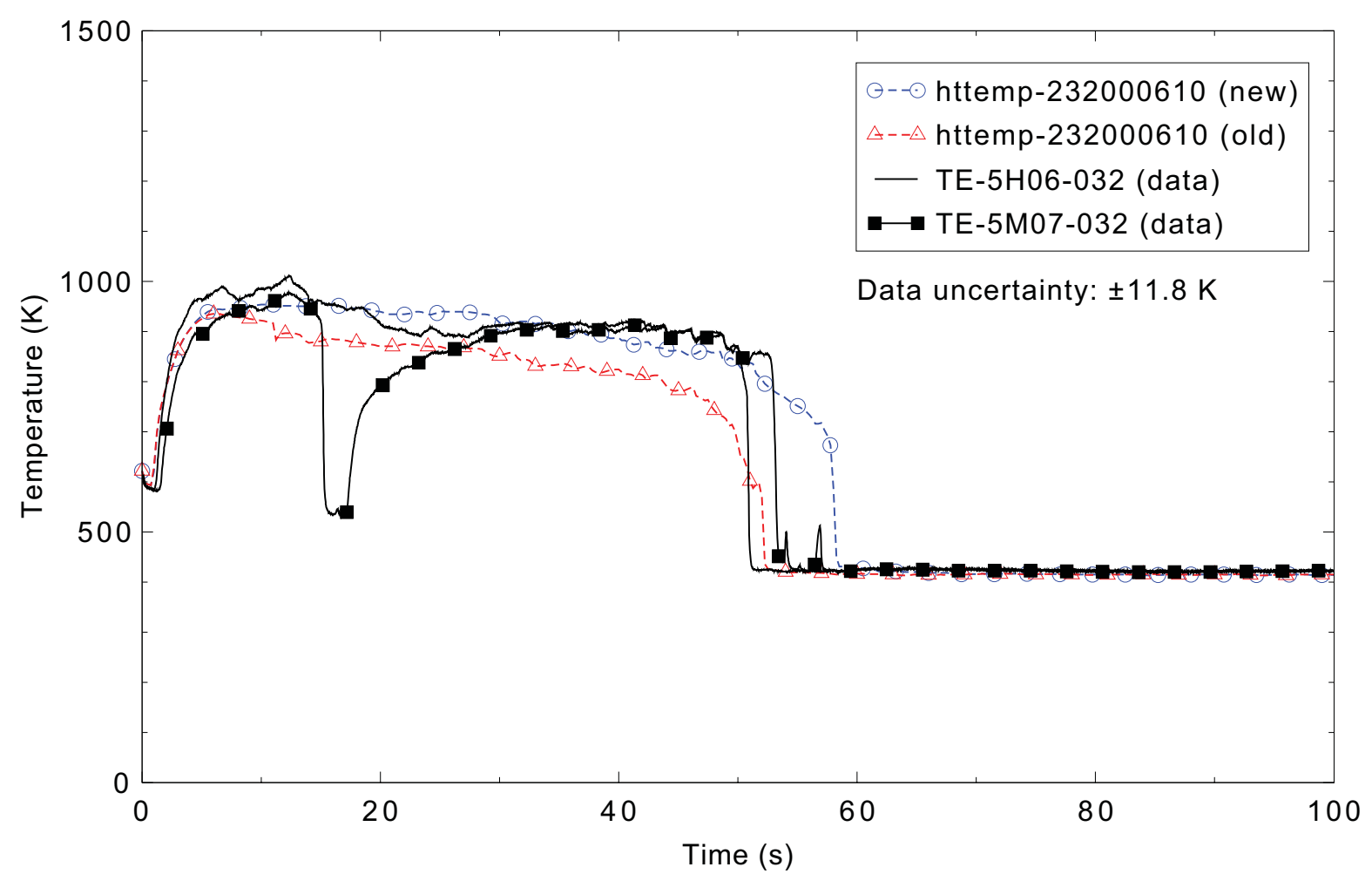

Figure 5.5-26. Measured and calculated fuel cladding surface temperature $0.81 \mathrm{~m}$ above the bottom of the fuel rod for the LOFT L2-5 1-D case. 


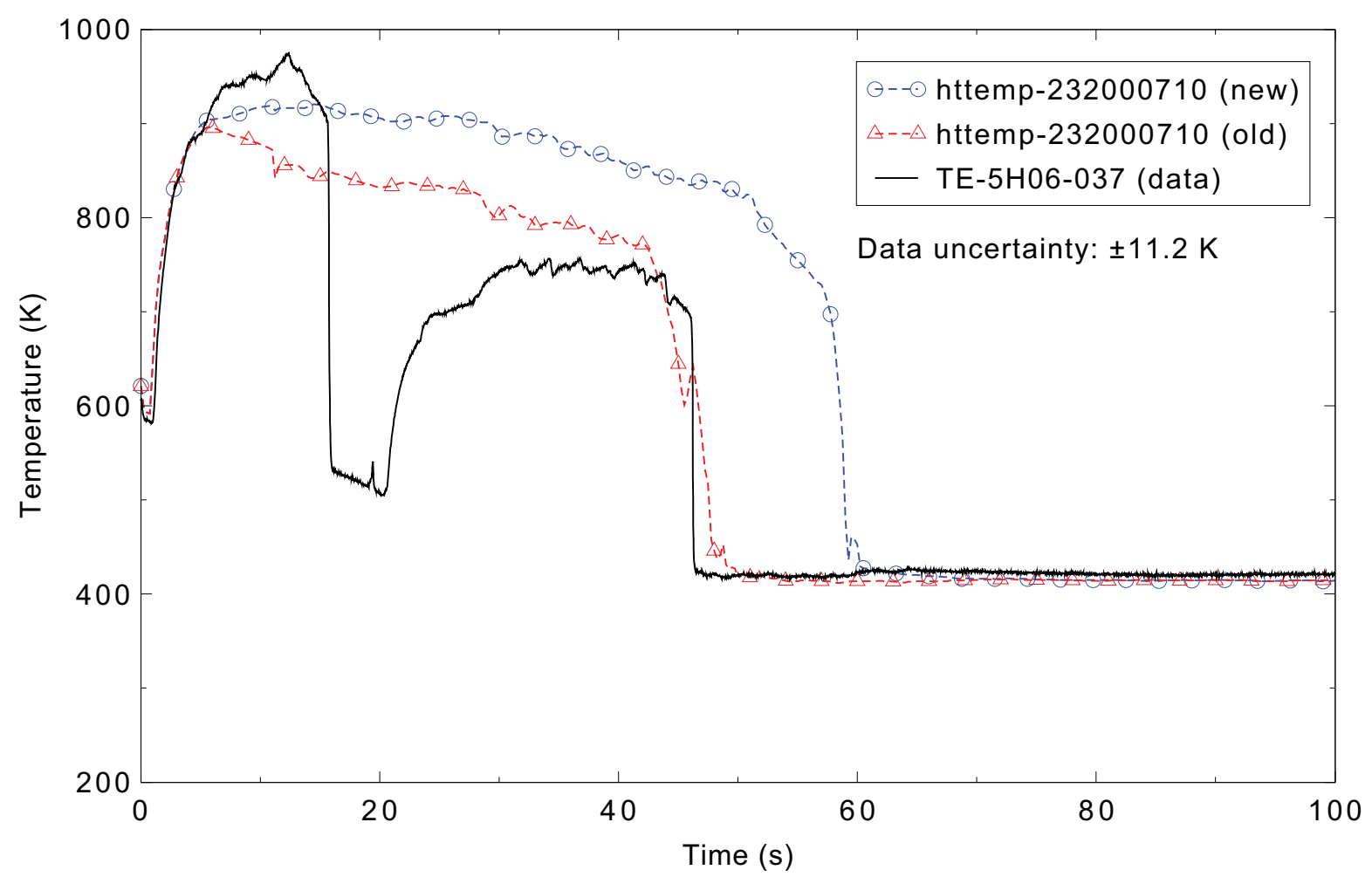

Figure 5.5-27. Measured and calculated fuel cladding surface temperature $0.94 \mathrm{~m}$ above the bottom of the fuel rod for the LOFT L2-5 1-D case.

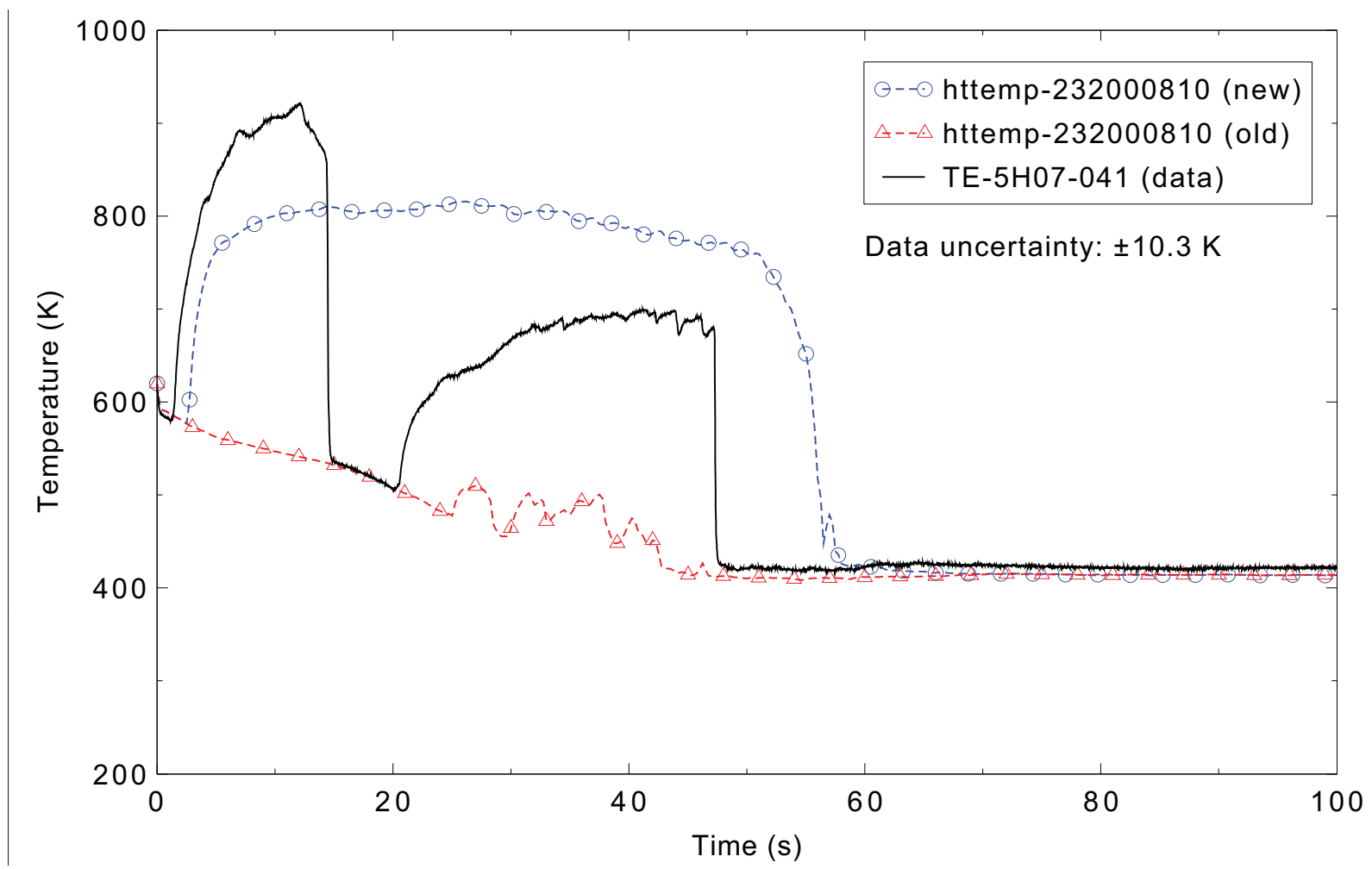

Figure 5.5-28. Measured and calculated fuel cladding surface temperature $1.04 \mathrm{~m}$ above the bottom of the fuel rod for the LOFT L2-5 1-D case. 


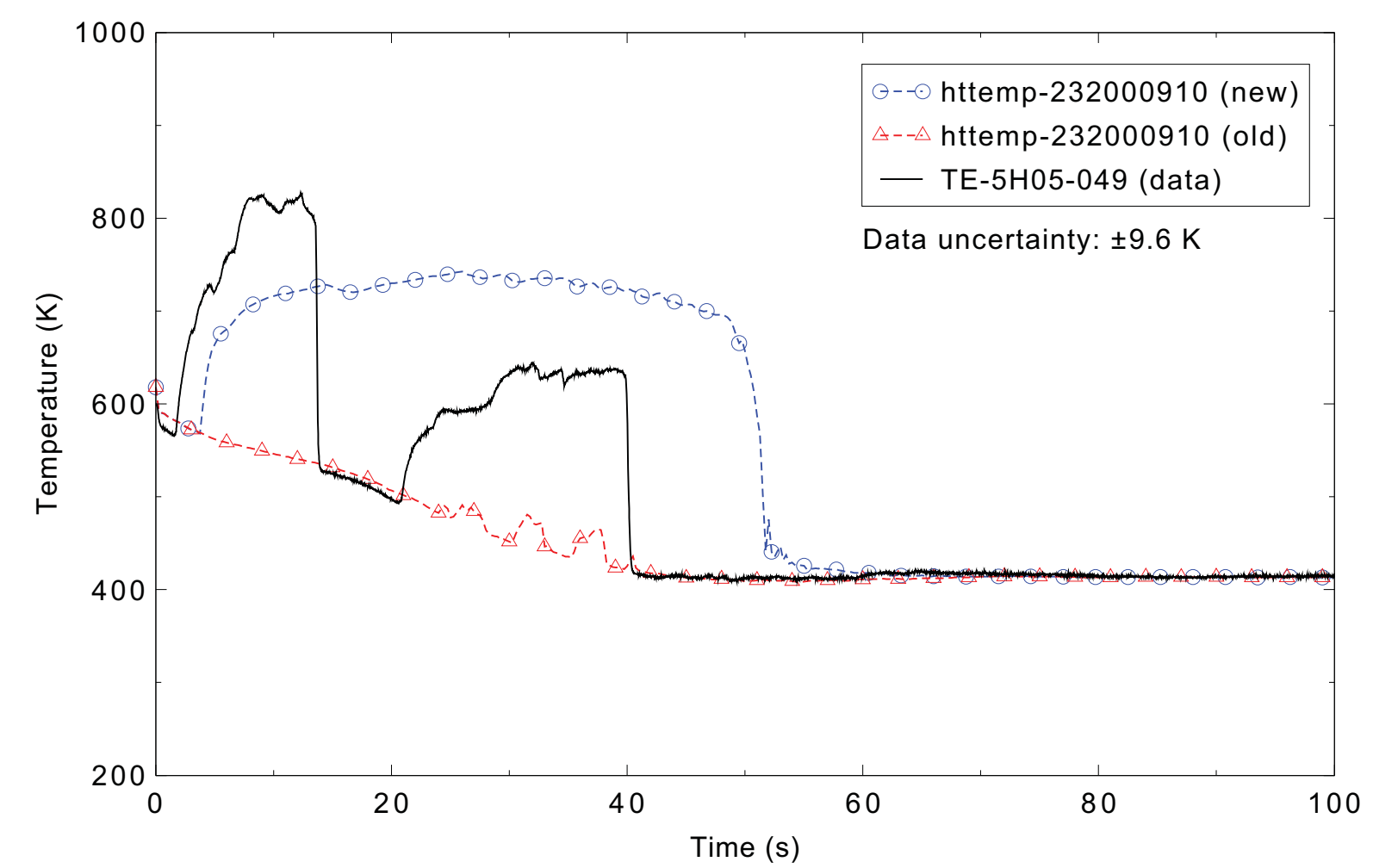

Figure 5.5-29. Measured and calculated fuel cladding surface temperature $1.25 \mathrm{~m}$ above the bottom of the fuel rod for the LOFT L2-5 1-D case.

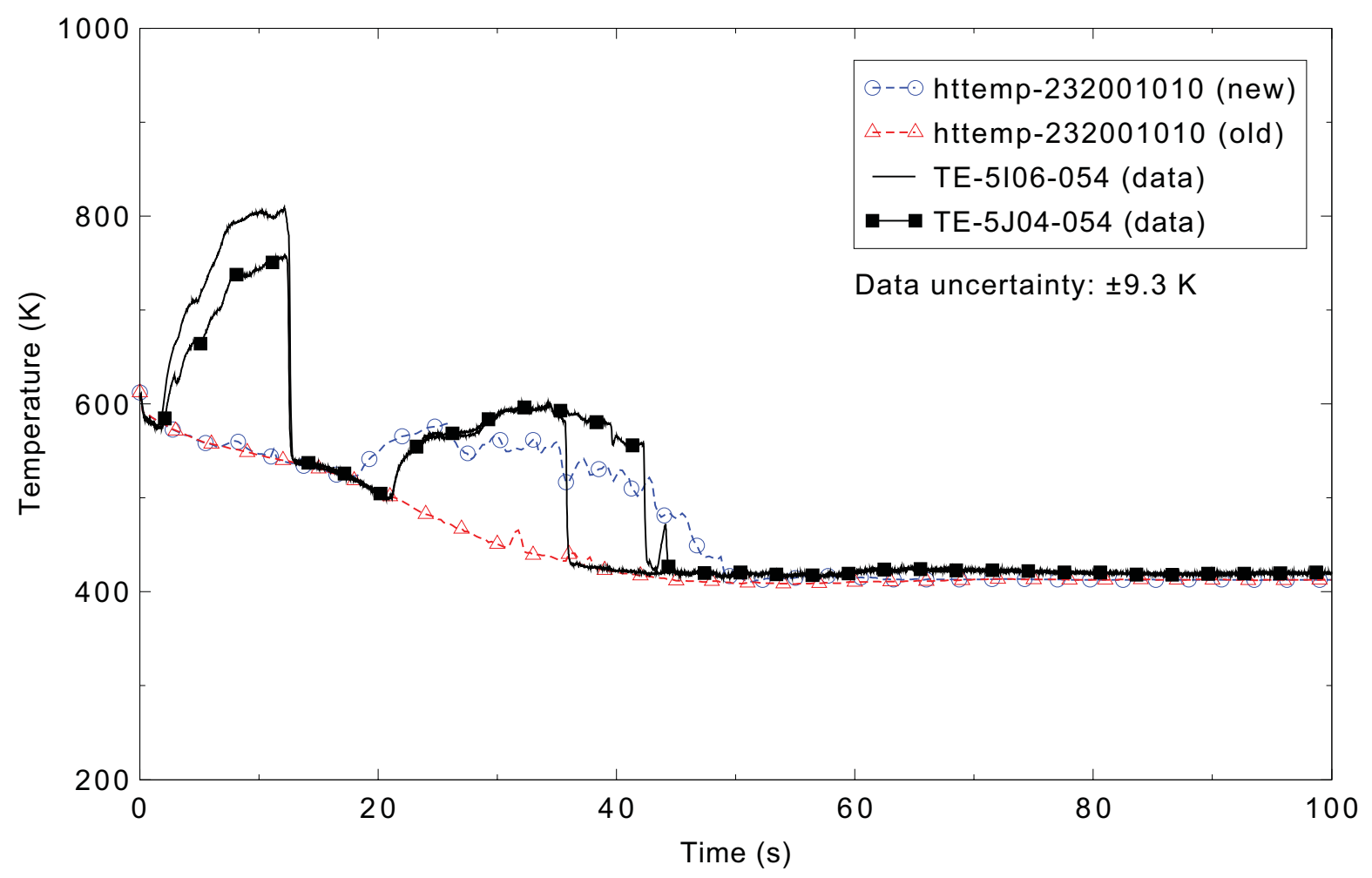

Figure 5.5-30. Measured and calculated fuel cladding surface temperature $1.37 \mathrm{~m}$ above the bottom of the fuel rod for the LOFT L2-5 1-D case. 


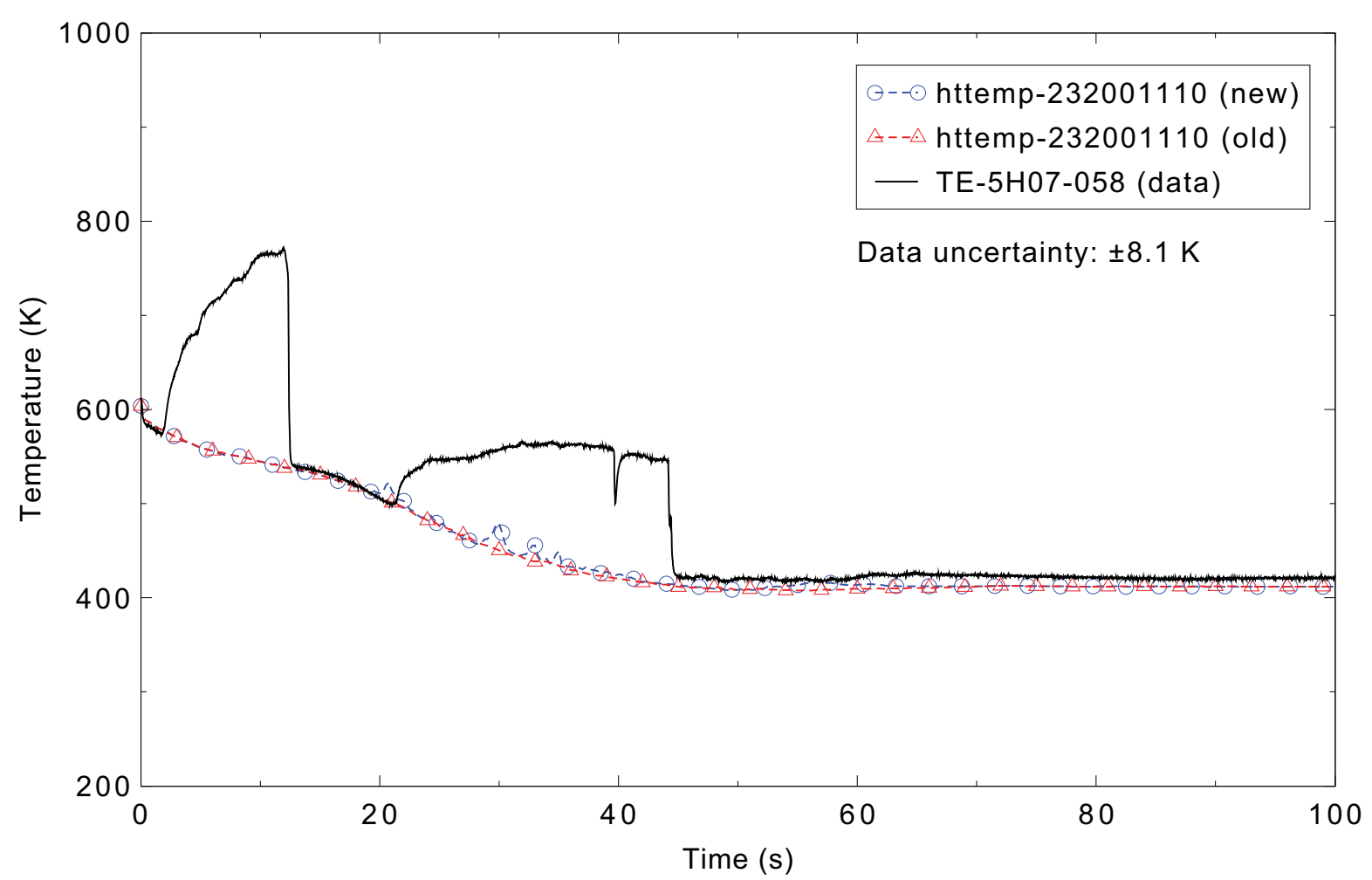

Figure 5.5-31. Measured and calculated fuel cladding surface temperature $1.47 \mathrm{~m}$ above the bottom of the fuel rod for the LOFT L2-5 1-D case.

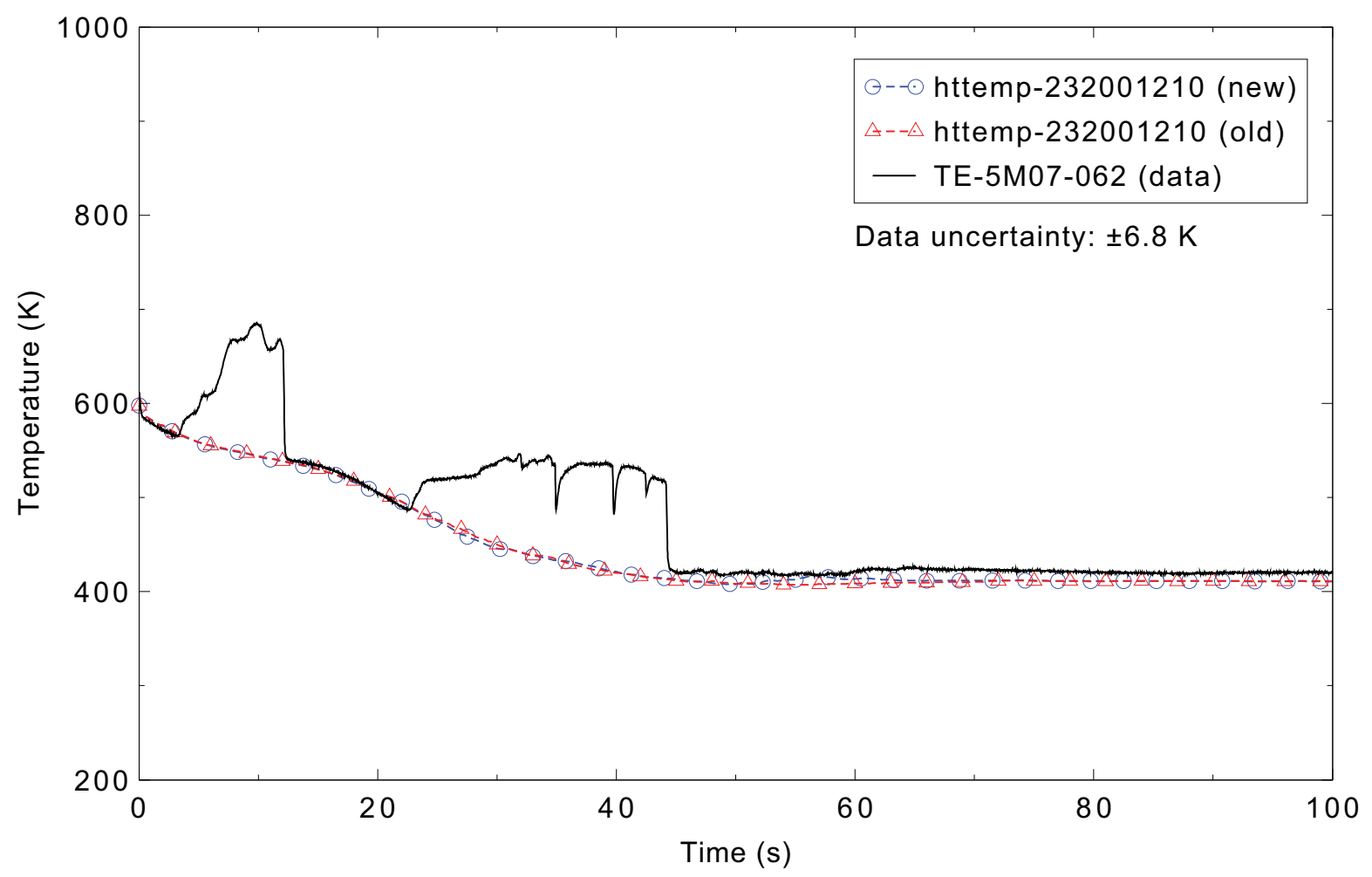

Figure 5.5-32. Measured and calculated fuel cladding surface temperature $1.57 \mathrm{~m}$ above the bottom of the fuel rod for the LOFT L2-5 1-D case. 


\subsection{LOFT Experiment L2-5 (3-D)}

Figures comparing simulations using two code versions are presented. Diagrams are included so that the figure numbering is the same as that in Volume III of the RELAP5-3D code manual. Significant differences were observed in Figures 5.6-23, 31, 32, and 33; noticeable differences were observed in Figures 5.6-5, 6, 7, 8, 9, 10, 11, 12, 13, 14, 15, 16, 17, 19, 20, 21, 22, 24, 25, 26, 27, 28, 29, 30, and 34.

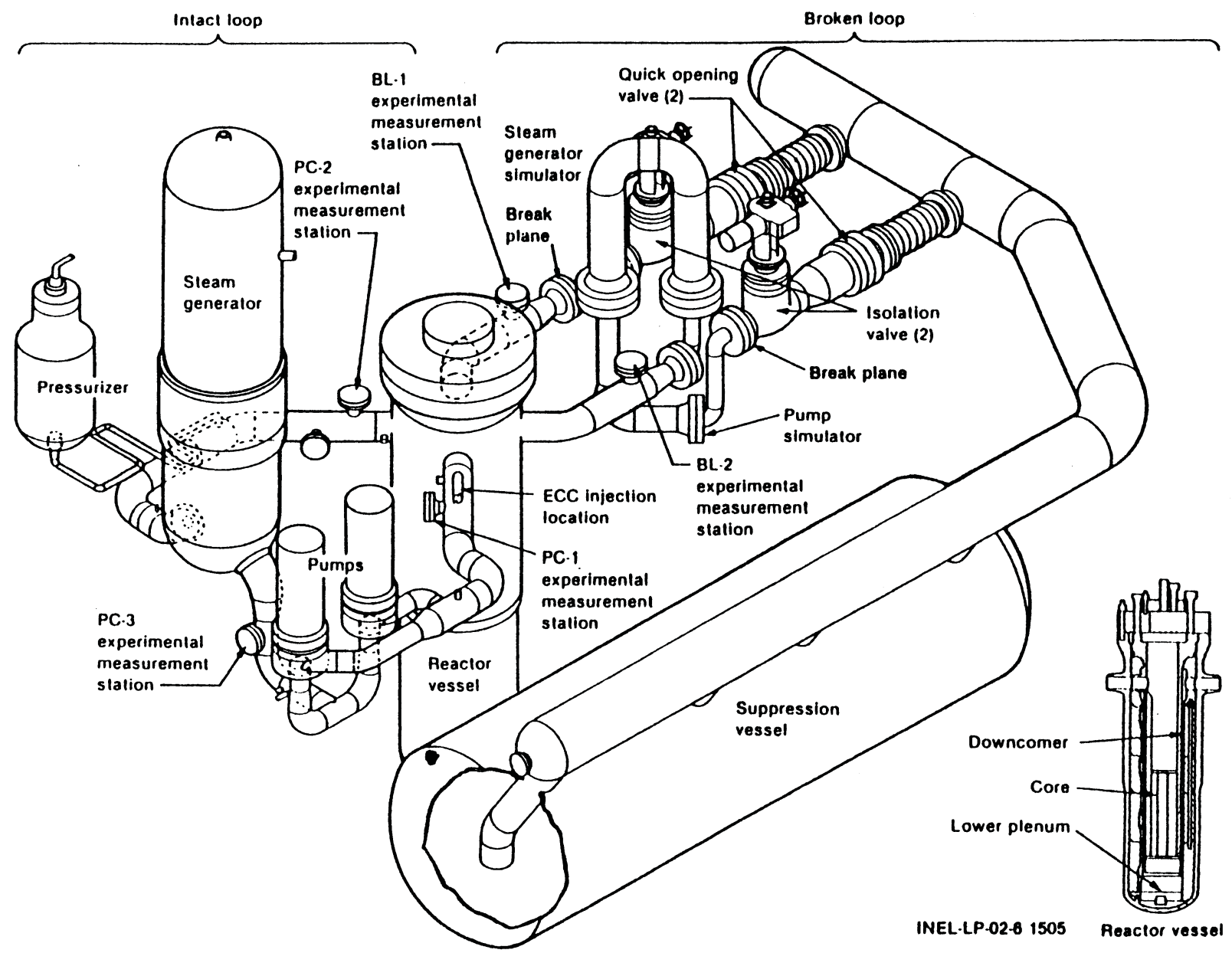

Figure 5.6-1. Schematic of the LOFT facility. 


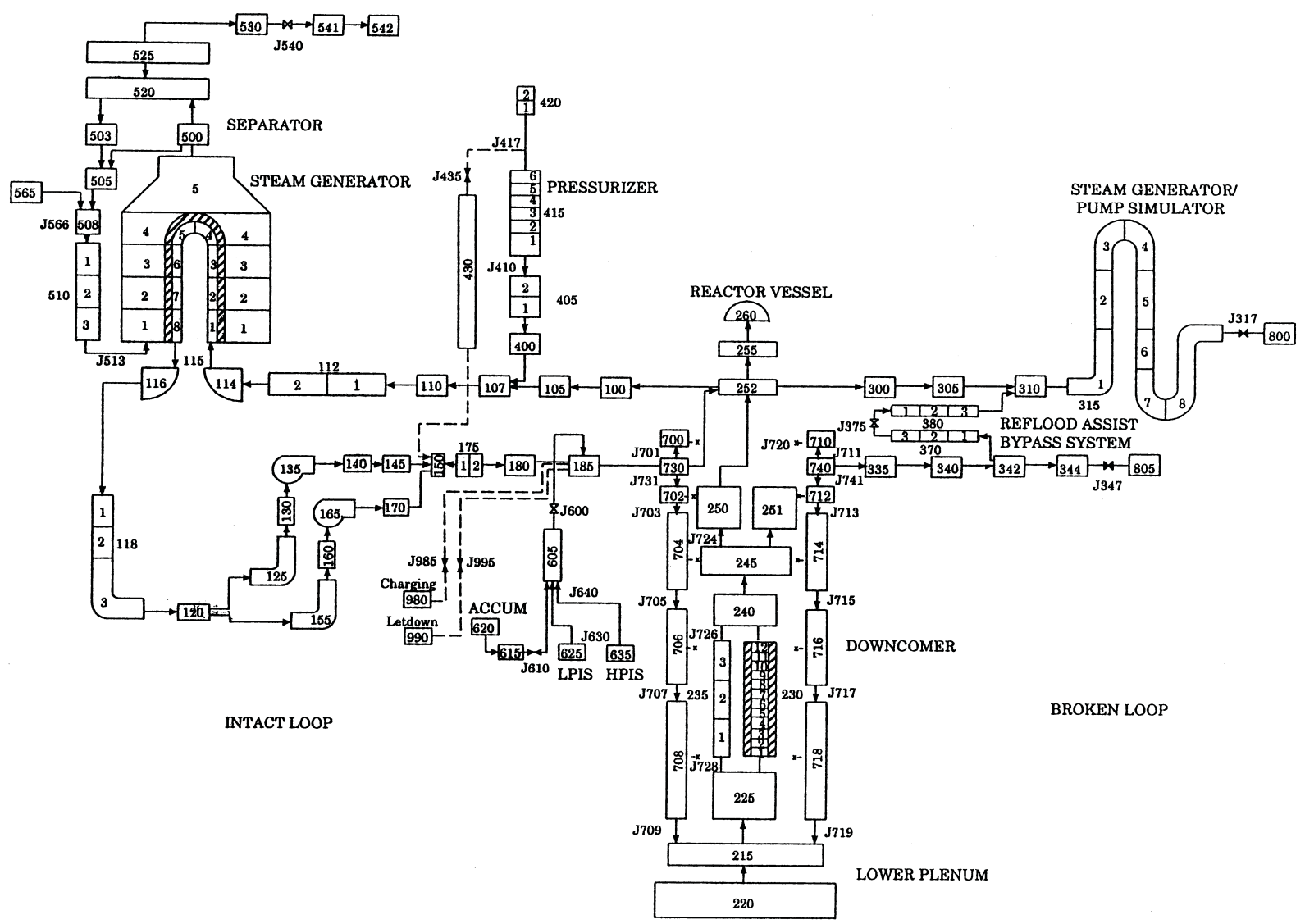

Figure 5.6-2. RELAP5-3D nodalization for the LOFT facility Experiment L2-5 (1-D vessel). 


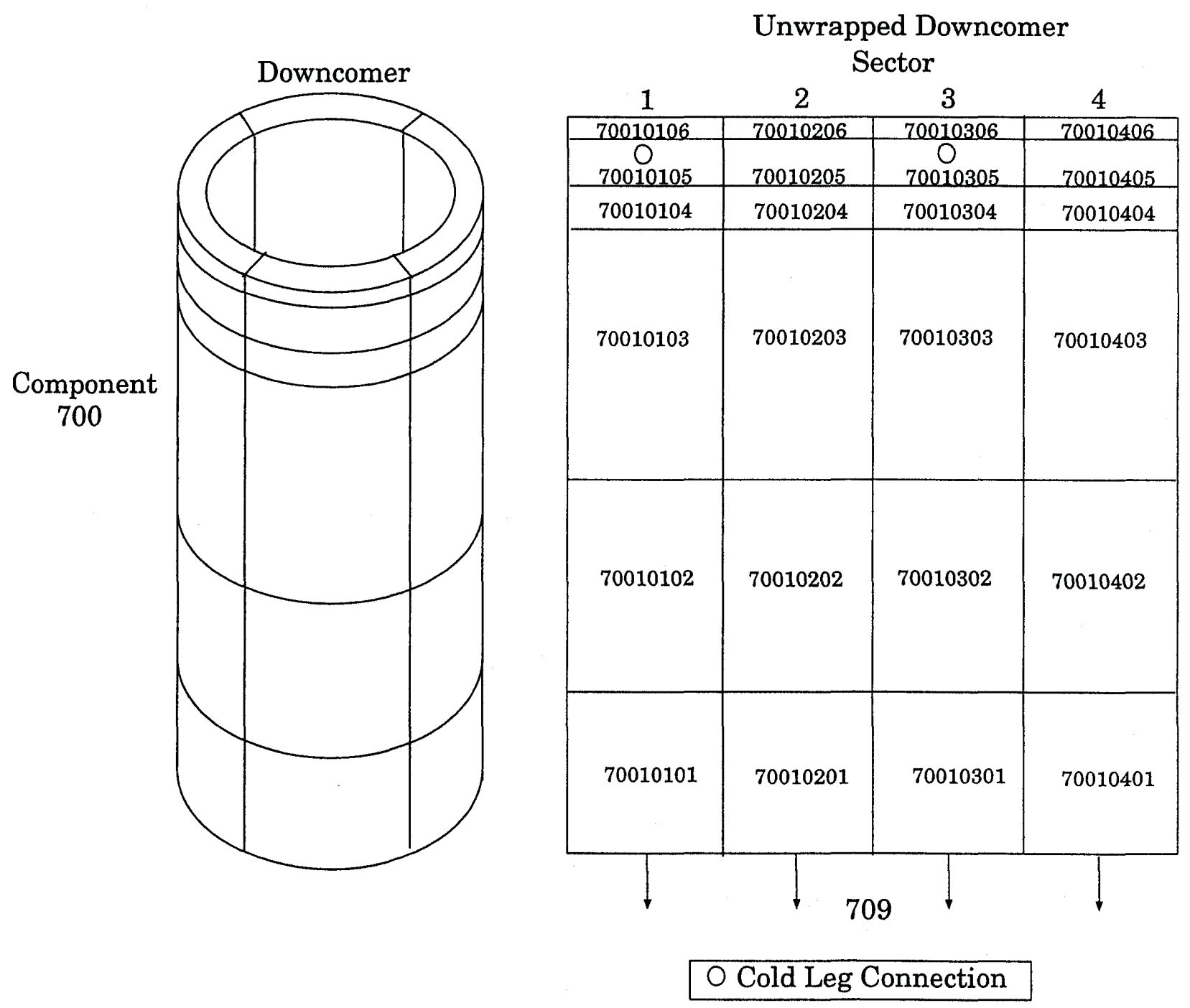

Figure 5.6-3. RELAP-3D nodalization for the LOFT reactor vessel downcomer (3-D vessel). 


\section{Sector 1}

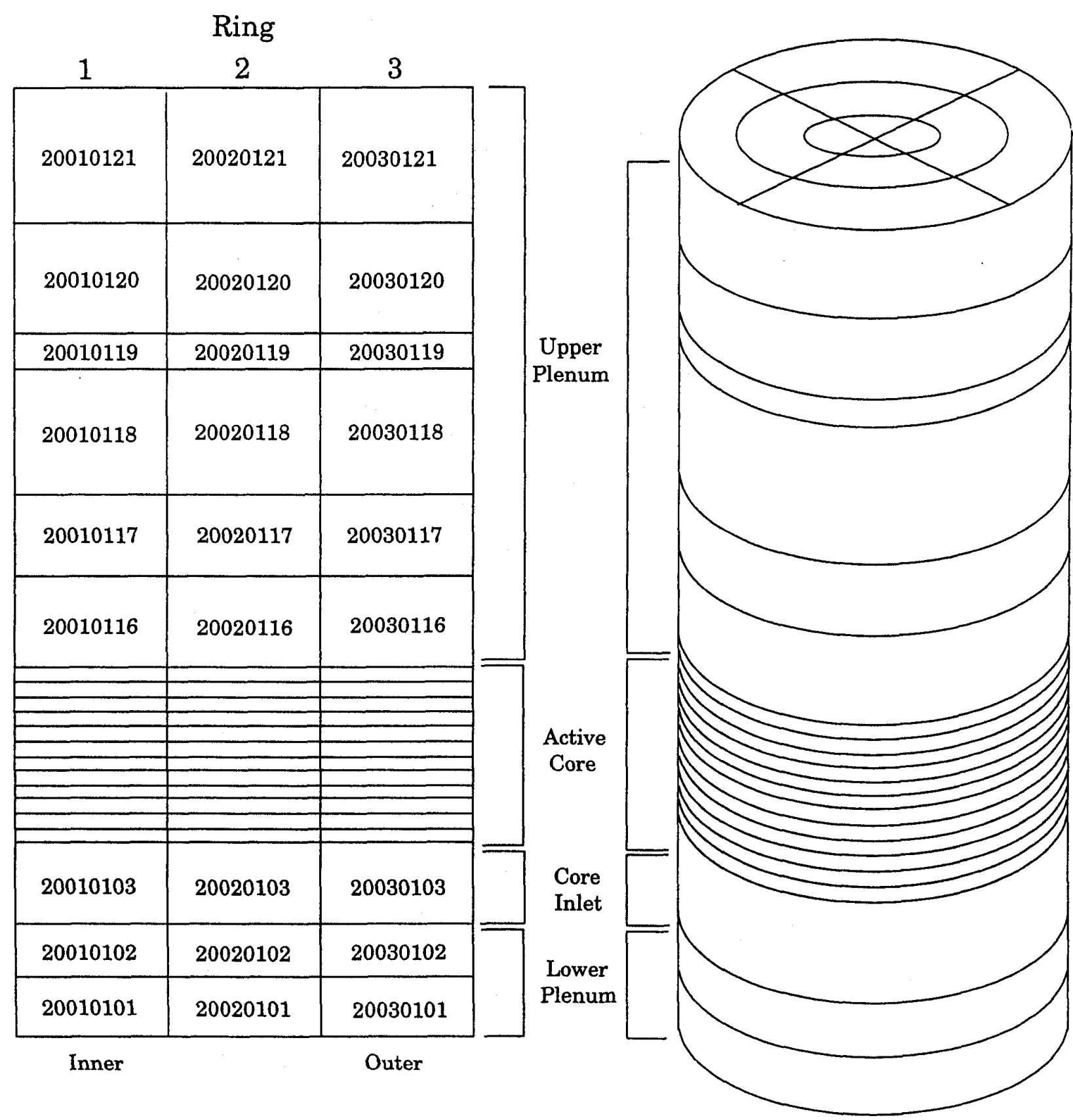

Figure 5.6-4. RELAP5-3D nodalization for the LOFT reactor vessel core region (3-D vessel). 


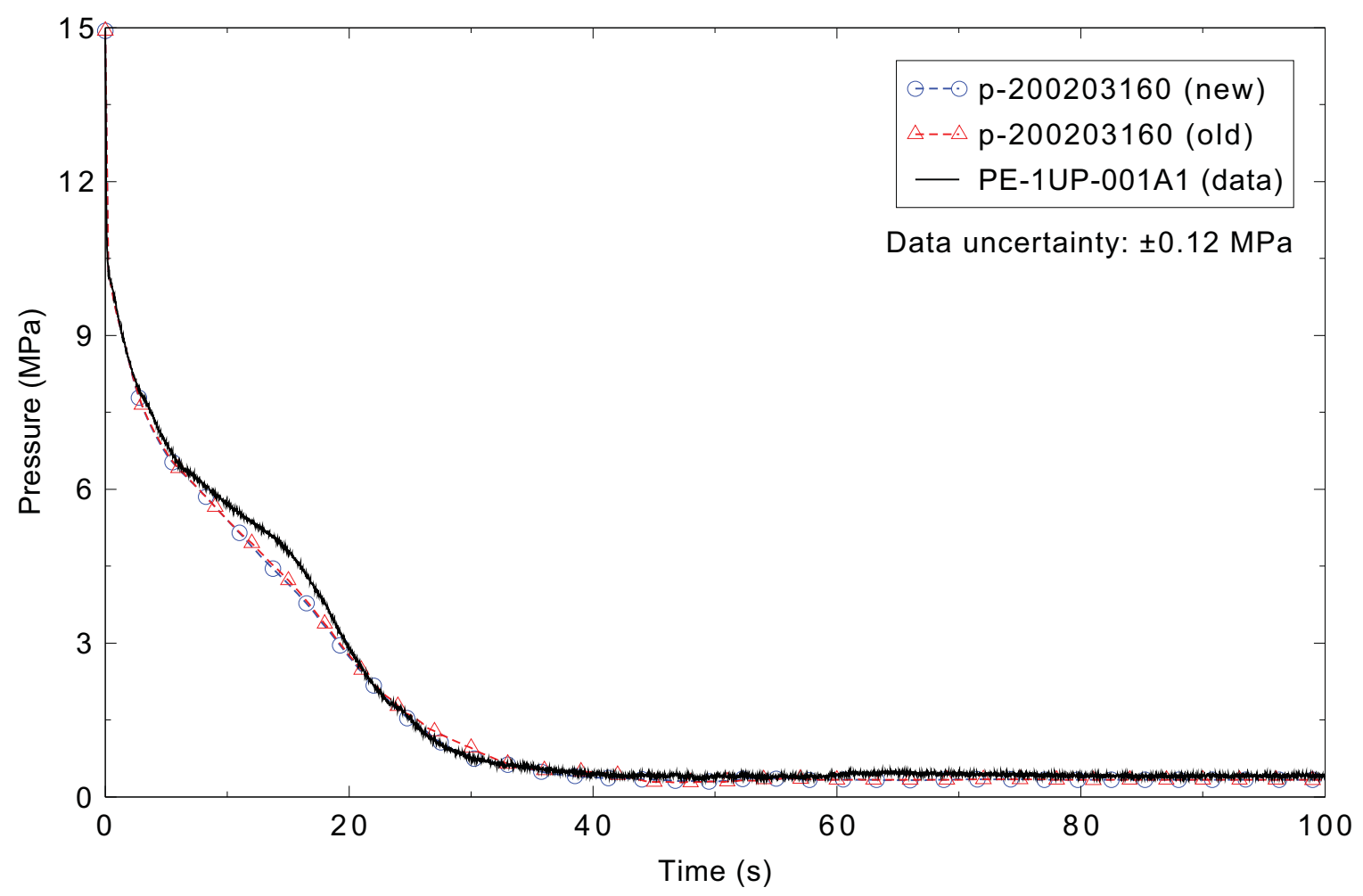

Figure 5.6-5. Measured and calculated reactor vessel upper plenum pressure for the LOFT L2-5 3-D case.

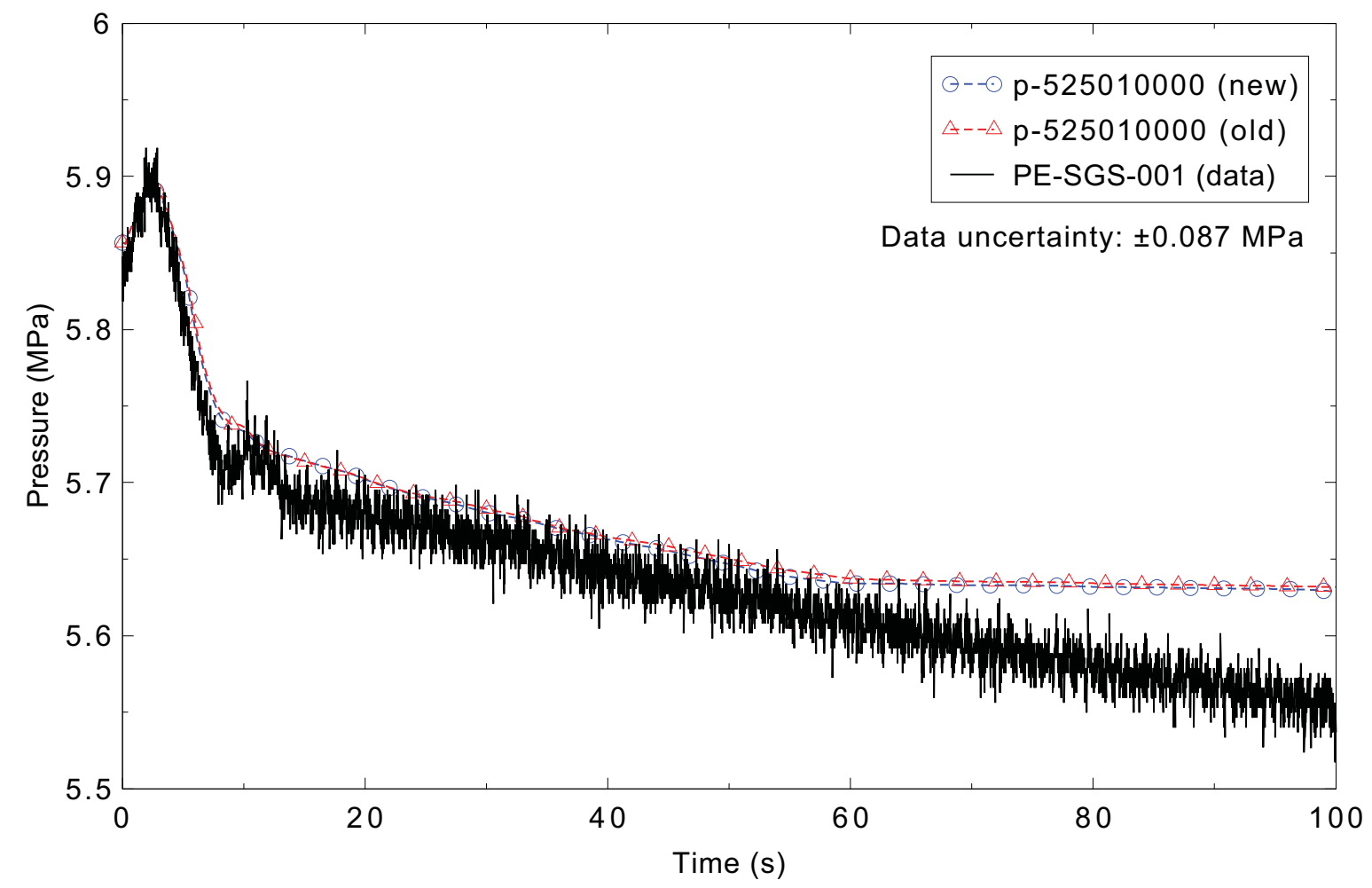

Figure 5.6-6. Measured and calculated steam generator pressure for the LOFT L2-5 3-D case. 


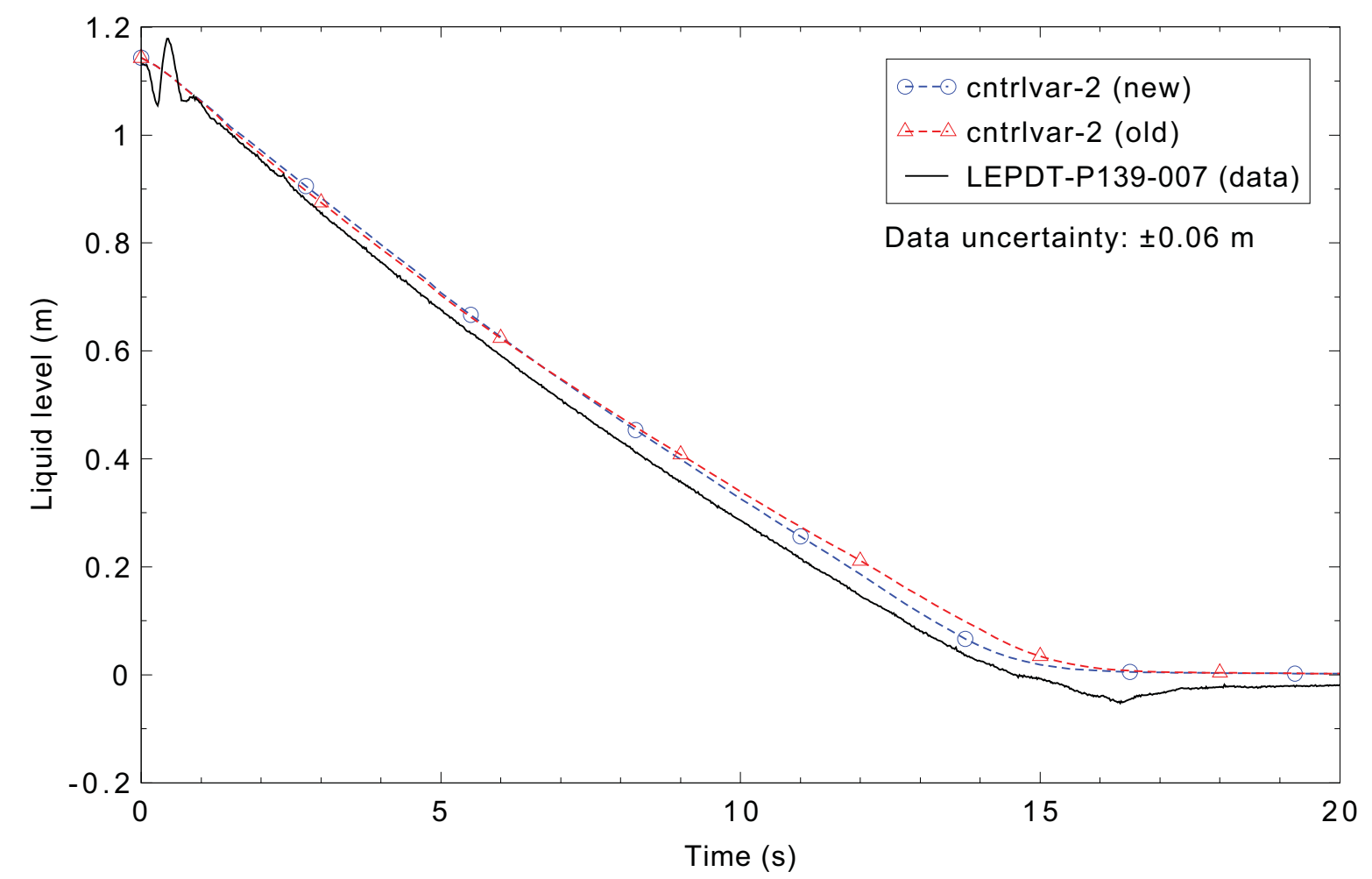

Figure 5.6-7. Measured and calculated pressurizer liquid level for the LOFT L2-5 3-D case.

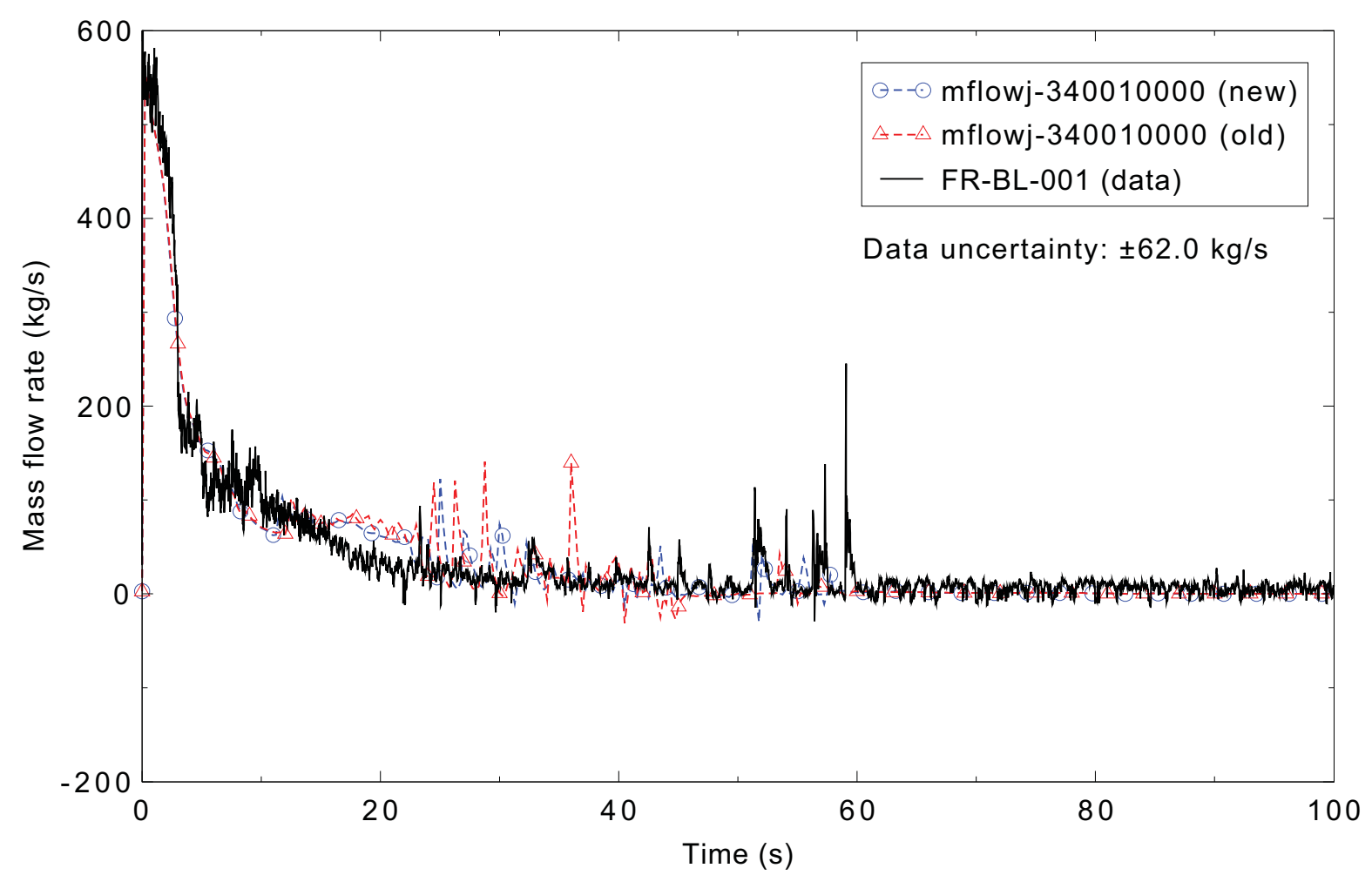

Figure 5.6-8. Measured and calculated mass flow rate in the broken loop cold leg for the LOFT L2-5 3-D case. 


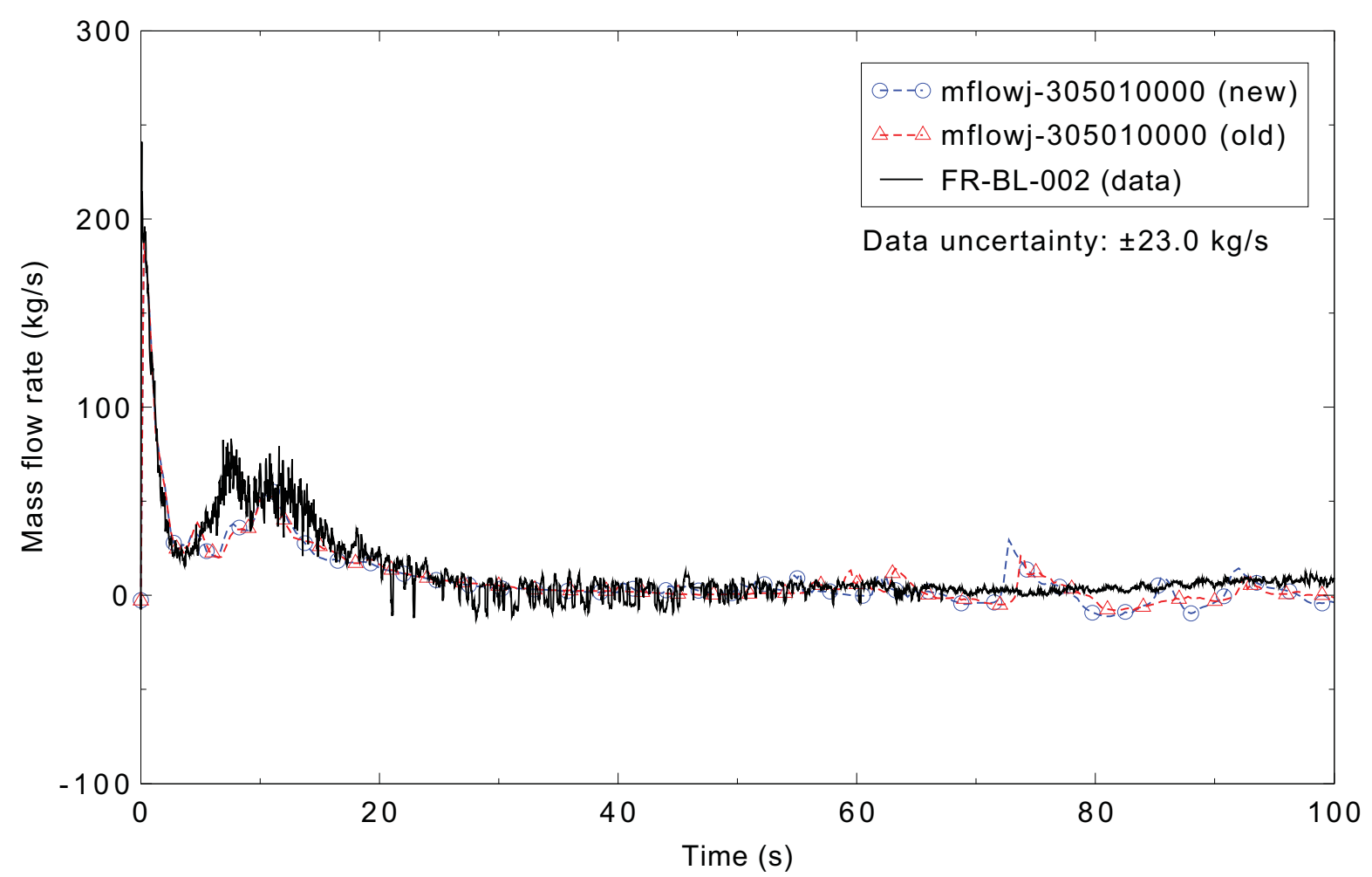

Figure 5.6-9. Measured and calculated mass flow rate in the broken loop hot leg for the LOFT L2-5 3-D case.

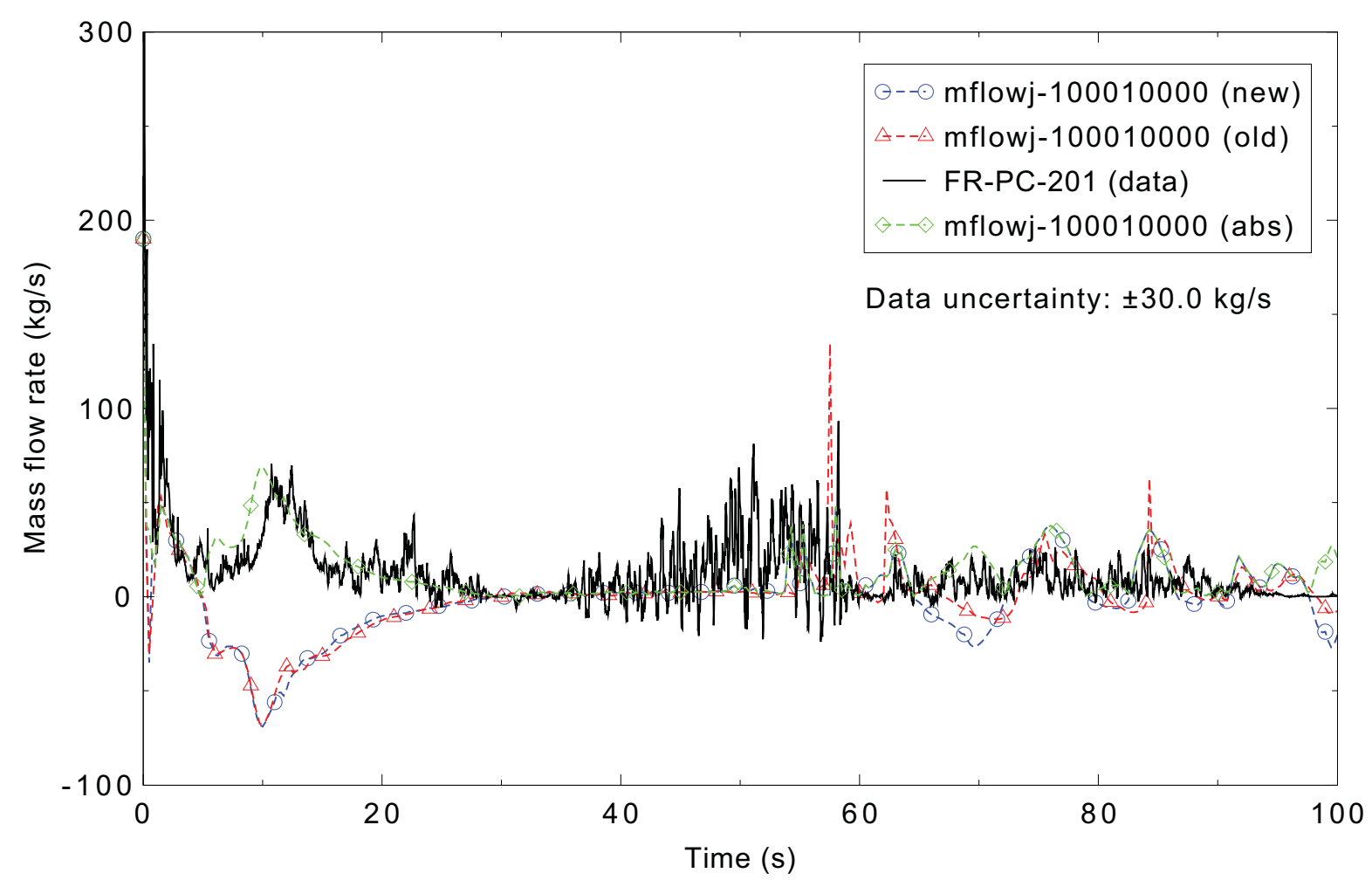

Figure 5.6-10. Measured and calculated mass flow rate in the intact loop hot leg for the LOFT L2-5 3-D case. 


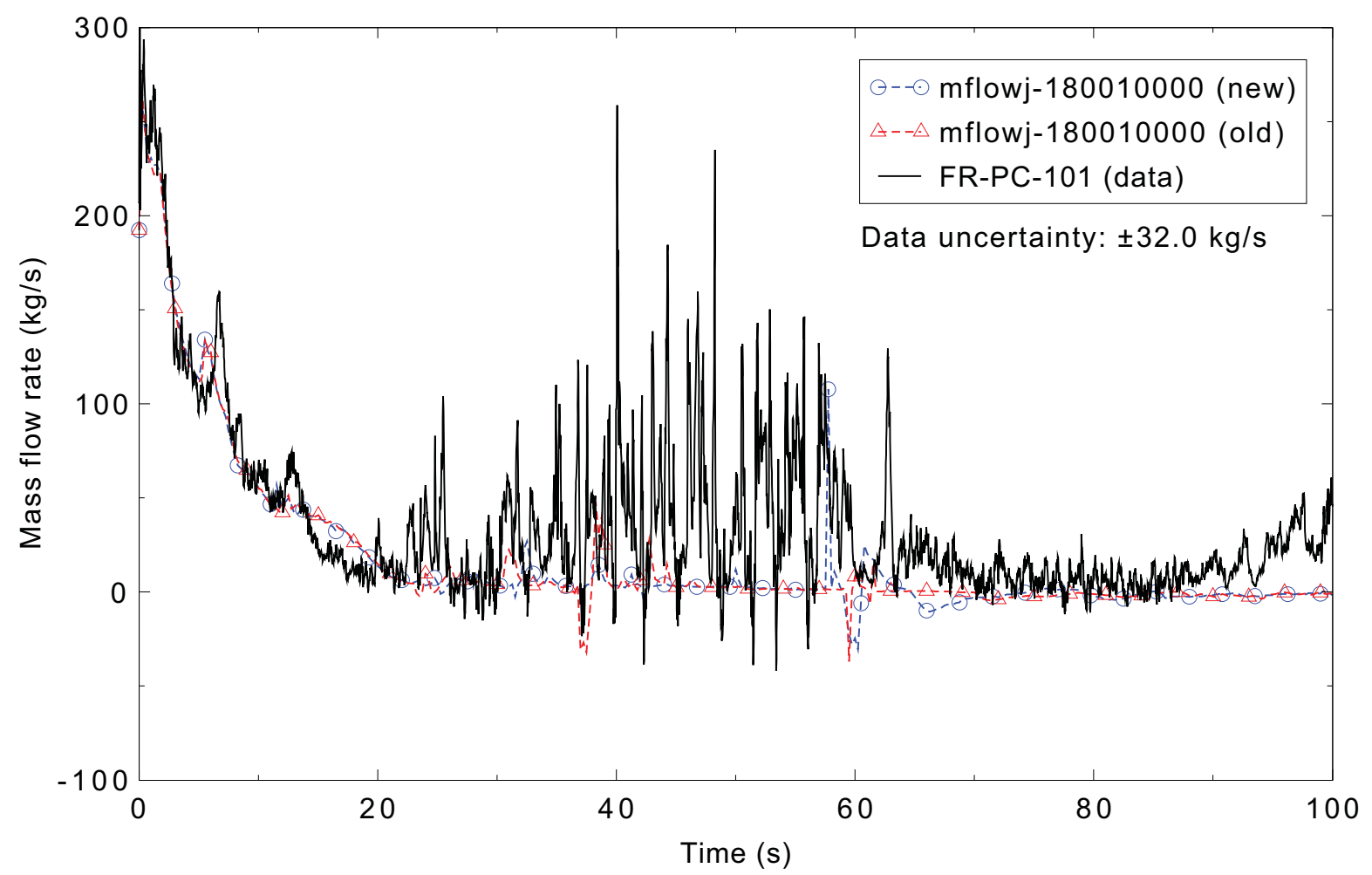

Figure 5.6-11. Measured and calculated mass flow rate in the intact loop cold leg for the LOFT L2-5 3-D case.

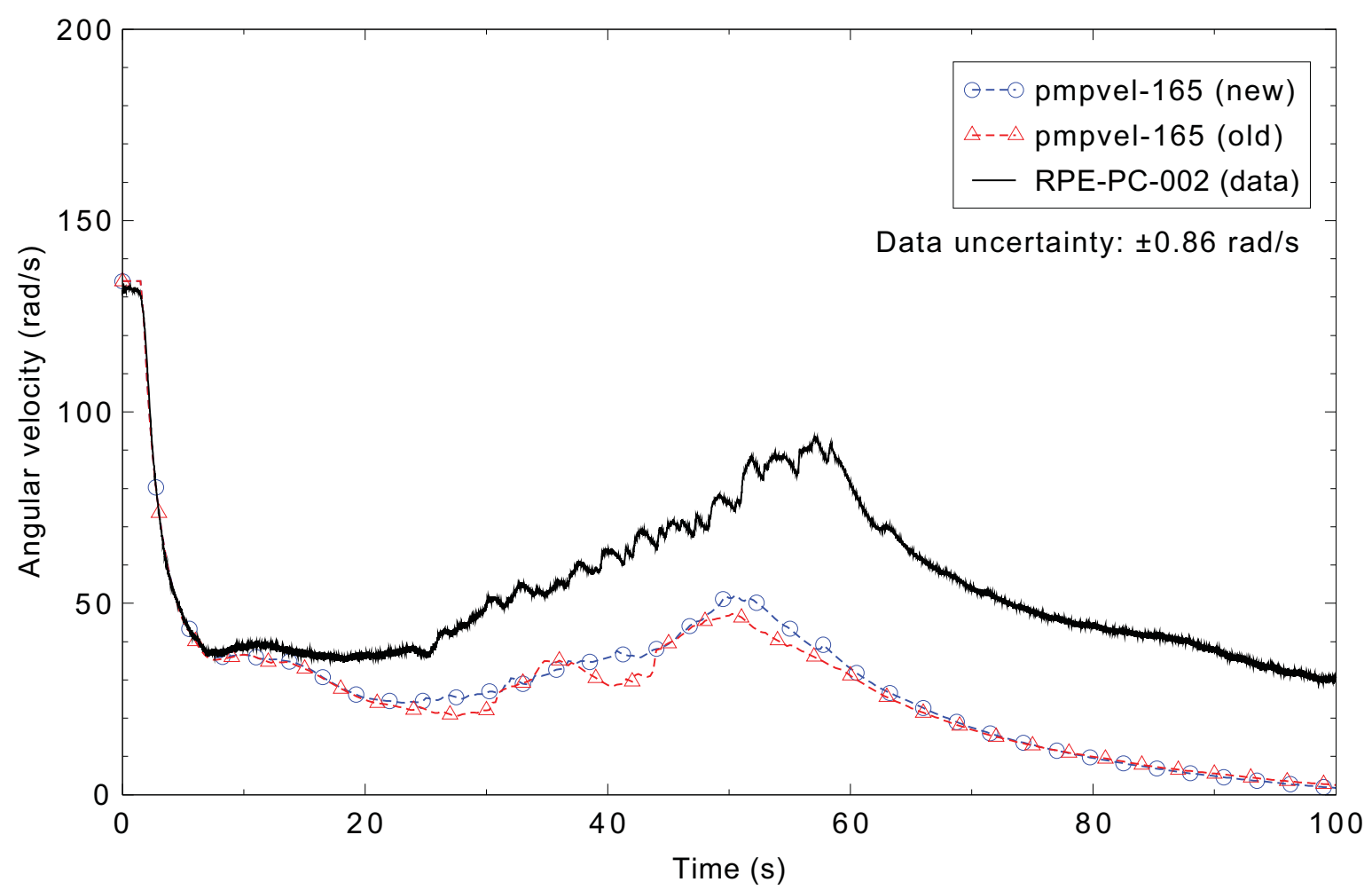

Figure 5.6-12. Measured and calculated speed for primary coolant pump 2 for the LOFT L2-5 3-D case. 


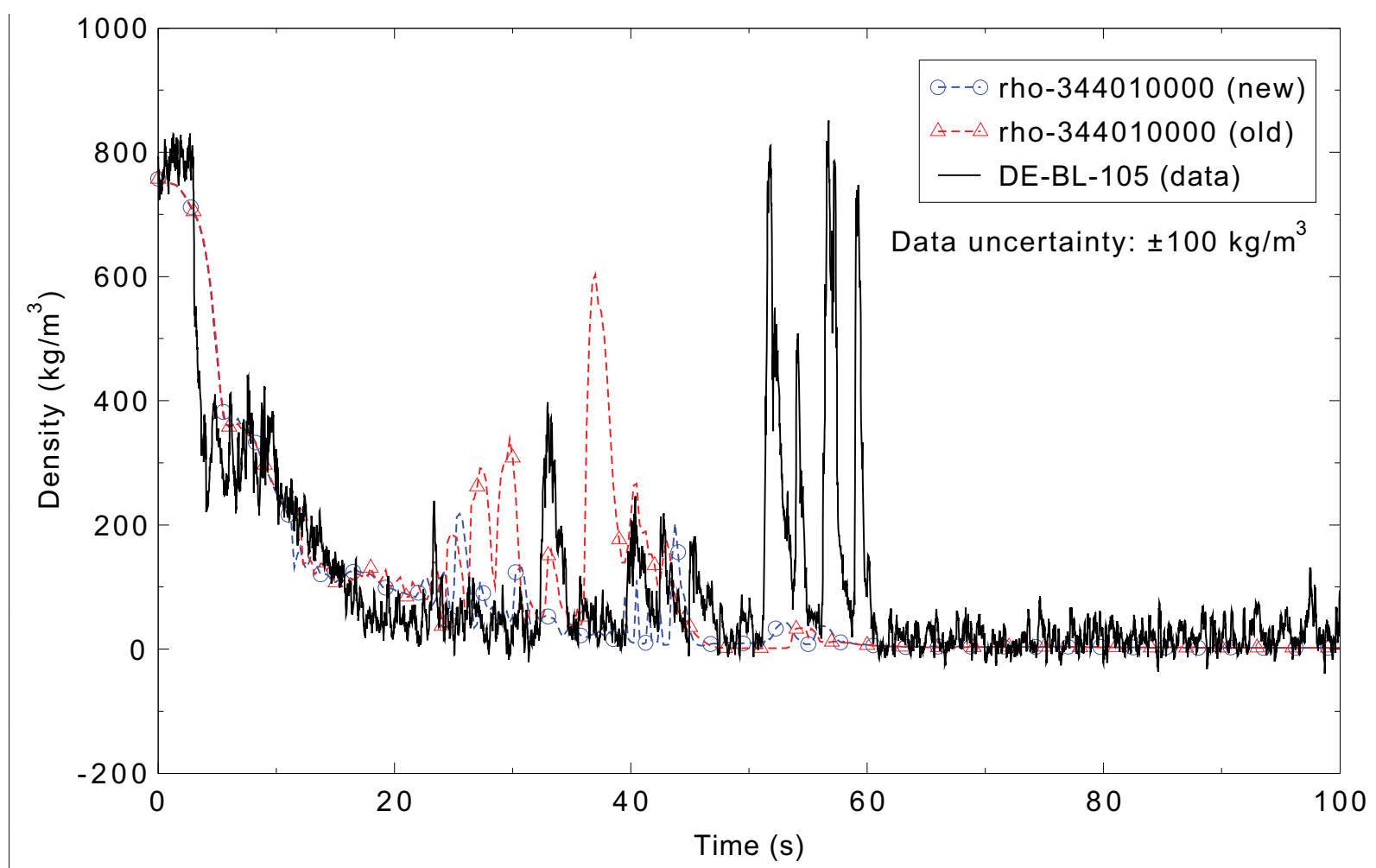

Figure 5.6-13. Measured and calculated density in the broken loop cold leg for the LOFT L2-5 3-D case.

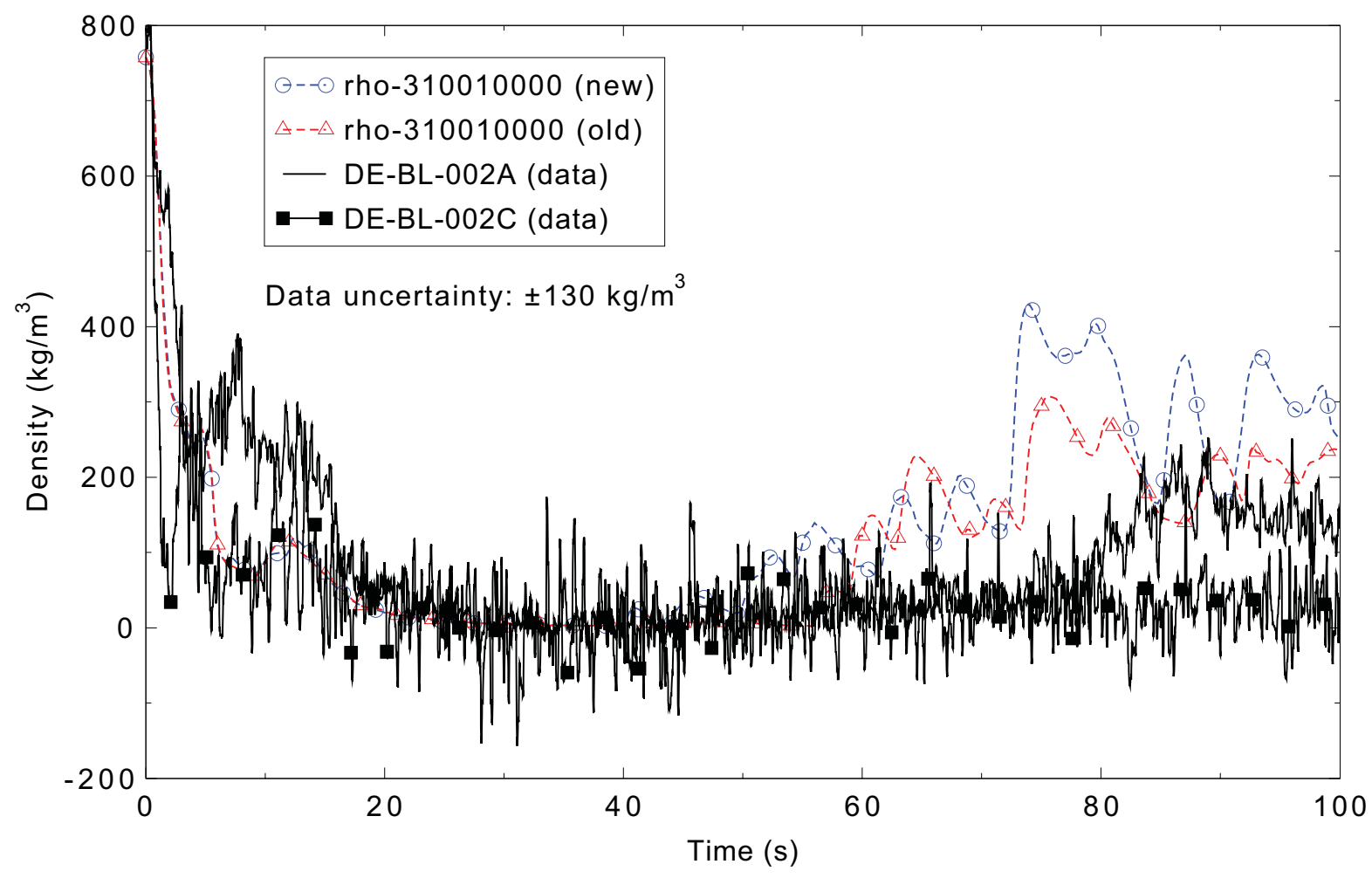

Figure 5.6-14. Measured and calculated density in the broken loop hot leg for the LOFT L2-5 3-D case. 


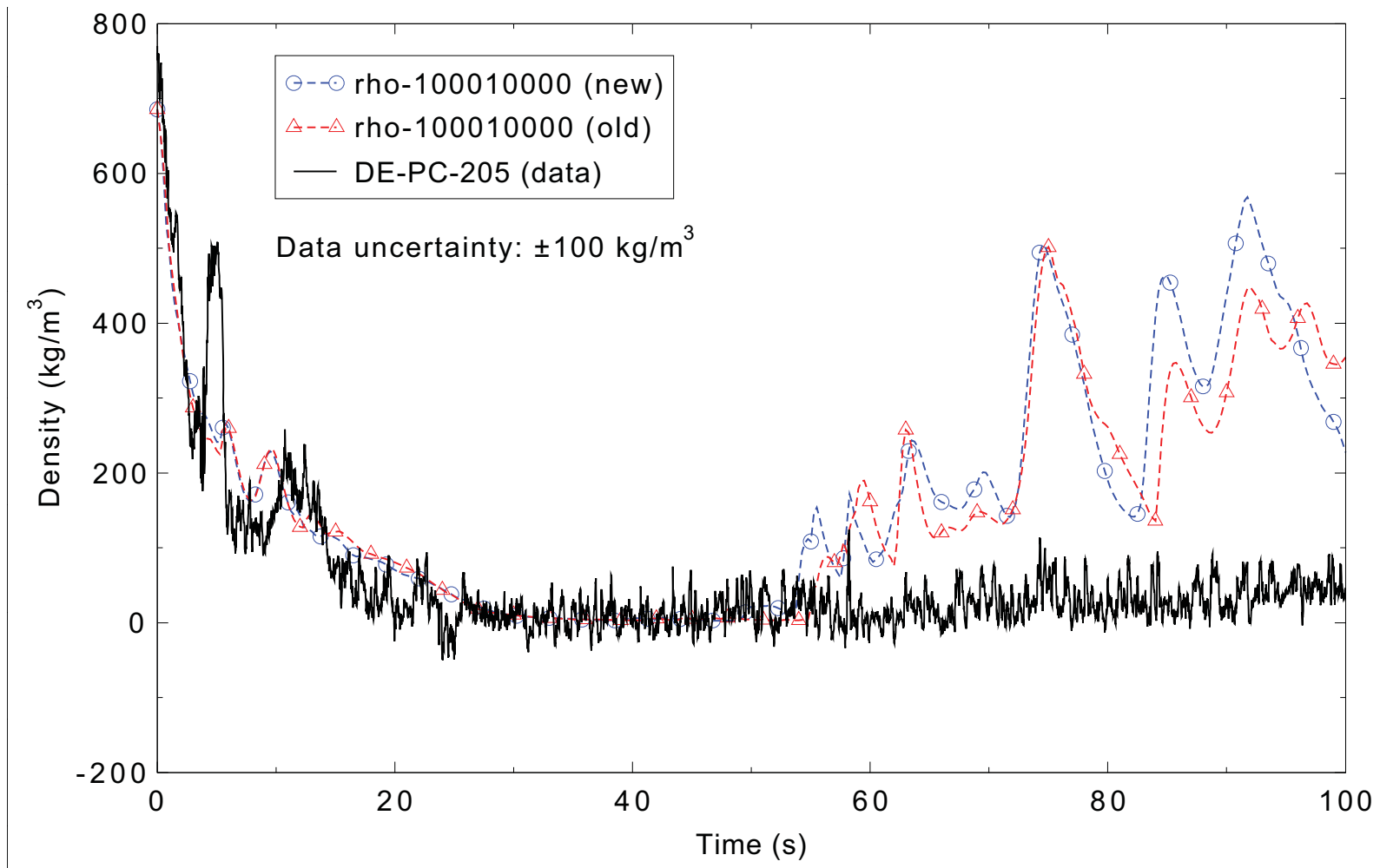

Figure 5.6-15. Measured and calculated density in the intact loop hot leg for the LOFT L2-5 3-D case.

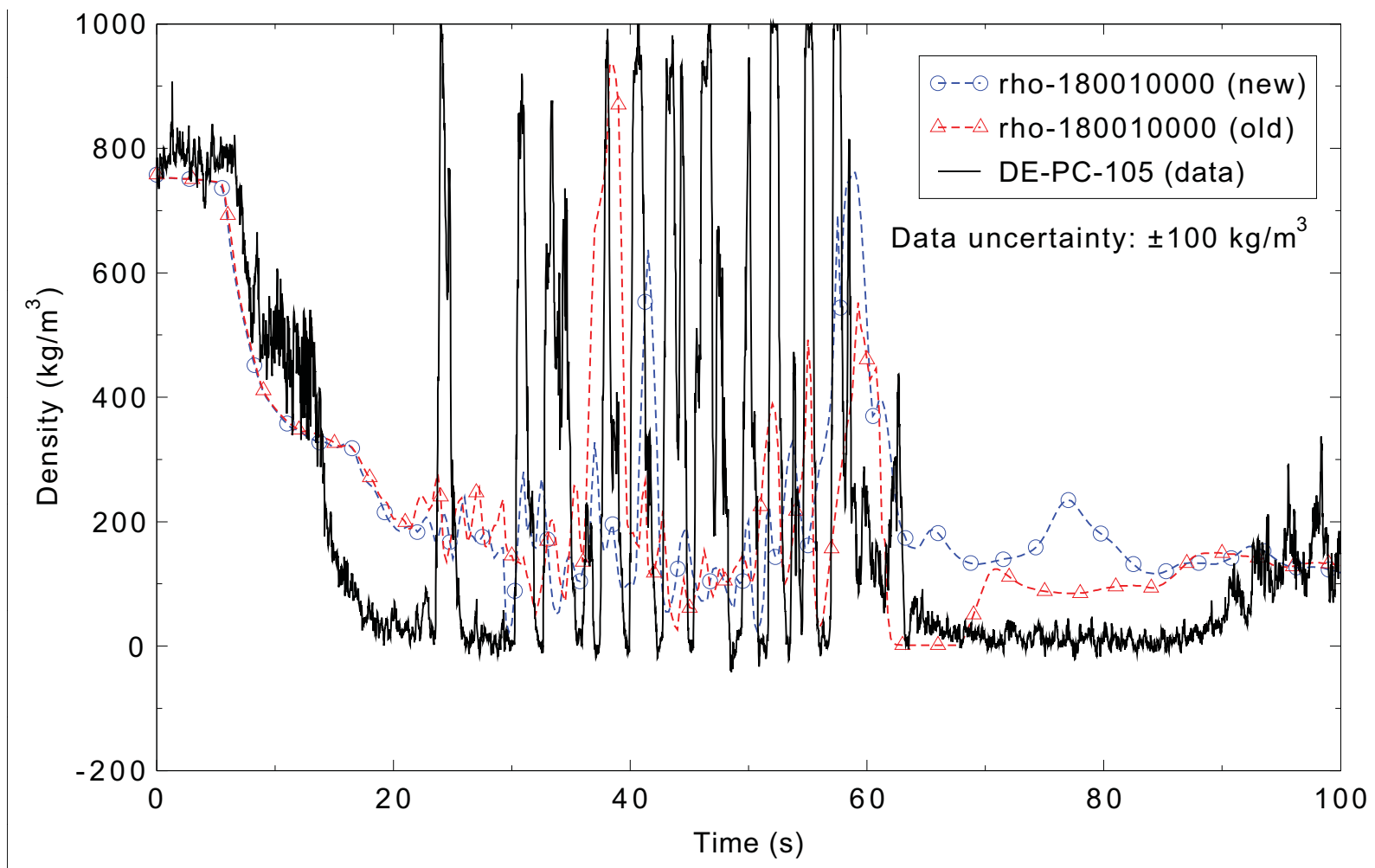

Figure 5.6-16. Measured and calculated density in the intact loop cold leg for the LOFT L2-5 3-D case. 


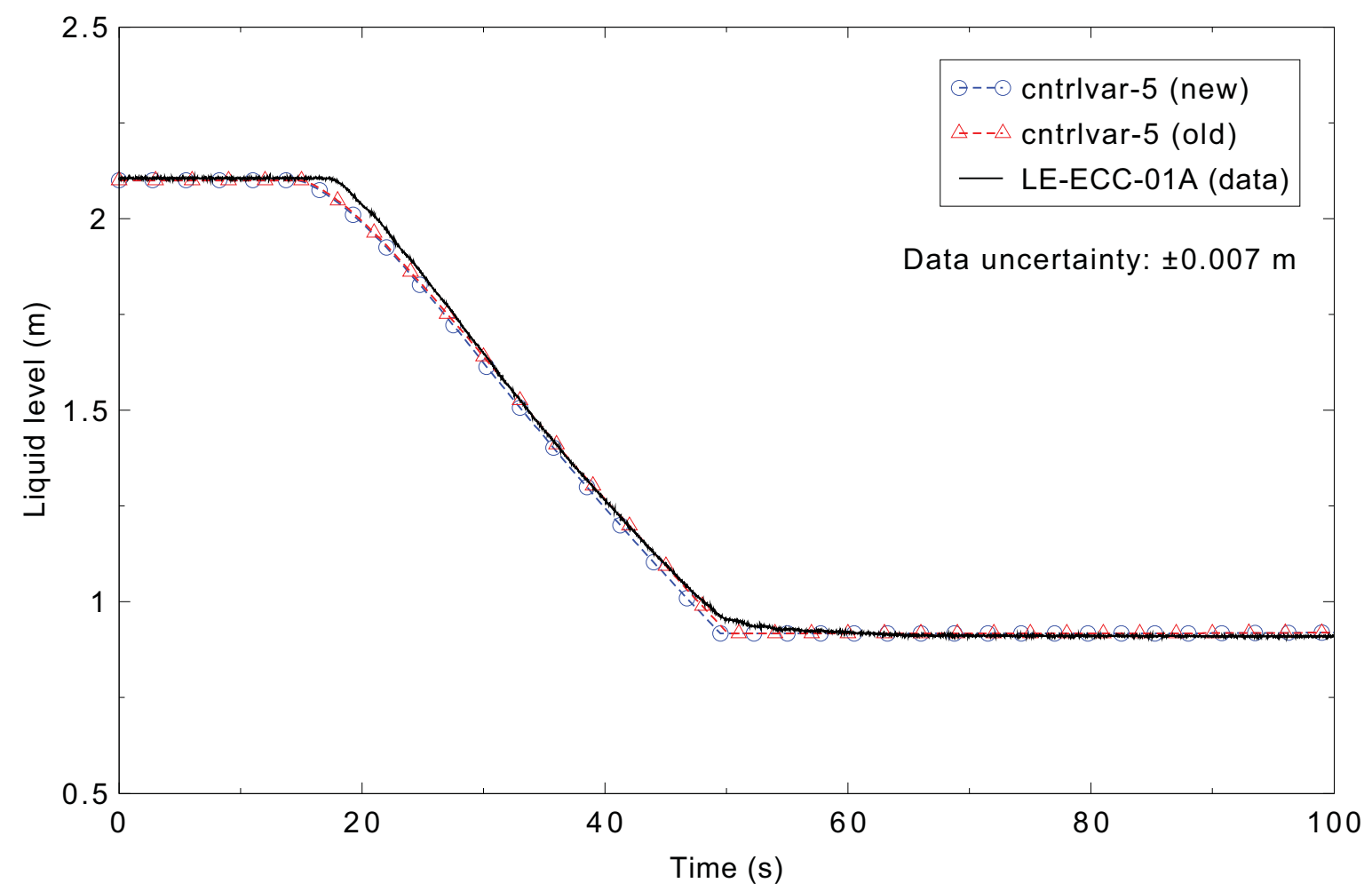

Figure 5.6-17. Measured and calculated accumulator liquid level for the LOFT L2-5 3-D case.

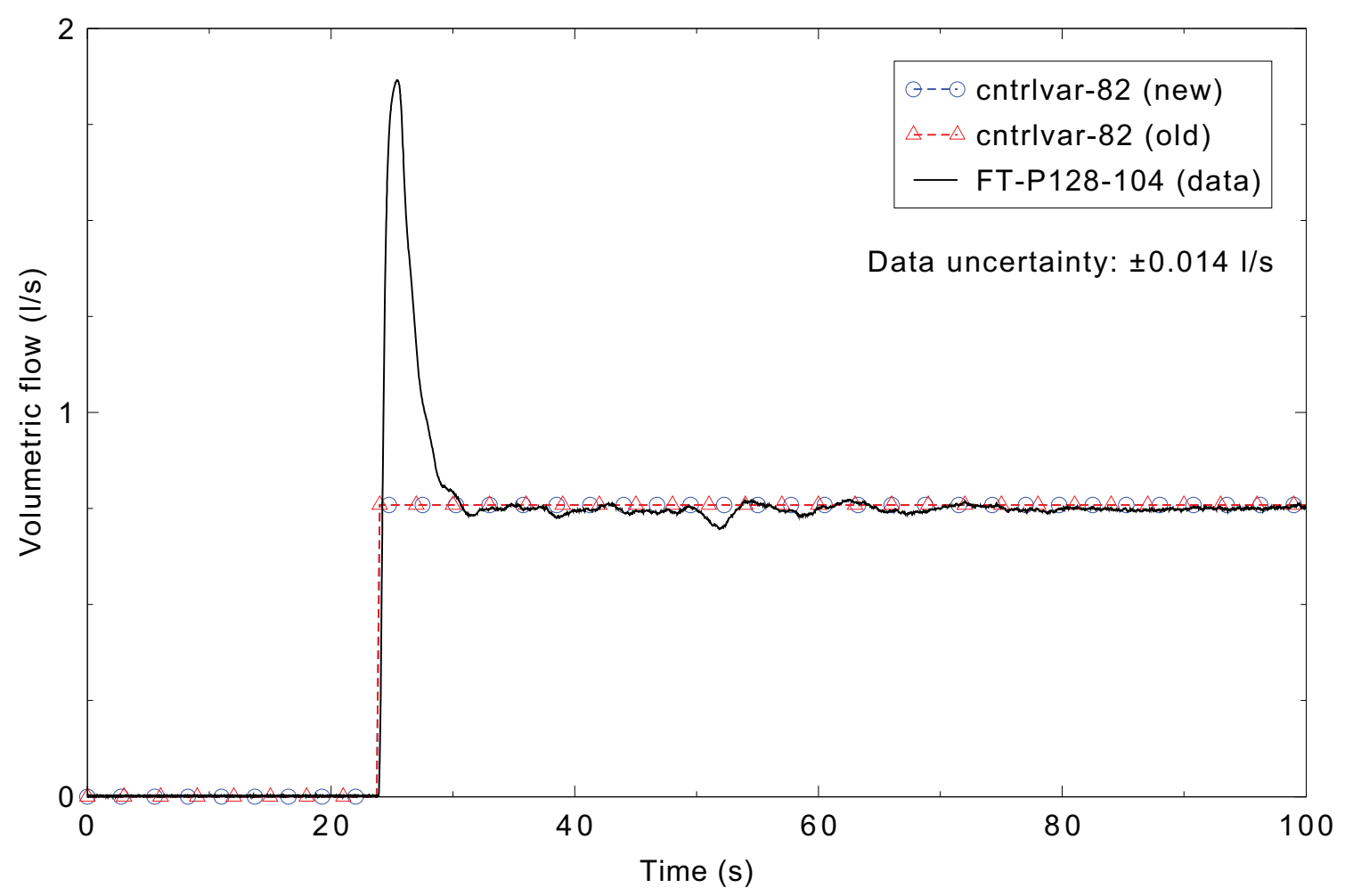

Figure 5.6-18. Measured and calculated HPIS flow for the LOFT L2-5 3-D case. 


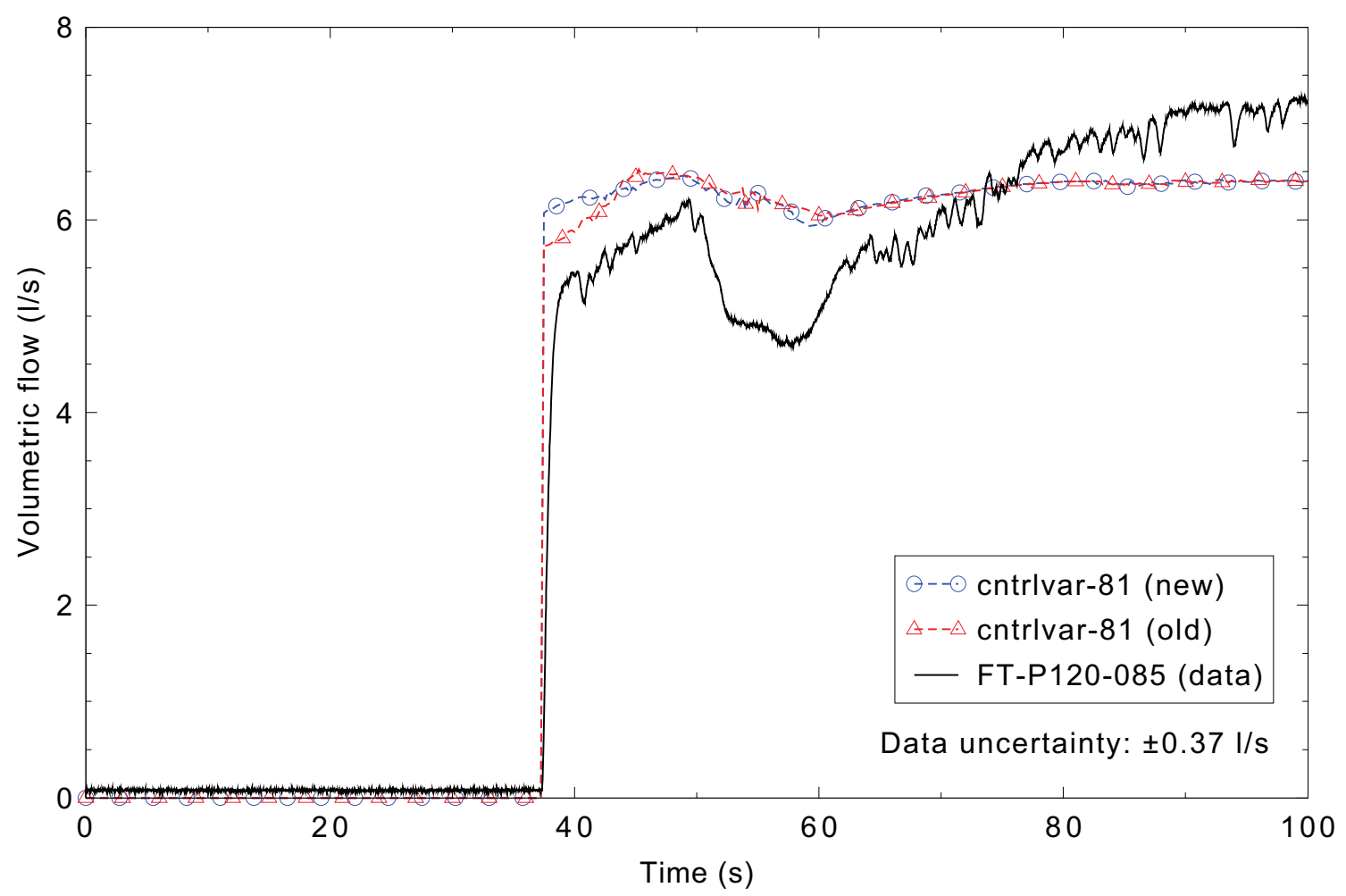

Figure 5.6-19. Measured and calculated LPIS flow for the LOFT L2-5 3-D case.

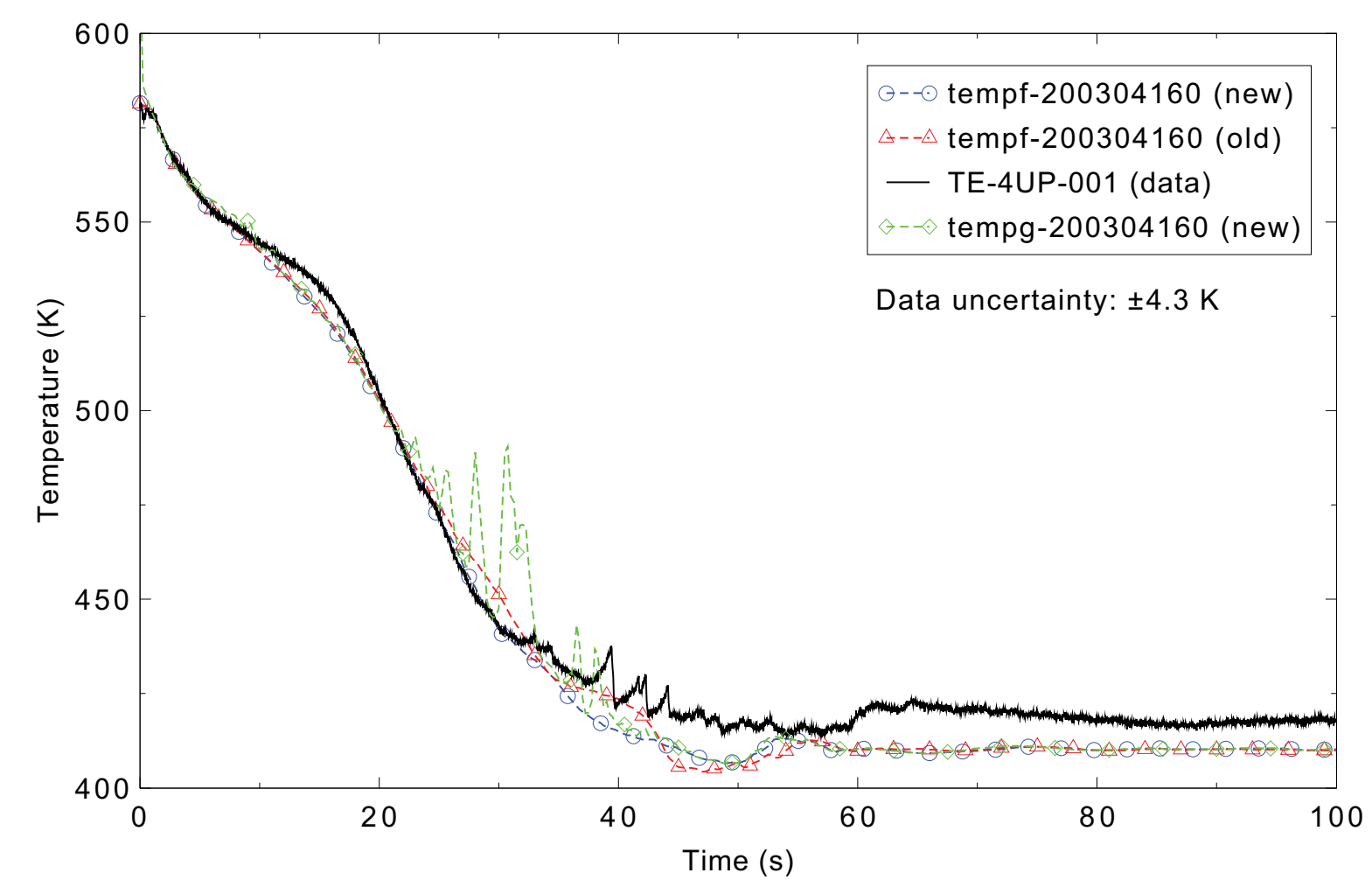

Figure 5.6-20. Measured and calculated reactor vessel upper plenum coolant temperature for the LOFT L2-5 3-D case. 


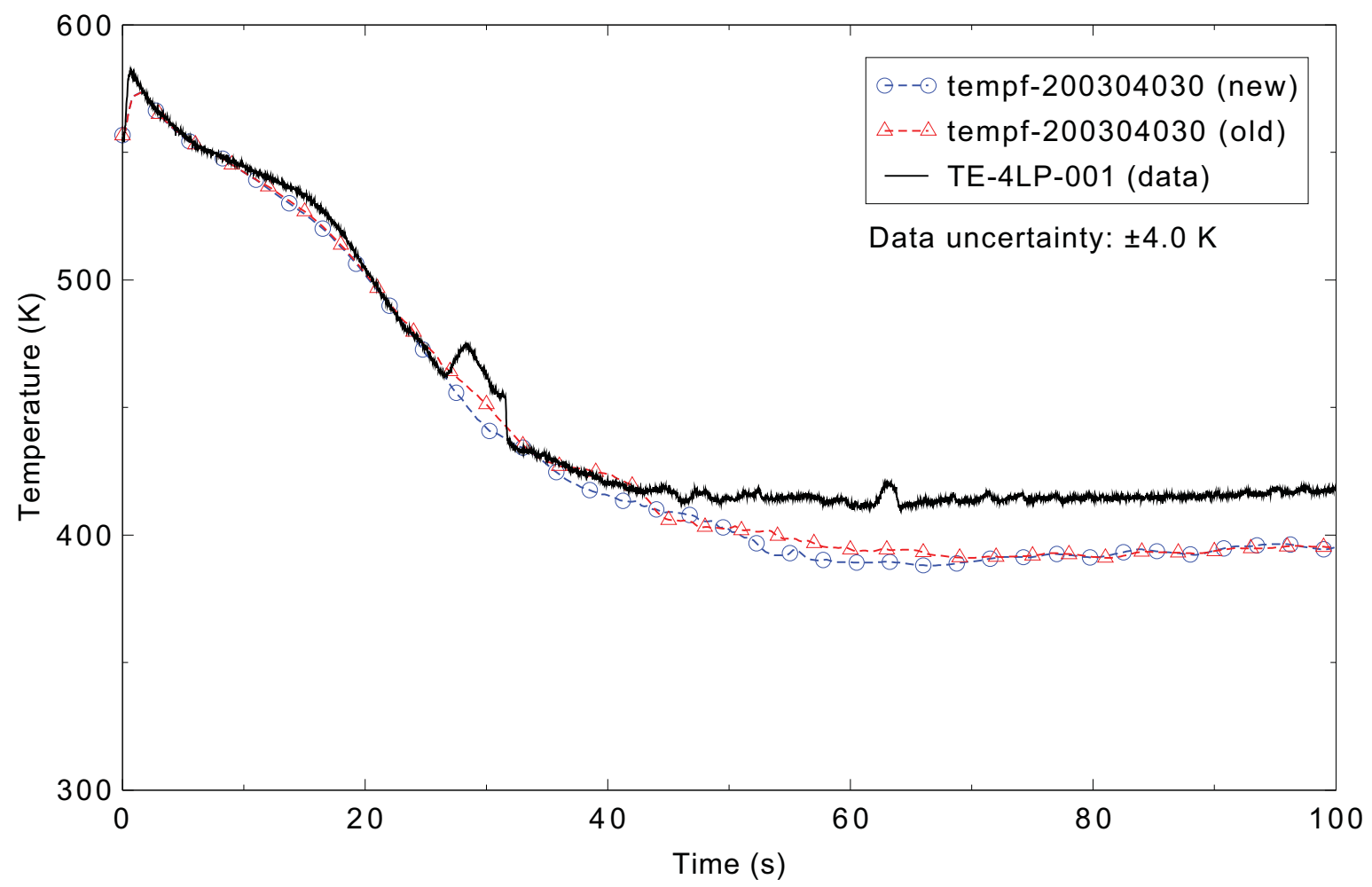

Figure 5.6-21. Measured and calculated reactor vessel lower plenum coolant temperature for the LOFT L2-5 3-D case.

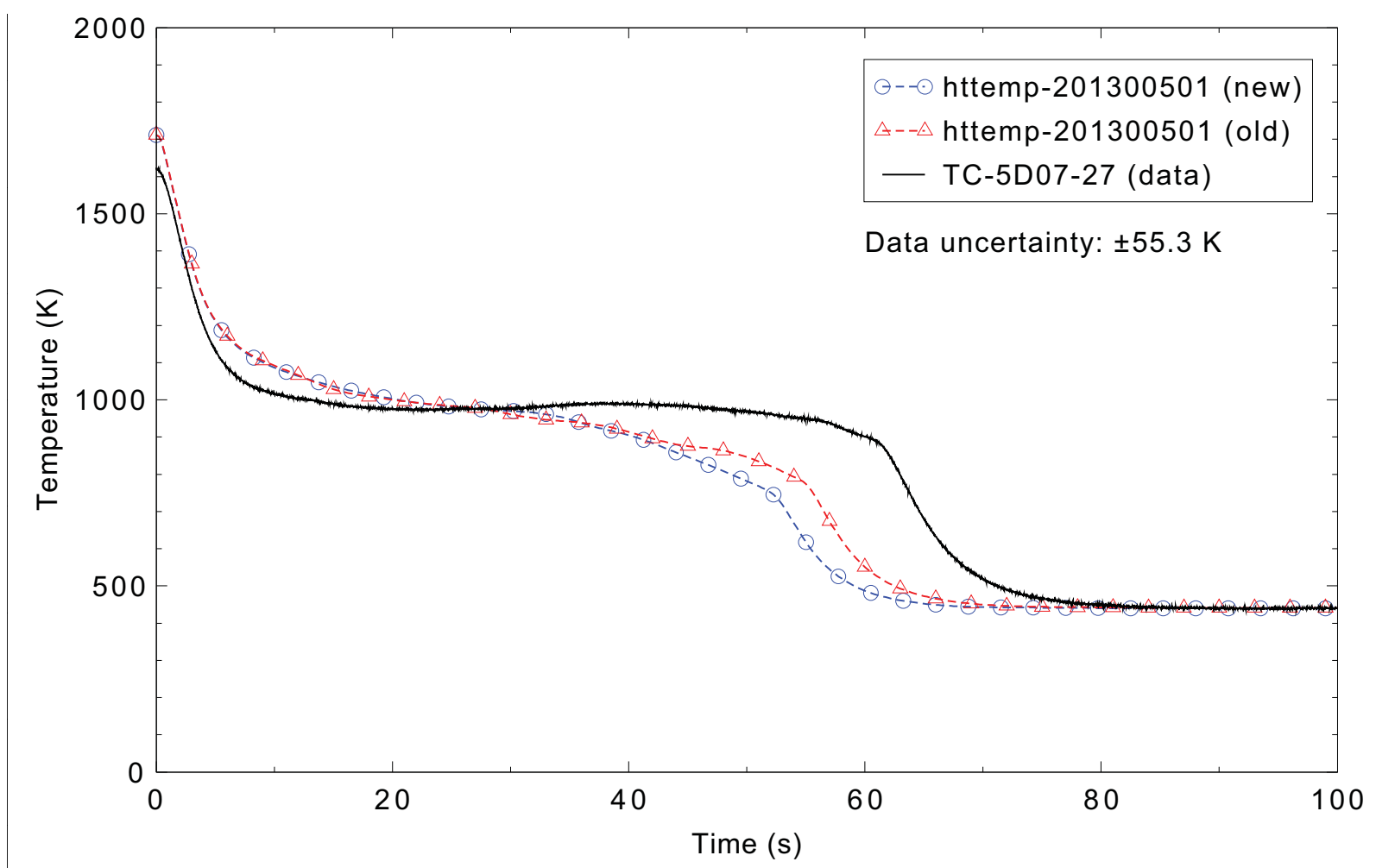

Figure 5.6-22. Measured and calculated fuel centerline temperature in Ring 1, Sector 3, $0.69 \mathrm{~m}$ above the bottom of the fuel rod for the LOFT L2-5 3-D case. 


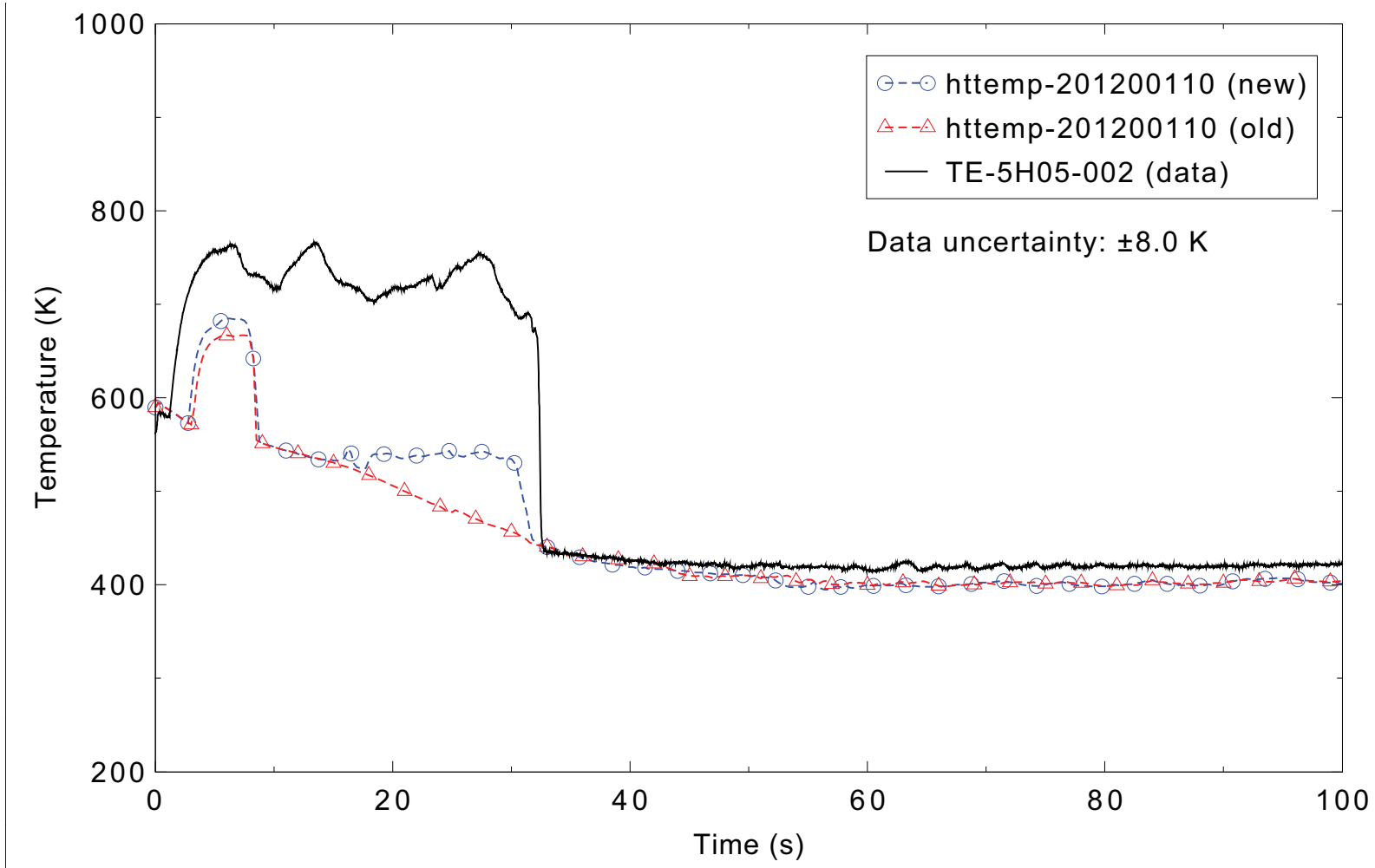

Figure 5.6-23. Measured and calculated fuel cladding surface temperature in Ring 1, Sector 2, $0.05 \mathrm{~m}$ above the bottom of the fuel rod for the LOFT L2-5 3-D case.

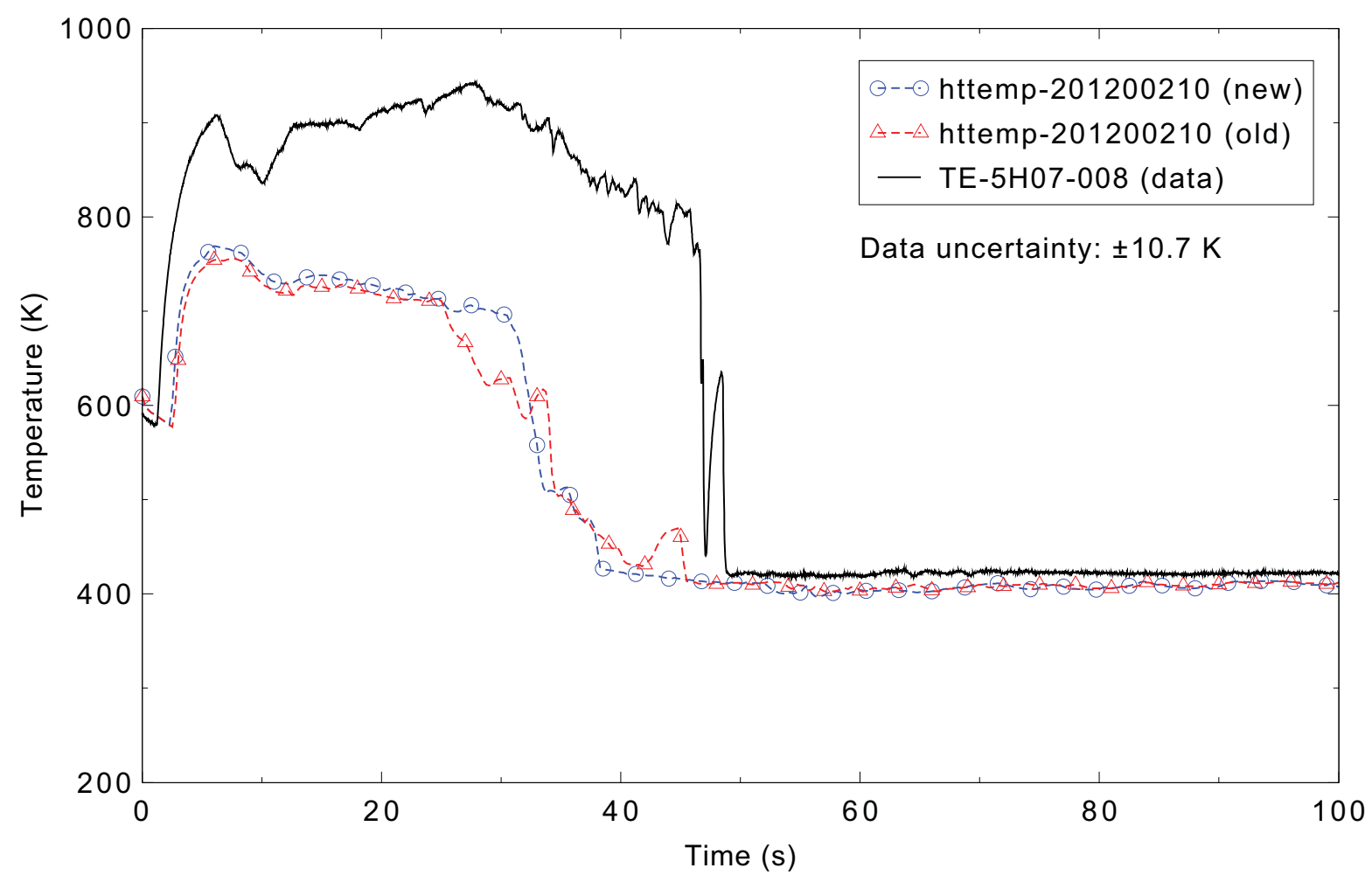

Figure 5.6-24. Measured and calculated fuel cladding surface temperature in Ring 1, Sector 2, $0.20 \mathrm{~m}$ above the bottom of the fuel rod for the LOFT L2-5 3-D case. 


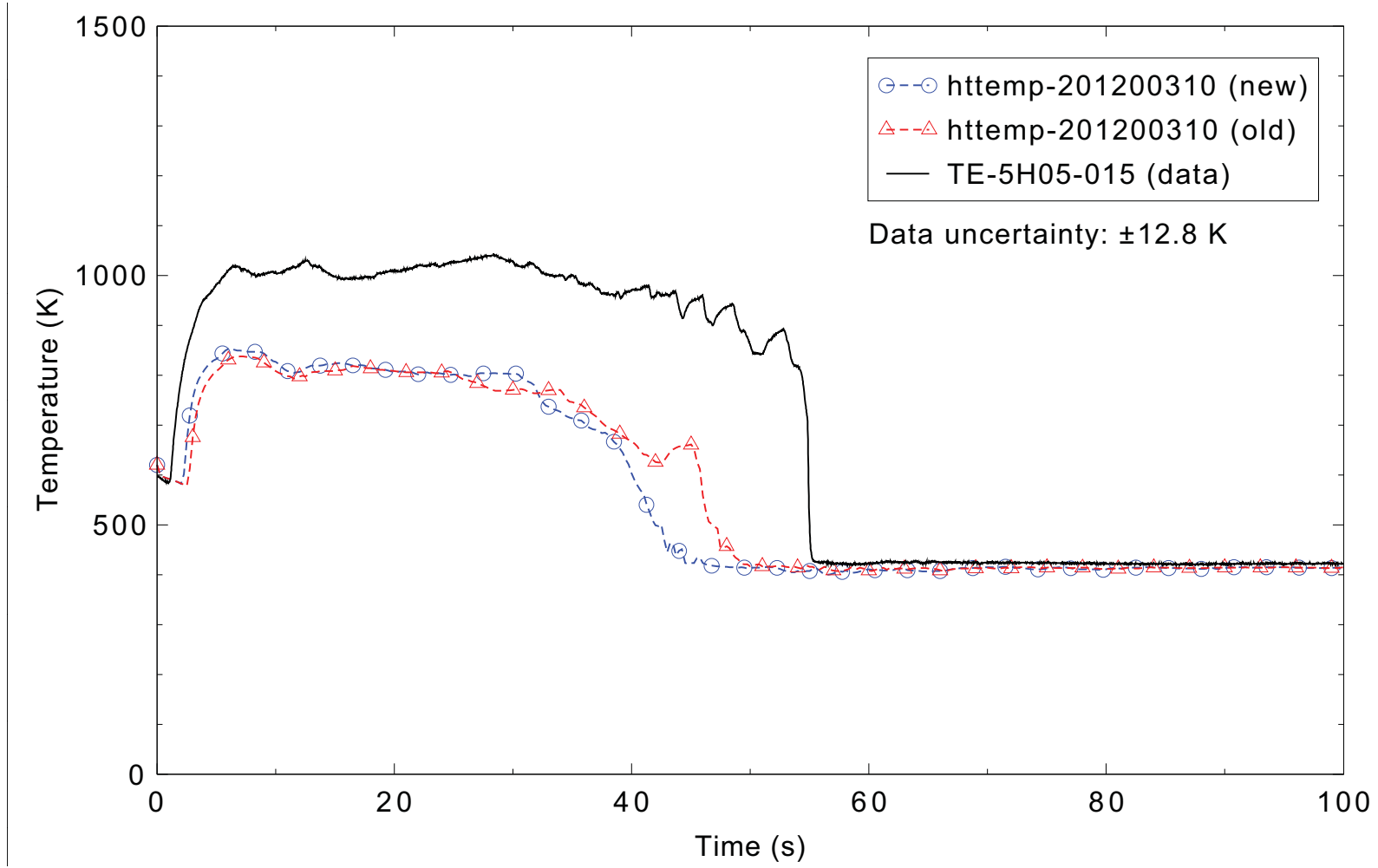

Figure 5.6-25. Measured and calculated fuel cladding surface temperature in Ring 1, Sector 2, $0.38 \mathrm{~m}$ above the bottom of the fuel rod for the LOFT L2-5 3-D case.

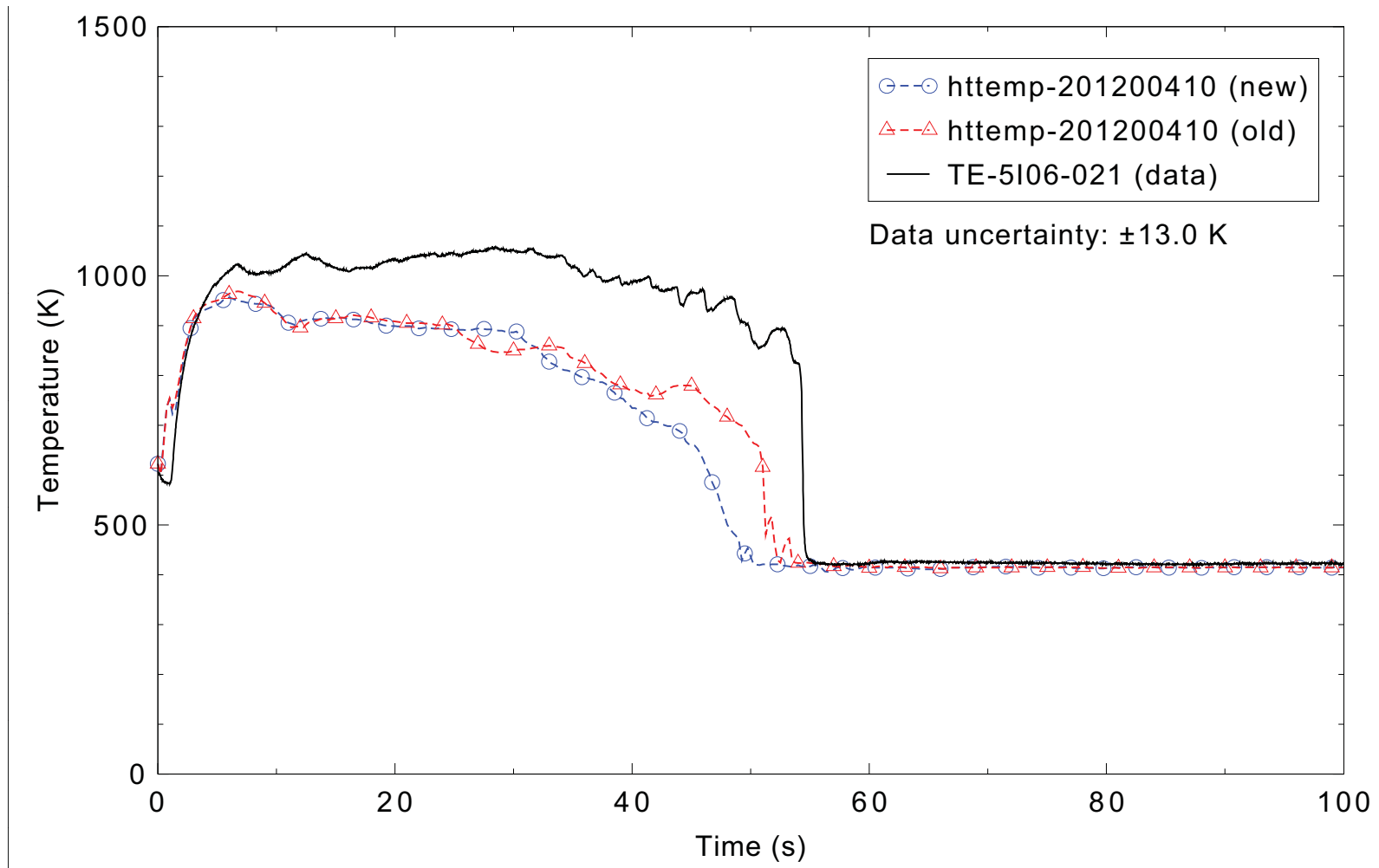

Figure 5.6-26. Measured and calculated fuel cladding surface temperature in Ring 1, Sector 2, $0.53 \mathrm{~m}$ above the bottom of the fuel rod for the LOFT L2-5 3-D case. 


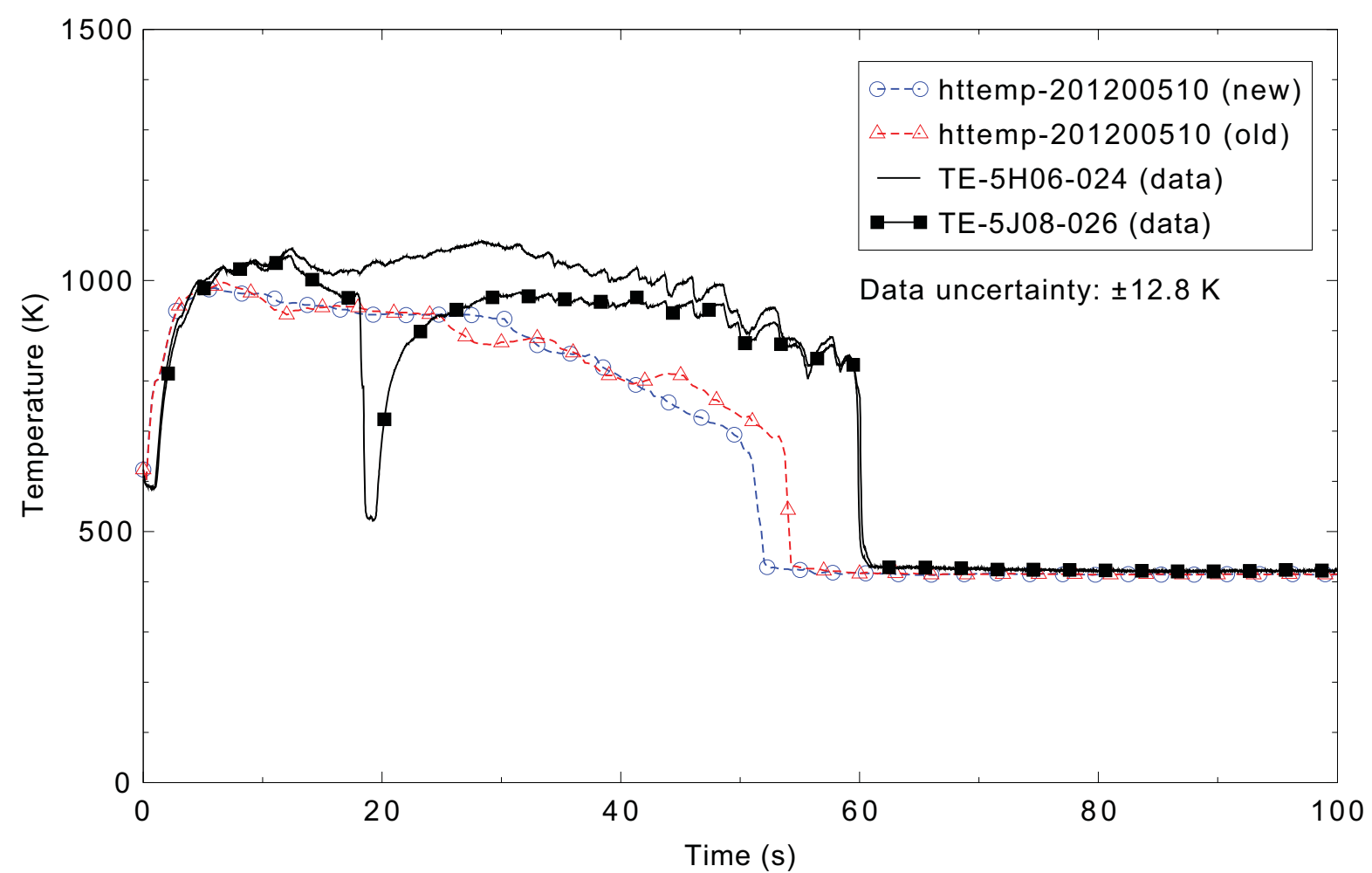

Figure 5.6-27. Measured and calculated fuel cladding surface temperature in Ring 1, Sector 2, $0.64 \mathrm{~m}$ above the bottom of the fuel rod for the LOFT L2-5 3-D case.

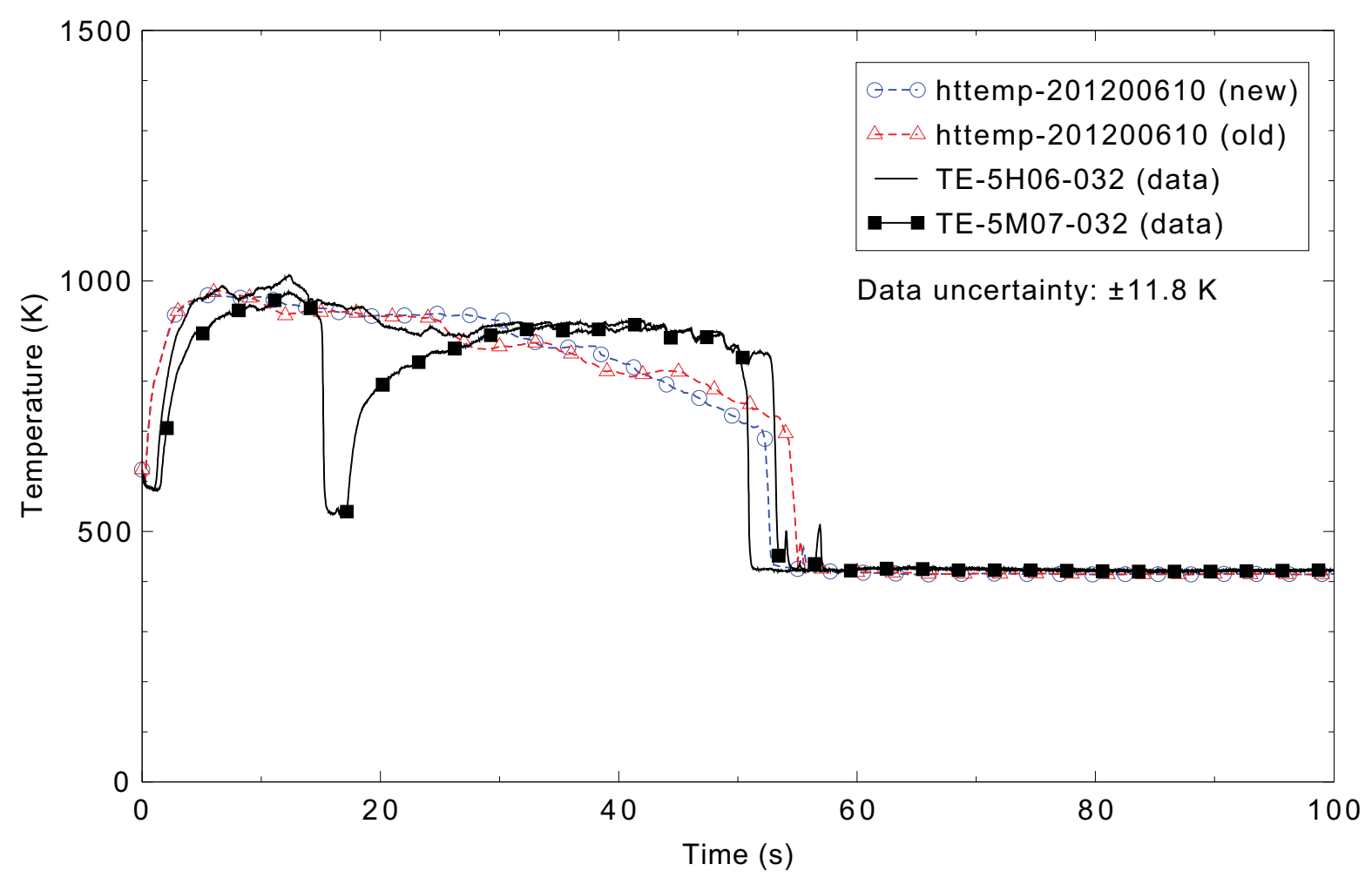

Figure 5.6-28. Measured and calculated fuel cladding surface temperature in Ring 1, Sector 2, $0.81 \mathrm{~m}$ above the bottom of the fuel rod for the LOFT L2-5 3-D case. 


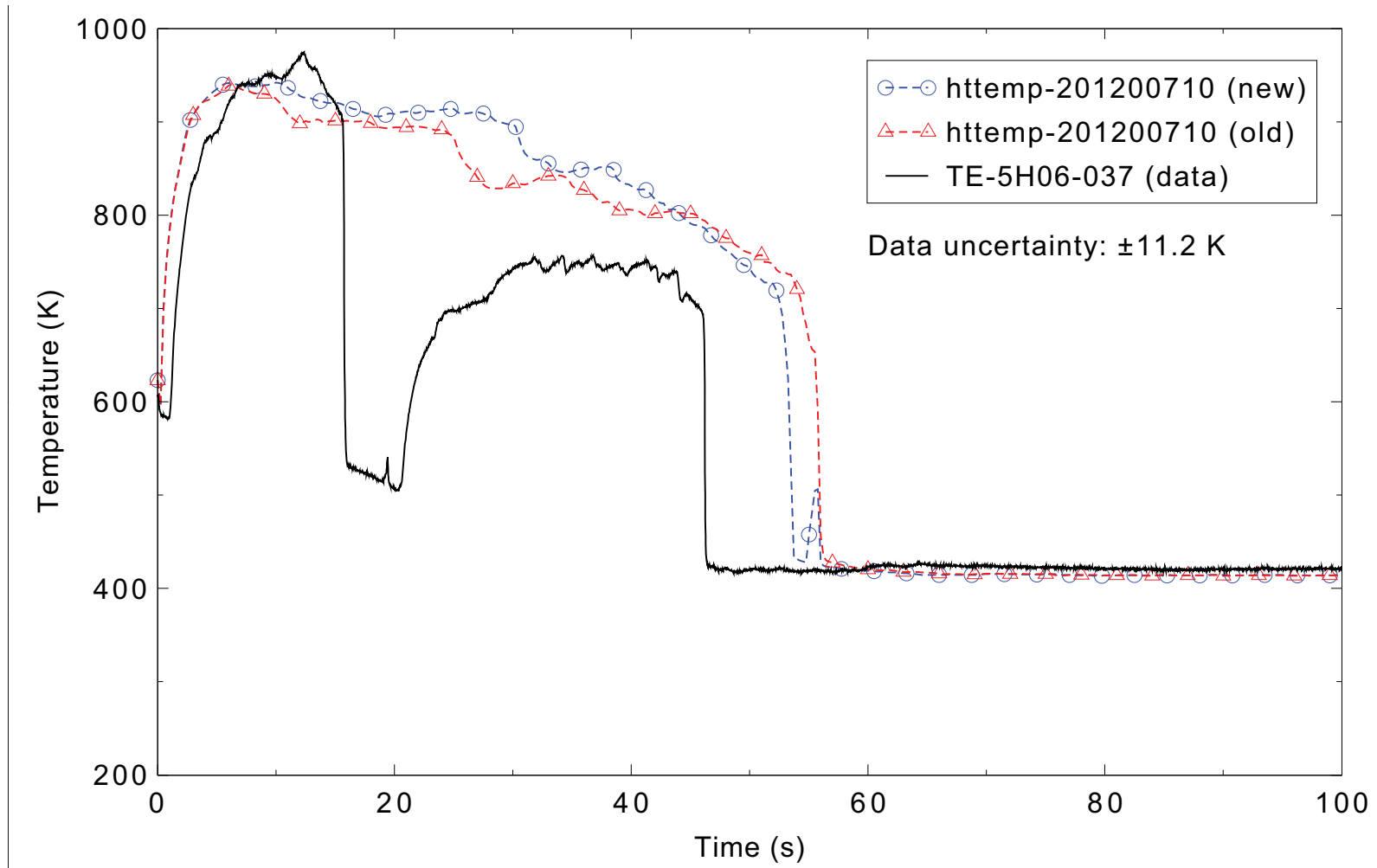

Figure 5.6-29. Measured and calculated fuel cladding surface temperature in Ring 1, Sector 2, $0.94 \mathrm{~m}$ above the bottom of the fuel rod for the LOFT L2-5 3-D case.

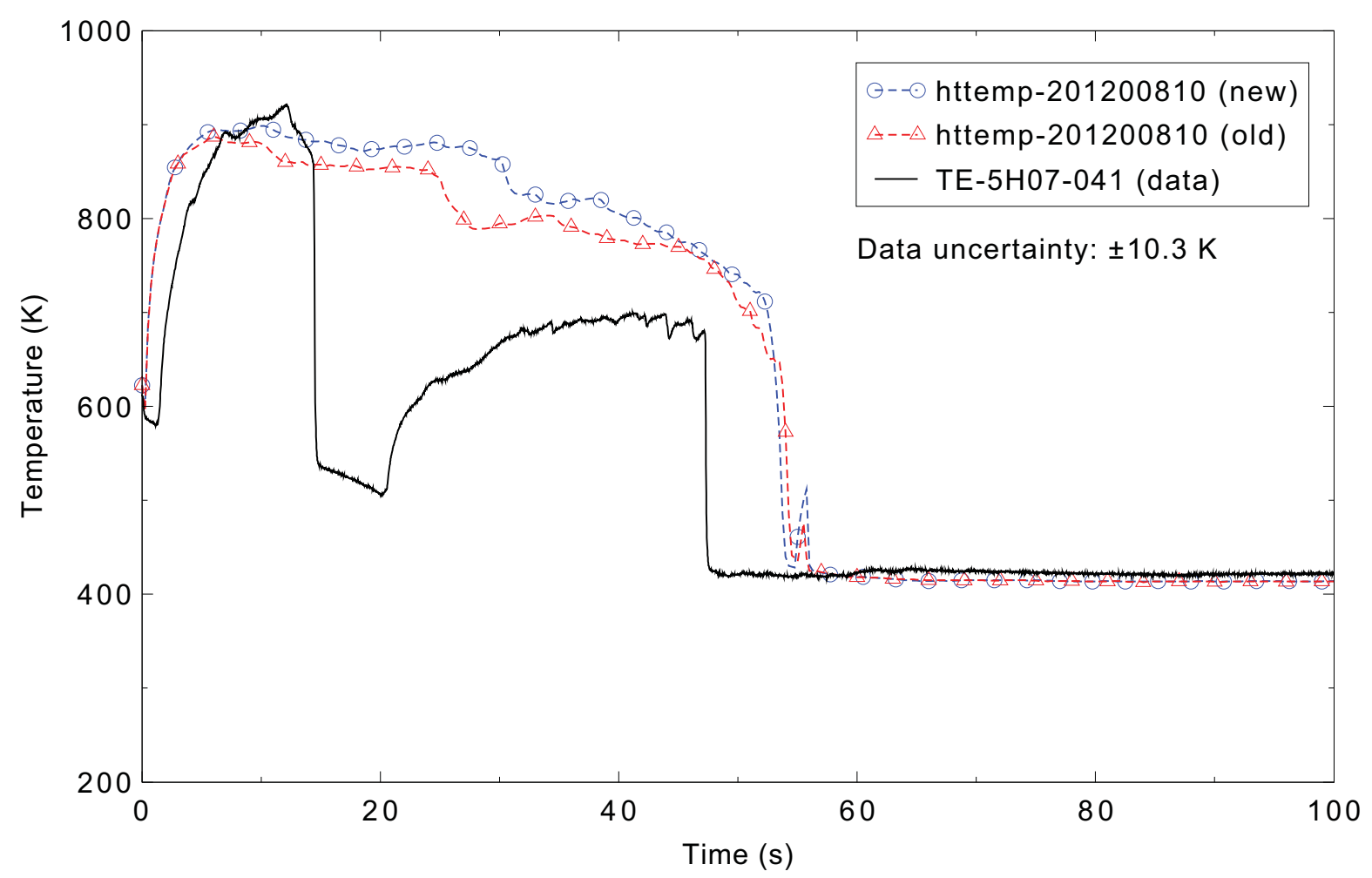

Figure 5.6-30. Measured and calculated fuel cladding surface temperature in Ring 1, Sector 2, $1.04 \mathrm{~m}$ above the bottom of the fuel rod for the LOFT L2-5 3-D case. 


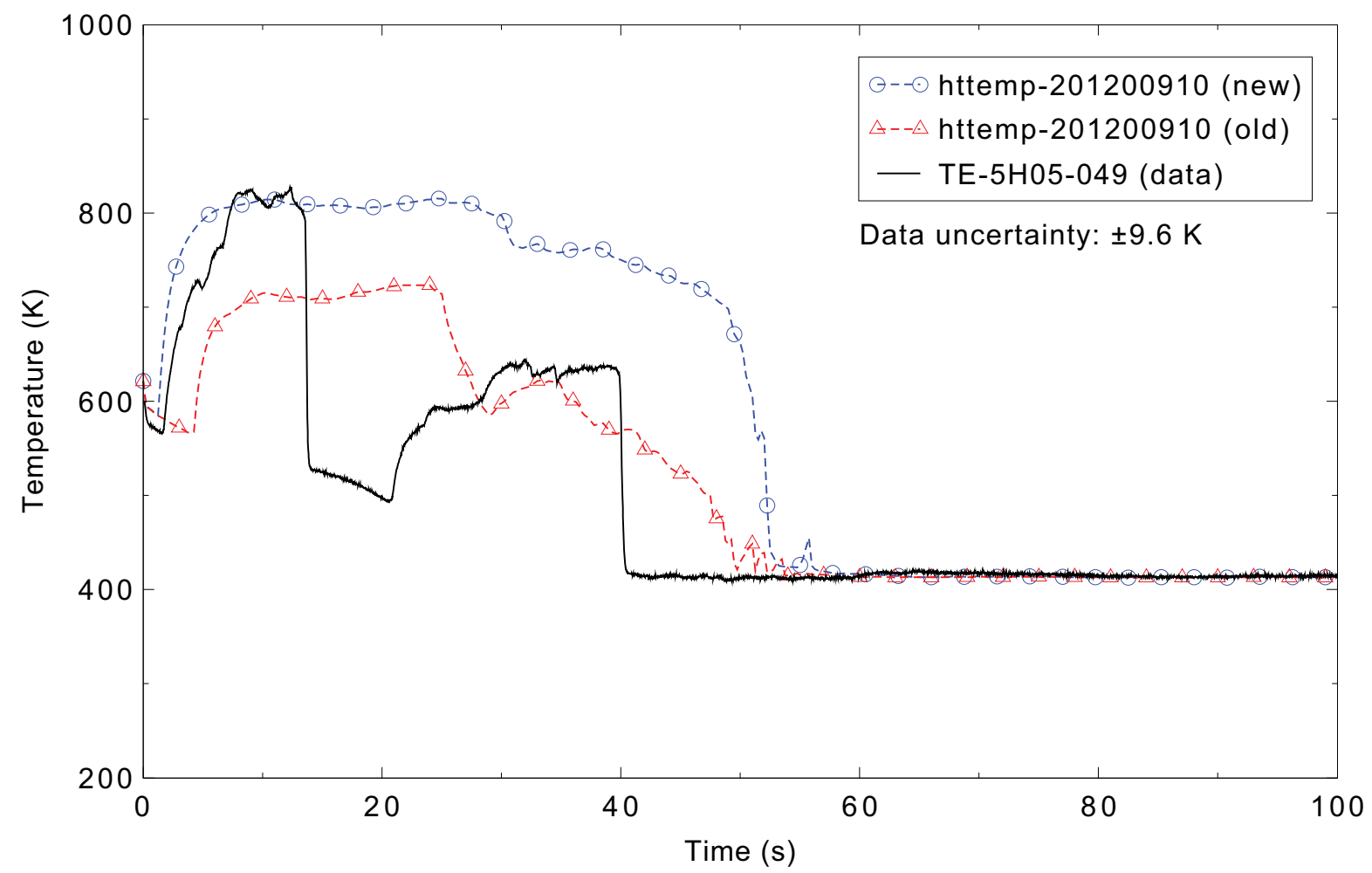

Figure 5.6-31. Measured and calculated fuel cladding surface temperature in Ring 1, Sector 2, $1.25 \mathrm{~m}$ above the bottom of the fuel rod for the LOFT L2-5 3-D case.

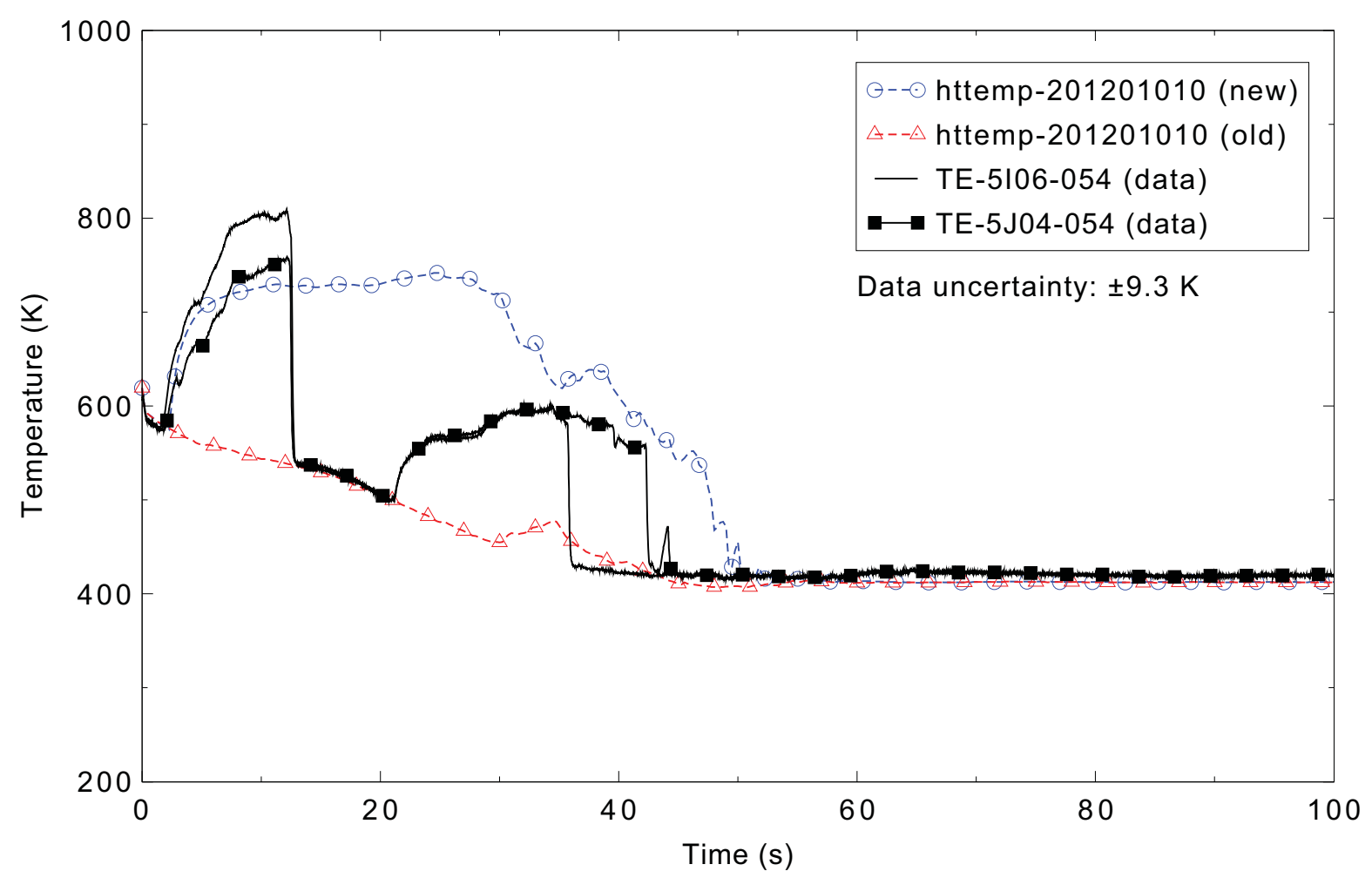

Figure 5.6-32. Measured and calculated fuel cladding surface temperature in Ring 1, Sector 2, $1.37 \mathrm{~m}$ above the bottom of the fuel rod for the LOFT L2-5 3-D case. 


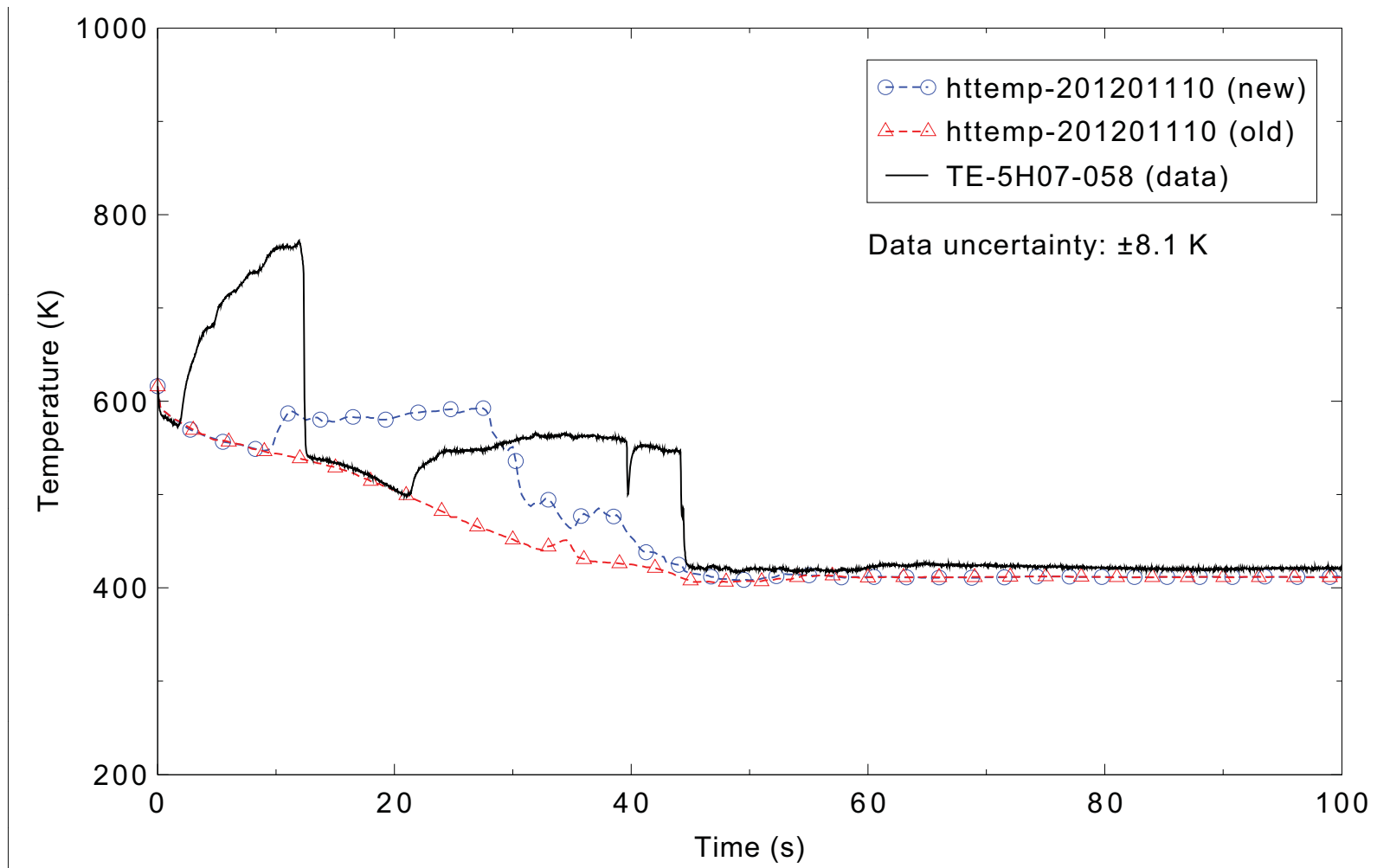

Figure 5.6-33. Measured and calculated fuel cladding surface temperature in Ring 1, Sector 2, $1.47 \mathrm{~m}$ above the bottom of the fuel rod for the LOFT L2-5 3-D case.

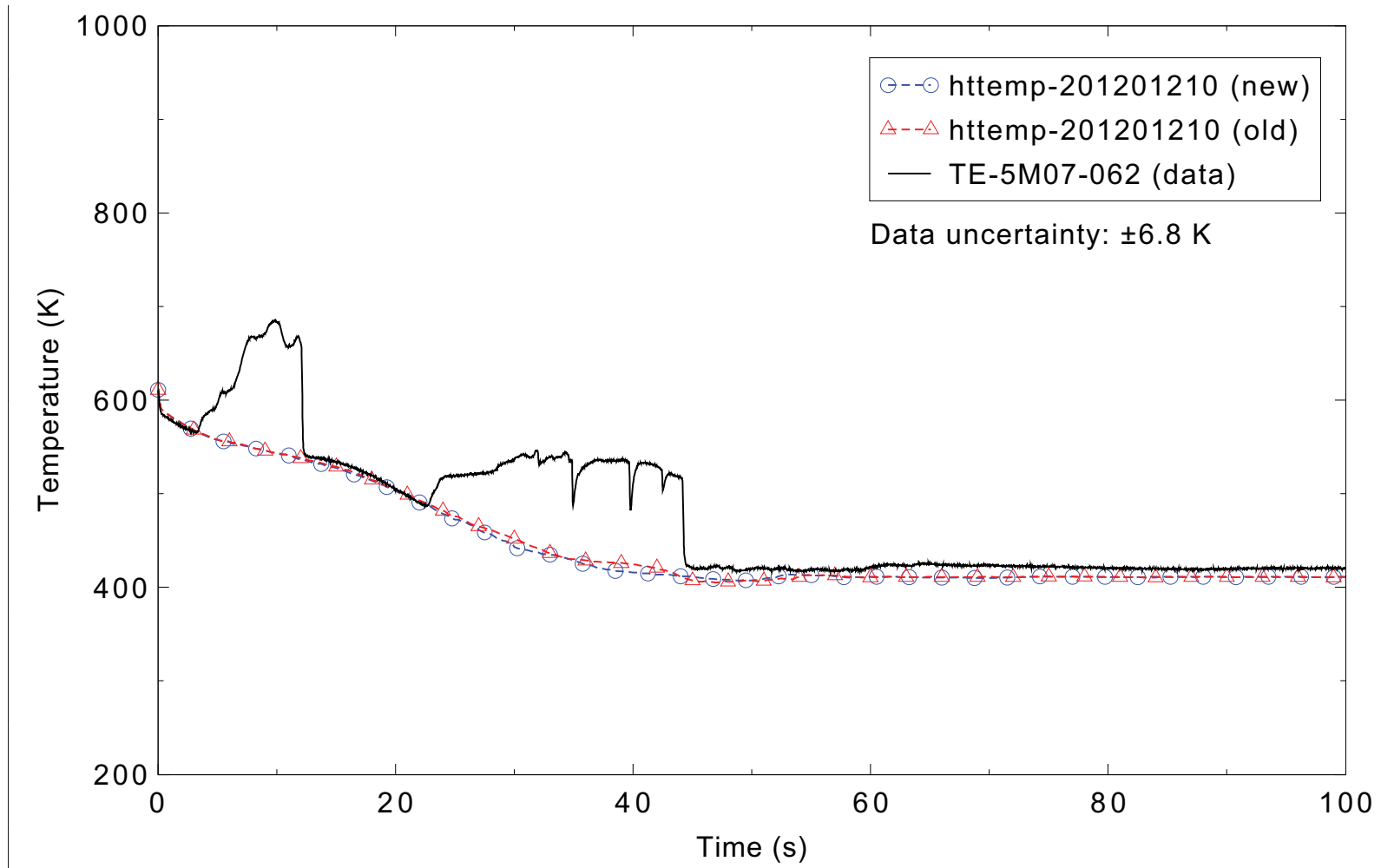

Figure 5.6-34. Measured and calculated fuel cladding surface temperature in Ring 1, Sector 2, $1.57 \mathrm{~m}$ above the bottom of the fuel rod for the LOFT L2-5 3-D case. 


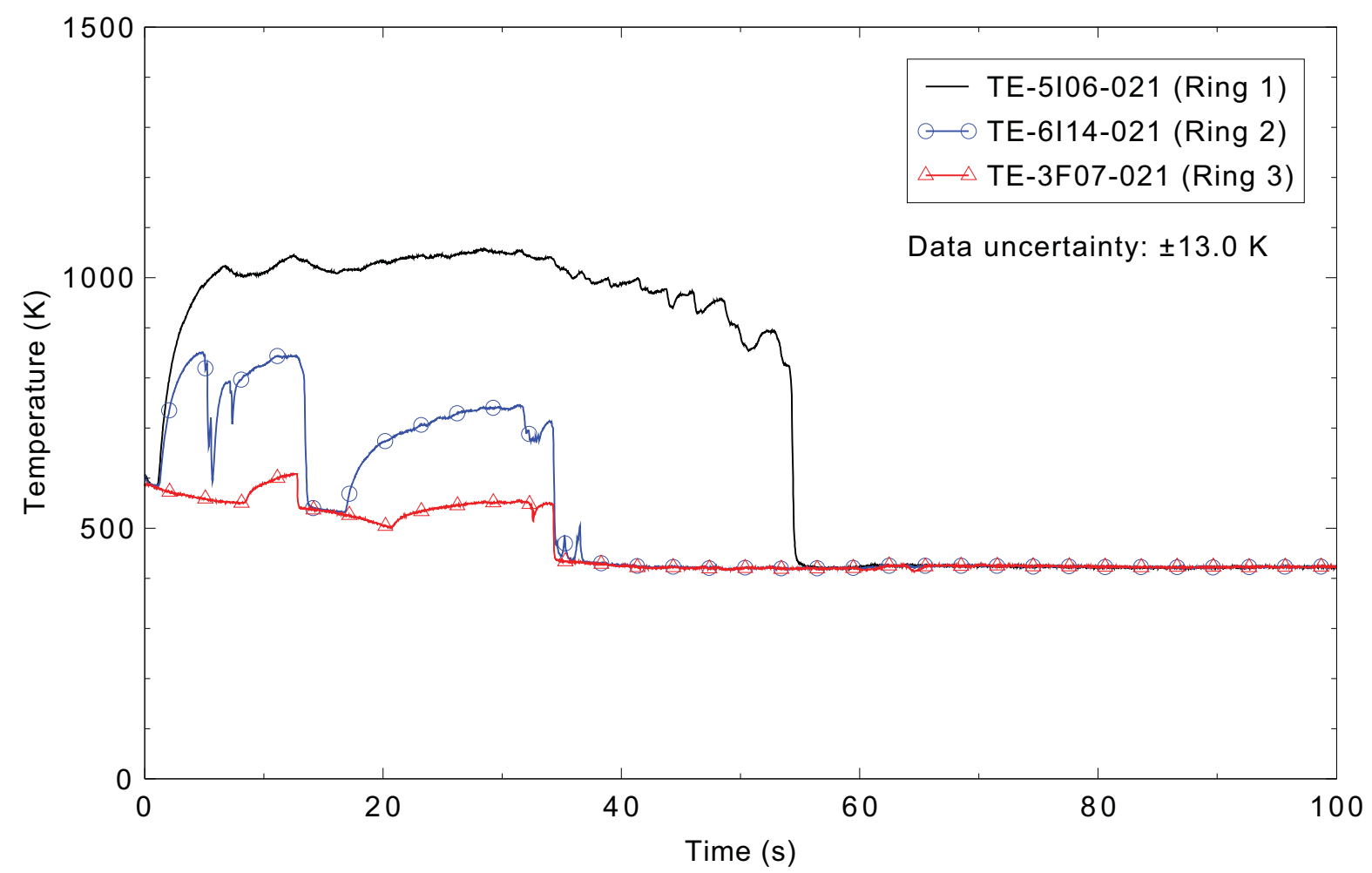

Figure 5.6-35. Measured values showing radial variation in the fuel cladding surface temperature $0.53 \mathrm{~m}$ above the bottom of the fuel rod for the LOFT L2-5 3-D case.

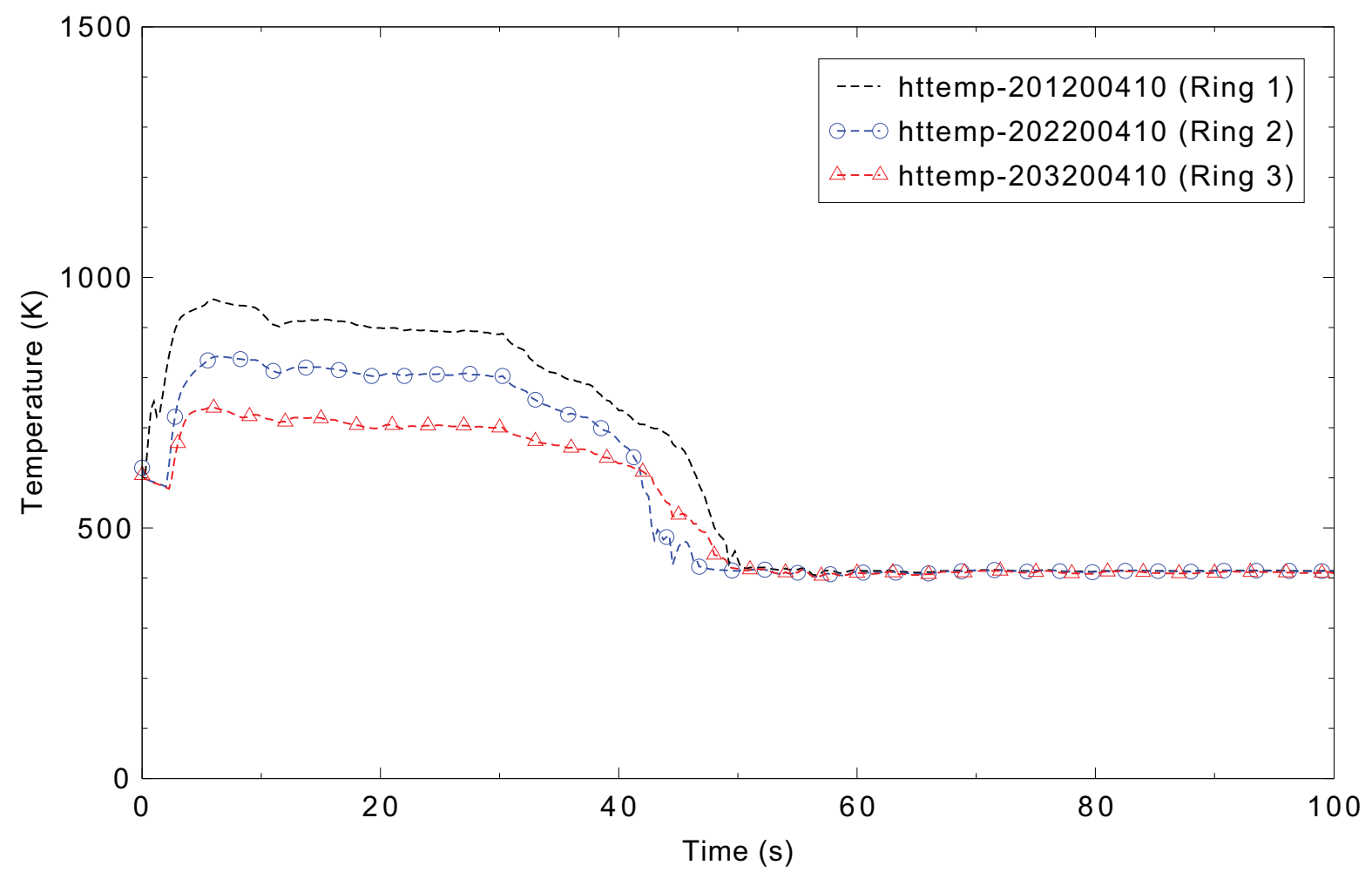

Figure 5.6-36. Calculated values showing radial variation in the fuel cladding surface temperature $0.53 \mathrm{~m}$ above the bottom of the fuel rod for the LOFT L2-5 3-D case. 


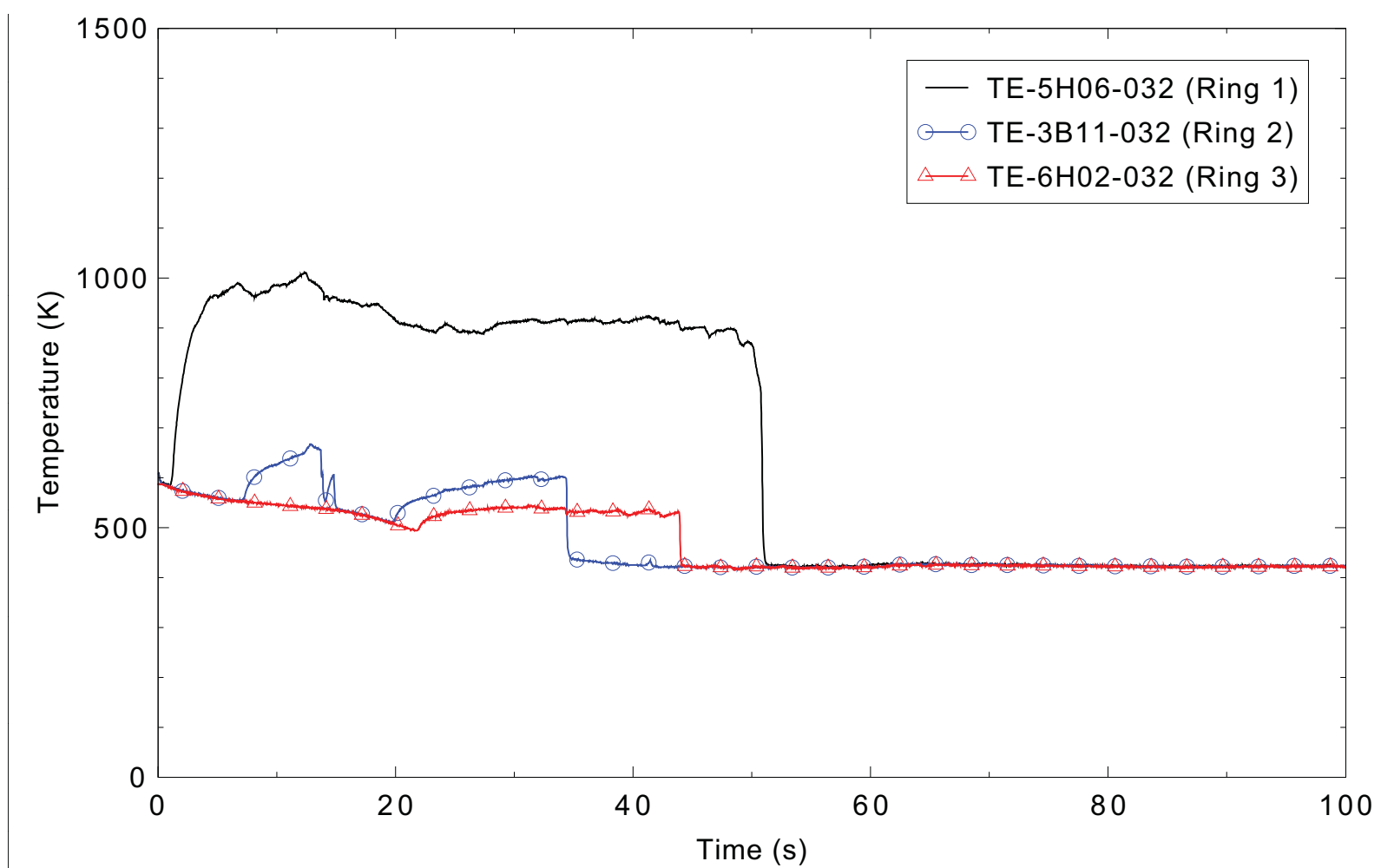

Figure 5.6-37. Measured values showing radial variation in the fuel cladding surface temperature $0.81 \mathrm{~m}$ above the bottom of the fuel rod for the LOFT L2-5 3-D case.

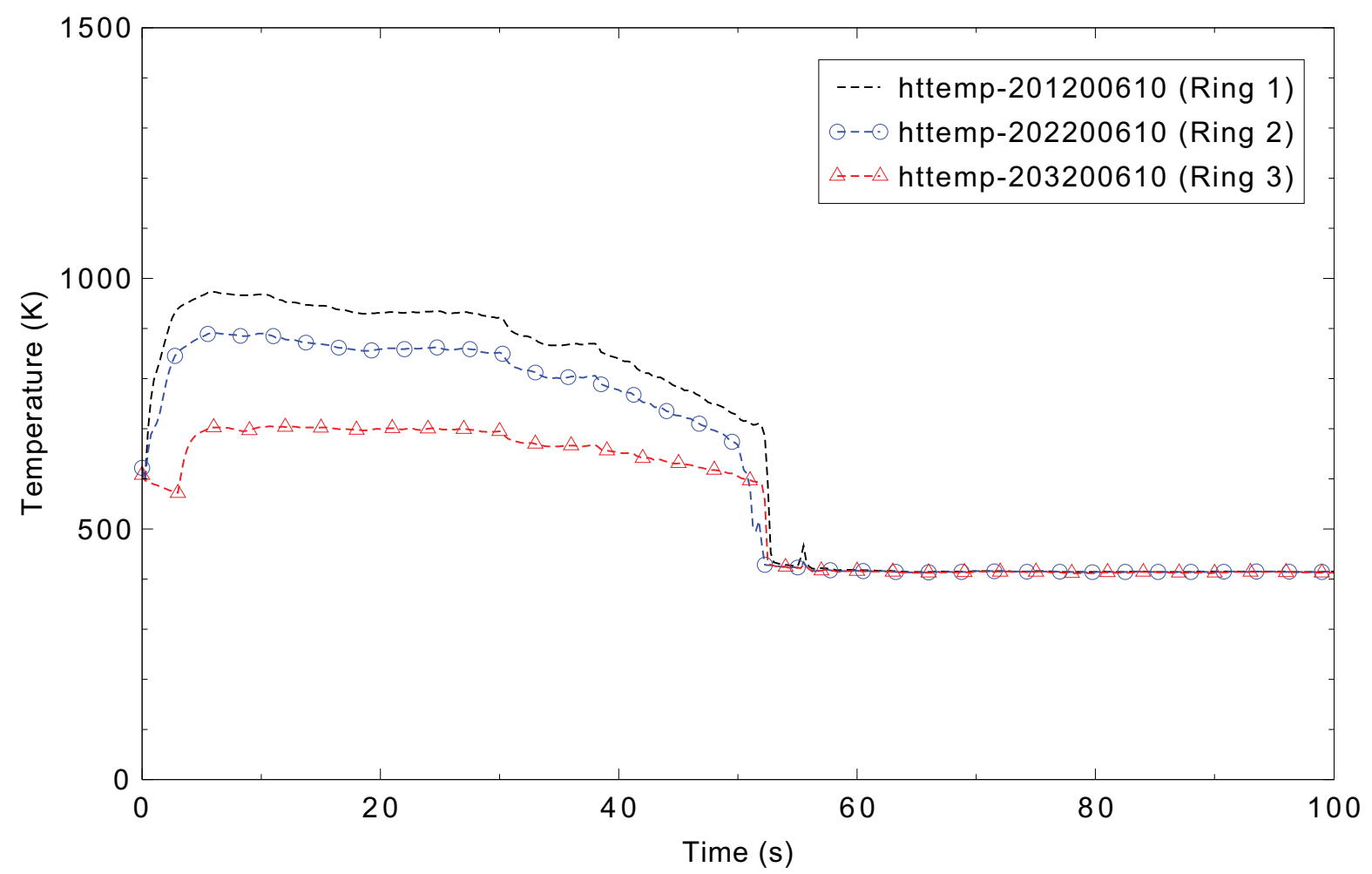

Figure 5.6-38. Calculated values showing radial variation in the fuel cladding surface temperature $0.81 \mathrm{~m}$ above the bottom of the fuel rod for the LOFT L2-5 3-D case. 


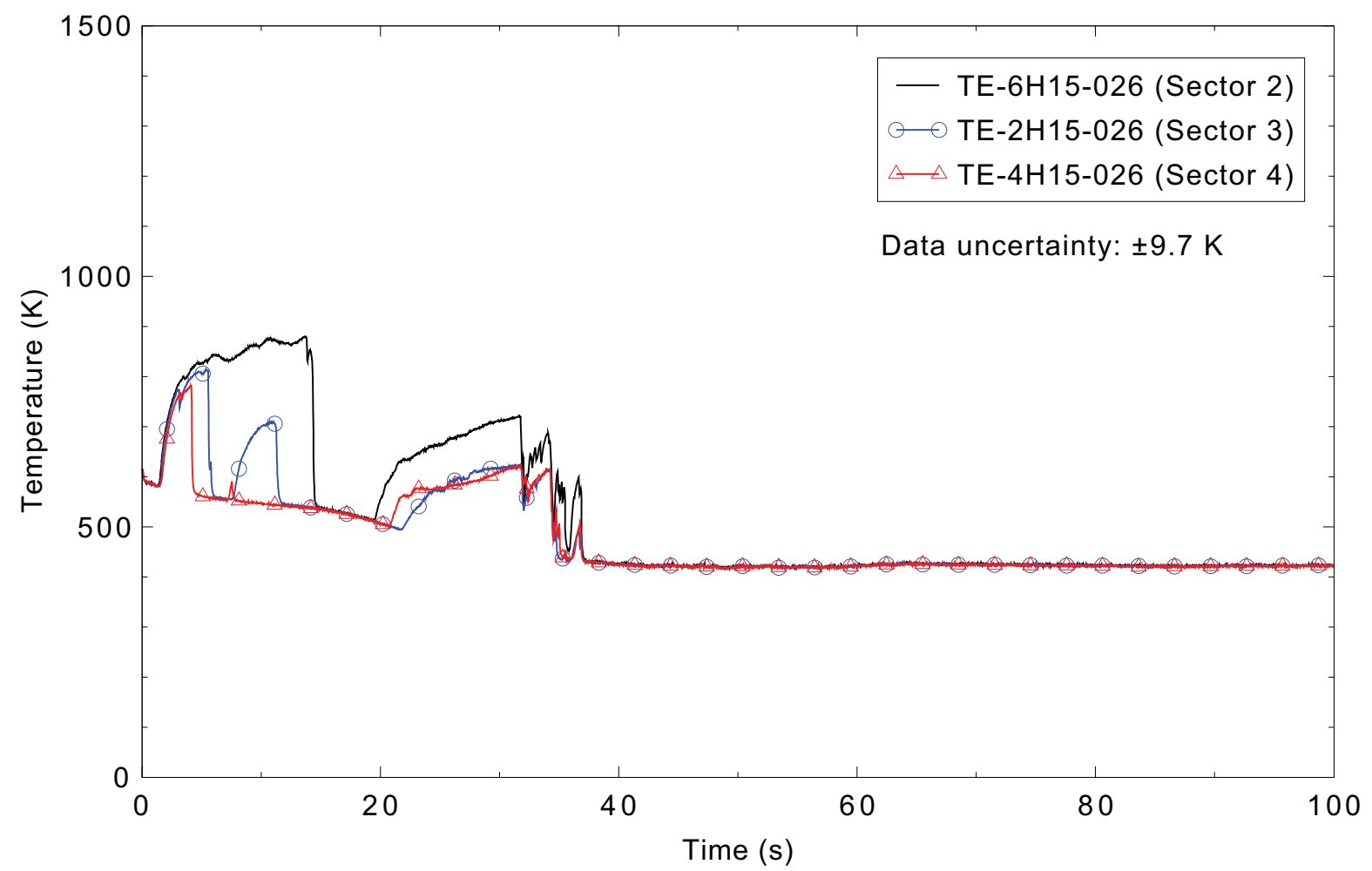

Figure 5.6-39. Measured values showing azimuthal variation in fuel cladding surface temperatures $0.66 \mathrm{~m}$ above the bottom of the fuel rod for the LOFT L2-5 3-D case.

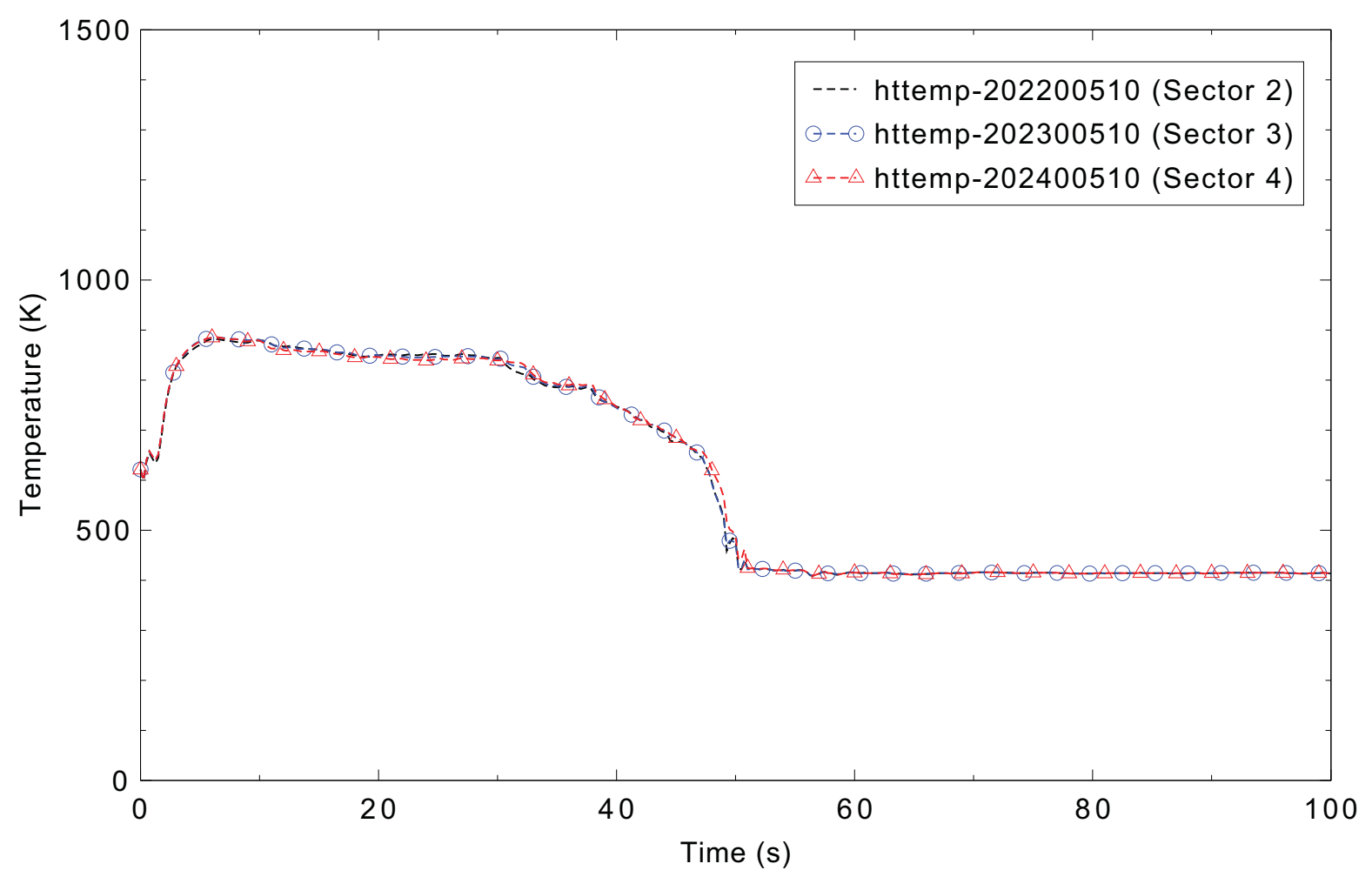

Figure 5.6-40. Calculated values showing azimuthal variation in fuel cladding surface temperatures $0.66 \mathrm{~m}$ above the bottom of the fuel rod for the LOFT L2-5 3-D case. 
RELAP5-3D/4.0.3 


\section{SUMMARY AND CONCLUSIONS}

New developmental assessment calculations have been performed for the RELAP5-3D computer code using version 4.0.3is. The results from these calculations have been compared to those from the previously published developmental assessment, which used version 2.4.2is. Comparisons were only made using the semi-implicit solution scheme.

The comparison plots were reviewed, and differences were divided into two categories. Significant differences signify that the assessment judgment may need to be changed. Noticeable differences signify that while the two simulations are different, a change in the assessment finding is unlikely. No differences were observed in most of the assessment cases; those that had differences are listed below:

- Water over steam (1-D) — three noticeable differences

- Water over steam (3-D) - four noticeable differences

- $\quad$ Bubbling steam through liquid — one noticeable difference

- $\quad$ Gravity wave (3-D) - three noticeable differences

- $\quad$ Pryor pressure - five noticeable differences

- $\quad$ Point kinetics ramp — one significant difference

- $\quad$ Marviken CFT-21 — two noticeable differences

- Marviken CFT-22 — one noticeable difference

- Marviken CFT-24 - one noticeable difference

- Moby-Dick air-water — one significant difference

- $\quad$ GE level swell Test 1004-3 — two noticeable differences

- $\quad$ GE level swell Test 5801-15 — four noticeable differences

- Bennett heated tube Test 5358 - one noticeable difference

- ORNL THTF Test 3.07.09B - one noticeable difference

- $\quad$ ORNL THTF Test 3.09.10I - two noticeable differences

- $\quad$ FLECHT Test 31504 — two significant differences, eighteen noticeable differences 
- $\quad$ FLECHT Test 31701 - one significant difference, fourteen noticeable differences

- UPTF Test 6 - five noticeable differences

- $\quad$ MIT pressurizer Test ST4 — two significant differences, two noticeable differences

- $\quad$ Neptunus Test Y05 - two noticeable differences

- $\quad$ MB2 - four noticeable differences

- $\quad$ LOFT Experiment L3-7 — fifteen noticeable differences

- $\quad$ ROSA Test SB-CL-18 — two significant differences, eighteen noticeable differences

- Semiscale natural circulation Tests $1,2,3$, and 10 - twenty four noticeable differences

- $\quad$ LOBI Test A1-04R — one significant difference, fifteen noticeable differences

- $\quad$ LOFT Experiment L2-5 (1-D) - five significant differences, twenty two noticeable differences

- $\quad$ LOFT Experiment L2-5 (3-D) - four significant differences, twenty five noticeable differences.

The large number of differences is likely unique to this comparison, as it has been about six years since the last code version was released, and there have been a number of error corrections in the interim. After evaluating these differences, some changes in the assessment judgments were made; these are listed in Table 6.0-1. The changes in the ORNL THTF and LOFT L3-7 judgments were not the result of changes in the calculations, but of a reevaluation of the comparisons to the data.

Table 6.0-1. Assessment changes from last code version.

\begin{tabular}{|c|c|c|c|}
\hline Case & Parameter & New Judgment & Previous Judgment \\
\hline \hline $\begin{array}{c}\text { Bubbling steam through } \\
\text { liquid, nearly-implicit }\end{array}$ & $\begin{array}{c}\text { mixture level tracking and } \\
\text { entrainment }\end{array}$ & insufficient & minimal \\
\hline Fill-Drain, nearly-implicit & mixture level tracking & excellent & reasonable \\
\hline $\begin{array}{c}\text { Manometer, without } \\
\text { mixture level tracking, } \\
\text { nearly-implicit }\end{array}$ & oscillations & minimal & insufficient \\
\hline Point kinetics ramp & fission power & excellent & insufficient \\
\hline ORNL THTF Test 3.07.9N & film boiling & minimal & reasonable \\
\hline Neptunus Test Y05 & pressurizer behavior & excellent & reasonable \\
\hline
\end{tabular}


Table 6.0-1. Assessment changes from last code version.

\begin{tabular}{|c|c|c|c|}
\hline Case & Parameter & New Judgment & Previous Judgment \\
\hline \hline LOFT L3-7 & $\begin{array}{c}\text { lower core fuel cladding } \\
\text { surface temperature }\end{array}$ & minimal & reasonable \\
\hline $\begin{array}{c}\text { LOFT L2-5 (1-D), } \\
\text { nearly-implicit }\end{array}$ & intact loop cold leg density & minimal & reasonable \\
\hline LOFT L2-5 (3-D) & broken loop hot leg density & minimal & reasonable \\
\hline
\end{tabular}

Although the Moby-Dick assessment did not change, there was a significant change in the calculated behavior that resulted from a code modification, in which the sonic velocity at the junction is now calculated in the same manner as that in the volume. (The previous model can still be obtained by using Card 1 Option 3.) The effect of the update was that the flow at the nozzle is no longer calculated to be choked.

One assessment case was added. The full-scale reactor coolant pump case addresses the pressure dependence in the two-phase pump curves, a model which was not available in Version 2.4.2is.

A general observation was that the nearly-implicit calculations had fewer problems than in the previous assessment, and were generally closer to the semi-implicit calculations than in the previous code version. Another improvement was that all of the manometer problem cases ran, whereas several of them failed in the previous code version. 